\title{
STEM Subjects Face the Haptic Generation:
}

\section{The iScholar}

\section{Tesis doctoral Nuria Llobregat Gómez}

Director Dr. D. Luis Manuel Sánchez Ruiz

Valencia, noviembre 2019 

A mi Madre, a mi Padre (t), a mis Yayos (t), y a mi Hija, sin cuya existencia esto no hubiese podido suceder. 



\section{Contents}

\section{Abstract. English Version}

Resumen. Spanish Version

Resum. Valencian Version

Acknowledgements

Introduction

Outsight _ـ13

Insight_—14

Statement of the Research Questions __ 15

Dissertation Structure _ـ16

SECTION A. State of the Art. The Drivers __ 19

Chapter 1: Haptic Device Irruption

1.1 Science or Fiction? Some Historical Facts 25

1.2 The Irruptive Perspective _ـ 29

1.2.1 i_Learn \& i_Different_ 29

1.2.2 Corporate Discourse and Education ___ 31

1.2.3 Size \& Portability Impact___ 33

First Devices __ 33

Pro Models $\longrightarrow 35$

1.3 Learning from Screens _ـ 37

1.3.1 Passive Screens _ 37

1.3.2 Interactive Screens___ 38

1.3.3 From Passive to Interactive _ 40

1.4 Haptic Device _ 42

1.4.1 Definition 42

1.4.2 Data _ 43

1.4.3 Device Features that Enhances Literacy Learning ___ 44

Digging for Learning ___ 44

Device Technical Specifications _ 45

Informing Learning with Assistive Features and Built-in Support___ 46

User Interaction__ 47

Devices and Literacy Facilitators__

\section{Chapter 2. Framing the Digital Scope}

2.1 Introduction 57

2.2 Spanish Generational Cohorts __ 60

2.2.1 The Grands __ 61

2.2.2 The Silents 62

2.2.3 The Boomers_ 64

2.2.4 XGens__ 65

2.2.5 YGens 67

2.2.6 ZGens_ 68 
2.3 Mashup Generation: The Digital Me 71

2.3.1. The Melting Pot

2.3.2. The digital "i"

2.3.3 Curating Formal Education

Formal Education and Digitalization

Major Educational Swifts

Web Development Stages and Formal Education

2.4 The Haptic Generation 86

2.4.1 First Contact with Digitalization 86

2.4.2 Digitally Savvy

2.4.3 A New Playmat 88

2.4.4 Switching on the Device 89 90

SECTION B. Research Design \& Data Collection 93

\section{Chapter 3. Methodology}

3.1 Research Philosophy 99

3.2 Research Approach 101

3.3 Research Design 103

3.3.1 Ethnographic Observation Guiding the Research 103

3.3.2 Ethnographic Design 104

3.3.3 Research Questions 107

3.4 Research Methods

3.4.1 Primary Data Collection used 109

B. ZC Case Study 111

C. Papers on Early Childhood using Haptic Devices with Learning Purposes ___ 111

3.4.2 Secondary Data Collection used ___ 112

3.4.3 Observational Research ___ 112

3.5 Sampling _ 113

3.6 Ethical Considerations _ـ 114

\section{Chapter 4. Data Collection}

4.1 HG Case Study

4.1.1 HG Research Variables__ 119

Home Setting ___ 120

Child Info___ 121

Device Used _ _ 121

Device Using Conditions___ 122

Emotional Constructs when Using the Device ___ 123

4.1.2 HG Aimed Reports ___ 124

4.1.3 Researcher's Observations___125

4.1.4 Family Overviews __ 126

4.1.5 Parents Survey Data Collection ___ 143

4.2 ZG Case Study _ 149

4.2.1 Situational Context: UPV, Valencia, Spain __ 149

4.2.2 ZC Survey Data Collection _ 151

4.2.3 ZC Essays___ 153

4.3 Papers on Early Childhood Using Haptic Devices with Learning Purposes __ 156

List of Peer reviewed Papers (2010-2018)___ 159 


\section{Chapter 5. Early Learning \& Haptic Devices}

5.1 Introduction 177

5.2 Gestating a Scholar Brain ___ 181

5.2.1 Social Interaction ___ 181

5.2 .2 Imitation

5.2.3 Starting to Think _ 183

5.2.4 How Learning Happens in Early Years __ 183

5.2.5 Earlier Haptic Interactions ___ 185

5.3 Child Involvement in the Learning Experience ___ 188

5.3.1 Active Learning ___ 189

5.3.2 Engagement 190

5.3.3 Haptic Interaction within the Social Context _ 190

5.3.4 Socio-Emotional Development ___ 191

5.3.5 Meaningful Learning ___ 193

5.3.6 Scaffolded Exploration __ 194

5.4 Adult Involvement _ 195

5.4.1 Home as a Context for Learning __ 196

5.4.2 Co-Using the Device ___ 197

5.5 Boosting Creativity and Learning __ 200

5.5.1 The Device as a Tool__ 200

Assistive Features and Built-in Support__ 201

Zooming In and Out _ 202

Multimodal Formats 202

5.5.2 Children Interaction_ 203

Fingertip 204

Built-In and Bluetooth Keyboards _ 204

Digital Pens__ 204

Intelligent Voice Assistant _ 206

Apps_ 206

(AR) Apps _ 207

5.6 Boosting Emergent Literacy Learning ___ 208

5.6.1 Reading Development___ 209

5.6.2 Core Skills: The 4 C's _ 211

5.6.3 Emergent Digital Literacy Skills ___ 212

5.6.4 Instances of Children Device Usage for Learning ___ 215

5.6.5 Desk Research on Haptic Devices as Literacy Facilitator __ 219

5.6.6 Avoiding Illiteracy __ 223

5.7 Boosting English Language Learning _ 226

5.7.1. Passive Exposure__ 227

5.7.2 New Scenario _ 229

5.7.3 Learning English with my Tablet _ 230

5.7.4 Bilingual Informal Education _— 232

\section{Chapter 6. The ischolar}

6.1 The 2030 University Student 239

6.1.1 The iScholar Birth _ 240

6.1.2 Context__ 242

6.1.3 Definition_245

6.1.4 The Future New Setting __ 246 
6.2 iScholar Core Learning

6.2.1 Digital Literacy Skills

Digital Competence Areas

250

Proficiency levels of Each Competence __ 252

6.2.2 Visual Literacy __ 253

6.2.3 Digital Citizenship __ 256

\section{Chapter 7. The Learning Atrium}

\subsection{Definition}

\subsection{The Foundations}

7.2.1 Major Paradigms

7.2.2 Understanding how Learning Happens __ 266

7.2.3 Explicit or Implicit Learning __ 267

7.3 The Panes _ 270

7.3.1 Formal, Informal \& non-Formal Settings — 270

7.3.2 Fostering Reasoning _ 272

7.3.3 Enhancing Knowledge Retention

Cognitive Strategies _ 274

Understanding and Integrating Strategies __ 275

7.3.4 Blending the Inner Space ___ 276

7.3.5 From STEM to STEHEAM — 278

7.4 The Experts __ 283

7.4.1 Feeling the Digital Diversity __ 283

7.4.2 Innovating__ 288

7.4.3 Driving Motivation _ 291

7.4.4 Smart Learning Scenario _ 292

7.5 iScholars Wandering Around ___ 295

7.5.1 Feeling the Rush 295

7.5.2 Pursuing Academic Learning 297

7.5.3 Expertise as Learning Output _ 299

7.6 The STEHEAM Scope _ 301

7.6.1. Embracing the ISTE Standards 301

7.6.2 Spanish Universities Heading $2030 \_303$

Conclusions _ـ 305

Conclusions on the Findings __ 311

Dissertation New Concepts

Implications

Further Research_ 316

Autobiographical Reflection __ 317

Reference List ___ 323

\section{Figure, Tables and Photo Captions}

Figure List _ 347

Table List__ 349

Photo Captions 
A HG_Case Study

A1. Family Summary template

A2. Informed Consent

A3. Young Children and Use of Table Survey. Google Doc. Template

A4. Niños entre 0-8 años y Tablets/móviles. Google Doc. Template

\section{B ZG Case Study}

B1 Alumnos y dispositivos móviles. Uso educativo. Google Doc. Template

B2. Essays. Templates 



\section{ABSTRACT}

Since 2006, Higher Education Institutions (HEls), educational policies, and stakeholders have addressed to the EU recommendations aimed to provide a framework for lifelong learning in the knowledge society. Strategies like "Europe 2020" or "Education and Training 2020" (ET2020), focusing on smart growth through the development of knowledge and innovation (COM, 2010), try to answer the new global challenges that the digital era brings. New concepts like smart specialization, digital competence, or digital citizenship, among others, are keystones to fulfil the labor market skills of the $4^{\text {th }}$ Industrial Revolution.

Recent surveys, among nowadays students, evidence high drop-out and repetition rates (OECD, 2016), and their low motivation to join our campuses following the existing methodologies. The gap between what the students expect and what they receive from faculty is nowadays insurmountable because the university model was created, developed, and updated in the prehaptic era when the Bologna Process for standardization of European higher education was incorporated into the curricula design (2010).

Technical Spanish universities, in an effort to meet the needs of the future engineers, are trying to design strategies that incorporate those crucial skills so that its graduates can prosper in a digital working society (OECD, 2019) in the best possible way.

Since 2010, the irruption of smartphones and tablets in our households (haptic devices) and normal life has brought a new gesture, the haptic interaction, to our social well-being and to our way of living. Within that interaction there are elements like global connectivity, digital formats, new media literacies, instant communication, interactivity, or personalization that have affected to all members of society no matter the age, including the Haptic Generation children ${ }^{1}$ that are, right now, spying and imitating all sort of gestures and behaviors performed around them while developing their personalities.

The ethnographic design from a Social Science perspective guides the research conducted in this dissertation confirming that haptic interaction in the hands of early childhood brings possibilities for boosting creativity, English language learning, and expert understanding, among other learning possibilities while using the device at its best capacity for literacy learning (using its inbuilt features). This capacity arises the research questions of this dissertation.

In no time, those children: the iScholars, who have acquired literacy learning with innate haptic gestures since early childhood will be filling our university campuses bringing different learning needs in a new scenario that blends formal, informal, and non-formal educative settings within a broader scope.

Having this landscape in view, a new learning scenario, the Learning Atrium is configurated to enable STEM subjects to face the Haptic Generation: the iScholars. The Atrium, like a polyvalent space, offers higher education the possibility to shape the university degrees from a STEHEAM scope that it is believed to meet the 2030 university student's needs in search of scholar knowledge, professional skills, and competencies acquisition.

\footnotetext{
${ }^{1}$ Haptic Generation Cohort: Children born after 2010.
} 



\section{RESUMEN}

Desde 2006, las Instituciones de Educación Superior (IES), las políticas educativas y los agentes de interés han abordado las recomendaciones de la UE destinadas a proporcionar un marco para el aprendizaje permanente en una sociedad del conocimiento. Estrategias como "Europa 2020" o "Educación y formación 2020" (ET2020), centradas en el crecimiento inteligente a través del desarrollo del conocimiento y la innovación (COM, 2010), intentan responder a los nuevos desafíos globales que trae la era digital. Nuevos conceptos como la especialización inteligente, la competencia digital o la ciudadanía digital, entre otros, son piedras angulares para cumplir con las demandas del mercado laboral de la 4a Revolución Industrial.

Recientes encuestas a alumnos actuales evidencian altas tasas de abandono y repetidores (OCDE, 2016), y su baja motivación para acceder a nuestros campus siguiendo las metodologías existentes. La brecha entre lo que los estudiantes esperan y lo que reciben del profesorado es, hoy por hoy, insuperable; porque el modelo universitario fue creado, desarrollado y actualizado en la era pre-háptica, cuando se incorporó el proceso de Bolonia para la estandarización de la educación superior europea al diseño curricular (2010).

Las universidades tecnológicas españolas, en un esfuerzo por satisfacer las necesidades de los futuros ingenieros, intentan diseñar estrategias que incorporen esas habilidades cruciales para que sus graduados puedan prosperar en una sociedad de trabajo digital (OCDE, 2019) de la mejor manera posible.

Desde 2010, la irrupción de teléfonos inteligentes y tabletas en nuestros hogares (dispositivos hápticos) y la vida normal ha traído un nuevo gesto, la interacción háptica, a nuestro bienestar social y a nuestra forma de vida. Dentro de esa interacción hay elementos como conectividad global, formatos digitales, alfabetización en nuevos medios, comunicación instantánea, interactividad o personalización que ha afectado a todos los miembros de la sociedad sin importar la edad, incluidos los niños de la Generación Háptica ${ }^{1}$ que, en este momento, están observando e imitando todo tipo de gestos y comportamientos llevados a cabo mientras desarrollan su personalidad.

El diseño etnográfico de la investigación desde una perspectiva de las Ciencias Sociales guía la labor realizada en esta disertación y confirma que la interacción háptica en manos de la primera infancia brinda increíbles posibilidades para impulsar la creatividad, la adquisición del idioma inglés y el aprendizaje experto, entre otras muchas posibilidades de aprendizaje si se usan estos dispositivos aprovechando al máximo sus características lecto-escritoras integradas que lo facilitan. Esta capacidad intrínseca motiva las preguntas de investigación de esta tesis.

En poco tiempo esos niños, los iScholars, que han adquirido mucho de su aprendizaje mediante interacciones hápticas innatas desde muy pequeños, llenarán nuestros campus universitarios trayendo consigo unas necesidades de aprendizaje diferentes en un nuevo escenario que combina entornos educativos formales, informales y no formales con una perspectiva más amplia.

Teniendo en cuenta este panorama, se configura un nuevo escenario de aprendizaje, el Atrium, para permitir que las asignaturas STEM acojan a la Generación Háptica: los iScholars. El Atrium, como un espacio polivalente, ofrece a la educación superior la posibilidad de configurar los títulos universitarios desde una perspectiva STEHEAM que se cree satisface las necesidades de los estudiantes universitarios de 2030 que anhelan conocimiento académico, habilidades profesionales y adquisición de competencias.

\footnotetext{
${ }^{1}$ Generación Háptica: Niños nacidos a partir de 2010.
} 



\section{RESUM}

Des de 2006, les Institucions d'Educació Superior (IES), les polítiques educatives i els agents d'interés han abordat les recomanacions de la UE destinades a proporcionar un marc per a l'aprenentatge permanent en una societat del coneixement. Estratègies com "Europa 2020" o "Educació i formació 2020" (ET2020), centrades en el creixement intel.ligent a través del desenvolupament del coneixement i la innovació (COM, 2010), intenten respondre als nous desafiaments globals que porta l'era digital. Nous conceptes com l'especialització intel-ligent, la competència digital o la ciutadania digital, entre altres, són pedres angulars per a complir amb les demandes del mercat laboral de la 4a Revolució Industrial.

Recents enquestes a alumnes actuals evidencien altes taxes d'abandó i repetidors (OCDE, 2016), i la seua baixa motivació per a accedir a nostres campus seguint les metodologies existents. La bretxa entre el que els estudiants esperen i el que reben del professorat és, ara com ara, insuperable; perquè el model universitari va ser creat, desenvolupat i actualitzat en l'era pre-hàptics quan el Procés de Bolonya per a l'estandardització de l'Educació Superior Europea es va incorporar al disseny curricular (2010).

Les universitats tecnològiques espanyoles, en un esforç per satisfer les necessitats dels futurs enginyers, intenten dissenyar estratègies per a incorporar aqueixes habilitats crucials per a que el seus graduats puguen prosperar en una societat de treball digital (OCDE, 2019) de la millor manera possible.

Des de 2010, la irrupció de telèfons intel-ligents i tauletes en les nostres llars (dispositius hàptics) i la vida normal ha portat un nou gest, la interacció hàptica, al nostre benestar social i a la nostra forma de vida. Dins de esa interacció hi ha elements com a connectivitat global, formats digitals, alfabetització en nous mitjans, comunicació instantània, interactivitat o personalització que ha afectat a tots els membres de la societat sense importar l'edat, inclosos els xiquets de la Generació Hàptica ${ }^{1}$ que, en aquest moment, estan observant $\mathrm{i}$ imitant tot tipus de gestos i comportaments que es realitzen al seu voltant mentre desenvolupen la seua personalitat.

El disseny etnogràfic de la investigació des de una perspectiva de les Ciències Socials guia l'investigació realitzada en aquesta tesi i confirma que la interacció hàptica en mans de la primera infància brinda increïbles possibilitats per a impulsar la creativitat, l'adquisició de l'idioma de l'anglés i el aprenentatge expert, entre altres possibilitats d'aprenentatge, sempre que s'usen aquestos dispositius aprofitant al màxim les seves característiques lecto-escritores integrades que el faciliten. Aquesta capacitat intrinseca motiva les preguntes d'investigació d'aquesta dissertació.

En poc temps, eixos xiquets: els ischolars, que han adquirit molt de la seva alfabetització amb gestos hàptics innats des de la primera infància, ompliran el nostres campuses universitaris portant amb ells unes necessitats d'aprenentatge differents en un nou escenari que combina entorns educatius formals, informals i no formals amb una perspectiva mes ampla.

Tenint en compte aquest panorama, es configura un nou escenari d'aprenentatge, I'Atrium, per a permetre que les assignatures STEM s'enfronten a la Generació Hàptica: els iScholars. L'Atrium, com un espai polivalent, ofereix a l'educació superior la possibilitat de configurar els títols universitaris des d'un abast STEHEAM que es cree satisfarà les necessitats dels estudiants universitaris de 2030 a la recerca de coneixement acadèmic, habilitats professionals and acquisició de competències.

\footnotetext{
${ }^{1}$ Generació Hàptica: Xiquets nascuts des de 2010.
} 



\section{Acknowledgements}

Being here would not have been possible without all the small gestures of trust, care, love, friendship, and support of many of my surroundings. Their smiles, silences and words have been my passport to accomplish a dream that comes from my first passion: learning. They trust me more than myself.

27 years ago, Andres Peña, my doctor, held my hand, looked into my eyes, and told me "allow me to help you" and he did despite I gave up all my senses. In his hands, I closed my eyes and life gave me a second chance. Then I met researchers in conferences that taught me the privilege of generating "small grains of sand" to improve society being at the university, to which I have been attached since 1996. They suggested me to retake my studies in 2005 and succumb to my second passion: research. Then, Tere, $M$. Teresa and Jose F. made me feel exceptional while exploring my third passion: teaching, a research field full of sweet moments and provocative challenges.

2012 arrived and brought me in the hands of Joe, my travel companion, the most wonderful present a person can have, my daughter. She is my sunshine, my love to the future, the one that teaches me to be brave. She brought the silica to build the sand. With her gestures, she inspired the questions where to ground my research, a desert stepped in by just a few scholars. She held my hand to walk into the desert despite my age and gave me water.

It was then when Luis, my supervisor, held my hand and told me "if you have an idea, let's go. I trust you" and he really did. He has stood by me during the whole dissertation process: 5 years of yeses, noes, I cannot, I can, tears, smiles, nights without sleep, distress, content, hard work... The whole process was like a heavy storm that reaches the calm. He has been giving me support like a father, a research father to whom I will always be grateful. Without his kind words and advice this dream -this specific writing-, would not have been possible.

The writing has been hard and long but heartwarming because of my people. Patricia, Sergio, Pablo, Javier, M. Jose, M. Ángeles, Estefanía, Raquel, sole, Mina and my Omaita, among others, trusted without questioning and thought my effort and dedication were worth it. My colleagues and friends from GRIM4E, HIDROGEO and ACUMA gave me UPV support with extraordinary patience. But among them, it was my UPV sister Teresín, lost in a profound silence during my writing, who injected me the commitment based on work well done to finish it, just as she did when we worked together. To all of you, thank you.

Anyway, all of that would not have been possible without those who gave me the gift of being alive, my parents, my Clarence Angels, Mari (Omaita) and Fede. They taught me how to be me, trusted without hesitation and infused unconditional love to any path and stone through life. In silence, without doing any noise, they placed the teaching of their genes in my heart, a seed to pass on to my little sunshine as a treasure to be kept.

There is no writing, no life possible, if there is no witness of the journey with whom to share failures and successes. During mine, I felt gifted spying how many witnesses I have at my side. They make me feel like George in "It's a wonderful life" movie: "the richest woman in town."

To my parents, to my child, to my travel companion, to my research father, and to all of you who feel part of the interline spaces of this dissertation: "This would have not been possible without you. With all my soul, thank you." 




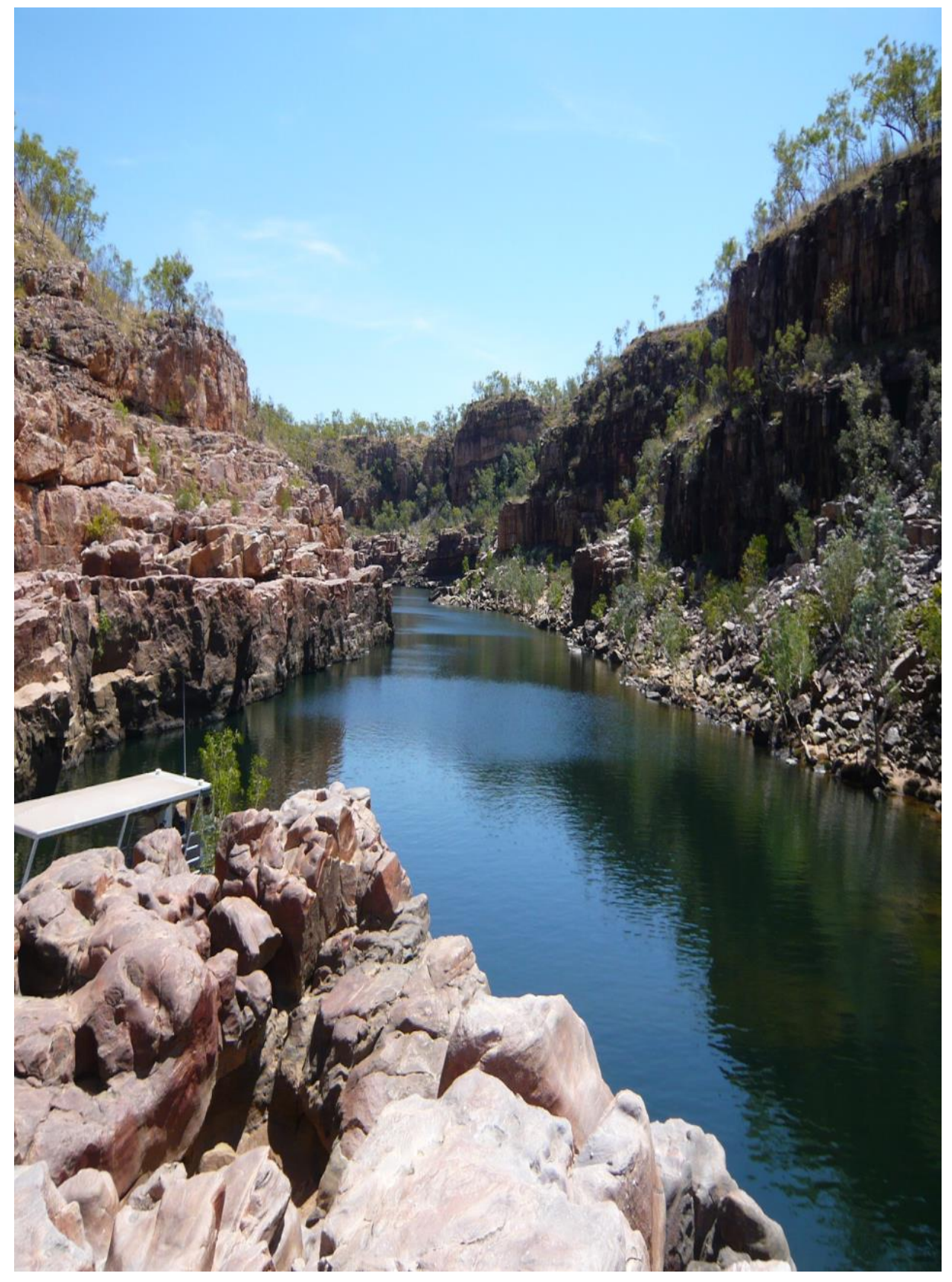

Introduction 

"Finding the world in the smallness of a grain of sand and holding infinities in the palm of your hand..."

Sting 



\section{Outsight}

they were network hubs, Higher Education Institutions (HEIs) communicate
faculty and students with the needs, goals, and challenges of any society. The
university hub broadcasts the incoming data from its teaching, researching and generated knowledge to all active public authorities, business community, society, and international Academia.

But different human generations bring different educational needs that require a different approach to teaching methodologies, tools, and spaces to face the same purpose since $1088^{1}$ : to better our society from knowledge.

Research Universities and HEls instruct students to improve society through critical thinking all over the world. After several years of following determined curricula and being supervised by lecturers and professors, students become professionals and researchers in fields like Science, Technology, Engineering, Humanistic, Arts, or Mathematics. The aim of those avid students is to answer future questions still not formulated by society. As Humboldt wrote "The student conducts research on his own behalf and the professor supervises his research and supports him in it" (Quoted in Christopher Clark, Iron Kingdom: The Rise and Downfall of Prussia, 1600-1947, p. 333) (Clark, 2007).

A closer look to the hub spots other connected elements of its map that feeds the transmission to excellence: degree subjects, learning objectives, tech-devices, hands-on experience, facilitators, and human connection. Elements that to be proficient swallow from innovation, collaboration, culture, personal experiences, research achievements, and digital integrators.

Since 2010, haptic devices, as digital integrators, have sneaked through the concrete slits breaking the configuration of the current university curricula. In less than five years the university map has changed from Paper-Based to Digital. The implication of the elements within the university mission is not the same for the generational cohorts that share the same space, neither will be for the 2030 future students to whom haptic interaction on touchscreens is one of the first and the most imitated communicative acts since 2007.

\footnotetext{
${ }^{1}$ Bologna University was the first university in the world.
} 


\section{Insight}

The baby citizens that society is nurturing since 2010 have innate digital skills learnt by imitation and observation. They are innate manipulators of interactive screens, indeed in most cases they do better than their parents.

Among those children we emphasize the presence of the iScholar: a Haptic Generation kid, born after 2010 witness of the irruption and avid observer of a new learning landscape full of digital habits that are combined with traditional ones.

iScholars are those students that aim to better knowledge as an extension of their passions, to benefit from the culture of long-life learning, and to solve problems still not known by our society with an Active role in their own learning, fostering Reasoning with an exceptional Open-minded vision, and driven by HAptic interactions as innate learning style to promote expert understanding.

Researchers, scholars, and lecturers should dig deeper into the new habits of the Haptic Generation, listen to them, observe how they relate to their surroundings, and interpret the meaning of those new abilities that will drive a new approach to learning.

As PISA 2015 Results (Volume I) Excellence and Equity in Education concludes, in Spain only the $23 \%$ of the individuals aged 16-65 have a good level of literacy and numeracy skills. In general, Spain has a high early dropout rate in higher education, and the students take too much time to complete their degrees, what means higher expenditure for public grants. Also important to mark that less than half of students learn a second foreign language (OECD, 2016), an important skill for the workforce of a country.

Lifelong learning covers from early childhood education to adult learning. An early start can have a long-lasting impact on the ability to learn. (Meltzoff, Kuhl, Movellan, \& Sejnowski, 2009) shows that children are able to acquire both cognitive and non-cognitive skills during infancy, and these early stages are crucial for enhancing their learning abilities, and boosting second learning language.

Programme for International Student Assessment for 2015 (OECD, 2016) results confirm that those children that attended early childhood education perform better when they are 15 years old. Universal access to knowledge while engaging children to learn is a challenge for any educative system irrupted by digitalization which should provide a full coverage on relevant skills to ensure an effective workforce.

The Organization for Economic Co-operation and Development (OECD) confirms in 2018 that the quality of compulsory education needs to improve in order to equip students with higher levels of skills and new sets of skills (Williams, Figueroa, Golden, \& Crosby, 2018).

Comparative international evidence from PISA "shows that successful education systems also set high standards for all students by modernizing their curricula and aligning them with evaluations 
that signpost the skills required at different stages. More diverse student populations also require more individualized teaching, which allows students to reach their goals through different pathways" (Williams et al., 2018).

But what do we know about the Haptic Generation children that are right now nurturing their creativity by playing with their parents' haptic devices?

For those who want this generation to succeed, there is a long debate to hold and some open questions to formulate: What is it so irruptive in the device that keeps researcher's attention to its learning opportunities?; Is it true that haptic devices can reverse the educative system that we have in our schools and universities?; If yes, how can we help early childhood to succeed surrounded by these new online behaviors, where the good, the bad and the unknown edges hold sides? ; When, at which age, should we open the digital opportunity for those kids, how many hours per day, in what specific fields?, Where should we start the process for real understanding of the irruption?

School, and university stakeholders should promote the enhancement of students for a responsible, smart, and resilient social attitude in a connected world where their digital literacies will allow them to solve new problems, and face challenges still not known.

\section{Statement of the Research Questions}

Could it be possible that a so simple gesture on a touchscreen (haptic interaction) from the tip of a tiny child finger, repeated all over again, provokes a new ecology for learning weakening the configuration of formal education in such a way that enforces to reshape the educational system?

My question, formulated as a premise in 2015, set the framework that grounds the research conducted. The answer is believed to affect education valuing haptic devices for learning, to condition university policies and strategies, and to suggest a new learning scenario that blends formal, non-formal, and informal settings and establishes a new curriculum to excel scholar learning.

The early access to authentic and curated knowledge by early childhood, nurtured in a digital and haptic atmosphere, boosts the acquisition of different literacy skills. As it can be deduced, those children will have different intellectual needs than those of previous generations whose education was based mainly on instruction, pen, and paper.

The purpose of this dissertation is to foresee the implication of this premise into the educative landscape by tackling the following research questions:

- RQ_1: Can Haptic generation children boost creativity, literacy, and bilingualism while using haptic devices?

- RQ_2: If children can boost expert knowledge, what type of student does Spanish higher educative system expect by 2030 ?

- RQ_3: Having iScholars thirst for reasoning around to which type of learning scenario should education (in general), and Spanish Engineering Higher Education (in particular), look at to fulfill their future learning needs? 


\section{Dissertation Structure}

This dissertation is arranged in three parts and follows a socio-ethnographic point of view to answer the research questions proposed. The concluding answers rely on available quantitative and qualitative research on this topic from different disciplines.

Part A (State of Art: The Drivers) describes the drivers that guide the writing as the state of the art to draw scientific analysis on. The first driver, the irruption of haptic devices (Chapter 1) has meant a social change that has affected the different generational cohorts (second driver) and has acquired a relevant position from an educative perspective in the last decade. (Chapter 2) frames the Digital Scope by describing the use of digital technology by the different generational cohorts. People from the different cohorts act as a driver for haptic generation children (HapGens) when they imitate how elder use the devices. For these children interaction with haptic devices is part of their routines and a way to communicate as well as to learn new things.

Part B (Research Design \& Data Collection) describes the Methodology (Chapter 3 ) followed during the data gathering and justifies the different decisions taken during the process of Data Collection (Chapter 4 ) where to fundament the findings and the conclusions.

Part C (Data Discussion and Implications) gives answers to the research questions proposed in Subsection 3.3.3 by discussing the findings, and narrates the implications that are going to affect all levels of the formal educative system, teachers, practitioners, caregivers, and parents.

Chapter 5 (Early Learning and Haptic Devices) gives answer to RQ_1 by analyzing the different variables that make possible for children to boost creativity, literacy, and bilingualism. The analysis confirms that not all the HapGens will achieve the same level of literacy expertise neither will have the same scholar interest when it is time to go to the university. But there is a group of children, to whom we call the iScholars that will master expert knowledge, and will demand different learning experiences to the traditional university configuration.

Chapter 6 (The iScholar) defines the generic and distinctive aspects that characterize the iScholars as those 2030 university students, from other members of their generational cohort. For this purpose, the meaning of "iScholar" is specified as an intentional unit (specifying the characteristics that define it) and is presented in an objective, concise and brief manner, thus responding to RQ_2. The way they are learning directed by haptic interaction is thought to be a precursor of better intellectual results; thereafter they will need a new learning scenario that takes their new skills for granted. 
Chapter 7 (The Learning Atrium) considers the iScholars as main participants of 2030 university degrees and proposes a new learning scenario. The sections crumble the foundations, panes, and different participants of the Learning Atrium. Our Atrium is a polyvalent space that seeks for iScholars wellbeing and fix scholar objectives under an STEHEAM Scope to face educative challenges from a systematic, feasible, efficient, ethical, participative, and disruptive perspective.

Haptic generation children seem to be technically innate, tech-savvy, and use interactive screens as if they happened to be another part of their bodies. Within a wink of an eye, smartphones and tablets started to be part of the new playmat where children can boost creativity, literacy skills and bilingualism.

Are we ready to learn about the 2030 university student that is right now at our side, spying on us? 



\section{SECTION A.}

State of the Art. The Drivers 



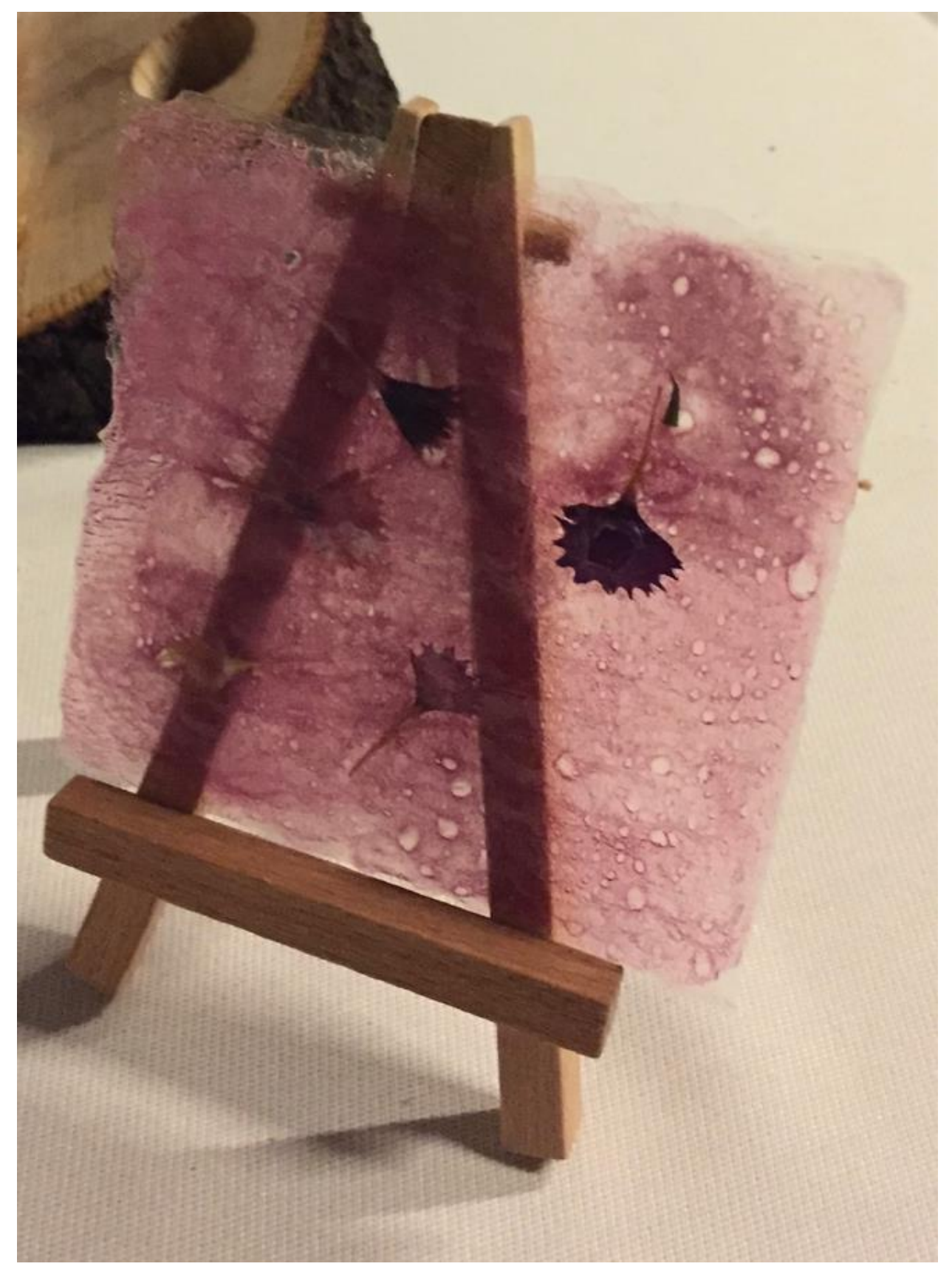

Haptic Device Irruption

Chapter 1 

"I never teach my students; I only provide the conditions in which they can learn."

Albert Einstein 



\subsection{Science or Fiction? Some Historical Facts}

1974 Arthur C. Clarke, science writer and co-writer of "2001: A Space Odyssey (1968)" screenplay, predicted, accurately that in 2001 every household would have a computer console (laptop) connected all over the world (internet). Clarke, as visionary, also commented on online shopping and banking, instant messaging, and web browsers. Being 1974, his words sounded nuts because it was something unthinkable at that time.

The most revealing of that interview (Fig. 1) was when Clarke affirmed that people would be ruled

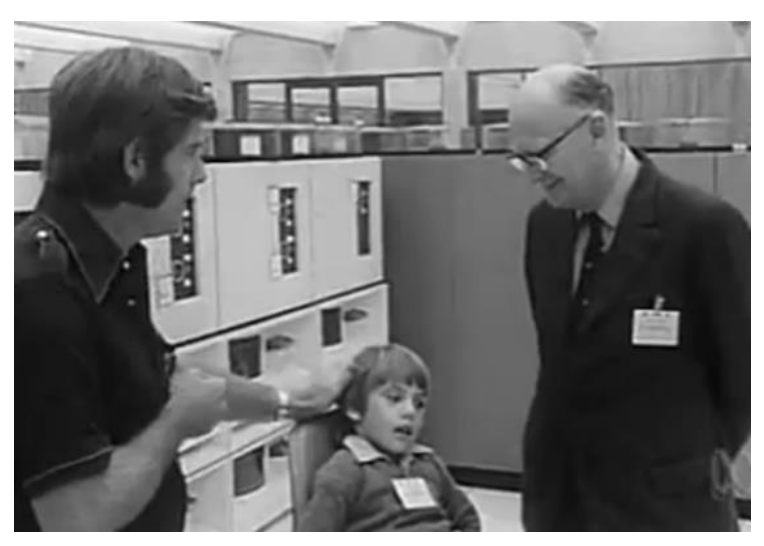
by online behaviors as part of a complex and modern society (global and digital) in the future (Ross, 1989). He also pointed out that those online behaviors would become the usual for citizen².

Fig. 1 Arthur C. Clarke Interview (1974)

\footnotetext{
2 [Interviewer]: "Now, with that movie 2001, you were projecting us into the 21st century. I've brought along my son Jonathan, who, in the year 2001, will be the same age as I am now. Maybe he will be better-adjusted to this kind of world that you are trying to portray."

[Clarke]: "The big difference, when he grows up, in fact, he won't have to wait for the year 2001, is that he will have, in his own house, not a computer as big as this, [points to nearby computer], but at least, a console through which he can talk, through his friendly local computer and get all the information he needs, for his everyday life, like his bank statements, his theatre re servations, all the information you need in the course of living in our complex modern society, this will be in a compact form in his own house ... and he will take it as much for granted as we take the telephone".
} 
The children of Generation X (b. 1965-1979) grow up with this movie in sight, and Neil Armstrong' first steps on the moon (1969) as promises of a different and modern future. Clarke, Isaac Asimov, Tom Swift Jr., or Philip K. Dick are just a few examples of science fiction writers that predicted from space travel to Artificial Intelligence, feeding the readers imagination, and dreams with any sort of machine or device that could transport the human being to a technological future landscape that, at that time, was impossible to believe. It was not until late 80 s when the first facsimile machines arrived to Spanish offices and public administration (1989); and the fourth generation of computers could be tested in public high schools (1986-1990).

In 1984, Faenet (the earliest internet connection in Spain) was created to improve science and research. Immediately, the IRIS project (Proyecto de Interconexión de Recursos Informáticos) linked work places and research labs to better communication among scholars and engineers, the early adopters ${ }^{3}$. In 1986, Telefónica launched Ibertex to expand the potential of tools further than research; and in 1990, the first connection to the internet in Spain using IXI, the "panEuropean" high speed network with $64 \mathrm{Kbps}$ of transmission was finally possible while members of Generation Y (b. 1980-1994) were at school and playgrounds (Think Big, 2012).

In 1993, the first Spanish web server appears at Universitat Jaume I, and the first email was sent by email using a technological enriched portable phone, precisely from a cell phone with added PDA functions: phone, pager, calculator, address book, and basic email (Cassavoy, 2007). The new technology had so much potential, that had to be expanded to households and private companies, and the Spanish government and Telefónica company started a dissemination campaign among the population. In 1995, there were more than 42.000 computers connected to the internet, mainly in public administration, including university campuses, and public schools. Those computers were connected to their local networks (WAN) as well as to the worldwide network (THE INTERNET). Around 1996, ADSL technology arrived to households, and the early adopters, citizens with high-tech curiosity, impacted the new market. With 320K internet users in Spain and $30 \mathrm{M}$ in the whole world, the Clarke's science fiction prediction became a fact (Think Big, 2012).

In 1996, children of Generation Z (b. 1995-2009) were in diapers, mobile devices were starting to span but they were used just to talk through. Anything surrounding the internet was exotic, weird, and dark. Its users were seen as odd people looking at a dark screen with green digits while waiting for internet connection that came through a slow and expensive modem. Furthermore, their purpose to do that was to speak with strangers using keyboards in IRC room chats.

Data regarding the use of the internet at home started to be analyzed in technical reports and national statistics. Experts on the topic participated in debates to inform regular citizens how to configure routers, navigate, or reach information that was not available in nearby libraries. But, despite the good opportunities, the asymmetric digital subscriber line technology (ADSL), which allowed to connect to internet at home, was very expensive and those citizens who were not related with public administration, business or university did not feel the internet as something useful for their lives.

Meanwhile, developed countries like the US, Finland and Japan betted on significant Information and Communication Technologies (ICT) addressed to population and social demand. The

${ }^{3}$ Early Adopter: a person who embraces new technology before most other people do. 
introduction in 1999 of wireless technology (Wi-Fi) (Virginia University, 2011) as a magic connection to the internet without any noisy modem or a physical wire helped to expand its use even more. Spanish Government, witness of the profound changes that ICT did in fields as diverse as leisure time, education, health care, work environment, and information access, invested in infrastructures (plan INNOVA. Plan Nacional de I+D 1996-1999. Ministry of Science and Technology, Spain) to bring ICT closer to the whole population, and studied exhaustively the adoption level of ICT by regular citizens (Fund. Telefónica, 2007).

From 2004 to 2005, Spain shifted the focus from infrastructure (networks and terminals) to the internet users with the aim of provoking a radical change in their attitude and gain more followers in lesser time (Fund. Telefónica, 2007).

Fundación Telefónica statistics until 2006 used to talk about services and their use, never about daily digital activities, and possibilities. Still in $2005,71 \%$ of the Spanish population claimed that the internet was not necessary for normal life either by ignorance or by inexperience. The population could not see any personal benefit in being looked up in a room, facing a desk computer waiting for connection and get information or be in contact with somebody. At that time, to have a computer at home connected into the internet was expensive, a waste of time, and the gaming use, that most young people were doing of it, was not enough reason for the investment that a family could afford.

In 2006, the sudden arrival of new online markets targeting leisure time shifted the concepts and personal preferences. Recommendation systems for digital music, online games like SecondLife (LindenLab, 2003) linked players from all over the world, online newspapers, IP voice technology, free cloud storage, email, or digital TV, among others were offered by free as marketing strategy to create the need and spread the word. The strategy brought also cheaper laptops and more leisure time spent on the computer (gaming, surfing the internet, reading, listening to music, etc.) The devices gave the opportunity to users to learn new things that were not written in books. New data indicators started to be taken into account to measure the type of activities that were more popular (more than 50\%) in communication services like browser, email, SMS, chat; and information services like leisure information or personal interest, news, education, search for telephone numbers and addresses (Fund. Telefónica, 2007).

The ICT benefits for administration, as well as for industry, education, and the development of the country were unquestionable, but the investment at home was not worth it. So, still in 2007, Spain had mainly young internet users using an internet connection at work, universities, public places, libraries, or cyber coffees; but not at home. Citizens did not have the feeling of digital need. Routines that today are performed digitally (i.e. to check a driven direction) were "analog" routines (i.e. to check a driven direction in a paper map) and required different devices according to the purpose (TV, CD player, DVD player, photo camera, video camera, lanterns, calculators) (Fund. Telefónica, 2008).

In 2007, touchscreen devices (smartphones), and "Gesture recognition" as a main feature of its inbuilt software attracted the interest of the Spanish population of all ages. "The Think Different ${ }^{\circledR ”}$ slogan of Apple Inc. company framed in a controlled and structured corporate discourse with a clear market target, started shaking costumer's desires by creating a new social need, and opening 
a new door for personal and digital information. Cellphones (mobile phones) evolved into interactive devices which increased the internet $3 \mathrm{G}$ technology subscriptions up to $20 \%$ in 2008.

The iPhone ${ }^{\circledR}$ 3G 8GB model launched in 2008, interactive, and useful for entertainment as well as for productivity, changed web surfing access forever. A simple touch with the tip of the finger brought a new concept for marketing (AppStore) songs or videos. Software applications designed exclusively to take advantage of the device and personalize it (Fund. Telefónica, 2009). The interaction with the device was so intuitive that irrupted drastically into the mobile market, provoked a sudden dissemination, and changed the habits of citizens forever.

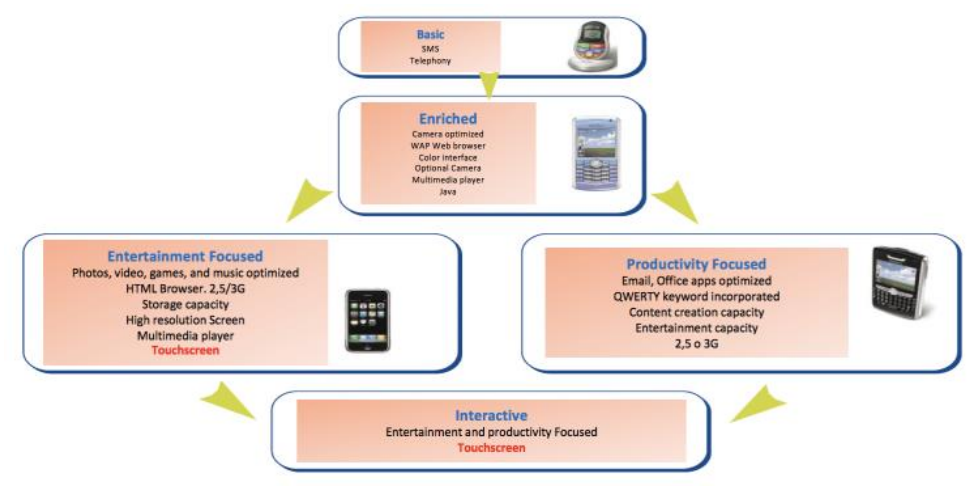

Fig. 2 From basic mobile phone to interactive

Fig. 2 shows the evolution of the mobile phone according to market and user's preferences. iPhone ${ }^{\circledR}$ (IOS) was first thought as a device centered in entertainment with touchscreen manipulation, and the Blackberry (Android) device was centered in productivity incorporating a small keyboard without touchscreen interaction. Competitiveness and marketing made devices evolve into touchscreen interactivity that would serve to both entertainment and productivity. The screen size of the touchscreen devices was evolving as well as its technological capacities doing that population could feel the need for personal use, thus becoming, in plain language, smartphones and tablets. These interactive devices will be defined as Haptic Devices in this dissertation.

The technological progress and the digital irruption have changed the way to understand consuming, relating, living, working, entertaining, and even learning. The impact of Haptic Devices on human habits has been so noticeable since 2010 that, the devices as such, have even been used to nurture and babysit some children since 2010, and have characterized the actual generation that will fill our university spaces by 2030. 


\subsection{The Irruptive Perspective}

\subsection{1 i_Learn \& i_Different}

The worldwide irruption of haptic devices in society cannot be understood without introducing Steve Jobs (1956-2011), founder of Apple Computer Inc. (1977), and his "Think Different $^{\circledR}($ slogan)" perspective. Jobs was a creative entrepreneur who applied imagination and inventiveness to personal computing (Isaacson, 2011). The new products that the company introduced into the market changed the technological landscape towards digitalization and individual digital experiences.

Apple ${ }^{\circledast}$ ignited the personal computer revolution in the 1970 s with Apple II. Jobs as the only face of the company, reinvented it in the 1980s with Macintosh, and started leading the industry in innovation with $\mathrm{iMac}^{\circledR}$ (computer) in 1998. The arrival of iMac in 1998, as an "all-in-one" product for home use (Isaacson, 2011), meant the iconic launch of the "i" of Apple products that revolutionized industry. The iMac was intended to be the first computer that made "easy to get on the internet" in just one plug and play.

The compact device was very personal, and the slogan "to think different" behind the iMac label targeted the personal use of computers at home; and brought new concepts like cyberspace (the home of the mind), global communication (global conveyance of thought), and digital democracy (ways by which electronic platforms can engage and secure the wider and more informed participation of the public) (Barlow, 1996) to common speech.

The marketed " $\mathrm{i}$ " in the name of the products, and logo emphasized that "the devices would be seamlessly integrated with the Internet", reminding also for "Individual, Inspire, Inform, and, Instruct" (Apple Events, 1998), as well as "me" showing the personal aspect of the campaign. The perspective gave the feeling of a new philosophy of life in terms of "Intuitiveness, Inspiring, Interactive, Instant, easy to use, easy to get on Internet and, deeply personal" that was added to digital integrators that provoked the differentiation of consumer/personal products from professional products within the technological divide.

In 2001 Apple launched three different products or concepts that transformed the way users were using technology till that moment, transformed industry, and made other companies like Microsoft to change their marketing strategies and the type of products that users wanted.

The first concept, iTunes ${ }^{\circledR}$ (application program), was aimed to understand the personal computer as a "digital hub" that coordinated a variety of devices and duplicated the contents for a better and comfortable use: CD/DVD players, cameras, hard drives, etc. All the devices were linked and synced with the computer in a way that allowed the user to have a "digital lifestyle" (Isaacson, 2011) meaning managing music, pictures, video and text at the same time. In-built software (Apps) like iDVD ${ }^{\circledR}$, iPhoto ${ }^{\circledR}$, Garage-Band ${ }^{\circledR}$, or iMovies ${ }^{\circledR}$, among others, were developed to "focus on making the product as simple as possible for the user, and on entertaining", both key factors to create a real need to modernize the devices. 
The second product was the $\mathrm{iPod}^{\circledR}$ (mobile digital device), innovative in terms of portability. The iPod was a pocket size device that could store thousands of songs in its first version, movies and podcasts in latter versions (Isaacson, 2011). iPod, as a device, became the essence of Apple products: "poetry connected to engineering, arts and creativity intersected with technology, bold design and simplicity in just one fingertip" (Silksoundbooks, 2015). Just one touch and users could manage their owned music, and audiobooks ${ }^{4}$ reversing the business around music towards digitalization.

The third one was the Apple Store ${ }^{\circledR}$ as a concept, and as a physical place. The Apple Store is a minimalist and airy place where users can try out the ethos of Apple products: playful, easy, creative, and on the bright side of the line between hip and intimidating (Isaacson, 2011). The Apple store became a new costumer experience that included demonstration and tests of the products. As a concept, the Apple Store reversed ITC sales and customer services.

In 2003, music industry was facing illegal copying. Swapping among digital contents evolved into piracy, and the sales of original formats were fading. "Napster", "Grokster", "Gnutella", "Kazaa" were web services that enabled people to download songs for free by sharing content among users (Isaacson, 2011). It was then when the iTunes online Store ${ }^{\circledR}$ was born with the aim to beat digital piracy by selling original songs that could be immediately downloaded into the digital hub and transferred into the iPod.

iTunes store reinvigorated the sales of recorded soundtracks in a digital format but also changed the way users listened to music and owned original songs. Before Apple, recorded music was played from CD format, fading cassettes, and LPs, difficult to carry out in handbags. The handy devices and $\mathrm{mp} 3$ digital format made the rest. With time, the platform included movies (to rent or buy), and free podcasts to listen, following the same path than the evolution of devices, the design, speed, usability, and storage capacity. By 2005 the iPod sales increased in a 207\% the ones of 2004 (Apple Inc., 2006), and cellphones increased their popularity among citizens in developed countries, (Isaacson, 2011).

IPod sales and cellphone extensive use were the two influential facts that pushed Apple, innovation leader, to develop a new product: " a screen ${ }^{5}$ with the ability to process multiple inputs at the same time" (Isaacson, 2011), nowadays known as multi-touch: the tablet.

The proposal became the first iPhone introduced in 2007, "a revolutionary mobile phone, a widescreen iPod with touch controls, and a breakthrough Internet communications device with desktop-class email, web browsing, searching and maps-into an small and lightweight handheld device" (Apple Inc., 2007).

First iPhone brought new features and concepts. The most important one was the introduction of a new user interface (pioneer software) based on a large multi-touch display that let the user to control the device with a finger instead of doing it with the pointing movement of the computer mouse (Apple Inc., 2007).

\footnotetext{
${ }^{4}$ First audiobooks were originated in 1920 in UK for blind people in high quality audio format.

${ }^{5}$ The screen, made by Gorilla Glass, was an interface for touching, typing, and swiping. It handles the surface pressures intrinsic to these devices and, enables more sensitive and accurate responses.
} 
Touch gesture system was implemented to support major user actions. "Tap", "drag", "sweep", "press" (Villamor, Willi, \& Wroblewski, 2011), and in-built Apps icons like photo camera, music player, photo library, calendar, agenda, weather report, maps, calculator, note taking, real-time stock market, internet browser, messages and telephone; were filling our pocket and creating a new dialect.

The device has been upgraded with GPS, processing speed, 3G/4G and wi-fi upgrades, voice control, multitasking, Secure Authentication Systems, AR features, and many more along its evolution, changing the competitor's point of view and models and making from any touchscreen device a vital tech-savvy tool to most of the population.

In 2010, Apple introduced the $\mathrm{Pad}^{\circledR}$, a revolutionary in between a smartphone and a laptop that changed, again, the landscape of the computer industry and electronic consumerism. The new device could be used "for browsing the web, reading and sending emails, enjoying photos, watching videos, listening to music, playing games, reading e-books and much more" (Apple Inc., 2010). The device was introduced to passively consume media in full capacitive multi-touch, super responsive, precise, portable, very thin, and high-quality display. Users could hold the internet experience in the hands (Allaboutstevejobs.com, 2010) by sitting in their favorite spot on earth enjoying the views.

In Jobs words, behind iPads "Apple tries to be at the intersection of technology and liberal arts. It tries to get the best of both to make them extremely advanced products from a technological point of view, but also make them intuitive, easy to use, and fun to use; so that they really fit the user's needs; and it is the combination of both that makes this creative product unique. We have a handson area next door" (Allaboutstevejobs.com, 2010).

Nowadays, the unplanned uses of Apple products, the unplanned opening to a multiform digital content, technical development of Apps, the evolution of the devices, together to other technological advances, have resulted in a hands-on area for education. The irruption of haptic device is becoming a sort of serendipity for the educative system and the students.

\subsubsection{Corporate Discourse and Education}

The "Think Different" slogan became a new form of corporate discourse that has influenced, from the business perspective, the social well-being, communication, educational landscape, family habits, etc., as well as other companies' sales campaigns in little span of time.

One fact that arises when reading the previous section is that Apple Computer Inc. (Apple Inc.) was not the first in launching products based on technological innovation like smartphones or tablets into market. IBM, Nokia, Blackberry, Windows, or Samsung products arrived earlier into market. Their devices were superior on paper but not in the consumer's hands. Apple Inc. used its own persuasive and corporate discourse style to give a glimpse into a future that any type of consumer could wish and have. To own a portable device with such characteristics was expensive, but it could bring many usage possibilities in its in-built features as well as save time and space; the perfect hook that consumers felt attracted to.

For (Breeze, 2013), to talk about corporate discourse within a linguistic approach, is how "corporations around the world communicate with individuals, with other collective entities and with the world at large. It is concerned with understanding how language works in business 
contexts and how corporate identity and personal and professional relationships are configured through discourse." The process of understanding how language works in a determined brand or company is linguistically governed by contextual phenomena like culture, society, and the situation where it happens; also it is influenced by closely related parameters such as the sender, the recipient, the particular incident, and the aim of the conversation (Kołata, 2009).

Apple Inc. persuasive discourse reflected the two goals of human communication: to be understood and to be believed, both able to affect out the audience's beliefs, desires and actions (Taillard, 2000).

Apple Inc. as a brand, and Steve Jobs as chief executive officer (CEO), pioneered Keynote addresses in Apple annual Worldwide Developers Conference (WWDC) since 1989. Apple unique style is also replicated in the Apple Special Events; where new Apple products are unveiled initially to technology and business journalists, software developers, but also to consumers. The revolting marketing is aimed to sell products or ideas by enhancing the consumer experience (Hopkins, 2012) by showing real examples and giving real experiences with the product.

Apple Inc. keynotes combine quality, invention, and innovation in the form of storytelling within the same frame, scenario and setting. CEO enters the stage in casual dressing, displaying leisure appearance, and speaking passionately to the audience creating excitement by simplicity when talking about their easy-to-use products. The CEO makes company ideas understandable and memorable through telling common stories, demonstrating how to use it, and focusing on one idea at a time. The way the speaker walks around the stage freely, comfortably and relaxed, is another feature that Jobs' keynotes introduced and changed the marketing scenario forever (Gallo, 2011).

The stage of the theater recalls Apple stores, serving two main purposes: to "test-drive" new products and make it desirable to buy by summarizing the key features of the products, when, and where customers can acquire it. The setting is sophisticated but images projected are simple, not only in the way they present the product but also in how they work. Keynote slides guide the audience towards a fixed goal and convey precisely what the company wants to sell by creating surprise and a psychological need in the audience.

From a linguistic point of view, Jobs not only delivered information, but informed, educated, and entertained. His main goal was to appeal to the largest possible audience, inside the theater, and outside, even online, and portray led himself as the typical consumer using the product and talking to the audience, like they were his closest friends. His clever rhetoric, as an internal dialog, increased the dramatic effect of his utterances, by using exclamations, and repetition of words like: "extraordinary, amazing, cool." The effect of this type of discourse in the audience was to feel positive, enthusiast and passionate about the product that was on the stage. His communication style, that other CEOs imitated, opened the cluster door in Education.

From a discursive and linguistic perspective, Apple uses TED ${ }^{6}$ conference style: short and powerful talks storytelling framed (free viewing online since 2006) delivered by expert speakers on education, science, business, etc. that seek a deeper understanding of the world in plain

\footnotetext{
${ }^{6}$ TED is a nonprofit devoted to spreading ideas, usually in the form of short, powerful talks where Technology, Entertainment and Design converge (ted.com).
} 
language, understandable for any type of audience. Ted Talk's aim is to spread ideas around the world in line with Silicon Valley ethos (ted.com).

Keynote style is specific of storytelling: selected vocabulary and expressions that recalls old stories and tales framed in a very familiar situation. The powerful style makes the audience to feel comfortable immerse in the atmosphere of excitement that the big theater portraits. The target is clear: to sell personal devices to users in the same way as if they were buying food, indispensable for life. Within the performance, the speaker demonstrates how they work, suited in a unique brand style that passionate its followers. In the same way that TED conferences, the power of the discourse is so intense that has transformed the introduction of any technological gadget, even any presentation of data to a big audience.

Storytelling follows the three-act narrative structure: setup, conflict, and resolution. The setup introduces the characters and provides the background to move the action forward. Then, the products are announced by headlines and introduced with a short and simple summary that describes them in one sentence creating surprise and expectation, introducing the audience inside the conflict. The resolution of the problem arrives with the product itself. On stage it is demonstrated its features and its usefulness for the user experience rather than the technology itself. It is the real experience, so close to people's entertaining experience, what drives towards excitement and encourages the use of the product announced and the spread of the word (Gallo, 2017).

Apple's discourses have influenced workers, students, children, scholars, researchers, adults, senior citizens, labs, households, hospitals, scientific fields, innovation, leisure time, and any step of society due to its innovative way to address common issues to improve their lives. The spread of the discourse tied mobile digital devices to citizens, which helped to converge in the digital society where society is immersed right now.

The device-person bond has made corporate discourse to step into the education landscape and target educators, learning, and students. While speaking, the narrator shows how the devices work, which helps to expand their use so that learners can get benefit from them, save money and time. The type of discourse gave an elegant and smart twist to how haptic devices could be used also to teach and learn, and therefore help educators to boost children's imagination, ignite their creativity, and flex education to let the students configure their own learning path.

\subsubsection{Size \& Portability Impact}

\section{First Devices}

in 2010 Apple Keynote brought into scene a beautifully designed device light, completely wirel ess, light, portable, very silent, and connected to the internet in a 9.7-inch touchscreen: the iPad. The stage hosted a magical and revolutionary device, more intimate than a laptop and more capable 
than the smartphone. iPad ergonomics and multitouch ${ }^{7}$ potential brought balance to work far away from the office and the possibility to game anytime anywhere, with the advantage that customers would benefit from the web experience and enjoy it (Apple Inc., 2010).

The corporate discourse used to introduce the device into personal habits, as well as its easiness of use, and its intuitiveness made the iPad excel in its touchscreen capabilities, despite it was not the first device into market. The feeling of comfort in a living room or terrace while browsing, listening to music, reading the paper, or watching movies displayed on that screen could be felt from the stage of the Apple Inc. event. Costumers could envision themselves enjoying their time at their places, with that device at their hands, and selecting on purpose the contents as easily as turning the pages on a book. The imaged portrayed by Jobs immediately seized the attention of popular culture, and speeded up the sales faster than any other device observed in the consumers' electronic history.

Corporate keynotes sent a direct message to costumers: technology alone was not enough; it was the experience with the device what made it to be irruptive. The use and the personal experience spread the word by itself not just to the young, but to people of all ages (Ritchie, 2015).

The iPad and the iPhone became a new cult culture by being part of the mainstream. It really gave people a new platform to embrace and fit a digital lifestyle. Older people, business people, students, teachers, children, and every other group saw the wisdom and the affordances of Apple mobile digital devices, while competitors were not able to figure out the secrets of the device that made them stand between the quick glances to the smartphones and the deep dives into a computer (Ritchie, 2015).

The iPad had an unquestionably and huge impact on the industry and on consumerism. In 2010, The Guardian, among others, predicted that there would be no escape from the iPad; Barack Obama, President of the United States (2009-2016), autographed an iPad (The Guardian, 2010); Oprah Winfrey, in her American TV show, called the iPad the best invention of the century (Oprah, 2010); The Time Magazine named the iPad Gadget of the Year (Time Magazine, 2010); and Shannon Rosa, the first blogger documenting the experience of an autistic kid, Leo, wrote how the iPad was a "near-miracle" for her son on the autistic spectrum (Des Roches Rosa, 2010). Before the iPad, Leo's autism made him dependent on others for entertainment, play, learning, and communication; after iPad arrival, Leo showed independence at daily skills (Des Roches Rosa, 2010).

The use of the iPad as a personal device was growing at home but also in schools like Roslyn High School on Long Island that embraced one of the first iPad's pilot programs in 2011 (Hu, 2011). Teachers at Roslyn declared that iPad allowed them to extend the classroom beyond their walls and that it brought individual technology into the classroom without changing the classroom setting.

The display that remained portable but increased in size during the device evolution had two major impacts. Firstly, the possibility to use two-hands on the device (useful for music and games);

\footnotetext{
7 "Commanding a computer, smartphone or tablet via a touchscreen or touchpad by using more than one finger. A multitouch display is sensitive to gestures, which are predefined motions that perform an action such as rotating an object" (encyclopedia2.thefreedictionary.com).
} 
and secondly, the type of things that could be performed could be shared by two or more people looking at the screen and using the same device at the same time, creating a comfortable conversation. The device is personal, for individual use, but can be shared in a comfortable way, a difference from personal laptops and smartphones (Ritchie, 2015).

From the industrial perspective, the impacts of the iPad or any other tablet in normal life were many. People started believing they could use and take benefit of the device. It opened the access to users of any age, from kids to the elderly, because it was easy and big enough to manipulate. Before it, any other digital personal device was not a gift people would consider buying for grandparents or kids, but with the tablet it was different. The sales with those users as targets was an important fact that influenced statistics in its use and had implications in demographics. Kids started growing up with these devices around and could have access to learning contents faster and before than any other generation. iPad was fun to use, it kept children attention, and was an improvised babysitting device for quiet family meals at restaurants. For an ethnographic researcher in the same scene, the device could entertain and teach new things.

The affordability of these models, and its apps have brought digital magazines and eBooks into users' hands and has changed customs in reading consumerism. Users have been taken into real skies and into the depths of the ocean without leaving their homes. The devices have been used to perform concerts and shoot movies. It is a platform for gaming and productivity. It has been used in sports and medicine, education and enterprise, entertainment and engineering, robotics, health care, etc. (Ritchie, 2015); and its use for different purposes continue growing.

Along its first five years of existence, the device was more portable, thinner, lighter, personal, and powerful in software. Additional features like Touch ID ${ }^{\circledR}$ (fingerprint identity sensor), Apple Pay ${ }^{\circledR}$ (mobile payments solution), Retina ${ }^{\circledR}$ (display), among many others, and powerful chipsets and the development of IOS_apps like iWork and iLife suites, Flipboard, Microsoft Office, Pixelmator, and Infinity Blade among many others made that users prefer to use iPad instead of laptops when doing regular computer tasks like reading, sending emails, writing notes, etc. Furthermore, it was easy to carry, and easy to connect to internet. The arrival of iPad re-defined the concept of "mobile", and had a profound impact on people's lives. It changed user's relationship with online services, data storage, data use, and mobile digital devices. Being digital meant "being interactive, being always and everywhere connected" (Ritchie, 2015).

\section{Pro Models}

Technological advance since 2015 has brought new features to touchscreen devices. The introduction of AR experiences, digital pens (computer input device), screen resolution and format has redefined the "smart" concept related to any device connected to internet (the internet of things) that any user can manipulate. They have played a major role in digitalizing people's everyday tasks and transforming how to approach education from a new perspective.

The integration of digital pens with suited apps has linked traditional handwriting to creative thinkers that till then, used paper as part of their workflow. It also has linked tradition to technology enhancing creativity as personal experience (Apple Inc., 2018b).

The technological giants have found in almost no time, the perfect driver to modify the setting of any educational institution to add Wi-Fi, smart boards, projectors, etc., allowing their students to use their own devices inside the lecture rooms, and adapting the curricula and the methodologies. 


\section{Haptic Device Irruption}

New haptic devices are designed to spark student's creativity, inspire them to succeed, make them believe they can learn something new and amazing by integrating it with other learning tools. Teachers can add drawing, music, film-making, video, or photography into their existing lessons plans, and the students can play them as many times as needed, in whatever place. The device irrupts as an opportunity for education to meet the expectations, actual and digital habits of the students (Apple Inc, 2018).

Haptic technology has brought to society digital improvements that affect life and have inspired every field from productivity, design, illustration, engineering, to health care, gaming, and entertainment, to global education. The impact of the arrival of haptic devices on the habits of the citizens and customs have transformed learning and creativity; there so, the educative system should take advantage of it and continue transforming formal learning.

Touchscreen devices are granted for kids since 2010. Society and the educative arena cannot pretend the devices do not influence children behaviors, and attitudes, among other reasons because adults cannot imagine themselves without their devices as part of their bodies or outfit. 


\subsection{Learning from Screens}

\subsubsection{Passive Screens}

The arrival of the television into our households in 1950 offered a new arena for learning or distracting by broadcasting media contents addressed to children. "Mr. Roger neighborhood" (USA, 1968), Sesame Street (USA, 1969), or "Barrio Sésamo" (Spain, 1979) are examples of TV shows with learning contents that bridged culture and education in a fun program addressed to young children.

Television and/or computer as teaching tools put early screen exposure into deep research to demonstrate if infants, toddlers, and preschool children could learn from passive exposure. Other questions that researchers tried to answer were if that learning could be beneficial or not for their brains (Zimmerman, Christakis, \& Meltzoff, 2007), and if the children could have the ability to transfer learning from television to real-life situations (Anderson \& Pempek, 2005). It is well known that along history, education has taken devices not originally created with educational purposes as tools to make themselves efficient in the educational landscape (Hemmi, Bayne, \& Land, 2009).

The first findings were not optimistic, and the term "video deficit effect" ${ }^{8}$ started to be used in pediatrics, conferences, and classrooms signaling that children could not learn from screens. there so, the fears of the unknown (what is behind a screen) in terms of learning when a child was in front of a TV, was also applied to any technological device that was sold in markets (a computer, a tablet PC, etc.). In that line, Meltzoff proved that despite infants were more proficient at imitating from real life situations than imitating from television, they could imitate from television (Meltzoff, 1988). So, the passive watching of the media contents (Fig. 3) could lead to learning, too.

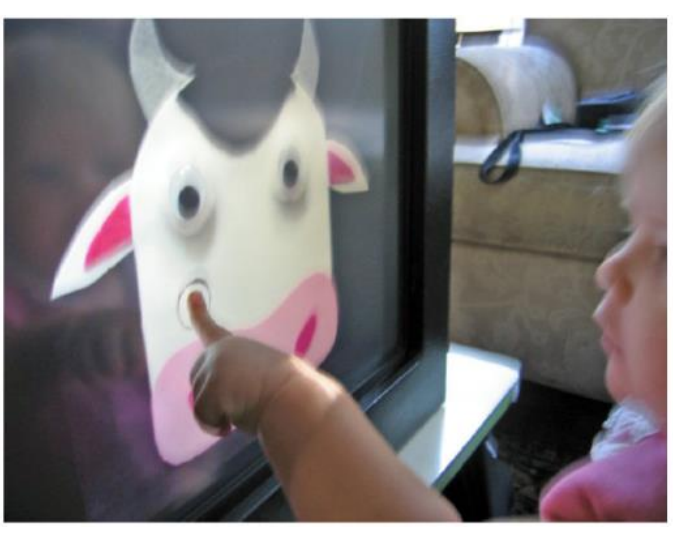

Fig. 3 First experiments with touchscreens (Zack et al., 2009)

In 2004, interactive games and books, addressed to children under three, appeared as a teaching tool ( $V$-smile and Leapfrog). Those new tools drove new lab experiments to test children's action of imitation with touch-screen procedures. The aim was to prove 15-month-old' learning transference from 2D/3D and 3D/2D encode and retrieval. According to Zack et all, "infant

\footnotetext{
${ }^{8}$ The term "video deficit" refers to the phenomenon in which toddlers show better learning from in-person demonstrations by a live teacher than the same demonstration presented on video (Kirkorian, Etta, Yoo, Jin, \& Skora, 2016).
} 
memory performance was enhanced by the precision of the match between the cues presented when encoding and retrieving" (Zack, Barr, Gerhardstein, Dickerson, \& Meltzoff, 2009). The demonstration opened the Pandora box towards a new learning and promising scenario that was coming with the arrival of touch-screen devices.

Other authors (Ganea, Pickard, \& DeLoache, 2008) analyzed different data as facilitators of learning transfer including manipulation, pointing, naming, performance, and pushing. It was argued that the addition of background sound to the object observed on the screen "created additional cognitive load, thereby disrupting 6- to 18-month-old infants' ability to encode actions appeared in a video demonstration" (Barr, Shuck, Salerno, Atkinson, \& Linebarger, 2010). Therefore, the video deficit effect was not so relevant. Touch-screen learning tests started to show results in young infant representational flexibility when performing tasks that involved transferring actions across dimensions (Zack, Peter, Meltzoff, \& Barr, 2013). Experiments proved also that infants have different event-related potential responses to a real-world object and its 2D representation, depending on any individual and stimulus.

\title{
1.3.2 Interactive Screens
}

First touchscreen was described by (Johnson, 1965) as:

\begin{abstract}
"A novel input/output device for computer systems that has wires, sensitive to the touch of a finger, on the face of a cathode-ray tube on which information can be written by the computer. This device, the 'touch display', provides a very efficient coupling between man and machine."
\end{abstract}

But it was in 1984 when the first device with multi-touch technology could read multiple points of contact. Bell Labs developed a touchscreen that could be manipulated by human finger touches and could modify images. Myron Krueger worked up an optical system that could track hand movements (M. Grunwald, 2008).

The creation of the 'sensing glove' by Scott Fisher in 1985 was an important milestone in haptic technology. With it, moving or grasping things could be simulated in virtual scenarios for the first time (Jütte, 2008). The sensing glove, its possibilities, and a new use of the haptic perception term in the technological field helped to first define Haptic Device as a "device that involves physical contact between the computer and the user, usually through an input/output device, such as a joystick or data gloves, that senses the body's movements" (Webopedia.com, 2011). By using these sensitive devices, the user can send and receive information from the software using part of the body, a hand, in the case of sensing gloves.

Humans interact with technological devices by using tools (i.e. keyboard) or by direct skin contact (i.e. fingertip). A fingertip on a regular screen gives no extra information, but on an interactive screen, the finger becomes a computer input just by contact or by displacement using large movements or small oscillations, prompting answers to touch interaction in the form of new and relevant information. The haptic touch interacts and it is immediately associated to visual and acoustic aids that provoke new floods of information (M. Grunwald, 2008).

Human haptic perception (the sense of touch) has been described in technology by (Jütte, 2008) as: "a skin sensation consisting of a number of discrete aspects like pressure, heat, cold and pain". The appearance of touchscreens and interactive monitors at the end of the $20^{\text {th }}$ century made computers easier to use and increased the human tactile experience provoking a new form of 
social behavior that John Naisbitt coined as "high touch" (1982, Megatrends); placing the definition outside of the science computer field.

Haptic devices are composed by sensors, electronics, control software that enable communication between the device and the external control computer, a region or workspace (screen), actuators (finger moves) and software toolkits or applications (Apps). A fingertip on a touchscreen involves direct contact and delimited interaction on Apps (M. Grunwald, 2008).

It was in 2007, when Apple released its innovative touchscreen technology in a mobile device (the iPhone) with a completely touch-based interface, that the term "touchscreen" started to be popular (Erickson, 2012). Since then, haptic movements on that type of screen became touch gesture for users. Zooming or pinching with gestures could be used to activate some subroutines as inputs, and therefore, to obtain answers or outputs. Intuitive touch gestures on an interactive screen was the origin for the habits that users have adopted so easily. The touchscreen market spread fast giving birth to haptic devices, a new subclass of mobile devices, that allowed access to digital content with one fingertip.

Gesture recognition ${ }^{9}$ has the goal to interpret human gestures with mathematical algorithms. Touch gestures use fingertips mainly as a way of interacting with devices and receive answers allowing to be more accurate and saving time when performing. By gesture recognition, it is possible to point the finger towards the computer screen so that the cursor will move accordingly (Vachher, 2014). Craig Villamor and his group defined in their touch gesture reference guide, the core gestures that perform major user's actions and are supported by touch gesture systems of the different haptic devices (Villamor et al., 2011).

The basic touch gestures defined are those made with:

- one fingertip: tap, press, double tap, drag, or flick;

- two fingertips: pinch, spread, press, press and tap, press, and drag, and rotate

- The major actions that the user can perform are classified as:

- basic actions: change mode, open or select;

- object-related actions: adjust, bundle, delete, duplicate, move, rotate, scale down, scale up;

- navigating actions: adjust view (rotate, zoom out, or zoom in), display commands, move through lists, pan, scroll, scrub;

- drawing actions: accept, cut, get help, reject, undo.

With these active haptic devices the user is able to perceive, manipulate, explore, and grasp information in a virtual environment using his sensory registers and place it in the working memory by just one touch (Atkinson \& Shiffrin, 1971). So, brain can benefit from its use by incorporating information in chunks that are composed by visual, auditory, and haptic senses at the same time (Baddeley \& Hitch, 1974).

\footnotetext{
${ }^{9}$ The mathematical interpretation of a human motion by a computing device (Whatls.com, 2018).
} 


\subsubsection{From Passive to Interactive}

Looking back at the ITC landscape in 2009, we observe two different types of technology: desktop/laptop that was difficult to carry on and mobile devices that included those devices that could be carried on in a hand bag. Technically, they were very similar and there was no standard format, size, or shape. Both types used virtual or real keyboards for data input, had screens that responded to either gesture, styluses, mousers, or touches; and both needed operating systems (MS-DOS, Windows, IOS) to perform actions.

From the user's experience, they were completely different (Traxler, 2010). Mobile devices included smartphones, game consoles, digital cameras, media players, netbooks, in-car satellite navigation, among others, and offered portability, affordability, and the capability to be used anywhere; features that computers did not share. Mobile devices allowed users to process information whenever and wherever they wanted; be instantly connected with other users, customize, and personalize the device for individual use. Users could tailor the applications to specific goals and purposes in those handy devices (Melhuish \& Falloon, 2010).

Mobile devices demolished the need to tie computer activities to a physical space or time. Placed in the hands of the students, new challenges and opportunities were added to support long-life learning by creating, using, consuming, and storing digital content. New concepts like connecting people, interchange information, or virtual collaborative spaces stimulated a rethink about when, where, and how learning could occur (Melhuish \& Falloon, 2010).

The sudden irruption of iPad in 2010 (iPad $1^{\text {st }}$ Generation) started to change the experimental setup and procedures to obtain results when researching about early childhood learning and its social surroundings. As (Melhuish \& Falloon, 2010) state "for the first time, there is a functional mobile device in which the readable touchscreen frees a learner from the constraints of a keyboard, removes the interface of a mouse, takes away the size constraints of smartphones, and removes the weight issues of laptops".

For the first time, adult users and children had, in just one device, the portability of mobile devices, the increased power of a computer, Wi-Fi access, Bluetooth connectivity, utility and productivity apps, media entertaining and, "on my way" possibilities of acquiring, storing, reading and, annotating informal learning.

With its irruption, a social transformation could be observed. Firstly, in the way adults used mobile devices on daily basis (as parents): to communicate, search for information, self-expression, buy, socialize, entertain, get directions etc.; and secondly, because those same adults were surrounded by early childhood ${ }^{10}$ (Paciga \& Donohue, 2017) watching and imitating them (as progeny) as silent observers of any performed task on the device. The evolution of the devices and its connectivity during the last eight years, also helped in the irruption. The sudden and quick irruption opened a

\footnotetext{
${ }^{10}$ Early Childhood: "children's age ranges (chronological age 0-8): infant (0-18 months), toddler (18-36 months), preschool (3-5 years), kindergarten (5-6 years), first grade (6-7 years), second grade (7-8 years)."
} 
huge door to globalization, innovation, online market, digital skills, multiple channels to communicate, etc.; what is nowadays known as digital society. Consequently, the educational paradigm started to demand a new focus, a new approach where evidence-driven and decisionmaking are key factors to personal pathways, together to information literacy skills. The digital awareness needs the educators' support by guiding, teaching, and helping to overcome new challenges. Classrooms or lecture halls become fluid environments where educators instead of show-and-tell exchange, can assess learning through the caption of learning experiences outside the classroom, in the form of images, videos notes and audio recordings, as well as the traditional hand taking notes (Melhuish \& Falloon, 2010).

Touchscreens devices allow students to share authentic learning situations with others, as well as to be part of online learning experiences by creating stories. When using the devices, users bring personal stories into life by touching, hearing, and seeing in just one finger tip, because they are selecting and deciding where to link to continue building the story. The selections match their intellectual preferences.

As it is well known, the stories that children listen to in their formal learning years, are not going to be remembered per se, but stay with them throughout their lives; and the same happens with the information that a finger touch brings to the screen, they are not going to be remembered but stay in the literacy acquisition process and in the mental process of understanding. People's brains are quicker at learning and retaining concepts conveyed via stories. Stories help learners to identify situations by using portrayed characters, and to evaluate the relevance of the content for their learning purposes (Kory Westlund et al., 2017). 


\subsection{Haptic Device}

\subsubsection{Definition}

Collins English Dictionary defines Haptic as an "adjective relating to or based on the sense of touch." The word comes from the Greek term haptesthai that means "to touch" (HarperCollins Publishers Limited, 2018). Technical dictionaries define haptics as "the science of applying tactile sensation to human interaction with computers" (Whatls.com, 2018).

As explained in Section 1.3, the first definition for Haptic Device referred to a device that could be manipulated with a joystick or data globes (Webopedia.com, 2011). Later technical dictionaries define Haptic devices as "those devices that user can not only feed information to the computer but can receive information from the computer in the form of a felt sensation on some part of the body" (Merriam-Webster, 2015).

But none of the previous definitions reflect the fingertips touches that act as inputs on a touchscreen, surely because those interactive screens did not exist and probably the term has not been updated. In fact, up to now, there is no formal definition that reflects the new capabilities of some mobile devices that have reversed the technological industry by inviting users of any age to interact with them, and open a new door to knowledge acquisition. Those devices have transformed people's lifestyle and have helped to create new habits that should be reflected in its definitions.

Taking the above into account, we define Haptic Device as a mobile digital device with high-resolution Multi-Touch ${ }^{\text {TM }}$ display and touchscreen interface that lets users physically interact with applications and content by using fingertips. The device should contain, at least, application programs, voice recognition software, integrated camera, internet connection and an operating system software to run the device.

The device includes an interface based on a large multitouch display that allows users to control the device intuitively with their fingertips, and interact with them as if they were computers. With the device, the user can handle many Apps for routinely automatized actions like surfing the web, reading, email checking, camera function, voice recorder, photos storage, play videos, listening to music, texting, GPS, etc. simply by finger taping a name, number, link, or App (gestures) on the screen an input, and receiving haptic feedback as an output. Haptic devices include any type of smartphone, tablet, wearables, and any future device that can be managed by finger touches.

Haptic interaction referred as haptic feedback by (Llobregat-Gómez \& Sánchez-Ruiz, 2015b) (Patchan \& Puranik, 2016) provides a way to physically engage users with tactile feedback to get attention on the action performed, and reinforce new ones. Haptic interaction has helped to open new human neural possibilities through new habits that involve the tactile, the auditory, and the visual sense in just one fingertip. With the arrival of new habits, new ways of understanding, expressing and approaching to knowledge are expected (Llobregat-Gómez \& Sánchez-Ruiz, 
2015b). The inclusion in our households of such devices has given birth to a new type of student, the iScholar, an already born member of the Haptic Generation.

\subsubsection{Data}

Nowadays, adults have active haptic devices at hand (smartphones, tablets, smart watches, etc.), and the average of device checking any type of notification is forty-seven times per day. Young adults aged between 18 and 24, check them an average eighty-six times per day (Wolfe, 2018). With this so frequent use, it is impossible to keep haptic devices hidden from kids and their innate curiosity and interest. If infants learn mainly by imitation (Gopnik, Meltzoff, \& Kuhl, 2001), and essentially by imitating their parents or caregivers, it is logical to highlight that children's way to approach learning is going to be surrounded by interactive screens, and that they will need new literacies to acquire knowledge. How children will approach learning with the different tools will depend on different factors that will be tackled in Chapter 5.

To avoid children to have contact with haptic devices is near to impossible because the devices serve to many very different purposes. Adults can avoid to text or surfing on the internet while there are children around because it is time consuming and can lead to bad device usage. But a sudden notification can require adult device manipulation having the kids around, or children can copy gestures from other adults of their surroundings when manipulating the device. To check for the weather, look for a GPS location, quick text answers, or bank transactions with the haptic devices have become common and unconscious personal routines quite difficult to perform without the attentive and spying look of a child at the bus, at the restaurant, or at home.

Bulky laptops, DVD players, Hi-Fi systems, and dashboard-mounted GPS devices among others, are disappearing in pro of the ubiquity of haptic devices. Device utility and productivity meet user needs, save time and space. One core gesture on the screen implies direct interaction, entertainment, communication with friends and colleagues, information, shopping, multitasking, learning, creativity, etc. Devices can be carried out in hand, pockets, or handbags; and provide users of any age the possibility to embrace a digital and online lifestyle.

As (Russo-Johnson, Troseth, Duncan, \& Mesghina, 2017) affirm the adoption of smartphones has permeated the socioeconomic status of most of the families, what can be interpreted as having at least one haptic device in any home regardless of the family's economy.

So, for example, in 2015 the $90 \%$ of US toddlers of low-income families had used touchscreen devices by the age of 2 , and the $83 \%$ of children under 5 had a tablet in their homes. Spanish data for 2015 is not very different. (DITRENDIA, 2016) and (Fund. Telefónica, 2016) statistics show that the $80 \%$ of the population own a smartphone, and in three out of four households there is a tablet. In 2018 the $97 \%$ of population owned a smartphone, and the $70 \%$ more than one haptic device, differentiating the use and possibilities of each device for different purposes by the different members of the same family (DITRENDIA, 2016), (Fund. Telefónica, 2016).

The wide use of haptic devices and apps in daily routines makes them almost become part of the human body, and provokes a debate on the mental developmental effects on children with issues like type of impact, effectiveness, exposition age, maximum time of exposition per day, the different uses that the kid can make of them, the possibilities of real learning experiences, and the acquisition of digital literacies implied with their use. 
From the educational point of view, it is reasonable to think that haptic devices, used actively ${ }^{11}$ by children, give the possibility to learn in ways their parents and grandparents never had, and that the device brings also not only learning but unknown effects on children's brains. The haptic perception relates to the sense of well-being of children in their learning environments because there is a relationship between the physical input played in the devices with the real and instant information displayed in the interactive screens. In relevant neuro-response, there is a direct relationship between what children are feeling or doing (input) and what they receive as answer (output) (Meltzoff, 2007a). By using haptic devices, the window of comprehension and understanding is wider. Its dynamism and portability, being at hand, its intuitiveness, and the possibility to enjoy the experience brings learning opportunities that no other device does.

During 2017, the $68 \%$ of the world population, and the $97 \%$ of the Spanish population owned a Smartphone and the $74 \%$ a tablet. The use of tablets is quite widespread (80\%) in children between 2 and 10 years old (DITRENDIA, 2018). The Haptic Generation (2010-...) has born surrounded by those devices sharing space with other toys, and games, as if they happened to be another member of the family.

When we observe children manipulating haptic devices, it is very clear that these are very appealing from children's point of view. Design, size, portability, multipurpose, access to different types of content, and finger interaction are features that make them the perfect tool to carry on everywhere for entertainment, and at the same time, to use it as an interactive window to authentic material exposure for learning in different formats maps, videos, songs, games, drawings, texts, etc.

\subsubsection{Device Features that Enhances Literacy}

\section{Learning}

\section{Digging for Learning}

No previous technological device has opened access to such vast amount of knowledge. For children, it is just magic, they receive immediate answers to their interactive movements without realizing from where the information is coming from. One finger touch on an interactive map brings real images of the place, and children can observe how the place looks like just as if they were there, creating vivid memories.

The devices allow users to game, write, sing, draw, watch a movie, communicate with family members, take pictures, search for real facts, etc. and surprisingly several things can be performed at the same time, anywhere, at any time, and in an optimized sized screen. Early childhood is able to use haptic devices and therefore, express, share and communicate their ideas to others in multimodal and meaningful ways (E. Khoo, Merry, Nguyen, Bennett, \& Macmillan, 2015)

\footnotetext{
${ }^{11}$ When the user interacts with the device, and participates in the process of the action performed with a positive attitude.
} 
improving their personal learning. The device is attractive enough to inspire at any age productivity, design, illustration, engineering, medicine, gaming, and entertainment, as examples.

If we think about education, the positive side of haptic devices is that they boost creativity and learning at any age (Chapter 5), and helps intellectual development also in case of brain injuries, learning disorders, and other human disabilities (Maich, Sider, Hall, \& Henning, 2017).

Digging inside the device one can find technical specifications, accessibility features for people with disabilities or people that do not have enough knowledge about the devices or connectivity, and built-in support for learning and literacy. Also, zooming in and out, the multimodal formats, the different types of user interactions (fingertip, keyboard, digital pencil, and apps), and the capabilities of the system (Augmented Reality, Multitasking, Notifications, Screenshots) contribute to the attractiveness and enhancement of the device experience in pro of the learning (Apple Inc., 2018b).

To account for the possibilities of learning when children or adults interact with the touchscreens, as well as the affordances of the devices, we will describe the features of IOS tablets as haptic devices.

The author of this dissertation has selected the IOS tablet device as main technological tool to be used in the HG Case Study as well as to obtain the results, trace, and report the findings. The children have used parents' tablets (IOS or Android) or own iPad (Child I) and parents' smartphones. Parents were using their smartphones or laptops to report the experiences.

\section{Device Technical Specifications}

Haptic devices substitute many personal gadgets that share space in personal handbags and at home (i.e. the agenda, e-reader, computer, camera, hard drive, etc.). The following technical specifications and functionalities help to understand the sudden substitution of other tech gadgets to complete some routines and tasks, and help to understand why the device can be, and is considered in our research a learning tool (Apple Inc., 2018b).

- $\quad$ Storage capacity, and portability (different sizes, weights and displays)

- Buttons and connectors (speakers, microphone, on/off, volume)

- Photo Camera, video recording

- Voice and video calling

- $\quad$ Speakers and microphones

- Cellular and Wireless

- GPS

- Identity sensors

- Mobile payments solutions

- Voice recognition software

- $\quad$ Intelligent Voice Assistant

- Power and battery

- Operating System software

- Accessibility: VoiceOver, Zoom, Dictation, Magnifier, Switch Control, Closed Captions, AssistiveTouch, Speak Screen

- Built-in Apps: email, Podcasts, web browser, maps, calendar, notes, reminders, stocks, clock, browser, storage 
- $\quad$ Language Support: quick type keyboard, predictive input, Siri languages, dictation languages, dictionaries, spell check

- $\quad$ Third parties Apps

Portability, accessibility, multiuse, and interaction are the main important features that have contributed to spread its use and substitute other devices that could perform only one thing. Interaction with the device is instant and instinctive. Users can take pictures or notes, watch videos, draw, gaming, and create new content without almost explanations just guided by the own device or with user trial and error experience.

\section{Informing Learning with Assistive Features and Built-in Support}

The devices have Assistive Features like zoom, font adjustment, or lens magnifier to increase the size of anything focused with the camera. The camera flash allows to light objects, and the camera allows to snap photos to get a static close-up. Dictation allows to convert spoken words, numbers and characters into text avoiding typing. The assistive features are built into the device to complement vision, hearing, motor skills, learning, and literacy learning.

Using the assistive feature, users can create, learn, work, play, or perform learning activities where and whenever they want without changing the device or the place.

Among others, the device offers some built-in support (Apple Inc., 2018b) that informs learning:

- Reading Support includes features like "Speak Screen", "Speak Selection", "Typing Feedback", and "Predictive Text" ${ }^{12}$. Those features add an auditory component to texts, and help users to improve pronunciation and reading. It reduces the visual clutter and minimize ads, buttons, and navigation bars, allowing the user to focus on the selected content. Configurated in another language helps also to improve pronunciation or comprehension of the language selected. Reading support features turns the device into a powerful augmentative communication device.

- Integrated dictionary helps to get quick access to definitions and commonly used phrases which aids with spelling, pronunciation, and grammar in the moment of writing in whatever app.

- Intelligent voice assistant (IVA) enables users to speak natural language voice commands to operate the device, while the device performs the commands: execute apps, math commands, checking on internet, etc. IVAs offer a faster, easier way to get things done.

- Screen Time limitation help users to stay focused on the task at hand, and it also helps parents and practitioners to limit the amount of time spent with Apps, schedule a block of downtime, or choose specific Apps that would always be available. Activity reports give a detailed breakdown of where time is spent, using Gesture-based screen reader to include a description of the actions performed during the time used.

\footnotetext{
${ }^{12}$ Suggest word options to the user while typing.
} 
- Voice and video calling let the user communicate visually, whether by using sign language, gestures, or facial expressions. The feature helps to connect face to face people and learning options like online tutors or teaching sessions.

- Integrated camera, music player, and video recording let the user create digital stories by mixing different formats to express themselves. Users construct personal narratives by capturing photos, and adding music or recorded situations that help to interpret their reality.

- Keyboard Shortcuts allow to create customized words or phrases the user frequently uses with the device.

- Switch control to operate with the device without touching it allows to control it from other devices like desktop computer, laptops, and other haptic devices.

- Guided Access, Assistive Touch, Hearing aids and sounds processors adapt the MultiTouch screen to comfortability of the user. Those features provide sound and visual aid, and touch accommodation to make the screen respond to the different personal need.

To execute, display, and use different file contents allow users to create, and share content in Multimodal Format, or in narrative multimodal stories. The creation of content tells stories in the form of images, videos, audios, drawings, or texts, either in individual format or mixing them up in one digital format (e.g. a video that includes a song, a small video, and typed words; or a note that includes handwriting, voice recording a picture selected from internet and some drawings). Multimodal stories enrich knowledge and literacy experiences. Learning how to use the file formats that can be used, helps users to serve their skills with different contents, share the ideas, offer a new point of view, and be more efficient.

\section{User Interaction}

When we speak about Haptic Inputs on the device we mean the different core gestures one can perform on the screen like tap, drag and press (Villamor et al., 2011). Those cause-and-effect actions require procedural knowledge to generate interaction between the user and the device. The interaction can be performed with fingertips, peripherals, and Apps. Compared with pointand-click technology (mouse technology), gestures can be intuitively performed as an extension of the pointing human gesture (e.g. do it here or there).

\section{Fingertip}

Users interact with devices by placing fingertips anywhere down on the screen, those actions are called Gestures. The gestures provoke interaction and feedback from the device or across the system and in every app. The standard Gestures can be performed with one or several fingers. The most frequent ones are (Villamor et al., 2011): 
- Tap: activates a control or selects an item

- Drag: moves an element from side-to-side or drags an element across the screen

- Flick: Scrolls or pans quickly

- Swipe: when performed with one finger, returns to the previous screen, reveals the hidden view in a split view controller, reveals the delete button in a tableview row, or reveals actions in a peek. When performed with four fingers on an iPad, switches between apps.

- Double tap: Zooms in and centers content or an image, or zooms out if already zoomed in.

- Pinch: Zooms in when pinching outward, zooms out when pinching inward.

- Touch and hold. When performed in editable or selectable text, displays a magnified view for cursor positioning. When performed in certain views, such as a collection view, enters a mode that allows items to be rearranged.

- Shake: Initiates undo or redo.

- Rotate: Rotates an image or view.

Some devices offer 3D touch for additional interactive responses when pressing lightly on the screen. With 3D Touch users can access additional functionality by applying varying levels of pressure to the touchscreen. Apps can respond by displaying a menu, showing additional content, or playing an animation.

\section{Built-In and Bluetooth Keyboards}

The built-in keyboard offers the possibility to type on the screen characters and numbers by tapping on the screen-keys. It includes several features that make typing faster and easier. While typing, the keyboard offers suggestions for the words the user is trying to type. Also, the device auto-correct common misspelled words automatically and serves of the in-built spell checker to show possible words from its internal dictionary. Long finger press hold on the screen brings a magnifying glass to cursor position allowing to correct misspelling mistakes and continue typing. To switch languages is also possible with a 3D touch gesture, and all the features are displayed in any language that the devices supports (Apple Inc., 2018a).

In recent models a cordless keyboard can be used with the tablets via Bluetooth (wireless technology standard for exchanging data over short distances). The keyboard is of the same type as for a computer, and offers the same suggestions, auto-correction, spellchecker, and dictionary suggestions as the built-in keyboard.

\section{Digital Pens}

The introduction of digital Pens as input in latest version of haptic devices acted as a game changer in education and reversed the debate about handwriting at early stages. The pen captures handwritten analog information, and the software translates it into digital data, allowing then to use this information in different applications and serve for a variety of purposes. An example of that can be seen in Fig. 4. 


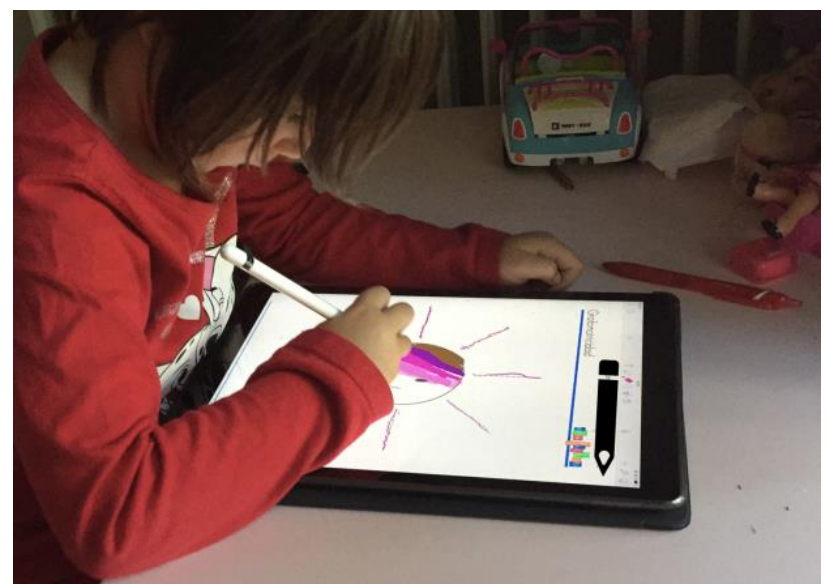

Fig. 4 Handwriting in a tablet device (Preschool)

Analogic handwriting is slower and does not offer automatic features, it also makes harder to take notes verbatim; but helps students to develop stronger conceptual understanding, sharp their critical thinking, and be more effective in memory recall (Mangen \& Balsvik, 2016). The impossibility to handwrite and the discomfort to write with the finger on the screen have made many adult users to reject a haptic device as a tool to be used at the same level as the personal computer, neither were they willing to lose the charm and freshness of the analog handwriting.

Personal computer has made many students switch to typing from handwriting. Finish educational system has dropped joined-up handwriting lessons in favor of typing due to digital impact (Taipale, 2014).

Typewriting and handwriting differ regarding the acquisition of hand motor skills, visuo-motor processing, and cognition. Handwriting leaves memory traces that contribute to memorization. During the handwriting process, the memory traces are reactivated to retrieve information stored in our brain, facilitating conceptual understanding (Gallese \& Lakoff, 2005).

One of the most frequent tasks when handwriting is note-taking. Depending on the setting (professional or educative) the process will get better benefit from handwriting or typewriting. (Mueller \& Oppenheimer, 2014) have found that in educative settings, typewriting can impede learning because of distractions in content processing as instead of brain storage, students use device storage.

Digital Pens are tools that feel familiar in hand, and transform user's interfaces in notebooks that better reflects the personality of the user, unifying handwriting to technology. The handy devices allow to input text with precision, and flexibility on a screen. It brings and encourages experimentation with the toothless surface of glass. Glass surfaces have been, previously, a material foreign to handwriting activities. Note-taking apps afford the possibility to organize thoughts, and document our knowledge by building on an idea no matter where the users are located, and they can do it by handwriting, then transferred to computer keywords, and then shared in multiple platforms, modes, and communicated to people (Gallagher, 2017). Writing on a touchscreen with a digital pencil becomes nonlinear, personal, fluid, spontaneous, instant, and multimodal. The user becomes comfortable and sensitive, as well as creative, free, and unique. Digital pens add an extra level of interaction to personal daily computing lives, and become new potential tools in the learning setting, a way to build out thoughts in a more creative way than 
keyboards and computer devices ever could; what makes the user to return to past customs, and recover writing traditions.

From the educative point of view, digital pencils allow drawing and scribbling which encourages student's imagination to snoop around the world with curiosity, and helps them to guess how things work. Random scribbling allows children and adults to articulate concepts that exist only in their imagination, concepts that cannot be said by words. The tool allows sketching to capture meaningful details in different style options.

\section{Intelligent Voice Assistant}

Intelligent Voice Assistant (IVA) is a voice-driven interface that includes a conversational agent able to recognize and respond to human voices. 2018 IVA agents in the market are Google, Siri, Alexa, and Cortana. IVA interfaces support a wide range of user commands using speech as an input and as a navigational tool (Apple Inc., 2018b), there so users need neither to look at or touch the screen to interact with the device.

Those commands include actions such as phone calls, checking information in one or more databases providing one or more search results, scheduling events and reminders, handling device settings, finding information on entertainment, checking map directions, among others. The actions engage with iOS-integrated apps to fully function. The autonomous technology of IVAs is going to drive personal devices into a new scenario in little span of time.

Voice recognition software was already widely used in fields like in-car systems, health care, military, aerospace, and also with second language speakers of English (Coniam, 1999). With the possibility to have it at hand, the assistants are being introduced in early childhood educational settings facilitating children to interact and perceive the objects (Druga, Williams, Breazeal, \& Resnick, 2017). Another field that is now under research consideration is the use of voice agents with people with neurodevelopmental disorders (Guo, Kamar, Vaughan, Wallach, \& Morris, 2019).

Haptic generation children will be working in environments with assistive voice devices, a new scenario that education must face from different points of view.

\section{Apps}

As any other computer device, haptic devices use intended applications (built-in or third-party Apps) to transform the haptic interactions (fingertips, digital pens, in-built keyboard, or voice assistant) into outputs or results such as checking for the weather forecast, calendar management, listen to music, take a photo, get directions with maps, email use, take audio or text notes, set alarms, control walking distance, light the flash in dark places, bank paying, etc.

Third-party Apps are aimed to communication, leisure and entertainment, creation, productivity, information, and literacy learning. This type of App interaction requires cognitive effort and strategy to navigate through its content and design. Interactive strategies involve scaffolding, and instruction, as well as appropriate support to guide the learning purpose.

App use in formal, informal, and non-formal learning transforms haptic device use into productive learning, and thoughtful engagement (Falloon, 2013b): 
- communicating learning objectives in ways young students can access and understand;

- providing smooth pathways towards achieving goals;

- including accessible and understandable instructions and teaching elements;

- $\quad$ incorporating formative, corrective feedback;

- combining an appropriate blend of game, practice and learning components;

- providing interaction parameters matched to the learning characteristics of the literacy target.

\section{Devices and Literacy Facilitators}

Haptic devices have some capabilities that contribute to learning, and are widely used not only in learning, but in daily tasks: Zooming in and out, Augmented Reality, Multitasking, Notifications, and Screenshots.

- Zooming in and out can be performed in any visual and digital resource shown on the screen: Pictures, videos, texts, characters. Zooming helps users to easily focus on specific details, or aspects of the visualized item of their interest. This engages and appeals to their visual and tactile senses. Google Earth App allows users to navigate cities and landscapes and view them at different scales and from many angles. After zooming in far enough, the imagery transitions show the same area with finer detail, which varies in date and time. Tapping on Street View (Google LLC, 2018) icon on the selected area and surroundings, the App displays $360^{\circ}$ panoramic street-level photos taken by cameras mounted on automobiles. Also, it has numerous layers in different forms of media, including photo and video, tours, etc. which allow

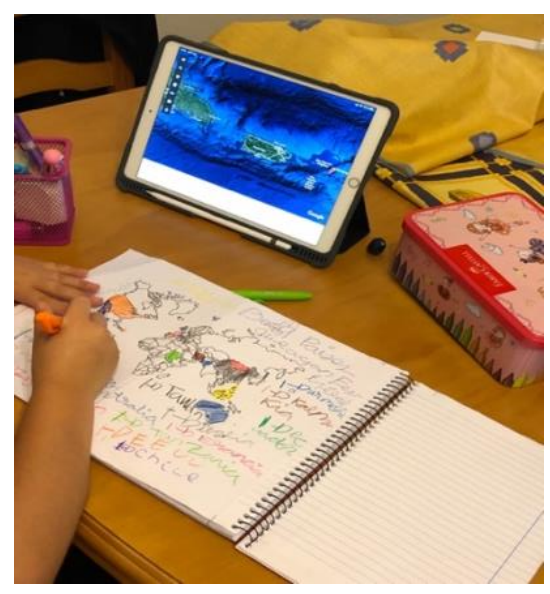
the user to learn about specific places (Google LLC, 2017).

In Fig. 5 we can see how Child I (HG Case Study) is using Google Earth to search for specific countries of a given homework task. The kid zooms in and out the spot in the tablet-App to compare if it matches with the country drew on the paper map that hands and where it matches. Once located in the paper map, she colors the country at her will and names it properly. The task is perfectly executed.

Fig. 5 Haptic device usage as literacy facilitator (Kindergarten)

- Multitasking lets users to quickly switch from one task to another at any time through an interface or by using a multi-finger gesture on the screen device. The swiping on the screen allows to use a second App without leaving the context of the current App (e.g. review email while searching on a browser App). For example, when creating a note, children can switch back and forth so they can introduce audio, photos from the internet, copied and pasted text from an email, etc. and produce a multi format note.

- Screenshots, also known as screen grabs, or screen captures, are digital images that capture exactly what is displayed on the screen. Screenshots are saved into the camera roll and can be used as any other photo made with the device, like share or storage it. They help for effective communication, and they serve to demonstrate something that would otherwise be difficult to explain in words. It also helps to keep record of the learning outputs, 
achievements, collaboration with others, and demonstrate how to perform functions on the device, among other uses.

- Augmented Reality (AR) refers to that technology able to complement the perception and the interaction with the real world through a real scenario augmented with virtual information (Orozco, Esteban, \& Trefftz, 2006). The technology allows to introduce text, images, video or $3 \mathrm{D}$ models inside the real scenario what allows the user to understand better the concepts or the learning output (Sherman \& Craig, 2003). AR (Augmented Reality) experiences bring virtual elements that appear and coexist in the same space as objects of the real world (Akçayır \& Akçayır, 2017). The process enhances the things that the user sees, hears, and feels generating augmented and super-imposed images in the user's real-world. As an example, one can explore how a lock works (Fig. 6) in the living room table with Jigspace App. The App explores and shares truly interactive and 3D knowledge for anything (Jig.space, 2018).

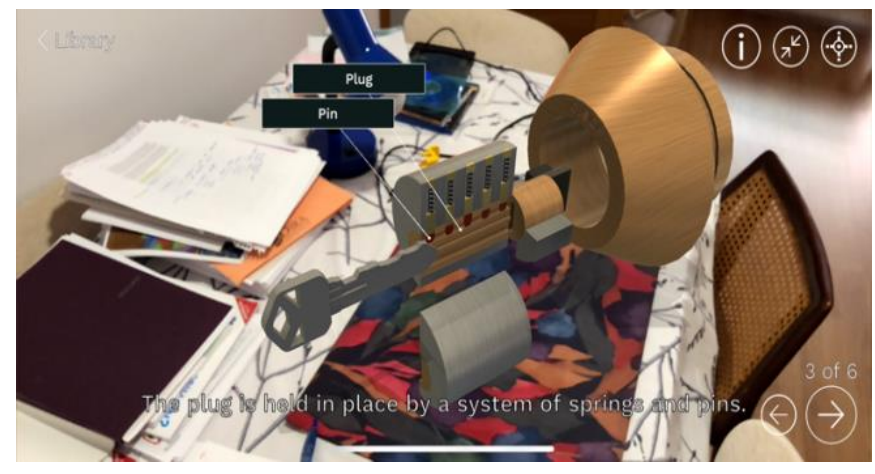

Fig. 6 AR: 3D Object from Jigspace App in a real home desk setting

An example of paper book with AR experience is "Abierto todo el día. Los cuadernos de Isidro Ferrer and Pep Carrio" (UPV) where the user can browse the sensitive, imaginative work of the authors through interactivity, animation and 3D modelling. The book presents texts and images that are activated with a touchscreen device giving access to a combined digital informative cartography where the user can surf and draw its own world map, being a different experience for any reader (Ferrer \& Carrió, 2013). 


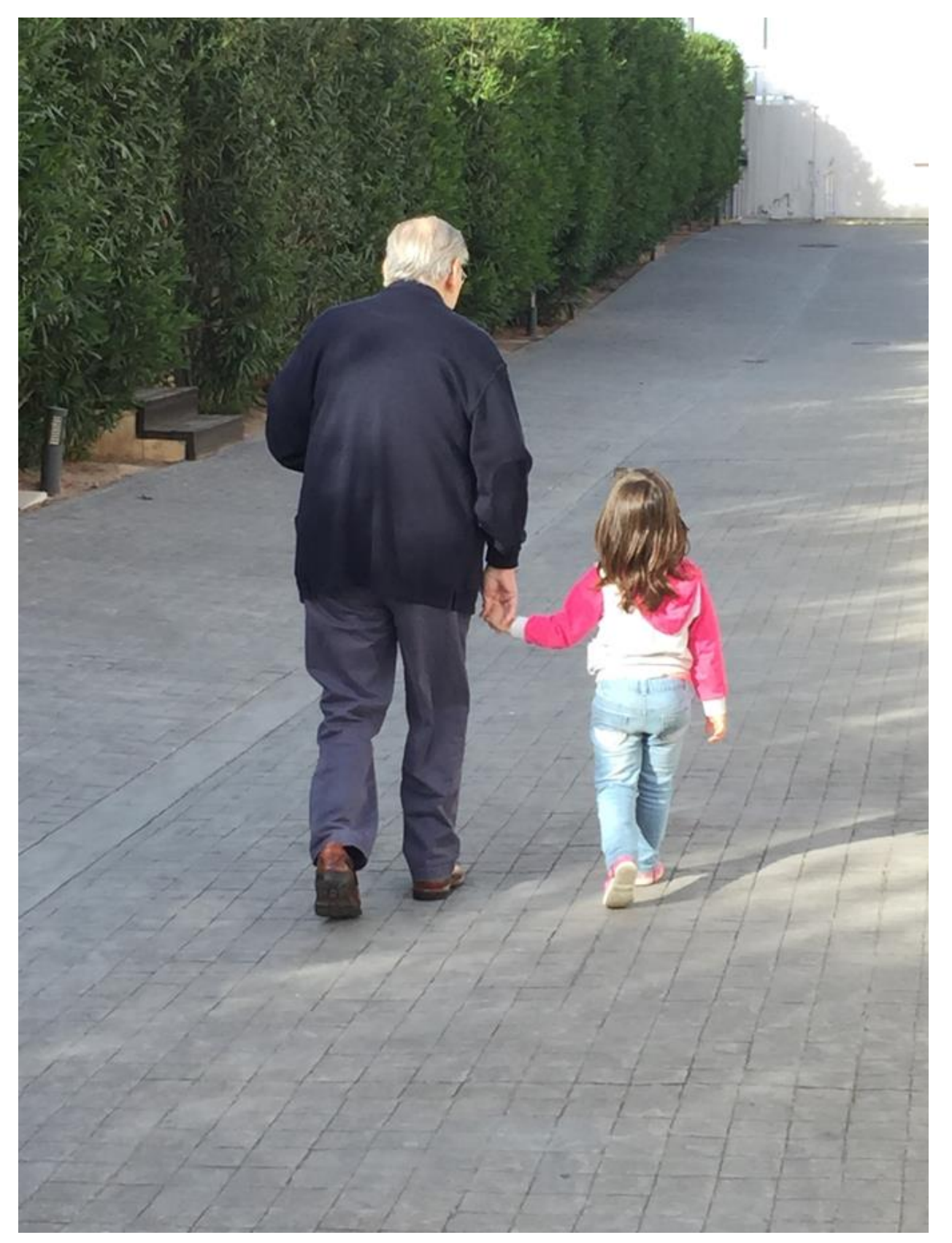

Framing the Digital Scope

Chapter 2 

"Every student can learn. Just not on the same day or in the same way."

George Evans 



\subsection{Introduction}

arrival of the World Wide Web and the introduction of haptic devices,
as we have described, meant a crucial change in communication, and has
brought new habits to citizens of all ages. Personal qualities like curiosity, flexibility, the need to solve a problem, or just the feeling of being easy to use when operating with the device, drive digital skills and proficiency in the use. It is also important to notice that the devices technical evolution over the last ten years, the intuitivism in these devices usage, along with the impact of cloud storage, the Internet of Things, online banking, online commerce, modernization of the government administration, and the personal online experience, unique for each user, have opened a new and global window not only to new forms of the acquisition of knowledge, but also to people that did not embrace technological advances in the first place.

Modern technology has automated daily routines gradually. Twenty century citizens have spied sudden changes in appliances and habits of their normal life. As examples: how home telephone became mobile and portable; how postal mailing or phone calling shifted to emailing, chatting, video calling, or posting online; how buying at the corner store was substituted by buying and selling online; how music lovers collected records, fading cassettes, and CDs to exchange or download them online; and the same with rented movies in VHS, DVD, and Blue-Ray to streaming servers that allow members to watch their selection at their pace; or to search for a direction first on a paper map, then in a bulky GPS, and right now using apps with the smartphone, among many other routines.

At the end of the Twenty century, the population witnessed the development of websites, avatars, and mods; started dating in chat rooms (online software where people meet via text); having fun online, and discovering new things without moving from their living room, while the advance in computer storage helped to keep data at home desktops and saving space in the house. For instance, that the computer could read CD music, and with minimal software, were kept in .mp3 files, saving space and at disposal of the user. The same happened with paper documents, using formats like .doc, .xls, .ppt, or .pdf, user could have their productions at hand and modify them 
without fear of losing them. All together towards a new form of storage in the cloud (Prensky, 2004).

Until 2007, the automatized and computerized tasks were done online from a wired and slow connection to internet, a fixed spot in offices or at home with the computer as protagonist, and spied by early childhood (YGens and ZGens). At home, when the computer was on, online and digital possibilities were opened, when the computer was off, users were back to manual or analogic tasks, slow motion, old records, CD music, DVD movies, TV, postal mail, face to face meetings, and board games.

From 2007 till date, the fingertip gesture on an interactive surface of the growing digital technology provoked a radical change in whatever task users were performing in their daily routines, as well as in business management, education, communication, or entertainment. Suddenly, online peer collaboration, active participation in forums, blogs, or debates; as well as sharing projects, coworking, texting, evaluating online experiences, gaming online, accessing to the news, learning online, interact social media sites, and so on, were at hand, in pockets. To join the new forms of communication was easy, and gave the perfect excuse to spread the persona device intuitiveness to people of all ages.

The birth and consolidation of social media as a phenomenon of entertainment, dissemination, and communication; as well as the use of virtual worlds, globalization, technical diversity, together to a $93 \%$ of market dependence on digital tools (Ofcom, 2018), including the creation of new forms of knowledge, implied, according to Bermejo-Sánchez, that nowadays there is no knowledge without technology because there is a sudden break up with traditions and settled assumptions towards casualness, and a social openness converging in a digital society (Fund. Telefónica, 2018c).

Since 2015, the smartphone is the primary technological device in all age cohorts and it is used in all life spheres. They coexist with other technological devices in the $98 \%$ of Spanish households, being the $54.5 \%$ of them tablets (haptic device with bigger screen) (Instituto Nacional Español de Estadística, 2018b). The haptic device irruption (Chapter 1), has affected parents, grandparents, children, youngers, and citizens, as well as habits, social spheres, etc. at the same time. It has become a global irruption, what means that age is no longer a differential factor in the use of this type of devices, neither the type of usability: communication; leisure and entertainment; creation and productivity; and information and learning. Children are able to use them as long as they have one at hand, in some cases they use them with more accuracy than adults.

Consequently, the irruption has provoked, in the different sectors of the society, a rising demand of digital skills learning, able to minimize the digital divide, and feel part of the digital society they are immerse in (McCrindle \& Wolfinger, 2009). Not all users use technology in the same way neither at the same pace, but the use ono they make is based on those skills, and these improve with their use.

In general, the educative system in Spain followed the same teaching pattern and did not include innovative approaches in its teaching methodologies until the Bologna process provided the framework to reform and modernize the higher educative system with the aim of a common approach in European Countries (European Commission/EACEA/Eurydice, 2012), which came along with the advance of technology. There were attempts to introduce innovative practices like 
"Plan de Innovación Educativa (PIE)" in 1989, or "Una Enseñanaza ORientada al APrendizaje (EUROPA) in 2000, at Universitat Politècnica de Valencia (UPV), but they were used by few lecturers and in some specific subjects, not in general (Marin-García, 2003).

One of the Bologna Process objectives for 2020 was to implement quality in higher education, connected with research and lifelong learning. Innovation in pedagogy and technology started to be reflected in the wide range of experiments aimed to expand the use of technology in the curricula delivery, but was not followed by practitioners due to the lack of digital skills and old lecturing habits (European Commission/EACEA/Eurydice, 2015). At UPV, modernized versions from the old PIE, PID, and EUROPA are being developed since 2010 to date, with the aim to better the teaching quality ("Proyectos de Innovación y Mejora Educativa" (PIME)); to emphasize the use of TICs, and the student's voice within the didactics of the subjects (Proyecto Docencia Inversa); and to establish lecturer groups with common innovative objectives called "Equipos de Innovación y Calidad Educativa" (EICE) (UPV-VECA, 2019), being one of them "Group of Innovative Methodologies and assessment For Engineering Education (GRIM4E).

The computer technological change did not take the same effort, neither meant the same to all generations, not even to the different members of any generation whatever function in the education process they had. The differential factor was the way members of the different generations approached to those devices since they appeared in the arena, which dependence on their needs, personal preferences, and habits. Haptic devices have provoked new social etiquettes, new literacies to learn, and new social rules to behave when accessing social networks.

Since 1971, Universitat Politècnica de Valencia (UPV) has been witness of how the social, economic, and technological change of the Spanish society have impacted on higher education and how its academics, researchers, staff, and students have changed methodologies and procedures towards a global and international commitment.

In the following sections, we are going to describe the digital diversity within the Spanish generational cohorts. Variables like: social and historical facts, psychological traits, learning methodologies, the irruption of the internet, and the arrival of haptic devices, are crucial to understand basic questions like:

- How people approached to technology since computers showed up?

- Which different digital attitudes and diversity (mashup generation) coexist nowadays?

- How is the influence of the mashup generation with the Haptic Generation?

- How is the influence of the Haptic Generation on the older generations? and

- What has it been reversed in formal education? 


\subsection{Spanish Generational Cohorts}

McCrindle defines "generation" (McCrindle \& Wolfinger, 2009) as a cohort or group of people united by age and life stage and influenced by the same social makers like technology, events, and experiences. The cohorts can vary depending on the country, the field of study that brought to the definition, or because they share historical references, sociological, economical breaks, even technological irruptions, among other possible classifications, that affected citizens' social milieu. In any case, from an anthropological and sociological point of view, generational cohort is defined as a group of people that was born in a 15-20 year period, and therefore share age, life stage, cultural, social and historical facts (Pilcher, 1994).

The birth year signals the generation to which each person belongs to, always in an approximate way, due to the different big events of one or another country, adjusting the cohort to the country, and society analyzed. Nowadays, in Spain coexist people from 7 different generational cohorts: The Grands, The Silents, The Boomers, XGens, YGens, ZGens, and the HapGens born after 2010. All of them have adjusted themselves to several technological and industrial advances, and have been witnesses of the digital irruption.

The historical fact that influenced the most to members of the Greatest (1901-1924) and the Silent generations (1925-1945) in Spain was the Great Depression, the Spanish Civil War (19361939), and the $2^{\text {nd }}$ World War. "Austerity" is their cohort birth mark (Concejo, 2018).

The Baby Boom (1946-1964) cohort was named due to a significant spike in birth during those years (Wallop, 2014), and influenced by the dictatorship period and the arrival of the TV in 1956. "Ambition" characterizes its members.

Generation X (1965-1979) was coined after a novel by Douglass Copeland, and marked by the US landing on the Moon (1969), and the Spanish constitutional transition (1978). "Obsessed with success" is their leitmotiv.

Generation Y (1980-1994) was coined by Neil Howe and William Strauss sociologists (Wallop, 2014), and it is characterized by the start of the digitalization. "Frustration" is their most frequent feeling.

Generation Z (1995-2009), coined after a USA Today contest (Horovitz, 2012), and influenced mainly by the entrance of the Euro coin, as well as the free access to internet contents (YouTube, Google). "Immediacy" is their milestone wherever, whenever, whatever they are doing.

And the most young of all, the Haptic Generation (2010-2025) coined by (Llobregat-Gómez \& Sánchez-Ruiz, 2015b) which members are being nurtured by haptic devices. "Inquisitiveness" is by now, the word that better defines their personal traits.

Those cohorts have responded differently to the technological disruptors. Firstly, because the type of devices has been very different from one generation to another and, secondly, because the technological attitude and diversity that population takes when the disruptors appeared. This second option converged when iPad irrupted in 2010, and it has had a huge influence in education. 
That is the reason why it is necessary to review some aspects related to technology, education, and customs that define and describe the different generational cohorts in Spain, global context of this thesis dissertation, during the XX and XXI Centuries, and see how those aspects affect in the current scenario.

The data used for the analysis related to Spanish comes from the National Statistic Spanish Institute (INEE) (Instituto Nacional Español de Estadística, 2018a); as well as specific UPV statistics for Personal Docente Investigador (PDI), Personal de Administración y Servicios (PAS), students, students of the Universidad Senior, and children enrolled in Centro Educativo Infantil de Vera, published in (SIUVP, 2019).

\subsubsection{The Grands}

The Spanish Greatest population (The Grands) are those citizens born between 1901 and 1924. It is the oldest Spanish living generation with 221,190 citizens, the $0.5 \%$ of the total population in 2017, thus the youngest being 93 years old by then (Instituto Nacional Español de Estadística, 2018a). At UPV there is no population belonging to this generation.

The Grands (from the word "grand-grandparents")' lifestyles and values were guided by a patriarchal society, political issues, agrarian activities, and analphabetism. They were born among political chaos what helped to their pessimist character, while looking for new forms of experimentation (avant-garde) (Pagán Velez, 2015). They have witnessed some of the most belligerent events, and have seen unprecedented civil changes.

During this cohort of time, female population, in case they were allowed to learn basic skills (like reading and writing), learnt while they were attending family chores at home. Most of the agrarian men learnt to basic literacy while they were in military services. The ones who could attend school used individual school slates and chalk. (Berengueras Pont \& Vera Mur, 2015).

For the Grands the digital world has been mostly nonexistent or irrelevant. They were seniors already when the internet irrupted, so the majority did not learn how to use it, neither were conscious of the advantages nor the disadvantages. To own a computer was very expensive and needed special skills that they could not learn by themselves, so it was not worth it to have one. But since 2007, haptic devices put around the same table several generations with the main purpose of being in touch and communicate in an easy way. It was at that moment, when some of them could understand some of the benefits of the new forms of communication.

Universidad Senior Unit at UPV opened in 2000-01 Academic year with the aim of elaborating, and organizing university courses for people aged more than 55 (Universidad Senior, 2015). Since its inauguration, 23,832 citizens (Grands, Silents and Boomers) have been enrolled in at least one of the courses ${ }^{13}$ organized.

In the 2012-13 academic year, courses on tablets and smartphones were organized due to the demand of the Universidad Senior students. The courses were fully covered, meaning that at least

\footnotetext{
${ }^{13}$ Universidad Senior Formative program is composed by courses (instead of subjects) with the same organized syllabus and tasks than any other subject in a UPV degree.
} 
150 citizens from older generations joined that academic year to learn how to use the devices. Based on their own words, they enrolled because the devices were attractive, other family members were using them, and they felt curious about them. Haptic devices are, according to one of the participants "a modern thing that reminds me my old school slate" (Maria, b. 1924) (UPV, 2013).

Nowadays, the Grands own a mobile or touchscreen device to be localized 24/7, and ask for help. Their motor and visual skills are degenerated in many of them by age reasons (Hayes, Van StolkCooke, \& Muench, 2015), so digital society and activities like bank transactions or online commerce are, for them, a sort of science fiction concepts.

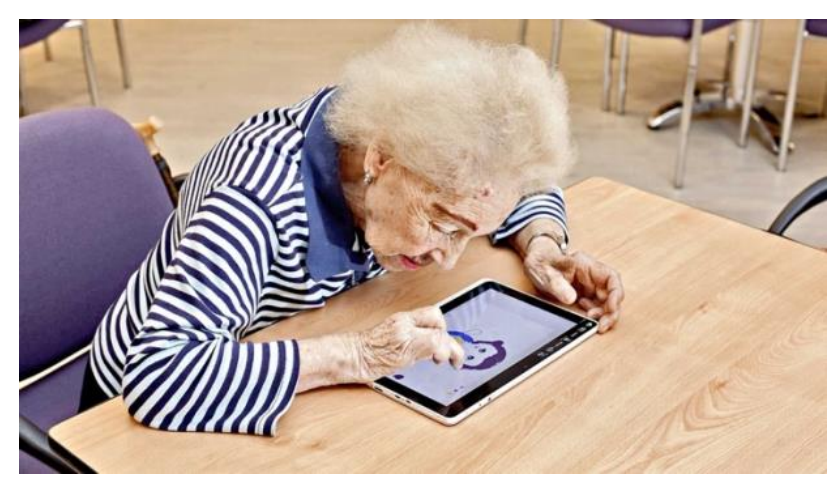

Fig. 7 96-year-old woman coloring with a haptic device

Their devices are normally advised and configurated by family members to monitor, and keep contact. No data has been found on their relationship with haptic devices, but statistics (Fund. Telefónica, 2007), and (Fund. Telefónica, 2015) show that since haptic devices arrived to the Spanish landscape, old population started using them, fact that did not happened with the irruption of the internet, or desktop computers.

The advantage of these devices for the Grands is related with health care. Haptic devices, shaped in different sizes in combination with app's use (Fig. 7) (e.g. Joyners app) (Ageing Well S.L., 2018) are some of the best technological tools to improve their quality of life (Mobileworldcapital.com, 2013), and keep them close to family in a tech-world that does not exclude them anymore. Also, in Spanish rural areas, the population is very old, and digital technology helps to keep online contact with health services that can monitor them and send immediate aid in real time (EuropaPress, 2018).

\subsubsection{The Silents}

The Silent generation cohort (The Silents) is composed of citizens born between 1925 and 1945. It is the current senior generation with 5,459,912 citizens, $11.7 \%$ of the total Spanish population in 2017, aged between 72-92 years old (Instituto Nacional Español de Estadística, 2018a). For the 2017-18 academic year UPV accounts for 2 Silent students (1 in Bachelor Degree, 1 in Doctorate); 6 Silent PDI, and no PAS (UPV, 2019). Universidad Senior got 607 Silents out of its 2,298 students enrolled in their courses (Universidad Senior, 2019). 
After the civil war, Spain sank in governmental control and censorship, and citizens behaved with a silent attitude. Their role was mainly to help to reshape the country with an austere behavior. They witnessed the first steps of the shift from an agrarian economy to a modern and industrialized one.

The values that marked the austere attitude and lifestyle of the Silents were mainly commitment, and moral responsibility. They were the first generation to have an important caring role for their grandchildren. The caring role, at the beginning unusual, has provoked that they had to learn to use digital devices from their grandchildren.

For the Silents, reading, writing, and numeracy skills were taught at school, and, also, at home, but formal education was not compulsory. During playing time, siblings helped with phonics, grammar rules, and basic numeracy (McCrindle \& Wolfinger, 2009), while doing other home chores. As technological tools for learning, the Silents were using slates and chalk at school in rural areas, and pencils and notebooks at school in cities. Wealthy families had the chance to send their progeny to the university. (Berengueras Pont \& Vera Mur, 2015).

The Silents were in their 50 s when their XGen progeny brought home computers, and the internet. They stayed digital observers and listeners until they become users, and internet consumers since 2012 (Fund. Telefónica, 2013). Being younger than their precedents, they had the chance and the need to learn how to use them by joining courses for basic skills and uses (Universidad Senior, 2015) or learning basic skills from their grandchildren who were immersed and spent many hours of their days connected.

The Silents have been the first generation to allow that youngers could teach the old without feeling guilty for that (Fig. 8). In fact, it has been the first time that some members of the generation admitted they did not know about something without regretting modernism. Curiosity, easiness, intuitiveness, and finger manipulation without real knowledge of programming software helped to increase communication among family members to share family photos, and daily updates (Tee, Bernheim Brush, \& Inkpen, 2009). Apps like WhatsApp, Facetime, or Skype have made from video, instant messaging, and voice, and text messages a way of daily communication with their loved ones no matter where they are living. Being far away from relatives is not barrier for the Silents anymore to be in touch through a screen, and prevents them from feeling alone.

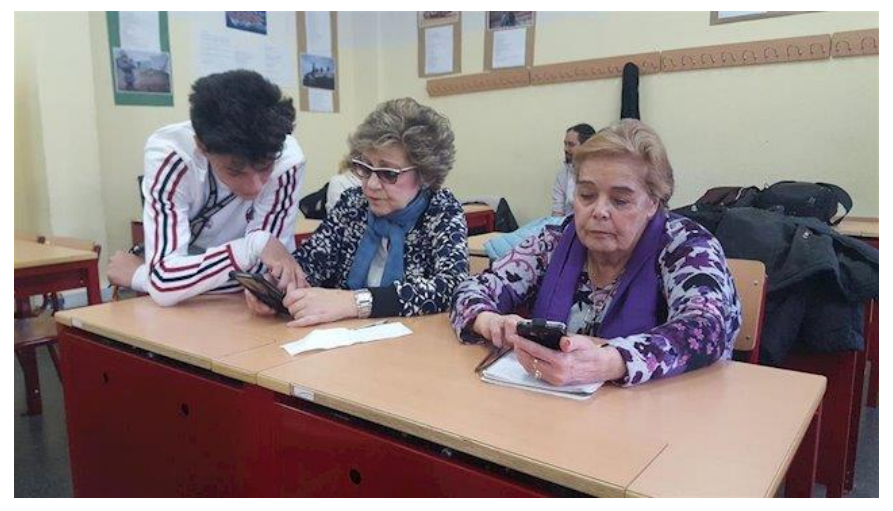

Fig. 8 ZGen teenager teaching Silents 
Internet, Wi-Fi, podcasts, WhatsApp, voice messages, YouTube videos, Facebook, or Google Earth are terms that they do not really understand, but they are getting used to name them, and some even use the referent tools. Their progeny, mainly, grandchildren, are in charge of teaching them how to update friends and family members with pictures, selfies, etc., and show them what is behind these abstract nouns: an open window to recall smiles and memories from their childhood among many other possibilities (e.g. a web page of their natal village with information and videos related with their past).

Haptic devices for the Silents, as well as for other generations, are an open door for health care, rehabilitation in neurological diseases like Alzheimer (Zmily, Mowafi, \& Mashal, 2014), dementia (Maiden et al., 2013), Cerebral Vasculitis, and a great help for patients with developmental disabilities (Stephenson \& Limbrick, 2015).

\subsubsection{The Boomers}

The Baby Boom generational cohort (The Boomers) is composed of citizens born between 1946 and 1964. There are 10,609,763 seniors and adult Boomers citizens in Spain, a 22.8\% of the total population in 2017, therefore aged between 53 to 71 years old (Instituto Nacional Español de Estadística, 2018a). For the 2017-18 academic year, UPV accounts for 200 Silent students (81 Bachelor, 22 Master, 97 doctorate) 911 Silent PDI, and 421 Silent PAS (UPV, 2019). Universidad Senior got 1,666 out of 2,298 students enrolled (Universidad Senior, 2019).

The Spanish dictatorship period started to decay and influences from other countries (e.g. music, hippie movement) shaped their generation. Ethics at work, questioning, participation, casualness, individuality, and ambition characterized their values to face common problems.

In formal education, reading and writing skills are taught through word, text, and list memorization. Instruction is the methodology to infuse knowledge, and there is no place for questioning or introducing other points of view. Paper books, notebooks, pens, pencils, and erasers were the best allies at school. (Berengueras Pont \& Vera Mur, 2015).

Boomers were born "analogs." They witnessed the birth of television (with valves), the change from black and white to color, the fixed telephone with operator, the automatic washing machine,

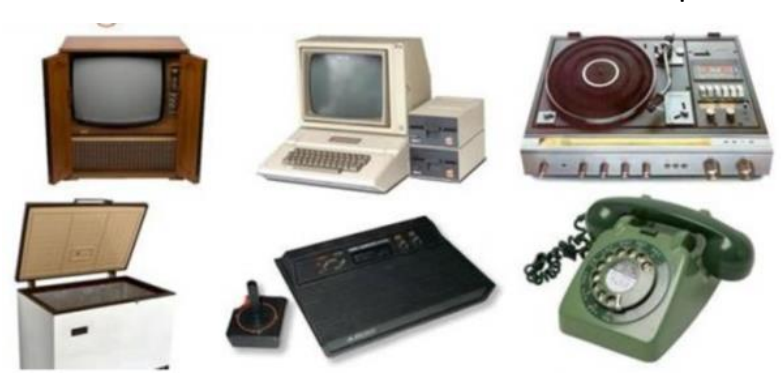
the fax machine, the primitive mobile phones, the bulky computers, and the modem. They like to watch TV, listen to radio shows, and read news on printed newspaper (Fig. 9). They like to read paper books, and have a handwriting agenda where to stick memories and to-do lists.

Fig. 9 Tech Gadgets in the seventies

The Boomers were between 27 and 45 years old when the internet irrupted. They reached adulthood without digital technology, and almost no impact of computer technology in their 
normal lives. Some Boomers, mostly related to academic fields and modern industry, embraced technology as it was emerging and become the early adopters of the generation, while others were very reluctant to it.

The arrival of haptic devices in 2007 and its consequences on all social and economic spheres, already mentioned, changed the negative attitude towards a greater or lesser accurate use. Nowadays, all of them have a smartphone or/and a tablet in their hands, in some cases more than one and two (Fund. Telefónica, 2016).

Boomers' use of haptic devices started by being sequential, structural, linear, and practical, mainly to achieve a function. After the function is performed, they put the device down. The device's new features, an increase of knowledge about social media and networks, new ways of working usages, some practices, new digital skills, and the type of activities that their progeny are doing within the net, had the effect to change also how they interacted with the device, integrating it also for entertainment and communication.

Nowadays, it is very difficult to observe any of the Boomers without a smartphone among their belongings. Some of them also add a laptop, a tablet, and/or an smartwatch (Ofcom, 2018).

\subsubsection{XGens}

The Generation X cohort (XGens) is composed of citizens born between 1965 and 1979. It is the Spanish current adult and workforce generation with 11,442,303 citizens, a $24.6 \%$ of the total population in 2017, aged between 38 and 52 years old (Instituto Nacional Español de Estadística, 2018a). The UPV, during the 2017-2018 academic year, accounts for 1,122 XGen students (394 bachelor, 153 master and 575 doctorate), 1544 XGen PDI, and 967 XGen PAS. (UPV, 2019).

XGens were born in a time of relative peace, but economic uncertainty. For them, to work hard is important, but not more than their families. They are very active in their progeny education. In general, they are over protective, over provider and over facilitator of their kids and their needs (Lissitsa \& Kol, 2016). They set new social behaviors by seeking the truth and believing that nothing is permanent. They impacted on the nation's mood and values with 80 s pop music, breaking the strict rules, being transgressors, and behaving in a more relaxed way than their parents (McCrindle \& Wolfinger, 2009).

They are the big bringers of the "modern technology" due to that they were born before people stopped talking about analog and electrical devices to start talking about electronic and digital devices. For them, having fun means going out with friends outside the houses: they learned to play in the street. They were the first to play role-playing games, and spend the evenings in recreational stores: Pacman, Tetris, Super Mario Bros, etc. They were when the arrival of the CD, the VHS, and the Walkman, and said bye to fading cassettes, and Blockbusters ${ }^{14}$. And, among others, their first contact with a keyboard was when learning to type in a typewriter.

For the first time in Spain, the General Education Spanish law of 1970 sat the basis for compulsory and free of charge basic education for all children between four and fourteen (Sanmartin Ortí,

\footnotetext{
${ }^{14}$ Blockbuster: American-based provider of home movie and video game rental services through a video rental shop.
} 
Prat Pérez, Rodríguez Felipe, Rubio Castillo, \& Jover Olmeda, 2016). Learning is instructional through the memorization of facts. Emphasis is placed on grammar, spelling, capitalization, and punctuation aimed to better express ideas, and perfection when writing. Students of that generation were very verbalized (the teacher is the main channel to obtain information), and curricula centered. They sit and listen, and have closed book exams. Paper and color pens were the best allies of students till the arrival of home computers irruption and its formatting possibilities. (Berengueras Pont \& Vera Mur, 2015).

XGens were in their teens when digital technologies began to emerge in Spain. In the seventies, computer technology was aimed to academics and had little impact in general population. XGens were the first students to learn basic computer skills in High School (optative subjects) and some of them had a home computer first for entertainment purposes, and then for practical and functional reasons. ZX Spectrum (Launched in Spain in SIMO '85 trade show) (BBC News, 2007), Commodore 64 or Amstrad CPC, were the first home computers landed in Spanish households.

Word processing applications in the 1980s and early 1990s, like WordPerfect for MS-DOS and Microsoft Windows eased the bulky tasks of formatting, writing and calculus avoiding handwriting, mistakes, and repetition (McCrindle \& Wolfinger, 2009).

Curious and autodidactic XGens (Fig. 10) adapted very

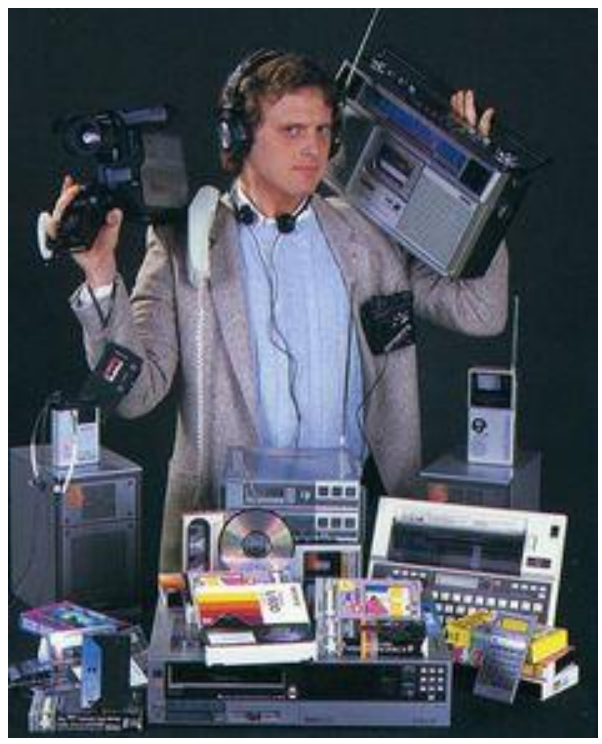

Fig. 10 Tech Gadgets in the eighties well to the irruption of the internet. The internet was a new way to travel without moving from home, work, and communicate faster, tasks that were included in their routines. Astonishment, amusement, and wonder were the drivers to be also early adopters for any new technological device that arrived to market (Castells, 1996). XGens are immersed in technology since the first iMac announcement in 1989, and their skills and attitudes toward haptic devices have been evolving with their own evolution towards consumer durables, discovering and using them at the same time that were introduced by market to society (Castells, 2007).

XGen's enthusiasm for haptic devices since 2007 was like the Apple's Think Different perspective, explained in Subsection 1.2.2 (Isaacson, 2011), a new way to understand life. The new devices were opportunities to be more efficient, innovative, creative and productive in repeated tasks: the perfect equation for an employee. They use smartphones, tablets, or laptops indistinctly and their preference for the device depends on the task to perform, and how comfortable they feel. They differentiate the use and device capacity more than YGens (McCrindle \& Wolfinger, 2009). 


\subsubsection{YGens}

The Generation Y (YGens) is composed of citizens born between 1980 and 1994. It is the current young adult generation with $8,347,242$ citizens in 2017 , the $18 \%$ of the total population, aged between 23 and 37 years old (Instituto Nacional Español de Estadística, 2018a). During the 201718 academic year, UPV accounts for 9,709 YGen students (4,727 Bachelor, 3,519 Master and 1,463 Doctorate), 176 YGen PDI and 37 YGen PAS (UPV, 2019).

YGens are the most over protected generation. They experienced economic security, and new family configurations that came in the hands of parental divorces, giving as a result immediate gratification what characterizes their life stages and their psychological traits (Livingstone \& Sefton-Green, 2016). Some of the consequences of this protective attitude are selfie narcissism, consume obsession and passivity (Álvarez_Monzonillo \& De Haro, 2017), reflected in little responsibility, commitment, interest, and effort as it has been informed in educational statistics and PISA results (Instituto Nacional Español de Estadística, 2016) of the last decade. Some of YGens are recalled NEET (Not in Education, Employment, or Training) (Spanish Ni-Nis). YGens that fall into this category are non-employed young people framed as lazy, work-shy and voluntarily out of employment and education; and that are still living at home eroding parents savings (McCrindle \& Wolfinger, 2011). These traits and societal change has had a big influence in compulsory education abandonment and lower results (Instituto Nacional Español de Estadística, 2016).

YGens were the Digital Natives of Prensky, who coined the term in 2001 to describe the first generation to grow up entirely surrounded by electronic technology in the form of computers, video consoles, CD and DVD players, video cameras, cell phones, printers, digital photography, and more than two TV channels (Prensky, 2001). When digital technology irrupted in their lives, it was assumed that they should know how it worked, but no one knew still how to handle it, so computer technology was around but not at their hands because they did not know how to deal with it.

During the 1980s, computer technology started to be popular among youngers started to influence in their learning routines. During the 1990s it is everywhere, and begins to connect technically skilled population around the globe. The problem for YGens was that nobody could teach them how to use that technology, they had to learn by themselves and could not see the relation with creation, productivity, information, or learning. For YGens technology was a real and an amazing toy, where gamming was breathtaking and far from their parents' control.

When they grew up, in their twenties (around 2006), the Tuenti social network (Simón Ruiz, 2008) helped to change the way to interact among friends. Online communication started to be used but, as the digitalization was still in diapers, it was not really a gamechanger at that moment. Similarly, to Boomers and XGens, some embrace its arrival in terms of productivity taking benefit of it; but others became addicted to, showing a compulsive use and isolating themselves from the rest. Computer isolation has driven to psychological consequences having an effect on social relationships, professional skills, and academic detriment (Young, 1998). 


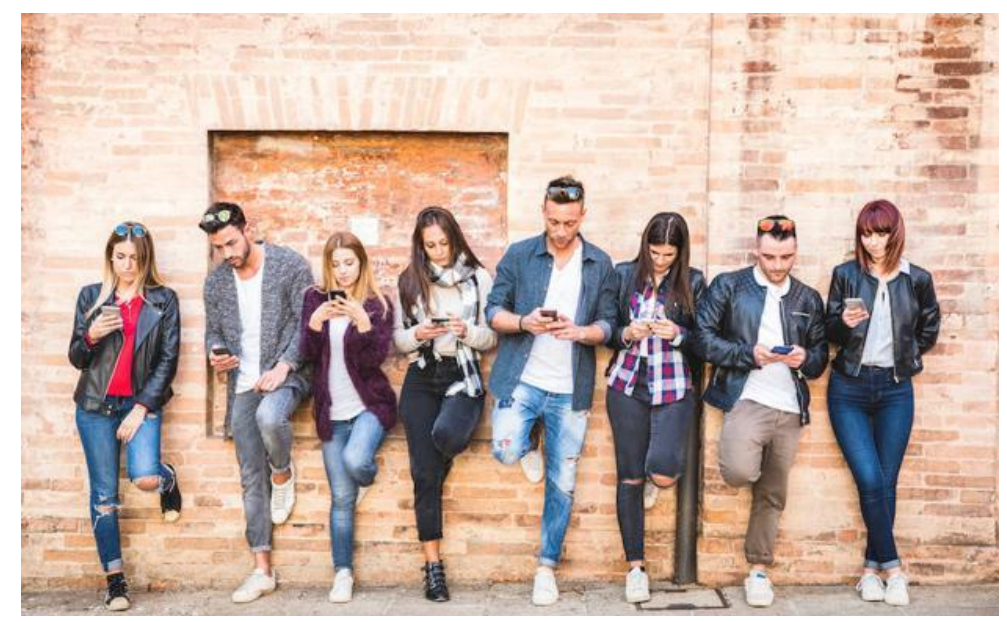

Fig. 11 YGens meeting friends

YGens still received formal education with pre-designed syllabus in a traditional classroom setting, and a teacher-center learning approach. Reading and writing is learned through exposure rather than instruction, but the presence of the teacher is very important. The learning is centered in the mentor instead of the student. Emphasis is placed on simplifying the contents by visual aids and easy language, instead of comprehension of original texts and essays. Book, keyboard and mouse were the best allies till the arrival of haptic devices, where fingerprint and touchscreens replaced any form of technological input (Berengueras Pont \& Vera Mur, 2015).

Driven by consumption and smart applications, in general, they are peer-oriented and followers of a social media reality that makes communication and life easier: Instagram, Facebook, Twitter, etc. They touch and try without instructions. For them, to acquire the use of new tools and devices in IT (Bencsik, Juhász, \& Horváth-Csikós, 2016) in a virtual environment was easy and quick, a way to escape from reality and far away from responsibility (Fig. 11).

\subsubsection{ZGens}

Generation Z (ZGens) is composed of people born between 1995 and 2009. It is the current young student generation with 7,057,103 citizens in 2017, the $15.1 \%$ of the total population, and aged between 9 and 23 years old (Instituto Nacional Español de Estadística, 2018a). During the 201718 academic year, UPV accounts for 14,503 ZGen students (14,001 in Bachelor degrees, 499 in Master degrees, and 3 in doctorate), there is no PDI nor PAS from ZGen generation (UPV, 2019).

This generation has been spending time largely indoors with computers, video consoles or TV as babysitters while both parents were working. Their schedules are very organized with extracurricular education, mainly in sports or languages, every working day, what implies little freedom, and little outdoor playtime. This is the generation with few or no siblings.

The speed of technological change is the defining feature of this generation. The radio, as an irruptive device took 38 years to reach 50 million users, the TV took only 13 to reach that same figure, the Web was available to 50 million users in only four years, while the iPod did it in three, and Facebook, in two. Innovative leaps are becoming shorter, and technologies more accessible, making the connection between generations more solid and their contrasts more blurred. 
ZGens are considered the first, and, for real, global generation because technology and the internet were already there when they were born. Also, they are the most technological saturated generation, internationally connected, and most engaged with worldwide brands, influencers, and social media. They like learning by their own, using their own creativity among other reasons because they feel they can innovate, and share it. The internet becomes the best ally to satisfy their curiosity, and it works as an open book that gives immediate answers and feedback. For them, diversity, democracy, and technology form a unique piece that gives them, as a generation, a high social value (Fig. 12) (Álvarez_Monzonillo \& De Haro, 2017).

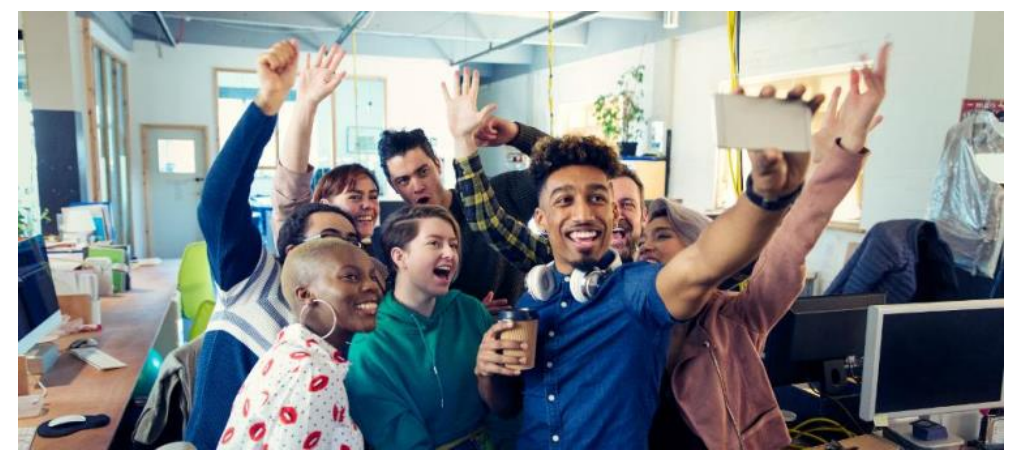

Fig. 12 ZGens meeting friends: A Selfie

For the first time, their formal learning also happens outside of the classroom, for instance, by consuming free YouTube videos (Álvarez_Monzonillo \& De Haro, 2017) that summarizes topics of interest quicker than reading. As their learning is based in experiences and practices, they click and wait for responses instead of sitting and listening like the precedent generations did (McCrindle \& Wolfinger, 2009). They accomplish any type of task with browser tabs, some software, and collaboration among peers.

Screen, mouse, and headphones were the primary tools until the arrival of haptic devices in 2007, when fingertip and $\mathrm{Wi}-\mathrm{Fi}$, together to cloud storing and the Internet of Things, took an irreplaceable spot in no time. The change was on-the-spot. Since then, instant messaging expressions and language, selfies, and emoticons are part of their vocabulary and writing skills when communicating, facts that are hard to avoid at university formal exams (McCrindle \& Wolfinger, 2011).

ZGens are the Guinea pigs of the Spanish educative system swift of the last decade. One of the key commitment in the Bologna process since 2009 (European Students' Union-ESU, 2015) was to switch from Teacher-centered to Student-centered practices. Innovative practices like problem-based learning or game-based learning, are just examples of strategies that started in a concrete field of teaching and expanded into general teaching (Barrows, 1986). Those practices, adapted to the different subjects and areas of study, were learned by teachers at the same time than they were implementing them in their teaching subjects during study courses.

Education along its different levels (primary, secondary, high school, and university) has tried to adapt digital tools and resources to the learning outputs (Innovative teaching practices) the students must acquire during their formal education. During those practices, students use videos as well as books, and interact with faculty staff through school apps, email, etc. For better accomplishment, school boards have to invest on faster computers and laptops, digital boards, and digital material they share through the learning platforms (e.g. PoliformaT at UPV). In any 
case, the innovative practices still have no significant statistics of the impact of the learning in the students.

Since 2013, some schools added into their programs "Bring Your Own Device" policies allowing students to bring a tablet or their own device to class (Caxton College, 2016). At university level and having the smartphone in pockets, the devices were already part of the outfit and material, and the students started to increase their use for learning purposes.

Information and Communication Technology (ICT) skills of ZGens differ from previous generations because those have always known how to zoom, pinch and swipe with a click on a mouse computer. They have grown up with hi-definition, Dolby Surround Sound, 3D projection, and the "smart" concept related to all sort of computer devices. The use of digital photography, and videos already available in websites, starts to be part of a sophisticated and complex visual imagery that avoid the writing of thoughts and ideas.

Those visual skills that ZGens start mastering, imply a swift in learning abilities and mental processes towards visual thinking strategies (VTS) (Yenawine, 2013). 90.4\% of Spanish ZGens declare that their favorite format used for multimedia content is the digital image (Fund. Telefónica, 2018a). Emojis are their informal communicative language spread by texting and it is also transferred to formal texts, and school exams (Kerslake \& Wegerif, 2017), and (McCaffrey \& Matthews, 2017). They have only known an hyperlinked, and user-generated world where one click with the mouse can bring them close to any piece of knowledge in the digital format desired (McCrindle \& Wolfinger, 2009).

For ZGens the big irruption arrived with haptic devices because the internet was already part of their lives. Device's portability and personalization, digital interaction, Wi-Fi, and ubiquity were technologically improving at the same time than children were growing up. Meanwhile, older generations where adapting their habits to them as a natural flow of the evolution.

After 2007, when fingertips starred computer-based tasks through apps to reach new knowledge, wherever it was digitally located, the adoption of the new digital technology was as easy as to place a fingerprint on a surface. Consequently, the possibilities for the ZGens to learn and create something new increased exponentially. They were more exposed to knowledge than previous generations. As young students, they are in the right moment and with the perfect tools for knowledge acquisition, but society still has not realize about its possibilities, so at the beginning it was like any other disruptor. This fact that makes ZGens to be very different from YGens in their relationship with computer technology, drop rates and academic achievement.

ZGens are very close to HapGens and share with them finding natural an interactive surface as the natural way to communicate with others, to access to multiple tools in just one device, to find random information, and it is perfect to produce digital and personalized scribblings that allow modifications. The interactive screen has transformed passive learning into active, has allowed access to scaffolded contents at student's pace, and has made possible the devices usage for more things than just gamming and media consuming. 


\subsection{Mashup Generation: The Digital Me}

The age at which people use technology for the first time determines how embedded it becomes in their lifestyle. But, since digital innovation irrupted suddenly in the way of living, diversity is placed on the benefits that citizens take from that technology in the moment they appear, and if they, as citizens, want to take advantage of it or not.

Users may see benefits on using the haptic devices for different purposes in different moments and places; and can realize what they can achieve by adapting their own lifestyle to the digital landscape that surrounds them. Social trends in digitalization are also key factors to determine the need to use the devices for any personal purpose.

The diversity then, is not placed in when that technology appears in citizens lives (generational cohorts), but in how citizens use the different haptic devices and for what purpose (communication, leisure and entertainment, creation and productivity, or information and learning), in brief, there is a tech-user digital diversity, no matter to which generational cohort (Section 2.2) they belong to.

Taking into account this tech-user digital diversity, we are going to describe the main traits of a new generation whose members use current digital tools for different purposes. They are nurturing the early childhood now and their traits are affecting formal education during the last 30 years, implicating people, tools, and the system.

We define, then, the Mashup Generation (Mashups), as the generational cohort formed by users of different ages that started using computer technology when it was available in the market and irrupted in the current society, and, consequently, in citizens lives, changing customs, habits, and perceptions.

Fig. 13 summarizes the situational context of this dissertation. Universitat Politècnica de Valencia (UPV) accounts for the 201718 academic year with 26,393 formal students, 2,646 PDI, 1,458 PAS, 2,298 Universitat Senior students, and 82 children aged 1 to 3 in its Centro Educativo Infantil de Vera. In total 32,877 people (UPV, 2019) of the different generational cohorts conform the UPV Mashup population.

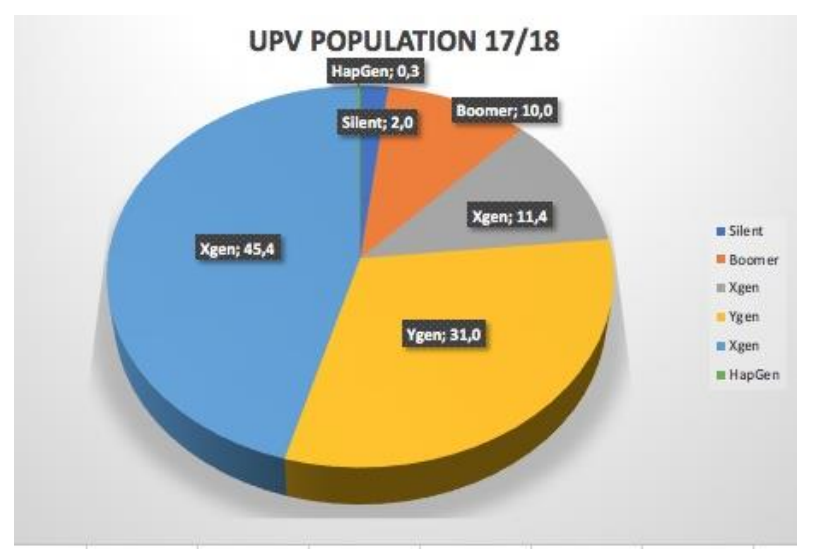

Fig. 13 UPV Population by Generational Cohorts 


\subsubsection{The Melting Pot}

The members of the different generational cohorts approached the arrival of computers, the internet, and other technological tools differently based on the information they had, and the use they thought they could do from them. But the irruption of haptic devices embraced all users at

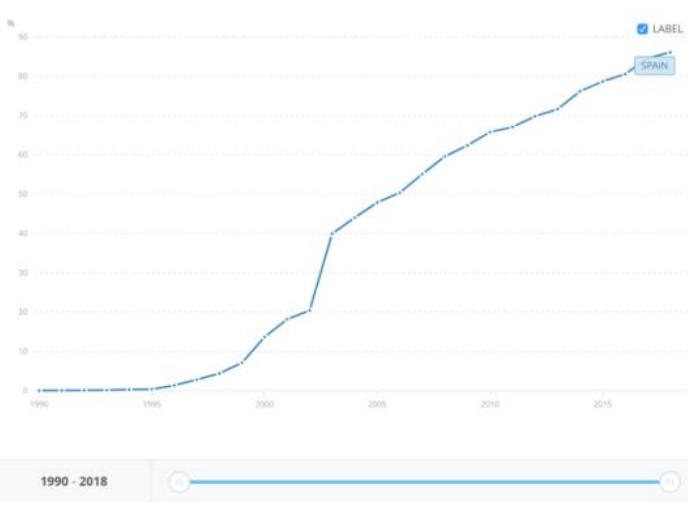
once aimed to catch up with any type of user, whatever age, whatever digital immersion they had previously.

(The World Bank, 2019) reports that the $86 \%$ of the Spanish population is using the Internet in 2018. Fig. 14 shows a steeply increase of users in the last ten years, the double of the previous seventeen, which coincides with the arrival of the haptic devices.

Fig. 14 Spanish Internet Users in 2018: 86\%

During 2018, as F. Telefónica statistics (Fund. Telefónica, 2019) indicate, the $51.2 \%$ of the internet users performed E-commerce activities when being connected, the $26.1 \%$ of those users being older than 64 . Other activities performed online were emailing (81.3\%), texting (94.3\%), social media interaction (67\%), and the use of Apps were aimed to Leisure and entertainment (37.5\%), for communication (34.7\%), productivity and learning $(24,7 \%)$. The preferred device to get online was the smartphone $(91.1 \%)$, the computer $(62,9)$, and the tablet $(29,7)$, the motivation for the selected device was user's comfortability when performing the different actions.

Some respondents of F. Telefónica surveys, as well of "Students and haptic devices" (ZG Case Study in Chapter 4) confirm having more than one device, in many of the cases they own the three of them and diversify the use: computer for productivity and learning, tablet for leisure and entertainment, and the smartphone for communication.

Digitalization after 2010 means not only a digital transformation in habits, but also in infrastructures, internet services, connected environments, and vertical markets that influence users' adaptation: connected cars, smart cities and homes, connected health, energy or industrial Internet of Things (IDATE Digiworld, 2017).

After 2015 citizens have been shaped into a digital, wireless, and online society and have embedded these tools into their lifestyles. The smartphone has become a bone, an extension of the body, being part of the user's personality, and becoming, together to the user, a oneness. Leaving or forgetting the device at home is, currently, "like being lost" said one of the respondents in Students and Haptic Devices survey (Chapter 4). The smartphone is next to keys and wallet, one of the items that users never leave home without (Quora, 2016), it is a camera to use in any moment, it keeps digital records of credentials, it shows maps with several itineraries according to real time traffic, GPS; shows the weather forecast of the city, allows instant communication, directs payments without the need of physical cards or cash, serves for online shopping, accesses 
to storage or streaming music or podcast when waiting or walking; it is used as torch, a calculator, agenda and many other utilities of user's needs. Citizens of any age use apps regularly, the difference is in the type of App (communication, entertainment, productivity, and learning) to use, or the number of apps installed to fulfill the needs (fig. 15).

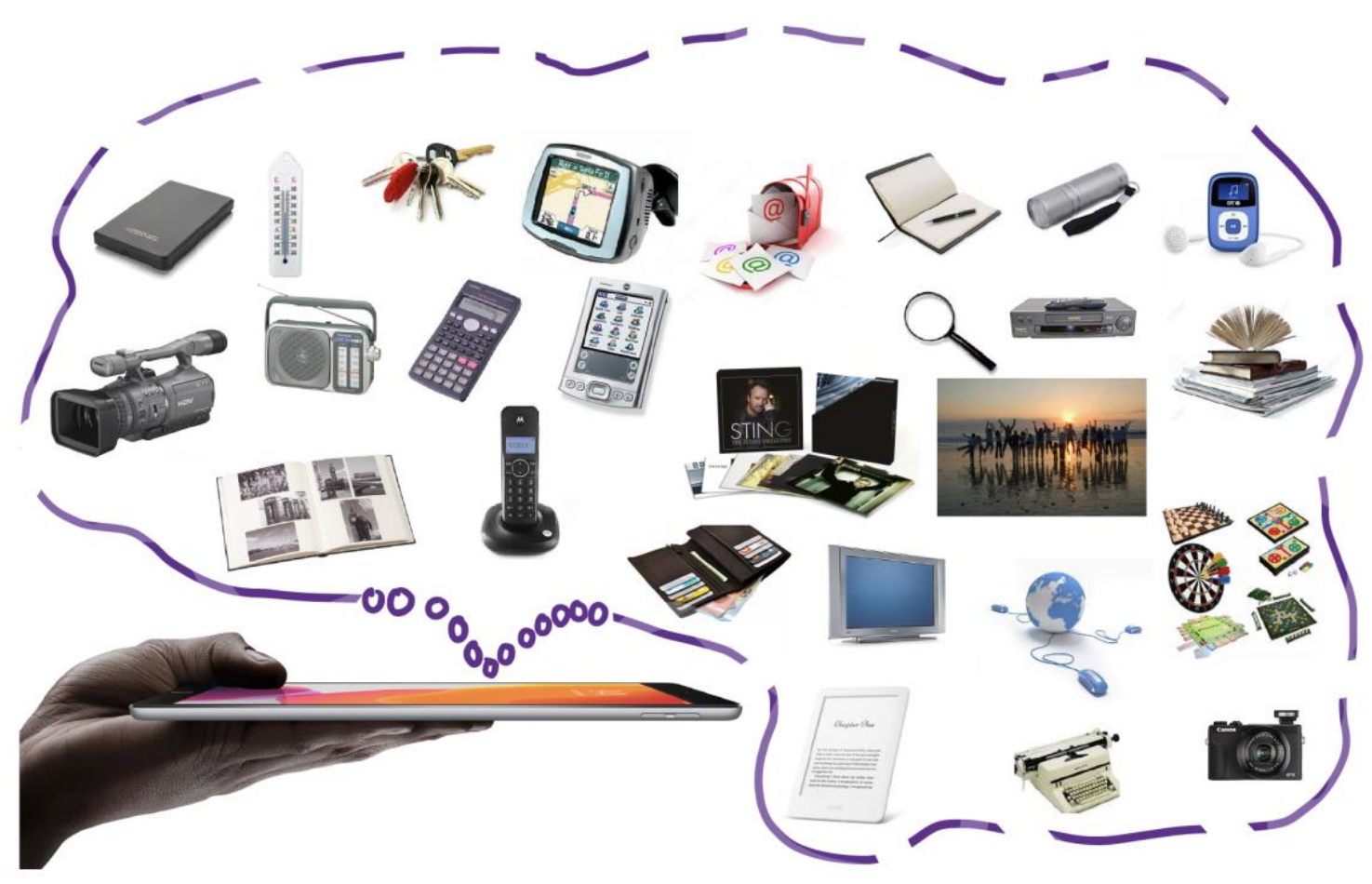

Fig. 15 Inserted personal gadgets in a Haptic Device

The phenomenon happens in Spain as well as in other occidental and economically developed countries mainly, because customs are shaped by the same emerging trends: digital community attitudes, E-commerce, mobile applications, mobile payment, social media and its influencers ${ }^{15}$, access to digital content through websites, low cost haptic technology, a culture of "Do it yourself", access to music and video on demand (IDATE Digiworld, 2017), and consumer services provided by online brands (Voxpro, 2015) where customers share their perceptions and feelings caused by the product or the online experience with others creating a cumulative effect of interactions with suppliers, products and other customers.

Data confirms that the access to digital content is unequal among countries, groups, cultures, and individuals. This fact does not mean a deeper inequality in education, or not access to those devices, but the opposite. Haptic devices and its learning possibilities can arrive where teachers

15 "Social Media Influencer is a user on social media who has established credibility in a specific industry, has access to a large audience and can persuade others by virtue of their authenticity and reach" (Pixlee team, 2017). 
cannot (Fernández Enguita \& Vázquez Cupeiro, 2016). Experiences like Hole-in-the-Wall of Sugata Mitra (Mitra, 2003) or Uganda Learning Lab at primary school level (Kanga, 2018) reflect how students can learn about literacies by themselves, or from peers if they have the chance to access to digital tools and content.

\subsubsection{The digital " $i$ "}

The Mashups are immersed in the same digital landscape, and data confirms that the technological change happens very fast (Reports from Fund. Telefónica: "Sociedad de la Información en España" (2006 to 2016), and "Sociedad Digital en España" (2017 and 2018). The birth cohorts described in Section 2.2, give emphasis to digital integrators instead of sociological and historical common facts. This is translated into a significant difference to previous sociological definitions, even though, the age at which we use technology for the first time, coincidentally, when it arrives to the user's lives, determines how embedded it becomes in their lifestyle and determine the tech-user diversity.

The marketed "i", as already described in Subsection 1.2.1 (Apple Inc., 2007) surpass the generational gap in a more Individual, Informative, Instant, Inspirational and Instructional me (i). Data reveals that, there are no generational differences for using the device in the last decade. Nowadays users move naturally among technologies, manipulating devices, consuming media, interacting in social media (Fernández Enguita \& Vázquez Cupeiro, 2016), but those actions do not make them experts. Users have different levels of technological competence depending on the different spheres where they want to interact with the device family, work, or education.

Technological diversity is graded by users' mastery and competence on digital tools and interaction graded in: basic, advanced, independent, and proficiency (Brandtzæg, 2010); and measured in terms of familiarity and attitudes. The familiarity is expressed in terms of knowledge of digital fundamentals, structure and basic commands, and awareness of SWOT (strengths, weaknesses, opportunities, and threats). Attitudes are, in turn, affected by factors like the type of the device used; personal motivation for its use, the frequency of use; the digital content preferences when interacting (gaming, socializing, utility oriented, shopping, information exchange, creativity); the purpose of the interaction (communication, leisure and entertainment, productivity and information, or learning), expectations and goals, the type of access, and the role that the user plays when interacting. Familiarity and attitudes ignite the mastery and competence the user acquire over time, that it is reinforced with the use of tools, and Apps (basic, advanced, independent, proficiency) (Brandtzæg, 2010).

The new digital setting, where the Mashups is nurturing the youngest generation, demands a new type of literacy: The Digital one. Kindergarten children should start learning to differentiate among the elements of digital literacies, adults too. The elements as (JISC, 2016) describes them include to learn about media literacy, communications and collaboration, career and identity management, ICT literacy, Learning Skills, digital scholarship, and information literacy; as well as to scaffold the learning to stronger understanding, and greater independence. Those elements aim to handle effective digital communication, appropriate use under digital responsibility, and reduce the technological diversity among users. An immeasurable amount digital sources of 
information, as well as, different types of online risks need a solid ground to move around, and guide other users.

Along the day, users find information in many physical places like home, school, university, libraries, museums, organizations, as well as in online hosts like MOOC courses, YouTube channels, online libraries, apps, social networks, and so on. The digital opportunity for learning in enormous not only for the Mashup Generation, but also for the Haptic Generation that is spying actions on smart devices and transferring those actions to toys, and role-play. Haptic devices serve as a hub for learning from the different cloud hosts and servers; allow to share the experience and voice through social media, allow to interact face to face, instill the user to make and create media content, to find and locate resources, learn other languages, etc. (Erikson Institute, 2017).

The personal use and engagement of digital technology, either by practitioners and caretakers who belong to the Mashup Generation, have an influential role in the way children use the devices. Educators at schools and parents at home, are nurturing Haptic Generation children with personal online practices by using digital communication, streaming services, cloud systems, smart devices, what underpin and haptic generation expertise before than them (Terras \& Ramsay, 2016). Children's relationships with haptic devices are individually different because they are imitating their parents' digital practices and the personal use of the device, nowadays mainly as Savvy tools, a single entity, a bone, an extension of their bodies.

As mentioned earlier, the nowadays standard adult life (Fig. 16) includes internet connection, and, at least, one haptic device, therefore, despite their differences in technology use, they are influencing and impacting either in a positive or negative way children's behaviors when using their haptic devices, a catalyst for future research and discussion among policymakers, parents, and practitioners (Terras \& Ramsay, 2016).

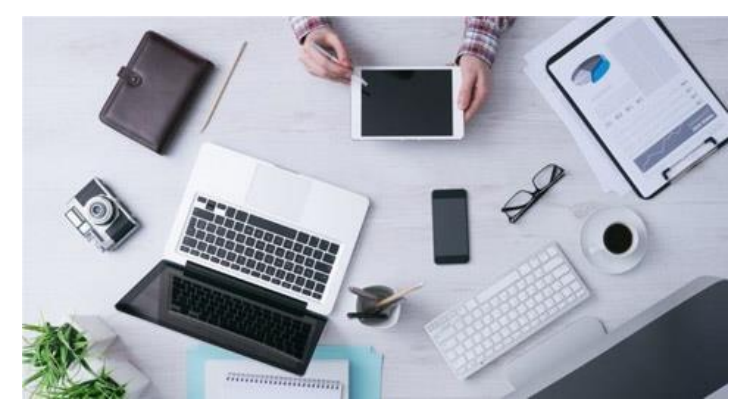

Fig. 16 Devices in a 2018 work setting

The educational system cannot neglect the socio-demographic factors in the adoption of those devices by children aged 0-8 years at home as a context for development (Ofcom, 2017); that the adoption occurs across countries; neither the opportunities for learning that haptic devices can offer under parents' perception and parental monitoring, mediation and control. Children perceive that haptic devices, and haptic interactions are the normal. For them being mobile, social, and entertained (Terras \& Ramsay, 2016) while interacting with an screen is natural, and gives access to a range of formal and informal information resources that feed their curiosity. Those kids are used to observe their parents using them. So, imitating their parents, children emulate what for older generations is incredible (surf the net, use apps, send emails, videocalls, etc.), but not for them. For children, the perception of haptic devices is, in general, very positive (Huber, Highfield, \& Kaufman, 2018b). 
The digitalization process is demanding to Higher Education new talents and better commanding of globalized digital skills for future multiskilled jobs with interdisciplinary knowledge. HEls are facing the arrival of new social elements like digital citizenship, new literacies, and the new technologically proficient students arriving in 2030 at universities, most of them citizens of the haptic generation. So, new learning strategies should be aware of how to engage students from their point of view, with a focus on what they want, and call for their attention, a better way to instruct the engineers of the future.

\subsubsection{Curating Formal Education}

\section{Formal Education and Digitalization}

Although there is a predisposition of the Mashups towards the use of digital technologies for

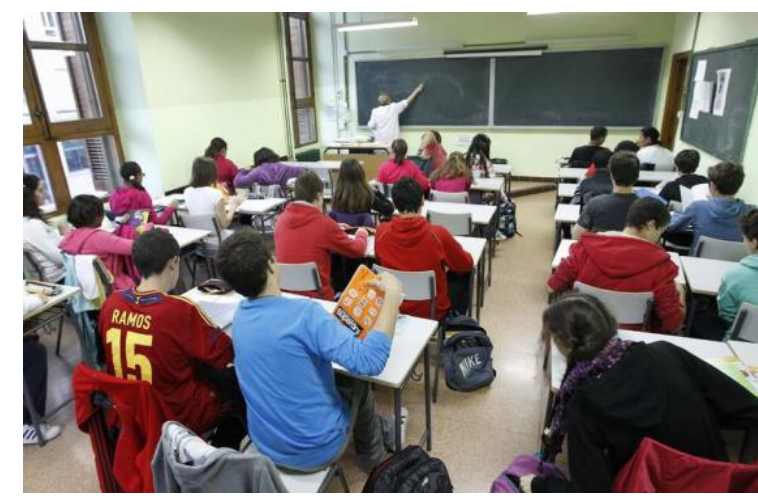
personal interest, it is not possible to transfer the use automatically to the educational system. For many years, the schoolrooms have been filled with individual desks arranged in rows looking at the blackboard. Teachers worked independently in each area or field, and their monologues were the solo protagonists. Sometimes there was time for dialogue between the students, but speaking or using devices went against learning.

Fig. 17 Most frequent Spanish Formal Classroom setting

Spanish educative system has been out of step, and is moving in slow motion (Fig. 17) compared to how students are using technology and devices out of the classroom in terms of communicating, socializing, and learning. Young people have been nurturing their hard and soft skills, and literacies in informal learning scenarios like the web that happened to be used for different purposes like consuming, creating, and contributing.

The comparison of the Spanish formal educational paradigm during the last 30 years to the stages of the web development (web 1.0, 2.0, 3.0, and 4.0) over the same period of time helps to understand the reasons of students' boredom in formal settings, what gives as a product low performance, motivation, and competence's level, as well as justify the high rate of repeater students in Spain according to PISA (Programme for International Student Assessment) for 2015 (Instituto Nacional Español de Estadística, 2016).

The juxtaposition of the delivery of formal education in schools to web development offers a broad explanation of the current learning scenario, and gives clues to help in the formulation of new pedagogical models that will step the haptic generation learning needs towards deep, surface, and strategic approaches to knowledge (Coffield, 2008). 
The Mashups -represented in this section by those who educate in formal settings-, are key elements when doing the analogy between formal education and the evolution of the World Wide Web. Mashups' educators are getting used to haptic devices at the same time than their students, and the possibilities for learning outside of the school fill enough space inside the future learning Atrium that needs curated guide.

Digital evolution creates a new space for dialog among policymakers, educators, and students (Chapter 7) where the walls and the open roof offer global interaction, and a positive dialog among participants of all generations established in different cultural settings.

It is of common sense to understand the student's real expectations by listening their voices, and observing their digital behaviors. It is obligated to try to envision how to avoid that society lose them as potential scholars. It will be, not until the next generation (those born after 2025) is arriving to formal classrooms, that educators of any level (primary, secondary, high school, and university) will be fully ready to meet student's needs and digital expectations for Web 4.0, and the $4^{\text {th }}$ Industrial Revolution.

\section{Major Educational Swifts}

Encyclopaedia Britannica, defines "Education" as a "discipline that is concerned with methods of teaching and learning in schools or school-like environments; and can be thought of as the transmission of the values and accumulated knowledge of a society" (Britannica, 2018). Therefore, current education, as a discipline, should include the accumulation of several historical and technological swifts in the transmission of that knowledge.

First swift was in 1440 with the printing press of Gutenberg. Printing ensured that the same information of manuscripts and oral accounts, stored mainly university libraries, saw light on the same number of pages, with the same numbering, tables of contents, and indices. This facilitated its quick spread and became common to the maximum population. Printing press also modified the process of reading, gradually moving from several centuries of oral and public readings to silent, and private.

By the end of the 1800s, the second swift arrived in the hands of "Typographers". A machine that had a lever that allowed to select the character to be printed and then pressed it against the paper. Manual typewriters were movable and used by individuals to typewrite personal correspondence or other documents by means of keyboard-operated types striking a ribbon to transfer ink or carbon impressions onto the paper. Electronic typewriters or electronic word processors since the 1930s until 1978 allowed modifications on the written texts without necessarily having to rewrite the whole text again, saving time and money. Those automatic machines were able to process texts, storing them in memory cards for later use or sending it physically to another person to edit or make more copies. It was a revolution for academia, researchers, education, makers, poets, artists, innovators, activists, and musicians among many others. In 1978, word processing software for computers added new automatic features to printed texts like design, color, and references, review options, formatting, storing, manipulating, entered from a keyboard, and providing a printout. To format text allowed to users the possibility to create, edit, and print documents from digital versions (Hinojosa, 2016), and contribute to social knowledge and education. 
The third swift arrived in mid-eighties and evolved drastically during the 2000s. The 2000s meant not only a change of century, but also a change at the heart of human activity in all spheres of life due to the World Wide Web birth, and later, the wireless communication network, cloud computing, and haptic interaction. The four elements have provoked a sudden change in the technological landscape that not only affected government, industry, research, and tools to manage available information, but it also affected citizens, education, health care, and the modernization of the administration.

The advent of this technology allows multimodal communication from anywhere to anywhere if there is appropriate infrastructure. Users manage documents stored in remote data centers accessible from any Internet-connected PC, or from any haptic device at hand. Geographically separated teams of people are able to work together on the same documents, what meet user's knowledge needs, as well as greater convenience, mobility, and collaboration support in new digital formats like images, audios, videos, or word texts (Webopedia.com, 2011). The access to digital documentation from personal and/or haptic devices, and through the net makes the research and the learning accessible to everybody everywhere: scholars, students, university members, and any individual that has learning interests, and little possibilities to be physically in a library or in a research institution.

World Wide Web enabled all kind of documents to be cloud stored. This happened with manuscripts, thesis, papers, journals, laws, proposal, reports, scripts, paper books, eBooks, videos, oral presentations, web sites, hypertexts, recorded classes from online university archives (MIT, Khan Academy, Coursera, etc.), among many other kinds, in online libraries, museums, universities, private collections, personal computers, clouds and USB hard drives (Fernández Enguita \& Vázquez Cupeiro, 2016).

Jacques Delors started his report about Education for the XXI century by saying that "In confronting the many challenges that the future holds in store, humankind sees in education an indispensable asset in its attempt to attain the ideals of peace, freedom and social justice" (Delors, 1996). Under this point of view, curated education becomes the best way for society to reflect and develop skills that aim to mold the future the society needs. Its methodologies are shaped and adjusted not only within the lecture room, but also from the household, with the game console, at the library, in the museum, with YouTube contents, and Google searches, playing, all of them an important role in the modern and digital society.

Hence, the learning scenario since 1989 is an evolving ecosystem that incorporates the World Wide Web, and its fast development into their walls. For new students is not an option, but the natural way to access to formal learning and knowledge. The incorporation of the new elements takes away the exclusivity of the instructive approach of monologist teachers, to give it to the dialog created in the Student-Centered approach (Benelux Bologna Secretariat, 2007) where students have the option to select among many type of documents, in any format, at their pace, and in whatever place of the world they are stored. 


\section{Web Development Stages and Formal Education}

Computer technology has had several stages from the user's point of view related with web development. The infrastructure for internet was already known in the sixties (Castells, Fernández-Ardèvol, Linchuan-Qiu, \& Sey, 2006) but only at university campuses, research, or government institutions. For common users, it was the evolution of the web and its possibilities what made a difference in communicative habits.

(Kumar, 2017) summarizes the internet evolution in four periods after the Pre-Internet period (Analog), where humans communicated through fixed and mobile telephones, SMS, and faxes before the last decade of the $20^{\text {th }}$ Century:

- Web 1.0 (the internet of Content), based mainly in content reading. Smart network showed up within the digital landscape together with email communication, web-based information, and entertainment (games, and chatrooms).

- Web 2.0 (the internet of Services) brought smart IT and it was based mainly in the offer of services and write-read interaction: e-productivity, e-commerce, and social media (Facebook, YouTube, Twitter), among others.

- Web 3.0 (the internet of People) was born after smartphones, apps, haptic devices, and tags was introduced. Communicating among people, sharing and creating contents though internet is basic during this timing.

- Web 4.0 (the internet of Things), an intelligent web with self-learning systems, gave responses to the introduction of smart data and ambient context where the conversations were held among machines instead of among humans (Vermesan \& Friess, 2015).

The rise and evolution contrast with how education has been dealing with the change of mentality towards the internet. Educational systems have been working comfortably within the chalk culture, so the integration of ICTs into the classrooms has not been easy, neither as quick as the technological evolution went on, and for sure, nor cheap.

It was then when educators started to adapt themselves to the use of haptic devices, and start adapting their learning lessons to new experiences giving to technology a chance inside the classrooms.

The introduction of technology in the classrooms, either desk computers, or haptic devices (Fig. 18) is being slow, and takes small steps to get into the classroom in comparison with the speed of the introduction of more digital advances. In Fig. 18 we can see a few 4/5 years old kids learning with tablets, but still in 2019, only a few schools work with them in a teaching session for that ages. Next, we expose how its timeline has been slow compared with the evolution of the internet. 


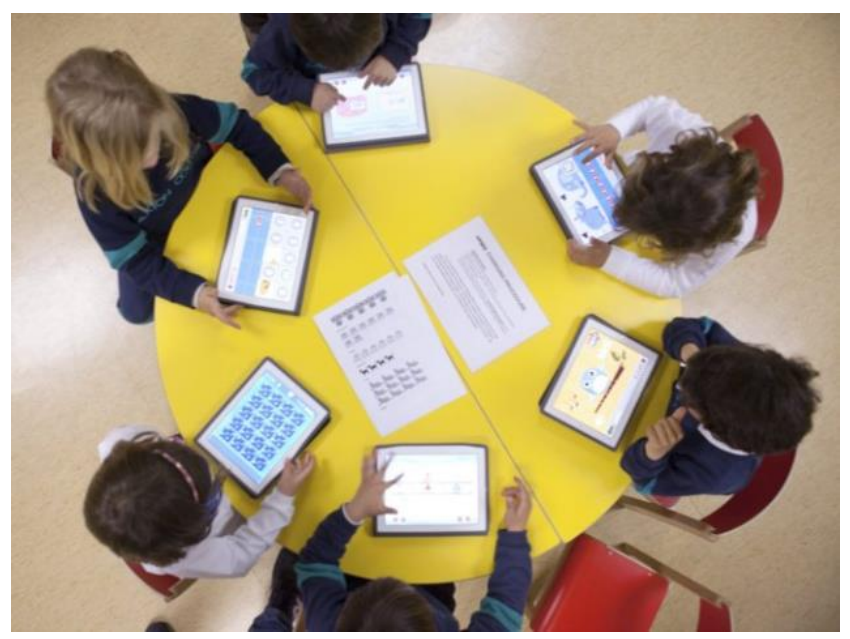

Fig. 18 Caxton Reception Class working with Tablets

\section{Stage $1.0(1989-2003)$}

The Internet was developed in the early 1970s by Vint Cerf and Bob Kahn (WIRED.com, 2012), and it is basically a huge network made up of smaller networks of computers that deliver packets of information to other computers: Arpanet (1969), FTP\&TCP/IP Protocol (1973) or Ethernet (1976). In 1989, Tim Berners-Lee while working at CERN brought to scene the concept of the Web (information rich platform and hypertext) that was, essentially that information that internet was delivering from one computer to another one, but in the form of webpages: the World Wide Web (Berners-Lee, Cailliau, \& ECP, 1990), in other words the web was defined as a techno-social network where humans interact, enhancing human cognition, communication, and co-operation.

From 1989 to 2003 Spanish internet users grew from 0.1\% of its population in 1990 to $39.93 \%$ in 2003. Regarding Worldwide Webpages available, data inform that it grew from one website (unique hostname) page in 1990 to 40.4 millions in 2003 (Development Data Group, 2018).

Web 1.0 embraces the basic internet, and its most basic appearance. It was characterized by being unidirectional and made on static content. Through the linking of documents (pages), users could read content available in link directories (Yahoo!) using first generation of browsers (Netscape and Internet explorer). If the webmaster did not update the content, the content could not change. Some browser providers gave access to free email accounts and started to be popular outside the academic and work (Österberg, 2016).

Some Web 1.0 based services that contributed to population to change their habits were Yahoo and Amazon (1994), Altavista, AOL, Java (1995), IRCnet (1996), Google.com (1997), Portable mp3 players (1998) Napster (1999), USB flash drivers (2000), Wikipedia, Google Earth (2001), Paypal, EBay (2002), and MySpace, iTunes, Flickr, Skype Podcast (2003) (Archive.org, 2001). At that time, all of them were poor in typography, had visible visitor counters, outgoing links and background imagery, to be displayed only in desk computers (Österberg, 2016). Devices like portable Mp3 players (1998) and USB flash drives (2000) made a change in sharing, consuming, and accessing to 
digital data, it made it more portable, easy to store and accessible in different places and moments.

As an example of how the technological revolution arrived to Spanish population during this period, we highlight, Internet Relay Chat (IRC) because its relevance among users at that moment. IRC was created in 1988, worldwide spread in 1993 and arriving to Spain in 1997/98 in the form of IRCnet. It was an application that facilitated text communication among users in real time. It was designed for group communication in channels but allowed one to one communication via private messages (IRChelp.org, 2013). One of the most popular in Spain was \#IRC chat with its chatrooms and nicknames. Users of IRCnet were the first to experience what today is known as cross-platform messaging (e.g. WhatsApp, Telegram), with the difference that people behind their nicknames were no friends neither family, and they have to be connected at the same time to chat like they were talking face to face. The \#IRC allowed to arrange live meetings of people from the same chatroom in whatever city or village of Spain. Those chatrooms were the first attempts to offer a collaborative space where people interchanged ideas. Nowadays we can find those chat groups in learning platforms.

During those years, technology gave access to information or data that could be disseminated, but did not allow the users to collaborate among them, or modify the contents.

Extrapolated to formal education, teaching was a unidirectional (teacher to student) process where students acquired the information provided by teachers with a passive attitude, inducing individual study instead of collaborative, as well as little participation, and no knowledge generation at all.

The type of instruction is Teacher-Centered and seeks, as a product of the learning goal, no more than the reproduction of contents. For students is just to pass exams by learning things without real understanding. The responsibility for the transformation of knowledge belongs to the teacher. Knowledge is understood as something constructed by others. Students' preferences are not considered. The interaction between the student and the teacher is minimal and unidirectional or at the most bi-directional to maintain attention or to ensure understanding and clarify doubts. The control of the content falls on the teacher. Interest and motivation should be promoted by the teacher (Gargallo-López, 2008). Subjects are prefixed in the school curricula and taught by certified teachers in an industrial classroom format that do not allow to move around. Contents are expelled out in front of passive listeners (students) who had only the information provided by the references selected in didactic paper books to shape their learning. Students work on the content by using own notes, library resources, textbooks, videos, and, during the last year, depending on the investment in technological infrastructure of the school (public, semi-public, or private), computers to share with access to the web (Rosique, 2009).

\section{Stage $2.0(2004-2009)$}

During this cohort of time, Spanish internet users grew from 44\% of its population in 2004 up to $62 \%$ in 2009, and the available webpages around the globe, grew from 51.6 millions (unique hostname) pages in 2004 to 238 millions in 2009 (Development Data Group, 2018), an increase of $361 \%$ in a five-year period. 
The web 2.0 concept is given to a participatory technology to share knowledge. It allows users to interact with other users or change content on the website, impossible to do with the web 1.0. People can share, publish, comment, and socialize online in their own webpages but also in others web pages. Web standards includes RSS (Really Simple Syndication) that allows people to read and write content, a substantial change in the evolution of web sites. With web 2.0 it is the consumer who generates the quality content and collaborate in blogs, wikis, crowdsourcing, social networks, etc. (Österberg, 2016). Here, personalization is key, but educators and subjects of study are still not ready for it.

Web 2.0 also became more functional with cloud computing services helping to avoid the need to install software on an own computer. Cloud computing is the on demand availability of services via internet, specially data storage and computing power, opposed to being provided from a company's own on-premises servers (Webopedia.com, 2011). Cloud computing implies also a centralization of personal in many different web-based or streaming services content with the same credentials.

Some Web 2.0 based services contributed to embrace the digital world, for instance TomTom navigation system (2004), YouTube (2005), Facebook (to public), Twitter, Blablacar, Nintendo Wii, Tuenti (only in Spain) (2006), Tumblr, Dropbox, Apple TV (2007), Street view in Google Earth (2008), Spotify, Bing, WhatsApp (2009), (Archive.org, 2001), with elements like search suggestions, navigation based on the visitor's history, video streaming, maps, social feeds. In Spain, some services become popular with a delay of 2 or 3 years later than in the rest of the world. The reason for that was that people did not use the services. At that moment, there was no need to do it. The use arrived in the hands of young people or early adopters, and again with entertaining and communicating purposes not for learning. Those services started being known and used with the arrival of smartphones that could be carried on, wireless 3G/4G connection, and the increase of Wi-Fi spots.

One of the most explicit examples has been (WhatsApp Inc, 2009). The App was created in 2009, and was slowly spread among users by passing the voice. WhatsApp is free and offers simple, secure, reliable messaging and calling, available on phones all over the world. It was born as a communicative and texting app, for immediate contact with friends and family, anytime, anywhere avoiding the payment of SMS (WhatsApp Inc, 2009). But Spain started using it in 2012 with the increase of smartphones sales. In 2018, WhatsApp leads the market in communication Apps, because it is the most popular, and allows the interchange of texts, video, photo, and voice messages. It supports geolocation, and recently has been used for teaching purposes in classes (Church \& de Oliveira, 2013) and (Gachago, Strydom, Hanekom, Simons, \& Walters, 2015). Other popular use in at professional settings to arrange meetings, send immediate information, feedback, to solve quick questions. This use avoids the waste of time over the phone, or waiting for an answer via email (Buchenscheit et al., 2014), and increases the productivity.

Another big impact of WhatsApp in common lives, is that the App brought a new way of family communication among all ages. Senior family members started using smartphones because WhatsApp allowed them to be in touch with their relatives and it was easy to use. For many it was the motivation to own a smartphone, and have $24 / 7$ care contact, obtaining immediate response to their needs. This simple App has been very important for older people because when using it, 
they are able to avoid loneliness feelings (Rosales \& Fernández-Ardevol, 2016), and physical distance.

Cloud services started to be known and spread with the arrival of Dropbox in 2007. Dropbox was one of the first cloud storage, instantly data updated that users could use for free, accessible from all the registered devices, avoiding portable USB and different versions of the same digital document (Dropbox Inc, 2007). Cloud storage and services made a difference also in how users accessed and consumed their own digital data.

Extrapolated to formal education, we parallel stage 2.0 to the ideal of the learning model: to be collaborative with the aim to create social knowledge in a bidirectional process (teacher = student). During this period is clear the transition from paper to digital format, and digital tools that help to personalize the learning according to the students, their interaction, exploration, and knowledge acquisition.

Students and educators could have adapted their learning goals to new formats giving to learning more meaning than ever. But the reality was very different. Despite that technological infrastructures and internet connections were possible at schools, there are very few pedagogical innovations. The traditional instructive and face to face model of teaching where the teacher dictates what needs to be learned, continues to prevail. Innovation depends very much on teachers' computer skills and how they apply these technological advances into their teaching, but educators were learning and adjusting to the new digital landscape at the same time than students (Rosique, 2009), in some cases, even later than their students. The consequence was a huge gap between formal learning and the learning obtained outside of the classroom.

During the period, the educational model within the classroom is not adjusted with the reality that students live outside of the classroom. The paper textbooks remain fixed to curricula contents, but the computer at home was offering a new window to gather information, to update the book information, and foresee new possibilities of learning within the same topic. The students' reaction to the gap is boredom, impatience, and low scores. In some cases, they dropped out from schools.

There was an educational gap affecting to a whole generation, and not all the students reacted to the consequences in the same way during those scholarly years, therefore the inner motivation as a factor was crucial for YGen and ZGen students.

Summarizing, we notice that despite schools and universities had infrastructures to accomplish the change, and that Bologna Process was demanding a new student-centered approach (Benelux Bologna Secretariat, 2009), the teaching methodology remained instructional.

Formal education itself was not transformed in a significant and broad-minded sense because of two main reasons: the Spanish educational community was still too embedded in the framework of Education 1.0 due to a strong tradition, educative policies, the lack of room for technological innovation; and because educators were not trained to adjust their subjects to technology. Indeed, the educators' effort to learn was bigger than children's because they had to blend concepts that were far away from their reality. 


\section{Stage $3.0(2010-2019)$}

During the stage cohort Spanish internet users grew from $65.8 \%$ of its population in 2010 to $84.60 \%$ in 2017 (37 millions of users of all ages), and in 2017 the internet accounted for 1,766 millions webpages available worldwide (Development Data Group, 2018), still increasing at the moment of writing.

The third generation of web concept makes technology and information smart and intelligent. It is cloud based, user adaptable, and usable. Web growth is driven by smart devices technology and the openness of new possibilities. A layer of metadata has been added to tag information in contextual meaning (Österberg, 2016), like those sentences placed in a specific paragraph that helps to understand the whole text. The information is stored to be accessed and contributed from different users from their preferred devices, either desktop, laptop, haptic devices, or wearables, and from their preferable physical spot.

Stage 3.0 refers to the web adjusted for apps and the multidevice web, including haptic devices and TVs. Web content and information are permanently available wherever and whenever the user tries to connect. It includes personalization and the elaboration of users' own contents. Web and cloud services adapt the content to the user based on explicit preferences and past activity. Those actions seem to be more precise in guiding their preferences towards relevant knowledge.

Some Web 3.0 based services and devices that contributed to embrace the digital landscape are FaceTime, in-built and other Apps, Pinterest, Instagram, Flipboard (2010), Siri, Newsflash (2011), Telegram, 3D printers, Waze (2013), Google glass (2014), Wearables, Apple Pencil (2015), Internet of Things, Artificial intelligence, Augmented Reality, Virtual Reality, etc. in constant evolution (Archive.org, 2001).

Flipboard or Newsflash are apps based in RSS "Really Simple Syndication" or "Rich site Summary" (Merriam-Webster, 2015), a way to easily distribute a list of newspaper headlines, update notices, and sometimes content to a wide number of people in just a few lines and summing up all the content. The reader can be informed about news with just a few lines instead of a whole article. If the topic and the headline are of user's interest, he simply follows the link to the real web page content with the whole article. There are many apps that use feeds.

Equally to the WhatsApp phenomenon, Twitter, an American online news and social networking service on which users post and interact with messages known as "tweets" (Twitter Inc., 2006), is a good and a known example of how RSS is used. Twitter started allowing a maximum of 140 characters per tweet, then 160 and last version up to 280 . This way of displaying information has changed the way users read digital content from reading to skimming or scanning the feed. So, the time users spent on internet increased, as well as it has increased the reading online with different devices. Users read more, but the quality of the reading is poor, and readers develop less critical thinking while reading. The affordances of more in less effort is translated into less traditional reading (paper book, e-book) and more feed reading that implies to read "words and images that covers in a few minutes the content of a 400-page book, and plus, the user can comment while watching or reading the feed" (Rich, 2018) generating a worldwide debate regarding reading literacy in any birth cohort, subject to research in children cohort. 
Extrapolated to formal education, and being witness of the consequences of paradigm 2.0, during this stage there is, among educators, a consciousness of a learning reality outside of the classroom. Teachers start being trained and informed in digital skills to help to minimize the educational gap advised by European directions (Benelux Bologna Secretariat, 2009) with an strong Student-Centered approach.

New pedagogical innovations arise in classrooms to make students experiential and participative, like "Proyectos de Innovación y Mejora Educativa" programs (2010-2020) of UPV (UPV-VECA, 2019) . The objective for teaching is based fundamentally on how to reach students attention and personalize their learning inside the classroom. The students live in an open book world, a link away from any piece of information summarized in a feed.

Other innovative methodologies have been tested with Spanish university students aimed at exploring the different possibilities of MOOCs, flipped learning, or project-based experiences in engineering. Some initiatives like the ones introduced in the papers of (Romero-Bruzon, RiojaDel-Rio, \& Morgado-Estevez, 2015), (Sánchez-Ruiz, Llobregat-Gómez, Moll, Moraño, \& Roselló, 2016), (Santiuste et al., 2017), and (Chapelle et al., 2018) give data of their application in small groups and the difficulty to set all the elements for full success.

Formal educators are aware of the students' needs and preferences: attendance is compulsory but learning is optional, giving as a matter of fact different type of learners: those that are truly self-motivated and intent on progressing using all the tools at their disposal, those who are waiting for the class to finish and start with their own learning preferences at home, or those that dropout because they do not want to follow instructions when learning.

Access to technology is taken for granted during this period, no longer feared by older generations, and begins to be valued as something positive among other reasons because haptic devices are used as a toolbox. The way digital technology is being implemented engages students, and is understood by their teachers. Teachers start speaking the same language than students (understanding by language the way students communicate through social media, texting, using emoticons, the way to use YouTube, etc.) then, students' curiosity, their ingenuity to solve questions, and their innate talent are invoked and have new collaborative responses that open a new door to knowledge. This new perspective is integral and interdisciplinary due to that you cannot separate fields or subjects of learning in the way it was done before which helps to foster cognitive and social skills.

The third educational phase based in the concept web 3.0 has surpassed the gap created in the second one. Teachers are also users of the digital devices, as any other citizen, and together to the rest of the Mashups, they are learning how to read, create, and share content among peers, and with students. Their devices are visible in the classrooms, and they are aware of that they are not the ones who possess the knowledge in the classroom, letting the students to introduce ideas, and participate in their own learning process. 


\subsection{The Haptic Generation}

The Haptic Generation (HapGens) (2010-2024) is the Spanish current preschooler and primary generation with $3,569,162$ citizens, the $7.3 \%$ of the total population. They are between 0 and 7 years old in 2017 (INE, 2018).

Universitat Politècnica de Valencia, despite being a Higher Education Institution, counts with services that provides non-formal education to, mainly, UPV staff offspring with the aim to reconcile work and family life. The UPV Summer School Camp (Summer Camp), organizes, during July, sport and STEM activities addressed to more than 1,500 children aged between 4 and 17 per year. Centro Educativo Infantil Vera attends and educate children aged between 1 and 3 years old ( $1^{\text {st }}$ cycle of kindergarten education), offspring of UPV staff since 1978.

During the 2017-18 academic year, the UPV accounts for 560 out of 1,660 HapGen children in the Summer School campus, and 82 children in its Centro Educativo Infantil Vera. Since 2010, the Center has attended around 700 HapGen children (UPV, 2017). Those young students will be in High School or vocational training around 2025, and hopefully, joining university degrees in 2030.

The Haptic Generation is also known as Alpha generation, term coined by sociologist and demographer Mark McCrindle following the Greek alphabet (Sterbenz, 2015). This generation is already exposed to diverse learning environments (school, home, and digital), generating complex conversational scenarios. In most of the cases, haptic devices have been their babysitter, and because the content displayed can be played in different languages, English learning plays the most important role (Vargason, 2017).

HapGens are still very young to try to figure out their psychological traits or characteristics. What we know is that smart devices will be the norm for them, and that they have a digital footprint ${ }^{16}$ even before they were born. Their parents' online actions and posts about them, together with medical records did it possible. So, they do not understand the term yet but they are widely exposed to multiple digital platforms either by themselves (App use) or because their parents create accounts or avatars with their data.

\subsubsection{First Contact with Digitalization}

Before HapGens opened their eyes for the first time, their parents constantly were interacting with haptic devices with great interest (Sharot, 2017), pictures and videos of their first day sent by WhatsApp, uploaded into Facebook or Instagram, instant family updates all of them through personal devices prove how their use has become a way of life. Due to their parents use of haptic

\footnotetext{
${ }^{16}$ Digital Footprint: information about a particular person that exists on the Internet as a result of their online activity (Whatls.com, 2018).
} 
devices and internet, they have a digital footprint ${ }^{17}$ and digital dossier ${ }^{18}$ since the day they were born (Church \& de Oliveira, 2013). They are widely exposed to multiple digital platforms, and being already users of learning apps, their personalized online experiences will increase as they grow (Epic! Creations, 2016).

For this generation, sight, hearing and touch, three of the five acts of perception, become just one that is activated with a simple fingertip on a touchscreen (Yau, Kim, Thakur, \& Bensmaia, 2016). Interaction on a screen is granted, and instinctive. Digital input, to discover things and facts further than their proximate space area, is the normal. Their main trend, haptic feedback, has transform passive touching into active interaction, a reason for those kids to have integrated technology in their lives as part of their bodies. If fact, this trend, accessible since 2007, has no precedent in previous generations.

Today, the $98 \%$ of Spanish households include haptic devices and connectivity (Fund. Telefónica, 2018a) within the walls. According to 2015 PISA study, the $32.4 \%$ of the children's population have used computers for the first time being younger than 6 . Denmark with $56.8 \%$ and Sweden with $55.2 \&$ scores the highest positions when talking about children haptic device usage at this age (OECD, 2015). As an important fact, the $90 \%$ of the children use digital devices and computers regularly at the age of 10 (Chaudron, Di Gioia, \& Gemo, 2018).

The qualitative study across Europe, focused in young children (0-8) and Digital technology, states that in the $94 \%$ of the households the parents and older siblings are using constantly haptic devices in their regular actions. Because of that, it is almost impossible to avoid that children interact with the devices. Up to date, and because their young age, there is no enough data to demonstrate that children innately interact with the devices, or to prove what they are doing with the devices. Data comes from the information provided by parents about how their kids are using the devices at home (Chaudron et al., 2018) what means that the use is mediated by parents, the use parents made of them, and the opinion they have about them. Not properly informed about the learning possibilities that the devices offer, may mean a no use of the devices with that purpose, i.e. children do not know they can use them in that way.

In a Spanish household, the tablet is one of the three favorite devices, and children are described as having learnt "on their own" to use digital media, explore the device through trial and error, or making the best of moments when adults interact.

Data extracted from (Chaudron et al., 2018) study state that socioeconomically disadvantaged families possess as much technology at home as other wealthy families. We can find the difference among families in the restriction to exposure and awareness of online dangers, having wealthy

\footnotetext{
17 Digital Footprint is "the unique data trace of a user's activities, actions, communications or transactions in digital media. This data trace can be left on the internet, computers, mobile devices or other mediums" (Janssen, 2016).

18 Digital Dossier is a "superset of user online data that includes secure private records as well as user public online identity. In addition to user contributions to the dossier, other people can make contributions to user dossier with pictures and other additions to the subset of data that makes up user public identity online" (Cheney, 2012).
} 
families more control over children's use of the devices. Other interesting fact is that, in early childhood, curiosity and instinct drive and shapes the use early childhood give to the device, its Apps and its contents. They show interest by playing and interacting with the device through topics that really keep their attention like learning about the parts of the human body, dinosaurs, super-heroes, plants, trees, etc.

Onsite observation (HG Case Study) indicates that the relationship of those kids with technology is like their relationship with parents, friends, or siblings, they interpret technology as an entity that grows while they grow, naturally, belonging to their environment. Being so young, parental attitudes, practices, and opinions in the home environment, as well as the family beliefs about technology use as educational support influence children's use of haptic devices (Terras \& Ramsay, 2016).

\subsubsection{Digitally Sarvy}

Haptic generation children are technically innate, tech savvy and use several screens while spying their role models: parents, and teachers of the Mashup Generation. They spend part of their time in online activities, and perform multiple connections. Those kids are immersed in a multicultural society that connect via text and images; the same blended items that help them to learn how the world is going to be. We could consider those kids future multilingual speakers because they are exposed not only to their mother tongue, like Spanish for a Spanish kid, but to the languages the haptic devices and perform while playing the different contents (e.g. English, because they play all the contents in English when interacting with the device). They can communicate in new idioms brought by instant communication like emojis, symbols, or pictures (McCrindle, 2011). As they become older and used to how the devices work, and the possibilities that brings they are able to share content in digital communities; they can produce their own digital stuff while playing with their own devices; or they are able to learn digital skills while playing games, among many others.

Compared to older generations, they follow different standards when dealing with content what induces to formulate inner questions that they solve by touching again the screen. They know only wireless, hyperlinked, user-adapted contents, where they are only a few taps away from any answer they are looking for (McCrindle \& Wolfinger, 2009). This bottom-up conversation, provoked by haptic interaction, is the digital opportunity that the educative system has found by serendipity to spark greater levels of knowledge (Turk, 2017) surpassing YGens and ZGens.

For this generation the strange technological tools are wired telephones without screen, typewriters, computers that cannot be interacted with fingers, the concept of paper Encyclopedia or dictionary, mp3 players, USB drivers, or floppy disks. Active observation on how toddlers and primary children interact with haptic devices show that babies, toddlers and children master touch-based interaction with haptic devices (Price, Jewitt, \& Crescenzi, 2015), and that they swift from one task to another rapidly, giving more value to speed than to accuracy (Hourcade, Mascher, Wu, \& Pantoja, 2015). Surprisingly, they love printed photos, notebooks, pencils, drawing with as many colors as possible, the things that parents are trying to avoid for themselves because it is driven by the environmental society (HG Case Study in Chapter 4). 


\subsubsection{A New Playmat}

HapGens start incorporating haptic devices, interactive toys, and intelligent voice assistant among their other toys as they play naturally (Druga et al., 2017). The selection of the play toys is based on what they see around them, and what they can mimic, as other generations did with other type of resources. For example, observed pretend play (a key opportunity for creativity) in an onsite experiment (HG Case Study, Chapter 4) has shown that children role-play doctors and

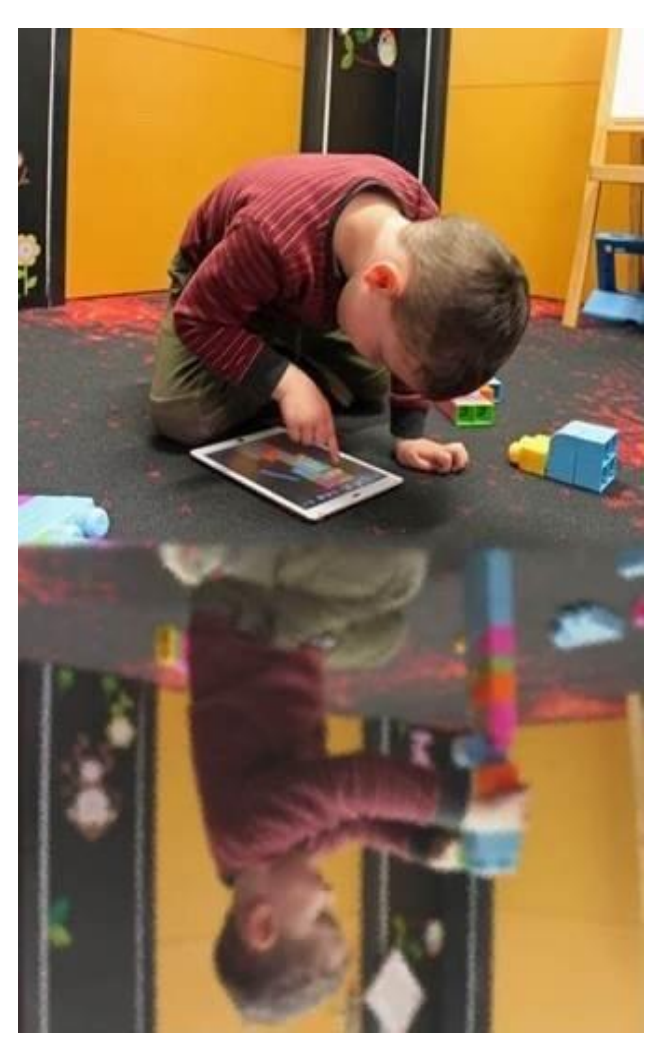
patients keeping data in their tablets, also, they selfie dolls while taking pretend coffee, they own a smartphone toy among personal belongings to get pretended directions, or buying staff, and also one of the kids was asking SIRI to calculate a math question in a pretend teaching classroom (HG Case Study. Chapter 4) without previous instruction. Parents use wearables for sports, or as normal watches, and kids roleplay with their smartwatches toys (VTECH, 2017). Linking haptic interactions to role play shows not only a normal imitated behavior, but also the introduction of fantasy and imagination as a learning skill (Fig. 19).

Smart toys are interactive and include technologies such as image or voice recognition and Apps to follow how the kid takes care of the toy (VTECH, 2017). For HapGen children, the intelligent assistants (Abdullah et al., 2017) like Alexa, Siri, Google Home and Cortana, are part of the family because their parents have introduced those devices in their homes (Vermesan \& Friess, 2015).

Fig. 19 Learning in a new playmat (Swinburne Babylab)

They learnt that intelligent assistants, AR experiences, tablets, and smart toys existed because they share the same playmat at home. They naturally ask to the speaker and the object answer. The voice recognition software is so close to natural, that understand 2 years old kid's speech, and provides answers to the kid. Since 2017, children are familiarized with them as they were friends and trustworthy (WIRED.com, 2017).

Robotics, smart devices, artificial intelligence, cloud computing, code literacy, and augmented/virtual reality scenarios are already implemented in Apps that children can use without knowing how to spell out their own name. Children only need their fingertip to move objects on an interactive screen. They cannot touch the objects but they interact with them through the screen as it was a real object. 
New tools based on smart systems start nurturing children personal learning with enhanced experiences, where gestural ${ }^{19}$ and voice interfaces will rival screen in a few years (Turk, 2017). Children will interact with their environment through those "natural" interfaces in a more fulfilling way, but it is important to bear in mind that current children do not think about these technologies as tools anymore, but as integrated singularly into their own lives (Mueller \& Oppenheimer, 2016).

\subsubsection{Switching on the Device}

When the haptic device is switched on, young children are able to perform many actions apart from the core gestures (tap, press, double tap, drag, or flick) like to change or edit photo in a profile, insert emojis in a text message, take a photo, record video and voice, find Apps, ask for directions to SIRI, play music, watch movies, create personal videos, send emails, even coding a robot (Ofcom, 2017).

Regarding early childhood preferences to spend their time when being online, their favorite routine is to watch cartoons on a screen, like any other previous generation. The difference between previous TV contents and the new ones is that the contents are available in streaming platforms, and children can select among the offer in the moment they want. YouTube or Netflix are the most used, accessible at any time, with the possibility of being controlled and preselected by their parents, and with the possibility to watch them in their original languages (Ofcom, 2017). This feature is, by serendipity, an extraordinary tool to acquire a second language in a passive way, as it is fully informed in Chapter 5.

Second higher use is for gaming via Apps normally that has been described as "educational" (Ofcom, 2017), and the third in the highest position is for creative activities like creating or editing photos, drawing pictures, making videos, writing notes with finger or Apple pencil input, sharing their creations afterwards to parents or family members and texting emojis in Apps like WhatsApp (Ofcom, 2017).

As they are still too young, social media (Instagram, Facebook, twitter) has not made a real impact in their lives, or at least it can be avoided with adult supervision. Data shows that older than 6 start using social media, and the use correlates with the level of studies achieved by the parents and how much they are informed about the online risks, and the type of source (reliable or not). The lower level of studies of the parents, they higher social media use by kids, as well as more permissibility in their use (Chaudron et al., 2018). Uncontrolled use and no supervision has been proved to more online and offline risks (Hadlington, White, \& Curtis, 2019).

Once the children join formal learning, it would be desirable that they were introduce to digital literacy, as well as to innovative education projects driven by technology and digital transformation with haptic devices as fundamental tool. Digital literacy start being introduce in schools thanks to formative and informative actions addressed to educators like EnlightED Summit

\footnotetext{
${ }^{19}$ By Gestural interfaces we understand interaction with digital content by using hand or body movements, using information collected by wearable devices or tracking sensors. It will allow to interact with virtual and augmented reality without the need to hold or touch a controller (Turk, 2017).
} 
(Spain) 2018 and 2019 promoted by Fund. Telefonica, where "experts on education, technology, and innovation promote a debate on education in the digital age" (EnlightED.education, 2019).

As an example of schools that are using haptic devices' in their formal teaching we have found "Centro Rural Agrupado de Ariño-Alloza (Teruel)" (state and rural school), Colegio La Anunciación, (Valencia) (semi-private school), Colegio León y Castillo (Telde, Gran Canaria) (state school), and Caxton College (private school), among many other. We should note that the implementation is still emerging, and many other schools are working on device use policies at school timing.

One of them, (Caxton College, 2015) has implemented the "bring your own device" policy for students older than 8 . And since 2015, its curricula include, among their core skills, digital literacy learning for kindergartens (Caxton College, 2015).

Caxton College started its innovative project already with ZGens. The students were asked to bring their own device to class starting in the fifth course. Younger children join a "computer lesson" per week where they work cooperatively with tablets and cover with different apps the topics they are working on during the semester.

The way to work with the devices is under project-based practices. This methodology uses meaningful texts and situations rather than instruction to cover the different subjects and skills at once. Grammar is taught within the context of reading and writing, nor systematically neither by repetition with strong academic guidance (Valdivieso Burón, Reoyo Serrano, Martín Antón, Carbonero Martín, \& Freitas Resende, 2016).

Children 4-5 years old use Apps for core literacy learning in phonics, and numeracy, as well as drawing to improve fine motor skills. Children 5-6 years old use the tablets to search for pictures published on internet, or produce a video using multiple formats that summarize their learning on the topic.

These innovative methodologies are aimed to better their resilience by acquiring problem solving skills and peer-to-peer learning in an environmentally friendly space, connecting humanities and art with technologies. Children use during sessions tablets or computers as well as books. They also do their homework either in Apps or in paper. They learn how to use the devices with formal hours teaching since kindergarten, included in the curricula as any other basic literacy skill and tool. The Schools use Apps to update parents, to build a classroom communities shared by teachers, students, and parents (ClassDojo, 2011), to create some game-based learning as homework, etc. 



\section{SECTION B.}

Research Design \& Data Collection 



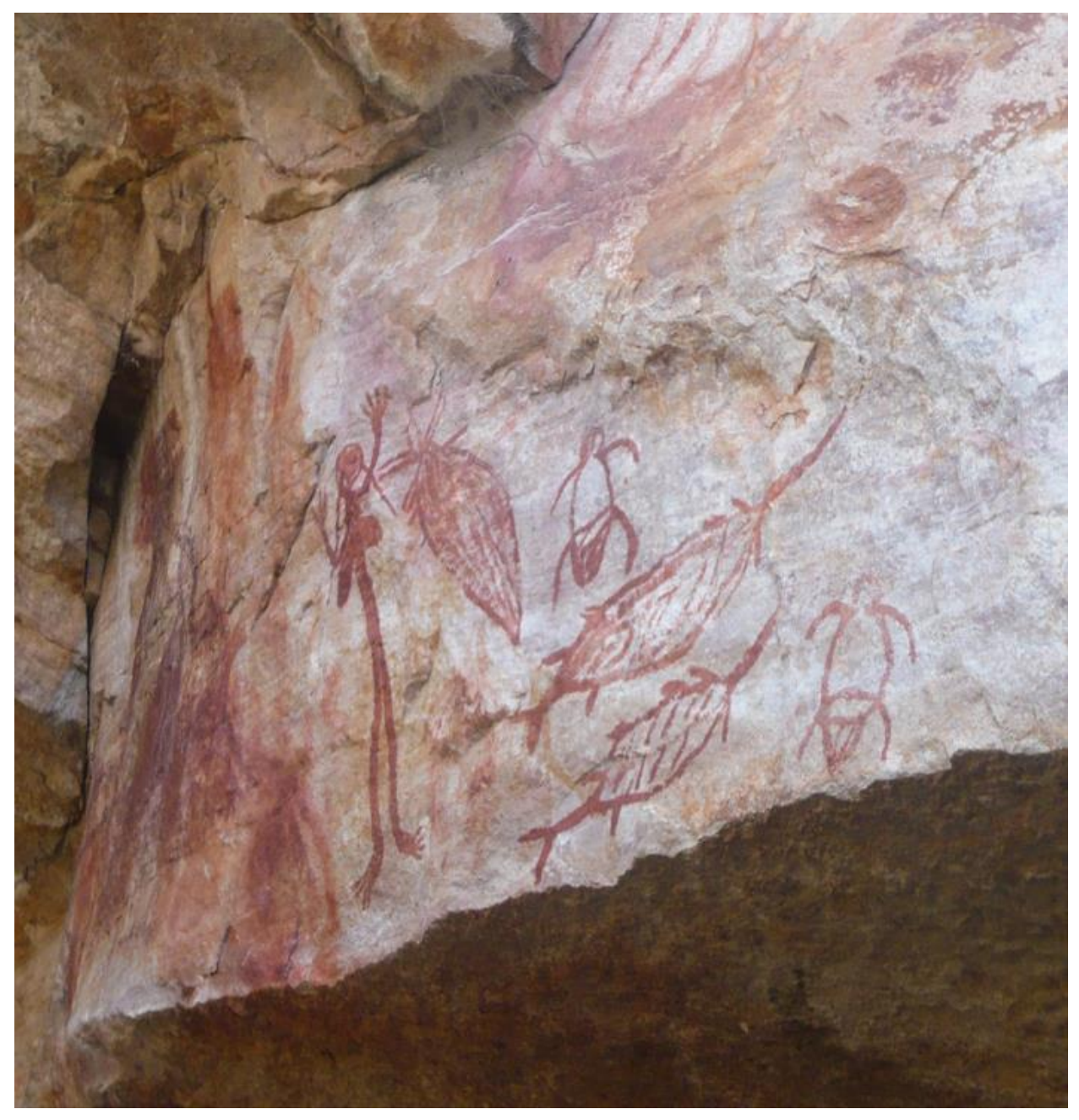

Methodology

Chapter 3 

"If you had an idea that was going to outrage society, would you keep it to yourself?"

Charles Darwin 



\subsection{Research Philosophy}

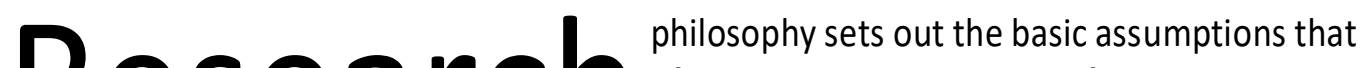

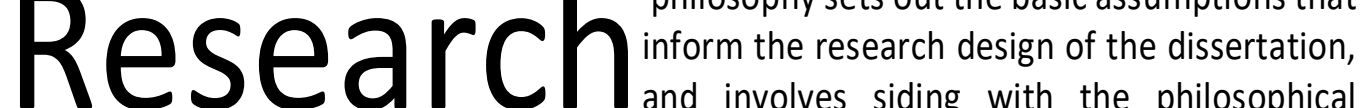 and involves siding with the philosophical}

approach that fundaments its main directives, as well as the research questions that during its development were formulated.

This dissertation is grounded in a multidisciplinary approach that includes among other fields educational, sociological, pedagogical, psychological, neurological, computer science, and engineering. Social Science, as a broad discipline, fundaments the core aim of this research where it is important to point out, how the actual human society is functioning through interpersonal relationships not only among people, but also between individuals and technology within the same society. Technology is currently part of the human body, and as a society we have started functioning as if technology happens to be another person that always stays at our side.

In Social Science at a fundamental level, the idealism approach (also known as Constructionism or Interpretivism) informs that our knowledge of the world is limited by our human capacities; we can never truly know the world "as it is actually."

The constructionist or interpretivist world-view emphasizes that knowledge is the product of human activity. How we perceive the world cannot be separated from what we do in relation to the world. For example, in 2010 haptic devices irrupted in our society because industry decided to advertise a small technological device that everybody could use without technological or computer knowledge. For the first time, a technological device was so intuitive, so easy to use, so small, and so light that people thought it was cool, the voice spread quickly, and right now it is part of their outfit, using the device in multiple scenarios in front of the attentive look of early childhood. According to (DITRENDIA, 2018) in 2018, the $97 \%$ of Spaniards used an smartphone to access to the Internet, and tablets has penetrated into the lives of $74 \%$ of the Spanish population. The industry, as well the users as a perfect tandem, took the leadership of the decisions making governments of developed countries to change some policies, and invest in infrastructure for communication within their territories to reach any household, business, administration, and school This fact moved the stock market, ignited the digitalization of the administration, and 
reversed citizen's lifestyles bringing new ways to profit environments, and collaterally, the search and implementation of innovative teaching methodologies without delay.

This in turn depends upon the assumptions people make about the devices, the use they give to them, the networks of knowledge and information in which they operate, and the previous experiences of all those involved. To justify how haptic devices have suddenly irrupted into the educative landscape, the collection of detailed data (beliefs, behaviors, social attitudes, etc.) that underpin financial, social, and educational decision-making through observational research is mandatory due to up-to-the-minute technological and digital advances.

Observational research provides understanding of what is happening as well as what users are saying and doing in their family life. This determines the level of engagement with mobile technologies in home contexts, and therefore the influence in early childhood. Observation in this thesis dissertation provides a 'rich' set of data for conceptual analysis.

Constructionism clearly shares much with organismic ontology. It treats the world as a living, developing process, where social actors actively try to make sense of each other actions. Understanding the world starts by collecting the different ways that social actors engage in sensemaking, which are gathered until the analysts feel that they are able to build a coherent account of what has happened. Rather than attempting to directly predict events, the constructionist Social Science approach offers possible scenarios based on its understanding of past events and ongoing process.

In brief, and for the purpose of our research, constructionism is the best epistemological point of view to explain how the society and the population within that society is behaving in the digital landscape that the irruption of haptic devices has provoked. From an Inductive Approach we analyze how the irruption is affecting learning in the early years, considering mixed methods to answer the research questions formulated in this dissertation. 


\subsection{Research Approach}

STEM subjects face the Haptic Generation: the iScholar dissertation envisions future scenario that has not been sufficiently addressed by the existing research literature, and has little documentation due to the novelty of the incursion of haptic devices into children's lives.

Scientific research builds on existing academic knowledge, in the form of theories and studies, but also builds on common sense. As any scientific method, it needs to be tested against empirical material to be credible. This means testing in a controlled environment how children use the tablets or smartphones on daily basis. The tests would be very difficult to set due to, mainly, the age of the participants (under 8 ), the type of actions that could be asked to perform in a closed experiment, and the timing.

There is little said about how children under 8 are using haptic devices with learning purposes, or how children can get more knowledgeable benefit with the use of haptic devices than with any other device. It is true that technology has been considered in education, but not haptic devices because haptic devices have been seen mainly as an entertainment and distracting tool, so few studies support my research.

The aim of the research conducted is to offer a new insight on the topic, and propose an alternative approach that education is demanding nowadays. The basis of the research conducted settles on an Inductive Approach, and considers haptic devices from a new point of view: education, never questioned before in research literature.

Through this inductive approach, I start describing the subject of study, and from real observation, one can affirm that children imitate parents, parents are using haptic devices, therefore children are imitating also how their parents use the devices. Then, I set a timing (from 2010 to 2018), and place (formal, informal, and non-formal education), and identify who is involved (children, parents, teachers, stakeholders), how they are involved, and what kind of things they are doing which either exacerbate or ameliorate the issue. The questions that come within this approach include the following:

- Who are the major stakeholders in this problem?

- What is the nature of their involvement?

- In which settings is this problem particularly prevalent?

- What is the historical background to its emergence?

The true nature of an issue is not always obvious. For example, in our topic, many parents are not fully informed about the learning possibilities that haptic devices have, and because of that the device is only used as babysitters with entertainment purposes.

The research conducted seeks to demonstrate that haptic devices, as multi-dimensional devices, have many different components, there so used under an educative perspective, it enhances learning and knowledge in a way not been addressed in depth before. Children may learn differently from previous generations, and that they will have different literacy needs, still not 
addressed in Spanish Education. Furthermore parents, school teachers, university lecturers, stakeholders, and university policymakers do not have the 'big picture' of how future Engineering students will be, and how they need to be taught when they become university students by 2030 .

Taking the above as a premise, we studied the existing body of literature, which helped to generate the research questions.

Having in mind the focus of this dissertation we have extensively studied the quantitative or qualitative research already conducted and published from 2010 to 2018, and available at UPV repositories, that considered the combination of at least the first two first of the following four variables:

- Variable $1 \rightarrow$ HD: The technological tool to perform the activities was a haptic device. Mainly the tablet type due to its size and dimension.

- Variable $2 \rightarrow$ Children. The subjects manipulating the devices should be children. Mainly students from different school grades (kindergarten, primary, secondary, high school).

- Variable $3 \rightarrow$ HapGen Children. The subjects manipulating the devices were children born after 2010.

- Variable $4 \rightarrow$ Literacy Learning. Acknowledge of acquired literacy learning when performing with the haptic device.

If the papers fulfilled the four variables in their findings, they were used as a primary data source; and as a secondary if they fulfilled the first variable in combination with any other of the rest.

As mentioned earlier, one of the main problems during the literature search has been the lack of research on children born after 2010, and that are the main subjects of this dissertation (around 191 papers, 3 reports, and 4 books since 2010). 


\subsection{Research Design}

The Research Design refers to the techniques of data collection and analysis followed during the research. In Social Sciences disciplines, one of the major distinctions is between the quantitative and qualitative methods that help to inform the results obtained. Quantitative methods gather numerical data that are treated through statistical analysis, while qualitative methods collect textual, visual, and audio data that are subject to systematic non-numerical analysis.

As the approach followed is inductive, it is important to formulate relevant research questions, and ensure that those questions are adequately considered into the data collection process as well as during the observational process. To ensure that the questions are fully answered, a mix of methods have been used which are going to be fully explained in the next Section.

This dissertation aims to give a better understanding of the implications that the use of haptic devices by actual early childhood will have for higher education, and the university degrees once those children reach the university by 2030. For that reason, the ethnographic is, among other qualitative designs, the one that best explores the issues subject of research. The ethnographic design focuses on describing a culture involving the beliefs of a community which in turn affects the behavior and thoughts of individuals within that community.

According to the definition of what an ethnographic research is, it has been studied the cultural pattern (use of haptic devices), and the perspectives of the participants (children, parents, teachers, lecturers mainly) under a subjective qualitative research (haptic device's influence on social and learning behavior of children). Then we have explored the nature of particular unstructured data (on-site observations, parent's opinions and reflections, personal notes, unexpected results when manipulating the devices, other technological advances, etc.).

The design purports enough reliability (capacity of the method to deliver consistent results), and validity (appropriate techniques) to generate meaningful results, as well as new knowledge that will help to develop future investigations.

\subsubsection{Ethnographic Observation Guiding the}

\section{Research}

In 2012 there was a strong irruption of tablets and smartphones in Spanish households. Since then, all the family members were enchanted by their affordances, intuitiveness, and easiness, what helped to get used to them in no time. The smartphone started to be an extension of every adult's body; enough reason to include the devices into any role-play game that children were mimicking. 
Smartphones and tablets started to share space with books, CDs, DVDs, games, in places like playmats, kitchens, cars, restaurants, and even cribs. The ubiquity of the devices helped to babysit children, as well as to introduce them to libraries far away from their neighborhood, exposing them to other cultures, and other languages different from their mother tongue.

As in any human activity, the more some children use the devices, the more digitally proficient they are. Comparatively, more than their parents, and with better digital skills than previous generations. When those children express themselves, they use linguistic expressions, math concepts, English language vocabulary, and twists of the language ahead of their age, surely learnt by using the Apps, or watching videos online. For them, learning new things using authentic material ${ }^{20}$ is at the tip of their fingers.

While children were using their tablets, onsite observation gave account of their learning while having fun. In fact, they were just like playing with another toy.

By 2015, it was clear that the sudden irruption of the haptic devices was, by serendipity, a new scenario for the educational landscape to promote expert learning, and that in 2030, a new type of student will be filling the university campus: the iScholar. It was then when I started to dig deeper and collect data to answer my research questions.

\subsubsection{Ethnographic Design}

Ethnographic research "builds theories of cultures - or explanations of how people think, believe, and behave - that are situated in local time and space" (LeCompte \& Schensul, 2010). It "seeks to understand what is happening, what it means, and its significance to the social group from an emic (native, insider) perspective rather than from an etic (external, outsider) perspective" (Grenfell et al., 2013) preventing decontextualization as "ethnographers attend to how cultural domains constitute and influence each other rather than splicing social life into variables" (Boellstorff, Nardi, Pearce, \& Taylor, 2012).

Other fundamental attributes considered by (Whitehead, 2005) to define of ethnography in line with the present dissertation, include the following:

Ethnography is:

- an integrated approach to the study of cultural systems,

- the study of the socio-cultural contexts, processes, and meanings within cultural systems,

- the study of cultural systems from both emic and etic perspectives,

- a process of discovery, making inferences, and continuing inquiries to achieve emic validity,

— an iterative process of learning episodes,

\footnotetext{
${ }^{20}$ We define authentic material to those texts, videos, audios that have not been created for intentional use in the teaching setting.
} 
- an open-ended emergent learning process, and not a rigid researcher-controlled experiment,

- a highly flexible and creative process,

— an interpretive, reflexive, and constructivist process;

and it requires the daily and continuous recording of fieldnotes, presenting the world of its participants in a real context of thickly described case studies.

Me, as a XGen member of the Spanish Society, lecturer of ZGens at Universitat Politècnica de Valencia, where we frame the context of this dissertation, mother of a HapGen child, and on top of that, educational researcher, I was curious about the meaning of the irruption for the early childhood that is growing up around us, and soon will be filling our university campuses. That is the reason why it is needed to give an emic perspective from the inside ( I am also taking part of the use and irruption of the devices), and from an etic perspective trying to give accurate data as a researcher about the meaning, the pros, and cons of the irruption of haptic devices when talking about education.

The evolution of the phenomenon is growing at the same pace that the children. As society, we need accurate research to trust, more data to analyze, and to see the effects on children learning behavior as they grow, to affirm whether the irruption will be finally positive or negative. During the research carried out, the positive consequences far outweigh the negative ones, and invite for a strong commitment to the belief that, behind every early childhood's user, there is a potential researcher that a smart society should not miss.

Ethnography uses several qualitative techniques, and two main research strategies: the researcher as participant, who is in direct contact with the participants influencing in their behavior in everyday actions for deeper understanding; and non-participant where the researcher is in the setting but does not influence participant's behavior (Gobo, 2008) to collect the data, and submit it to further analysis.

The dissertation serves from both strategies in the fieldwork (HG Case Study): The researcher, and the parents acting as researchers in their households, had direct contact with the children during their interaction with the haptic devices, but tried to do not have any influence in the use of the devices. The children, as participants, were using the devices passively (they were not aware of using the device for any particular purpose), on their own, after watching how their parents were manipulating the devices: finding information, taking pictures, playing videos, or music, notetaking, consulting the weather, as GPS App, playing games, sending emails, etc. The adults who participated agreed on using the devices normally, under their beliefs, with as much normality possible. The actions performed on the device, on normal daily basis, were imitated by the children, and their accuracy in performing was according to their age in the very moment of the observation. The adults tried to avoid any pressure, and let children to use the devices according to their parental rules when accessing the technology.

Following this double technique, data is gathered primarily through observation, annotating, framing, or recording situations as they happen, giving meaning of the events at the time (LeCompte \& Schensul, 2010) to fully understand the phenomenon, formulate the research questions, and answer them. 
To frame the fieldwork, the following variables have been proposed:

- the socio-cultural context (household and families, kindergarten, bars and restaurants, playgrounds);

- the socio-cultural process that includes the interactions of the participants in the physical context, and with other participants; and

- the socio-cultural meaning related with education, learning and teaching.

To inform, describe, focus and select the phenomena during the different fieldwork interactions, we follow Spradley and Whitehead categories (Spradley, 1980) (Whitehead, 2005):

- Social Setting refers to the space used during the observations:

- Thesis: household, kindergarten, bars, restaurants, playgrounds

- Objects are the objects of the culture found in the social setting, and how this object is used within the culture by the participants:

○ Thesis: Haptic Devices

- The individual Actors of the experience, and their specific characteristics:

$\bigcirc$ Thesis: Children born after 2010

- The Social Systemic Context of the participants:

○ Thesis: Spanish middle-class family

- The Behaviors carried out while using the objects:

- Thesis: use of haptic devices with entertainment, and learning purposes: inbuilt Apps, 3rd parties' Apps. Digital Skills. Attitude

- The Language used by the children during the experience:

- Thesis: English and Spanish

- Other forms and elements of Expressive Culture found in the social setting beyond the objects to produce the same outputs than with the objects:

- Thesis: books, toys, games, crayons, pencils, notebooks, paper, scissors, tape, television, CD/DVD player, compass, paper maps, etc.

- Patterns of Interaction carried out by the actors within the social setting:

- Thesis: manipulation of the devices, and the purposes of use: entertaining, learning, or creating

- Discourse Content reflected in the language, expressive culture, and social interactions:

- Thesis: Language expression and use according to their age or ahead to their age in some cases

- Emotional Level of the discourse used when using the objects:

- Thesis: children's free expression of their feelings when using the devices

- Ideational Elements that guide the experiences, and are present in the social setting:

- Thesis: parental beliefs, attitudes, values, rules, and behaviors when interacting with the devices

- Broader Social Systems that might influence the actors, and their behaviors during the experiences:

- Thesis: other kids using devices, kindergarten and school using haptic devices or other technological tools like computers, smart boards, etc. 
- The goals, and motivations within the social setting.

$\bigcirc$ Thesis: Literacy learning

- Human Need fulfillment that is attempted or met within the social setting or interaction.

○ Thesis: Digital Citizenship

\subsubsection{Research Questions}

Every piece of research requires a set of research questions that frame the dissertation, point out towards the methods that will be used to generate the possible findings, and guide the decisions taken. Research questions resemble the kinds of SMART targets typically set in project management. They must be very Specific, Measurable, imply different type of Answers, and deliver information that is Relevant and Targets the initial problem.

The literature used points out processes, variables, factors, relationships, models, terms, and other ways of describing the observation, and organizing the topics that will direct and inform the research questions. Once properly formed, the research questions will also indicate the kind of information required to answer them properly.

The fundamental issue with research design is whether it genuinely delivers the empirical material that is appropriate to address the core research questions, therefore the questions formulated should ground in the framework developed for the research conducted, and be meaningful in relation to the context that has been discussed.

The context to give answer to the core research questions that guide the dissertation is defined by the irruption of haptic devices (Chapter 1 ), and the digital scope (hapter 2 ) that surrounds children born after 2010 .

Consequently, the framework that grounds the research is defined by the implications in the educative landscape of the possibility, for those kids, to access to knowledge since they were born. As can be deduce, those children, nurtured in a digital and haptic atmosphere, will have different intellectual needs than those of previous generations whose education was based on instruction, pen, and paper.

The research questions that ground in the framework established and related with the context discussed are:

- RQ 1: Can Haptic generation children boost creativity, literacy, and bilingualism while using haptic devices?

- $\quad$ Chapter 5 analyzes the different variables, demonstrates how literacy can be boosted and conclude that yes, children can master expert knowledge, even in a second language.

- RQ 2: If children can boost expert knowledge, what type of student does Spanish higher education system expect by 2030?

- Chapter 6 let us know that not all the HapGens will achieve the same level of expert knowledge neither will have the same interest in formal education. 
That is why we that assume in 2030 University degrees will face different type of students, being one of them the ischolar.

- RQ 3: Having iScholars thirst for reasoning around, to which type of learning scenario should education (in general), and Spanish Engineering Higher Education (in particular), look at to fulfill their future learning needs?

- They will need a polyvalent space (The learning Atrium) that seeks for their wellbeing and development of their curricula within a STEHEAM scope (Chapter 7).

Surveys, interviews, desk research, and on-site observation conducted, give enough favorable data to believe that the irruption of haptic devices is one of the best opportunities to get rid of the bad literacy learning statistics that Spanish children have demonstrated, improve drop-rates, and avoid illiteracy, as PISA Spanish results show (Instituto Nacional Español de Estadística, 2016).

The educational landscape is facing new drivers: a new generation with extreme longevity, digital citizenship, haptic devices, global economy, and new media ecology, that will need new literacy skills learnt since kindergarten: visual, digital, and coding.

The new drivers have implications for teaching staff, governmental policymakers, educational institutions, society, and industry. The implications should be reflected in a new educative landscape that considers a multidisciplinary subject approach, new literacies, and the student voice.

University degrees, under this perspective, should be rethought, reconfigured, and remodeled if they want not just to excel academic learning and be an international referent, but to provide adequate education in the Digital Age. 


\subsection{Research Methods}

There are several tools for gathering and treating data associated with the analytic framework that has been built for the research design.

The most common methods used in Quantitative Research include:

- Surveys/Questionnaires: These are good at pulling together standardized responses across large samples of respondents. Weak at capturing complexity in responses and context.

- Experiments: Good at providing high levels of control over variables. Weak at external and ecological validity.

- Analysis of secondary data: Good at providing complex material for multiple forms of analysis. Weak at allowing the researcher direct control over what information is collected.

- 'Big Data' analysis: Good at providing 'real world' information. Weak at accessing participants' own reasoning.

The most common methods used in Qualitative Research include:

- Interviews: Good at providing in-depth information. Weak at delivering immediate comparable results.

- Focus Groups: Good at gaining quick access to opposing points of view. Weak at controlling for self-presentation issues.

- Ethnography/Participant Observation: Good at resourcing thick accounts of social life. Weak at gaining a wide spread of data beyond the immediate population.

- Historical/Archival Analysis: Good at capturing context and temporal dimension. Weak at allowing a researcher to control data collection.

- Analysis of 'naturally occurring data' (i.e. recordings made of social practices in action): Good at allowing access to what people actually do rather than what they say they do. This method is weaker at allowing access to participants' own experiences.

To generate the data, this research has analyzed:

- $a$ database of papers that give account of the literacy skills acquired by children under 8 when using haptic devices (Desk Research) and aimed to respond to RQ_1;

- two case-study approach where it has been triangulated a range of different research tools like surveys, analysis of secondary data, interviews, focus group, ethnographic observation, essays, analysis of "naturally occurring data," and observational data collected in digital media format: video, audio, photos, screenshots, and notes to capture as much as possible of children's interactions. 
- HG Case Study collects the data generated for children of the Haptic Generation under study and the use that they make from the haptic devices, family concerns, etc. The data of HG case study are aimed to answer RQ_1 and RQ_2 which results can be followed in Chapter 5 and Chapter 6.

- ZG Case Study was organized to be taken as a starting point to answer RQ_3 and therefore inform Chapter 7 with the latest students' points of view. It collects the information provided by ZGen and YGen students during academic year 2017-2018 in the situational context of the Universitat Politècnica de Valencia.

\subsubsection{Primary Data Collection used}

\section{A. HG Case Study}

On-Site observation with Haptic Generation children (born after 2010) summarizes the information collected as well as the introduction of the researcher in the field of work, taking part during the different stages and periods followed. The case includes:

- Family Overviews (5 Families) of the data collected:

- Interviews with participants parents in on-site observation were conducted in January 2015, January 2017, and January 2019.

- Observational Notes for Child I Recompilation of the child experiences with the tablet device photos, videos, draws, notes, emails, etc.

- Some aimed reports were used to replicate experiences in on-site experiences:

- Paciga, K. A., \& Donohue, C. (2017). Technology and Interactive Media for Young Children: A whole Child Approach Connecting the Vision of Fred Rogers with Research and Practice. Latrobe, PA.

- Khoo, E., Merry, R., \& Macmillan, N. (2015). iPads and opportunities for teaching and learning for young children (iPads $n$ kids) iPads and opportunities for teaching and learning for young children.

- Chaudron, S., Di Gioia, R., \& Gemo, M. (2018). Young Children (0-8) and Digital Technology - A qualitative study across Europe - European Commission. EUR 29070, 1-266. https://doi.org/10.2760/294383

- Surveys aimed to parents with children born after 2010. It collects information about what they know about the learning possibilities of the devices, and the opinion they have about the use of the devices by children.

One of the main purposes of this dissertation is to measure the frequency of haptic interaction (HA_int) as well as the proficiency level in the use of haptic devices of the HapGens during early childhood and determine the type of student that 2030 university will be hosting. 
The classification established for HA_int is the following:

- The iScholars (> 75\% of HA_int) pursuit expert knowledge, skills, and competences. They have a highly-specialized level of digital competence in the areas of information and data literacy, communication and collaboration, digital content creation, safety, and problem solving. They are able to solve complex problems with many interacting factors, propose new ideas and processes to the field, and pursuits content creation that serves their and others purposes.

- The Hi-Techs (> 50\% of HA_int) show an advance digital competence level in the four areas. They are able to adapt to others in complex digital contexts, guide them in digital use, apply and evaluate digital contents.

- The Savvy-Techs (> 25\% of HA_int) have an intermediate level of digital competence. They are good in performing routine device tasks by themselves. They show an independent use according to their needs. They are able to understand digital contents.

- The Analogs (> 0\% of HA_int) with a basic level of digital competence that show little autonomy, need guideline, perform very simple tasks, and are able to remember digital content but prefer other means to obtain information. These users are competent in communicating with haptic devices and are media consumers, but do not have any interest in other areas.

\section{B. zG Case Study}

ZGen students of UPV give insight of how they are studying nowadays, the devices they use, their feeling about teaching methodologies, etc. all of that in the context of UPV where I teach. The case study includes:

- Situational Context: Spanish Educative System. Universitat Politècnica de Valencia, Spain.

- Surveys aimed to formal students. It collects information about the haptic devices they use with learning purposes, and how much satisfied they feel about the teaching methods followed by their lecturers.

- Students Essays are structured texts (long answers) that respond to the questions posed and provides their point of view about actual university teaching and learning methods they use (long answers).

\section{Papers on Early Childhood using Haptic Devices with Learning Purposes}

To give answer to RQ_1 a database was built with peer reviewed papers on early childhood using haptic devices with learning purposes. This subsection enumerates the 201 papers identified and accessible from UPV resources. This collection helps to inform Chapter 5 . From them we studied those papers that obtained favorable results in literacy skills learning, which were summarized in

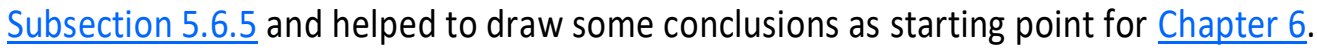




\subsubsection{Secondary Data Collection used}

The Secondary data used helps to fundament the selection of the drivers for the conducted research from macro to the micro level. The secondary data review previous research findings to gain a broad understanding of the field, and helps to provide proper knowledge to answer the research questions from the taken perspective.

We have selected information from existing resources accessed from UPV repository:

- Research Publications aimed to haptic devices, and learning

- Books aimed to haptic devices, early childhood, and learning

- Newspaper publications on technology and their use by children

- Statistics reports on Technology Evolution

- Reports on Generational cohorts

\subsubsection{Observational Research}

As pointed out by (Danby, 2017), "the observational research provides understandings of what participants are saying and doing". The case study followed in this dissertation has the children using haptic devices as subjects to get information from. Hence our interest is the daily use of the devices in the family and school life and therefore we must explore how children build their interactions at home and school settings.

Having those children as active participants in the research design, we must bear in mind some implications when conducting the research like: that the context must be familiar to them to feel comfortable and confident; that being part of their plays, requires sensitivity, and understanding; that maybe children do not want to participate, or they are not in the mood during the observation; that the experience must afford children to express their perspectives, follow them up, and act on if possible; and that the research conversations with children imply listening to them and respecting their timing, their mood, and their desires.

Children participation in this dissertation are considered co-researchers (J. L. Miller, Paciga, Danby, Beaudoin-Ryan, \& Kaldor, 2017). This perspective recognizes that children actively draw on their social interactional resources and challenges traditional views of childhood as a place where children passively accept or take up adult social structures, including those related to research contexts. 


\subsection{Sampling}

Sampling is defined as "a specific principle used to select members of population to be included in the study" (Proctor, 2005). Researchers use samples when population of interest is too large to work with directly. In our case we have developed this research with no financial aid, what drives to work on existing research published in their research field and constrain to the means that were available and feasible.

For HG case Study, I selected one child to follow, personally and in a deep way, her learning attitudes using haptic devices as well as four more families giving inputs based on their own observations when their kids were using the tablets at their pace. All the families were following family rules on the use of technology at home.

Our samples are taken from the Spanish cultural perspective, city environment, middle class families, home setting, and aimed to learning goals which contribute to draw some conclusions about the learning of the youngest population.

(Brown, 2006) summarizes the advantages of sampling in the following points:

- Makes the research of any type and size manageable;

- Significantly saves the costs of the research;

- Results in more accurate research findings;

- Provides an opportunity to process the information in a more efficient way;

- Accelerates the speed of primary data collection.

The process of sampling involves the following stages for HG Case Study:

- Defining target population: Haptic Generation

- Determining sampling size: 8 children

- Choosing sampling frame: 5 Children Born in 2012, 2 born in 2014, and 1 born in 2017.

All of them using tablets, and smartphones in a passive and playful way.

- 5 families.

- 6 kids are native Spanish speakers, and 2 native English speakers.

- Centro Educativo Infantil Vera (UPV): 3 children in courses 13-14, 14-15.

- School: 5 of the children join Public School, and 3 of them Private school.

- Among the kids, we find 3 pairs of siblings.

- City: 5 of them live in Valencia, 2 of them in Huelva.

For ZG case study, I selected students enrolled during academic year 2017/18 and 2018/19 in B2 English subjects to whom I lectured and who gave consent on giving their opinion for thesis purposes.

The process of sampling involves the following stages for ZG Case Study:

- Defining target population: Z Generation

- Determining sampling size and frame: Students of English B2 Subjects in ETSII and ETSID engineering degrees at UPV during 2018-19 academic year. 


\subsection{Ethical Considerations}

Universitat Politècnica de València, like all good universities, has a Code of Practice for Research Ethics that any research undertaken at all levels, not just doctoral, at the University has to adhere to. This code ranges from general statements about respecting the rights, interests and dignity of research participants and related persons or the compliance with relevant laws and legislations, to more specific expectations (e.g. obtaining informed consent from participants) for empirical research.

As my dissertation contains primary data collection under an ethnographic approach, and that human beings are participating, including children, extensive ethical considerations are required, therefore I declare that I stay true to the following statements:

Students and parents answered the surveys voluntarily and anonymously. No personal data has been collected. Informed consents were signed (Addenda);

Surveys/Interview/Focus group questions do not contain offensive, discriminatory, or other unacceptable language;

Privacy and anonymity of sample group members are maintained;

The works of other authors that are going to be used in any part of the dissertation are going to be acknowledged with the use of APA $6^{\text {th }}$ edition referencing system;

The author has maintained high levels of objectivity in discussions and analyses throughout the research. 


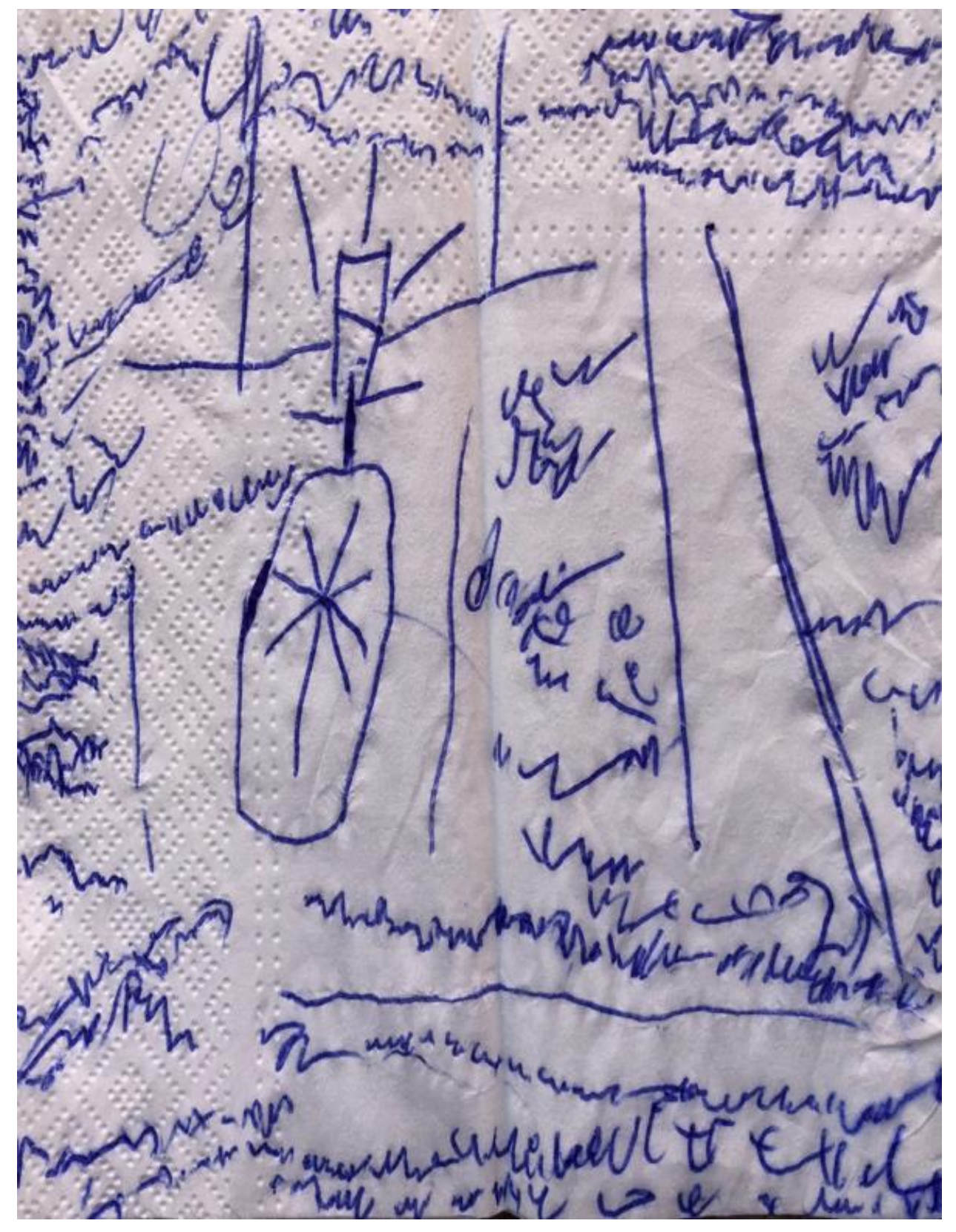

Data Collection

Chapter 4 

"We do not learn from experience; we learn from reflecting on experience."

John Dewey 



\subsection{HG Case Study}

HG Case Study collects the information provided by the on-site
observation, surveys, interviews, and some replicated experiences from
aimed reports of 8 children born after 2010 in 5 family settings while using haptic devices, mainly tablet. When this was not possible, a smartphone was used with the same purposes. Observational notes on Child I collect the most relevant experiences of the child when using the tablet and the learning outputs obtained.

HG case study data helps to answer RQ_1 and RQ_2 and give deep justification for the writing of the dissertation, fully covered in Chapter 5.

\subsubsection{HG Research Variables}

Research variables have been determined for $\mathrm{HG}$ case study to analyze the same parameters and determinate the frequency in use of Haptic Interaction, used for results discussed in Chapters 5 and 6 . All the variables with its corresponding definition were fully explained to the parents of the five families, and every family provided the information during informal interviews where they provided examples, observational notes, or pictures collected from 2013 to 2019. The information for or from the families was provided in Spanish Language in four of the families, and one in English. Spanish interventions have been translated into English for the writing of this dissertation.

The families have been selected under the condition of having children born after 2010, and after expressing consent for the research purpose (Addendum: Letter of Consent). 


\section{Home Setting}

Home setting reflects the family individual data, parental attitude, and context that surrounded the children and the device while conducting the research. It reflects the context where the family use devices at home, and if the family use could be determined as casual or frequent (Chapter 2 ).

\section{Family data:}

- Family members: Role in the family: mum, dad, friend, grandma, etc.

- Generational cohort: Grand, Silent, Boomer, XGen, YGen, ZGen, HapGen.

- Education attainment: (highest degree of education completed): primary, secondary, high school, university degree.

- Employment Status: Public employee, Private employee, Self-employed, non-employed now.

- Type of work: highly skilled professional (combining intellectual labor, and manual labor), salaried professional (general office workers and management), manual labor, working with people, environmental workers, artists.

- Living in: city, countryside, village.

Home environment:

- Number of haptic devices in 2012, 2015 and 2018, and type (smartphone, tablet, smartwatch, Intelligent voice assistant, etc.)

\section{Adult device's interaction:}

- Communication; Leisure and entertainment; creation and productivity; information and learning.

Physical space where the children can use the device:

- All around the house, in the living room only with adult supervision, restaurants, waiting rooms, car, playgrounds, etc.

Parenting style for haptic device use following (Baumrind, 1966) and (Chaudron et al., 2018):

- Pro (Authoritative): Consent use and control child's use. Give priority to child's benefit and abilities when using the device; Encourage children independent use, autonomy, curiosity, and creativity, offering opportunities for learning, active approach, support, and co-usage.

$\bigcirc$ Clear rules, monitoring, support

- Moderate (Permissive): low enforcement of rules when using the devices. High acceptance of use whatever use they want to do, little interaction when using the devices, little control on the activities. Rarely guiding or teaching.

- No rules, negotiation, support

- Prudent (Authoritarian): Expecting obedience while using the device. Not ready to accept independent use. Neglect child's curiosity towards the device. Little communication when reasoning the use or not. Highly directive behaviors.

○ Rules, control, no support 
- Neglected (Negligent): little interaction with the child, inattentive to the uses of the devices, only entertainment purposes, no control of contents.

○ No rules, no support, "babysitter"

Parents and child relationship when using the device:

- Instructive, co-using, restrictive, etc.

Language for interaction with the device:

- English, Spanish, Swedish, Valencian, etc.

\section{Child Info}

(Burnett et al., 2005a) defines Early childhood, "as the period from birth to eight years old" and points out that it is "a time of remarkable growth with brain development at its peak. During this stage, children are highly influenced by the environment and the people that surround them."

During early childhood the child develops some theoretical milestones of his/her development during the different stages that vary according to age, physical development, environment, and people surrounding him.

Following (Paciga \& Donohue, 2017), we determinate the following chronological children's age ranges:

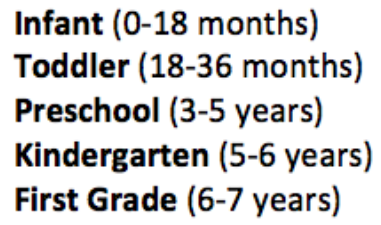

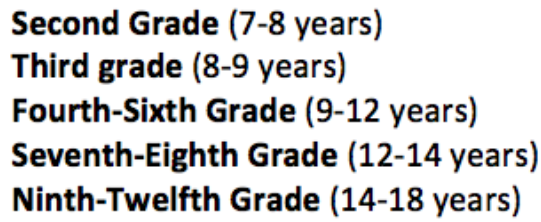

Along dissertation the general term of children, or early childhood will equally refer to: infant, toddler, preschool, kindergarten, first grade, in case that the information about the concrete range is not relevant.

Variables to be studied:

- Child age at first interaction: Infant (0-18 months), toddler (18-36 months), preschool (3-5 years), kindergarten ( $5-6$ years).

- Child motivation to use the tablet: Curiosity, imitation, learning, having fun, no interest.

- Child involvement in the learning experience: active role, engaged, purposeful, scaffolded exploration, no involvement, no interest for learning.

\section{Device Used}

This variable determines the type of tablet that the child has been using at home during the observed experiences: IOS or ANDROID, all of them having the technical features described in Section 1.4, aimed mainly for learning purposes. 
Type of Apps used

- Developers' apps: educational, school homework, family communication (video, audio, text), media streaming content, game, lifestyle, entertaining, book reading, creativity (drawing, writing, video and audio recording)

- Web search apps: information, videos, random words, images, locations.

- In Built apps: messages, clock, calculator, camera, weather, podcast, flash camera, notes, calendar, audio notes, photobooth.

\section{Device Using Conditions}

Following (Paciga \& Donohue, 2017), the context setting should reflect the circumstances and factors where the children are interacting with the devices. In our case we look at the conditions that ruled the use of the tablet set by parents, and how they were using them under these rules.

\section{Conditions:}

- Who supports the child's interactions with the tablet, and provide advice, answer to doubts, guide the use:

Peers, siblings, parents/caregivers, other adults.

- Places allowed to use the devices.

- Who owns the used devices?

- Was it used as a babysitter?

- Were the children using other digital/technological/personal devices?

- Timing: How long could they use the device?

- Child general Interaction: by their own, parent interaction and participation, with peers or siblings.

- Activity Code: Determinate how the tool was used, provide examples of the activity performed.

To code the type of activity that the children were performing in the family context, we follow the 6 proposed by (E. Khoo, Merry, et al., 2015), and we add the seventh. the device was used as (Activity Code):

1. Relational Tool: Parents/adults and children shared information and experiences together with the same device, creating a conversation.

2. Communicative Tool: Children were allowed to Facetime, send emojis through any crossplatform messaging to family members, send emails, what allowed children to connect and share their concerns.

3. Documentation/Reflective Tool: Children used the camera and note-taking apps to record whatever they wanted. Most of them drawings and scribblings. They could select videos and photos of their preference to illustrate the interest. Those records are evidences of their learning, as well as use of the device for more than playing.

4. Informational Tool: When the children had question about the topic of their interest, they were allowed to Google search. This action empowered the tool to access information at their pace, wherever, and whenever they feel like. 
5. Observational Tool: Capturing photos or videos of their interest, and then reviewing the recordings, help to focus on in topics of their interest, learning at the same time how to manipulate the device.

6. Scaffolded Children's Learning Interactions: Provoking a (parent-child or child-child) dialog about the experience using questions that bring new questions, and bringing their own theories about what it is happening in the experience. That leads to use of creativity, imagination, curiosity, etc.

7. Second Language Acquisition: Watching contents in another language, provokes passive exposition to a second language learning, what can result in the acquisition of the language instead of learning it.

\section{Emotional Constructs when Using the Device}

Apart from the developmental age of the children when performing with the tablet, the researcher must consider not only the mood of the children at the moment of performing and observing the activity, but also their emotions, and how they deal with them when their haptic inputs bring outputs that requires another haptic input: e.g. correct, incorrect answers in the App; scribblings reflect what they want; finding or not finding what they want, etc.

(Paciga \& Donohue, 2017) offers a list of relevant emotional constructs to look for when interpreting their reactions when manipulating the haptic device, and we offer possible adult intervention if needed to help or encourage when dealing with the device.

- Dealing with Frustrations: "emotion that arises when the path toward a goal is blocked. When a child is frustrated there are typically overt cues that signal the child is experiencing a strong emotion. These include gestures, words, and facial expressions signaling anger, sadness, confusion, or hostility."

- Adult intervention: by telling the children they can ask for help, or change the strategy by showing them another way to perform, or taking a break, o a different game.

- Dealing with mistakes, "action or judgement that is misguided or wrong. Children normally deal with mistake in a calm way, and try to solve it if they are alone."

- Adult intervention: being empathetic, show how to move through the emotions by being aware of the mistake.

- Mindset: "to love learning and persist when they are faced with challenges. They recognize that they have a choice and persist through frustration and mistakes."

- Adult intervention: be supportive, encourage the attitude.

- Taking positive risks: "is any action, behavior, or activity that is precipitated by careful thought and involves deciding to move from the comfort zone."

- Adult intervention: giving examples of how to take decisions, personalizing failure in a positive way, verbal recognition or if positive risks are taken.

- Empathy or awareness: "the ability to take the perspective of and empathize with other within the setting, or with the action that is happening on the screen." 
- Adult Intervention: Giving examples of empathetic responses, point of view. Telling them how to be good listeners.

- Sense of trust: Reliability on the gestures performed on the devices to obtain results: being responsible, recognition, shared interest.

- Adult intervention: providing comfort when using or sharing Apps activities, acknowledging the positive possibilities of using the device

- Sense of self-worth: could be developed by "understanding that they are able to learn and knowing that learning is worthwhile."

- Adult intervention: praise when the child has performed the actions with positive effort, and results. To appreciate the positive learning steps that children make when performing. To show respect for the child when performing. To understand the performing as a gaining competence. Giving examples of how to express ideas or feeling surrounding the activity.

- Curiosity: when using the device, as with any other object in their hands, because children possess a natural sense to explore, to try out, and test beyond limits.

- Adult Intervention: nurture their curiosity by conversational interactions, practical examples, ideas, suggestions, tips.

- Capacity to look and listen carefully: "sustained attention fosters deliberate thought. Looking and listening carefully can be the outcome of curiosity."

- Adult intervention: To ask children to attend to something in their environment by sight or hearing. To identify the conditions that maximized or reduced child attention.

- Capacity to play: "Children engage in their own kind of thinking about the world through deliberate and sustained play, helping them to build trusting relationships, and develops physical/motor, cognitive, and linguistic skills."

- Adult intervention: To follow their learning activities, or play, their social and emotional signals. To ensure a safe and inviting play space. To play with them and be part of their pretending games.

- Time of solitude: "time for a child to pause, reflect, observe quietly, or to be alone but not lonely. Being alone is not necessarily a bad thing."

- Adult intervention: giving them time to play alone for replaying videos, repeat activities, discover the device by themselves, etc. Offering cues of how to be in silence, work in appropriate pacing to focus better, giving moments of quiet solitude and rest.

\subsubsection{HG Aimed Reports}

The following reports were used to set the variables described in the previous subsection, and serve to replicate some of the experiences using haptic devices. They were adapted to our research group focus and the technological device under study: 
Paciga, K. A., \& Donohue, C. (2017). Technology and Interactive Media for Young Children: A whole Child Approach Connecting the Vision of Fred Rogers with Research and Practice. Latrobe, PA.

Khoo, E., Merry, R., \& Macmillan, N. (2015). iPads and opportunities for teaching and learning for young children (iPads $n$ kids) iPads and opportunities for teaching and learning for young children.

Chaudron, S., Di Gioia, R., \& Gemo, M. (2018). Young Children (0-8) and Digital Technology - A qualitative study across Europe - European Commission. EUR 29070, 1-266. https://doi.org/10.2760/294383

\subsubsection{Researcher's Observations}

This subsection presents the general findings of the research on HG Case Study obtained while conducting the interviews, analyzing the observational notes, and looking at the commonalities of how parents manage and perceive digital technologies and the use of haptic devices with learning purposes. The findings have been collected along the research period (2015-2018), the three purposed interviews conducted, and during informal conversation with parents of children that age in different situations and places. The interviews were informal while the children played.

\section{In General:}

- Children first contact with interactive screens was at very early age (less than one year old).

- Children learn very quickly how to interact with the devices by imitating the behavior of their parents.

- Children main use is for entertainment and communication, but as they grow, the ones that use the device as a learning tool, are more interested in other usages like creation and information.

- Every family allows children haptic interaction for different reasons, but mainly to watch TV Shows in different places, and gamming.

- The use that parents allow is the same than the use they do because it is what they can control. The monitorization is motivated by fears of negative effects on health issues and online risks like exposure to inappropriate content.

- The parents that have an authoritarian parenting style see the digital evolution as something wrong for children but inevitable. It is curious that they do not ask for guidance neither search for curated information about the real risks or benefits.

- The behavior of the children with the device is just the same than with any other toy, so, family rules to apply are the same than with other toys.

- Parents are, in general, not aware of the learning possibilities that the devices offer. In every interview the researcher has explained some haptic inputs and Apps to enhance children's potential for learning and development. Parents tried, they were surprised with the possibilities, and they tried. In doing so, they observed that the children were really interested in, and they enjoyed. But little documentation was provided. 
- Age has been an important milestone for parents to allow the use, and try new Apps.

- All the children knew the existence of the haptic devices, and they see them as normal. They are aware that the devices offer an open window to many things.

- During the four years of the study, there is an obvious advance in the use of the devices within the society. The manipulation is becoming increasingly normal, it is not rare anymore, and the parents that were more reluctant to allow children's use at the beginning, now they are not. They are skeptical, but not reluctant.

- Children are growing up, in all the sense, and the schools are implementing digital literacy in the lessons, some schools in higher degree than others.

- Parenting style rely on mainly in parent's perception of digital technologies, their personal experience, and the use they give to the haptic devices, what correlates with the use children make from the device.

- Schools play the major influence when perceiving the haptic devices as a tool for learning, creation of contents, information gatherer, etc. There are few schools that use them with learning purposes, then parents are more open to the use. Other schools use haptic devices to read in electronic format to avoid the purchase of paper books. But most state schools do not use the devices yet, among other reasons, because the teachers are not trained in the different uses.

\subsubsection{Family Overviews}

The family overviews provide a summary of the information provided by parents during the 3 interviews set for the research period, and informal meetings, as well as informal conversations or text messages with the anecdotes the parents felt they were curious. The information was mainly provided in Spanish, therefore to illustrate the findings we have translated and narrated the more significant data provided for the research questions within the sample size.

All families expressed consent for the research purpose (Addendum: Letter of Consent). 


\section{Family I. Child I}

Interviews with parents on January 2015 for period 2013-14, January 2017 for period 15-16, and January 2019 for period 17-18.

\section{Family variables}

Family composed of 2 adults (mum and dad), and 1 child (Child I)

Family data:
- Family embers: Mum (XGen) \& Dad (Boomer)
- Education attainment: University Degree
- Employment status: Public employees
- Type of work: highly skilled professional
- City: Valencia

Home environment: number of haptic devices:

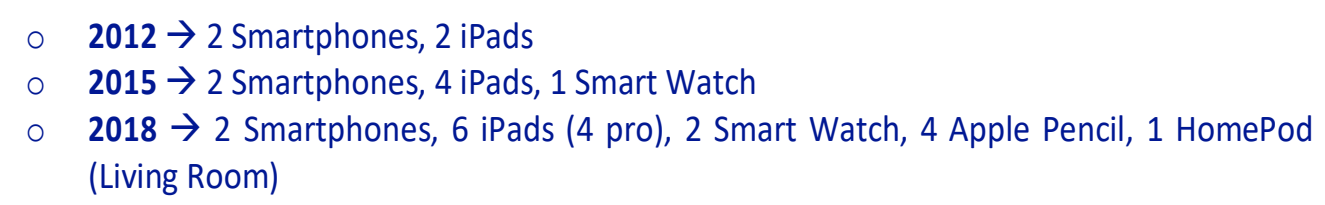

Adult device's interaction:
- Communication
- Leisure and entertainment
- Creation and productivity
- Information and learning

Physical space where the children can use the device: All around the house, restaurants, waiting rooms, car, etc.

Parenting style for haptic device use following (Baumrind, 1966):

- Pro (Authoritative): Consent use and control child's use. Give priority to child's benefit and abilities when using the device; Encourage children independent use, autonomy, curiosity, and creativity, offering opportunities for learning, active approach, support, and co-usage.

Parents and child relationship when using the device: Instructive, co-using most of the time, restrictive when family rules are not followed.

Language for interaction with the Device: English mainly.

Parents motivation to allow children to use it: literacy learning, entertainment, reading, communicating.

Time allowed to use the device: as much as she wants except for entertaining purposes, where it is allowed mainly in weekends, or exceptional moments like doctor's waiting room, exceptional car trips, etc.

\section{child 1}

Born: 2012

Child age at first interaction: Infant (0-18 months),

Child motivation to use the tablet: Curiosity, imitation, learning, having fun.

Child involvement in the learning experience: active role, engaged, purposeful, scaffolded exploration 


\section{HG Case Study: Family I}

\section{Device used:}

IOS Tablet (iPad) and Apple Pencil.

The Child owns her own device under strict supervision and configuration of the parents.

Type of Apps used

- Developers' apps (the most used):

- Educational: Tiny Hands, Smile and Learn, Jig Space, C Anatomy '20, Bones3D, Letter School, 22Learn Apps, KidsMath, Starfall, aprender a leer,

- School homework: Puffin Academy, ShowMe, SchoolDojo, Jolly Phonics

- Family communication: FaceTime, WhatsApp, Telegram

- Media streaming content: Amazon Music, Netflix, Clan RTTV, YouTube

- Entertainment: Peppa Paintbox, Baby Karaoke, duplo Trains, Toca Band, Word Finder

- Book reading: Epic, Smile and learn, Khan Kids

- Creativity: drawing, note-taking, video and audio recording

- Web search apps: Google Earth, Google Chrome, Safari

- In Built apps: messages, clock, calculator, camera, weather, podcast, flash camera, notes, calendar, audio notes, photobooth, email.

\section{Device using conditions}

- Who supports the child's interactions with the tablet, and provide: advice, answer to doubts, guide the use? The Parents

- Places allowed to use the devices: wherever we found learning moments

- Who owns the devices? The child

- Was it used as a babysitter? Yes, in restaurants, and waiting rooms until she was 5.

- Were the children using other digital/technological/personal devices? Yes. Apple TV, desktop computer, laptop.

- Timing: How long could they use the device? With learning purposes, as long as she wants, for entertaining, under strict family rules, depending on the day of the week, school period/vocational period, health moment, etc.

- Child general Interaction: By her own. When she wants to share, then with mum.

- Activity Code: Determinate how the tool was used, provide examples of the activity performed.

- Relational Tool: Family videos to comment (since 6 months-old), search for information together (18 months-old).

- Communicative Tool: Facetime with grandma (Infant), send emojis through WhatsApp to other family members (toddler) send emails (kindergarten)

- Documentation/Reflective Tool: Selfie (toddler), take pictures (toddler) drawings and scribblings (toddler). Select videos and photos of her interest (preschool).

- Informational Tool: Google search alone or with parent's help (toddler), songs search in google (preschool), Google Earth to do homework (first grade)

- Observational Tool: Capturing photos (preschool). Capturing videos of her interest and review them (preschool), create videos with her own photos, scribblings, and messages (kindergarten)

- Scaffolded Children's Learning Interactions: Ask for a search for carnivore plants on internet to know how it looks like (toddler), search for cities in New Zealand, and Australia by her own (kindergarten). Ask questions, and when she could not understand the whole meaning, asked the parents to look into Google (toddler) or ask SIRI (preschool) 


\section{HG Case Study: Family I}

- Second Language Acquisition: Using streaming services: Clan TV, and Netflix in English language (infant). Sentences like "I'm going backwards" imitating what it means was spell out in class (kindergarten).

\section{Emotional constructs when using the device}

- Dealing with Frustrations $\rightarrow$ She shows frustration according to her age, as interacting with any other type of toy, or person. She dealt with it by giving up and trying in another moment again.

- Dealing with mistakes $\rightarrow$ When she makes a mistake, she tries again. When the task is very difficult (a word that she does not understand) she gets frustrated, but it is not because the device, it is because the level of the input.

- Mindset: She loves reading with the tablet, she looks for things and places by herself. She learnt herself to send emails by guessing and following predictive text from the device.

- Taking positive risks: She tries new things that require thinking and leaving the comfort zone without asking for help. She makes parents participate when the thing she tries is finally achieved. E.g. try to find a song played at school without knowing the title of the song, just pressing what she thought it was correct in the keyboard, and goggle search made the rest. Her finding was positive.

- Empathy or awareness: when watching a video of real people, like kids, from another cultures, she feels empathy and ask about how they live, learn, or study. E.g. kids in New Zealand.

- Sense of trust: She gestures on the tablet without hesitating, she learnt by herself watching us. She even tries new movements.

- Sense of self-worth: She is aware that she can learn new things and search for new ones.

- Curiosity: She explore, try out, and understand, as much as she likes.

- Capacity to look and listen carefully: "Understand perfectly the contents of the video she is watching (in English) and is able to retell what is happening in Spanish since she was 4.

- Capacity to play: She guess how the games work by herself.

- Time of solitude: She spends a lot of time guessing, and using the device. When she wants to share, we share time and experiences. When she wants to stop using it, she stops. We use it to read books together.

\section{Researcher's observations}

Parents use haptic devices for work, reading, entertainment, communication in front of her, at any moment. They have included haptic technology in their normal lives, customs, and behaviors.

The child incorporates the tablet in every play she likes. For her it is like another object of her backpack, and she carries it away in every trip.

The child interacts with digital literacy, tablets and desk computers at school since she was 4 (1 h/week).

RESULT

\begin{tabular}{|c|c|c|c|c|}
\hline$\%$ haptic Use & 2013-14 & $15-16$ & $17-18$ & $\begin{array}{c}\text { Arithmetic } \\
\text { Mean }\end{array}$ \\
\hline Child I (2012) & 100 & 100 & 100 & 100 \\
\hline
\end{tabular}

Child I (2012) shows a 100\% HA_int frequency. iScholar 


\section{Family II. Child Ila and Child IIb}

Interviews with parents on January 2015 for period 2013-14, January 2017 for period 15-16, and January 2019 for period 17-18.

Family variables

Family composed of $\mathbf{2}$ adults (mum and dad), and $\mathbf{2}$ children (Child Ila and IIb).

Family data:

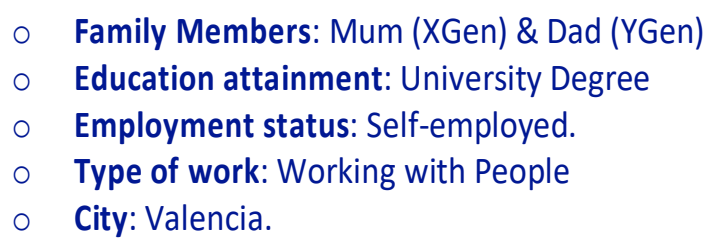

Home environment: number of haptic devices:

\begin{tabular}{l}
$\circ \quad \mathbf{2 0 1 2} \rightarrow 2$ Smartphones, 1 iPads \\
$\circ \quad \mathbf{2 0 1 5} \rightarrow 2$ Smartphones, 2 iPads \\
\hline$\quad \mathbf{2 0 1 8} \rightarrow 2$ Smartphones, 2 iPads
\end{tabular}

Adult device's interaction:
- Communication
- Leisure and entertainment
- Creation and productivity
- Information and learning

Physical space where the children can use the device: All around the house, restaurants, waiting rooms, car, etc.

Parenting style for haptic device use following (Baumrind, 1966):

Moderate (Permissive): low enforcement of rules when using the devices. High acceptance of use whatever use they want to give, little interaction when using the devices, little control on the activities.

Parents and child relationship when using the device: co-use.

Language for interaction with the Device: English, Swedish.

Parents motivation to allow children to use it: entertainment, communicating.

Time allowed to use the device: $2 \mathrm{~h}$. day maximum.

child $11 a$

Born: 2012

Child age at first interaction: Infant (0-18 months),

Child motivation to use the tablet: imitation, having fun, play games.

Child involvement in the learning experience: semi-active role, engaged 


\section{HC Case Study: Family II}

\section{child $\| b$}

Born: 2014

Child age at first interaction: Infant (0-18 months),

Child motivation to use the tablet: imitation, having fun, play games.

Child involvement in the learning experience: semi-active role, engaged. When he is with the $\mathrm{Pad}$, he disappears.

\section{Device used:}

Family IOS Tablet (iPad).

\section{Type of Apps used}

- Developers' apps (the most used):

- Educational: math, "painting", puzzles, vocabulary, etc. Even cartoons teach valuable concepts sometimes. Swedish app to learn new words.

- School homework: Puffin Academy, ShowMe, SchoolDojo, Jolly Phonics

- Family communication: FaceTime

- Media streaming content: Amazon Music, Netflix, YouTube

- Entertainment: Candy Crush

- book reading: Kindle

- Creativity: drawing, note-taking, video, and audio recording

- Web search apps: Safari

- In Built apps: messages, clock, calculator, camera, weather, podcast, flash camera, notes, calendar, audio notes, photobooth, email.

\section{Device using conditions}

- Who supports the child's interactions with the tablet, and provide: advice, answer to doubts, guide the use? parents

- Places allowed to use the devices: dining room

- Who owns the devices? The parents

- Was it used as a babysitter? Yes, in waiting rooms

- Were the children using other digital/technological/personal devices? TV

- Timing: How long could they use the device? It depends on the day of the week, school period/vocational period, health moment, etc.

- Child general Interaction: between the two children

- Activity Code: Determinate how the tool was used, provide examples of the activity performed.

- Relational Tool: Family videos to comment (toddler), search for information together (preschool).

- Communicative Tool: Facetime with grandparents (Infant), send emojis through WhatsApp to other family members (toddler)

- Documentation/Reflective Tool: Selfie (toddler), take pictures (toddler) drawings and scribblings (toddler). Select videos and photos of her interest (preschool).

- Informational Tool: Google search alone or with parent's help (preschool).

- Observational Tool: Capturing photos (preschool).

- Scaffolded Children's Learning Interactions: Ask for information learnt at school like song, and some words

- Second Language Acquisition: Not really. If randomly there are contents in Spanish, they watch them. The rest is used in English. 


\section{HG Case Study: Family II}

Emotional constructs when using the device

- Dealing with Frustrations $\rightarrow$ When they feel frustrated, we guide the App use.

- Dealing with mistakes $\rightarrow$ they try again.

- Mindset: not observed

- Taking positive risks: yes, different levels in Apps.

- Empathy or awareness: when they see something that makes them feel comfortable, they smile, as it was another person.

- Sense of trust: No hesitation when fingertipping.

- Sense of self-worth: not really. We prefer to rely on books.

- Curiosity: When they feel no one is watching, they try adults Apps.

- Capacity to look and listen carefully: like TV watching.

- Capacity to play: follow screen recommendations.

- Time of solitude: Not really with the tablet.

observations, and researcher's conclusions.

Parents use a lot of social media services for work, as well as their smartphones and desk computers.

Children are exposed to digital literacy at school with tablets, and desk computers. They know because children comment at home.

Children see smartphones as something normal, and the tablet as it was a TV screen, they are not conscious of the possibilities of the haptic interaction, but they behave with them naturally.

Both children behave equally with the tablet, with the same purposes, but one is younger that the other.

RESULT

\begin{tabular}{|c|c|c|c|c|}
\hline \% haptic Use & 2013-14 & $15-16$ & $17-18$ & $\begin{array}{c}\text { Arithmetic } \\
\text { Mean }\end{array}$ \\
\hline Child Ila (2012) & 70 & 75 & 80 & 75 \\
\hline Child IIb (2014) & - & 70 & 80 & 75 \\
\hline
\end{tabular}

- Child lla (2012) Shows a 75\% of HA_int frequency. iScholar.

- Child IIb (2014) shows a 75\% of HA_int frequency. iScholar. No data for period 13-14 because the child was born in 2014. 


\section{HG Case Study: Family III}

\section{Family III. Child III}

Interviews with parents on January 2015 for period 2013-14, January 2017 for period 15-16, and January 2019 for period 17-18.

Family variables

Family composed of 2 adults (mum and dad), and 1 child (Child III)

Family data:
- Family Members: Mum (Boomer) \& Dad (Boomer)
- Education Attainment: University Degree (mum), secondary (dad)
- Employment status: Public employee (mum), Private employee (dad)
- Type of work: Working with People (mum), manual labor (dad)
- City: Valencia.

Home environment: number of haptic devices:

$$
\begin{aligned}
\circ & \mathbf{2 0 1 2} \rightarrow 2 \text { Smartphones } \\
\circ & \mathbf{2 0 1 5} \rightarrow 2 \text { Smartphones, } 1 \text { tablet } \\
\circ & \mathbf{2 0 1 8} \rightarrow 2 \text { Smartphones, } 1 \text { tablet }
\end{aligned}
$$

Adult device's interaction:

$$
\begin{array}{ll}
- & \text { Communication } \\
\circ & \text { Leisure and entertainment } \\
- & \text { Information and learning }
\end{array}
$$

Physical space where the children can use the device: All around the house, restaurants, waiting rooms, car, etc.

Parenting style for haptic device use following (Baumrind, 1966):

- Moderate (Permissive): low enforcement of rules when using the devices. High acceptance of use whatever use they want to give, little interaction when using the devices, little control on the activities.

Parents and child relationship when using the device: co-use.

Language for interaction with the Device: Spanish

Parents motivation to allow children to use it: entertainment, communicating.

Time allowed to use the device: $2 \mathrm{~h}$. day maximum.

\section{child III}

Born: 2012

Child age at first interaction: Infant (0-18 months),

Child motivation to use the tablet: imitation, having fun, play games.

Child involvement in the learning experience: active, when gamming he disappears, no learning purpose.

\section{Device used:}

Family Android 


\section{HG Case Study: Family III}

Type of Apps used

- Developers' apps (the most used):

- Educational: math, "painting", puzzles, vocabulary, etc.

- School homework: none

- Family communication: none

- Media streaming content: YouTube

- Entertainment: App games.

- Book reading: none

- Creativity: drawing

- Web search apps: Firefox

○ In Built apps: none

\section{Device using conditions}

- Who supports the child's interactions with the tablet, and provide: advice, answer to doubts, guide the use? parents

- Places allowed to use the devices: dining room

- Who owns the devices? The parents

- Was it used as a babysitter? Yes, in restaurants, waiting rooms

- Were the children using other digital/technological/personal devices? TV

- Timing: not controlled

- Child general Interaction: alone. Even he has bought occasionally game Apps without supervision.

- Activity Code: Determinate how the tool was used, provide examples of the activity performed.

- Relational Tool: no performed

- Communicative Tool: no performed

- Documentation/Reflective Tool: Selfie (toddler), take pictures (toddler) drawings and scribblings (toddler).

- Informational Tool: Google search alone or with parent's help (preschool).

- Observational Tool: Capturing photos (preschool).

- Scaffolded Children's Learning Interactions: no observed

- Second Language Acquisition: No

\section{Emotional constructs when using the device}

- Dealing with Frustrations $\rightarrow$ When he feels frustrated, he gives up.

- Dealing with mistakes $\rightarrow$ he tries again.

- Mindset: not observed

- Taking positive risks: yes, different levels in games' Apps.

- Empathy or awareness: not showed

- Sense of trust: No hesitation when fingertipping.

- Sense of self-worth: not really. We prefer to rely on books.

- Curiosity: When they feel no one is watching, they try adults' Apps.

- Capacity to look and listen carefully: like TV watching.

- Capacity to play: follow screen recommendations.

- Time of solitude: yes, allowed 


\section{HG Case Study: Family III}

observations, and researcher's conclusions.

Parents do not normally use haptic devices for work.

The child sees smartphones as something normal, and the tablet as it was a TV screen.

He is not conscious of the possibilities of the haptic interaction.

Parents do not know the learning possibilities of the haptic interaction.

The child plays with the smartphone (alone) when he is with other children if he asks for the device, then there is no interaction with the other kids during the same period of time.

\section{RESULT}

\begin{tabular}{|lc|c|c|c|}
\hline \multirow{2}{*}{$\begin{array}{l}\text { \% haptic Use } \\
\text { Child III (2012) }\end{array}$} & 2013-14 & \multicolumn{1}{c}{ 15-16 } & \multicolumn{1}{r|}{$\begin{array}{c}\text { Arithmetic } \\
\text { Mean }\end{array}$} \\
\cline { 2 - 6 } & 25 & 30 & 15 & 23.3 \\
\hline
\end{tabular}

- Child III (2012) Shows a 23.3\% frequency of HA_int. Analog. 


\section{Family IV. Child IVa and Child IVb}

Interviews with parents on January 2017 for period 15-16, and January 2019 for period 17-18.

Family variables

Family composed of 2 adults (mum and dad), and 2 children (Child IVa and IVb)

Family data:

- Family Members: Mum (XGen) \& Dad (XGen)

- Education attainment: High School (mum), Secondary (dad)

- Employment status: Private employee (mum), Public employee (dad)

- Type of work: manual labor (mum), environmental worker (dad)

- City: Huelva (in the countryside)

Home environment: number of haptic devices:

$$
\begin{array}{ll}
\circ & \mathbf{2 0 1 2} \rightarrow 2 \text { Smartphones } \\
\circ & \mathbf{2 0 1 5} \rightarrow 2 \text { Smartphones. } 1 \text { Tablet } \\
\circ & \mathbf{2 0 1 8} \rightarrow 2 \text { Smartphones. } 1 \text { Tablet }
\end{array}
$$

Adult device's interaction:

$$
\text { - Leisure and entertainment }
$$

Physical space where the children can use the device: All around the house, restaurants, waiting rooms, car, etc.

Parenting style for haptic device use following (Baumrind, 1966):

- Neglected (Negligent): little interaction with the child, inattentive to the uses of the devices, only entertainment purposes, no control of contents.

Parents and child relationship when using the device: co-use.

Language for interaction with the Device: Spanish

Parents motivation to allow children to use it: entertainment

Time allowed to use the device: no rules

child IVa

Born: 2014

Child age at first interaction: Infant (0-18 months),

Child motivation to use the tablet: imitation

Child involvement in the learning experience: passive, hooked. No learning purposes.

child IVb

Born: 2017

Child age at first interaction: Infant (0-18 months),

Child motivation to use the tablet: sibling imitation

Child involvement in the learning experience: passive. No learning purposes. 


\section{HG Case Study: Family IV}

Device used:

Android

Type of Apps used

- Developers' apps (the most used):

- Media streaming content: YouTube

- Entertainment: app games

\section{Device using conditions}

- Who supports the child's interactions with the tablet, and provide: advice, answer to doubts, guide the use? there is no interaction.

- Places allowed to use the devices: kitchen, dining room, bedroom.

- Who owns the device? Parents

- Was it used as a babysitter? Yes

- Were the children using other digital/technological/personal devices? TV

- Timing: How long could they use the device? Mostly at lunch, and dinners, and before to go to sleep.

- Child general Interaction: no interaction. Just watching contents.

- Activity Code: Determinate how the tool was used, provide examples of the activity performed.

- Relational Tool: no with the tablet.

- Communicative Tool: no with the tablet.

- Documentation/Reflective Tool: no with the tablet

- Informational Tool: Occasional Google search for videos (preschool).

- Observational Tool: no with the tablet

- Scaffolded Children's Learning Interactions: No.

- Second Language Acquisition: No.

Emotional constructs when using the device

Not observed.

observations, and researcher's conclusions.

Parents use the tablet occasionally; they prefer the smartphone.

Both children behave equally with the tablet but one is younger that the other.

Both children use the tablet as it was TV, mainly as a babysitter.

Children do not ask for the tablet to play, but when they play with them or watch YouTube videos, they seem hooked.

Children do not have any interaction with digital literacy at school.

Children do not know the possibilities of learning because the parents do not know them. 


\section{HG Case Study: Family IV}

RESULT

\begin{tabular}{|lc|c|c|c|}
\hline & \multicolumn{2}{c}{} & \multicolumn{1}{r|}{$\begin{array}{c}\text { Arithmetic } \\
\text { \% haptic Use }\end{array}$} & \multicolumn{2}{c}{ 2013-14 } & \multicolumn{1}{c}{$15-16$} & \multicolumn{1}{c}{$17-18$} & \multicolumn{1}{c|}{ Mean } \\
\cline { 2 - 5 } Child IVa (2014) & - & 20 & 20 & 20 \\
\hline Child IVb (2017) & - & - & 10 & 10 \\
\hline
\end{tabular}

For child IVa there is no data available for period 2013-14.

For child IVb there is no data available for periods 2013-14 and 15-16.

Children were born after the periods.

- Child IVa (2014) Shows a 20\% of HA_int. Analog.

- Child IIb (2017) shows a 10\% of HA_int. Analog. 


\section{Family V. Child Va and Child Vb}

Interviews with parents on January 2015 for period 2013-14, January 2017 for period 15-16, and January 2019 for period $17-18$

Family variables

Family composed of 2 adults (mum and dad), and 2 children (Child Va and Vb). They are twins.

Family data:

- Family Members: Mum (XGen) \& Dad (XGen)

- Education attainment: University Degree

- Employment status: Public employees

- Type of work: highly skilled professional

- City: Valencia

Home environment: number of haptic devices:

- $2012 \rightarrow 2$ Smartphones

- $2015 \rightarrow 2$ Smartphones. 1 Tablet

- $2018 \rightarrow 2$ Smartphones. 1 Tablet

Adult device's interaction:

- Communication

- Leisure and entertainment

Physical space only in presence of parents at home.

Parenting style for haptic device use following (Baumrind, 1966):

- Prudent (Authoritarian): Expecting obedience while using the device. Not ready to accept independent use. Neglect child's curiosity towards the device. Little communication when reasoning the use or not. Highly directive behaviors.

Parents and child relationship when using the device: strict parent's supervision

Language for interaction with the Device: Spanish

Parents motivation They do not allow them to use it. But they see that many children use them, so, time to time the allow them to use it.

Time allowed less than half an hour when possible.

child $\vee a$ and $\vee b$

Born: 2012

Child age at first interaction: Infant (0-18 months),

Child motivation to use the tablet: curiosity

Child involvement in the learning experience: pro-active, scaffolded exploration, Learning purposes. 


\section{HG Case Study: Family V}

\section{child IVb}

Born: 2012

Child age at first interaction: Infant (0-18 months),

Child motivation to use the tablet: have fun

Child involvement in the learning experience: semi-active role. Sibiling observation.

Device used:

Android

\section{Type of Apps used}

- Developers' apps (the most used): media streaming content.

- Web search apps: information, videos, random words, images, locations.

- In Built apps: messages, clock, calculator, camera, weather, podcast, flash camera, notes, calendar, audio notes, photobooth.

\section{Device using conditions}

- Who supports children's interactions with the tablet, and provide: advice, answer to doubts, guide the use? There is almost no interaction. They were not allowed to use it until 2018 , then the parents but not too much.

- Places allowed to use the devices: dining room

- Who owns the device? Parents

- Was it used as a babysitter? No

- Were the children using other digital/technological/personal devices? TV

- Timing: less than half an hour per week.

- Child general Interaction: They ask for interaction because their peers interact with the devices in their homes

- Activity Code: Determinate how the tool was used, provide examples of the activity performed.

- Relational Tool: No

- Communicative Tool: No

- Documentation/Reflective Tool: NO

- Informational Tool: Occasional Google search for information (preschool).

- Observational Tool: no with the tablet

- Scaffolded Children's Learning Interactions: No.

- Second Language Acquisition: No.

\section{Emotional constructs when using the device}

Not observed. 


\section{HG Case Study: Family V}

observations, and researcher's conclusions.

Parents do not allow children to see how they are using the smartphone or tablet, but parents use them.

Both children are interested in haptic devices but they were not allowed to use it until they turned 5.

After being 5 they occasionally use the tablet but there are not records.

At the age of $5 \mathrm{Va}$ was caught hiding the tablet that he previously had stolen to their parents to play with the tablet.

RESULT

\begin{tabular}{|c|c|c|c|c|}
\hline \% haptic Use & 2013-14 & $15-16$ & $17-18$ & $\begin{array}{l}\text { Arithmetic } \\
\text { Mean }\end{array}$ \\
\hline Child Va (2012) & 10 & 40 & 60 & 36.7 \\
\hline Child Vb (2012) & 10 & 20 & 30 & 20 \\
\hline
\end{tabular}

- Child Va (2012) Shows a 36.7\% frequency of HA_int. Savyy-Tech.

- Child Vb (2012) shows a 20\% frequency of HA_int. Analog. 



\subsubsection{Parents Survey Data Collection}

Parents of children born after 2010 were asked to fill anonymously a retrospective survey for data collection: "Young Children and the use of Tablets (0-8)" during November 2018 to understand the parental attitude towards haptic devices. The survey was set using Google Forms format which link was distributed by email. Spanish parents answered to the Spanish version (Spaniards), and foreign parents (foreigners) living in Valencia answered to the English version.

The retrospective survey asks parents about events from the past, memories of anecdotes of the children while using the device, apart from other information. By deploying this kind of survey, we can gather data based on past experiences and beliefs regarding haptic devices.

All parents expressed consent for the research purpose (Addendum: Letter of Consent).

Next, we summarize the most relevant answers provided that are of statistical significance for the research conducted.

Conclusions are inserted in the writing of Chapter 5.

Question 2: Think about the use you give normally to your tablet or Smartphone:

Only the $2 \%$ of the Spaniards use the tablet with other purposes but communication and leisure and entertainment, contrary to foreigners where the $2 \%$ is related with the ones that only use the device with that purposes.

Foreigners are more aware of the different uses of the tablet regarding creation, productivity, information, and learning.

\section{Question 3: Which actions do you think that your kid is imitating from you when you interact with your device? Name a few.}

All the things I do on the device from checking my email, watch online movies, take pictures, record video, record voice, take notes, read, search on google, etc.

Camera use for sure! Also FaceTime... and Candy Crush from their grandmother - doh.

Camera use and facetime.

He does different things: leisure, drawing. Or school related: homework, FaceTime with Friends while homework,...

Pretend to use the phone, swiping, pressing

Camera, game apps (Mindcraft, Chess, others), Google (search, Translate, Maps) searches for content, Youtube

Camera, weather app

Camera use

App use and video calling

Listening music

My agitation! Camera use too. App use.

Camera, typing messages, sending emojis 
Consulta y búsqueda de información. Ver películas/series. Estudiar otras lenguas.

Búsqueda/consulta de información. Hacer fotos y vídeos. Escuchar música

Cámara, llamar, leer prensa, WhatsApp

Ver películas y series

Intento que no me vea usando el móvil para retrasar su interés

buscar información de alguna cosa... Pero la verdad es que me ven muy poco usarla

En nada la usamos para cosas distintas

Usar la cámara y enviar un mensaje con WhatsApp

Cámara

camara, llamar a familiares

no puede imitarme, lo utilizo para leer la prensa o buscar cosas puntuales que me interesan, como una ubicación, una empresa, un producto... (es preferible a través de la tablet que a través del móvil y más rápido y operativo que el ordenador). No lo utilizo con ellos delante.

Cámara

usar la cámara, Ilamar, WhatsApp

Based in the answers provided, children imitate them in normal performing: camera use, App games, listening music, email sending, pretending games using the devices, etc. Even they copy physiological attitudes (i.e. "agitation").

Remarkable for this question is the answer of some Spaniards respondents that affirm they do not use the devices with the children around.

Question 4: Do you think your kid has acquired new skills while using the tablet/smartphone? Name them. e.g.: information search, creativity, oral skills, linking ideas, etc.

Yes. Create videos. Audios. search for information. learn English expressions.

She loves to do educational games on the tablet - math, "painting", puzzles, vocabulary, etc.

Even cartoons teach valuable concepts sometimes.

He really likes his Swedish app which helps him learn new Swedish words.

Create and edit videos, search information

Take pictures and video

Yes. My child has learned how to find answers to unknown questions on the web. In addition to

developing his sense of independence around his intellectual pursuits, he has a very clear understanding for what will make good search words; also through Mindcraft, my child has learned to create and manipulate virtual environments.

Recording, create videos

No, primarily because we do not allow our children to use cell phones, tablets, or computers.

We have a no-screen policy except for occasional movies on the weekends. Our children do not have and are not allowed to use any touch-screen device in our home, and we purposely try to avoid such devices among friend-groups and in school.

Improved speech

Improving language skills

Not really. Nothing they would not learn otherwise. It's been mainly a form of entertainment instead of TV

No 
Hacer vídeos, búsqueda de información para temas escolares (google). Pintar y diseñar casas, ropa, etc.

Aprendizaje de idiomas viendo vídeos, películas en otras lenguas. Buscar información (google) Idiomas, buscar información

Tiene algunos juegos educativos

Hacer búsquedas en internet

buscar información que le interesa, aprender alguna cosa, canciones, escribir con el teclado...

Buscar información sobretodo

Mi hijo de 6 años no la utiliza. Solo para jugar y pocas veces. Si que veo que tiene muchas más facilidad con las nuevas tecnologías que personas de mayor edad....igual si sería capaz de buscar información.

hacer vidos

no

no porque únicamente lo utilizan para ver dibujos, documentales o escuchar música que les guste

Seleccionar información que le interesa.

hacer vídeos, tomar fotos, buscar el google

$60 \%$ of the respondents either Spaniards or foreigners believe children are acquiring new skills using haptic devices, and some think that despite the children do not used them, they would have easiness to do it.

Question 5: Can you name any anecdote relating your kid and the use of the tablet/smartphone that kept your attention because it was unexpected? Retell please

at the age of 4 she expressed in English (being Spanish) "I'm walking backwards" learned from Peppa Pig on the tablet.

I told her that "you can even read newspapers on your iPad" and she said, "What's a

newspaper?"...!!!

He doesn't yet have homework but he is always super-excited to sit with his big sister for the homework she has on the iPad.

- Pretending that a block was a phone, my (then) 3 year old looked at the imaginary screen and shouted, "Oh my god I'm late for a meeting!" She then put it to her ear, apologized profusely, and got to work. - My 4 year old says "press the page" or "pass the page" when reading a book. The former comes from me letting her turn the pages for me on my kindle, and the latter is Spanglish ("pasar la paging"). - When pretending to take photos with an imaginary phone, my kids always show the photos to the subject immediately after

None

I don't understand this question

Manejo con mucha habilidad y soltura de dispositivos electrónicos

Uso de dispositivos electrónicos de forma ágil, sobretodo los dispositivos táctiles

El ya sabia manejarla con 3 años solo de vernos

Ha aprendido a escribir en el teclado por pura necesidad de buscar sus vídeos favoritos 
Nuestros hijos no usan mucho la tablet, por lo que las anécdotas de sorpresas se han producido en otros ámbitos. Si hay que destacar algo de la tablet, bueno, me pareció que aprendieron muy rápido a programar el wedo de lego, pero tampoco le han dedicado mucho... El manejo en general lo hace mas fluido y de forma intuitiva Simplemente la habilidad que tiene desde bien pequeño utilizando el dedo en cualquier pantalla....ya cualquier pantalla piensa que es táctil solo usa el movil muy pocas veces para fotos, nunca LA TABLET sabe atajos para llegar a cosas que yo no conocía hasta que lo vi a él

The answers to this question illustrate how children have haptic devices as any other tool, they are learning digital skills naturally by using while their parents have to learn it on purpose. Also some of the respondents give examples of learning vocabulary from passive content.

\section{Question 6: Do you think your kid is learning when using the tablet?}

The $65 \%$ of the Spaniards and the $25 \%$ of the foreigners think that their children are not learning while using the tablet. There is a difference again between the beliefs for Spaniards and foreigners regarding the haptic devices that could be caused due to a difference in timing for technological perceptions related with cultural factors.

Question 7: If Yes. What do you think the kid has learnt? e.g. reading, maths, English/Spanish Vocabulary, create videos or audios, etc.

reading. Mathematics. communicate with relatives by video calling

It has helped her practice vocabulary and maths skills and she also did a Girls in STEM class where they used their tablet to learn basic coding.

Problem solving, songs, alphabet and numbers.

other skills, maths practice, grammar practice

Maths, topical information (nature; geography; etc)

Animals vehicle names facetiming

A bit of Spanish when watching cartoons in that language.

Idiomas (vocabulario) al ver películas y dibujos en otros idiomas. Geografía actualizada y de forma muchos más interactiva: posibilidad de variedad de fotografías reales de los lugares que estudia; gran cantidad de información de los lugares, incluso información directamente de las personas que viven en los lugares.

Idiomas. Anatomía del cuerpo humano. Ciencias naturales. Conocimiento de letras y sonidos Leer

Conectividad, globalidad, idiomas

Estas cosas las han aprendido sin tablet

un poco de todos lo que ponéis de ejemplo

Aprende lo que le interesa y de quien le interesa. Escoge cómo le gusta recibir la información. cuando usa las app de aprender a leer

The answers illustrate the positive interactions that children have for literacy learning in the opinion of parents. 


\section{Question 8: Do you think tablet use will have an impact in your kid's learning style?}

Despite the general opinion that children cannot learn while using the tablet, more than $70 \%$ of the respondents affirm that the tablet will have an impact in children learning style in formal learning, $50 \%$ of the respondents in a positive way, $30 \%$ still are not sure if it is going to be positive or negative, and a $20 \%$ declares that it is going to be negative and that "Destroys concentration span and ability to focus/ follow through on one task"; as he answers provided for question number 9 illustrate.

\section{Question 9: Tell us why?}

She uses more images so less reading than before and less writing

Some of her homework from school is even on the tablet. When learning is "gameified" and fun for the kid, they are so much more eager to do the work.

I think it will completely change the way kids learn. More and more apps will be designed to 'hack' learning and make it fun and easy.

Immediate search for information

Will affect their attention and concentration

I believe learning styles are inherent, not shaped by external forces. However, I do think that easy access to information can impact the range and depth of learning my child pursues on a given subject matter. Before tablets and the web, gathering or producing information from which to learn on a single topic was a time consuming and laborious process, if it was available at all. Tablets are handheld dopamine-injection devices: everything about them is designed to provide a tiny burst of pleasure (this applies to both children and adults). My concern with educational apps for children is that they reward the child for every interaction, and encourage continued interaction with the device. I consider these devices to be detrimental to learning not just because of what they provide (easy, repeated, addictive hits of dopamine), but because of what they allow children to avoid: boredom, frustration, and imperfect outcomes. I don't mention a lack of human interaction because we can assume that the alternative to a tablet might be some other independent activity, though I do think that tablets are unique in that they generally negate the possibility of true human interaction. Anyway, imperfect outcomes I think are especially differentiating because most of these educational games for young children have outcomes that are binary: one that is "correct" and pleasing, the other is incorrect but still pleasing because it encourages more attempts, often with reduced difficulty. While there might be an overall score or level change, the individual actions that a child performs are either right or wrong. My issue with this is that when a child writes a letter on a piece of paper, it can be too big or too small, or too bumpy or too square, it can be backwards or half-formed... but it is rarely exactly right or exactly wrong. Similarly, when a child learns a new word in another language in real life, that word can be mispronounced, misheard, misused, misunderstood, or a combination of all of the above, but it might still function as a word. Analyzing these imperfect outcomes is, in my opinion, an essential part of the learning process: it requires that children internalize expected results, establish a personal goal, and reflect on the quality of their attempt(s). Learning is not a race to the right answer; it is a process of imperfect attempts that must themselves be valued and offer satisfaction. Accepting imperfect outcomes is also an important part of building resilience and confidence. Educational apps, in my opinion, take all of this away from the child. These games limit the possible outcomes, set the expectations and goals, and decide whether 
an attempt was satisfactory or not. The child is given an illusion of control because the interactive nature provides constant stimulation and reward, but in reality the child is completely hemmed in, like a rat in a maze. So... do I think tablet use will have an impact on my kids' learning styles? Yes, it would if I allowed tablets, which is why I don't. ;) It will mainly add to lack of attention span, app addiction and grumpiness.

Destroys concentration span and ability to focus/ follow through on one task

La búsqueda de información se agiliza muchísimo tanto en casa como en el colegio. La creatividad se desarrolla también ya que les da herramientas para crear de forma fácil: hacer vídeos, pintar, consultar ideas (por ejemplo, de gente de todas partes del mundo por medio de youtube)

Si, es mucho más ágil a nivel de búsqueda de información. Trabajar temas actuales y tener los recursos más innovadores al alcance de todos

Aprender a manejar contenidos audiovisuales y tecnología

En el colegio utilizan otros métodos

Vídeos. Se ha acostumbrado a ver documentales en YouTube, sin duda será para él en el futuro una forma prioritaria de aprender cosas nuevas

Estoy seguro que influirá, lo que no tengo claro es si para bien o no...

Sobretodo en la inmediatez con los que se solucionan las inquietudes

SU FORMA DE RAZONAR Y SUBJETIVIDAD CAMBIA

forma de pensar y relacionarse

No creo que el aprendizaje de cosas básicas sea mejor a través de la tablet.

Sabe distinguir lo que es un buen comunicador. Se aburrirá más con las clases magistrales. 


\subsection{ZG Case Study}

\subsubsection{Situational Context: UPV, Valencia, Spain}

Universitat Politècnica de Valencia (UPV) is established as University by Decree 495/1971, in March $11^{\text {th }}, 1971$, giving continuity to the Instituto Politécnico Superior de Valencia created in 1968. The Vera Campus, in Valencia, headquarters of UPV is a large space that allows the communication and interaction of students and lecturers of different technical or humanistic disciplines, aiming to boost research and generation of knowledge with quality, rigor, and ethics in science, technology, arts, and business, and to contribute to technical, economic, and cultural progress.

UPV opened its campuses with the best pedagogical technology of the moment invented through history: typewriters (1873), chalkboard (1890), pencils (1900), overhead projectors (1930s), ballpoint pen (1940) headphones (1950s), slide rulers (1950s), videotapes (1950s), photocopiers (1950s), microfilm viewer at the library (1960s), liquid corrector fluid for mistakes when typewriting (1960), and hand-held calculators (1970s) as the most advance ones (Jeff Dunn, 2011). As higher education, and research institution, UPV has been integrating the technological advances that the forthcoming decades were offering: integrating desktop computers (1977) in the classrooms, internet connection (1991), VLEs system (PoliformaT (2010)), and, any sort of device that could improve teaching (laptops, e-readers). Since 2010, UPV is also witness of how haptic devices were being introduced in the pockets of its population (students, and teaching staff), having since 2015 a huge presence in the classrooms at students' hands.

Following Table 1, UPV has a population of 31,978 members during 2017-18 academic year distributed in six generational cohorts (UPV, 2019) among the following categories: Universidad Senior ${ }^{21}$ students (Senior), Teaching Staff (PDI), administrative staff (PAS), bachelor, master, and doctorate students (Student), and children of Centro Educativo Infantil Vera ${ }^{22}$ (Toddler).

\footnotetext{
${ }^{21}$ Universidad Senior is a UPV unit that develops and organizes university training programs for people older than 55 since 1999.

${ }^{22}$ Centro Educativo Infantil Vera at UPV attends, and educates children aged between 1 and 3 years old (1st cycle of Spanish kindergarten education), offspring of UPV staff since 1978.
} 


\begin{tabular}{|l|c|c|}
\cline { 2 - 3 } \multicolumn{1}{c|}{} & UPV POPULATION 17/18 & $\%$ \\
\hline Silents & 627 & 2.0 \\
\hline Boomers & 3211 & 10.0 \\
\hline XGens & 3633 & 11.4 \\
\hline YGens & 9922 & 31.0 \\
\hline ZGens & 14503 & 45.4 \\
\hline HapGens & 82 & 0.3 \\
\hline
\end{tabular}

Table 1 UPV population. 2017-18 Academic Year (own source)

The Silents represent the $\mathbf{2} \%$ of the total in Senior, PDI, and Student categories. The Boomers represent the $10 \%$ of the total in Senior, PDI, PAS, and Student categories. XGens represent the $11.4 \%$ of the total in PDI, PAS, and Student categories. The YGens represent the $\mathbf{3 1 \%}$ of the total in PDI, PAS, and Student, categories. The ZGens reach the $45.4 \%$ of the total population under the category of Student, and the HapGens represent the $\mathbf{0 . 3 \%}$ in the Toddler category (UPV, 2019) and (SIIU, 2019).

UPV first mission is to train people by promoting the development of their competences, ${ }^{23}$ with quality training, oriented to the needs of the society. Following the guidelines framed in the Bologna process (European Commission/EACEA/Eurydice, 2012), the UPV has opted for implementing innovative methodologies for teaching. To do this, the university has moved towards learning models that ensure that the students acquire the necessary skills to occupy an adequate job. To achieve this goal, it is essential to make the student the center of the learningteaching process via the implementation of active methodologies that integrate the development and acquisition of skills.

Higher education at UPV is organized in its 13 engineering schools and faculties, 1 Doctorate School, and 42 teaching departments that organize the 37 Bachelor, 7 Double Bachelor, 74 Master, 9 Double Master Degree, and 30 Doctorate Programs offered to its 25,536 students enrolled during 2017-2018 academic year (UPV, 2019). Its curricula cover 13 competences distributed among 2383 Bachelor subjects, and 1620 Master subjects. From them, 300 degree/master subjects are delivered in English Language (High Academic Performance groups).

The UPV has implemented along its 50 years of experience, several actions that try to reflect the latest advances in methodologies, different learning scenarios, evaluation systems, etc. to substantially improve the quality of the lessons taught and thus achieve excellence (NMC Horizon Report, 2016).

The commitment to educational innovation since 2010, includes the following actions for 201718 academic year (UPV-VECA, 2019):

- The "Docencia Inversa" Project whose objective is to involve students in their own formative process, make them responsible for their learning, and at the same time, manage to awaken in them the motivation to learn.

${ }^{23}$ Competence is a combination of knowledge, skills and attitudes/values (OECD, 2018b). 
- The "Docencia en Red" Project is a line of action to intensify the use of new ICTs in teaching.

- "Innovación y Calidad Educativa" Teams (EICE) are stable teams of teachers, from the same or different disciplinary fields, who share common objectives of educational innovation and research

- "Innovación y Mejora Educativa" (PIME) Projects have a significant impact on the development of more active teaching, aimed at improving the quality of student learning.

The participation in these programs has not been high. For instance, from its 4,003 subjects, only 256 (6.4\%) participated in the Docencia Inversa Project. The PDI involved into that program was $270(\mathbf{1 0 . 2 \% )}$ out of 2,637, and there were 2,320 (9\%) out of 25,526 Students during 2016-17 academic year (data for 2017-18 were not available at the moment of the thesis publication) (UPV-VECA, 2019).

\subsubsection{ZG Survey Data Collection}

ZGen students enrolled in English B2 Subjects in ETSII at UPV during 2018-19 academic year were asked to complete anonymously a cross-sectional survey for data collection: "Students and Haptic devices: Educative use" during December 2018 and January 2019 to get knowledge of students' attitude towards haptic devices when learning. The survey was set in Spanish using Google Forms format which link was distributed by email.

The cross-sectional analysis analyzes the variables in a given point of time across the sample population, what helps to understand the habits of the students in the moment they answer the questions. By deploying this kind of survey, we can gather data based on nowadays teaching and learning methodologies under the point of view of the students.

All the students expressed consent for the research purpose (Addendum: Letter of Consent).

Next, we summarize the most relevant answers provided that are of statistical significance for the research conducted.

\section{Question 1, 2: University motivation}

Around $51 \%$ of the respondents say that they are motivated to be at UPV, and the $66 \%$ affirm they like what they are studying.

\section{Question 3, 4, 5: Smartphone, tablet, and laptop}

The $100 \%$ of the respondents own a smartphone that they use mainly with communicative purposes. Only a $37 \%$ own a tablet and the $17 \%$ use the tablet to search information about the topics they like, and the $13 \%$ with entertainment purposes.

The $100 \%$ of the respondents own a desktop computer or a laptop, using it mainly with learning purposes and university tasks (61\%), entertainment (20\%), create digital contents (14\%). 
Question 6: Better understanding of English Language visiting web pages in English

The $54 \%$ of the respondents say that the English level got better, the $29 \%$ affirm they are not conscious of the learning. $7 \%$ say they have not learnt any English and 10\% affirms they do not visit web pages in English.

Question 7: Learning Tasks that they have tried to do with a haptic device:

Collaborative work in the cloud, use of social media to follow a specific topic, and email writings with their class mates are the most frequent tasks they perform.

Question 8: Haptic devices have creative functions. Signal which ones you use:

Mainly Apps, multitask, and skype. The best advantage that they find is that they save time.

Question 9: Gather opinion about teaching methodologies observed in their subject's classes.

Only the $15 \%$ of the respondents affirm that teachers present the contents in an adequate way.

Question 10: Gather information about the type of digital content that they use when studying for a subject.

$89 \%$ of the respondents use text/pdfs, the $69 \%$ use videos, and the $46 \%$ use images.

\section{Question 11: Asks about the methodology used while learning}

The $57 \%$ of the respondents rewrite what it has to be learnt. The $49 \%$ searches for information online. The $37 \%$ apply what they learn to real problems examples.

The $46 \%$ still learn by heart the contents, and only the $5 \%$ create multimedia contents.

Question 12: Requires their opinion about learning digital literacy at the university.

$77 \%$ of the respondents affirms that they have learnt and they are very necessary, and the $15 \%$ affirm that they have not learnt them but they need to learn them.

Question 13: Gathers information about if they think they are going to be prepared for specialized jobs when finalizing the university.

Only the $9 \%$ affirm they are going to be prepared, the $24 \%$ say good enough, $41 \%$ say maybe, and the $27 \%$ said they are not going to be prepared.

Question 14: Asks them about the relationship between their university learning and the use they can give about when working

$73 \%$ affirm that they not only the formal learning but also the informal learning is needed to work and they complement each other. 
Question 15: Asks them to complete the sentence: My motivation for learning will increase when...

Some of the respondent gave answers that had nothing to do with the questions posted (i.e. "ella me quiera") invalidating the results, that is why we give account of the answers related with the real meaning and purpose of the question:

Consiga ver que tiene resultados tangibles en mi vida

me enfrente a una situación que requiera conocimientos de clase

vea que puedo aplicar a problemas reales lo aprendido en "clase".

encuentre lo que realmente me apasione

la asignatura me parezca interesante o me llame la atención

cuando no todo el peso de las notas recaiga en los exámenes

Tenga buenos profesores

tenga asignaturas más específicas

Vea más útil lo que aprendo

Curse asignaturas que de verdad se aplica a la vida laboral y no a lo que quieren los profesores Llego a entender de lo que me explican en clase

el sistema educativo se preocupe de cada alumno y personalice la enseñanza, sin ser solo un

"numero" mas o una obligación.

Apliquen la teoría a problemas que podamos vivir en un futuro en nuestros respectivos

trabajos. Mi carrera (GITI) es un océano de conocimientos de $1 \mathrm{~cm}$ de profundidad, no indagan en nada y las prácticas son escasas e inútiles

compruebe prácticamente que los conocimientos que estoy obteniendo me van a ser útiles

para mi vida profesional

No todo el peso de la nota o la mayor parte de ella dependa de exámenes.

encuentre realmente lo que me apasiona y quiera profundizar y especializarme en ello

The answers illustrate that the curricula followed at the university is outdated and the students that really want to pursuit and excel scholar knowledge expect a change either in their lectures' teaching methodologies, in the application of the learning in real-life problems, in the personalization of the learning, and the assessing system.

\subsubsection{ZG Essays}

An essay is defined as a piece of writing that gives the author's own argument on a particular theme or subject, usually in prose and generally analytic, speculative, or interpretative.

For the purpose of this dissertation we have collected interpretative essays where the student is expected to produce an organized text in English language that responds to the question posed for the research purpose. The questions proposed for the essays contributes to collect data about the learning methodologies the students use nowadays, and confirm if they get bored during formal university classes, and what they would do to avoid it.

Students from subject 12610 Ingles Nivel B2 (ETSID- TA) agreed on giving their opinion about the two questions in essay format: 


\section{Question 1: As a member of the generation that you are (Z or Y), tell me your learning preferences}

The most relevant answers have been:

"My learning preferences has to do with the teacher"

"With the help of PoliformaT where you can study whenever you want and wherever you are" "I don't like to waste time handwriting, so I prefer technology"

"those related to effective learning: teacher assisted learning to better understand the lessons" "Z generation are self-taught because apps of learning, methods are more practical and useful in the long term"

"Search for information in Google, tutorials in YouTube, text with partners by social networks." "work in team techniques, using devices like tablet to save money and the planet, not learning every exam by heart"

"self-learning, tutorials or interactive videos"

"Visual and auditory. Learn better by listening"

"With dynamic teachers that make classes participatory"

"practical lesson that allow yourself to introduce in the real life"

"With a teacher that transmits passion, power and positive energy to encourage students to be attend during all the class"

"with videos and other resources, some time to make exercises, and a good relationship among teacher and the student"

"Study in the library with summaries of the subject"

"Teacher should create a good feeling to promote a nice environment"

"applying the theoretical part into a dynamic project. Doing failures, trying or knowing and seeing the reactions of something. By visuals"

"practical way. Interactive lessons"

"I like to study on paper because then it don't hurt my eyes"

"set up interactive lessons through webcam or video-calling"

Some of the students start using haptic devices for learning and are aware of the need of visual literacies as well as new learning methodologies.

Conclusions are inserted in the writing of Chapter 7.

Question 2: As university lecturers, we think that you get bored when learning at university. Normally, this is because something: boring lessons, boring ways to teach, not feeling that you are learning, boring lectures, or whatever other personal reasons. From your experience, write why you get bored at university classes, and what would you change to improve them and help to end with the boredom.

The most relevant answers have been:

"Cause: Because the exam method causes lack of interest.

Solution: making classes more interactive and practical."

"Cause: I get bored when the teacher speaks all the time with the same level voice

Solution: Introduce practical parts." 
"Cause: some classes make to lose interest

Solution: more interaction between the lecturers and the students."

"Cause: Teacher's attitude

Solution: prepare teacher for more motivation and dynamism, introducing technology for creating dynamism."

"Cause: the schedules, too many hours, repeating things among subjects, some teachers only read."

Solution: more communication among departments to avoid repetition

"Cause: subjects do not have a direct connection with the career chosen then teachers do not create a good environment to transfer the interest to their students.

Solution: both have to be involved to create a better environment."

"Cause: when I do not get involved in the class

Solution: more interaction between the teacher and the students."

"Cause: similar subjects

Solution: learn through work."

"Cause: Teachers do not interact with the students and master classes are outdated

Solution: watching videos or talking more with their students."

"Cause: compulsory assistance and the way of teaching

Solution: try lessons more dynamical to catch student's attention."

"Cause: it depends on teachers

Solution: to do different activities to participate more."

"Cause: repetitive subjects

Solution: practicing."

"Cause: subjects do not arose an interest

Solution: make the class less linear, remember terms of previous classes to avoid misleading, avoid excessive information."

"Cause: not using technologies to teach

Solution: new teaching methods and new technologies."

The answers give us insight of the existent gap between what formal teaching offers and what the students demand according to the things they find in their surroundings different to formal to acquire knowledge.

Conclusions are inserted in the writing of Chapter 7. 


\subsection{Papers on Early Childhood Using Haptic Devices with Learning Purposes}

(Zack et al., 2009) publication was one of the first research attempts to foresee the acquisition of literacy skills by infants using a Tablet PC, precursor of touchscreen devices appeared in early 2000.

(Couse \& Chen, 2010) explored the viability of the use of those tablets by early childhood, concluding that the interaction allowed children to create original works as a means of personal expression; provided opportunities for peer collaboration; developed motivation, and persistence in solving tasks among children; and reinforced children's interest and determination in completing tasks without feeling frustrated.

Following those two papers, as precursors of research conducted and proved data of acquisition of literacy skills that the early childhood has while using the haptic devices, I settled the keywords, variables, and criteria to follow during the desk research to triangulate the information that could give evidence on Research Question number 1.

An extensive search of electronic peer reviewed papers has been done from January 2015 to December 2018. The databased used was the UPV physical and online repository, in the fields of psychology, education, neurology, social science, and computer science mainly.

The keywords used to find relevant papers to answer the research objectives of the dissertation were: "iPad, touchscreen, tablets," related with "education/learning," and "early childhood, children, kids."

The main inclusion criterion has been that the papers should report the use of touchscreen devices (tablet/iPads) and/or Apps with educative purposes by young children, and when possible that they were born after 2010 in their research methodology. The search result is aimed mostly to set what has been concluded until now and how my questions could give new insights on the topics, and offer a scientific point of view of the use of haptic devices to parents, teachers, school and university stakeholders, and any other citizen or organization related with education, among other uses.

The inclusion criteria were:

- Peer reviewed papers that reported the use of touchscreen devices,

- educative perspective and use of haptic devices,

- reporting children usage born after 2010,

- positive or negative impact for learning outputs,

- publication period: 2010-2018, and

- English language. 
The description of the variables is:

$\Sigma$ Variable $1 \rightarrow$ HD: The technological tool to perform the activities was a haptic device. Mainly the tablet type due to its size and dimension.

$\Sigma$ Variable $2 \rightarrow$ Children. The subjects manipulating the devices should be children. Mainly students from different school grades (kindergarten, primary, secondary, high school).

$\Sigma$ Variable $3 \rightarrow$ HapGen Children. The subjects manipulating the devices were children born after 2010.

$\Sigma$ Variable $4 \rightarrow$ Literacy Learning. Acknowledge of acquired literacy learning when performing with the haptic device.

\begin{tabular}{|l|c|c|c|c|c|c|c|c|c|c|}
\hline & 2010 & 2011 & 2012 & 2013 & 2014 & 2015 & 2016 & 2017 & 2018 \\
\hline Var_1 HD & 1 & 2 & 8 & 23 & 13 & 33 & 38 & 40 & 43 \\
\hline I1\&2 Children & 0 & 1 & 5 & 16 & 12 & 26 & 28 & 23 & 37 \\
\hline I1\&2\&3 HapGen & 0 & 0 & 0 & 1 & 1 & 7 & 15 & 15 & 23 \\
\hline
\end{tabular}

Table 2 Number of papers reviewed that met the different variables set (own source)

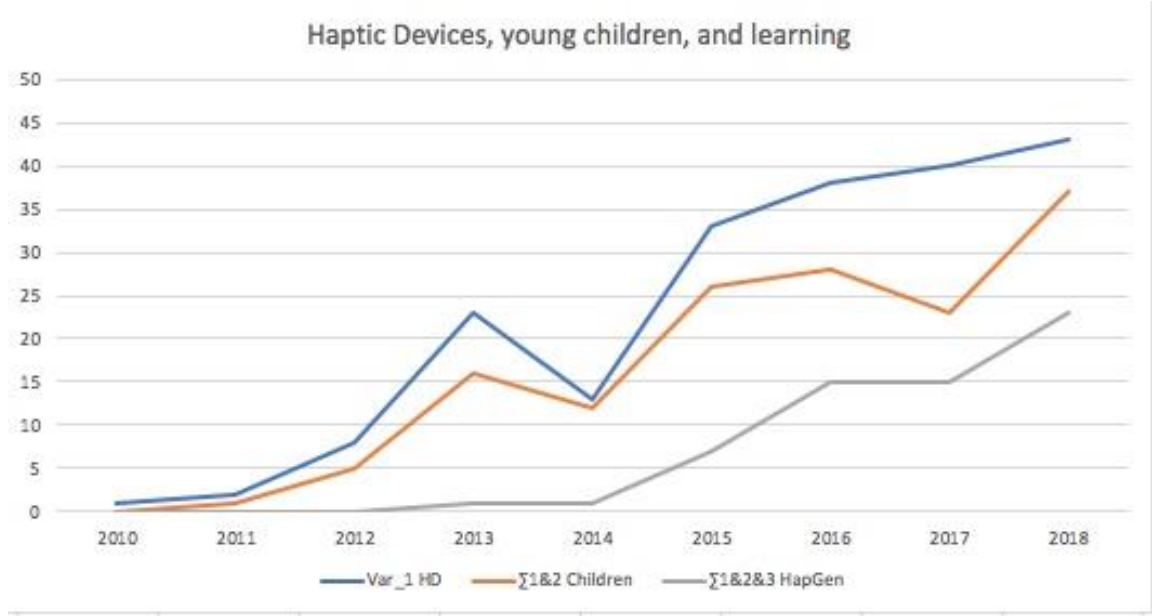

Table 3 Chart showing the increase of papers conducting research with haptic devices (own source)

As we observe in Tables 2 and 3 there are 201 peer reviewed papers identified under Var_ 1 HD, considering educative or family use of touchscreens. From that first identification, 148 papers met the criteria of Var_1 and Var 2: early childhood using haptic devices. 62 out of 148 are aimed at children born after 2010, therefore meeting the Var_1, Var_2, and Var_3 criteria.

For research question number 1 , it was important to detect how many of those peer reviewed papers where aimed to find instance of literacy learning. For that reason, we include Var_4 "positive literacy learning demonstrated" once the 201 papers where identified under Var_1. 


\begin{tabular}{|lrr|r|r|r|r|r|r|r|r|}
\hline & 2010 & 2011 & 2012 & 2013 & 2014 & 2015 & 2016 & 2017 & 2018 \\
\hline & 1 & 2 & 8 & 23 & 13 & 33 & 38 & 40 & 43 \\
\cline { 2 - 10 } Var_1 HD & 0 & 0 & 4 & 12 & 8 & 17 & 14 & 8 & 19 \\
\hline 31\&2\&3\&4 HapGen & 0 & 0 & 0 & 0 & 0 & 4 & 7 & 6 & 14 \\
\cline { 2 - 10 }
\end{tabular}

Table 4 Positive literacy learning demonstrated. Number of papers (own source)

\section{Literacy Learning and HD}

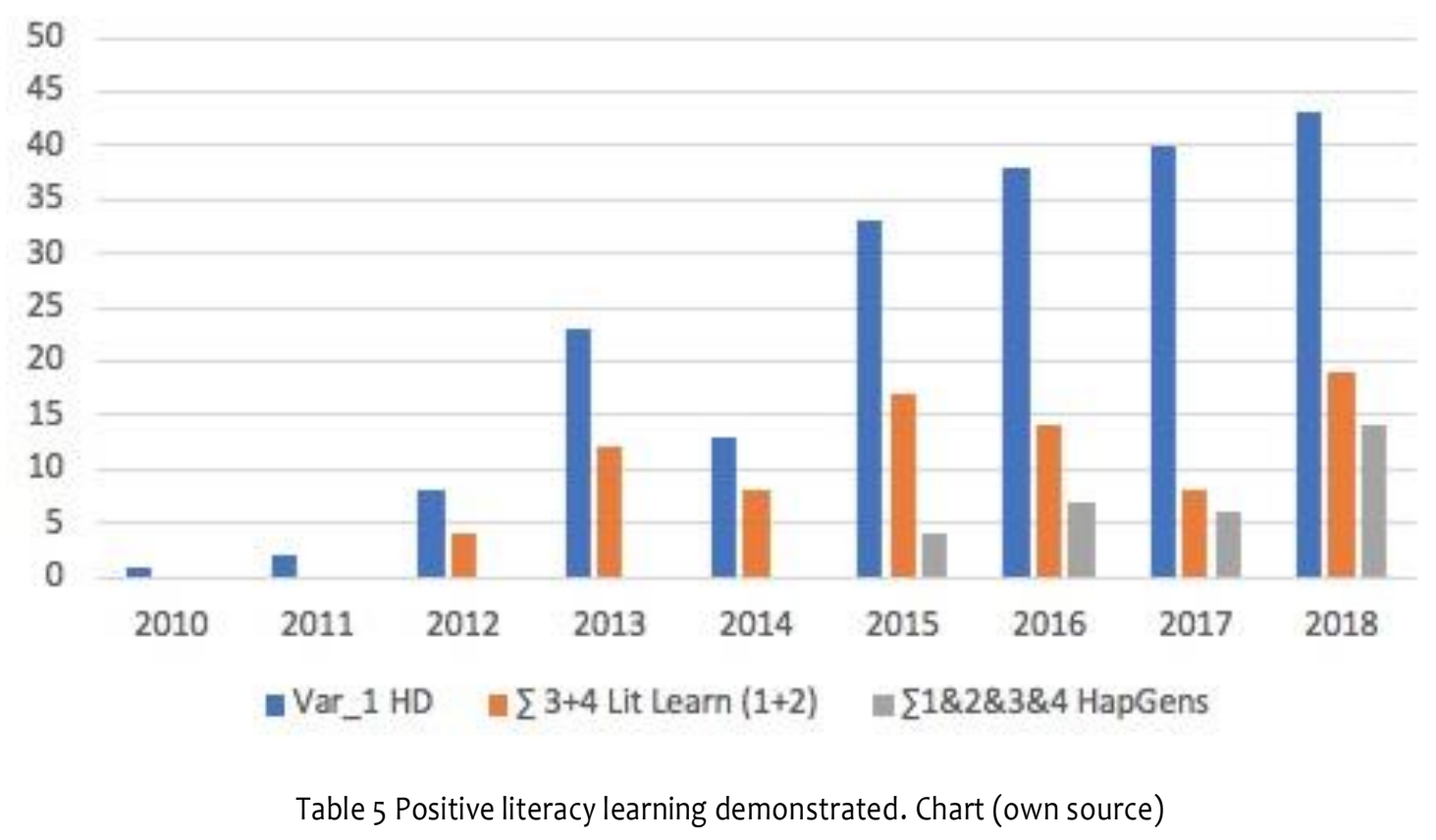

As we observe in Tables 4 and 5 from the 201 peer reviewed papers identified under Var_1 HD, 82 matched criteria Var 2 and Var_4 (literacy learning demonstrated). 31 out of the 82 demonstrated literacy positive literacy learning in children born after $\mathbf{2 0 1 0}$ (Var_3). 


\section{List of Peer reviewed Papers (2010-2018)}

\begin{tabular}{|c|c|c|c|c|c|c|}
\hline Author(s) & Year & Title & Var_1 & Var_2 & Var_3 & Var_4 \\
\hline $\begin{array}{l}\text { Melhuish, K., \& Falloon, } \\
\text { G. }\end{array}$ & 2010 & $\begin{array}{c}\text { Looking to the future: M-learning with } \\
\text { the iPad. }\end{array}$ & 1 & & & \\
\hline $\begin{array}{l}\text { Higgins, S. E., Mercier, E., } \\
\text { Burd, E., \& Hatch, A. }\end{array}$ & 2011 & $\begin{array}{c}\text { Multi-touch tables and the relationship } \\
\text { with collaborative classroom } \\
\text { pedagogies: A synthetic review. }\end{array}$ & 1 & & & \\
\hline $\begin{array}{l}\text { Plowman, L., Stevenson, } \\
\text { O., Mcpake, J., } \\
\text { Stephen, C., \& Adey, C. }\end{array}$ & 2011 & $\begin{array}{l}\text { Parents, pre-schoolers and learning with } \\
\text { technology at home: Some implications } \\
\text { for policy. }\end{array}$ & 1 & 1 & & \\
\hline $\begin{array}{l}\text { Cockburn, A., Ahlström, } \\
\text { D., \& Gutwin, C. }\end{array}$ & 2012 & $\begin{array}{l}\text { Understanding performance in touch } \\
\text { selections: Tap, drag and radial pointing } \\
\text { drag with finger, stylus and mouse. }\end{array}$ & 1 & & & \\
\hline $\begin{array}{c}\text { Henderson, S., \& Yeow, } \\
\text { J. }\end{array}$ & 2012 & $\begin{array}{l}\text { IPad in education: A case study of iPad } \\
\text { adoption and use in a primary school. }\end{array}$ & 1 & 1 & & \\
\hline $\begin{array}{c}\text { Hutchison, A., } \\
\text { Beschorner, B., \& } \\
\text { Schmidt-crawford, D. }\end{array}$ & 2012 & $\begin{array}{c}\text { Exploring the use of iPad for Literacy } \\
\text { Learning. }\end{array}$ & 1 & 1 & & 1 \\
\hline $\begin{array}{c}\text { McClanahan, B., } \\
\text { Williams, K., Kennedy, E., } \\
\text { \& Tate, S. }\end{array}$ & 2012 & $\begin{array}{l}\text { A Breakthrough for Josh: How Use of an } \\
\text { iPad Facilitated Reading Improvement. }\end{array}$ & 1 & 1 & & 1 \\
\hline Molnar, G. & 2012 & $\begin{array}{c}\text { New learning spaces? M-learning's, in } \\
\text { particular the iPad's potentials in } \\
\text { education. }\end{array}$ & 1 & & & \\
\hline $\begin{array}{l}\text { Sandvik, M., Smørdal, } \\
\text { O., \& Østerud, S. }\end{array}$ & 2012 & $\begin{array}{l}\text { Exploring iPads in practitioners' } \\
\text { repertoires for language learning and } \\
\text { literacy practices in kindergarten. }\end{array}$ & 1 & 1 & & 1 \\
\hline $\begin{array}{l}\text { Soprunov, S., } \\
\text { Yakovleva, E., \& Leibo, I. }\end{array}$ & 2012 & Educational microcosms on iPad. & 1 & & & \\
\hline Wong, L. & 2012 & $\begin{array}{c}\text { A learner-centric view of mobile } \\
\text { seamless learning. }\end{array}$ & 1 & 1 & & 1 \\
\hline $\begin{array}{l}\text { Beschorner, B., \& } \\
\text { Hutchison, A. }\end{array}$ & 2013 & $\begin{array}{c}\text { iPads as a literacy teaching tool in early } \\
\text { childhood. }\end{array}$ & 1 & 1 & & 1 \\
\hline Cowie, B., \& Williams, J. & 2013 & Special Issue : iPads. & 1 & & & \\
\hline $\begin{array}{c}\text { Coyne, J., Potter, J., \& } \\
\text { Hollas, T. }\end{array}$ & 2013 & $\begin{array}{c}\text { Teacher-Friendly Technology } \\
\text { Applications for the Twenty-First Century } \\
\text { Learner }\end{array}$ & 1 & & & \\
\hline $\begin{array}{l}\text { Dhir, A., Gahwaji, N. M., } \\
\text { \& Nyman, G. }\end{array}$ & 2013 & $\begin{array}{l}\text { The role of the iPad in the hands of the } \\
\text { learner. }\end{array}$ & 1 & & & \\
\hline Falloon, G. & 2013 & $\begin{array}{c}\text { Young students using iPads: App design } \\
\text { and content influences on their learning } \\
\text { pathways. }\end{array}$ & 1 & 1 & & 1 \\
\hline Falloon, G. & 2013 & $\begin{array}{c}\text { Creating content: Building literacy skills } \\
\text { in year } 1 \text { students using open format } \\
\text { apps. }\end{array}$ & 1 & 1 & & 1 \\
\hline Fleer, $M$. & 2013 & $\begin{array}{l}\text { Digital positioning for inclusive practice } \\
\text { in early childhood: The cultural } \\
\text { practices surrounding digital tablets in } \\
\text { family homes. }\end{array}$ & 1 & 1 & & 1 \\
\hline $\begin{array}{l}\text { Hatherly, A., \& } \\
\text { Chapman, B. }\end{array}$ & 2013 & $\begin{array}{l}\text { Fostering motivation for literacy in early } \\
\text { childhood education using iPads. }\end{array}$ & 1 & 1 & & 1 \\
\hline Hunter, J., \& Daly, N. & 2013 & $\begin{array}{c}\text { iPads in teacher education: integrating } \\
\text { a range of language learning } \\
\text { knowledges through a technological } \\
\text { medium. }\end{array}$ & 1 & 1 & & \\
\hline
\end{tabular}




\begin{tabular}{|c|c|c|c|c|c|c|}
\hline Author(s) & Year & Title & Var_1 & Var_2 & Var_3 & Var_4 \\
\hline $\begin{array}{l}\text { Khoo, E., Bennett, T., \& } \\
\text { Macmillan, N. }\end{array}$ & 2013 & $\begin{array}{l}\text { Early childhood education teachers' } \\
\text { iPad-supported practices in young } \\
\text { children's learning and exploration. }\end{array}$ & 1 & 1 & & 1 \\
\hline Kucirkova, N. & 2013 & $\begin{array}{l}\text { Children's interactions with iPad books: } \\
\text { Research chapters still to be written. }\end{array}$ & 1 & 1 & & 1 \\
\hline $\begin{array}{c}\text { Kucirkova, N., Messer, } \\
\text { D., Sheehy, K., \& Flewitt, } \\
\text { R. }\end{array}$ & 2013 & $\begin{array}{c}\text { Sharing personalised stories on iPads: a } \\
\text { close look at one parent-child } \\
\text { interaction. }\end{array}$ & 1 & 1 & & 1 \\
\hline $\begin{array}{l}\text { Miller, B. T., Krockover, } \\
\text { G. H., \& Doughty, T. }\end{array}$ & 2013 & $\begin{array}{l}\text { Using iPads to teach inquiry science to } \\
\text { students with a moderate to severe } \\
\text { intellectual disability: A pilot study. }\end{array}$ & 1 & 1 & & 1 \\
\hline $\begin{array}{l}\text { Northrop, L., Killeen, E., } \\
\text { \& Ng, U. S. I. }\end{array}$ & 2013 & $\begin{array}{l}\text { A Framework for using iPads to build } \\
\text { early literacy skills. }\end{array}$ & 1 & 1 & & \\
\hline Ovens, A. & 2013 & $\begin{array}{l}\text { Sustaining high quality pedagogy in the } \\
\text { changing technological landscape. }\end{array}$ & 1 & & & \\
\hline Pellerin, $M$. & 2013 & $\begin{array}{c}\text { E-inclusion in Early French Immersion } \\
\text { Classrooms: Using Digital Technologies } \\
\text { to Support Inclusive Practices That Meet } \\
\text { the Needs of All Learners }\end{array}$ & 1 & 1 & & 1 \\
\hline $\begin{array}{l}\text { Simpson, A., Walsh, M., } \\
\text { \& Rowsell, J. }\end{array}$ & 2013 & $\begin{array}{l}\text { The digital reading path : researching } \\
\text { modes Literacy. }\end{array}$ & 1 & & & \\
\hline $\begin{array}{l}\text { Snell, S., \& Snell-Siddle, } \\
\text { C. }\end{array}$ & 2013 & $\begin{array}{l}\text { Mobile learning: The effects of gender } \\
\text { and age on perceptions of the use of } \\
\text { mobile tools. }\end{array}$ & 1 & 1 & & 1 \\
\hline $\begin{array}{l}\text { Spencer, K. M., Coutts, } \\
\text { T., Fagan, T., \& King, A. }\end{array}$ & 2013 & $\begin{array}{l}\text { Connections, diversity, coherence: } \\
\text { Three vignettes exploring learning with } \\
\text { iPads in primary schools. }\end{array}$ & 1 & 1 & & 1 \\
\hline $\begin{array}{l}\text { Tootell, H., Plumb, M., } \\
\text { Hadfield, C., \& Dawson, } \\
\text { L. }\end{array}$ & 2013 & $\begin{array}{l}\text { Gestural Interface Technology in early } \\
\text { childhood education: A framework for } \\
\text { fully-engaged communication. }\end{array}$ & 1 & & & \\
\hline $\begin{array}{l}\text { Williamson-Leadley, S., } \\
\text { \& Ingram, N. }\end{array}$ & 2013 & $\begin{array}{l}\text { Show and tell: Using iPads for } \\
\text { assessment in mathematics. }\end{array}$ & 1 & 1 & & \\
\hline Wright, N. & 2013 & $\begin{array}{l}\text { CoWpads: Sharing iPads in a range of } \\
\text { secondary school classrooms. }\end{array}$ & 1 & & & \\
\hline $\begin{array}{l}\text { Zack, E., Gerhardstein, } \\
\text { P., Meltzoff, A. N., \& } \\
\text { Barr, R. } \\
\end{array}$ & 2013 & $\begin{array}{l}\text { 15-Month-Olds' Transfer of Learning } \\
\text { between Touch Screen and Real-World. }\end{array}$ & 1 & 1 & 1 & \\
\hline $\begin{array}{l}\text { Blackwell, C. K., } \\
\text { Lauricella, A. R., \& } \\
\text { Wartella, E. }\end{array}$ & 2014 & $\begin{array}{l}\text { Factors influencing digital technology } \\
\text { use in early childhood education. }\end{array}$ & 1 & 1 & & \\
\hline Chou, Mei-Ju & 2014 & $\begin{array}{l}\text { How are our prince and princess } \\
\text { satisfying with IPad learning. }\end{array}$ & 1 & 1 & 1 & \\
\hline Ciampa, K. & 2014 & $\begin{array}{l}\text { Learning in a mobile age: an } \\
\text { investigation of student motivation. }\end{array}$ & 1 & 1 & & \\
\hline $\begin{array}{l}\text { Crescenzi, L., Jewitt, C., } \\
\text { \& Price, S. }\end{array}$ & 2014 & $\begin{array}{c}\text { The role of touch in preschool children ' } \\
\text { s learning using iPad versus paper } \\
\text { interaction }\end{array}$ & 1 & 1 & & 1 \\
\hline Falloon, G. & 2014 & $\begin{array}{c}\text { What's going on behind the screens? } \\
\text { Researching young students' learning } \\
\text { pathways using iPads }\end{array}$ & 1 & 1 & & 1 \\
\hline Falloon, G., \& Khoo, E. & 2014 & $\begin{array}{c}\text { Exploring young students' talk in iPad- } \\
\text { supported collaborative learning } \\
\text { environments. }\end{array}$ & 1 & 1 & & 1 \\
\hline Kucirkova, N. & 2014 & $\begin{array}{l}\text { iPads in early education: separating } \\
\text { assumptions and evidence. }\end{array}$ & 1 & 1 & & \\
\hline $\begin{array}{l}\text { Kucirkova, N., Messer, } \\
\text { D., Critten, V., \& } \\
\text { Harwood, J. }\end{array}$ & 2014 & $\begin{array}{l}\text { Story-making on the iPad when children } \\
\text { have complex needs: Two case studies. }\end{array}$ & 1 & 1 & & 1 \\
\hline
\end{tabular}




\begin{tabular}{|c|c|c|c|c|c|c|}
\hline Author(s) & Year & Title & Var_1 & Var_2 & Var_3 & Var_4 \\
\hline $\begin{array}{l}\text { Kucirkova, N., Messer, } \\
\text { D., Sheehy, K., \& } \\
\text { Fernández, C. }\end{array}$ & 2014 & $\begin{array}{l}\text { Children's engagement with } \\
\text { educational iPad apps: Insights from a } \\
\text { Spanish classroom. }\end{array}$ & 1 & 1 & & 1 \\
\hline $\begin{array}{l}\text { Milman, N. B., Carlson- } \\
\text { Bancroft, A., \& Boogart, } \\
\text { A. Vanden. }\end{array}$ & 2014 & $\begin{array}{c}\text { Examining Differentiation and Utilization } \\
\text { of iPads Across Content Areas in an } \\
\text { Independent, PreK-4th Grade } \\
\text { Elementary School. }\end{array}$ & 1 & 1 & & 1 \\
\hline Neumann, M. M. & 2014 & $\begin{array}{c}\begin{array}{c}\text { An examination of touch screen tablets } \\
\text { and emergent literacy in Australian pre- } \\
\text { school children }\end{array} \\
\end{array}$ & 1 & 1 & & 1 \\
\hline $\begin{array}{l}\text { Neumann, M. M., \& } \\
\text { Neumann, D. L. }\end{array}$ & 2014 & $\begin{array}{c}\text { Touch Screen Tablets and Emergent } \\
\text { Literacy. }\end{array}$ & 1 & 1 & & 1 \\
\hline $\begin{array}{l}\text { Zhao, J., Soukoreff, R. } \\
\text { W., Ren, X., \& } \\
\text { Balakrishnan, R. }\end{array}$ & 2014 & $\begin{array}{l}\text { A model of scrolling on touch-sensitive } \\
\text { displays. }\end{array}$ & 1 & & & \\
\hline $\begin{array}{l}\text { Allen, M. L., Hartley, C., } \\
\text { \& Cain, K. }\end{array}$ & 2015 & $\begin{array}{c}\text { Do iPads promote symbolic } \\
\text { understanding and word learning in } \\
\text { children with autism? }\end{array}$ & 1 & 1 & & 1 \\
\hline Bird, J., \& Edwards, S. & 2015 & $\begin{array}{l}\text { Children learning to use technologies } \\
\text { through play: A Digital Play Framework. }\end{array}$ & 1 & 1 & 1 & 1 \\
\hline $\begin{array}{l}\text { Bus, A. G., Takacs, Z. K., } \\
\quad \& \text { Kegel, C. A. T. }\end{array}$ & 2015 & $\begin{array}{l}\text { Affordances and limitations of } \\
\text { electronic storybooks for young } \\
\text { children's emergent literacy. }\end{array}$ & 1 & 1 & & 1 \\
\hline ChanLin, L.-J. & 2015 & $\begin{array}{l}\text { Tablet Reading Service for College } \\
\text { Students. }\end{array}$ & 1 & 1 & & 1 \\
\hline $\begin{array}{l}\text { Chien, M. E., Jheng, C. } \\
\text { M., Lin, N. M., Tang, H. } \\
\text { H., Taele, P., Tseng, W. } \\
\text { S., \& Chen, M. Y. }\end{array}$ & 2015 & $\begin{array}{l}\text { iCAN: A tablet-based pedagogical } \\
\text { system for improving communication } \\
\text { skills of children with autism. }\end{array}$ & 1 & 1 & & 1 \\
\hline $\begin{array}{l}\text { Connell, S. L., Lauricella, } \\
\text { A. R., \& Wartella, E. }\end{array}$ & 2015 & $\begin{array}{l}\text { Parental Co-Use of Media Technology } \\
\text { with their Young Children in the USA. }\end{array}$ & 1 & 1 & & \\
\hline Cristia, A., \& Seidl, A. & 2015 & $\begin{array}{l}\text { Parental reports on touch screen use in } \\
\text { early childhood. }\end{array}$ & 1 & 1 & & \\
\hline Falloon, G. & 2015 & $\begin{array}{l}\text { What's the difference? Learning } \\
\text { collaboratively using iPads in } \\
\text { conventional classrooms. }\end{array}$ & 1 & 1 & & 1 \\
\hline $\begin{array}{l}\text { Flewitt, R., Messer, D., \& } \\
\text { Kucirkova, N. }\end{array}$ & 2015 & $\begin{array}{l}\text { New directions for early literacy in a } \\
\text { digital age: The iPad. }\end{array}$ & 1 & 1 & & 1 \\
\hline $\begin{array}{l}\text { Hiniker, A., Sobel, K., } \\
\text { Hong, S. R., Suh, H., Irish, } \\
\text { I., Kim, D., \& Kientz, J. A. }\end{array}$ & 2015 & $\begin{array}{c}\text { Touchscreen Prompts for Preschoolers: } \\
\text { Designing Developmentally Appropriate } \\
\text { Techniques for Teaching Young Children } \\
\text { to Perform Gestures. }\end{array}$ & 1 & 1 & 1 & 1 \\
\hline $\begin{array}{l}\text { Hirsh-Pasek, K., Zosh, J. } \\
\text { M., Golinkoff, R. M., } \\
\text { Gray, J. H., Robb, M. B., } \\
\text { \& Kaufman, J. }\end{array}$ & 2015 & $\begin{array}{l}\text { Putting Education in "Educational" } \\
\text { Apps: Lessons From the Science of } \\
\text { Learning. }\end{array}$ & 1 & & & \\
\hline $\begin{array}{l}\text { Hourcade, J. P., } \\
\text { Mascher, S. L., WU, D., \& } \\
\text { Pantoja, L. }\end{array}$ & 2015 & $\begin{array}{l}\text { Look, My Baby Is Using an iPad! An } \\
\text { Analysis of YouTube Videos of Infants } \\
\text { and Toddlers Using Tablets. }\end{array}$ & 1 & 1 & 1 & \\
\hline $\begin{array}{l}\text { Kabali, H. K., Irigoyen, } \\
\text { M. M., Nunez-davis, R., } \\
\text { Budacki, J. G., \& } \\
\text { Mohanty, S. H. }\end{array}$ & 2015 & $\begin{array}{l}\text { Exposure and Use of Mobile Media } \\
\text { Devices by Young Children. }\end{array}$ & 1 & 1 & 1 & \\
\hline $\begin{array}{l}\text { Khoo, E., Khoo, E., } \\
\text { Merry, R., \& Bennett, T. }\end{array}$ & 2015 & $\begin{array}{c}\text { "I want to say ..." Privileging young } \\
\text { children ' s voices in iPad-supported } \\
\text { assessment for learning. }\end{array}$ & 1 & 1 & & 1 \\
\hline $\begin{array}{l}\text { Kucirkova, N., Sheehy, } \\
\text { K., \& Messer, D. }\end{array}$ & 2015 & $\begin{array}{l}\text { A Vygotskian perspective on parent- } \\
\text { child talk during iPad story sharing. }\end{array}$ & 1 & 1 & & 1 \\
\hline $\begin{array}{l}\text { Laidlaw, L., \& Mara, J. } \\
\text { O. }\end{array}$ & 2015 & $\begin{array}{l}\text { Rethinking Difference in the iWorld: } \\
\text { Possibilities, Challenges and } \\
\text { 'Unexpected Consequences' of Digital } \\
\text { Tools in Literacy Education. }\end{array}$ & 1 & 1 & & \\
\hline
\end{tabular}




\begin{tabular}{|c|c|c|c|c|c|c|}
\hline Author(s) & Year & Title & Var_1 & Var_2 & Var_3 & Var_4 \\
\hline $\begin{array}{l}\text { Moser, A., Zimmermann, } \\
\text { L., Dickerson, K., Grenell, } \\
\text { A., Barr, R., \& } \\
\text { Gerhardstein, P. }\end{array}$ & 2015 & $\begin{array}{l}\text { They can interact, but can they learn? } \\
\text { Toddlers ' transfer learning from } \\
\text { touchscreens and television }\end{array}$ & 1 & 1 & 1 & \\
\hline $\begin{array}{l}\text { Nacher, V., Jaen, J., } \\
\text { Navarro, E., Catala, A., } \\
\text { \& González, P. }\end{array}$ & 2015 & $\begin{array}{l}\text { Multi-touch gestures for pre- } \\
\text { kindergarten children. }\end{array}$ & 1 & & & \\
\hline $\begin{array}{l}\text { Nee, N., Walker, C., \& } \\
\text { Gleaves, A. }\end{array}$ & 2015 & $\begin{array}{l}\text { An exploration of students ' lived } \\
\text { experiences of using smartphones in } \\
\text { diverse learning contexts using a } \\
\text { hermeneutic phenomenological } \\
\text { approach. }\end{array}$ & 1 & & & \\
\hline Neumann, M. M. & 2015 & $\begin{array}{c}\text { Young children and screen time: } \\
\text { Creating a mindful approach to digital } \\
\text { technology }\end{array}$ & 1 & 1 & & \\
\hline $\begin{array}{l}\text { Noorhidawati, A., } \\
\text { Ghalebandi, S. G., \& } \\
\text { Hajar, R. S. }\end{array}$ & 2015 & $\begin{array}{l}\text { How Do Young Children Engage with } \\
\text { Mobile Apps? Cognitive, Psychomotor, } \\
\text { and Affective Perspective }\end{array}$ & 1 & 1 & & 1 \\
\hline $\begin{array}{c}\text { Percival, J., \& Claydon, } \\
\text { T. }\end{array}$ & 2015 & $\begin{array}{c}\text { A Study of Student and Instructor } \\
\text { Perceptions of Tablet PCs in Higher } \\
\text { Education Contexts. }\end{array}$ & 1 & & & \\
\hline $\begin{array}{l}\text { Price, S., Jewitt, C., \& } \\
\text { Crescenzi, L. }\end{array}$ & 2015 & $\begin{array}{c}\text { The role of iPads in pre-school children ' } \\
\text { s mark making development. }\end{array}$ & 1 & 1 & 1 & 1 \\
\hline $\begin{array}{l}\text { Pruet, P., Ang, C. S., } \\
\text { Farzin, D., \& Chaiwut, N. }\end{array}$ & 2015 & $\begin{array}{c}\text { Exploring the Internet of 'Educational } \\
\text { Things' (IOET) in rural underprivileged } \\
\text { areas. }\end{array}$ & 1 & & & \\
\hline $\begin{array}{l}\text { Radesky, J. S., } \\
\text { Schumacher, J., \& } \\
\text { Zuckerman, B. }\end{array}$ & 2015 & $\begin{array}{l}\text { Mobile and Interactive Media Use by } \\
\text { Young Children: The Good, the Bad, } \\
\text { and the Unknown. }\end{array}$ & 1 & 1 & & \\
\hline Strasburguer, V. & 2015 & $\begin{array}{c}\text { Should babies be watching and using } \\
\text { screens? The answer is surprisingly } \\
\text { complicated. }\end{array}$ & 1 & & & \\
\hline $\begin{array}{l}\text { Toohey, K., Dagenais, } \\
\text { D., Fodor, A., Hof, L., } \\
\text { Nuñez, O., Singh, A., \& } \\
\text { Schule, L. }\end{array}$ & 2015 & $\begin{array}{l}\text { "That Sounds So Cooool": } \\
\text { Entanglements of Children, Digital Tools, } \\
\text { and Literacy Practices }\end{array}$ & 1 & 1 & & 1 \\
\hline $\begin{array}{l}\text { Vatavu, R., Cramariuc, } \\
\text { G., \& Schipor, D. M. }\end{array}$ & 2015 & $\begin{array}{c}\text { Touch interaction for children aged } 3 \text { to } \\
6 \text { years: Experimental findings and } \\
\text { relationship to motor skills. }\end{array}$ & 1 & 1 & & 1 \\
\hline Wartella, E. & 2015 & $\begin{array}{l}\text { Educational apps: what we do and do } \\
\text { not know. }\end{array}$ & 1 & & & \\
\hline $\begin{array}{l}\text { Westlund, J.K., Dickens, } \\
\text { L., Jeong, S., Harris, P., } \\
\text { DeSteno, D., \&Breazeal, } \\
\text { C. }\end{array}$ & 2015 & $\begin{array}{l}\text { A comparison of Children Learning New } \\
\text { Words from Robots, Tablets, \& people }\end{array}$ & 1 & 1 & & 1 \\
\hline Wohlwend, K. E. & 2015 & $\begin{array}{c}\text { One Screen, Many Fingers: Young } \\
\text { Children's Collaborative Literacy Play } \\
\text { With Digital Puppetry Apps and } \\
\text { Touchscreen Technologies. }\end{array}$ & 1 & 1 & & 1 \\
\hline Wong, S. S.-H. & 2015 & $\begin{array}{c}\text { Mobile Digital Devices and } \\
\text { Preschoolers' Home Multiliteracy } \\
\text { Practices. }\end{array}$ & 1 & 1 & 1 & 1 \\
\hline $\begin{array}{c}\text { Wronska, N., Garcia- } \\
\text { zapirain, B., \& Mendez- } \\
\text { zorrilla, A. }\end{array}$ & 2015 & $\begin{array}{c}\text { An iPad-Based Tool for Improving the } \\
\text { Skills of Children with Attention Deficit } \\
\text { Disorder. }\end{array}$ & 1 & 1 & & \\
\hline $\begin{array}{l}\text { Aladé, F., Lauricella, A. } \\
\text { R., Beaudoin-ryan, L., \& } \\
\text { Wartella, E. }\end{array}$ & 2016 & $\begin{array}{l}\text { Measuring with Murray: Touchscreen } \\
\text { technology and preschoolers ' STEM } \\
\text { learning. }\end{array}$ & 1 & 1 & 1 & 1 \\
\hline $\begin{array}{l}\text { Allen, M. L., Hartley, C., } \\
\text { \& Cain, K. }\end{array}$ & 2016 & $\begin{array}{c}\text { iPads and the use of "apps" by children } \\
\text { with autism spectrum disorder: Do they } \\
\text { promote learning? }\end{array}$ & 1 & 1 & & \\
\hline $\begin{array}{l}\text { Arnott, L., Grogan, D., \& } \\
\text { Duncan, P. }\end{array}$ & 2016 & $\begin{array}{l}\text { Lessons from using iPads to understand } \\
\text { young children's creativity. }\end{array}$ & 1 & 1 & & 1 \\
\hline
\end{tabular}




\begin{tabular}{|c|c|c|c|c|c|c|}
\hline Author(s) & Year & Title & Var_1 & Var_2 & Var_3 & Var_4 \\
\hline $\begin{array}{l}\text { Bedford, R., Urabain, I. } \\
\text { R. S. De, Cheung, C. H. } \\
\text { M., Karmiloff-smith, A., } \\
\text { Smith, T. J., Barr, R., \& } \\
\text { Smith, T. J. }\end{array}$ & 2016 & $\begin{array}{c}\text { Toddlers ' Fine Motor Milestone } \\
\text { Achievement Is Associated with Early } \\
\text { Touchscreen Scrolling. }\end{array}$ & 1 & 1 & 1 & \\
\hline Clarke, L., \& Abbott, L. & 2016 & $\begin{array}{c}\text { Young pupils', their teacher's and } \\
\text { classroom assistants' experiences of } \\
\text { iPads in a Northern Ireland school: "Four } \\
\text { and five years old, who would have } \\
\text { thought they could do that?" }\end{array}$ & 1 & 1 & 1 & 1 \\
\hline $\begin{array}{l}\text { Diago Nebot, P. D., } \\
\text { Ortega Pons, M., Puig } \\
\text { Espinosa, L., \& Ferrando } \\
\text { Palomares, I. }\end{array}$ & 2016 & $\begin{array}{c}\text { Diseño e implementación de tareas de } \\
\text { modelización con iPadß's: un enfoque } \\
\text { dual. }\end{array}$ & 1 & & & \\
\hline $\begin{array}{l}\text { Ditzler, C., Hong, E., \& } \\
\text { Strudler, N. }\end{array}$ & 2016 & $\begin{array}{c}\text { How Tablets Are Utilized in the } \\
\text { Classroom Technology evaluation View } \\
\text { project }\end{array}$ & 1 & & & \\
\hline $\begin{array}{c}\text { Dunn, J., Gray, C., } \\
\text { Moffett, P., \& Mitchell, } \\
\text { D. }\end{array}$ & 2016 & $\begin{array}{l}\text { 'It's more funner than doing work': } \\
\text { Children's perspectives on using tablet } \\
\text { computers in the early years of school. }\end{array}$ & 1 & 1 & & \\
\hline Eisen, S., \& Lillard, A. S. & 2016 & $\begin{array}{l}\text { Just google it: Young children's } \\
\text { preferences for touchscreens versus } \\
\text { books in hypothetical learning tasks. }\end{array}$ & 1 & 1 & 1 & 1 \\
\hline $\begin{array}{l}\text { Furtado Rosseto, A.D, } \\
\text { Dutra, A. }\end{array}$ & 2016 & $\begin{array}{l}\text { The analysis of the use of mobile } \\
\text { technology in 6-8 years old children's } \\
\text { literacy process. }\end{array}$ & 1 & 1 & & 1 \\
\hline $\begin{array}{l}\text { Gerth, S., Klassert, A., } \\
\text { Dolk, T., Fliesser, M., } \\
\text { Fischer, M. H., } \\
\text { Nottbusch, G., \& } \\
\text { Festman, J. }\end{array}$ & 2016 & $\begin{array}{c}\text { Is handwriting performance affected by } \\
\text { the writing surface? Comparing } \\
\text { preschoolers', second graders', and } \\
\text { adults' writing performance on a tablet } \\
\text { vs. paper. } \\
\end{array}$ & 1 & & & \\
\hline $\begin{array}{l}\text { Gómez-Domingo, M., \& } \\
\text { Badia-Garganté, A. }\end{array}$ & 2016 & $\begin{array}{l}\text { Exploring the use of educational } \\
\text { technology in primary education: } \\
\text { Teachers ' perception of mobile } \\
\text { technology learning impacts and } \\
\text { applications ' use in the classroom. }\end{array}$ & 1 & 1 & & 1 \\
\hline $\begin{array}{l}\text { Haßler, B., Major, L., \& } \\
\text { Hennessy, S. }\end{array}$ & 2016 & $\begin{array}{l}\text { Tablet use in schools: A critical review of } \\
\text { the evidence for learning outcomes. }\end{array}$ & 1 & & & \\
\hline $\begin{array}{c}\text { Hubber, P. J., } \\
\text { Outhwaite, L. A., } \\
\text { Chigeda, A., McGrath, } \\
\text { S., Hodgen, J., \& } \\
\text { Pitchford, N. J. } \\
\end{array}$ & 2016 & $\begin{array}{c}\text { Should touch screen tablets be used to } \\
\text { improve educational outcomes in } \\
\text { primary school children in developing } \\
\text { countries? }\end{array}$ & 1 & 1 & & \\
\hline $\begin{array}{c}\text { Huber, B., Tarasuik, J., } \\
\text { Antoniou, M. N., Garrett, } \\
\text { C., Bowe, S. J., } \\
\text { Kaufman, J., Team, B. }\end{array}$ & 2016 & $\begin{array}{l}\text { Young children 's transfer of learning } \\
\text { from a touchscreen device. }\end{array}$ & 1 & 1 & 1 & 1 \\
\hline $\begin{array}{l}\text { Khoo, E., Falloon, G., \& } \\
\text { Nguyen, N. H. }\end{array}$ & 2016 & $\begin{array}{l}\text { iPad-mediated talk in young children 's } \\
\text { learning and exploration of interests }\end{array}$ & 1 & 1 & & 1 \\
\hline $\begin{array}{l}\text { Kirkorian, H. L., Choi, K., } \\
\text { \& Pempek, T. A. }\end{array}$ & 2016 & $\begin{array}{c}\text { Toddlers ' Word Learning From } \\
\text { Contingent and Noncontingent Video } \\
\text { on Touch Screens }\end{array}$ & 1 & 1 & 1 & 1 \\
\hline $\begin{array}{c}\text { Kwok, K., Ghrear, S., Li, } \\
\text { V., Haddock, T., } \\
\text { Coleman, P., Birch, S. A. } \\
\text { J., \& Ford, R. }\end{array}$ & 2016 & $\begin{array}{c}\text { Children Can Learn New Facts Equally } \\
\text { Well From Interactive Media Versus } \\
\text { Face to Face Instruction. }\end{array}$ & 1 & 1 & 1 & \\
\hline $\begin{array}{l}\text { Lovato, S. B., \& } \\
\text { Waxman, S. R. }\end{array}$ & 2016 & $\begin{array}{l}\text { Young children learning from touch } \\
\text { screens: Taking a wider view. }\end{array}$ & 1 & 1 & 1 & 1 \\
\hline $\begin{array}{l}\text { Marsh, J., Plowman, L., } \\
\text { Yamada-Rice, D., } \\
\text { Bishop, J., \& Scott, F. }\end{array}$ & 2016 & Digital play: a new classification. & 1 & 1 & 1 & \\
\hline
\end{tabular}




\begin{tabular}{|c|c|c|c|c|c|c|}
\hline Author(s) & Year & Title & Var_1 & Var_2 & Var_3 & Var_4 \\
\hline McLean, K. J. & 2016 & $\begin{array}{l}\text { The implementation of bring your own } \\
\text { device (BYOD) in primary [elementary] } \\
\text { schools. }\end{array}$ & 1 & & & \\
\hline Neumann, M. M. & 2016 & $\begin{array}{l}\text { Young children's use of touch screen } \\
\text { tablets for writing and reading at home: } \\
\text { Relationships with emergent literacy. }\end{array}$ & 1 & 1 & 1 & 1 \\
\hline Palaiologou, I. & 2016 & $\begin{array}{c}\text { Children under five and digital } \\
\text { technologies: implications for early } \\
\text { years pedagogy. }\end{array}$ & 1 & 1 & & \\
\hline $\begin{array}{l}\text { Patchan, M. M., \& } \\
\text { Puranik, C. S. }\end{array}$ & 2016 & $\begin{array}{l}\text { Using tablet computers to teach } \\
\text { preschool children to write letters: } \\
\text { Exploring the impact of extrinsic and } \\
\text { intrinsic feedback. }\end{array}$ & 1 & 1 & 1 & \\
\hline $\begin{array}{l}\text { Pitchford, N. J., \& } \\
\text { Outhwaite, L. A. }\end{array}$ & 2016 & $\begin{array}{c}\text { Can touch screen tablets be used to } \\
\text { assess cognitive and motor skills in early } \\
\text { years primary school children? A cross- } \\
\text { cultural study. }\end{array}$ & 1 & & & \\
\hline $\begin{array}{c}\text { Rattanasone, N. X., } \\
\text { Davies, B., Schembri, T., } \\
\text { Andronos, F., \& Bradley, } \\
\text { E. D. }\end{array}$ & 2016 & $\begin{array}{l}\text { The iPad as a Research Tool for the } \\
\text { Understanding of English Plurals by } \\
\text { English, Chinese, and Other L1 } \\
\text { Speaking 3- and 4-Year-Olds. }\end{array}$ & 1 & 1 & 1 & \\
\hline $\begin{array}{l}\text { Schroeder, E. L., \& } \\
\quad \text { Kirkorian, H. L. }\end{array}$ & 2016 & $\begin{array}{c}\text { When seeing is better than doing: } \\
\text { Preschoolers' transfer of STEM skills using } \\
\text { touchscreen games. }\end{array}$ & 1 & 1 & & 1 \\
\hline $\begin{array}{l}\text { Semmelmann, K., Nordt, } \\
\text { M., Sommer, K., Röhnke, } \\
\text { R., Mount, L., Prüfer, H., } \\
\text {... Koldewyn, K. }\end{array}$ & 2016 & $\begin{array}{l}\text { U Can Touch This: How Tablets Can Be } \\
\text { Used to Study Cognitive Development }\end{array}$ & 1 & & & \\
\hline $\begin{array}{l}\text { Sharkins, K. A., Newton, } \\
\text { A. B., Albaiz, N. E. A., \& } \\
\text { Ernest, J. M. }\end{array}$ & 2016 & $\begin{array}{c}\text { Preschool Children's Exposure to } \\
\text { Media, Technology, and Screen Time: } \\
\text { Perspectives of Caregivers from Three } \\
\text { Early Childcare Settings. } \\
\end{array}$ & 1 & & & \\
\hline $\begin{array}{c}\text { Sheehan, K. J., \& Uttal, } \\
\text { D. H. }\end{array}$ & 2016 & $\begin{array}{l}\text { Children's Learning from Touch Screens: } \\
\text { A Dual Representation Perspective. }\end{array}$ & 1 & 1 & & 1 \\
\hline $\begin{array}{l}\text { Suárez-guerrero, C.., } \\
\text { Lloret-catalá, C., \& } \\
\text { Mengual-andrés, S. }\end{array}$ & 2016 & $\begin{array}{c}\text { Teachers ' Perceptions of the Digital } \\
\text { Transformation of the Classroom } \\
\text { through the Use of Tablets: A Study in } \\
\text { Spain. }\end{array}$ & 1 & 1 & & \\
\hline $\begin{array}{c}\text { Terras, M. M., \& Ramsay, } \\
\text { J. }\end{array}$ & 2016 & $\begin{array}{l}\text { Family Digital Literacy Practices and } \\
\text { Children's Mobile Phone Use. }\end{array}$ & 1 & 1 & 1 & \\
\hline Tilton, $\mathrm{S}$. & 2016 & $\begin{array}{c}\text { Tablet as researcher's kit: An analysis of } \\
\text { how social scientists use tablet } \\
\text { computers in the field. }\end{array}$ & 1 & & & \\
\hline $\begin{array}{l}\text { Wang, F., Xie, H., Wang, } \\
\text { Y., Hao, Y., \& An, J. }\end{array}$ & 2016 & $\begin{array}{l}\text { Using Touchscreen Tablets to Help } \\
\text { Young Children Learn to Tell Time }\end{array}$ & 1 & 1 & & 1 \\
\hline $\begin{array}{l}\text { Wollscheid, S., Sjaastad, } \\
\text { J., \& Tømte, C. }\end{array}$ & 2016 & $\begin{array}{c}\text { The impact of digital devices vs. Pen } \\
\text { (cil) and paper on primary school } \\
\text { students ' writing skills e A research } \\
\text { review. }\end{array}$ & 1 & & & \\
\hline $\begin{array}{l}\text { Wood, E., Petkovski, M., } \\
\text { Pasquale, D. De, } \\
\text { Gottardo, A., Evans, M. } \\
\text { A., Savage, R. S., \& } \\
\text { Wood, E. }\end{array}$ & 2016 & $\begin{array}{c}\text { Parent Scaffolding of Young Children } \\
\text { When Engaged with Mobile } \\
\text { Technology. }\end{array}$ & 1 & 1 & 1 & \\
\hline Zack, E., \& Barr, R. & 2016 & $\begin{array}{l}\text { The Role of Interactional Quality in } \\
\text { Learning from Touch Screens during } \\
\text { Infancy: Context Matters. }\end{array}$ & 1 & 1 & & \\
\hline $\begin{array}{l}\text { Ziemer, C. J., \& Snyder, } \\
\text { M. }\end{array}$ & 2016 & $\begin{array}{l}\text { A Picture You Can Handle: Infants Treat } \\
\text { Touch-Screen Images More Like } \\
\text { Photographs than Objects. }\end{array}$ & 1 & 1 & 1 & \\
\hline $\begin{array}{l}\text { Briz-ponce, L., Pereira, } \\
\text { A., Carvalho, L., Juanes- } \\
\text { m, J. A., \& Jos, F. }\end{array}$ & 2017 & $\begin{array}{l}\text { Learning with mobile technologies - } \\
\text { Students ' behavior }\end{array}$ & 1 & & & \\
\hline
\end{tabular}




\begin{tabular}{|c|c|c|c|c|c|c|}
\hline Author(s) & Year & Title & Var_1 & Var_2 & Var_3 & Var_4 \\
\hline $\begin{array}{l}\text { Cheung, C. H. M., } \\
\text { Bedford, R., Urabain, I. } \\
\text { R. S. De, Karmiloff-smith, } \\
\text { A., \& Smith, T. J. }\end{array}$ & 2017 & $\begin{array}{l}\text { Daily touchscreen use in infants and } \\
\text { toddlers is associated with reduced } \\
\text { sleep and delayed sleep onset. }\end{array}$ & 1 & 1 & 1 & \\
\hline Chmiliar, L. & 2017 & $\begin{array}{l}\text { Improving Learning Outcomes: The iPad } \\
\text { and Preschool Children with Disabilities. }\end{array}$ & 1 & 1 & 1 & 1 \\
\hline $\begin{array}{l}\text { Coelho, L. A., \& } \\
\text { Gonzalez, C. L. }\end{array}$ & 2017 & $\begin{array}{l}\text { The visual and haptic contributions to } \\
\text { hand perception. }\end{array}$ & 1 & & & \\
\hline $\begin{array}{c}\text { Coyne, S. M., Radesky, } \\
\text { J., Collier, K. M., Gentile, } \\
\text { D. A., Linder, J. R., } \\
\text { Nathanson, A. I.., ... } \\
\text { Rogers, J. }\end{array}$ & 2017 & Parenting and Digital Media. & 1 & 1 & 1 & \\
\hline $\begin{array}{l}\text { Crompton, H., Burke, D., } \\
\text { \& Gregory, K. H. }\end{array}$ & 2017 & $\begin{array}{l}\text { The use of mobile learning in PK-12 } \\
\text { education: A systematic review. }\end{array}$ & 1 & & & \\
\hline $\begin{array}{c}\text { Druga, S., Williams, R., } \\
\text { Breazeal, C., \& Resnick, } \\
\text { M. }\end{array}$ & 2017 & $\begin{array}{l}\text { "Hey Google is it OK if I eat you?" Initial } \\
\text { Explorations in Child-Agent Interaction. }\end{array}$ & 1 & 1 & 1 & \\
\hline $\begin{array}{c}\text { Duijzer, C. A. C. G., } \\
\text { Shayan, S., Bakker, A., \& } \\
\text { Schaaf, M. F. Van Der. }\end{array}$ & 2017 & $\begin{array}{l}\text { Touchscreen Tablets: Coordinating } \\
\text { Action and Perception for } \\
\text { Mathematical Cognition }\end{array}$ & 1 & & & \\
\hline Falloon, G. & 2017 & $\begin{array}{l}\text { Exploring Student Thinking, Problem } \\
\text { Solving, and Collaboration in iPad- } \\
\text { Supported Learning Environments. }\end{array}$ & 1 & 1 & & \\
\hline Fokides, E. & 2017 & $\begin{array}{c}\text { Tablets, Very Young Primary School } \\
\text { Students, and Basic Programming } \\
\text { Concepts. }\end{array}$ & 1 & 1 & & 1 \\
\hline $\begin{array}{c}\text { Geer, R., White, B., } \\
\text { Zeegers, Y., Au, W., \& } \\
\text { Barnes, A. } \\
\end{array}$ & 2017 & $\begin{array}{l}\text { Emerging pedagogies for the use of } \\
\text { iPads in schools. }\end{array}$ & 1 & 1 & & \\
\hline $\begin{array}{l}\text { Ihmeideh, F., \& } \\
\text { Alkhawaldeh, M. }\end{array}$ & 2017 & $\begin{array}{c}\text { Teachers' and parents' perceptions of } \\
\text { the role of technology and digital } \\
\text { media in developing child culture in the } \\
\text { early years. }\end{array}$ & 1 & 1 & & \\
\hline $\begin{array}{l}\text { Jahnke, I., Bergström, P., } \\
\text { Mårell-Olsson, E., Häll, L., } \\
\text { \& Kumar, S. }\end{array}$ & 2017 & $\begin{array}{l}\text { Digital Didactical Designs as research } \\
\text { framework: iPad integration in Nordic } \\
\text { schools. }\end{array}$ & 1 & 1 & & \\
\hline $\begin{array}{l}\text { Jameie-oskooei, S., Al- } \\
\text { khudairi, R., \& Lobo, R. }\end{array}$ & 2017 & $\begin{array}{l}\text { iPads in clinical rotations: a student } \\
\text { perspective. }\end{array}$ & 1 & & & \\
\hline Karavanidou, E. & 2017 & $\begin{array}{c}\text { Is handwriting relevant in the digital } \\
\text { era? }\end{array}$ & 1 & & & \\
\hline $\begin{array}{l}\text { Kory Westlund, J. M., } \\
\text { Jeong, S., Park, H. W., } \\
\text { Ronfard, S., Adhikari, A., } \\
\text { Harris, P. L.. ... Breazeal, } \\
\text { C. L. }\end{array}$ & 2017 & $\begin{array}{l}\text { Flat vs. Expressive Storytelling: Young } \\
\text { Children's Learning and Retention of a } \\
\text { Social Robot's Narrative. }\end{array}$ & 1 & & & \\
\hline $\begin{array}{l}\text { Kostyrka-Allchorne, K., } \\
\text { Cooper, N. R., \& } \\
\text { Simpson, A. }\end{array}$ & 2017 & $\begin{array}{l}\text { Touchscreen generation: children's } \\
\text { current media use, parental supervision } \\
\text { methods and attitudes towards } \\
\text { contemporary media. }\end{array}$ & 1 & 1 & 1 & \\
\hline $\begin{array}{l}\text { Kucirkova, N., \& } \\
\text { Zuckerman, B. }\end{array}$ & 2017 & $\begin{array}{l}\text { A guiding framework for considering } \\
\text { touchscreens in children under two. }\end{array}$ & 1 & 1 & 1 & \\
\hline $\begin{array}{l}\text { Kumpulainen, K., \& } \\
\text { Gillen, J. }\end{array}$ & 2017 & $\begin{array}{c}\text { Young Children's Digital Literacy } \\
\text { Practices in the Home: A review of the } \\
\text { Literature. }\end{array}$ & 1 & 1 & 1 & \\
\hline $\begin{array}{l}\text { Li, H., Hsueh, Y., Wang, } \\
\text { F., Bai, X., Liu, T., \& Zhou, } \\
\text { L. }\end{array}$ & 2017 & $\begin{array}{c}\text { Do Young Chinese Children Gain } \\
\text { Anthropomorphism after Exposure to } \\
\text { Personified Touch-Screen and Board } \\
\text { Games? }\end{array}$ & 1 & 1 & 1 & \\
\hline $\begin{array}{l}\text { Maich, K., Sider, S., Hall, } \\
\text { C., \& Henning, M. }\end{array}$ & 2017 & $\begin{array}{c}\text { Making the iPad an accessible tool for } \\
\text { students with exceptionalities: Assessing } \\
\text { and teaching its essential prerequisite } \\
\text { skills. }\end{array}$ & 1 & & & \\
\hline
\end{tabular}




\begin{tabular}{|c|c|c|c|c|c|c|}
\hline Author(s) & Year & Title & Var_1 & Var_2 & Var_3 & Var_4 \\
\hline $\begin{array}{l}\text { Mang, C., Brown, N., \& } \\
\text { Piper, L. }\end{array}$ & 2017 & $\begin{array}{l}\text { "Old school" meets "new school": Using } \\
\text { books and tablets to improve } \\
\text { information literacy and promote } \\
\text { integrative learning among business } \\
\text { students. }\end{array}$ & 1 & & & \\
\hline $\begin{array}{l}\text { Mclay, K., Renshaw, P., } \\
\text { \& Phillips, L. G. }\end{array}$ & 2017 & iBecome: iPads as a tool for self-making & 1 & & & \\
\hline $\begin{array}{l}\text { Mehairy, A. Al, Adnan, } \\
\text { S., Juma, S., \& Allam, H. }\end{array}$ & 2017 & $\begin{array}{c}\text { The influence of tablets on children's } \\
\text { learning. }\end{array}$ & 1 & 1 & 1 & \\
\hline $\begin{array}{l}\text { Miller, J. L., Paciga, K. } \\
\text { A., Danby, S., Beaudoin- } \\
\text { Ryan, L., \& Kaldor, T. }\end{array}$ & 2017 & $\begin{array}{l}\text { Looking beyond swiping and tapping: } \\
\text { Review of design and methodologies } \\
\text { for researching young children's use of } \\
\text { digital technologies. }\end{array}$ & 1 & 1 & & \\
\hline $\begin{array}{l}\text { Montrieux, H., Raes, A., } \\
\text { \& Schellens, T. }\end{array}$ & 2017 & $\begin{array}{l}\text { 'The best app is the teacher' } \\
\text { Introducing classroom scripts in } \\
\text { technology-enhanced education. }\end{array}$ & 1 & & & \\
\hline $\begin{array}{c}\text { Neumann, M. M., } \\
\text { Finger, G., \& Neumann, } \\
\text { D. L. }\end{array}$ & 2017 & $\begin{array}{c}\text { A Conceptual Framework for Emergent } \\
\text { Digital Literacy. }\end{array}$ & 1 & 1 & 1 & 1 \\
\hline Nishizaki, M. & 2017 & $\begin{array}{c}\text { Visualizing positive and negative } \\
\text { affordances in infancy using mobile } \\
\text { augmented reality. }\end{array}$ & 1 & & & \\
\hline $\begin{array}{l}\text { Piotrowski, J. T., \& } \\
\quad \text { Krcmar, M. }\end{array}$ & 2017 & $\begin{array}{l}\text { Reading with hotspots: Young children's } \\
\text { responses to touchscreen stories. }\end{array}$ & 1 & 1 & 1 & \\
\hline $\begin{array}{l}\text { Ramírez-Montoya, M. S., } \\
\text { \& García-Peñalvo, F. J. }\end{array}$ & 2017 & $\begin{array}{l}\text { Presentación. La integración efectiva } \\
\text { del dispositivo móvil en la educación y } \\
\text { en el aprendizaje. }\end{array}$ & 1 & & & \\
\hline $\begin{array}{l}\text { Reed, J., Hirsh-Pasek, K., } \\
\text { \& Golinkoff, R. M. }\end{array}$ & 2017 & $\begin{array}{l}\text { Learning on hold: Cell phones sidetrack } \\
\text { parent-child interactions. }\end{array}$ & 1 & & & \\
\hline $\begin{array}{l}\text { Russo-Johnson, C., } \\
\text { Troseth, G., Duncan, C., } \\
\text { \& Mesghina, A. }\end{array}$ & 2017 & $\begin{array}{c}\text { All tapped out: Touchscreen } \\
\text { interactivity and young children's word } \\
\text { learning. }\end{array}$ & 1 & 1 & 1 & 1 \\
\hline Souleles, N. & 2017 & $\begin{array}{l}\text { iPad versus traditional tools in art and } \\
\text { design: A complementary association. }\end{array}$ & 1 & & & \\
\hline $\begin{array}{l}\text { Stacy, S. T., Cartwright, } \\
\text { M., Arwood, Z., } \\
\text { Canfield, J. P., Kloos, H., } \\
\text { \& Hubber, P. J. }\end{array}$ & 2017 & $\begin{array}{c}\text { Addressing the Math-Practice Gap in } \\
\text { Elementary School: Are Tablets a } \\
\text { Feasible Tool for Informal Math } \\
\text { Practice? }\end{array}$ & 1 & 1 & & 1 \\
\hline $\begin{array}{l}\text { Strouse, G. A., \& } \\
\text { Ganea, P. A. }\end{array}$ & 2017 & $\begin{array}{c}\text { Parent-Toddler Behavior and Language } \\
\text { Differ When Reading Electronic and } \\
\text { Print Picture Books. }\end{array}$ & 1 & & & \\
\hline $\begin{array}{l}\text { Tarasuik, J., Demaria, A., } \\
\text { \& Kaufman, J. }\end{array}$ & 2017 & $\begin{array}{c}\text { Transfer of Problem Solving Skills from } \\
\text { Touchscreen to 3D Model by 3- to 6- } \\
\text { Year-Olds. }\end{array}$ & 1 & 1 & 1 & 1 \\
\hline $\begin{array}{l}\text { Villani, D., Morganti, L., } \\
\text { Carissoli, C., Gatti, E., } \\
\text { Bonanomi, A., } \\
\text { Cacciamani, S., \& } \\
\text { Confalonieri, E. } \\
\end{array}$ & 2017 & $\begin{array}{c}\text { Students 'acceptance of tablet PCs in } \\
\text { Italian high schools: Profiles and } \\
\text { differences. }\end{array}$ & 1 & & & \\
\hline $\begin{array}{l}\text { Völkel, S., Wuttke, M., \& } \\
\text { Ohler, P. }\end{array}$ & 2017 & Preschool Learning with a Fingertip & 1 & 1 & 1 & 1 \\
\hline $\begin{array}{l}\text { Yadav, S., \& } \\
\text { Chakraborty, P. }\end{array}$ & 2017 & $\begin{array}{c}\text { Using smartphones with suitable apps } \\
\text { can be safe and even useful if they are } \\
\text { not misused or overused. }\end{array}$ & 1 & 1 & & \\
\hline $\begin{array}{l}\text { Zimmermann, L., Moser, } \\
\text { A., Lee, H., } \\
\text { Gerhardstein, P., \& Barr, } \\
\text { R. }\end{array}$ & 2017 & $\begin{array}{l}\text { The Ghost in the Touchscreen: Social } \\
\text { Scaffolds Promote Learning by Toddlers. }\end{array}$ & 1 & 1 & 1 & 1 \\
\hline $\begin{array}{c}\text { Antrilli, N. K., \& Wang, S. } \\
\text { H. }\end{array}$ & 2018 & $\begin{array}{c}\text { Toddlers on touchscreens: immediate } \\
\text { effects of gaming and physical activity } \\
\text { on cognitive flexibility of } 2.5 \text {-year-olds in } \\
\text { the US }\end{array}$ & 1 & 1 & 1 & \\
\hline
\end{tabular}




\begin{tabular}{|c|c|c|c|c|c|c|}
\hline Author(s) & Year & Title & Var_1 & Var_2 & Var_3 & Var_4 \\
\hline $\begin{array}{l}\text { Brito, R., Dias, P., \& } \\
\quad \text { Oliveira, G. }\end{array}$ & 2018 & $\begin{array}{l}\text { Young children, digital media and smart } \\
\text { toys: Hw perceptions shape adoption } \\
\text { and domestication. }\end{array}$ & 1 & 1 & 1 & \\
\hline $\begin{array}{l}\text { Chen, Y., Mayall, H. J., } \\
\text { York, C. S., \& Smith, T. J. }\end{array}$ & 2018 & $\begin{array}{l}\text { Parental perception and English } \\
\text { Learners ' mobile-assisted language } \\
\text { learning: An ethnographic case study } \\
\text { from a technology-based funds of } \\
\text { knowledge approach. }\end{array}$ & 1 & & & \\
\hline $\begin{array}{c}\text { Cheng, Y., Yen, K., } \\
\text { Chen, Y., Chen, S., \& } \\
\text { Hiniker, A. }\end{array}$ & 2018 & $\begin{array}{l}\text { Why Doesn ' † It Work? Voice-Driven } \\
\text { Interfaces and Young Children 's } \\
\text { Communication Repair Strategies. }\end{array}$ & 1 & & & \\
\hline $\begin{array}{l}\text { Cordero, K., Nussbaum, } \\
\text { M., Ibaseta, V., Otaíza, } \\
\text { M.J., \& Chiuminatto P. }\end{array}$ & 2018 & $\begin{array}{c}\text { Read, write, touch: Co-construction and } \\
\text { multiliteracies in a third-grade digital } \\
\text { writing exercise }\end{array}$ & 1 & 1 & & 1 \\
\hline Donahoo, D. & 2018 & $\begin{array}{c}\begin{array}{c}\text { Unpacking screentime: What should } \\
\text { digital technology and early childhood } \\
\text { look like? }\end{array} \\
\end{array}$ & 1 & 1 & & \\
\hline Dunn, J., \& Sweeney, T. & 2018 & $\begin{array}{l}\text { Writing and iPads in the early years: } \\
\text { Perspectives from within the classroom. }\end{array}$ & 1 & 1 & 1 & \\
\hline Dunphy, K. F., \& Hens, T. & 2018 & $\begin{array}{l}\text { Outcome-Focused dance movement } \\
\text { therapy assessment enhanced by iPad } \\
\text { app MARA. }\end{array}$ & 1 & & & \\
\hline Fleer, $\mathrm{M}$. & 2018 & $\begin{array}{l}\text { Digital animation: New conditions for } \\
\text { children's development in play-based } \\
\text { setting }\end{array}$ & 1 & 1 & 1 & 1 \\
\hline $\begin{array}{l}\text { Fridberg, M., Thulin, S., \& } \\
\text { Redfors, A. }\end{array}$ & 2018 & $\begin{array}{c}\text { Preschool children's Collaborative } \\
\text { Science Learning Scaffolded by Tablets. }\end{array}$ & 1 & 1 & 1 & 1 \\
\hline $\begin{array}{c}\text { Gillen, J., \& Kucirkova, } \\
\text { N. }\end{array}$ & 2018 & $\begin{array}{l}\text { Percolating spaces: Creative ways of } \\
\text { using digital technologies to connect } \\
\text { young children's school and home lives. }\end{array}$ & 1 & 1 & 1 & 1 \\
\hline $\begin{array}{l}\text { Hatzigianni, M., \& } \\
\text { Kalaitzidis, I. }\end{array}$ & 2018 & $\begin{array}{l}\text { Early childhood educators' attitudes } \\
\text { and beliefs around the use of } \\
\text { touchscreen technologies by children } \\
\text { under three years of age. }\end{array}$ & 1 & 1 & & \\
\hline $\begin{array}{c}\text { Hatzigianni, M., } \\
\text { Gregoriadis, A., } \\
\text { Karagiorgou, I., \& } \\
\text { Chatzigeorgiadou, S. }\end{array}$ & 2018 & $\begin{array}{l}\text { Using tablets in free play: The } \\
\text { implementation of the digital play } \\
\text { framework in Greece. }\end{array}$ & 1 & 1 & 1 & 1 \\
\hline $\begin{array}{l}\text { Hermes, J, Rakoczy, H. } \\
\text { \& Behne, T. }\end{array}$ & 2018 & $\begin{array}{c}\text { Making sense of conflicting information: } \\
\text { A touchscreen paradigm to measure } \\
\text { young children's selective trust }\end{array}$ & 1 & 1 & 1 & \\
\hline Herodotou, C. & 2018 & $\begin{array}{c}\text { Young children and tablets: A } \\
\text { systematic review of effects on learning } \\
\text { and development. } \\
\end{array}$ & 1 & 1 & 1 & 1 \\
\hline $\begin{array}{l}\text { Holloway, D., Haddon, } \\
\text { L., Green, L., \& } \\
\text { Stevenson, K. }\end{array}$ & 2018 & $\begin{array}{c}\text { The parent-child-app learning } \\
\text { assemblage: Scaffolding early } \\
\text { childhood learning through app use in } \\
\text { the family home }\end{array}$ & 1 & 1 & 1 & \\
\hline $\begin{array}{l}\text { Huber, B., Highfield, K., } \\
\text { \& Kaufman, J. }\end{array}$ & 2018 & $\begin{array}{l}\text { Detailing the digital experience: Parent } \\
\text { report of children's media use in the } \\
\text { home learning environment. }\end{array}$ & 1 & 1 & 1 & \\
\hline $\begin{array}{l}\text { Huber, B., Yeates, M., } \\
\text { Meyer, D., } \\
\text { Fleckhammer, L., \& } \\
\text { Kaufman, J. }\end{array}$ & 2018 & $\begin{array}{l}\text { The effects of screen media content on } \\
\text { young children's executive functioning. }\end{array}$ & 1 & 1 & 1 & 1 \\
\hline $\begin{array}{l}\text { Johnston, K., Highfield, } \\
\text { K., \& Hadley, F. }\end{array}$ & 2018 & $\begin{array}{l}\text { Supporting young children as digital } \\
\text { citizens: The importance of shared } \\
\text { understandings of technology to } \\
\text { support integration in play-based } \\
\text { learning. }\end{array}$ & 1 & 1 & 1 & \\
\hline $\begin{array}{c}\text { Kanero, J., Geçkin, V., } \\
\text { Oranç, C., Mamus, E., } \\
\text { Küntay, A.C., \& Göksun, } \\
\text { T. }\end{array}$ & 2018 & $\begin{array}{c}\text { Social Robots for Early Language } \\
\text { Learning: Current Evidence and Future } \\
\text { Directions }\end{array}$ & 1 & 1 & & 1 \\
\hline
\end{tabular}




\begin{tabular}{|c|c|c|c|c|c|c|}
\hline Author(s) & Year & Title & Var_1 & Var_2 & Var_3 & Var_4 \\
\hline Kirkorian, H. L. & 2018 & $\begin{array}{l}\text { When and How Do Interactive Digital } \\
\text { Media Help Children Connect What } \\
\text { They See On and Off the Screen? }\end{array}$ & 1 & 1 & & 1 \\
\hline $\begin{array}{c}\text { Kirova, A. \& Jamison, } \\
\text { N.M }\end{array}$ & 2018 & $\begin{array}{l}\text { Peer scaffolding techniques and } \\
\text { approaches in preschool children's } \\
\text { multiliteracy practices with iPads }\end{array}$ & 1 & 1 & 1 & 1 \\
\hline $\begin{array}{l}\text { Kucirkova, N., \& Falloon, } \\
\text { G. }\end{array}$ & 2018 & $\begin{array}{c}\text { iPad apps and visual methodologies: } \\
\text { Empirical and ethical issues in achieving } \\
\text { authentic data. }\end{array}$ & 1 & 1 & 1 & \\
\hline $\begin{array}{l}\text { Kucirkova, N., Littleton, } \\
\text { K., \& Kyparissiadis, A. }\end{array}$ & 2018 & $\begin{array}{c}\text { The influence of children 's gender and } \\
\text { age on children's use of digital media } \\
\text { at home. }\end{array}$ & 1 & 1 & & \\
\hline $\begin{array}{l}\text { Marsh, J., Plowman, L., } \\
\text { Yamada-rice, D., } \\
\text { Bishop, J., Lahmar, J., \& } \\
\text { Scott, F. }\end{array}$ & 2018 & $\begin{array}{c}\text { Play and creativity in young children's } \\
\text { use of apps }\end{array}$ & 1 & 1 & 1 & 1 \\
\hline $\begin{array}{l}\text { Mckenzie, S., Spence, } \\
\text { A., \& Nicholas, M. }\end{array}$ & 2018 & $\begin{array}{c}\text { Going on Safari: The Design and } \\
\text { Development of an Early Years Literacy } \\
\text { iPad Application to Support Letter- } \\
\text { Sound Learning. }\end{array}$ & 1 & 1 & & \\
\hline $\begin{array}{l}\text { Moser A., Olsen S., } \\
\text { Rusnak, S.N., Barr, R. } \\
\text { Gerhardstein, P. }\end{array}$ & 2018 & $\begin{array}{c}\text { How self-generated labelling shapes } \\
\text { transfer of learning during early } \\
\text { childhood: The role of individual } \\
\text { differences }\end{array}$ & 1 & 1 & 1 & 1 \\
\hline Neumann, M. M. & 2018 & $\begin{array}{l}\text { Using tablets and apps to enhance } \\
\text { emergent literacy skills in young children }\end{array}$ & 1 & 1 & 1 & 1 \\
\hline $\begin{array}{c}\text { O'Byrne, W. I., Stone, R., } \\
\text { \& White, M. }\end{array}$ & 2018 & $\begin{array}{c}\text { Digital storytelling in early childhood: } \\
\text { Student illustrations shaping social } \\
\text { interactions. }\end{array}$ & 1 & & & 1 \\
\hline $\begin{array}{l}\text { Oliemat, E., Ihmeideh, } \\
\text { F., \& Alkhawaldeh, M. }\end{array}$ & 2018 & $\begin{array}{c}\text { The use of touch-screen tablets in early } \\
\text { childhood: Children 's knowledge, skills, } \\
\text { and attitudes towards tablet } \\
\text { technology. }\end{array}$ & 1 & 1 & 1 & \\
\hline $\begin{array}{c}\text { Otterborn, A., } \\
\text { Schönborn, K., \& Hultén, } \\
\text { M. }\end{array}$ & 2018 & $\begin{array}{c}\text { Surveying preschool teachers' use of } \\
\text { digital tablets: general and technology } \\
\text { education related findings. }\end{array}$ & 1 & 1 & & \\
\hline $\begin{array}{l}\text { Papadakis, S., } \\
\text { Kalogiannakis, M., \& } \\
\text { Zaranis, N. }\end{array}$ & 2018 & $\begin{array}{c}\text { The effectiveness of computer and } \\
\text { tablet assisted intervention in early } \\
\text { childhood students' understanding of } \\
\text { numbers. An empirical study conducted } \\
\text { in Greece }\end{array}$ & 1 & 1 & & \\
\hline $\begin{array}{l}\text { Peebles, A., Bonus, J. A., } \\
\text { \& Mares, M-L. }\end{array}$ & 2018 & $\begin{array}{l}\text { Questions+answers+agency: Interactive } \\
\text { touchscreens and children's learning } \\
\text { form a socio-emotional TV story }\end{array}$ & 1 & 1 & 1 & 1 \\
\hline Ralph, R. & 2018 & $\begin{array}{l}\text { Media and Technology in Preschool } \\
\text { Classrooms: Manifesting Prosocial } \\
\text { Sharing Behaviours When Using iPads. }\end{array}$ & 1 & 1 & & \\
\hline Samur, Y. & 2018 & $\begin{array}{c}\text { Kes Sesi: A mobile game designed to } \\
\text { improve kindergarteners' recognition of } \\
\text { letter sounds }\end{array}$ & 1 & 1 & 1 & 1 \\
\hline $\begin{array}{l}\text { Tirado-Morveta, R., } \\
\text { Aguaded-Gómez, J. I., } \\
\text { \& Hernando-Gómez, Á. }\end{array}$ & 2018 & $\begin{array}{l}\text { The socio-demographic divide in } \\
\text { Internet usage moderated by digital } \\
\text { literacy support. }\end{array}$ & 1 & & & \\
\hline $\begin{array}{l}\text { Trifunović, A., Čičević, } \\
\text { S., Lazarević, D., } \\
\text { Mitrović, S., \& Dragović, } \\
\text { M. }\end{array}$ & 2018 & $\begin{array}{l}\text { Comparing tablets (touchscreen } \\
\text { devices) and PCs in preschool children' } \\
\text { education: Testing spatial relationship } \\
\text { using geometric symbols on traffic signs }\end{array}$ & 1 & 1 & & 1 \\
\hline $\begin{array}{l}\text { Vatalaro, A., Culp, A. M. } \\
\text { D., Hahs-Vaughn, D. L., } \\
\text { \& Barnes, A. C. }\end{array}$ & 2018 & $\begin{array}{l}\text { A Quasi-Experiment Examining } \\
\text { Expressive and Receptive Vocabulary } \\
\text { Knowledge of Preschool Head Start } \\
\text { Children Using Mobile Media Apps. }\end{array}$ & 1 & 1 & 1 & 1 \\
\hline
\end{tabular}


Papers on Early Childhood and HD

\begin{tabular}{|c|c|c|c|c|c|c|}
\hline Author(s) & Year & Title & Var_1 & Var_2 & Var_3 & Var_4 \\
\hline $\begin{array}{l}\text { Walczak, S., \& Taylor, N. } \\
\text { G. }\end{array}$ & 2018 & $\begin{array}{c}\text { Geography learning in primary school: } \\
\text { Comparing face-to-face versus tablet- } \\
\text { based instruction methods }\end{array}$ & 1 & 1 & & \\
\hline $\begin{array}{l}\text { Xie, H., Peng, J., Qin, M., } \\
\text { Huang, X., Tian, F., \& } \\
\text { Zhou, Z. }\end{array}$ & 2018 & $\begin{array}{l}\text { Can Touchscreen Devices be Used to } \\
\text { Facilitate Young Children's Learning? A } \\
\text { Meta-Analysis of Touchscreen Learning } \\
\text { Effect. }\end{array}$ & 1 & 1 & & \\
\hline Yelland, N. J. & 2018 & $\begin{array}{c}\text { A pedagogy of multiliteracies: Young } \\
\text { children and multimodal learning with } \\
\text { tablets. }\end{array}$ & 1 & 1 & 1 & 1 \\
\hline Yuill, N., \& Martin, A. F. & 2018 & $\begin{array}{c}\text { Curling Up With a Good E-Book: } \\
\text { Mother-Child Shared Story Reading on } \\
\text { Screen or Paper Affects Embodied } \\
\text { Interaction and Warmth }\end{array}$ & 1 & & & \\
\hline $\begin{array}{l}\text { Zabatiero, J., Straker, L., } \\
\text { Mantilla, A., Edwards, S., } \\
\text { \& Danby, S. }\end{array}$ & 2018 & $\begin{array}{l}\text { Young children and digital technology: } \\
\text { Australian early childhood education } \\
\text { and care sector adults' perspectives }\end{array}$ & 1 & 1 & & \\
\hline
\end{tabular}





\section{SECTION C.}

Data Discussion. Implications 



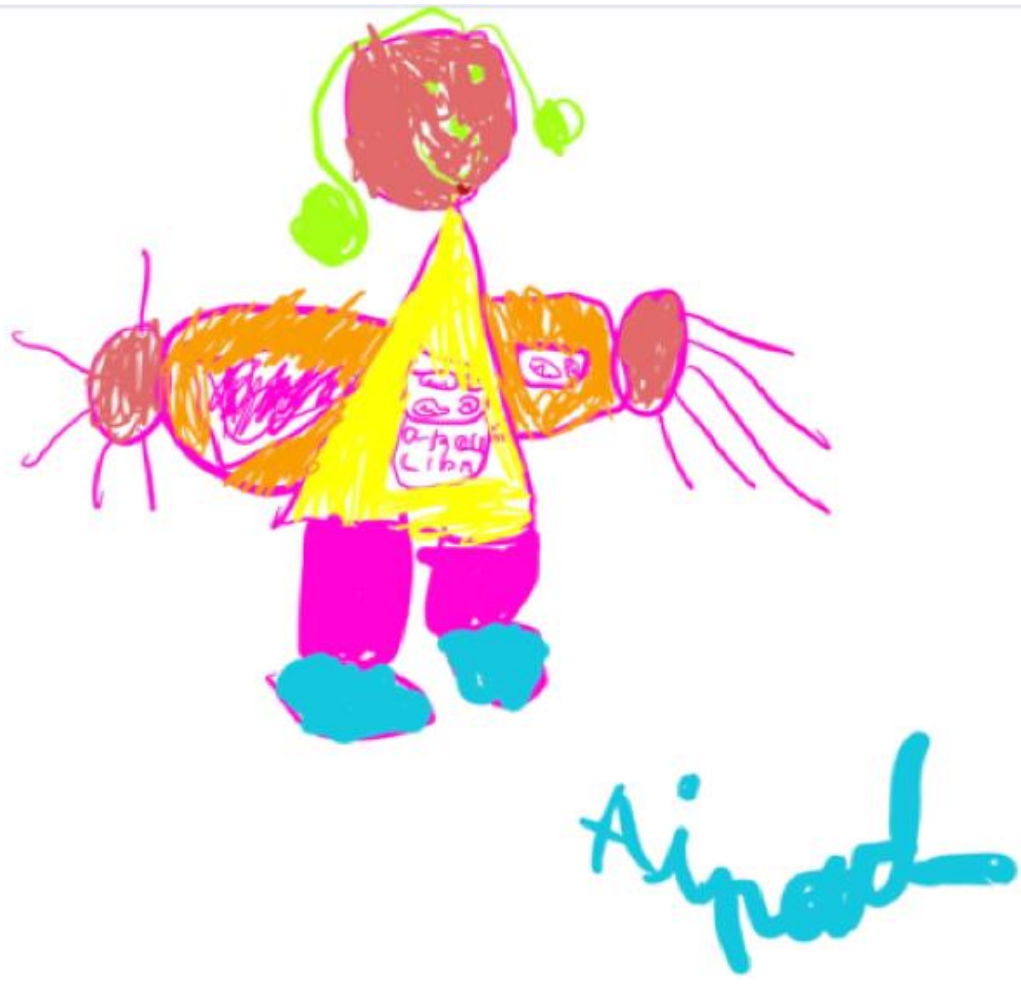

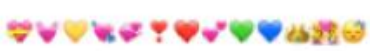

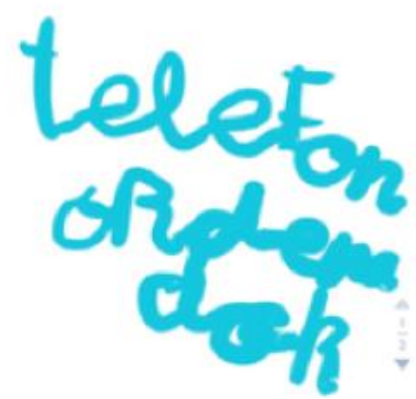

Early Learning \& Haptic Devices

Chapter 5 

"When babies listen, what they're doing is taking statistics on the language that they hear."

Patricia K. Kuhl 



\subsection{Introduction}

$$
\begin{aligned}
& \text { J. Couse and Dora W. Chen were the first ones in studying } \\
& \text { the viability of using 2008's android-based tablet computers } \\
& \text { with stylus-interface technology to implement ISTE } \\
& \text { technology standards of } 2007 \text { (focusing in creativity and } \\
& \text { innovation among them) for early education. Compared with }
\end{aligned}
$$
today's tablets, those were meant only to draw from a professional perspective never under a learning perspective, and they did not have any internet connection, neither Apps, touch interface, or interactive screen. The addition of the stylus-interface gave to the tablet potential as a learning tool. Their premise to conduct the study (Leslie \& Dora, 2010) was that drawing on a tablet was very similar to doing it on a paper, adding a new dimension to learning by allowing the kids to express their ideas in their classrooms.

Active learning in early childhood (children aged 0 to 8) comes by drawing and painting, precursors to formal writing. Before the advent of computer technology, children used traditional writing tools, such as crayons, paintbrushes, markers, paints, and pencils. When PC-computer showed up, children added to the above, computer mouse ${ }^{24}$ with its fixed movements, and configurated figures that prevented creativity. The new tablet offered something like hand expression freeing the movements on the screen. Children were able to create their own original work, similar to

\footnotetext{
${ }^{24}$ Computer Mouse: hand-held device used to control the cursor movement and select computing functions without keying (Whatls.com, 2018).
} 
hand drawing on a paper as explained in (Leslie \& Dora, 2010). This study explored several levels of tablet use: level $\mathbf{1}$ Explore/Experiment, level $\mathbf{2}$ Investigate, and level $\mathbf{3}$ Create; as well as the affective response when used. Comparing the results on tablet drawing with computer drawing, one of the advantages was that the new device allowed to create the same draws and personal writings as they were done on a paper, including personal handwriting. The user could create dashes, dots, blobs, and spots with the length desired by using his fingers. Those drawings were unable to be created with a mouse.

(Leslie \& Dora, 2010) conclusions were further than just demonstrating the viability of the stylusinterface. They also found that the tablet was very effective in keeping children motivated and engaged. Their interest and persistence seemed to have no signs of frustration. All the children, even the ones that did not choose to draw as a way of expression, showed their creativity. Children demonstrated high interest in learning how to use it, as it was a new language tool, etc.

It was in 2011 that iPad (with internet access, Apps, touch interface, interactive screen, and other functions) showed up into the learning scenario in the research: "iPads $n$ Kids" conducted by (E. Khoo, Merry, et al., 2015) in New Zealand, which highlighted its positive influence in learning.

Interaction with computer technology, either to learn or to improve productivity, has evolved since the first computer arrived to our households around 1990. PC computers and laptops used computer mouse and hard keyboard; Palm (PDA) (1996-2007) and first tablet computer (2008) used styluses. Since 2007, smartphones, and tablets in 2010, started to use the finger as input for any type of interaction. Since 2015, the interaction is produced with the fingertip, or the digital stylus that emulate writing with the finger over the screen, and Bluetooth keyboards.

Since 2012, haptic devices are present at home in a variety of scenarios, not excluding each other. In first scenario, the haptic device takes the role of babysitters to entertain children when parents want to have silent or relaxed moments. Secondly, it is used as a plain book with pdf content to read, or as a TV screen. Third, the device is used with educational Apps with the aim of learning. And in the fourth, the possibilities of the devices are not questioned, it is just another tech gadget around, which can be used with multiple purposes or no one. With the evolution of the devices toward a scenario for learning, the capacities of the device to help with the learning started to be questioned. (Spencer, Coutts, Fagan, \& King, 2013), and (J. L. Miller et al., 2017) have found some instances of not learning at all when using it. We find this hard to believe because just using the device, children learn basic gestures that can be applied in other contexts.

As we have discussed in Chapter 2, the Haptic generation is surrounded by haptic technologies that should be analyzed from different perspectives and evaluated to test if they promote effective learning. Human learning happens because social learning, imitation, and sensorimotor experience (Meltzoff et al., 2009) and children learn through social interaction with other people using social skills like imitation, shared attention, and empathic understanding.

In the observation conducted for the HG case study described in Chapter 4, we observed how children behave with tablets or with the smartphones without adult interaction. Children pretend the device is someone to be and play with because the device interacts with them. They use the device to role-play their parents in their jobs, they learn words as well as their pronunciation in 
the displayed language, they deduce complex meanings by watching authentic videos ${ }^{25}$. Also, they use the in-built features of the device like the magnifying glass to interact with maps, record their own songs, or videotape their play. Children use apps to draw and take notes with all the features the App offers while interacting: changing colors, shapes, typed text, handwriting text, eraser, navigate, etc.; and of course, they found apps to watch cartoons by themselves.

The interpretation of the results is simple: children are social interacting, imitating, and having sensorimotor experience. Consequently, according to (Meltzoff et al., 2009) they are learning. If the relationship with technology is very similar to personal relations because, when interacting, the kid receives answers and feedbacks, therefore, to understand the educational side of the device, the device should be analyzed from the Science of Learning point of view.

Science of learning has evolved as an interdisciplinary field that "works to provide knowledge to improve significantly people's abilities to become active learners who seek to understand complex subjects matter and are better prepared to transfer what they have learned to new problems and settings" (Bransford, Brown, \& Cocking, 1999).

New insights from many fields like linguistics, education, psychology, neuroscience, machine learning, sociology, and computer science interconnect research, practice, and policies with the study of the way students acquire knowledge, skills, and competences; that as (Meltzoff et al., 2009) points out learning varies as a combination of personal characteristics, interests, mindsets, and beliefs, converging in an scenario that may transform education.

Apart from those fields, science of learning also includes topics like language learning by machines or humans, early understanding of mathematics, navigation, robotics, and literacy, among other topics; with the aim to approach learning from different disciplines and fields. The macro setting includes the analysis of tools aimed to enhance learning by connecting it to the "learning hub" in the same line and with the same influence as teachers, schools, and curricula (Meltzoff et al., 2009). In our case, the tool to be included in this "learning hub" is the haptic device.

The dissertation focuses on members of the haptic generation or actual early childhood that, at the time of writing, were up to 8 years old. Children of those ages perform actions, responses, and learning in different ways. According to chronological age early childhood is subdivided in infant (0-18 months), toddler (18-36 months), preschool (3-5 years), kindergarten (5-6 years), first and second grade (6-8 years), (Paciga \& Donohue, 2017).

When talking about researching how haptic devices are used by early childhood as learning tools to enhance and optimize human learning, one must bear in mind firstly, the context where the interaction of the kid with technology and media is going to take place. And secondly, the variables that facilitate the learning experience: child involvement, the learning environment, and the adult interaction. The device using conditions are then informed by the people who are going to be present to support the interaction: adults or peers; the purpose of the interaction according to age: Communication; Leisure and entertainment; Creation and productivity;

\footnotetext{
${ }^{25}$ Authentic videos refer to those videos that have not been created for intentional learning.
} 
Information and learning; and the physical place where the interaction takes place: school, home, or other spaces.

The variables set as well as the device using conditions, described in the HG case study (Chapter 4), are going to be analyzed in this chapter to demonstrate the device feasibility and affordance to boost children creativity and learning, including the analysis of its technological capabilities that allow learning, how the device promotes early literacy learning, and the serendipity of acquiring English as a second language that early childhood could absorb while using the device. 


\subsection{Gestating a Scholar Brain}

Children are fascinated by parents, their parentese language ${ }^{26}$ (Corthals, 2011) and the things parents do. According to Apple Developer, iPhone users unlock their phone or make pickups 80 times a day on average in 2016 (Apple Developer, 2016). Nowadays, Pickups ${ }^{27}$ on a haptic device is the most common gesture that a parent does in front of a child no matter the age of the kid.

According to (Meltzoff, 1999) "infants are carefully watching our actions and committing them to memory. Babies naturally do as we do, not as we say. And what they see influences their behavior even after long intervals. Parents matter because babies are learning from us. Young children even infants, look to us for guidance."

From a neurological point of view by the end of their first year of life, a child's brain is about $70 \%$ of adult size. By five years, a child's brain is about $90 \%$ of adult size, and have most of the neurons that build the brain while accompanied by a tremendous amount of learning (ILABS, 2016). A child's brain is uniquely primed to learn from the experiences that they have every day. At this stage, the brain is like a rough draft, ready for any type of interactions and experiences that will help to develop and grow, particularly by playing, to continue shaping it into the specialized brain of an adult. Children are especially sensitive to experiences that help to build these connections that shape communication preverbal skills, language, and emergent literacy.

As an example, we have speaking. From 6 to 12 months babies are beginning to say their first words. As infants hear more and more language, their brains are beginning to connect and coordinate neurons while developing and shaping complex brain network areas where early experiences matter (ILABS, 2016). Parentese talk and adult caring immerse infants in the sound of the language, and as they begin to talk, parents encourage their learning by having growing complexity conversations (Kuhl, 2010).

In a little span of time, infants learn to talk, to walk, and to imitate their relatives and peers, through four sources of behavioral change: maturation changes in the sensory, motor, and cognitive system (Gesell \& Frances, 1949), trial and error (Skinner, 1963), independent invention and discovery (Piaget, 1976), social interaction and imitation (N. E. Miller \& Dollard, 1941).

\subsubsection{Social Interaction}

Face-to-face quality interactions make children trust others and gain confidence to explore their world and preparing them to be part of their community. This social readiness includes mental skills, like problem-solving and impulse control, social skills like awareness and relationshipbuilding (take turns, seek for help, and communicate emotions). Specific features of face-to-face

\footnotetext{
${ }^{26}$ Parentese: speech-language register adults switch to when talking to children.

${ }^{27}$ Pickups: the number of times one picks up the haptic device to interact with the device.
} 
interactions can be found in everyday situations that contribute to young children learning (Yang, Sidman, \& Bushnell, 2010):

- The special tone of the voice, called infant-directed speech, or "parentese" (RamirezEsparza, Garcia-Sierra, \& Kuhl, 2017);

- people's eye gaze, a form of non-linguistic communication that infants use as a signal for what a person is interested in or what they are talking about. Eyes provide the crucial clue about where someone is looking. This places them on a path toward understanding the thoughts and intentions of others;

- imitation: ability to learn behaviors by observing other people's actions and make connections about how the things work and the social norms that adults apply on objects; learning that others are "like them" (Meltzoff, 2007b);

- verbal and nonverbal back-and-forth interactions by providing labels for the objects in the interaction;

- scaffolding to help children process information supporting or adjusting the information to a more advanced behavior: pausing, pointing, inviting to participate; and

- the background of the caregiver: own education, prior experiences, values, culture, and his/her access to resources.

\section{2 .2 Imitation}

(Meltzoff \& Moore, 1977) showed the importance, power, and functional significance of imitation to preverbal children. He states that imitation is a tool that children use to learn more about the world and themselves. In the process, they also develop better awareness of other people that share their culture.

From their first day of life, children watch others and imitate their actions to learn about the physical world and their culture. Infant "imitate facial movements, vocalizations, body movements, and actions on objects" (Meltzoff, 2002). Learning by imitation increases and changes with age, and it is also determined by the social situation, and the purpose of the action.

As they grew older, they can remember actions for longer (deferred imitation), and use them to navigate through new situations (generalization). Deferred imitation is defined when it exists a delay between the action to imitate and the final imitation, as an example: one model demonstrates a behavior and when the child has an opportunity to imitate the action, not necessary in the same moment. Generalization is defined when a child transfers what he observes in one context, under a specific set of conditions, to a new context under different conditions (ILABS, 2014).

Imitation "provides a social-emotional connection between infants and people," as well as achieving milestones in cognitive development. Imitation helps children to learn about objects in their environment. Consequently, children learn a lot about themselves, other people, and the world simply by observing their surroundings. "Between one and one-and-a-half years of age, children learn 1 to 2 new behaviors a day through copying the actions of other people" (Gopnik et al., 2001). They remember actions after longer periods of time and can even infer another person's 
intentions. When they are three, children learn strategies and rules that other people use by spying actions that soon will be duplicated in other contexts like school or playgrounds.

\subsubsection{Starting to Think}

Babies and toddlers get easily distracted by anything that calls their attention. Their brains are immature for a long period of time, flexible, and designed by evolution to change, create, learn, and explore (Gopnik et al., 2001). They cannot intentionally focus on things in the same way that an adult does, but they take lots of information and details from given events at once. Children are uninhibited and explore freely what is around. They spend much of their time using their imagination to figure out different possibilities and test them. The pretend play helps them to understand the people around and how they behave (Gopnik et al., 2001).

Very young children play unconsciously by innate touching and trying. They explore cause and effect while experimenting on things, as an effective way to discover how things works. When they try and experiment, they are learning from their experience showing extraordinary learning abilities at this stage. This learning strategy has many advantages, but learning only takes place when at first, adults put work and care at their service. Being helpless dependent infants, they trust and believe in adult actions and experience. "The intelligence and flexibility of adults correlate with the immaturity of babies. The adult capacities for focus, planning and efficient action depend on the long learning that occurs in childhood" (Gopnik, 2009).

This unconscious way to process information, parallels the methods of scientific discovery. Cognitive science states that "the brain is a kind of computer designed by evolution and programmed by experience" (Gopnik \& Schulz, 2007). Knowledge and imagination come in hand of adults caring.

Those abilities, so intrinsic to what it means to be a human being, appear in their purest forms during early childhood (Gopnik, 2009).

\subsubsection{How Learning Happens in Early Years}

The Early Years Foundation Stage (EYFS) framework for 2017 highlights that "Children are born ready, able and eager to learn. They actively reach out to interact with other people, and in the world around them." (UK Government, 2017). Therefore, when a child (unique child) does a proper and active use of haptic devices (Enabling Environment) aimed to literacy learning and digital skills (positive Relationship) then, the child learns to be resilient, capable, confident, and self-assured resulting in learning and development (iScholar) as Fig. 20 summarizes. 


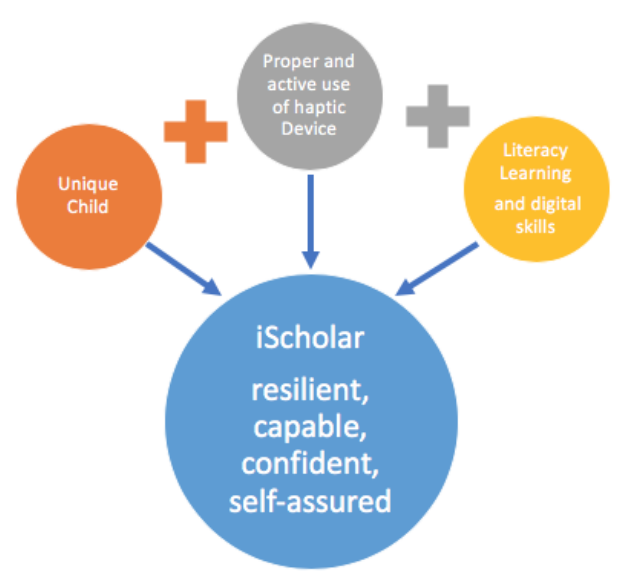

Fig. 20 EYFS 2017 framework adapted to haptic devices.

Children need to feel emotionally secure, and confident to exploit their powerful learning mechanisms during their development. Development mainly happen through the movement of their bodies; through conversations with adults and peers, and trough play. Playing and experimenting with materials, hands, and tools, they go from simple actions to more complex and coordinated movements, but also, they develop social, emotional, sensory, linguistic, and physical development.

If they exploit their learning mechanism, children feel curious about their world, and then they become competent and creative learners, and at the same time skillful communicators who connect with others through language, symbol-making, and play (UK Government, 2017).

Either in formal school learning or informal learning at home, according to EYFS, progress to learning goals is achieved when the areas of learning are covered during interactions, and when the child has essential attributes (UK Government, 2017).

The EYFS Framework establishes:

- Learning goals: Supports communication, develops relationships and attachments, provides opportunities for depth and breadth: widens horizons and provides, rich firsthand experiences, develops dispositions to learn, in tune with child development, Considers the entire planned learning experience.

- Areas of Learning: personal, social, and emotional development; communication, language, and literacy; problem solving, reasoning and numeracy; knowledge and understanding of the world; physical development, and creative development.

- Interactions: relationships and attachments, communication, curiosity about the world, play, creative thinking.

- Child essential attributes: dispositions to learn, a sense of belonging and wellbeing, perseverance through difficulty, collaboration, and cooperation.

For haptic generation children there is a new type of interaction: Haptic interaction with which early childhood is also able to achieve the learning goals described by the framework.

Haptic devices as tools for learning used appropriately to pursuit learning, cover the areas of learning already described towards the learning goals. Children have a high disposition to learn 
while playing with the device. When using the devices, they feel they belong to the same environment as the adults because adults are using the devices to for many actions; they are perseverant through difficulty when something does not happen at the first touch, they do it again, they collaborate and cooperate with peers, they teach each other, when they are in groups (Falloon \& Khoo, 2014) and HG Case study (Chapter 4).

As examples of how haptic interaction help to progress towards the early learning goals, we describe some experiences occurred during our research for HG Case Study:

- $\quad$ Support communication $\rightarrow$ video and audio calls, constructive talk between adult and kid while exploring either apps or media contents.

- Develops relationships and attachments $\rightarrow$ FaceTime with other members of the family and peers, Face to Face conversations about the contents to learn: songs, literacy contents, games, avatars, task to be done, exercises to be solved, etc.

- Provides opportunities for deep learning providing rich first-hand experiences $\rightarrow$ YouTube videos with authentic material, DIY videos, and aimed apps for children with scaffolded information that behaves as games, etc.

- Develops dispositions to learn $\rightarrow$ the device is very attractive, easy to carry, and they know it is useful for many things, they want to have it. With an appropriate use (avoiding social media), proper control of the device by adults, and using the device for learning, they increase the interest for learning and knowledge.

- $\quad$ In tune with child development $\rightarrow$ educative Apps are informed about proper age to use. Scaffolded learning through different levels inside the Apps, let children advance their own learning according to their development.

- Considers the entire planned learning experience $\rightarrow$ the haptic interaction per se is a complete learning experience that covers the all the areas at the same time, it makes children to be curious while enjoying, and they become skillful digital communicators.

\subsubsection{Earlier Haptic Interactions}

Mainly since 2012 in Spain, one of the first actions that newborns find themselves familiar with, and therefore, in the moment they are physically ready, they imitate and reproduce, is how an adult manipulates a haptic device to take pictures of them, send them to family members via WhatsApp, and upgrade the status in social media about the good news or advances in motor development (first smile, first grabbing of an object, first steps, first draws, and so on). That simple, but at the same time, complicated action is repeated in front of the newborns every other time.

The first gesture that the newborn understands as a sign of communication is touch. Touch in the sense of the sweet touch of their caregivers to tie social and emotional interactions, a way to say "I love you" (Meltzoff \& Kuhl, 2016), but also as an interaction from their caregivers with an inanimate device they hold in their hands (haptic device) provoking the same effect: tying social and emotional interactions, as a way to say "I'm touching part of my body". As (Meltzoff \& Kuhl, 2016) point out "Touch and a sense of one's own body are essential in infant development and mental health."

Infants, as soon as they can see, they start paying attention to human faces and imitating simple facial expressions (Meltzoff, 2002). For example, when there is device interaction with a haptic 
device, the adults express something in front of them. While watching, infants learn rapidly from the expression that, at the same time, is representing cultural cues, including habits, customs, and look for emotional guidance in uncertain situations, like it is to have a haptic device at hand being so young. If the adults interact, infants, when role-play are going to include a haptic device, or a touching gesture on any surface, or simply are going to desire the device because it is part of the adult behavior and social environment.

For a human being, the most important years for learning are early years. Then, if we induce those repeated actions and gestures in their surroundings (haptic interaction), the learning scenario will have a new component: the interactive screen, that we cannot underestimate.

As humans, children prefer to learn from actions performed by people they trust better than from inanimate devices, but this does not mean that they do not learn from inanimate devices (Meltzoff \& Kuhl, 2016). Experiments on prelinguistic infants (up to 6 month-old) have demonstrated they imitate from TV screens with 2D content and transfer the action into 3D real environments (Zack et al., 2009). Haptic devices are not the same than TV screens. As said in Chapter 1, they have a touch interface that allows smart communication between the user and the device. The device has gained interaction by offering answers and feedback as if they were performed by another human being, so the device performs smart actions that can help early childhood to code social or emotional constructs, the most important for an effective learning are capacity to play, to deal with mistakes and frustrations, to take positive risks, to look and listen carefully, and to have curiosity among others (Paciga \& Donohue, 2017).

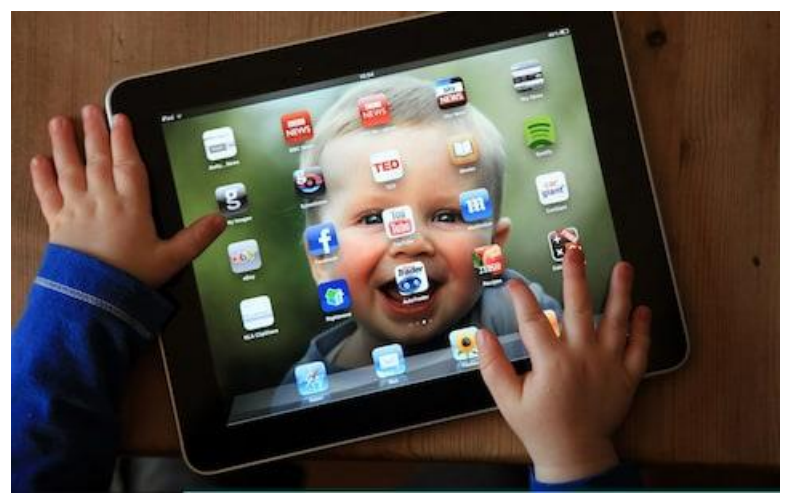

Fig. 21 Infant manipulating a tablet

Haptic interaction is the new early experience that shapes brain growth, promotes social, emotional, language, and cognitive development. Haptic generation children are exploring the world through touch interface technology mainly, and its relation with adults (Fig. 21). The relationship with haptic devices becomes stronger because they have everyday interactions, either by role-playing their caregivers or by individual guided exploration or observation. They are not just watching the screen; they are active participants in the interaction. The interaction provokes cause-and-effect between the object and children's touch, what is called intervention, the same type of intervention that scientist use to figure out if there is a cause-and effect relation in the world. Through device's use children learn persistence and cooperation, practice problem solving and develop creativity.

Early childhood environment shapes the quality of the interactions with haptic devices, and how children use them. Children perform interventions and test out their assumptions and theories on the touchscreen to observe what happens.

Like if they were researchers working in their laboratory, the infant experiments, tries and learn from mistakes and results when manipulating the device: 
- They form and revise their thinking through meaningful interaction, they interconnected domains while cause-effect by placing their fingertip on the screen.

- They collect evidence, make observations, and change their own assumptions in a highly science-like fashion from App interaction (Goldman, 2012).

- They generate theories, beliefs, and desires while interacting, and make transitions from simple symbols to more complex ones transferring the learning to different scenarios.

Interacting with haptic devices, children are predisposed to master skills and concepts early in age, develop literacy, and build STEHEAM skills (Science, Technology, Engineering, Humanities, English, Aesthetics, and Math) at early age so they can acquire expert knowledge, as they were scholars, in adulthood by boosting their motivation and creativity.

The native use of haptic devices makes from touch exploration something innate that excels children skills and powers their knowledge towards proficient expertise. Under this perspective, those early childhood users will afford a scholar brain due to their Active role in their own learning, the pursuing of Reasoning with an exceptional Open-minded vision, and driven by HAptic interactions as innate learning style to promote expert understanding. AROHA Learning Style steps forward a new type of student heading university in 2030: the iScholar.

The question that arises, as with any technological gadget in the education landscape, is whether children can obtain effective learning when using haptic devices as tools to promote learning or not. 


\subsection{Child Involvement in the Learning Experience}

According to (Hirsh-Pasek et al., 2015) children learn best while scaffolded exploration, when they are actively involved, engaged with the subject to learn, undistracted, having meaningful experiences that relate to their lives, and having positive social interaction within the context for the learning goal. Also, their socio-emotional development gives them social cues about when, what, and from who is worth it to learn.

The haptic generation is predisposed to pay attention to people at the same rate than to haptic devices daily, therefore children are motivated to copy the actions they see others do, and infer learning from those actions and gestures. The learning experience is set then, by digital inputs in a flexible context that supports scaffolded exploration while searching on internet or using apps, and obtaining outputs in the form of visual and hearing responses to the gestures performed on the touchscreen device.

When analyzing Child-centric pillars of learning, that is, how children younger than 8 are involved (or not) in the learning experience and how they learn best; questions like the ones proposed by (Hirsh-Pasek et al., 2015) when analyzing educational apps, arise also for haptic devices:

- Are children active and mind-on when using the device?

- Are children engaged in the learning experience and remaining on task?

- Are they finding meaning that can be transferred to real life or role-playing contexts? can they have social interaction with others?

- Do they have scaffolded exploration towards conscious or unconscious learning goals? Do they infer real content like literacy, math's, digital skills?

Results from HG Case study (Chapter 4) inform that despite some research advocate against (Spencer et al., 2013), and (J. L. Miller et al., 2017), haptic devices enhance and optimize human learning no matter the age of the user.

Research on educational TV programming have helped to document the teaching effectiveness of TV passive viewing experiences for literacy learning (Fisch, 2004). Positive or negative effects of exposure (passive screen media) depend on the content of the media; if the contents are viewed alone or with an adult as a co-viewer; the age of the child (Russo-Johnson et al., 2017), the type of content showed, among other factors.

Touchscreens, opposed to passive screen media, allow physical interaction with the screen because the gesture on the screen provides a response. As (Russo-Johnson et al., 2017) indicates "individual differences in motor skills, dexterity, and decision making now play a role in how a medium is experienced". Consequently, physical interactivity with the screen gives the user the capacity to select what happens. The individual child's characteristics, actions and preferences decide the purpose of the interaction. 
Following the Science of Learning precepts, and the research already conducted on educational TV by (Hirsh-Pasek et al., 2015), we propose the following pillars of learning when interacting with haptic devices: Active Learning, Engagement, Interaction within the Social Context, and Meaningful Learning.

In the next sections, we analyze the pillars proposed with haptic devices in mind instead of Apps, and we add other two important pillars when analyzing the haptic device under this perspective: socio-emotional development and scaffolded exploration.

\subsubsection{Active Learning}

Summarizing, when using haptic devices, users are physically active (e.g. gestures on the screen). Also, when users perform activities that require thinking as well as intellectual manipulation (e.g. to solve a puzzle), they are mentally active (minds- on or thinking, reflecting, effortful mental activity).

Devices are configured as a rich environment (Hirsh-Pasek et al., 2015) to promote active learning through in-built apps and other apps, engaging learners in a continuous collaborative process. (Grabinger \& Dunlap, 1995) define Rich Environment for Active Learning as a "body of learning activities that engage students in a continuous collaborative process of building and reshaping understanding as a natural consequence of their experiences and interactions within learning environments that authentically reflect the world around them". Haptic devices are effective way to reflect the world around us in an authentic way, with real inputs (e.g. pre-recorded videos of family members that passed away and are significant for the infant exposed to it. The voice of the person, the gestures, the expression of the face. Or face-to-face video chatting with grandparents that live far away of the infant).

Deep learning in early childhood requires to use playing, drawing, retelling, dialogic reading, and dynamic visualization for better retention. In college students they need imagery when reading, and adults need feedback. In all cases, learners of any age, boost academic and social outcomes when they are active and engaged in the experience. When using haptic devices for active learning one must take decisions about the what, the when, and the how to process the information for deep learning.

The device itself directs the attention to guide creativity and interaction for positive effects on socio-emotional outcomes. In its use, cognitive activities are involved to understand oral language, numbers, musical scales, geographic maps, visual icons, and when performed in second language acquisition (L2), etc. because it exists direct manipulation of virtual objects. Also, devices allow to take notes for better problem solving, to give and receive instant feedback when working on a task in a collaborative way, allowing participants to teach, forcing students to be more active, minds-on, and mind-set during the activity, to listen to lectures as many times as they need, pausing, repeating, or manipulating (Hirsh-Pasek et al., 2015).

In our opinion, the activities performed on a touchscreen promote active learning if there are no pop-up features that prevent for learning like: ads, strident sounds, and images, etc. 


\subsubsection{Engagement}

Science of Learning has highlighted the importance of focused engagement in learning in early childhood. Engagement is defined as "the ability to stay focused on a task and undistracted" (Hirsh-Pasek et al., 2015). Different types of engagement help to foster staying on task: a) Behavioral engagement in the form of rule-following, effort, persistence, participation; $b$ ) emotional engagement while dealing with frustration and distraction, and c) cognitive engagement in the form of investment in learning, flexibility in thinking and problem solving (Fredricks, Blumenfeld, \& Paris, 2004).

Deep engagement occurs when using haptic devices in the form of: a) contingent interactions (Children feel in control, maintain their focus, and continue the interaction when gesturing on the touchscreen.); b) extrinsic motivation; c) feedback (on-screen environments respond to children's activities with meaning-full feedback; and d) intrinsic motivation (manipulating the device, children can discover their abilities and start feeling passion for different things that boosts the creation of new interests) (Hirsh-Pasek et al., 2015).

This sort of devices have the ability to support children's engagement with the learning process as long as Apps do not perform distracting entertaining content (Hirsh-Pasek et al., 2015) like popup adds, seductive details, noises, and so on; in the form of real videos playing, real sound, games that mimic real life, and scaffold core learning skills.

Distraction plays an important role when talking about engagement and attention span ${ }^{28}$, early childhood are particularly susceptible to distraction, because they do not have too much ability to inhibit attention (Hirsh-Pasek et al., 2015). As a guideline some research suggests to use child's age as a general starting point for the number of minutes a child can attend to a single assigned task; i.e. 5 minutes for a 5-year-old or 7 minutes for a 7-year-old (Metlife F., 2004). When talking about distraction, one should bear in mind the age, the media used, the type of task and the objective set.

To ensure engagement, haptic devices should keep balance between challenging and accessible, and direct children's attention to important content.

\subsubsection{Haptic Interaction within the Social Context}

Social interaction allows early childhood to observe and imitate parents, caregivers, and peers. By doing so, they learn how the events in real life unfold to be part of their learning. Information is transmitted in complex social environments and interchanged between the individuals in a natural

\footnotetext{
${ }^{28}$ Attention span is the amount of concentrated time a person can spend on a task without becoming distracted (Metlife F., 2004).
} 
pedagogy, benefiting language. Social interaction in school benefits collaborative learning and critical thinking skills when having to explain one's reasoning to others increases children's motivation to learn (Hirsh-Pasek et al., 2015). Haptic devices have a powerful impact on social interaction; it allows face-to-face interaction what derives in a natural give-and-take communication.

Learning can be improved using a haptic device through a variety of interactions, including contingent feedback, or an on-screen character with whom the child has an emotional relationship, either real or as a cartoon while interacting: e.g. when playing there are possible questions that prompt, and a friendly avatar gives answers, using prerecorded sentences. If we observe the kid and the interaction, it seems they are having a real-time conversation (Hirsh-Pasek et al., 2015).

Parental co-interacting is key factor when talking about social interaction in early childhood. An active role from a parent, or somebody that plays its role in the life of an infant, actively engages children in the educational aspect. Using the haptic device under the supervision of an adult enrich the interest, the curiosity, the active participation, the creativity, improves vocabulary learning, and ignites second language acquisition.

Haptic devices offer instant mediated interactions such as: video conferencing, IP audio voice, screen-sharing apps, collaborative visual communication (typing, drawing, or interacting with real or virtual objects), or by receiving immediate response. Immediate Face-to-Face interaction (video-chat) in a portable device sets the disruptive difference when comparing them to other media interactors like: television, game console, digital camera, computer, laptop, interactive whiteboard, MP3 players, DVD players (Plowman, Stevenson, Mcpake, Stephen, \& Adey, 2011).

Research indicates that children as young as 12 months successfully use video as a source of information when an adult on screen interacts with them in a social contingent setting (Myers, LeWitt, Gallo, \& Maselli, 2017). When infants are exposed to social interactions in which their partner's behavior is contingent on their own, they can not only learn new words and behaviors more effectively, but also begin to develop and create social relationships with their on-screen partners. Thus, active engagement with a responsive on-screen partner seems effective in helping young children to learn from video. (Russo-Johnson et al., 2017).

\subsubsection{Socio-Emotional Development}

Fred Rogers pioneered in the 60s the use of television -the emerging medium of that time-to nurture and educate young children. Under the legacy of Mister Rogers' Neighborhood, an American half-hour educational TV show aimed to preschoolers that started in 1963, where Fred spoke directly to kids about various issues, Fred Rogers outlined in 1983 "the ways in which television can support or detract from the development of a child's readiness to learn and also suggested the key role that relationships influence in learning readiness" (Fred Rogers Center, 2015). Conducted research on Mister Roger's Neighborhood (1963) Sesame Street (1966), Barney \& Friends (1987), That's English (1993), Pocoyo (2005) show their effectivity in children development when assimilating knowledge, values, and attitudes, there so acquire learning. 
Apps and media for haptic devices have been designed, developed, created, and aimed to early childhood since 2012. A way to use the device is to communicate things, build positive relationships with children and their families to foster learning. According to Fred Rogers "children can learn almost anything both easily and well so long as they are ready to learn" (F. Rogers \& Head, 1983).

Following (Gopnik et al., 2001) a child is ready to learn vocabulary while in the womb, and start making sense of people, objects, and language around her while on the crib. Young children absorb an amazing amount of information through watching and listening to us and do their own mini-experiments to try to sort everything out.

Children are fascinated by parents, their parentese language (Corthals, 2011), and the things they are doing. According to Apple Developer, iPhone users unlock their phone 80 times a day on average in 2016 (Apple Developer, 2016), meaning that gestures on a touchscreen device are the most common gesture than a parent does in front of a child.

Early childhood have their own framework for looking at things, and they interpret the world through the filter of their cognitive structures (Gopnik et al., 2001). There is no innate tendency to desire haptic devices, but early childhood love them. Nowadays, when a notification shows up in the touchscreen of any haptic devices, someone jumps up from whatever activity is doing, takes the device, sweep the screen and answer. The same if you need to find a place, you need light because it is dark, search for information, take a picture, instant message, check the weather, set the clock alarm, follow the news, listen to music, play a movie, take some notes, etc. Parents do not need to use different devices anymore; they just touch the personal haptic device of its preference as it was a toolbox or a handbag and gestures. Babies desire one of them even before they can hold it. They love it because the adult loves it. Babies are just reflecting what they have at sight.

(Paciga \& Donohue, 2017) conducted a research setting the learning readiness variables that, according to (F. Rogers \& Head, 1983), focus on early childhood education and technology interaction, and at the same time, advocate for positive potential technology to support children, families, educators, and caregivers. The learning readiness and socio-emotional development involve: a) technology and media content; b) child involvement when using the device; c) the context where the interactions take place; d) the interaction with adults and other children; and e) the purpose of the interaction.

Social and emotional learning involves "fostering social and emotional competencies through explicit instruction and through student-centered learning approaches that help students engage in the learning processes and develop analytical, communication, and collaborative skills" (Weissberg, Durlak, Domitrovich, \& Gullotta, 2015). Haptic devices have a positive potential for socio-emotional skills modeled in the device that are, at the same time, learnt, practiced, and applied to other contexts of the child environment. Apps like FaceTime, Skype, or Smile and Learn, among others, help children to develop social cognition, deal with emotions, and learn to selfregulate as they receive positive or negative feedback from their interaction.

As when learning a second language, in social and emotional learning what matters is quality not quantity. Quality requires input from their parents or characters that play their role in apps, they need them as models otherwise the learning goal cannot happen (Ramirez-Esparza, Garcia-Sierra, 
\& Kuhl, 2014). Haptic devices allow social learning, because the interaction with the screen keeps their attention, as it was parenting interaction, while receiving instructions and guidelines, different from TV screen. As it has been analyzed for HG Case Study (Chapter 4), when the children are manipulating the device and its apps, they deal with frustration and mistakes, they develop mindset, take positive risks, and develop empathy or awareness (Paciga \& Donohue, 2017). They also are developing essential learning readiness by increasing a sense of self-worth, a sense of trust, showing curiosity, looking and listening carefully by interactive gestures, playing, and having time for solitude to pause, reflect, observe quietly, and think about the learning goal (F. Rogers \& Head, 1983).

Effective and appropriate use of technology in early years together with active mediation of parents with the role of supervisor or co-user through child's interaction support early learning in the different contexts: home, school, formal or informal learning. It is the blended balance of the interaction what enhances specific domain knowledge in literacy, language, math and science (Paciga \& Donohue, 2017). (Herodotou, 2018) reported findings on literacy development, on science, technology, engineering, and math's, socio/emotional effects, generic skills such as problem-solving, collaboration, and fin motor skills' development when using touch screen devices.

Humans learn best when setting relationships including those that enable media experience to contribute positively to social and emotional development. Haptic devices are so present in our lives that we cannot imagine without them. There is no limits or restriction to learning in whatever diverse family, and support children, educators, caregivers, and the diverse communities, from low socio-economic status to higher, support linguistically diverse backgrounds and different needs and rights (Paciga \& Donohue, 2017).

\subsubsection{Meaningful Learning}

Meaningful learning means to "connect new material to existing knowledge and expand it to create new conceptual understanding" (Hirsh-Pasek et al., 2015). To achieve greater retention and spur conceptual change, the child needs to link his life through meaningful interactions like learning something personally relevant or linking the new learning to a preexisted knowledge. Previous knowledge and skills need also to be built, and part of their acquisition depends on drill and practice. In that sense, haptic devices promote meaningful learning offering context that stimulate greater motivation. Using Face-time with family members, or YouTube videos to see real objects and learn how they work (clock) or behave (carnivore plant); children are building knowledge in narrative contexts (HG Case Study. Chapter 4). Information embedded within a meaningful context provokes more connections across brain areas, so it improves learning outcomes (Hirsh-Pasek et al., 2015).

Haptic devices tap into child's personal history and extend important interpersonal experiences (a face-time video call to reach a parent on a trip), activate prior knowledge, build a rich narrative helped by images and sounds on one tap (record personal video or taking pictures); relate domains of knowledge, such as history, geometry, or science that require to solve problems (games). 


\subsubsection{Scaffolded Exploration}

Science of Learning suggests that the four pillars of learning: active, engaged, meaningful, and social are significant for learning if the experiences are imbedded in an educational context, if there are well-defined learning goals that stands for scaffolded exploration, and if it provokes questioning, and discovery (Hirsh-Pasek et al., 2015).

Haptic devices accomplish all the above, therefore can be considered significant for learning. Devices promote exploration, play, and curiosity either when used for free play or when used with direct instruction. Children manipulate the physical object as a toolbox where touching, hearing, and seeing become just one; it is actively explored and guided by gestures, allowing them to acquire new concepts and understandings. Other benefits are the dynamics visualizations in spatial cognition when playing with geometric materials in scaffolded interaction (Hirsh-Pasek et al., 2015). The multiple possibilities that the context offers foster language development and literacy under adult supervision. Children are guided by play-based vocabulary intervention. Children, when exploring, figure out the problem, and try to find a possible solution before receiving direct instruction. The action of figuring out and find solutions deepens the understanding. 


\subsection{Adult Involvement}

In previous sections we have introduced that adults play the most important role in early childhood education and care. Adults are in responsibility to help children to be healthy, stay safe, enjoy, achieve their goals, make positive contributions to their environment, and bring off economic wellbeing. Adults should help children to be curious about their world, to enjoy being part of the cultural and social experience, to feel secure and confident, and to connect with others through language, symbol-making and play.

As caregivers they should focus in children development and learning, and make them feel welcomed and valued, make them fit in the community they belong to, as well as to try to help them to achieve their goals, understand the world that surrounds them, enjoy, and engage learning (UK Government, 2017). Without engagement, the attitude towards learning is negative and bring fatal consequences like school abandonment, low performance, risk of academic failure, low literacy skills, and low digital performance, among others (OECD, 2018a) and (Instituto Nacional Español de Estadística, 2016).

Not only early childhood from Haptic generation, but also ZGen students are facing education from a system that do not fit completely their standards for engagement. Nowadays, engagement must include ICT (Information and Communication Technology), and digital skills. As it has been explained in Section 2.3, there is a gap between digital reality outside, and inside the school. Innovative pedagogical methodologies are including ICTs as a complementary tool to achieve the learning goals ${ }^{29}$, but still the implementation of technologies in Spanish classrooms is very low, except in rural areas where children have an intense technology life associated with the school (Chaudron et al., 2018).

The social environment where the children are moving around influences their developing interest and the passions that will form part of their intrinsic personalities. Those include independence and autonomy in favor of discovering the potential of haptic devices, evolution of digital activities and skills, self-exploration and self-learning, use of new vocabulary (e.g. influencers, emojis, YouTuber), new digital culture and customs, sudden society demand of digital skills, etc. (Chaudron et al., 2018).

To understand how nowadays children participate in digital activities to achieve goals, learn new practices, achieve knowledge, and engage with others (Danby, Evaldsson, Melander, \& Aarsand, 2018), is important because adults are having the same experiences for the first time at the same time than them, what unbalances the relationship.

\footnotetext{
${ }^{29}$ Learning goal refers to "the observed knowledge or skill acquisition. It usually can be reflected as the extent to which students recall, comprehend, or transfer what they have learned from an instructional task" (Xie et al., 2018).
} 
Adult involvement is needed to enhance and optimize human learning (Meltzoff \& Kuhl, 2016) and they are part of the new scenario where haptic device play a major role. Children are easily ready to embrace with enthusiasm the new activities that an adult propose, especially if they involve other children, pets, fun, sports, as well as shared activities with haptic devices (Chaudron et al., 2018).

\subsubsection{Home as a Context for Learning}

At home, the use of technology varies according to family preferences, and economic wellbeing as main instances for inclusion. Technological home devices also vary depending on the age of the family members, the type of work the adults do, and the use family make of the different devices like computers, mobile phones, Smart TV, game consoles, speakers with voice assistance, music, and video players, etc. The internet access adds a new online dimension to those devices, incrementing the digital practices of all family members like access to social media, online shopping, cloud storage, personalized media consume, etc.

Contrary to other technological home devices like TV, haptic devices are "physically interactive, have the possibility to scaffold children's learning, and can provide immediate, contingent feedback in the absence of a social partner, making them possess many similar features to play in the real world" (Huber, Highfield, \& Kaufman, 2018a). The play potential of the devices can be observed in many domains (fantasy, exploratory, dramatic, manipulative, games with rules, creative) and settings (role play with physical toys, playing with friends, etc.)

Adult media use and technological family practices, as it has been reported previously, influence significantly in children behavior, because they reflect their attitudes, preferences not only with the haptic devices, but also in the parenting style used when children are using the device (Terras \& Ramsay, 2016). Parental perception of haptic devices, possibilities for children's use (communication, leisure and entertainment, creation and productivity, and information and learning) and digital skills are internally balanced and applied into four different styles: authoritative, authoritarian, permissive and laissez-faire (Baumrind, 1966). The factors that influence their parental perception are: social norms, digital integration in society, social economic background, digital integration in schools, experiences in use, confidence in use, attitudes, skills, knowledge. According to the style and how they perceive the possibilities of the devices, they set children's rules for using the device, control their screen time in the different interactive activities, and support their children in the use and learning.

Parental mediation strategies range from protection to warm support and co-usage motivated by fears of possible negative impacts on the physical and cognitive health of children about eyesight, concentration, cognitive capacities, social behavior, sleep deprivation etc., and the risks of exposure to inappropriate content, commercial requests, social media use, screen time that will lead to difficulties to acquire auto-regulation, addictive attitudes, etc. (Chaudron et al., 2018).

During the HG Case Study interviews, we confirm that parents feel powerless, lack information about how devices work, skills, and the time needed to guide children when using haptic devices. To enhance children learning with a such type of tools, adults should be proactive and open to devices, apps, and websites visits; they should co-usage the devices with children to follow their 
digital activities, and the most important, they should be aware of the importance as a "copying model" as children imitate their gestures, behavior, way of expressing, and even their attitudes while using those tools.

Being aware of the role they play, adults can focus on critical thinking, creative activities, and responsible online actions of their children when using haptic devices. Conversations about the activities performed on the devices must be carried on, even if adults do not like some topics (sexting ${ }^{30}$, cyberbullying), and try to cover the good (e.g. learning possibilities), the bad (e.g. online risks, contact with strangers) and the unknown (e.g. safety, digital footprint). To provoke those type of conversation is necessary because the children activities are part of the social digitalization and personality, and secondly because it gives the chance to create a trustful relationship on the subject.

Parental mediation strategies should consider also the positive impacts on the cognitive health of their children. Haptic devices are widely being use to improve literacy learning of deaf and blind children, those that fall into the autistic spectrum, those with brain injury, learning disorders, intellectual disabilities, etc. and the results are very positives (Chien et al., 2015), (Maich et al., 2017). It is logical that if there are positive and proved results on children with disabilities, the results with any other mental state and age, should be at least, equally beneficial.

It is easily observable that the more children use digital technologies, the better their digital skills are. Children perceive the device as a space of freedom-attractive, positive relationship, fun and entertaining moment, even as a social interaction. Digital media are a natural flow of their lives. So, managed in a correct way, it can be very positive for learning goals. The devices act as an open space where children have plenty of authentic choices where to dive and take advantage of. It is in those cases, where parental mediation should be more attentive to favor the pedagogical potential (Johnston, Highfield, \& Hadley, 2018). The positive, active, explicit, and supportive attitude generates a shared space where adults connect positively with their children and anticipate strategies to follow up their development. As an example, adults can explain how to search online content properly (showing them how to avoid risks), or how to use functionalities such as voice recognition tools, or predictive keyboard (us eful to overcome spelling obstacles) to guide their active and positive learning. Findings have shown positive results for language and vocabulary development when adults are present and interact with infants and toddlers (WalterLaager et al., 2017).

\subsubsection{Co-Using the Device}

Home environment provides multiple possibilities for learning engagement. Children are surrounded by family members who exert certain expectations through their own practices, knowledge, values, and ways of navigating the spoken and written word.

\footnotetext{
${ }^{30}$ Sexting is defined as the act of sending, receiving, or forwarding sexually explicit messages, photographs, or images.
} 
The survey on "Young children and the use of tablets (0-8)" (Chaudron et al., 2018) tries to give light on the parental attitudes, practices, and opinions about their own kids using tablets. From the answers we can conclude the following:

- If parents use the device for creation, productivity, information, and learning, then they tent to allow the use, control the contents, time of exposure, and, sometimes, interact and guide the kid in the use or by explaining content. The device is seen as a learning opportunity that offers active participation.

- If parents see in the device just an entertainment or babysitting tool, as it was a normal TV, then they extrapolate the same rules than for TV but into an interactive screen. Here we find two different answers: some show that the kids tend to be left on their own when using the tablet, therefore kids can be exposed to online risks without supervision, and some tend to forbid the use, surely because ignorance about what other uses the device can have, trying to avoid the unknown aspects, and undesirable harm; avoiding also the learning opportunity that the device offer. It should be noted that online risks do not apply to TV exposure because TV screen is passive and just by watching the kid cannot interact with the elements neither expect answers or feedback.

- If the main use of the device is as a communicative tool, then parents will allow the use but with precautions, being alert for the unexpected reactions or moods of the kids, and in many cases not paying attention to their own use of social media apps or privacy or security measures. In the $100 \%$ of the cases they use haptic devices (smartphones, tablets, or both) on daily basis. In $65 \%$ of the cases, parent did not know about the digital opportunity that haptic devices can have, a $98 \%$ did not know about digital literacies themselves, and $100 \%$ of their kids used the tablet at home at some point, they are assigned at school with online homework to complete either with tablets or with computers, and want to use the tablet because is fun and "can do many things" (Child I).

On the side of the children, the interviews also have showed that kids ask parents about the things happening around them but with a new element: children expect answers extracted from the devices. This action demonstrates that children rely on the device, it is completely integrated in their lives, and that they are demanding a co-use because they feel curious, and want the information from real source to understand the concepts. Children are not aware of the novelty of including the device in the scene that it represents for the Mashups. In a normal situation parents use common language for explaining instead of a video, the real thing, or a real photo. Children demand guided use of their devices, and are telling society how they want the information from now on because for Haptic Generation that is the new normality.

In the HG Case Study described in Chapter 4, Child I at the age of 4 said: "what is a carnivore plant, mum?", mum tried to answer with finger gestures, but the kid, immediately interrupted: "show it to me in YouTube". When asked "where did you learn that?" or "where did you learn this word?" the child provided answers like: "on my tablet" (Child I), "in YouTube" (Child Ila), "in google" (Child 1), or just "here" signaling a browser App in the tablet (Child IIb). When doing something that they wanted to keep, they say things like "Mum, a selfie" (Child III) or "Dad, a video" (Child Ila) or "Now, I create a video" (Child I). 
The joint activity should provoke children to create new theories and questions. Haptic interaction let them explore curated content to fulfill those questions giving the chance to create new content. Adult's role is to co-explore while children are guiding their own learning; they know what they want and the device is a vehicle to get there when the child is executively functional ${ }^{31}$ ready to get there. Haptic co-exploration supports smarter thinking due to adults are modeling critical thinking, reasoning, inquiry, and communication. Haptic gestures on the device mediate the learning experience by collecting information and skills; relating those contents with their understanding, creating new content; sharing their solutions to instigate new questions and new knowledge at child pace.

Examples of digital co-using practices are:

- bedtime reading by grandparents that are not in the same place than the children,

- scaffolded writing instruction,

- complex vocabulary understanding,

- language-in-context practice while feeding curiosity by taping a link and accessing material and online resources.

Adult routines on haptic device usage like reading (building vocabulary), writing (email or taking notes), listening and watching educational videos (playing guitar, cooking recipes, etc.), or communicating with the device; emphasize imitative routines and aspects for literacy development in their social context. Those activities observed or role-played can be integrated through joint activity of the adult with the child (Zhang et al., 2013).

${ }^{31}$ Executive function refers to "capacities of the human mind to develop and carry out plans, to get and stay organized, to make decisions, to hold information in working memory, and to focus attention on the task at hand" (D. Wilson \& Conyers, 2016). 


\subsection{Boosting Creativity and Learning}

For centuries, students used quill and ink, crayons and paper, pencils, and pens to create their own ideas. Since the 80s, keyboards and mouse of personal computers were introduced to write ideas as a representation of understanding in the form of automatized writing that excelled the format. Word processing applications (WordPerfect, 1982) showed up to ease the task of writing without mistakes and avoiding the inconveniences of the typewriters. Step by step, new forms of creating digital content started to appear and technological skills made them available for all type of users. In essence, art and beauty launched innovation and productivity just combining Video, photography, music, drawing, and writing (Reich, 2013).

The introduction of haptic devices in the learning environment of a child, more specifically device's flexibility, personalization, portability, connectivity, social interaction, and technical specifications, has made that children want to manipulate them under any circumstance. There is no restriction to sit and access to digital content and manipulate it with one finger. Touch technology interacts with the infant and makes things happen on the screen. Infants then, classify objects in the world instead of using words or symbols by making gestures (Wood, Bruner, \& Ross, 1976), their hands are an extension of their thoughts that they apply them digital or physically.

According to (Marsh et al., 2018) creativity "consists of imaginative thinking or behavior which is purposeful and leads to an original outcome which is of value in relation to the original objective." One of the creative acts performed on the haptic device could be the drawings, scribblings, videos, or photos that a child can perform by himself. Imaginative thinking is traced by the process of creativity identified through observable behaviors associated with three main areas: exploration, involvement and enjoyment, and persistence. Play enables children to explore, develop ideas and make new things as a result of incorporating creative thinking in their creative act.

Haptic device informs creativity by using digital objects (avatars or characters found in apps games) during play situations (e.g. using a small card as it was a smartphone in pretend play (Child I)), that stimulates and completes the play. The devices used for role play situations, or as tools to think with and solve STEHEAM problems can boost creativity and learning when combined with the technical specifications of the devices, haptic inputs, and the Apps support.

We describe in the next subsections examples of how usage of the device as a learning tool usage can boost learning and creativity during early childhood.

\subsubsection{The Device as a Tool}

As specified in Subsection 1.4.3, haptic devices concentrate technical specifications and functionalities that allow children to perform quotidian tasks using one device. The devices that can substitute are the camera, phone, apps, $\mathrm{mp} 3 / \mathrm{mp} 4$ player, video, audio, game console, TV screen, drawing table, and notebooks among others. 
Children can easily carry the device around and use it to explore the device itself or other learning goals of their interest. They can also play games aimed to literacy skills, have fun, access to information of their interest, follow map instructions, ask Siri to play music, open a file, reach people by opening contacts, etc. They can operate and interact with the device, no matter where they are by using it instant and instinctively. They can take pictures or notes, watch videos, draw pictures with their fingers, follow App instructions, or imitate parents' actions on a similar device. Parents can sit with them and follow the actions or the story they are reading together (E. Khoo, Bennett, \& Macmillan, 2013).

Teachers and parents can help children to easily surf the web (e.g., Google, YouTube), or use different apps for communication (FaceTime, Skype), play music or video (iTunes), podcast episodes or programs in other languages, etc. Young children own strategies when using apps without adult help include progress, instructing other peers, monitor their own actions and problem solving skills (Danby et al., 2018). To share the haptic experience creates a new educational space for communication and learning for adults and children. All these actions allow just-in-time exploration of early childhood interests and literacy skills learning. Also, from an assessment learning perspective, haptic devices enable reporting/communicating feedback about kids work and progress to their families with immediacy (ClassDojo, 2011).

\section{Assistive Features and Built-in Support}

Some Assistive features (VoiceOver, color filters, switch control, hearing aids, sound processor, and AssistiveTouch) complement vision, hearing, and motor skills to support learning, and literacy (Apple Inc., 2018b) of children with exceptionalities (e.g. autism and developmental disabilities) as well as other children, helping to individualize the device as an effective and efficient tool that support diversity in gesture use and individual abilities. Children adapt their own strategies for use, access, communicate, and organize their own learning at their own pace (Maich et al., 2017).

As examples, some Assistive features helps children older than three, to zoom and magnify over objects seen through the camera lens, adjust the font size for better visualization; flash on objects to see them better, or snap photos on the objects they are interested in (Child I). Kindergarten and first graders can convert spoken words, numbers, and characters into text without typing by using dictation feature (Child Ila). They can incorporate sounds, images, and design into their stories enhancing independence and motivation (Child I age 5).

Children older than 5 that could read already, have been observed using features for Reading Support, including Intelligent voice assistant, and dictionary (Child I age 5). Those features add an auditory component to texts and help them to improve the pronunciation and reading of some words in a different language (in our case of study: English). The predictive function suggests words that pushes their literacy towards an enriched vocabulary. The dictionary helps children with their spellings using predictive text and the autocorrect function. The device places a red line under incorrect words, and children can go back to edit the words and correct them. The production of multimodal text by adding visual items, like photos, emojis, stickers and illustrations without having to draw enables new possibilities for creativity that support reading. Voice is used instead of pencils or keyboards to give instructions to the devices (Jill Dunn \& Sweeney, 2018). 
Children were using the built-in support features accidentally while trial an error or because they were imitating parents actions in the same device or similar device (Apple Inc., 2018b). In both cases the result was an increment of active options they could use during the use.

Children and adults use speech and recording, text messages (iMessage), video calls (FaceTime), or keyboard shortcuts for oral stories or communication to engage or create communicative situation where even the most reluctant to participate cannot avoid the participation because is fun, the activities are not seen as work or learning tasks, and the use is very similar to a game.

Guided Access and Screen Time help parents to control and set limits when their children are using the device, depending on the age of the children and the type of activity they are performing. According to American Academy of Pediatrics (AAP) screen time has to be limited although not equally for all type of screens (Lerner \& Barr, 2014). There are key variables like the quality of the content and the context in which the screen is used, that imply noticeable differences operating on interactive screens or passive screens. Also differentiates if the use of the screen is educational or entertaining, age of the user, at what time is used, and the participation of the adult in the experience. AAP set some recommendations for use (www.zerotothree.org), and the iOS 12 include a new feature that helps parents and teachers to limit the amount of time spent with App categories such as social networking, games, entertainment, etc.; or schedule periods of downtime in which the device cannot be used, or select specific apps like Phone or Apple Books that will al ways be available. Activity Reports give a detailed breakdown of where time is spent, and App Limits let you set a specific time to spend in an App (Apple Inc., 2018b). By now, the setting is quite simple and onsite experiments have proven that, kindergarten kids that are able to read, are capable of avoiding the limitation at their convenience by following the instructions on the screen. The screen does not differentiate if the watcher is the kid or the adult and the instructions are very simple.

\section{Zooming In and Out}

Gesturing on an App by zooming to show bigger or smaller images, kids have real and authentic information about the world so family stories and facts can be told from the perspective of the real place where they happened. Family stories fascinate kids. Replaying family stories in a 2D-3D context through private speech and authentic pictures helps the kids to have a better understanding of the problems presented and the solutions constructed in the narratives, resulting in better self-regulation and emotional development (Harris, 1990).

\section{Multimodal Formats}

Children can take photos, record their own voice narrating something, film a video of themselves, play music, write words or texts, and draw their own pictures about the same story and insert all of them in their own learning story. Individual pictures can be enriched by text or audio and can be dragged onto a positioned place in the filmstrip. They can add, edit, or delete the formats and repeat them, as well as repeat the actions as many times as they want. There is no limit on the kind of pictures selected for users' stories besides the family rules. Images can be photos, scanned drawings, or hand-drawn digital drawings, there is no restriction on the length of the text or the sound recording (Kucirkova, Messer, Critten, \& Harwood, 2014). 
Multimodal and screen text include signs and symbols to report how children make sense of them: emojis, speech bubbles, voice, colors can be added to their stories and enrich the product to show. (Jill Dunn \& Sweeney, 2018) were conducting some experiments and obtained evidences of how the iPad used in the early years can enhance children's creativity by sharing and discussing their writings with classmates enhancing motivation and independence. Learning how to use the device, and mixing what they have learnt while using it, offer kids the opportunity to create a different product where they can be screenplay writers and main actors at the same time.

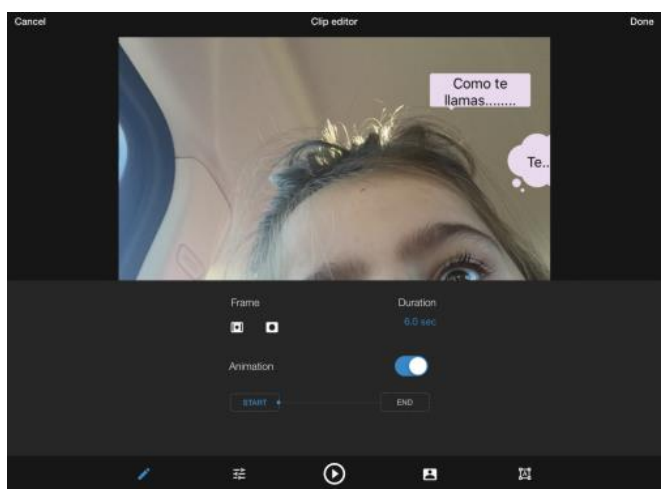

Fig. 22 WeVideo Screenshot.

Fig. 22 shows a screenshot of a video created by Child I with WeVideo App (WeVideo, 2011). The capture of the video gives account of some of the elements that the child included in the video. She included: a selfie, music and video stored in the device, and color squares with typed words. The action was screen-casted on the device by relating her findings, mixing images with recorded video, and using her own discoveries on the tablet. Child I parents reported that when she did it, they did not know how the App worked, it was downloaded because the kid knew it from school context. The same kid created more videos and included some images of her parents found while surfing the internet.

Students are constantly documenting and inferencing learning from different sources enabling meaningful connections with scholars, peers, parents, lecturers, society, science, art, etc. Early childhood is learning to bridge deep-learning with lifestyle through gestures, and haptic interaction.

\subsubsection{Children Interaction}

Children undergo many physiological and cognitive changes in the early stages. Those changes reflect their ability to understand and manipulate the environment. As they grow up, children achieve fine levels of motor control which, combined with cognitive development, lead to achievement of the most complex motor and learning skills (Vatavu, Cramariuc, \& Schipor, 2015). Gestures on the screen like tap, drag, drop, flick, tilt, swipe, pinch, and press (Villamor et al., 2011) are intuitive. Compared with point-and-click technology (mouse technology), gestures can be easily performed in any cognitive development stage at early childhood, core gestures (tap, press, swipe) since sensorimotor stage (from birth to 2 years), and the rest from preoperational period (2-7 years). During the sensorimotor period, development prioritizes fine motor activity while children acquire knowledge through physical interactions and trial-and-error mechanisms. During 
the preoperational stage, kids learn language skills, and develop motor skills, memory and imagination (Vatavu et al., 2015).

In the next paragraphs, there are individual descriptions of the haptic inputs (fingertip, built-in keyboards, digital pencil, and intelligent voice assistant), and how early childhood can take advantage of them in their learning process.

\section{Fingertip}

Affordability of intuitive touchscreen interaction with simple gestures helps children to acquire knowledge by trial-and-error mechanisms even when fine motor skills and not perfectly defined. As children grow up, they become faster at tapping and dragging items on the touch-screen surface (Vatavu et al., 2015). From Children's point of view, to touch the device is fun and prompts answers to the finger gesture so, they become more interested in what it is happening on the screen and they look for more reactions when interacting. From digital literacy's point of view while playing, children are learning function-operational skills on the device like switching on and off, searching for information, storing, selecting, locating information, downloading, retrieving, and so on.

\section{Built-In and Bluetooth Keyboards}

Reading and writing abilities continue to develop throughout the life span, the early childhood years-from birth through age eight-are the most important period for literacy development. Knowledge of the forms and functions of print serves as a foundation from which children become increasingly sensitive to letter shapes and names, to sounds, and to words (NAEYC, 1998). With the built-in keyboard children type on the screen firstly, randomly, and later searching for the correct word spelling to describe, explain, and learn letter and number shapes. The children while typing make themselves serve from auto-correction, spell checker and in-built dictionary in any language they want to perform.

The built-in keyboard accessible to early childhood in their App games and interactions, offers exposure to concepts about print, linguistic awareness, spelling, and offers the possibility to enhance vocabulary development, proficiency in letter naming, that all together help the child in the progress of reading when guided reading or independent practice (NAEYC, 1998).

\section{Digital Pens}

Writing is a complex and sophisticated human skill commonly ascribed a fundamental role in children's cognitive and language development, and a milestone on the path to literacy. Writing is, by definition, the production of some kind of text on some kind of surface or display (paper, screen), employing some kind of technical device (pen(cil)s, stylus, keyboard) (Mangen \& Velay, 2010). Computers in education bring new research questions to stage when talking about beginning writing instruction with pencil or keyboard.

Technology in writing has profound implications in sensory motor skills, cognitive skills, and memory. Neuroscience evidences that writing and tracing movements are involved in 
memorization. In handwriting, motor commands and kinesthetic feedback are closely linked to visual information at a spatial as well as a temporal level, while this is not the case with typewriting, locating and tapping keys on the keyboard do not entail any such information to the brain. (Mangen \& Balsvik, 2016).

In recent years, there is a growing awareness of how the replacement of handwriting by keyboard writing may affect aspects of beginning reading and writing, which may also have long-term consequences (Mangen \& Balsvik, 2016). There is a real marginalization and occasional abandonment of teaching handwriting as skill in schools in Finland since 2016, and generating debates in France or US where pens are being replaced by keyboards (Karavanidou, 2017), and reading is being replaced by visual learning.

Haptic devices are immersed in the debate. The existence of positive and negative aspects gives, necessarily, rise to controversies in Education (Heuer, 2016), but the affordance of handwriting on the touchscreen with digital pens, has change for the better the consideration of haptic devices in early education. The precise input device brings the power of handwriting to technology, adds accuracy, pressure sensitivity, tilt detection and palm rejection on a touchscreen; and offers new levels of creativity and productivity (Apple Inc., 2018a).

Technology emphasized the importance of keyboarding over print penmanship ${ }^{32}$. The digital age, with its typing, email communication and texting, had left users unable to jot down the simplest notes, or the immediate spreading of their legacy and thoughts in pro of speediness. But handwriting is also an art form, an historical tradition, a very personal way of expression, a personal piece of art. There is nothing more personal and creative and artistic than our handwriting, nothing that leaves more of ourselves behind (Fig. 23). Every handwriting message bridges the personality of the writer in the very moment of interplay with hand, eye, mind, pen, and paper or screen, a legacy that as humans we cannot lose and that we are able to keep using digital pens with our devices.

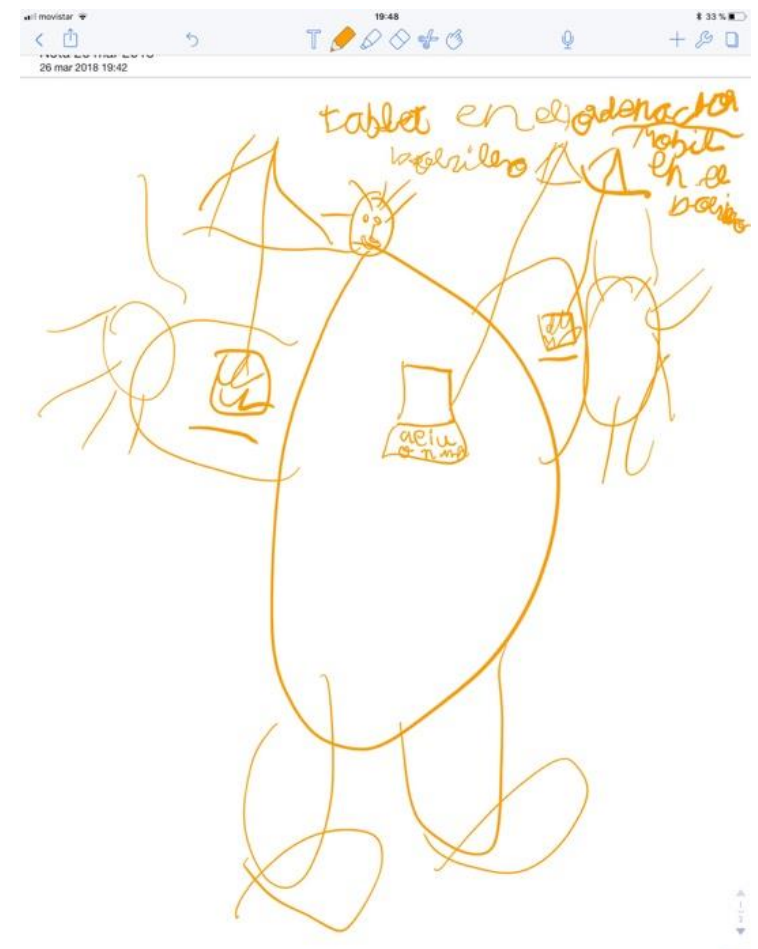

Fig. 23 Digital Pen Scribbling (Preschool)

\footnotetext{
32 Penmanship is the art or skill of writing by hand (handwriting).
} 


\section{Intelligent Voice Assistant}

Voice commands are becoming an increasingly present feature in children and young people's lives who use the tool. Haptic generation is the first generation to whom talking to technology is normal. A recent survey by Childnet found that 7 out of 10 children use voice assisted technology as a source for getting information from, advice and ask for help as well as being a source of entertainment (Childnet, 2018).

MIT study (Druga et al., 2017) and onsite observations of the HG Case Study (Chapter 4) show that children use voice technology on their own terms, and interact with agents as if they were real people by asking personal or fanny questions, making them to play specific music, setting clock alarms or timers, to get advice or help, or just for fun. To ensure that the conversation is successful, children apply face-to-face communication skills, and struggle to be understood. If they fail, they apply self-repair conversational strategies (Cheng, Yen, Chen, Chen, \& Hiniker, 2018) like repetition, speaking loudly, sentence's variation. When they fail, they also, seek for parents' support, what happens with less frequency as the child gets better in digital skills, and age.

\section{Apps}

Among the external apps that can affect children learning we find gaming apps with set goal and progressive increase in difficulty; creating apps that involve constructing activities in a no-fail environment with a range of possible outcomes; educational apps, that include literacy learning interactive electronic books with a built in narrator to read the story (Neumann \& Neumann, 2014). In all of them we recognize basic levels from easy to learn and compelling to master, and learning by doing with immediate feedback. While they learn by interacting with those Apps, they learn basic digital skills like how to use the device, gestures on the screen, and finding the correct one.

Teachers and parents can use different apps to support children emergent literacy skills like letter name and sound knowledge, early writing, print concepts, and phonological awareness, important precursors of future reading and writing ability (Neumann \& Neumann, 2014). The use of the device can provide a range of developmental learning and exploration possibilities, including: a) social skills, e.g. collaborating, negotiating, and turn taking; b) communicative and participatory learning skills (E. Khoo, Merry, et al., 2015); and c) and literacy skills and digital competences.

As an example, (Kuato Studios, 2018) develops gaming Apps that focus on engaging children in narrative learning play (learnifying gaming instead of gamifying learning) ${ }^{33}$. Their games allow children and parents to share and create tales and stories by dialogic reading style, where the adult engages in conversation about the story, which is particularly helpful for learning and engagement (Yuill \& Martin, 2018). Learning features in Kuato apps (e.g. Tales App, Noddy Toyland

\footnotetext{
${ }^{33}$ Learnifying gaming refers to making 'educational' games to start with a subject (e.g. math) - and then try to 'gamify' it. Gamifying learning refers to start with a game in a compelling learning environment, and then seed it with subject matter or skills.
} 
detective) are: Building language skills through reading and storytelling, Question-forming, and sentence structure, developing creativity through play, memorizing patterns and sequences, word knowledge and comprehension, vocabulary enrichment, Nurturing, caring, and empathic skills.

\section{(AR) Apps}

Augmented Reality (AR) Apps provide access to learning through physical interaction because it invites a child to physically manipulate the elements (e.g., with a finger) presented on the screen. For example, the objects are right in front of the user, in beautiful, interactive 3D. Kids can dive through dozens of objects, scrutinize them through rotating or zooming it while learning at their own pace and satisfy their own curiosity (Xie et al., 2018).

The way AR works with guided apps is so simple that early childhood can browse for interactive learning experiences and view step-by-step interactive 3D breakdowns of complex ideas that parents were not able to offer them in normal circumstances. AR makes the understanding of the concepts faster and can include authentic material (real objects in a real place). Learning spaces become the cosmos, the surgical table, visualized industrial equipment, a university campus, a research lab, and a prehistoric museum can offer the past as vivid as the present.

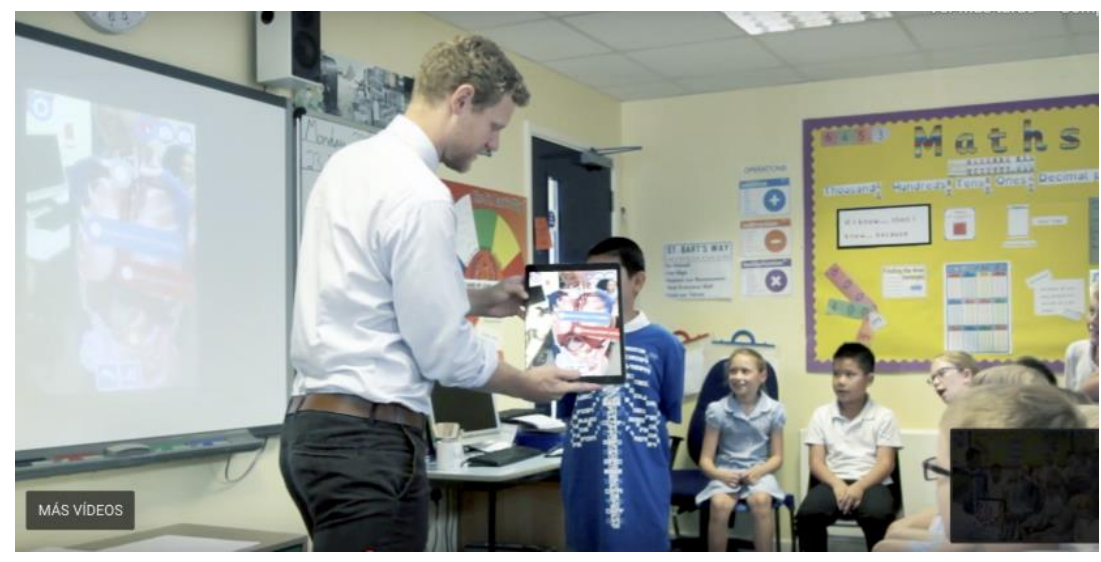

Fig. 24 Using AR in primary Teaching. Curiscope App.

AR allows to break down the complicated mechanics of each one to be analyzed before doing it for real, so it allows to practice as many times as needed. Again, the possibilities for learning are virtually limitless (Fig. 24) (Apple Inc., 2018a). 


\subsection{Boosting Emergent Literacy Learning}

Literacy as a term has evolved, with the irruption of the internet and the technological advance, from its traditional meaning "ability to read and write" (Merriam-Webster, 2015), to a wider meaning "the ability to use, understand and create media and communications in a variety of contexts" (Ofcom, 2017); what includes digital and non-digital contexts in the definition.

UNESCO has acknowledged the complexity and the dynamism of the concept for the academic community: from acquiring basic literacy skills (reading, writing, arithmetic) to socio-economic development, critical reflection, and social awareness (EFA_Global, 2005), that together with the digitalization of the society, understands literacy as a "means of identification, understanding, interpretation, creation, and communication in an increasingly digital, text-mediated, information-rich and fast-changing world" (UNESCO, 2017b)

Nowadays literacy is developed across contexts and globalization. Learners benefit from the involvement of facilitators like teachers, parents, peers, and mentors, also from key settings like internet, formal school, home, virtual environments, TV and playgrounds, key tools like printed and digital material, books, computers and, on top of that from haptic devices allowing an open learning experience by imitation, discovery, enjoyment, and interaction.

The meaning of the modern term has been expanded to include the ability to use language, numbers, images, digital information, and other basic means to understand, create, compute and communicate, using printed and digital materials associated with varying contexts to enable individuals to gain useful knowledge, achieve their goals, solve mathematical problems, use the dominant symbol systems of a culture (Burnett et al., 2005b), and participate in their community, extended to digital society. Being literate has added "digital" as a new dimension of basic skills to meet the literacy benchmarks of the new citizens.

But literacy learning, either with its traditional or modern meaning, varies according to the different ages of the learner. For Michelle M. Neumann "Emergent Literacy develops from birth when infants begin their visual exploration of surrounding print" (Neumann, 2018). The development of emergent literacy skills, like phonological awareness, emergent writing, alphabet knowledge, and print concepts during preschool years influences, strongly, the future reading and writing ability of children (Neumann, 2018).

Children can use haptic devices better than other technologies, because they are easier and more intuitive. Also the portability and the touch interaction are important to stimulate young children concentration, motivation, and engagement to enhance early literacy in any type of learning environments (individual or collective) (Flewitt, Messer, \& Kucirkova, 2015).

According to (Tyner, 2012) a teaching approach should focus on the development of oral language for literacy acquisition, using "progressive practice in reading and writing giving emphasis on developing knowledge and fostering identities". For that, "the methodology to use must ensure 
that learning occurs in supportive, safe environments free from discrimination with access to quality, culturally appropriate teaching, resources and practice."

As we have seen in Chapter 1, haptic devices have multimodal features (text, audio, video, images) that help to increase its use among children in any environment where they are using them. Its educational and entertainment possibilities, its assistive technology, as well as its Apps aimed to communication, creativity, information, and learning have made of this type of technological devices the most used among young population (Ofcom, 2017). Its in-built-apps help to engage early childhood attention in multisensory ways by stimulating the hearing, the touch, and the sight senses; as well as they give testimony about children surroundings through interactive experiences helping them to give sense to the object or idea learnt (Neumann \& Neumann, 2014).

The interactivity between the learner and the haptic device, whatever his preferences on the device are, not only ensures Tyner's vision but also, facilitates language acquisition, and reading development from the different linguistics' subfields point of view: lexicography, morphology, phonetics, phonology, pragmatics, semantics, sociolinguistics, and syntax. The interaction fosters scaffolded reading and letter recognition that facilitates spelling, building vocabulary, acquisition of grammar patterns, and helps to enrich understanding (Flewitt et al., 2015), (Clarke \& Abbott, 2016), and (Jill Dunn \& Sweeney, 2018).

With the use of haptic devices, YouTube videos, google searches on the internet, etc. the main input to increase literacy is the image, so the learner must learn how to read printed text and images, accessing to the same stages of literacy than by printed spelling.

\subsubsection{Reading Development}

Emergent literacy aligns with reading development. According to (Brace, 2017), "Literacy involves the ability to receive and express messages through a highly abstracted code that - on the surface - does not represent the language for which it stands but has the ability bring isolated sound to text and meanings, either from the imagination or of the intellect or of both". In other words, reading development is fundamental to acquire literacy skills.

Following the National Reading Panel (Shanahan, 2005) there are five pillars to reading development: phonemic awareness, phonics instruction, vocabulary development, fluency practice and comprehension; or in a more practical description, from sound within words to words, then phrases and sentences, and finally texts in whatever form they want to express themselves: poems, photos, videos, graphs, essays, tales, etc. by talking, by reading, by writing or by digital storytelling.

Literacy development requires the strengthening of word recognition skills, building of vocabulary; guided reading; guided writing; the shaping of discourse (or oral language); the development of knowledge; the establishment of practices and the fostering of literate identities (Brace, 2017). (Chall, 1996) accounts for literacy development in five stages from 0 to 18 years old: "Stage 0: Pre-reading development; Stage 1: Initial reading \& decoding; Stage 2: Confirmation \& fluency; Stage 3: Learning the new; Stage 4: Applying multiple perspectives (personal, disciplinary \& critical); Stage 5: Constructing \& reconstructing knowledge and practice". Those stages can be achieved using printed materials or using digital formats. 
Educational apps arrange literacy aimed activities by levels (e.g. (Epic! Creations, 2016)). Guided picture visualization and adult supervision during stages 0 to 3 , help children to talk for oral language development, for shaping discourse, and for fostering verbal reasoning; to read to others or to their own; and to write or draw with the finger, keyboard, or a digital pencil, during the different stages.

The haptic device, as a tool, helps early childhood to develop core skills, intermediate skills, and disciplinary knowledge; as well as to do it in a playful environment that helps them to build content knowledge, using the skills as tools for understanding actions. Digital screen's interaction provides "rich opportunities for students to gain and express meaning in multiple knowledge domains and modes through scaffolded speaking, listening, reading, writing, viewing and representing" (Brace, 2017) what adds new habits of the mind at early stages.

From a cognitive point of view, for attention, memory, visualization, pattern recognition, motivation, interest, creativity, understanding, or even learning, human brains try to segment core literacy skills to make them fully blend, and achieve understanding. Environmental and instructional qualities are needed to balance all the open and active tools we have around such as books, images, videos, actions, and sounds that help humans to learn (Stahl, 2011). What it means that not only printed but also with digital formats can boost learning.

Reading is the foundation for academic achievement. Instructional learning, to be of quality, needs disciplinary knowledge and practices on verbal and non-verbal cues (phonics and cultural understanding) on the different contexts, and specific language purposes, as much as to use the conventions established (alphabet) to make sense of the learning goals.

Qualitative reading cannot be achieved without core fundamental skills like: phonological awareness, phonics, reading fluency, and vocabulary (Paris, 2005); and Intermediate skills, that include the necessary skills to receive information, and re-interpret it under child own perspective, including comprehension, grammar composition, development of general vocabulary, and background knowledge, to offer structured talk, and cultural-based multimodal texts with cues from their social and personal environments (Paris, 2005).

Research in literacy learning reveals that experiences, environments, intentions, motivation, and cognitive skills, influence in language and reading comprehension, expression, fluency, content knowledge, and expertise (Paris, 2005).

Digital information accessed through interactive feedback influences on the learner's development of emergent literacy skills during the different stages, just as the traditional and instructional learning normally does. So, the actual concept of literacy should include "language development (e.g. vocabulary, language knowledge, syntax, etc.), confidence and competency with speaking \& listening skills; reading, viewing \& responding; writing \& representing"; as Stahl affirms (Stahl, 2011) not only in conventional texts, but also in digital, and multimodal texts. Both ways (traditional, and digital) will help to develop understanding, foster learner's motivation, learning habits, positive attitudes, and self-awareness (Stahl, 2011) according to the different stages of the learners.

Early childhood literacy learning requires structured and sequenced training to consolidate reading skills. At these stages, the training will depend on children's own interest, and the adult 
interaction. They can experience with more advanced skills completed through assistance, scaffolding, modelling of an experienced adult or guided by digital applications. Emergent literacy skills are fundamental to configurate students critical thinking (elements of thought): concepts, assumptions, implications and consequences, point of view, purpose, question at issue, information, interpretation and inference (Richard Paul \& Elder, 2007).

\subsubsection{Core Skills: The 4 C's}

Haptic devices as a hub for learning help to acquire literacy skills in a variety of times, social and digital spaces by using multimodal formats (video, photography, and audio). The use of dedicated software to consume, and to create in digital multimodal formats, as well as to know how they work, in a basic way, on the different apps, are essential to function effectively in the digital society that $21^{\text {st }}$ century embraces, in brief, once those children arrive to higher levels of education (high school, university, vocational training, etc.) they will need digital skills.

Digital contexts are rich grounds to grow curiosity, imagination, resilience and self-regulation aimed to develop skills, knowledge, values, and future key competences to transform society and shape citizens future (OECD, 2018b).

Within these learning ecologies where haptic devices play an important role, educators recognize that there are core skills and concepts that learners need to be able to draw on, to begin the process of becoming literate (Shanahan, 2005). Those are the four Cs (Yelland, 2018):

- Critical thinking that helps children to figure out for themselves and find different solutions,

- Creativity (that empowers children to see concepts in a different light,

- Collaboration that get peers to work together, achieve compromises, and get the best possible results from solving a problem, and

- Communication that glues all the other three. They are regarded as being more critical for learners than knowing many facts.

Those $4 \mathrm{C}^{\prime} \mathrm{s}$ can be targeted in multimodal texts, and will document the learning process. The multimodal texts include: video recording, text, oral recordings, electronic paint, draws, and information obtained from the Internet either by purposed searches or by chance. In the same way, children can produce creative multimodal text with their own understanding of the subject matter once they start reading, and writing.

Educational apps aimed to storytelling, writing of notes, drawing, or video edition (WeVideo App) with creative control where the children can edit video, photos, audios, and texts (WeVideo, 2011) allow the creation of personal contents. Used in collaboration with other children leads to conversations, among them or with adults, about the creative process, and about the result. Human, and non-human interaction through computer-based tools as technical scaffolding, overlap and transfer skills between the digital and non-digital elements, emergent literacy and emergent digital literacy help children become proficient users in conventional literacy, and digital literacy (Neumann, Finger, \& Neumann, 2017). 
Summing up, multimodal texts give account of children interest and creations connecting several ways of expressions. By including the children in the process it gives them more autonomy and confidence, makes the learning more visible, and children are more able to select the most effective mode to communicate their ideas and participate in collaborative real-world experiences at younger ages (Yelland, 2018).

\subsubsection{Emergent Digital Literacy Skills}

(Neumann et al., 2017) defines digital literacy as "the use of digital tools to create meaning and communicate effectively with others, including the ability to use visual representations, integrate different digital texts, navigate non-linear digital texts, and evaluate digital information".

Children practicing reading and writing along the stages (Chall, 1996) becomes proficient fundamentally by sociocultural interactions with non-digital texts, and digital text. Emergent digital literacy skills emerge at the same level, and pace than the emergent literacy skills.

When defining digital literacy, (Neumann et al., 2017) differentiates Emerging digital literacy defined as "the skills, knowledge, and attitudes that are presumed to be the developmental precursors of proficient digital literacy skills", from Proficient digital literacy referring to "the use of digital texts and tools to access, manage, create information, and communicate effectively with others".

Children's emergent digital literacy includes "emerging digital print concepts" (Javorsky, 2014) that are necessary to read stories in a digital format, and includes basic navigation and knowledge of icon functions. It also includes, "digital navigation (use of menu buttons), key identification when typing on a pop-up keyboard, technical operation of devices, knowledge of digital terminology, user control methods (click, swipe, tap, home, scrolling), storage and retrieval, and hyperlink use" among others (Neumann et al., 2017).

In the digital context reading equals to read "pieces viewed on the web that may contain hyperlinks, videos, audio clips, images, interactive graphics, share buttons, or a comments section" (Heitin, 2016) while navigating and interacting.

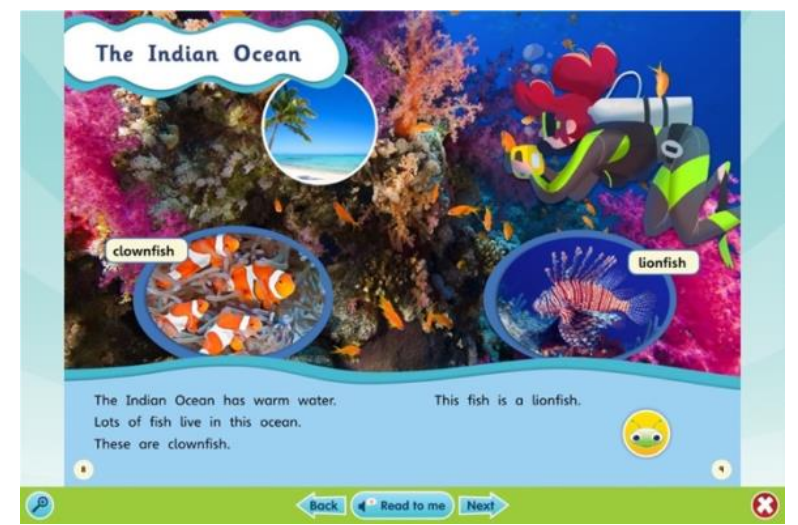

Fig. 25 ActiveLearn Platform Screenshoot (Preschool)
As an example of a digital story, in Fig. 25 we see and screenshot of ActiveLearn platform from Pearson UK, that displays interactive leveled books, and related math games for kindergarten. The books have icons: a) printings of letters/words/numbers/musical notes/drawings, b) how to advance the page (back, Next), c) the read to me icon; d) a brand bug to assess scaffolded reading (Bug club icon), e) a magnifying glass, and f) the exit icon (Pearson UK, 2016). 
Digital reading differs from printed reading fundamentally in the design and incorporation of the interactive contents. It contains features that force the reader to stop and take decisions rather than simply reading the page from top to bottom. In that way, every reader has a different experience, and decides when to click, how long to read, the information that he prefers to read, and how to access the information. Instead of doing it with table of contents and indexes to locate the information, they surf on online spaces, where is fundamental to learn how to navigate through results, skim information, use keywords, and be competent in cultural awareness and expression, entrepreneurship, citizenship, Personal, social and learning. (Heitin, 2016).

Children's interactions with the digital text promotes the reading of brand logos and the identification of same type of icons making possible the transference between digital and nondigital tools. During observation in HG Case Study, Child I, being infant, recognized the same logo (Coca Cola, Amazon, Google, Corte Inglés) already seen in tablet manipulation with her mum when the child spied them in non-digital context (TV add, physical stores, city publicity), giving proofs of transferring the knowledge from digital context to non-digital context. Pairing icon and meaning helps with the acquisition of decoding skills for reading (Child I).

Scaffolded use of appropriate apps on tablets can elicit complex behaviors that are like paper book reading interactions that include photo-visual, reproduction, branching, information, and socioemotional literacies that allows learning. During the HG Case Study, it was observed that while co-reading with an adult, the child manipulates the device, listen attentively to the voice of the App and the explanations of the caregiver, points with fingers at figures depicted during the reading, and responds to the adult questions (Child I, Ila, and IIb). The app-mediated story-sharing context produced a harmonious and smooth interaction typical of 'happy' oral stories (Kumpulainen \& Gillen, 2017).

(Maich et al., 2017) proposed an emergent digital literacy inventory for students, based in McDowell model aimed to students with low vision (McDowell, 2013) focusing on digital skills operated on a iPad like gestures, features, iPad words, operate camera, iPad care, iBooks, and advocacy. The inventory has been applied to the experiences of Child I during the time of study, and what (Maich et al., 2017) paper specified for Beginner, Intermediate and Advanced skills, have been proven as part of the emergent digital skills of the kid. With the following relationship:

$\ddagger$ Being infant $(0-18 \mathrm{~m}) \rightarrow$ operated with Beginner skills,

$\ddagger$ Toddler (18-36 m.), and Preschooler (3-5-year-old) $\rightarrow$ operated with Intermediate skills, and

$\ddagger \quad$ Kindergarten (5-6-year-old) $\rightarrow$ operated with advanced skills. 


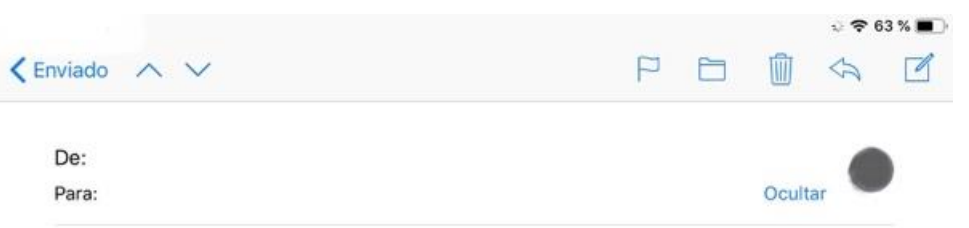

Si estas conduciendo solo te quiero dicir que te quiero mucho 0

22 de abril de $2019,16: 20$

iPad-eando

Fig. 26 Sending an email without instructions (Kindergarten)

Fig. 26 shows a screenshot of an email sent by Child I to her parent without asking for help, not even asking for the email address. She guessed with her intuitiveness and the assistive features displayed on the device screen.

Table 6 shows a summary of the type of actions the Child I could do with her tablet described by age stages.

\begin{tabular}{|c|c|c|}
\hline $\begin{array}{c}\text { Early } \\
\text { Childhood } \\
\text { Stage }\end{array}$ & Procedural Observation & Operated Digital Skills on HD \\
\hline $\begin{array}{c}\text { Infant } \\
\text { (0-18 months) }\end{array}$ & $\begin{array}{l}\text { Basic Operations } \\
\text { No really knowing what } \\
\text { they are doing } \\
\text { Playing. Touching. } \\
\text { Discovering by chance }\end{array}$ & $\begin{array}{l}\text { Remove cover } \\
\text { Core Gestures: Tilt, Tap targets, Swipe (to change screens or unlock device), Double tap, Pinching } \\
\text { (to zoom), Drag and drop, Flick (scrolling) } \\
\text { Touching an app icon and see what happens, Observe how others manipulate the device }\end{array}$ \\
\hline $\begin{array}{l}\text { Toddler } \\
\text { preschooler } \\
\text { (18 months } \\
\text { to } \\
5 \text { years) }\end{array}$ & $\begin{array}{l}\text { May use combinations of } \\
\text { beginner skills } \\
\text { Requires procedural } \\
\text { knowledge }\end{array}$ & $\begin{array}{l}\text { Turn the device off / on (using the top button) } \\
\text { Keyboard use (switch; split; minimize the keyboard) } \\
\text { Camera use (switch between front and back camera; use top button and home key to take screen } \\
\text { shots) } \\
\text { Double click home key to access running apps } \\
\text { Draw with digital pencil } \\
\text { Swipe up (close apps; access settings) } \\
\text { Swipe down (access notifications) } \\
\text { Four finger pinch to close apps (return to home screen) } \\
\text { Select all, copy, paste } \\
\text { Hold to highlight } \\
\text { Lock screen button } \\
\text { Unlock device (using password or touch ID) } \\
\text { Hold power button (restart) }\end{array}$ \\
\hline $\begin{array}{l}\text { kindergarten } \\
\text { (5-6 years) }\end{array}$ & $\begin{array}{l}\text { May use complex } \\
\text { combinations of skills } \\
\text { Adjustments for personal } \\
\text { preferences }\end{array}$ & $\begin{array}{l}\text { Changing brightness level (using the swipe up function) } \\
\text { - Changing the volume (using swipe up function or side buttons) } \\
\text { Mute using side button } \\
\text { Connect to internet (using the swipe up function) } \\
\text { Organizing apps } \\
\text { Create folders, hold down apps to activate, press home key to stop activation of apps, delete apps } \\
\text { Lock rotation (using side button or swipe up) } \\
\text { Use keyboard microphone } \\
\text { Attend to battery charge } \\
\text { Wire connection for battery charge } \\
\text { Hold down home key (to activate Siri }{ }^{\text {) }} \text { ) } \\
\text { Switch on/off flash to use it as a torch } \\
\text { Switch on/off timer, clock alarm } \\
\text { Search on internet } \\
\text { Reading } \\
\text { Using Assistive features for reading support (predictive text) }\end{array}$ \\
\hline
\end{tabular}

Table 6 Child I at different stages manipulating her tablet (own source) 
Once the emergent digital literacy is mastered, the learning of digital skills for school graders (618 years) should focus on applying critical thinking to technology: notice facts, and the computing data and information behind the screens to raise awareness on safety issues and determine trustworthy sources, curated information, and distinguish it from fake news, and misinformation. Critical thinking applied to digital skills include "Information literacy: Understanding facts, figures, statistics, and data; Media literacy: Understanding the methods and outlets in which information is published; and technology literacy: Understanding the machines that make the age of information possible" (Chaudron et al., 2018).

Proficient digital literacy is indispensable for future university students. Digital literacy curriculum and digital competence play a key role in the digital enculturation of the new generations. The Digital Competence Framework for Citizens, also known as DigComp 2.0, identifies the key components of digital competence in 5 areas: Information and data literacy, Communication and collaboration, Digital content creation, Safety, and problem solving (Vuorikari, Punie, Carretero, \& Van Den Brande, 2016).

To develop emergent digital literacies since infancy, will help to build digital competence and raise children's awareness on online safety issues, as well as start building critical thinking and reasoning on accessed contents, or apps used through their haptic devices. Schools have a major role in teaching for "being digitally competent": the acquisition of the 21 digital competences set by The European Digital Competence Framework (DigComp 2.1) (Vuorikari et al., 2016). The possibilities of the Haptic devices as facilitators for learning and creative content confirm that the devices are active learning tools as opposed to the first concept mere information sources with entertaining purposes (Vuorikari et al., 2016).

\subsubsection{Instances of Children Device Usage for}

\section{Learning}

The fundamentals of haptic devices applied to learning ecosystems help to see the devices as learning facilitators, settings, and tools to foster literacy development while providing assistance, scaffolding, and guidance with different digital material, Apps, and internet-based experiences.

Next, we recall the facilitative features to pursue literacy development using the device as a tool (Brace, 2017):

\section{The Apps}

App use fosters motivation for literacy acquisition (Ciampa, 2014). Some Apps are highly engaging. They offer scaffolded didactic materials enriched with music, sound, videos, and prompts where basic steps guide the user through the programmed tasks. The software offers progress reports, rewards, and provide opportunities for students to practice, share among peers, try higher levels, avoid the comfort zone, discover new elements, and study the subject matter in a playful atmosphere, what helps to grow as a learner because they can monitor, and reflect their academic 
improvement. Apps can be personalized while using them according to user interests and reading level in a fun, safe and kid-friendly environment (e.g. EPIC (Epic! Creations, 2016)).

Educational Apps contain emergent literacy activities as letter matching, tracing, drawing, alphabet recognition, print contents, and letter shaping (S. S.-H. Wong, 2015), as well as animated pictures enriched with music and sound (Bus, Takacs, \& Kegel, 2015). (Neumann, 2018) conducted research among children aged between 2 and 8 to conceptualize a common framework for literacy development either emergent and digital emergent. Results show that young children develop understanding and knowledge in those elemental skills.

\section{HG Case Study}

Parallel tests have been conducted in our Case Study it the results are very similar. Children of Case Study showed learning when dealing with educative Apps as well as they gave cues of digital understanding when manipulating the device.

\section{Authentic Material}

The device gives instant digital access to authentic material from real world (images, videos, audios, texts, infographics, real geographical sites, etc.) that enrich learning. The material, not created intentionally for learning enhance the experience because it can be framed in a real context. The authentic materials serve for meaning-making purposes and provide opportunities that initiate children into literacy practices aimed to self-taught, demonstration, understanding, and reasoning (Fleer, 2013).

\section{HG Case Study}

Parent of Child I (preschool) explained her how to farm mussels using authentic material videos of YouTube in English. The video provoked a turn of questions and answers about what was happening on the video. The conversation was held in English because the video was filmed in English language.

\section{Wireless Connection}

Wireless connection allows students to pace reading, problem solving, writing, and critical thinking wherever they are and whenever they want. It allows to practice independent reading, language learning, math concepts, and visual materials by using age- and skill-appropriate apps that are of interest and of relevance; and the practice can be fostered at any time, any place (restaurant, doctor's waiting room, airports, classrooms, home, etc.). 


\section{HG Case Study}

All the children of the case study, except for child $V a$, and $V b$, were using wireless connection in waiting rooms, restaurants, airports, at home, etc. to perform the activities of their preference.

It was also observed that in restaurants, and waiting rooms there are many children of any age using the devices, either to keep them quiet, or because the kid demands the device for his own purpose (mostly gamming).

\section{Digital Formats}

The use of multiple digital formats helps to link prior concepts to new ones, enrich the vocabulary, and consolidate knowledge according to the child preferences or abilities. Not all the children have the same preferences, neither the same preference during the different age stages (Chall, 1996). The formats should be selected by adults, what it will add guided knowledge in and out of the learning experience: video format, audio, pdf, word, email, etc.

\section{HG Case Study}

All the children were using video, audio, text, and draws to perform the activities on the tablet, if they were allowed to do it. In case of Child Va and $v b$, they performed some activities with the smartphone due to the tablet was not allowed to use because family rules.

\section{English as a Vehicular Language}

When surfing the web, the educative Apps, and the contents of any video streaming service, one can find contents in English Language giving access to English inputs and outputs while using the devices. The use of formal or informal material in their original language, or intended in English in any digital format (audio, video, text) helps to acquire and nurture a second language. If children use authentic English material, the learning experience provides reading opportunities that immerse students into a natural exposure of the language in a variety of practices, as diverse as learners needs and preferences (Akbari \& Razavi, 2016). Authentic second language material helps them to acquire reading, listening, speaking, and writing in that language, allowing learners to communicate, interpret, inform, criticize, and behave in a bilingual mode (0. Dunn, 2011). 


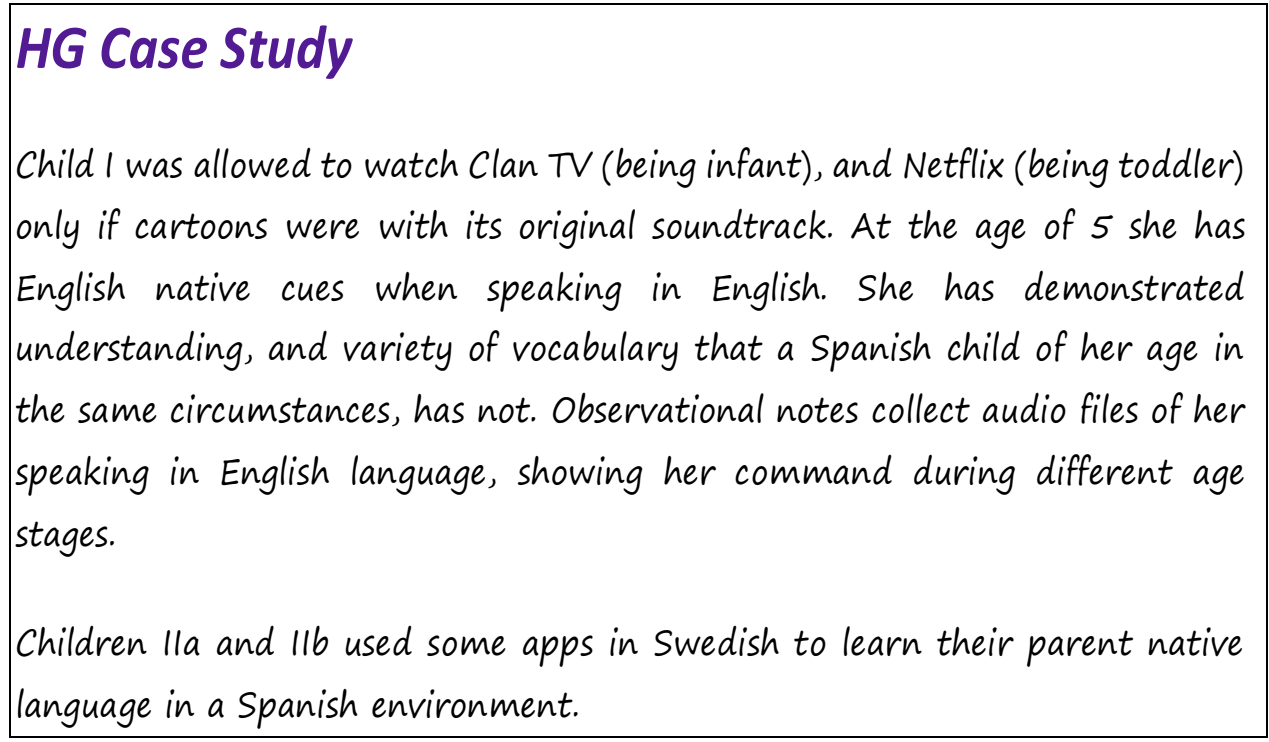

\section{Cooperative Use}

Performing Cooperative and networking activities, as well as using the device in group with peers could empower discussion of images and texts, tackle complex concepts, and develop new comprehension strategies to accomplish the tasks, and add value to the learning outcome. Using the device with peers in informal scenarios is not frequent because parents are not familiarized with the learning possibilities of the devices. Furthermore, there are parents (Child I, Child Ila, Child IIb) that seek for traditional games, and avoid device time when they share time with other kids in pro of personal relationships. Being so young, cooperative use should be promoted in school settings where teachers can control the use, the Apps, and the contents.

\section{HG Case Study}

For Child I, and Child IIa, it was reported that the school provided cooperative and networking activities with the tablet in their "tablet" week session. The children were working on solving some problems in a game scenario asked by their teachers. Children had to apply common reasoning to find the solutions.

\section{Digital Curated Content}

To curate content is a process of gathering relevant information about a specific topic, and make it digitally accessible. Children can benefit from access to curated online resources adding academic value to the information they are accessing to, and avoiding false claims, and fake information (Cohen \& Mihailidis, 2013). Curated content is hosted in digital spaces, from different places to home or school, at different timings (24/7 hours open), allowing formative experiences anytime anywhere, and suitable to their personal stage of development, as well as their diverse 
learning capacities. The learners receive and expresses messages, develop knowledge, conceptualize, take part in communities of practice, and develop interests to pursue goals, creating their own curated content and storing the files to better and future use.

\section{HG Case Study}

For Child 1, Child IIa, and Child 116 , the school provided some curated contents in the website activelearningprimary.co.uk, where children could review the most important contents covered during the school sessions, and perform activities to fix the acquired knowledge. At home the website was used through the tablet. Parents reported that with the tablet, using the finger instead of the mouse, the children payed more attention to the content instead of trying to figure out how the mouse could achieve the buttons to advance in the subsequent screens.

\subsubsection{Desk Research on Haptic Devices as Literacy Facilitator}

Having haptic devices as facilitators, early and emergent literacy learning has been studied and brought into the educative arena since the irruption of the iPad in 2010. Disciplines like psychology, neuroscience, education, computer science, medical health, sociology, have studied the implications of the use of the devices into early development.

During the writing of the thesis dissertation, desk research has been conducted to review the research findings on literacy learning by early childhood. 201 research papers published from 2010 to 2018 have been identified to consider tablets in early educative contexts recognizing the growing importance of digital devices in young children's daily lives.

A growing corpus on iPad or other haptic devices and early childhood give evidence-based account of how the devices support and extend learning opportunities for young children in ECE ${ }^{34}$ contexts. The following table provides the favorable findings found in $\mathbf{8 2}$ papers out of 201. From the 82 papers, 31 have studied the use of haptic devices by children born after 2010. Research published after $31 / 12 / 2018$ has not been considered for the writing of the dissertation due to timing reasons.

\footnotetext{
${ }^{34}$ Early Childhood Education.
} 


\begin{tabular}{|c|c|}
\hline Citation & Literacy Skill \\
\hline $\begin{array}{l}\text { (Hutchison, Beschorner, \& Schmidt- } \\
\text { Crawford, 2012) }\end{array}$ & $\begin{array}{l}\text { Support student learning, and students were also highly } \\
\text { engaged and able to demonstrate unique and creative ways } \\
\text { of responding to text. }\end{array}$ \\
\hline $\begin{array}{l}\text { (McClanahan, Williams, Kennedy, \& Tate, } \\
\text { 2012) }\end{array}$ & Focus attention and much more metacognitive in his reading \\
\hline (Sandvik, Smørdal, \& Østerud, 2012) & $\begin{array}{l}\text { Scaffold for language learning. Allows exploratory talk as a } \\
\text { learning potential. Opportunities for children to engage in } \\
\text { useful and purposeful first and second-language and literacy } \\
\text { interactions with sensitive interlocutors, both adults and peers. }\end{array}$ \\
\hline (L. Wong, 2012) & $\begin{array}{l}\text { Support children's metacognitive skills development or } \\
\text { "learning to learn skills". }\end{array}$ \\
\hline (Hutchison et al., 2012) & $\begin{array}{l}\text { Provide young children with valuable learning experiences } \\
\text { that enhance their learning and development }\end{array}$ \\
\hline (1) & $\begin{array}{l}\text { Interaction with the devices enhances literacy, numeracy, and } \\
\text { problem-solving capabilities. }\end{array}$ \\
\hline (Falloon, 2013a) & $\begin{array}{l}\text { Student dialogue through working in pairs. Students actively } \\
\text { involved in creating content. }\end{array}$ \\
\hline (Fleer, 2013) & $\begin{array}{l}\text { Social practices of the family (use of iPad) demonstrated a } \\
\text { new form of family pedagogy that supported the development. }\end{array}$ \\
\hline (Hatherly \& Chapman, 2013) & Motivation and engagement \\
\hline (E. Khoo et al., 2013) & $\begin{array}{l}\text { Relational, communicative, documentation and informational } \\
\text { tool for supporting child-led learning. }\end{array}$ \\
\hline (Kucirkova, 2013) & iPad books for children foster literacy skills \\
\hline $\begin{array}{c}\text { (Kucirkova, Messer, Sheehy, \& Flewitt, } \\
\text { 2013) }\end{array}$ & $\begin{array}{l}\text { smooth interaction achieving a coherence that is typical of } \\
\text { "happy" oral stories }\end{array}$ \\
\hline (B. T. Miller, Krockover, \& Doughty, 2013) & $\begin{array}{l}\text { higher motivation, engagement, and independence in inquiry } \\
\text { investigation }\end{array}$ \\
\hline (Pellerin, 2013) & Acquisition of a second language \\
\hline (Snell \& Snell-Siddle, 2013) & Increase children's understanding of the learning process \\
\hline (Spencer et al., 2013) & Afford deep, personalized approaches to learning \\
\hline (Crescenzi, Jewitt, \& Price, 2014) & Positive impact on developing children's early literacy skills \\
\hline (Falloon, 2014) & $\begin{array}{l}\text { Insights into how students go about solving problems within } \\
\text { apps, and highlights the importance of knowledge, affective } \\
\text { and dispositional elements, and good app design to profitable } \\
\text { interaction. }\end{array}$ \\
\hline (Falloon \& Khoo, 2014) & $\begin{array}{l}\text { Talk students engaged. Developing numeracy, literacy, and } \\
\text { problem-solving/decision-making skills }\end{array}$ \\
\hline (Kucirkova, Messer, Critten, et al., 2014) & $\begin{array}{l}\text { foster children's motivation to engage in communication and } \\
\text { literacy-related activities such as story-sharing and story- } \\
\text { creation }\end{array}$ \\
\hline $\begin{array}{l}\text { (Kucirkova, Messer, Sheehy, \& Fernández, } \\
\text { 2014) }\end{array}$ & $\begin{array}{l}\text { Apps support opportunities for open-ended content and } \\
\text { children's independent use of increasingly difficult features }\end{array}$ \\
\hline (Milman, Carlson-Bancroft, \& Boogart, 2014) & $\begin{array}{l}\text { Provide different choices for engaging students with content. } \\
\text { Encouraged students to delve deeper into the content }\end{array}$ \\
\hline (Neumann, 2014) & Help to acquire name writing and letter sound knowledge \\
\hline (Neumann \& Neumann, 2014) & potential to enhance children's emergent literacy skills \\
\hline (Allen, Hartley, \& Cain, 2015) & Learning new word-referent relations using an iPad. \\
\hline (Bird \& Edwards, 2015) & Learning to use technologies through play \\
\hline (Bus et al., 2015) & $\begin{array}{l}\text { children's positive answers to embedded questions about } \\
\text { complex words or about the story content }\end{array}$ \\
\hline (ChanLin, 2015) & $\begin{array}{l}\text { Engage students for reading and avoiding illiteracy in } \\
\text { underserved communities }\end{array}$ \\
\hline (Chien et al., 2 & $\begin{array}{l}\text { Enhanced the children's concentration and their willingness to } \\
\text { learn and interact with others }\end{array}$ \\
\hline
\end{tabular}




\begin{tabular}{|c|c|}
\hline Citation & Literacy Skill \\
\hline (Falloon, 2015) & $\begin{array}{l}\text { Supported learner collaboration in coordination, } \\
\text { communication, material organization, negotiation, } \\
\text { interactivity, mobility. Blurring in the line between learning in } \\
\text { formal school and informal environments }\end{array}$ \\
\hline (Flewitt et al., 2015) & $\begin{array}{l}\text { Help to equip all children with different levels of technological } \\
\text { confidence and competence }\end{array}$ \\
\hline (Hiniker et al., 2015) & $\begin{array}{l}\text { The way children are prompted to interact with the tablet apps } \\
\text { directly impacts their understanding and their ability to engage } \\
\text { with content. }\end{array}$ \\
\hline (E. Khoo, Khoo, Merry, \& Bennett, 2015) & Support young children's emerging learning and interests \\
\hline (Kucirkova, Sheehy, \& Messer, 2015) & $\begin{array}{l}\text { dynamic co-construction of the authentic and multimedia } \\
\text { stories parents and children shared }\end{array}$ \\
\hline (Noorhidawati, Ghalebandi, \& Hajar, 2015) & $\begin{array}{l}\text { Learning engagement: collective sensory experience, } \\
\text { emotional expression, and verbal expression }\end{array}$ \\
\hline (Price et al., 2015) & $\begin{array}{l}\text { Continuous provision for drawing on a regular basis in } \\
\text { fostering the development of literacy skills. Additional playful } \\
\text { approach to drawing }\end{array}$ \\
\hline (Toohey et al., 2015) & $\begin{array}{l}\text { By creating digital products externalize their implicit } \\
\text { knowledge of the topic, build an argument, uses language, } \\
\text { make choices, }\end{array}$ \\
\hline (Vatavu et al., 2015) & $\begin{array}{l}\text { development of motor skills in children and relation with digital } \\
\text { literacy acquisition }\end{array}$ \\
\hline (Westlund et al., 2015) & Word learning \\
\hline (Wohlwend, 2015) & collaborative literacy play \\
\hline (S. S.-H. Wong, 2015) & $\begin{array}{l}\text { Children multimodal literacy practices, motivates literacy } \\
\text { learning and provides opportunities for independent } \\
\text { exploration and creation }\end{array}$ \\
\hline $\begin{array}{l}\text { (Aladé, Lauricella, Beaudoin-ryan, \& } \\
\text { Wartella, 2016) }\end{array}$ & $\begin{array}{l}\text { Greater transfer of knowledge. Interactivity contributed to } \\
\text { better performance on near transfer tasks. }\end{array}$ \\
\hline (Arnott, Grogan, \& Duncan, 2016) & $\begin{array}{l}\text { allow children to articulate their creative play and to encourage } \\
\text { involvement in the research process }\end{array}$ \\
\hline (Clarke \& & $\begin{array}{l}\text { Improvements and greater readiness in pupils' ability to grasp } \\
\text { initial key concepts in literacy and numeracy. Motivation, } \\
\text { concentration, and confidence grew. Spontaneous peer } \\
\text { collaboration. Improved pupil communication, listening and } \\
\text { fine motor skills. }\end{array}$ \\
\hline (Eisen \& Lillard, 2016) & $\begin{array}{l}\text { Children's preferences to learn about different topics: cooking, } \\
\text { today's weather with a tablet }\end{array}$ \\
\hline (Rossetto \& Dutra, 2016) & $\begin{array}{l}\text { Allow to use visual elements that encourage reading and } \\
\text { writing }\end{array}$ \\
\hline (Gómez-Domingo \& Badia-Garganté, 2016) & $\begin{array}{l}\text { use of a set of Apps in the classroom facilitates access to } \\
\text { information and increases engagement to learning }\end{array}$ \\
\hline (Huber et al., 2016) & Children transfer learning from tablet to physical versions \\
\hline (E. G. L. Khoo, Falloon, \& Nguyen, 2016) & $\begin{array}{l}\text { Potential as a shared, public learning device, and enabled } \\
\text { young children's ease of sharing content and working } \\
\text { together. }\end{array}$ \\
\hline (Kirkorian, Choi, \& Pempek, 2016) & Learning words from contingent video in a touchscreen \\
\hline (Lovato \& Waxman, 2 & $\begin{array}{l}\text { Power of interaction: learning transfer and word learning. } \\
\text { Social interaction: Shared story time }\end{array}$ \\
\hline (Neumann, 2016) & \begin{tabular}{|l}
$\begin{array}{l}\text { Potential benefits of tablet writing for emergent literacy } \\
\text { learning }\end{array}$ \\
\end{tabular} \\
\hline (Schroeder \& Kirkorian, 2016) & Interactivity leads to learning from watching instead of playing \\
\hline (Sheehan \& Uttal, 2016) & Interactivity and multimodal \\
\hline (Wang, Xie, Wang, Hao, \& An, 2016) & Transfer knowledge from touchscreen to other media \\
\hline (Chmiliar, 2017) & $\begin{array}{l}\text { improvement in learning outcomes in areas like: shape and } \\
\text { color recognition, letter recognition, and tracing letters }\end{array}$ \\
\hline
\end{tabular}




\begin{tabular}{|c|c|}
\hline Citation & Literacy Skill \\
\hline (Fokides, 2017) & $\begin{array}{l}\text { iPad as a game-like application is a satisfactory tool when } \\
\text { teaching programming concepts to young students }\end{array}$ \\
\hline (Neumann et al., 2017) & $\begin{array}{l}\text { Relationship between emergent literacy skills, emergent } \\
\text { digital literacy skills, and proficiency in reading and writing }\end{array}$ \\
\hline (Russo-Johnson et al., 2017) & $\begin{array}{l}\text { Learning words from the content and transferring to the real } \\
\text { object }\end{array}$ \\
\hline $\begin{array}{c}\text { (Stacy, Cartwright, Arwood, Canfield, \& } \\
\text { Kloos, 2017) }\end{array}$ & $\begin{array}{l}\text { Motivate children's informal math practice, independently of } \\
\text { the setting, the student's age, or the math concept that was } \\
\text { tackled }\end{array}$ \\
\hline (Tarasuik, Demaria, \& Kaufman, 2017) & $\begin{array}{l}\text { 4-6-year-old children are capable of transferring the ToH } \\
\text { learning from touchscreens to the physical version of the } \\
\text { puzzle. }\end{array}$ \\
\hline (Völkel, Wuttke, \& Ohler, 2017) & $\begin{array}{l}\text { Supports development of children on three central } \\
\text { dimensions: emergent literacy, the understanding of numbers } \\
\text { and quantities, and media literacy }\end{array}$ \\
\hline $\begin{array}{c}\text { (Zimmermann, Moser, Lee, Gerhardstein, \& } \\
\text { Barr, 2017) }\end{array}$ & \begin{tabular}{|l|l|l}
$\begin{array}{l}\text { Social demonstrations enhance learning from novel } \\
\text { touchscreen tools during early childhood }\end{array}$ & \\
\end{tabular} \\
\hline $\begin{array}{c}\text { (Cordero, Nussbaum, Ibaseta, Otaíza, \& } \\
\text { Chiuminatto, 2018) }\end{array}$ & multimodality and technology support reading and writing \\
\hline (Fleer, 2018) & $\begin{array}{l}\text { Digital animation promotes play complexity and increase } \\
\text { social and cognitive demands: children's development }\end{array}$ \\
\hline (Fridberg, Thulin, \& Redfors, 2018) & \begin{tabular}{|lll}
$\begin{array}{l}\text { Learning science phenomena. Opportunities for literacy } \\
\text { learning }\end{array}$ & & \\
\end{tabular} \\
\hline (Gillen \& Kucirkova, 2018) & $\begin{array}{l}\text { promote productive spaces for children's continuous and rich } \\
\text { experiences together with home activities. }\end{array}$ \\
\hline $\begin{array}{c}\text { (Hatzigianni, Gregoriadis, Karagiorgou, \& } \\
\text { Chatzigeorgiadou, 2018) }\end{array}$ & $\begin{array}{l}\text { Motivation, engagement, enthusiasm and eager to explore } \\
\text { anything new }\end{array}$ \\
\hline (Herodotou, 2018) & $\begin{array}{l}\text { Literacy development, mathematics, science, problem- } \\
\text { solving, and self-efficacy }\end{array}$ \\
\hline $\begin{array}{c}\text { (Huber, Yeates, Meyer, Fleckhammer, \& } \\
\text { Kaufman, 2018) }\end{array}$ & $\begin{array}{l}\text { Children's working memory improved after playing the app. } \\
\text { Executive functioning, interactivity and content should be } \\
\text { considered than simply "screen time". }\end{array}$ \\
\hline (Kanero et al., 2018) & Interaction with social robots scaffold language learning \\
\hline (Kirkorian, 2018) & Interactivity promotes transfer information across contexts \\
\hline (Kirova \& Jamison, 2018) & $\begin{array}{l}\text { The kids already had rich digital experiences so they can } \\
\text { focus in creating multiliteracy texts through targeted } \\
\text { verbalization, questioning, joint problem solving, } \\
\text { demonstration, and modeling. }\end{array}$ \\
\hline (Marsh et al., 2018) & promotes play and creativity using apps not aimed at their age \\
\hline $\begin{array}{l}\text { (Moser, Olsen, Rusnak, Barr, \& } \\
\text { Gerhardstein, 2019) }\end{array}$ & $\begin{array}{l}\text { Toddlers' ability to self-generate labelling. Better imitation } \\
\text { performance }\end{array}$ \\
\hline (Neumann, 2018) & $\begin{array}{l}\text { platform to take ownership of their learning and explore print } \\
\text { using a stimulating and engaging touch-based digital tool. }\end{array}$ \\
\hline (O'Byrne, Stone, \& White, 2018) & $\begin{array}{l}\text { emerging digital storytellers. Develop enhanced } \\
\text { communication skills by learning to organize their ideas, ask } \\
\text { questions, express opinions, and construct narratives }\end{array}$ \\
\hline (Peebles, Bonus, \& Mares, 2018) & interactivity promotes learning \\
\hline (Samur, 2019) & $\begin{array}{l}\text { self-supported learning contexts with little adult input and with } \\
\text { minimum outside interference }\end{array}$ \\
\hline $\begin{array}{c}\text { (Trifunović, Čičević, Lazarević, Mitrović, \& } \\
\text { Dragović, 2018) }\end{array}$ & enhancing children's knowledge about traffic signs \\
\hline $\begin{array}{l}\text { (Vatalaro, Culp, Hahs-Vaughn, \& Barnes, } \\
\text { 2018) }\end{array}$ & increase children vocabulary knowledge \\
\hline (Yelland, 2018) & $\begin{array}{l}\text { Acquisition of foundational literacy (and numeracy) skills, } \\
\text { creating multimodal texts }\end{array}$ \\
\hline
\end{tabular}


In 2019 more research is giving answers of the relevant place that haptic devices are taking into education, and the implications for children, parents, teachers, health professionals, and policymakers, e.g.:

\footnotetext{
Hietajärvi, L., Salmela-Aro, K., Tuominen, H., Hakkarainen, K., \& Lonka, K. (2019). Beyond screen time: Multidimensionality of socio-digital participation and relations to academic well-being in three educational phases. Computers in Human Behavior, 93, 13-24. https://doi.org/10.1016/J.CHB.2018.11.049

Hightower, B., Lovato, S., Davison, J., Wartella, E., \& Piper, A. M. (2019). Haptic explorers: Supporting science journaling through mobile haptic feedback displays. International Journal of Human Computer Studies, 122(September 2018), 103-112. https://doi.org/10.1016/j.ijhcs.2018.09.005
}

Sangiorgi, A., Gorlewicz, J., \& Schembra, G. (2019). Demo: Propelling Haptic Devices into the Mobile World to Advance K-12 STEM Learning, 403-404.

From the above we conclude that haptic devices can foster knowledge, literacy, and reasoning. They are transversal tools to develop knowledge and understanding in literacy learning within different contexts, motivations, ages, diversity, and interests. A combination of technological and traditional approach will encourage and balance the learning experience.

Haptic devices and Apps give learners the opportunity to self-instruct, and improve their own learning process according to their interests and needs, and without waiting for peers, school years to pass, or fulfill academic level to achieve it. The stages for knowledge development are not fixed anymore, depend on the learner capacities and abilities. Also, this type of devices brings learning and teaching to all types of learners, including, learners with developmental disorders such as autism, learning, communicative, and psychomotor disabilities; learners with exceptional intellectual abilities, and learners of all ages in whatever physical condition they are, or job there are developing.

\subsubsection{Avoiding Illiteracy}

Literacy can be approached as a process of acquiring basic cognitive skills (emergent literacy), where young people and adults develop literacy as an autonomous set of skills (reading, writing, oral, numeracy, visual, and digital), and use those skills to contribute to socio-economic development, to increase social awareness capacity and critical reflection as a basis for personal and social changes (Burnett et al., 2005b).

Literacies can be divided in two blocks: core literacies that imply the ability to read and write (the three Rs: Reading, wRiting, and aRithmetic); and the ICT literacies that include the digital and the visual that enable access to digital information, and its proper interpretation.

Although reading, writing, and arithmetic literacies have been a high priority on the development agenda of the Sustainable Development Goals of the United Nations Educational, Scientific and Cultural Organization (UNESCO) over the past decades, UIS data show that 750 million adults of the world are considered illiterate because they lack basic reading and writing skills in 2016. 102 million out of those 750 are people between 15 and 24 years old (UNESCO, 2017c). 
"The education for All" (EFA) in its global Monitoring Report gives account of the benefits of the acquisition of the literacy skills on individuals, families, communities, and nations (EFA_Global, 2005). As (Stromquist, 2005) affirms "in modern societies, literacy skills are fundamental to inform decision-making, personal empowerment, active and passive participation in local and global social community". The benefits are classified as human (self-esteem, empowerment), political, cultural (cultural change, preservation of cultural diversity, social (health, education, reproductive behavior, gender equality), and economic (economic growth, returns to investment). To reduce all forms of illiteracy in any sector of the population at any age is one of the core challenges raised by $\mathrm{EFA}^{35}$ Goals.

Sugata Mitra ignited in 1999 in India his project "Hole in the Wall" that gave account of how groups of children can learn almost anything by themselves in a collaborative way if they have a computer connected to internet (Mitra, 2003). The School in the cloud launched in 2014 with The SOLE (Self Organized Learning Environment) were aimed at children with no educational opportunities. The experiments proved that exposure to IT allows children to acquire the ability to read, understand, search and analyze deep questions (Big Questions are the spark that ignites a SOLE session) if they work in groups (Mitra \& Quiroga, 2012).

The affordances of the tablets, among other future haptic devices, could be the logical evolution of Mitra work, and also could help to reduce illiteracy all over the world (UNESCO, 2017c). The size, storage capacity, ubiquity, portability, price, and in-built features for learning purposes make of the haptic devices the best allies of any educative organization to enhance the literacy skills and practices of all individuals worldwide.

Initiatives aimed at eradicating illiteracy in the third world are beginning to emerge since digitization is not an idea, but a fact. For example, Fund. Telefonica, Spain is developing programs aimed to increase education using tablets. As Cesar Alierta (Fund. Tel. CEO) explains, in the frame of Profuturo developing programs in Lupane (Africa) (the program is aimed to increase education among African kids) the total cost per kid from 5 to 17 years old is 270 euros (Fund. Telefónica, 2018b). The project is a unique opportunity that will not only allow them access to a quality education, but also recover the hope and future prospects without which they had to live in the past years (Profuturo Educacion, 2017).

The use of those devices helps to personalize learning implemented in vulnerable environments, with or without connectivity available. Haptic devices can be adapted to each educative institution, even country cyber-laws, attending to the academic level, language, sociocultural context, and the educational needs of the students and their teachers. Students and teachers are trained in the use of digital tools, what helps them to improve digital competence and invites them to promote collaborative work. This is aimed at creating a major international network of centers to teach, learn and share knowledge, resulting in breaking down the "walls of the school" (Kanga, 2018).

${ }^{35}$ EFA: Education for All (UNESCO). 
The advantages of the haptic devices can also be seen in the personalization of the devices into their cultural practices and customs. The possibility of content creation also could help to preserve their languages, keep record of their traditions, and in cases of small tribes, avoid cultural extinction.

Another important advantage is placed in the preservation of cultural heritages. For example, the accessibility on a haptic click of passing down Indigenous Australian knowledge recorded with the original voices of the Grands. As their culture explains "The only way to gain a deeper understanding is to go back to country, sit around with family and listen to stories and just leave behind our western world to learn about our heritage because that's part of our blood" (Morelli, 2017)

For some cultures, dreamtime stories of creations are passed down through storytelling, paintings, song, and dance, so this makes it easy for children to learn at a young age, therefore to have access to these creations from a haptic device gives the cultural heritage to be preserved for other generations and cultures of the world. 


\subsection{Boosting English Language Learning}

Children are born with the ability to master language as a product of the experience, and with the ability to distinguish the sounds of all the languages of the world (Ramirez-Esparza et al., 2017). The infant brain has an innate predisposition to learning, and is wired to gather information from experiences (the context) showing incredible abilities to acquire one or multiple languages by eye or by ear in case of natural exposure. The more children hear the more specialist they become in the languages the children have been exposed to.

According to Stephen Krashen's and his "theory of Second Language acquisition", a second language can be "learned" or "acquired". By acquisition, learners use an intuitive, subconscious process very similar to the acquisition of the mother tongue. It requires meaningful interactions in the target language while giving emphasis on the act of communication, and no purposed instruction is given. It is not important the form of the utterances, but the message conveyed and understood. By learning, learners follow formal instruction, so the mental process is conscious. During the instruction, learners focus on concepts and rules of the target language. Fluency in a second language comes from what learners "acquire" instead of "learn," and that the best way to acquire the target language is by exposition to authentic materials and beyond their current level of competence (natural comprehensible input). Motivation, self-confidence, and low anxiety are variables that help to be confident and do not see the target language as a challenger, but natural (Krashen, 1989). Chomsky theorizes that children "have a language acquisition device in their brains that is pre-programmed to recognize and learn the rules that govern a language," and identifies a critical period to acquire the language target that spans from birth to puberty. According to Chomsky if children are exposed during this critical period, they develop multilingual skills (Chomsky, 2000). Other theories excel the importance of real-life scenarios to acquire faster.

Exposure to language during the first year of life influences the brain's neural circuitry, and enhances children's awareness of the different properties and structures of language (phonemes) (Kuhl, 2010). This linguistic awareness is best acquired during the sensitive period ${ }^{36}$ where the brain is ready to learn specific skills by developing new ways to combine visual, auditory, and language information (ILABS, 2017). Sound awareness is acquired during the first year of life, word learning during the second one, and by the third the own speech skills and vocabulary; what it can predict children easiness to learn to read and write in several languages (Garcia-Sierra et al., 2011).

\footnotetext{
${ }^{36}$ Sensitive period: time in development when the brain is especially ready to learn a specific skill (ILABS, 2016).
} 


\subsubsection{Passive Exposure}

Haptic devices in the hands of children give an excellent scenario for meaningful interactions in English language in a bilingual mode or even multilingual through media content no dubbed to Spanish, and with the possibilities of subtitles for better understanding in other languages like French, Chinese, or German. The media content available in their original language can be considered natural comprehensible inputs (authentic material) that goes beyond learner's competency level. Children are using the target language while interacting with the device, playing with games, watching streaming videos in native language, what offers many examples of meaningful social contexts where the target language is used by native speakers in native contexts. The experiences offer personal motivation, self-confidence, low-anxiety to acquire the fundamentals of a second language naturally, among other reasons because the learner is not conscious of the learning.

Benefits in bilingualism can be found either in simultaneous or sequential bilingualism. The simultaneous bilingualism refers to the experiences of a child who receives language input from two different languages simultaneously beginning either at birth or typically very early on in infancy. The sequential bilingualism refers to the experiences of a child who learns one language after the other. Research shows that in both cases there are cognitive benefits for bilingual learners during the infant period.

The bilingual children, in difference with monolinguals, must code switch (alternate between the two languages) when interacting. To do that they need different cognitive resources that those used for simple language acquisition. The benefits have been observed in how bilingual children focus better than monolingual in one particular aspect of the action, change predicted responses, switch attention from one task to another, and show better self-control when acquired at early ages (Sorace \& Serratrice, 2009). There are also positive results of better performing at mental puzzles (Martin-Rhee \& Bialystok, 2008) what suggests that the bilingual experience improves reasoning, to plan ahead, to solve problems, better control of attention (Olsen et al., 2015), and better description (step by step) of all the facts that have happened in a specific situation in any of the languages (Olsen et al., 2015) For our HG Case Study, Child I described what has happened from one moment to another, giving details of any action or thing she could observe, even all the actions she took when performing a task with her tablet, switching from English into Spanish and vice versa. Giving so many details means that she does not miss anything happening at her surrounding, even if the things are happening in another language.

Despite bilingual children show different language learning patterns, the best way to support children language growth is encouraging high-quality language inputs, increasing language time exposure, and doing it in an attractive context where children feel comfortable.

Entertainment with passive content (movies, TV shows) is one of the favorite pastimes of children when manipulating haptic devices and also one of the main uses that parents give to the device (Chaudron et al., 2018) (Child III, Child IVa, Child IVb). Online streaming video platforms like Netflix, Prime Video, HBO, Clan TV offer movies, TV shows, documentaries, etc. in original language (films, TV shows), what it is a nice opportunity to encourage exposure to high-quality language inputs in English by increasing language time exposure with an attractive tool. 
According to (Kurkela, Hämäläinen, Leppänen, Shu, \& Astikainen, 2019), "passive exposure alone can enhance the learning of foreign speech sounds. The ability to understand and subsequently speak a new language requires the ability to accurately discriminate speech sounds of a given language. In early infancy passive sound exposure is enough to enhance auditory discrimination during the sensitive period" (Kurkela et al., 2019). According to that, children exposed to videos recorded in original language listen speech sounds and enhance their phonemic discrimination ability while they train their brains to detect the differences with their mother tongue. Haptic devices also bring authentic material in their original languages at hand, and offer the possibility to be repeated as many times as the children want. These actions could result very beneficial when learning the language in monolingual families that strive for children's second language proficiency and do not know the language, or traditional classes where they use material in both languages (Olsen et al., 2015).

Apart from cognitive advantage, and discrimination of speech sounds, other aspects of second language acquisition can be promoted when the children are allowed to watch passive content in the haptic device and there is an intentional adult selection of the language of those contents. Those aspects are: better concentration skills, increased creativity, deeper understanding of other cultures, and memory improvement (Mcquillan, 2006). Passive content in English language allows children to be exposed to the language in the same way that a simultaneous bilingual is exposed to two native languages. This exposure gives the chance to acquire the language, through a subconscious process during which they are unaware of grammatical rules, instead of learning it. The mental process used for the second language is similar to the way native speakers use it their mother tongue. Children get a feel for what is and what is not correct by using the language instead of learning by heart the rules.

In order to acquire language, the learner needs a source of natural communication (VanPatten \& Benati, 2015), without direct instruction in the rules of the language, neither conscious knowledge of the new language. Haptic devices allow casual learning environments (Apps, YouTube, video streaming) full of digital authentic material in different formats. Children can learn through play, and improve knowledge using repetition, scaffolding, and audio-video exposure that mix image, sound, and interaction as it was in a real-world situation.

During the passive watching of Disney movies for instance, children receive no instructions on grammar, neither conscious knowledge of the language, but a natural exposure to idiomatic expressions, vocabulary and aspects of the culture that are matched with strong visual hints and authentic pronunciation cues delivered by characters that show the relation and inferences with the language inputs. The authenticity of the learning exposure helps to comprehend and retain information while having fun and provides an excellent soil to create a habit. Unconsciously there is an improvement of speaking, listening, vocabulary, and communication skills in the second language as well as a cultural awareness (Albiladi, Abdeen, \& Lincoln, 2018) that children will demonstrate with time and with more closeness to the second language either in formal setting or informal settings. 


\subsubsection{New Scenario}

Children are natural language acquirers and imitators; they are self-motivated to pick up language without conscious learning. They have the ability to imitate pronunciation and work out the rules for themselves (0. Dunn, 2011). Language input, speech style, and social context has been associate with language acquisition and learning, and have an important impact on early language learning in children, either monolingual children and bilingual (Ramirez-Esparza et al., 2017). One of the best ways to acquire and learn the language is by authentic material or texts which are made by native speakers for non-pedagogical purposes (Bacon \& Finnemann, 1990).

Authentic material offers means for cultural information, and it reflects real situations that the learner will face in any language-speaking environment. Those materials are best suited for the development of skills in speaking, oral, listening, and writing comprehension. Some of the benefits of learning with authentic material is conveying and perceiving meaningful information, to afford the sufficient context for correct interpretation of the symbol with its meaning during the language acquisition process and, a positive attitude towards the target culture (C. Rogers \& Medley, 1988).

Haptic Devices help to use English authentic material in the form of videos, audios, texts, games, and App activities. The English digital material that parents can find and use is endless, updated, interactive, and provides visual stimulation. So, early childhood while using the device with English contents (Fig. 27) can acquire English as a second language rather than consciously learn it. When acquiring the language instead of learning it, the speaking and listening skills improve, the understanding and the deduction of grammar rules improves, the vocabulary improves, as well as the feeling for the culture needed to fully language acquisition. These can happen as the kid is using individual and innate language-learning strategies without conscious learning.

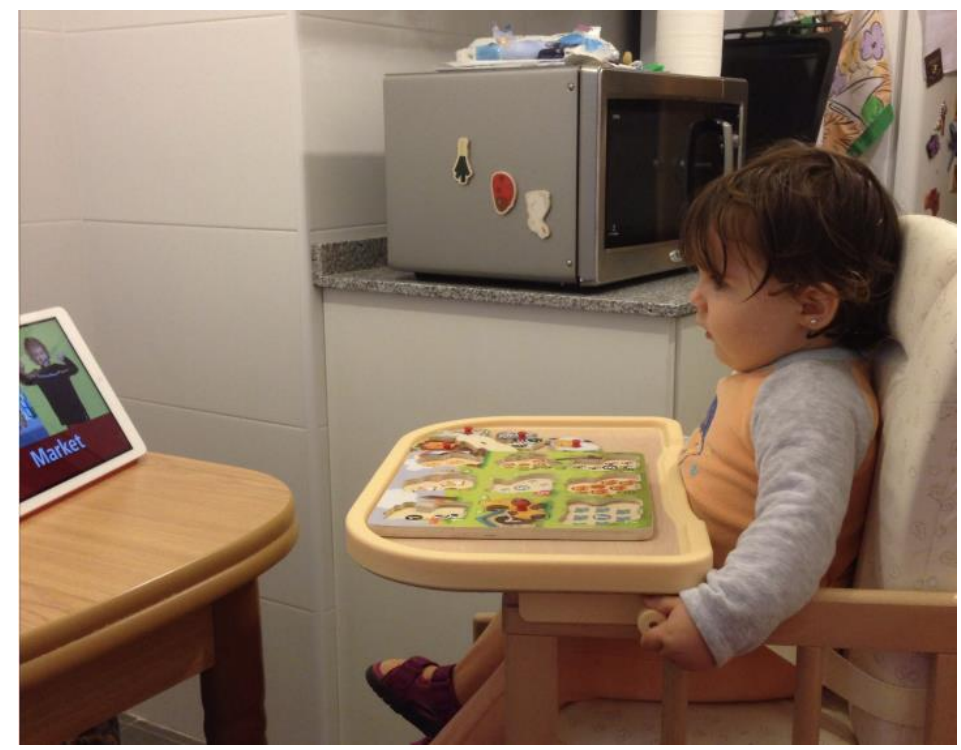

Fig. 27 Watching English contents with the tablet while playing Puzzles (Toddler) 


\subsubsection{Learning English with my Tablet}

Detailed observation has been paid to one of the children of the HG case study (Child I), whose parents have seen the device as a source of English contents since the day the child was born. They have promoted the use of the device with this purpose and have prescribed as a family rule that any use of the tablet had to be done in English language when possible, and only under learning purposes. The device could not be used with the only purpose of playing non-educative games like: soda crush, diamonds, Toy Story, Snow fall, etc. This latter type of use has been allowed when the kid was 6 . As the parents noticed that there were different types of activities that the child could perform with the tablet, the screen time allowed was also differentiated by type of activities: passive exposure to streaming content, personal learning, and school demands. The screen time allowed for streaming content increased as the child grew up, up to two hours per day. For learning purposes and school demands, parents used common sense paying attention to parental policies in what concerned to the when, where, how, and with who.

Child I is an Spanish kid living in Spain has been exposed to digital English contents since she was able to pay attention to a screen (Baby Einstein, Peppa Pig, Doc McStuffins, Disney Movies, etc.) using an iPad. When attending regular classes at her school during the first term of Reception course (being 3 years and 10 months old), she was able to pronounce the sentence "I'm going backwards!!!" while walking backwards repeating the action. According to her teacher, the abstract concept of the action was very difficult to understand for a 3 years old kid, more if the mother tongue was different than English, in this case: Spanish. Also, the teacher pointed out that the word was never spelled out or used in class. When the kid was asked where she learnt it, she answered "Peppa Pig DOES it in my tablet."

The researcher wants to point out the word "does" instead of "said" what implies the understanding of the action and not just knowing the meaning of the sentence "going backwards."

Being 5, the kid demonstrated full command of the second language as it was her mother tongue (simultaneous bilingual) for a kid her age, and compare with Child Ila, who is an English native speaker of the same age (Fig. 28). 


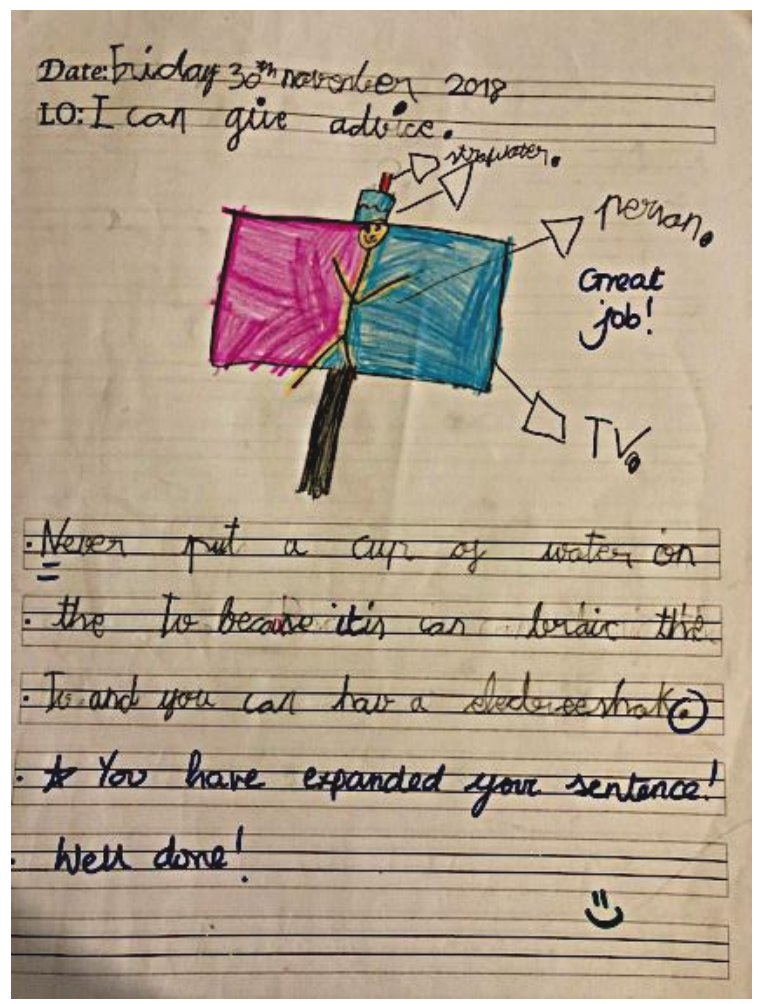

Fig. 28 Child I English writing. (Kindergarten)

Child I plays with language twists in English like in adults do with jokes, search for information or songs in google by typing English language and sounds directly on a browser, and retell the stories that she is watching adding understanding, meaning, and critical thinking to the exposition of second language passive contents. The kid also has showed language transfer (applying the rules of syntax from the first language to the second language), code switching (alternate between the two languages) and code mixing (using both languages in the same sentence when the kid detected a word she could not provide in the intended language but she had it in the other one "Mami dame el overall (Sp. Babero))" or sentences in Spanish with English pronunciation because she does not know the pronunciation in Spanish.

Child I lives in a completely Spanish environment (monolingual), and owns a tablet as a main source for second language contents, authentic material, and passive exposure. She follows the English system for formal education (nursery, reception, year 1, and year 2), where there are other Spanish kids that share Spanish environment and culture, class group, and have been attending the same academic years as Child I.

The Child at 6 has demonstrated higher command of the second language than the other Spanish children that share classroom with her. Being the same number of hours in an English context, and being with the same teachers, we find a difference in the proficient use of the English language. Parents of the other children were asked about this special use, and they stated that, despite having a tablet at their disposal, it was not used with this purpose mainly because the parents did not realize that could be used with this purpose, confirming that children did not use the tablet with English contents, but Spanish. 
Child $\mathrm{I}$ is able to use the vocabulary with the grammar and syntax expressions typically used by a native of her age, and has shown exceptional ability to compare, classify, synthesize, evaluate and infer in the second language, signs of advance fluency that is acquired being 5-7 years in school (Meisel, Clahsen, \& Pienemann, 1981) at her age. Child I is near-native in their ability to perform in content area learning with only 4 courses of English instruction. Her accent, intonation, and word stress used at her age is extremely close to native, if not equal, what signals a huge difference with the rest of the Spanish kids in her class.

Child I uses the second language while role-playing with toys, while explaining something that has happened in English in a real situation, or found with a haptic interaction, when the social context is in English (peers, meetings that she realized are not in Spanish), while using the device under any circumstances. Parent's observation note that the kid does not realized when something happens in English or in Spanish because she does not care, neither pay attention to the language used, and does not do exceptional effort to use any language. When asked "which language did you use?" she answered "I don't know." Her command of both languages is increasing not only by second language acquisition stages but through child mental development stages, as any other native speaker of the same age. Her pronunciation is not biased by Spanish cues, but as she imitates what she hears in media content, is completely natural and native feel.

Child $\mathrm{I}$ is still in her six, and as it has been reported from school, her command of the English language (spelling, reading, writing, listening, expressing ideas, and understanding) exceeds the expectations for her age at academic level.

\subsubsection{Bilingual Informal Education}

To learn a second language so early has multiple benefits not only in language acquisition but also in brain development (Meltzoff \& Kuhl, 2016). By using haptic devices in other language different to mother tongue, the children spend time playing at the same time than learning through gaming activities in an informal context.

Oral expression and drawing are developed before writing, and reading. The mental maturation process brings to children the gradual building up of utterances from one word. They add new words from their informal vocabulary spontaneously: "Peppa" "that's Peppa Pig," and their own input: "Mum, Peppa Pig is eating." The frequency of the exposure and the quality of the experience will help to the creation of whole sentences, in the same way that the acquisition of the first language (O. Dunn, 2011).

When talking about understanding digital contents, it should be noted that it is always greater than only speaking because the input is calling three sense: sight, hearing, and touch, what increases comprehension. Children's skills to understand social contexts in another language should not be underestimated, because for full understanding, they are applying the same context clues than in their mother tongue social context. Equally to their first language, they may consciously not fully understand all the words they are hearing, but the whole situation, and with enough clues to interpret the meaning in the same way that they do in their own language. 
Monolingual Spanish parents that want to provide a bilingual education to their kids, have in haptic devices the perfect melting pots to contribute to increase their children time of exposure to the English language with high-quality and authentic material. The device per se is attractive enough to keep children attention and scaffold the learning through aimed apps or with passive exposure through videos, movies, and TV shows in their original language.

The use of haptic devices to boost English as a second language can be compared with the acquisition of a second language by simultaneous bilinguals even if their parents are monolingual speakers. Children can interact directly with the screen at their pace, as they were interacting with a peer in their mother tongue. Doing it, they do not confront frustration or mistakes when learning the language, because they are not learning the language, they are acquiring the language, so there are no correct or incorrect answers. If children have an opportunity to hear the adult, the character, or avatar repeating the same piece of language correctly (and they can because is a digital content and can be repeated as many times as they want), they will self-correct their mistakes and will improve the language.

High-quality language inputs in English and higher time of exposure using multimedia stories, accelerate at a faster rate the learning or acquisition of a language (Rivera, Mason, Moser, \& Ahlgrim-Delzell, 2014) and determine user's language outcomes. Multimodal digital stories incorporate auditory cues (prosody, pitch, voice characteristics), and visual stimuli (images or representation of the concepts), as well as writing or printing representations of concrete and abstract concepts that can be listened or read it during the same literacy act, enriching the experience and offering a new framework for boosting the learning of a second language at early ages in environments where the second language is not deeply acknowledged by adults, but contrary there is a conscious awareness of the future educative implications of that learning. The more the adults are aware of the possibility of learning a second language if children use passive content with their devices, the less fear the parents will feel concerning the use of interactive contents in English allowing extra exposure and great brain benefits (Kuhl, 2010). 



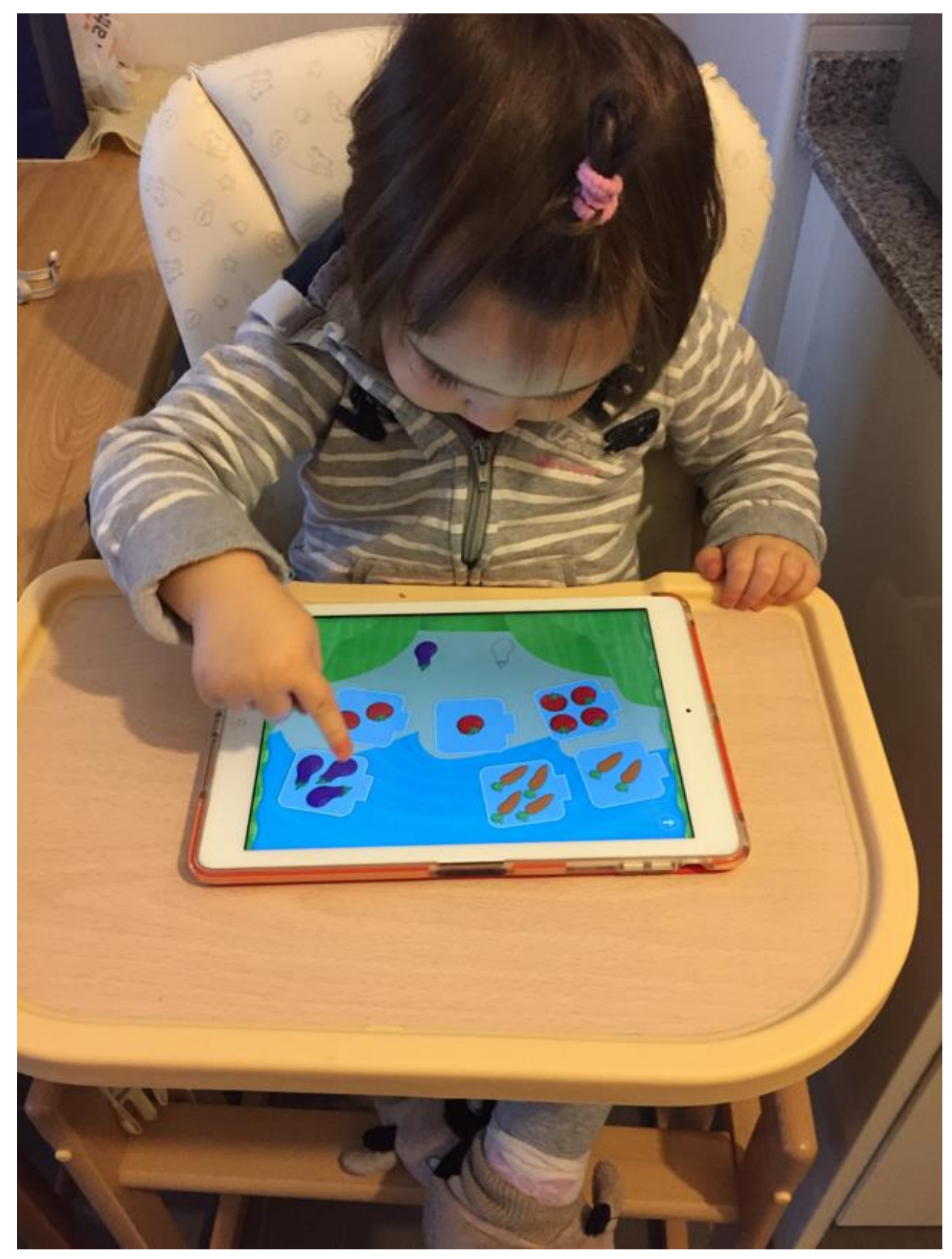

The ischolar

Chapter 6 

"It is not about making learning happen; it is about letting it happen."

Sugata Mitra 



\subsection{The 2030 University Student}

Chapter 5, we were answering the research question "Can Haptic generation children boost creativity, literacy, and bilingualism while using haptic devices?". After analyzing the research conducted, we posit that "yes, children can boost expert knowledge with the use of haptic devices" what it hurries up us to consider research question number two: "If children can boost expert knowledge, what type of student does Spanish Higher Education System expect by 2030?"

Those children will face university degrees as students by 2030, and they will presume to match their needs and future careers once they arrive, but, as in any other previous generation, not all the children will have followed the same educational path during their early years.

As we have posited in previous chapters, the education path will depend not only on their personal preferences, their culture, their positive relationships, the enabling environment that surrounds them, and how important is for the family the concept of learning, but also their relationship with haptic device usage. Including the interaction with haptic devices as a variable of influence, the diversity increases, as we have seen for children of HG case study.

Right now, there is a controversy regarding the use of haptic devices by young children, and the debates go around if they can boost or harm learning, the amount of screen time desirable under pediatrics point of view, if the devices have teaching capabilities or not, or if they can substitute formal learning settings.

"Swinburne Babylab" (http://www.swinburne.edu.au/research/mental-health/facilities/babylab/), "The Institute for Learning \& Brain Sciences (I-LABS)" (http://ilabs.uw.edu/), or "The New Zealand Council for Educational Research (NZCER)" (www.nzcer.org.nz), are examples of research institutions that are conducting studies on how haptic devices are being used by children and the implications in their brains, and therefore, in their learning. 
Researchers like Garry Falloon (Professor of Digital Learning and the Fairfax Foundation Chair in Education at Macquarie University in Sydney, Australia), Michelle N. Neumann (Lecturer in the field of early childhood, computer, and science education at Griffith University, Australia), Jordy Kaufman (Associate Professor and Babylab director at Swinburne University of Technology in Hawthorn, Australia), Brittani Huber (Post-doctoral Researcher at Swinburne University of Technology in Hawthorn, Australia), Natalia Kurcikova (Professor of Early Childhood Education and Development at University of Stavanger, Norway), and Andrew N. Meltzoff (Professor and Co-Director of the University of Washington Institute for Learning \& Brain Sciences, USA), among others, are obtaining positive results on how the use of tablets support emergent, and early literacy learning either in formal, or home environments. Patricia Kuhl (Professor and Co-Director of the University of Washington Institute for Learning \& Brain Sciences, USA) researches on early language and brain development, bilingualism, and foreign-language experience in infancy. Due to HapGen children are still very young (the oldest is 9 years old in 2019), it is very difficult to guess the learning potential of those kids by 2030, as well as the bilingual acquisition in appropriate circumstances, a difficult topic to investigate under lab conditions. Andrew N. Meltzoff and Patricia Kuhl participated in EnlightED 2019 (Reinventing Education in a Digital World) panels like "Should high quality STEM education be the top priority?" and "Language Learning and Technology" promoting a debate about the topics already envisioned when formulating the research questions of this dissertation: the future implications for education of the irruption of haptic devices in our society, and consequently, in early childhood lives; a research field still very incipient.

\subsubsection{The ischolar Birth}

\section{"2,620 Kg. newborn arrived to town. Welcome Home."}

From the hospital delivery room, the good news is instantly texted to relatives and friends that wait outside the room or even in another cities. A selfie of the happy family is immediately shared by WhatsApp, and Telegram. Happy feelings are broadcasted through YouTube and Facebook, Twitter and Instagram instantly uploaded. Different pictures of the newborn in differ ent positions, alone, with hospital staff, with dad, with mum are taken the only purpose to keep the moment in their memories, but also in the memory of the haptic devices. They are at hand, several in the same room. The baby is Geo-located, social-network introduced, snap-shots cloud stored, blogged, emailed, inserted in google birthday's calendar to remember, and, consequently, immediately socially community liked and commented by acquaintances or just anonymous people, with just a few fingertips on a small screen connected to internet.

The welcoming scene, a digital introduction to their families using one fingertip on a smart screen, is the most repeated scene in any hospital since 2012, and it just requires a pocket haptic interface, essential item in the handbags of the proud parents.

Once at home, around them, together with other toys, a haptic device is always in sight to interact with (Smartphone or tablet). And when they start fixing the attention, their caregivers show them family photos and videos stored in their devices. Parents speak about family people from real inputs, and use the language to start the process of recognition and name labelling. 
Real images of the members of the family that are not around at that moment, are immediately related with sounds, faces, and memories. Babies can, at the same time, listen to the music stored in the haptic devices, or kept in streaming services. They can also listen to family real voices that say hello to them in a voice message of in a FaceTime video chat. There is no wait nor distance to show the loving emotions that their lives have brought to the family.

Just being a few months old, those babies receive many learning inputs from just one haptic movement that involves the touch, the hearing, and the sight senses in one. On-site experiences of babies among two to five months old, show they are fixing their attention directly to the finger haptic tips (Kabali et al., 2015). The small little movement made by just one fingertip capture their attention completely associating several senses in just one tip: the auditory, the tactile, and the visual senses.

(Saby, Meltzoff, \& Marshall, 2013) have reported findings regarding how babies rapidly learn new skills and customs while imitating others' actions. Those actions are influenced by many factors, including the specific means by which the observed action is carried out. (Meltzoff, 2007a) made head-touch studies in preverbal babies incorporating a remote effect, and results show that infants can learn novel interventions by just pure observation. Touching an icon on a haptic device, as specific facilitator used to accomplish a goal, like any other action, is preserved in infants' action representations (Meltzoff, 2007a) giving as a result: imitation, integration of new habits and routines, creation of new-personal skills; and new brain abilities. All those results allow infants to go beyond the limits of their own capabilities (L. Vygotsky, 1978), and creativity.

It is well known that not all the kids learn at the same pace or in the same way, neither at the same speed, nor with the same resources, tools or the same motivation (Marina, 2012). It is also true that humans learn by different means: priming, habituation, conditioned responses, semantic learning, through action (National Research Council, 2000), and also by creativity, a way of gaining imaginative knowledge by transferring rules from one context to a completely different one (Hoffmann, 2011).

The irruption of the haptic interaction (Chapter 1 ) brought another form to gain knowledge where, in just one fingertip, it converges the rest of the learning precursors. The specific movement, so frequent nowadays, is going to innovate the entire educative system incorporating a new personal portfolio of alternatives (Hill, Brandeau, Truelove, \& Lineback, 2014).

Haptic devices introduce new habits in users' brain. If a preverbal baby learns from haptic feedback, the habit acquired will rarely be altered. A haptic habit starts with just repetition of a few regular "moves" and ends up with a flexible orchestration and deployment of actions opening a whole new world to learn new things, to research, to create, to collaborate and share with peers, and to become expert in multi-fields (Gardner \& Davis, 2013). Neuroscience has proven that the brain is continually organized by itself in response to different kinds of stimulations (Boyle \& Gill, 1998). Haptic feedback let us infer a modified brain that will accelerate children's language and cognitive growth (Gardner \& Davis, 2013), will allow kids to become experts before age cues, and will solve problems that still do not exist with solutions that do not even know, enabling those kids to grow as the iScholars of the Haptic Generation. 


\subsubsection{Context}

In Section 2.4 we described the main customs and attitudes that are guiding how children are being nurtured. As a member of the current society, they are growing up as the wealthiest, technology supplied, and formally educated generation.

Following (McCrindle \& Wolfinger, 2009) those kids will have the student's label longer than any other generation, and will be surrounded by more than 5 screens, voice assistant, and big data. If we observe children from a global and distant perspective, we notice that children have at their hands different technological powerful tools to enhance learning at any age. As described in Chapter 5 , the haptic devices could act as extension of their brains to allow expert knowledge since the very beginning (Gopnik et al., 2001). As learning tools, those devices are the most effective if they are used adequately.

It is clear that children imitate parent's behavior with interactive screens (smartphones, and tablets). The parent's haptic interactions have different purpose and frequency, according to their personal behaviors regarding the devices, type of jobs, and education attainment. Behaviors that children mimic easily because at these age stages children imitate what their caregivers are doing, as we can infer from HG Case Study.

The HG Case Study shows that home support and the family approach to haptic devices as a tool for learning, link children's exploration and involvement with the devices. Family usage and perspective on the device, make that not all the children use the devices in the same way, neither with the same purpose. Individually, after the analysis of the data collected, we observe that children have different frequencies in haptic interaction that are directly related to family rules, and their curiosity for new knowledge (expert knowledge and reasoning), leading in some cases to literacy learning ahead to their age.

To infer the frequency of haptic interaction (HA_int) and device's use, as it has been determined in Chapter 3 , and fully described in Chapter 5, we take into account several of the variables described as well as the family behaviors toward haptic devices that have been reported in Chapter 4:

- Home environment: number of haptic devices in 2012, 2015 and 2018. User/owner of the device.

- Adult device's interaction: Communication; Leisure and entertainment; creation and productivity; information and learning.

- Main Use of the device in the hands of the children from parents' point of view: to calm down or babysit, learning, communication, gamming, other.

- Parenting style for haptic device use (Baumrind, 1966):

- Pro (Authoritative): Consent use and control child's use. Give priority to child's benefit and abilities when using the device; Encourage children independent use, 
autonomy, curiosity, and creativity, offering opportunities for learning, active approach, support, and co-usage. (Family I)

- Moderate (Permissive): low enforcement of rules when using the devices. High acceptance of use whatever use they want to give, little interaction when using the devices, little control on the activities, (Family II) (Family III)

- Prudent (Authoritarian): Expecting obedience while using the device. Not ready to accept independent use. Neglect child's curiosity towards the device. Little communication when reasoning the use or not. Highly directive behaviors. (Family V)

- Neglected (Negligent): little interaction with the child, inattentive to the uses of the devices, only entertainment purposes, no control of contents (Family IV)

- Language for interaction: English, Spanish.

- Child device interaction

- Child's motivation: literacy learning, gaming, imitating, entertainment, reading, communicating.

- Child involvement in the learning experience: active role, engaged, purposeful, scaffolded exploration, motivated

Summarizing the results obtained after three interviews with the parents realized in January 2015 over the period 2013-14, January 2017 over the period 15-16, and January 2019 over the period 17-18, we can read from Tables 6 and 7 (Chapters 3 and 7 ) that:

- Child I (2012) shows a 100\% HA_int frequency. iScholar.

- Child lla (2012) shows a 75\% HA_int frequency. iScholar.

- Child IIb (2014) shows a 75\% HA_int frequency. ischolar.

- Child III (2012) shows a 23.3\% HA_int frequency. Analog.

- Child IVa (2014) shows a 20\% HA_int frequency. Analog.

- Child IVb (2017) shows a 15\% HA_int frequency. Analog.

- Child Va (2012) shows a 36.7\% HA_int frequency. Savvy-Tech.

- Child Vb (2012) shows a 20\% HA_int frequency. Analog.

\begin{tabular}{|c|c|c|c|c|}
\hline \% haptic Use & 2013-14 & $15-16$ & $17-18$ & Arithmetic Mean \\
\hline Child I (2012) & 100 & 100 & 100 & 100 \\
\hline Child Ila (2012) & 70 & 75 & 80 & 75 \\
\hline Child IIb (2014) & - & 70 & 80 & 75 \\
\hline Child III (2012) & 25 & 30 & 15 & 23.3 \\
\hline Child IVa (2014) & - & 20 & 20 & 20 \\
\hline Child IVb (2017) & - & - & 10 & 10 \\
\hline Child Va (2012) & 10 & 40 & 60 & 36.7 \\
\hline Child Vb (2012) & 10 & 20 & 30 & 20 \\
\hline
\end{tabular}

Table 7 Haptic Use and Interaction during research (own source)

As we can observe in case of Child IIb and Child IVa there is no data in period 2013-14, neither for Child IVb over the periods 2013-14 and 15-16 due to they were not born until next studied period. 


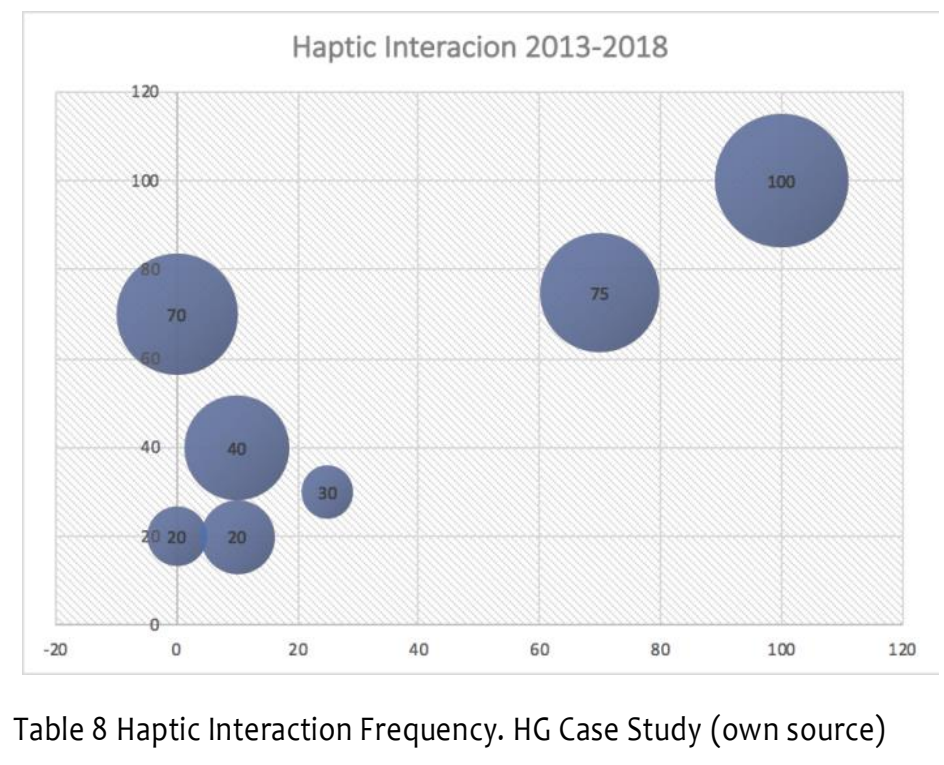

The results show that there are different frequencies that lead to different future uses and implication for learning, and we point out that there is no child with $0 \%$ frequency in Haptic Interaction. The $100 \%$ of the children under research have used haptic devices in the home environment at some point. Even when the parents were not in favor of its usage, they recognized that they cannot prevent them from touching the devices despite they tried very hard because other children around them were using the devices. They feel the topic controversial because they do not want their children "to be out of what is considered normal for the rest." (Children V parent comment).

We conclude that when children reach more than $75 \%$ of HA_Int, they are endowed with an innate Learning Style that promotes expert understanding since they are:

- really involved in the learning experience (engaged, purposeful, scaffolded exploration),

- with an Active role in their own learning process,

- fostering Reasoning activities when learning,

- with an exceptional Open-minded vision,

- and driven by HAptic interactions to nurture their academic knowledge, skills, and competencies

Then they are bestowed to stand out in scholar achievement and therefore should be approached from a different perspective to get benefit of their knowledge and reasoning at adult stages whatever the field they choose to develop their careers. Society has in the haptic generation children the possibility to avoid all types of illiteracy.

We define iScholar to those top learners (> 75\% HA_Int) that will be filling university campuses from 2030, and will have different learning needs. iScholars are the perfect excuse to review how formal learning is organized, to acknowledge of the practices that are not in line with the way they want to work with the information and the subject contents, and that, nowadays is moving ZGen students away from the educative system. 
Haptic devices, together with the imitative gesture that guides learning in early childhood are drivers that enable to propose a new paradigm to understand learning as the best human capacity to excel people aptitudes, make them fit in the global and modern chain of the digital society, and having formal education as part of their breeding soil.

\subsubsection{Definition}

iScholars are defined as those children of the haptic generation (fully digital environment) (20102024) that are nurturing their academic knowledge, skills, and competences through haptic inputs on interactive screens since early childhood (Llobregat-Gómez \& Sánchez-Ruiz, 2015b). They are fully influenced by the digital landscape where they live immersed since they were born. Using tools like haptic devices since they are very young, the learners try new ideas and possibilities, through trial and error, and have no fear to risk. A simple fingertip sparks their curiosity to wards an active, resilient, open, and haptic action.

iScholars learn by being Active actors of their own learning process. For them, Reasoning and discovery come innate and instinctive with every finger touch on an interactive screen. They use an Open-minded ${ }^{37}$ attitude, and growth mindset ${ }^{38}$ to solve problems taking advantage of their creativity, curiosity, talent, and innovative skills. They perform HAptic actions on tech-devices to excel their skills and power their knowledge through one simple gesture that brings three senses in one: touch, hearing, and sight.

iScholars improve understanding and reasoning through test, trial, and error mainly in digital spaces with no borders, or limits. They approach every subject, question, concern, argument, theme, or issue from their personal know-how that includes digital searches and information. Haptic device use combined with personal traits like artfulness, wit, ability, skill, cleverness, intuition, confidence, talent, intelligence, and grit become interest for learning. Interest become motivation. Motivation becomes wonder. Wonder brings passive learning into active exploration. And active exploration becomes expert knowledge and reasoning. Ideas and solutions come in hands of their own resilience to solve problems as well as from Apps, websites and videos that are accessible anytime anywhere.

Haptic feedback (Llobregat-Gómez \& Sánchez-Ruiz, 2015b) (Patchan \& Puranik, 2016) and haptic interaction provides a way to physically engage users through tactile sense with the online experience inferring attention, and reinforcing the actions. Haptic interaction has brought a "haptic age" to our front door (Jütte, 2008) and has made that humans return to the first phases of natural learning, not only in history but also in infancy: by touch.

Through tactile exploration young infants learn about the world, the self, and the environment. This human perception can increase the natural way of learning through new habits that involve the tactile, the auditory, and the visual sense in just one fingertip.

\footnotetext{
${ }^{37}$ Open-minded: willing to consider ideas and opinions that are new or different to your own.

${ }^{38}$ Growth mindset: The understanding that abilities and intelligence can be developed (Blackwell et al., 2007).
} 
With the arrivals of new habits, it is expected to generate new ways to create new knowledge, provoke understanding, and reach expert reasoning (Llobregat-Gómez \& Sánchez-Ruiz, 2015b) that help learners to improve without being tied to old teaching methodologies, and adapt to new learning designs and spaces.

With the use of the devices, children are own-trained through sensory search to look for information with their personal preferences (videos, images, text), and strategies that the latest technology are able to provide. With this training, and the research skills that are innated used during the experience, they demonstrate that there is not a single solution to problems, and that questions can have more than one answer.

Their scholar expertise can be achieved and promoted from novice with the correct theoretical foundations, appropriate context to foster knowledge retention and reasoning, and guided by expert denizens that really understand what the haptic inputs mean from an educative perspective.

\subsubsection{The Future New Setting}

Bologna process sat a model centered in the student (Benelux Bologna Secretariat, 2009), and with the advance of the digitalization, fully digitally skilled "Digital Education Action Plan) (COM, 2018). After strategies aimed to meet the 2020 set by European Commission "Europe 2020 strategy" (COM, 2010), we should start thinking and including Innovative teaching strategies that will meet the expectations not only of the new students that will arrive around 2030, but also of the demands of the industry.

The possibilities of discover-driven learning and design thinking (Hill et al., 2014) that the irruption of the haptic feedback has brought into the learning settings increase every day. The way population, members of the mashup generation (Chapter 2), and the iScholars use the haptic interface by interaction, let us think about the type of learning environment that could nurture soon the thirst for knowledge that a single fingertip generates.

Children are building already their personal learning portfolio out of universities. It is for that reasons that society should set a new space where people are willing to share and combine their talents and passions. The space should fill students perspectives, and feel need of belonging (Hill et al., 2014).

The University of 2030 could be that open and flexible space where formal, non-formal and informal learning become one, with the main purpose of holding a multifield, collaborative, and positive conversation where any learner, but specially the ischolar, that it is the university future engineering student that bring in his backpack native active learning, self-motivation, high level of creativity, and a digital citizenship can take advantage of the new open space, and generate more knowledge. 
As an example of a new learning environment aimed to elementary school children, we have

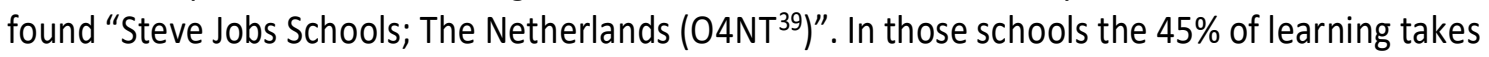
place with the iPad. Since 2013, They give emphasis to the use of the iPad for learning. The aim is to stimulate the iScholar in a unique way aimed to discover their own talents and to develop skills that are of vital importance for the world of tomorrow. The system teaches them how to find information, to filter it to its relevance and to apply it, based on their own inquisitiveness, and at their own pace. Other characteristics are that there are no formal lesson plans, no groups of children of the same age, neither notebooks. They attend 6-weeks workshops that has input from professionals as well as from permanent teachers (Novak_Djokovic, 2015).

Once those iScholar arrive to higher education institutions, they will know, already, how to ask good questions, how to provide adequate context ensuring rigor, they will be and behave creatively (Prensky, 2010), and the most important of all, they will advocate for their point of view (Hill et al., 2014) giving valuable feedback in return to the academic staff. The iScholar will have an active role in the design of their personal learning portfolio.

The iScholars are the fresh air that any educative system needs if the real purpose is to promote learning practices, enhances talent and creativity, to spark linguistic expression, to promote authentic and real situations for learning, to nurture collaboration, communication, and critical thinking, and to inspire the love for learning by rewriting the Spanish intellectual and educational history. ischolars, and their haptic way of learning are the perfect drivers to revise the educative system, and have it as the main priority of the country; as European Commission advanced by having a student-center model aimed to acquire $21^{\text {st }}$ century skills (Commission/EACEA/Eurydice, 2018).

University stakeholders and their educational policies should look at the iScholars that are starting to build up their knowledge in a digital way. They way of learning is different to how previous students learnt. The iScholars are keystones of their own future. For that reason, education should introduce an active and innovative perspective by giving them a prominent role that helps them to succeed without delay. iScholars will imprint a unique digital fingerprint in the instant, global and Digital world where they are cohabitating.

${ }^{39}$ O4NT: Education for a new Era. 


\section{2 ischolar Core Learning}

As it has been explained in RQ 1, the iScholars are developing other core literacies (digital, visual, bilingual) since they start having contact with technology. Framed in a game-context, the children start building their key competences for lifelong learning, and consequently, increasing their universal literacy. As they grow, they need tools, skills, resources, and educators to guide the learning, and face future university subject successfully.

The 2018 Council Recommendation on Key Competences for Lifelong Learning frames the eight key competences ("combination of knowledge, skills and attitudes that students develop and apply for successful learning, living, and working") needed to achieve universal literacy (Council of European Commision, 2018). The competence requirements have change with the irruption of the technology in all working and life areas, what requires citizens to be more resilient and more adaptable. Support for the acquisition should be ensured at all levels of education, training and learning pathways.

The defined Key competences are:

- Literacy competence.

- Multilingual competence.

- Mathematical competence and competence in science, technology, and engineering.

- Digital competence.

- Personal, social, and learning to learn competence.

- Citizenship competence.

- Entrepreneurship competence.

- Cultural awareness and expression competence.

All the key competences contribute to the successful life of any individual in society, and should be nurtured from early childhood through adult life:

"Competences can be applied in many different contexts and in a variety of combinations. They overlap and interlock; aspects essential to one domain will support competence in another. Skills such as critical thinking, problem solving, team work, communication and negotiation skills, analytical skills, creativity, and intercultural skills are embedded throughout the key competences" (Council of European Commision, 2018)

In Europe, an estimated $20 \%$ of adults lack the digital literacy skills they need to function fully in a modern society. Technology is linked with livelihoods, work and social participation (UNESCO, 2017a). The future needs of the haptic generation have the urge to change from low-skilled to proficient-skilled at any scale in education what includes new policies, new curricula, new educative models, and affects teaching staff, parents, and caregivers. 


\subsubsection{Digital Literacy Skills}

The digital Education Action Plan "stresses the need to strengthen critical thinking and media literacy among children and young people" (COM, 2018). It also recognizes the important benefits of digital skills (understood as key competences) at the early childhood education and care (ECEC) to promote, at later stages, creativity, innovation, and digital competence (OECD, 2019). The Agenda credits that the use of digital tools, like haptic devices "can contribute to quality and effectiveness of education, as well as better motivation, understanding and learning outcomes of the students" (Vaikutytè-Paškauskè, Vaičiukynaitè, \& Pocius, 2018).

The iScholars at the age of 6 can operate haptic devices (smartphones, and tablets) with advanced technical skills. Emergent digital and non-digital literacy skills (in general, the ability to read and write) go hand in hand while improving academic learning in formal settings, as well as in informal and non-formal environments by using the devices with personal purposes. Included into their education, as a core learning, the ischolars should master proficient digital literacy (student's ability to create a multimodal text by accessing, reading, organizing, and interpreting online sources, to integrate digital information with non-digital information), and technical knowledge (e.g., basic apps operation, device functionalities) to fully succeed in their careers. The capacity to find, discriminate, use, and orchestrate digital information is the most important ignitor of literacy and knowledge for the haptic generation.

By Proficient digital literacy, we refer to (Neumann et al., 2017):

"the use of digital texts and tools to access, manage, create information, and communicate effectively with others, including the ability to use visual representations, integrate different forms of digital texts, successfully navigate through non-linear digital texts, and critically evaluate digital information Skills involved in critically evaluating and analyzing digital texts encompass searching, selecting appropriate software programs to fulfil a specific task, and identifying erroneous, irrelevant, or biased information".

The Proficient digital literacy skills where the users should be proficient at includes (Neumann et al., 2017):

- Photo-visual literacy: involves the ability to read visual representations (integrated images, words, sounds) of digital text.

- Reproduction literacy: involves the ability to create new information through the integration of fragments of different types of digital texts.

- branching literacy: involves the ability to navigate efficiently through non-linear texts.

- Information literacy: involves the ability to critically evaluate digital information.

- Socio-emotional literacy: involves the ability to effectively communicate with others using digital media.

- Realtime thinking skills that involves the ability to process and evaluate high levels of digital information through, for example, digital games or online chat room experiences.

And also (Simpson \& Walsh, 2017):

- Coding skills: decoding digital texts, operational skills such as scanning, scrolling.

- Semantic skills: using search engines for research, applying inference skills, understanding functions of intertextual links. 
- Pragmatic skills: using hyperlinks, utilizing Google definitions, creating digital texts such as PowerPoints.

- Critical thinking skills: analyzing and evaluating online information, detecting bias, understanding author/audience text purpose.

For learners is a need to implement since the beginning of their scholar lives the teaching of digital literacy to succeed as iScholars. In playmats they have demonstrated that they are already witty apps consumers, extraordinary digital storytellers, clever website inquirers in search of curated content, and resilient problem solvers.

By being proficient in digital literacy, the ischolars will be fully prepared for the challenges of an increasingly and demanding digital world. Those students have been using digital tools to solve problems, communicate, and create innovative digital stories according to their command, cognoscitive development, and age. When using the haptic devices, users should think critically, collaborate effectively, be creative, and solve problems from nothing.

Nowadays, learning does not need a formal or fixed space to produce and consume contents without considering the own learners. Citizens are the protagonists of their own learning process, and the achievement of knowledge by producing and discussing rich media contents, and application. iScholars older than six start using readily available digital content creation tools (video, graphic, or editing tools) to narrate and illustrate a blended understanding of the subject matters. The traditional classroom is, right now, disrupted by creative students that approach to subjects from different digital perspectives. But the digital perspective also represents a cognitive challenge that requires fully understanding for proficiency in some different areas to be acquired along the academic life.

Next paragraphs show the descriptors and aims of the digital competence areas defined by the Joint Research Centre (JRC), the European Commission's science and knowledge service, in the digital Competence Framework for Citizens (DigComp 2.1). There are other frameworks like: "Essential Skills Framework" (UK); "International Computer Driving License;" "International Society for Technology in Education (ISTE)"; "Mozilla Web Literacy", or "Northstar Assessment" that conceptualize, and organize digital competences, and serve as a guidance for educative curriculum. The digital competences and their proficiency levels are described for employment and learning where the future students will develop their careers (Carretero, Vuorikari, \& Punie, 2017).

\section{Digital Competence Areas}

\section{Competence: Information and Data Literacy}

\section{Descriptors:}

- Browsing, searching, filtering data, information, and digital content.

- Evaluating data, information, and digital content.

- Managing data, information, and digital content. 
Aims:

- Be better at detecting bias, assessing accuracy, and making positive use of the information sources that are relevant,

- identify a need for certain information,

- critical awareness and skills to find, evaluate, interpret, and apply information that is relevant to the situation,

- able to effectively manage and ethically share that information for appropriate purposes.

\section{Competence: Communication and Collaboration}

\section{Descriptors:}

- Interacting through digital technologies.

- Sharing through digital technologies.

- Engaging in citizenship through digital technologies.

- Collaborating through digital technologies.

- Netiquette.

- Managing digital identity.

Aims:

- About respectful, positive, and effective participation in digital network,

- presenting the self in an authentic, courteous way and demonstrating respect for the feelings and opinions presented by others,

- be a capable, confident consumer of information and technology,

- active participant as a producer of content.

\section{Competence: Digital Content Creation}

\section{Descriptors:}

- $\quad$ Developing digital content.

- Integrating and re-elaborating digital content.

- Copyright and licenses.

- Programming.

Aims:

- To become a confident creator of digital content,

- bringing together the knowledge gained in each unit of study with own analysis and ideas about a topic or issue,

- leading to the creation of innovative solutions and engaging communication. 


\section{Competence: Safety}

\section{Descriptors:}

- Protecting devices.

- Protecting personal data and privacy.

- Protecting health and well-being.

- Protecting the environment.

Aims:

- Digital Footprint traces of personal and professional information left online, intentionally, and unintentionally.

- Protect privacy: Keeping devices, access passwords, and personal details secure is paramount, as is learning to spot probable identity theft.

\section{Competence: Problem Solving}

\section{Descriptors:}

- Solving technical problems.

- Identifying needs and technological responses.

- Creatively using digital technologies.

- Identifying digital competence gaps.

Aims:

- To access to learning materials,

O how to communicate effectively with other students and staff using email and discussion boards,

o which software to use for producing better: Learn basic coding,

- discover some of the free software tools for presenting and managing content on the web,

- basic knowledge of how technologies like computers, haptic devices, and software programs work.

\section{Proficiency levels of Each Competence}

To acquire Digital literacy is complex. It requires autonomy of use, developing of cognitive domain (remembering, understanding, applying, evaluating, creating), knowledge, skills, and attitudes as part of the personal digital citizenship that will support living, learning, and working. Proficiency in literacy increases over time and reach level of fluencies (identify, explain, illustrate, respond, assess, create) that depend on many factors like motivation, need, and practice among many others. JRC Science Hub has defined eight levels of digital proficiency based in the cognitive domain that is used when performing the competence described. 
Foundation 1.- Identify, find at basic level, and with guidance.

Foundation 2.- Identify, find at basic level with autonomy and appropriate guidance when needed.

Intermediate 3.- Explain, perform well-defined and routine, on my own and solving straightforward problems.

Intermediate 4.- Illustrate, organize, describe organize, independently, according to my own needs.

Advanced 5.- Respond, apply, show, propose by myself and guiding others.

Advanced 6.- Assess, adapt, explain, vary strategies, according to my own needs in complex contexts.

Highly Specialized 7.- Create solutions to complex problems with limited definition, integrate own knowledge to contribute to professional practice and knowledge and guide others.

Highly Specialized 8.- Create solutions to solve complex problems with many interacting factors, propose new ideas and processes.

As specified before, an iScholar at the age of six (Child I), can identify, explain, illustrate, respond, assess, and create digital contents but in line with his physical and cognitive development (motor skills, growth, brain, cognitive). The video created (independently, without adult help) with the App WeVideo contains the user as a main character, basic sentences to explain what she is doing, photos obtained in google, music, and her own persona as a narrator. The egocentric, irreversible, centered, and animatic ${ }^{40}$ story does not have a concrete purpose under adult point of view, but it shows how digital proficient she is because:

$\ddagger \quad$ she has identified the contents she wanted to show in the video (Foundation);

$¥ \quad$ she has explained and illustrated what she was doing (Intermediate),

$\ddagger$ the final video assesses the product the kid wanted to show (Advanced),

$\mp$ and as a creative output, the video shows the many interacting factors that she had to evaluate, understand, remember, and apply to videotape, save, and keep in the device memory (Highly Specialized).

\subsubsection{Visual Literacy}

Images and videos are the natural environment of digital information, communication, creation and productivity, leisure and entertainment, and learning. The arrival of haptic devices has brought the transformation of any textual input into visual formats that summarize information, concepts, and exploration in just one 2D/3D image probably placed in an AR or VR scenario.

To interpret visual information we need "visual literacy" a term coined by Debes from Eastman Kodak in 1969 (Debes, 1969):

\footnotetext{
${ }^{40}$ Animatic: Egocentrism, animism, irreversibility, and centration are characteristics of preoperational Children's reasoning (Kuther, 2019).
} 


\begin{abstract}
"Visual literacy refers to a group of vision-competencies a human being can develop by seeing and at the same time having and integrating other sensory experiences. The development of these competencies is fundamental to normal human learning. When developed, they enable a visually literate person to discriminate and interpret the visible actions, objects, and symbols natural or man-made, that he encounters in his environment. Through the creative use of these competencies, he is able to communicate with others. Through the appreciative use of these competencies, he is able to comprehend and enjoy the masterworks of visual communications" (Debes, 1969)
\end{abstract}

Benedict it defines visual literacy "as the ability to understand and produce visual messages" (Benedict \& Benedict, 1989); And Philip Yenawine as:

"...the ability to find meaning in imagery. It involves a set of skills ranging from simple identification (naming what one sees) to complex interpretation on contextual, metaphoric, and philosophical levels. Many aspects of cognition are called upon, such as personal association, questioning, speculating, analyzing, fact-finding, and categorizing. Objective understanding is the premise of much of this literacy, but subjective and affective aspects of knowing are equally important" (Yenawine, 2013)

Summarizing, visual literacy involves the ability to understand, interpret, infer, produce, and use culturally significant images, objects, and visible actions. As from other literacies, learners can develop the ability to remember, understand, apply, analyze, interpret, evaluate, and create distinct syntax and semantics of the different visual formats through lifetime to increase better skills for effective oral communication, visual, writing, and in a second language (Felten, 2008). Scaffolding teaching should cover thinking from concrete to abstract: factual, conceptual, procedural, and metacognitive in any of the following concepts: technical, visual, contextual, and conceptual (Photopedagogy.com, 2018).

The physical act of seeing involves active construction, and critical interpretation because seeing is not simply a process of passive reception of stimuli but also involves active construction of meaning. Nowadays learners visualize images, and understand the whole concept, but also, they need to write about them, communicate the meaning, the feelings and the believes through the production of other visual products. Interest, needs, and technology are engaged in the same process.

Our iScholars are catalysts of the change in how information arrives to population, and is processed via an explosion of sudden and quick images. For them all can be summarized in an image or in a video. When they are manipulating the devices they are blending, mixing, and matching knowledge drawn from diverse media and sources. They need to develop and acquire competencies for processing and interpreting visual messages, that help them to understand, discriminate, comprehend, and enjoy the visual information that they encounter in the environment.

As we have researched during the dissertation, children get amazed by haptic input. With only one fingertip a sudden image with sound appears in front of them, and they must interpret what it means and what it is for. The haptic input can be considered a literacy event that promote three main areas of learning "extending knowledge of the world (subject knowledge), acquiring operational skills (the functions of items such as the mouse and on/off switches, as well as the ability to operate them) and developing dispositions to learn (a range of affective, social and cognitive features of learning to learn)" (Sandvik et al., 2012). This literacy event belongs to 
iScholars' culture and background, and help them to interpret the world under their own context that includes: physical features, expectations, family customs, likes, and dislikes, interests, etc. IScholars should reconstruct the meaning of visual inputs, frame them into the referential context of the input, and relate it with their own experience. To do that the learner needs to ask questions, decode, evaluate, and respond to the images, considering the intention of the author, and the own content. Images allow learners to read the world from a different perspective where the reader creates or recreates the story behind the image, taking an active role instead of a passive.

The iScholars are, since kindergarten, critical consumer of visual media, therefore they should be competent in contributing to a body of shared knowledge and culture by reading, planning, creating, and combining visual information and literacy. Once the iScholar arrives to the university, and according to ACRL Visual Literacy Competency Standards for Higher Education, in an interdisciplinary, higher education environment, as visually literate individuals, they should be able to understand, use, and create multimodal texts in academic work (ACRL, 2008):

- Determine the nature and extent of the visual materials needed.

- Find and access needed images and visual media effectively and efficiently.

- Interpret and analyze the meanings of images and visual media.

- Evaluate images and their sources.

- Use images and visual media effectively.

- Design and create meaningful images and visual media.

- Understand many of the ethical, legal, social, and economic issues surrounding the creation and use of images and visual media, and access and use visual materials ethically.

One way to facilitate discussion about images is the method Visual Thinking Strategies (VTS) designed by Philip Yenawine and Abigail Housen (vtshome.org). "VTS transforms the way students think and learn through programs based in theory and research that use discussions of visual art to significantly increase student engagement and performance" (Rice, 2016); and helps students to develop skills in critical thinking, observation, teamwork, and communication. The method activates the process of asking questions to gather information, and encourages a reflection-andresponse style of learning. Abigail House affirms that the process involves asking students (Housen, 2002):

- What is the picture about?

- What do you see to let you think that way?

- What else can you find? Or What else can we infer?

Applying VTS to early childhood allows to all the students to participate. Teachers paraphrases what children are saying with proper vocabulary and grammar, then the kids interchange information and create links among them. During the reflection process they dialog, give, take, and accept other's opinion, as well as, more cultural cues; and convert the simple description of an image, in a habit of reflection and wonder. To talk about an image, and interchange opinion fosters confidence, and imagination by the natural ability of simple observation.

VTS promotes grit learning (information sticks and is remembered easily), complex vocabulary use, observation, listening, communication, and teamwork. It also builds an interest in and capacity to write, avoid comfort zone, and promote speaking through a discussion process (Yenawine, 2013). 


\subsubsection{Digital Citizenship}

The knowledge practices of the iScholars are different from other members of their generation, and from previous generations. As assessed in RQ_1 they extend their minds in a different way due to the continued use of haptic devices. Their productive participation in the emerging digitalinnovation-driven knowledge-creation society (digital citizenship) where they are going to live in, require the cultivation of sophisticated innovative competencies, knowledge, and skills; and combine them with awareness of the implications, reflection, and imagination.

Furthermore, the 4th Industrial Revolution calls for skill sets that embed technical savvy, creativity, and complex thinking, and signals the following ten essential skills to be needed in the labor market in 2020: "Complex problem solving, critical thinking, creativity, people management, coordinating with others, emotional intelligence, judgment and decision making, service orientation, negotiation and cognitive flexibility" (Adams Becker, Pasquini, \& Zentner, 2017).

Those future adult citizens will envision fresh perspectives, will be potential creators of knowledge, and will be self-efficient if they reach expert levels of knowledge and performance. As high scholar potentials, they will deliver strong results and credibility; will master new types of expertise, and will recognize that behavior counts (Ready, Conger, \& Hill, 2010). Their intrinsic characteristics are: dynamic (ability to quick read opportunities, use the intuition), catalytic learning capability (scan for new ideas, absorb them, and translate them into productive actions), enterprising spirit (taking risks, leaving the comfort zone), and driven to excel (make sacrifices to advance, making hard choices to be the best).

Future citizens apart from knowing how to use technology, and the content-creation tools, must be able to acclimate to new digital environments, develop lifelong learning habits, and continue their path to expertise in new skills for new technological advances. They must applicate critical judgment to their selection of digital tools, evaluate their contributions to digital space, and the potential reach of their own knowledge. The most vital skills of the iScholars will be to have the ability to judge the reliability of content, be resilient, and be able to assess the findings (curate content) (Llobregat-Gómez \& Sánchez-Ruiz, 2015c).

As there are multiple ways to engage with online information, iScholars arriving to the university should master abilities to follow scholar authority.

Scholar authority is seen as "the reflective discovery of information, and the understanding of how the information is produced and valued, with the aim to use this information to create new content aimed to ethical participation in learning communities" (Merriam-Webster, 2015). According to (Adams Becker et al., 2017), learners should be aware of how authority is constructed within its context. They must acknowledge that information follows a process to be created and to acquire its value. For that, it is necessary for any university learner to understand research as inquiry, scholarship as a conversation, and searching as a strategic exploration. 
Digital technologies are growing and evolving (IoT, big data, VR/AR/MR, wearables, cloud computing, voice agents, BOTs, Artificial Intelligence) at the same pace and speed than the meaning of digital citizenship.

New tools will bring new skills for new needs. Haptic devices will be easier to use, more accessible, and more powerful when talking about creativity expression and knowledge acquisition. Media content production and consumption will be essential for social life, so there is an urge to create new learning spaces where all drivers and its implications are considered to build an open and innovative perspective that brings excellence, and expertise out of novice learning. 



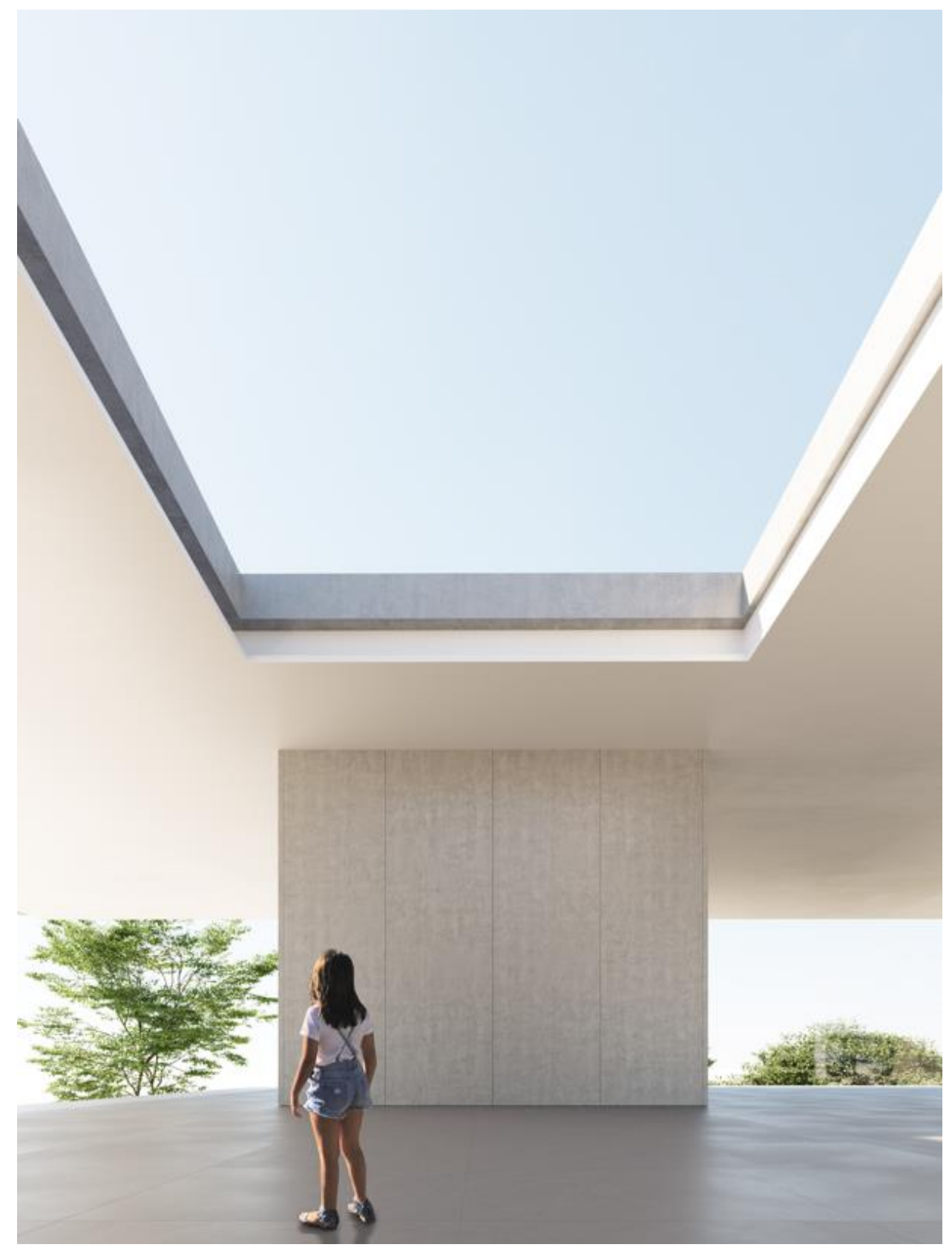

The Learning Atrium

Chapter 7 

"If you are going to teach people to make observations, you should show that something wonderful can come from them."

Richard Feyman (Nobel Prize) 



\subsection{Definition}

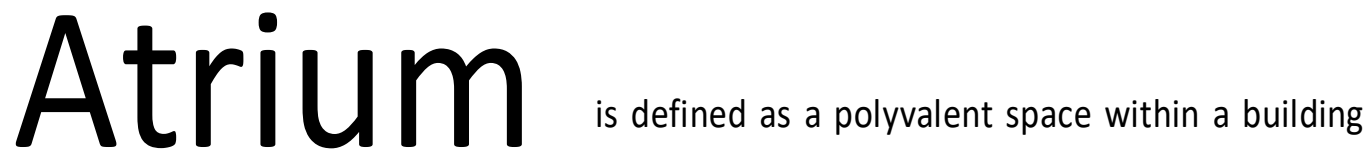

skylight covered. The classical atrium served to illuminate, distribute the inner space, collect the rainwater, or just to show the family fortune in by columns, statues, ponds, mosaics, wall paintings, etc. (Plaza Escudero, Morales Gómez, Bermejo López, \& Martínez Murillo, 2014).

Nowadays, the modern atrium is seen as a transitional space that connects the indoor and the outdoors of a building. Its movable and multipurpose lounges serve to open debates, host collaboration, and create new spaces that combine research, work, art, performing, science, play, and digital dimension, all as a symbol of innovation. The Genzyme Headquarters (USA), or the United Nation offices (Copenhagen), are examples of magnificent atriums. Its occupants (denizens) socialize and connect with the environment through the open sky-lit that facilitates a privileged spot for cityscapes, sunlight, and open mindset (Vassilev, 2015).

Atria are usually wide, very open, and large spaces that allow freedom in its design and the disposition of the movable elements distribute the natural lighting from the skylight to spread an

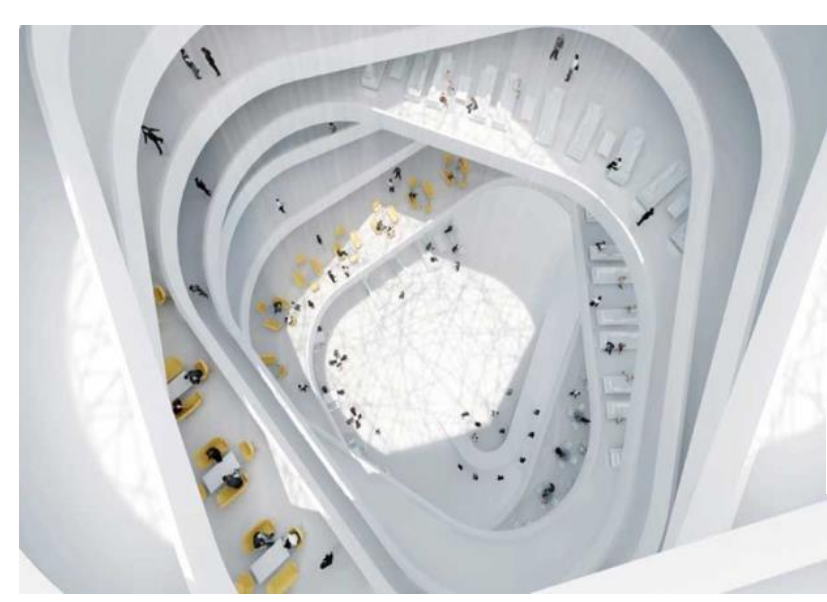
enjoyable internal environment. Imposing stairs, original materials and indoor gardens interact with the surroundings of the building, revitalize and incite human interaction as we can deduct from Fig. 29 (Hung, 2003).

Fig. 29 Helix Hotel 
Under this view, we could say that the atrium is the heart of the building, therefore, the heart of education should be the Learning Atrium. Both seek for denizen's wellbeing and basic functions like comfort, integration, socialization, motivation, confidence, passion, and pragmatism to be fulfilled. The Learning Atrium is the place where labor market seeks for iScholars to obtain the answers to new problems still to come. To be effective, the Atrium is presented as a hub for learning where the foundations are the ground soil that nurtures the learning goals, the panes are those movable bricks that customize the personalization of the learning experience, and the experts are those denizens that organize the inner space to obtain expert knowledge out of novice, and where the ischolars, already thirsty for knowledge, find a global learning space to nurture their inner skills, and expert reasoning.

For society, the labor market demands are the priority, so the Learning Atrium should have as a priority the promotion of knowledge, skills and competencies, key contributors to the society wellbeing and the economy growth. The digital irruption that has reversed education makes the educational system rethink learning, and the way it was understood until now. A fortiori, it is necessary to recognize the future demands for skills job requirements, innovate education and training by offering long life learning itineraries, and personalization adapted to different timetables and spaces, with full symbiosis between the humanistic and scientific approach when tackling a problem.

The Learning Atrium seeks to create a personal and unique experience that traces denizens' curiosity to help them to find how to express themselves and pursuit expertise from the different formal, non-formal, and informal learning spaces. The different configurations of the inner space will help them to develop academic achievement through inhabitation and memory. The learning atrium serves as a catalyst to raise questions and provide inventive solutions with a passionate, robust, and open-minded approach.

The atrium role is to facilitate dialogs, interaction, collaboration, and positive encounters among the learners, the movable elements that will guide their learning path, the experts, and foundations that guide the process, while promoting a transparent and exciting journey during the phases of learning. Its flexible spaces should feed off a large naturally lit central space that brings formal, non-formal, and informal learning as a unique entity, without differentiations. The structure highlights the great aesthetic value and serves for a lot of purposes where denizens and their haptic devices speak a dynamic language (Fig. 30).

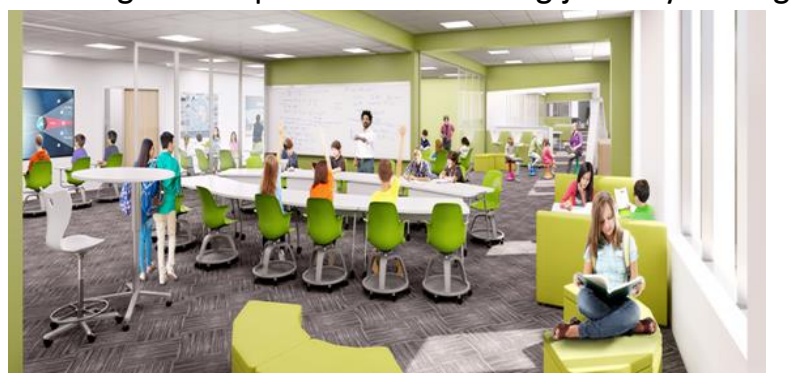

Fig. 30 Atrium as example of flexible space

Summarizing, The Learning Atrium, as a broad perspective, is a global space where our iScholars, children of the haptic generation, nurture their knowledge, skills, and competencies to become experts out of novices. The proposed Atrium is characterized by lifelong learning; shaped by the ubiquity of the information retrieved by haptic feedback that enhances learning; and guided learning from the community. Personalization, collaboration, and informalization (informal learning) are at the core of the denizens' learning paths, giving rise to new skills and literacies required for a new way of learning (Kampylis, Punie, \& Devine, 2015). 


\subsection{The Foundations}

The Learning Atrium being at the heart of education, offers a flexible space where the community members start developing a blended STEHEAM ${ }^{41}$ conversation with the future denizens. The aim of the conversation is to boost iScholars knowledge, enhancing their academic performance, skills, and competencies in a privileged environment: the digital landscape (haptic devices, web 4.0, and digitalization) where technology is not a trend any more, but part of their bodies and thoughts since the moment they were born. The educational paradigm cannot ignore the digital presence as an enhancer of knowledge and as a priority for any professional development (Llobregat-Gómez \& Sánchez-Ruiz, 2015a).

The ground soil of the Learning Atrium helps panes, experts and iScholars to understand how learning works by building its foundations in the major paradigms that applies in an active, authentic, bilingual, and student-centered approach. The following paragraphs contextualize and give a general overview of the implications of those learning approaches in higher education.

\subsubsection{Major Paradigms}

Learning theories started to emerge after the study and observation of the animal behaviors in the early 1900s. During the 1930s, researchers wondered about children's learning and new theories emerged to give sight on how humans acquire knowledge.

Humans acquire knowledge following a process. For Behaviorists, learning is a process of reacting

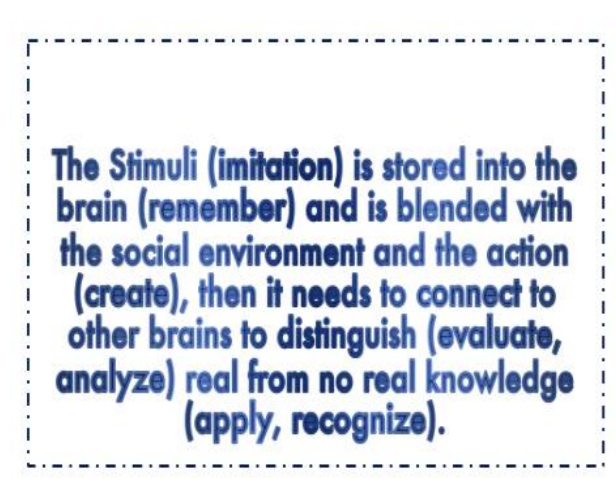
(response) to external stimuli, imitating the model by remembering (Bates, 2018). Cognitivists understand learning as a process of acquiring and storing information (Bates, 2018). Constructivists study learning as process of constructing subjective reality based on social interactions, social activity, collaborating and discussing (Bates, 2018). And for Connectivists, learning is a process of creating connections among specialized information within a network of complexity, residing outside of the individual (Siemens, 2005).

But, as Nobel Laureate Herbert Simon pointed out, "the meaning of "knowing" has shifted from being able to remember and repeat information to being able to find and use it" (Simon, 1996).

The Science of Learning emerged as a new theory of learning to give voice to the study of the mind during the last five decades. There were evidences of how learning was changing the functional organization and the physical structure of the brain. Scholars introduced rigorous qualitative research methodologies from different disciplines in educational paradigms of

\footnotetext{
${ }^{41}$ STEHEAM stands for Science, Technology, Engineering, Humanities, English, Aesthetics, and Mathematics.
} 
western, industrialized, and educated countries, to provide a scientific perspective on learning that complement and enrich traditional theories, grounding ways to facilitate learning to develop deep understanding (expert) that benefits the majority of learners (National Research Council, 2000).

The arrival of haptic devices to our society has produced an increase in information and knowledge faster than ever before. Furthermore, accessing to it with a simple touch cannot be controlled by any formal educative system. The development of understanding has shifted from the exclusivity of the formal classroom to the acceptance of the inclusion of new informal and non-formal settings. It is obvious that education should change its goal from just providing knowledge, to help students to develop learning strategies and intellectual tools that allow them to use critical thinking and fundamental understanding when facing any opportunity for learning.

The multidisciplinary approach of the science of learning includes disciplines like philosophy, computer science, anthropology, several branches of psychology, and neuroscience, among others. It also considers issues like memory, language, cognitive development affecting the processes of knowing from a scientific perspective to place the accent on "learning with understanding" rather than with memory (National Research Council, 2000).

\subsubsection{Understanding how Learning Happens}

Learning happens every day from different settings, encouraged by any input, and in different ways. It happens as people age across their life span. Because of that learning, as a process, cannot be avoided.

Since early childhood and throughout all life activities, people serve from actions to make sense of their world. Among others, we refer to playing, using haptic devices, chatting, reading, or being read, being alone, watching videos, smelling essences, interpreting images, interacting with technology, even eating; while adding cognitive and biological predispositions, emotions, likes and dislikes; goals, strengths, and weaknesses; social relationships, family, prior experiences, individual identity; culture, memories; interests, goals, dreams etc. Denizens organize individual thoughts and actions to interpret and face problems, ideas, and new situations that change along their own life experiences.

The cultural nature of learning is a "function of dynamic processes that occur within a dynamic system that depends on people, time, and context" (Academies of Science, Engineering, and Medicine, 2018a). From motivational, emotional, cultural, social, biological, cognitive, or physiological experiences, in temporal and physical contexts, and framed in teaching strategies raise any kind of individual learning. Once and again, adaptation and experience shape person's abilities, capabilities, and skills to new scenarios throughout their lives.

It is the very individual who monitors and controls his own learning within the different contexts. Individual learning is biased by cultural and social cues that regulate, improve, and make it successful. Each learner reacts to a group of experiences, moments, and circumstances to shape his own interests when learning occurs in a specific moment of space and time. 
Human being coordinates at brain level different cognitive procedures to learn. Those procedures include among others concepts like attention, memory, and network connection. Memory is defined as "the capacity to store and retrieve knowledge and information," (Academies of Science, Engineering, and Medicine, 2018a) that allows the learner to use past experiences when trying to solve present problems, and creates new connections among them.

The developmental process of learning requires then, a multi-field approach that link biology (biological and neurological processes of the brain), culture, and context with all sort of social, emotional, and physical influences. Neurologists, biologists, ethnographers, psychologists, and sociologists (among others) help to explain the characteristics as well as the contexts where learners interact; including other people that care and spy the process, in children's case, parents, caregivers and educators (Academies of Science, Engineering, and Medicine, 2018a).

The culture that surrounds learners, shapes the "how people learn," the "where they learn," and the "what they learn." Cultural beliefs and behaviors influence in their social interactions with others, and projects learning expectations with new beliefs. Within the same cultural community, learners take different roles, participate in different activities, and use different rules. Learning, is then a social activity (L. S. Vygotsky, 1987) where new experiences adapt to new social demands and new interactions not only with adults and peers, but also with technological devices, in this dissertation, haptic devices.

The ethnographic approach shows that learning comes in hand with the cultural practices of the community, changing also with the pass of time. For instance, adults used different physical and psychological tools when they started their own learning process influenced by their generational cohort. To learn how to use those tools is very important for learner's development. The teaching is passed along to generations and modified according to social evolution (Wertsch, 1991), shaping the way learners think, solve problems, and remember.

The emotional factor influences also the neurological and biological processes that affect learning. Emotion is very important when reacting to the different inputs that provoke learning, and when establishing the learning outputs. It is easily contrastable how people work harder when they are emotionally involved in the content and the skills needed. Humans learn when the object to learn is seen as something useful for their own sake, and deeply engaged to their hobbies, interests, motivations, and knowledge goals (Academies of Science, Engineering, and Medicine, 2018a).

On the other hand, an excess of anxiety undermines learning provoking low motivation, lack of interest and apathy. Nutrition, sleep, exercise, exposition to environmental toxins, and other aspects of health influence also the learning process and the development of the brain.

\subsubsection{Explicit or Implicit Learning}

The factors already observed (context, culture, learner characteristics and interest, and biology) interplay and support learning with different brain processes, tools, and strategies across the life span. Next, we summarize different types of learning that are combined in different learning scenarios to respond to complex environments in which learners take deliberated and unconscious decisions when learning, and integrate personal skills that mature their knowledge.

Science of Learning researchers have differentiated between "knowledge lean" or implicit learning (learning patterns and habits), and "knowledge-rich" or explicit (inferential learning) to 
classify basic universal types of learning. Implicit type happens outside of the learner's consciousness and requires limited verbal mediation. Explicit learning includes the intention of the learner when following models (Academies of Science, Engineering, and Medicine, 2018a).

In the following paragraphs we summarize the universal types of learning, all of them observed to happen with haptic interaction:

- Conditional Learning is defined as "nonconscious form of learning in which one automatically adjusts one's decisions and behaviors when particular and familiar contextual cues or triggers are present. These decisions and behaviors can be strengthened when they are closely followed by rewards." The rewards can be external or generated by the learner (i.e. practicing a lot because a habit can lead to expertise) (Academies of Science, Engineering, and Medicine, 2018a). To generate habits takes effort and time, but once acquired frees attentional cognitive resources for more demanding tasks (i.e. mental calculus with an abacus).

- Perceptual and Motor Learning occurs through sensory experiences, and the procedure cannot be explained but pursued. Learning to differentiate sounds when playing music, or different types of darks in an x-ray photo, learning to swim, or ride a bike, etc. are examples. It requires a high degree of specificity and practice. In academic knowledge it supports abilities to see and discriminate text types, but also professional vision developed with training and the passing of time (Toor \& Ofori, 2008). This type of learning is fundamental to expertise. Experts do not realize how much they know about something, how self-apparent their perceptions are, until they try to think as novices.

- Observational: This type of learning occurs by looking at and modeling other's attitudes, emotions, or behaviors. It allows to add new attitudes, emotions, and behaviors to the ones already enjoyed. According to Blackmore "Learning by observation is a sophisticated skill requiring advanced cognitive capacities for imitation, interpretation, and inference; and it requires the learner to observe something that may not be immediately visible (Blackmore, 2000). The learning happens without receiving external rewards or feedback. Parent or peer observation could be key as a source of information in social settings when there are common rules to follow not explained explicitly; or for instance, when learning how to use haptic devices with or without explicit instructions, and observing the consequences of the haptic interaction.

- Implicit Pattern Learning: "involves the learning of regular patterns in a particular environment without actively intending to do so. This kind of learning requires extended exposure to a pattern sufficient for unconscious recognition of regularities in an otherwise irregular context, without conscious attention and reflection" (Willingham, Nissen, \& Bullemer, 1989). This happens, for instance, with language learning where learners recognize language patterns, categories, and attributes by observing but cannot be easily verbalized or explained. 
- Learning of Facts and information by memorization. The learning can happen by single exposure or by repeating, intentionally or unconsciously. For example, the learning of important dates to connect facts in history, simple math formulas, family phone numbers, information easy to retain, etc. The learned facts are unified and fill a rich net of knowledge easier to remember and extract from memory when needed in other learning processes (Benjamin \& Tullis, 2010).

- Learning by making Inferences or by giving possible explanations from observation can help to make sense of the world and move forward even if the inferred is incorrect. Learners set models to seek for new information or predicting in novel situations. The models should consider the purpose of itself because it can lead to incorrect predictions; but if the model is consistent, the prediction can be used in other scenarios, fields, topics, or situations. According to Bruner: "The value of constructing models for understanding and organizing material has been associated with specific learning approaches, including discovery learning, inquiry-based learning, problem-based learning, learning by invention, learning by doing, and constructivism. In each of these approaches learners are encouraged to either discover for themselves or explore with guidance the applicable rules, patterns, or principles underlying a phenomenon" (Bruner, 1961). 


\subsection{The Panes}

The Learning Atrium needs to function efficiently, movable panes that shape the different learning configurations that allow its denizens to achieve academic knowledge, personal skills, and professional competences. Different to bricks, the panes are conditioned and personalized according to the context where the learning takes place, the relationships established, and the tools that support the core learning values within the social context.

As explained in Section 7.2, learning is a process in constant change that requires the synchronization, at least, of the neurological and the metacognitive systems. It includes context for learning, the personal definition of culture, the technology, and the people that surround the learner's life. These relations support not only the consciousness of facts and procedures to manage the information, but also the emotions, and the motivations of the learner, and the interests placed on the stage in the moment of learning (National Research Council, 2000).

The panes of the Learning Atrium help to configurate the dynamic system that surrounds the denizens, and shape their skills to grow into active and expert ischolars who seek to take control of their own learning, understand complex concepts, and be proficient in transferring what they have learnt into new scenarios to solve problems still not known (National Research Council, 2000).

The movable panes consider the different settings (formal, non-formal, and informal) where the learning is happening guided by haptic interaction, the processes that help to foster reasoning, the strategies that will enhance knowledge retention in order to activate full learning, and the STEHEAM scope where the educative system can base the responses to the new needs and demands of the labor market. Those panes focus mainly in the promotion of expert learning where reflection and self-assessment support reasoning, an option that is no readily at hand with memorization. (National Research Council, 2000).

\subsubsection{Formal, Informal \& non-Formal Settings}

In formal ${ }^{42}$ and non-formal ${ }^{43}$ settings (yeu-international.org, 2017), the selection of the strategy for expertise understanding will depend on the subject matter, grade level, and desired outcomes. None of the strategies is better than the others, neither it should be selected depending on the preferences of the student to learn because, individually, they serve for a different purpose (i.e. conceptual maps, learning by heart, summarizing, infographics). To understand better the idea, it would be like trying to determine which tool is better for eating:

\footnotetext{
${ }^{42}$ Formal Education: "the hierarchically structured, chronologically graded 'education system', running from primary school through the university and including, in addition to general academic studies, a variety of specialized programs and institutions for full-time technical and professional training" (yeu-international.org, 2017).

${ }^{43}$ Non-Formal Education: "Any organized educational activity outside the established formal system - whether operating separately or as an important feature of some broader activity - that is intended to serve identifiable learning clienteles and learning objectives" (yeu-international.org, 2017).
} 
knife, fork, spoon, stick chops, or fingers. The answer is quite logical, we will select the tool depending on what we want to eat and in which cultural setting we are going to do it. We cannot eat pizza with a spoon neither a soup with a fork.

Current Informal ${ }^{44}$ settings are enhanced by haptic feedback, and use several of those strategies at the same time to promote the acquisition (at any age) of knowledge mainly by using Apps and web-based content. The difference here lies in the preferences when selecting the device and the format of the contents: more attractive design, more retention of students. Interactive screens as well as computer-based strategies also allow lecture-based, skill-based, and inquiry-based techniques performed either individually or in groups in the form of simulations, AR, VR, assessment apps, communication apps, QR codes, etc.

The strategies promoted by haptic devices, formal and non-formal teaching, evolve as a rich body of opportunities and options from which an STEHEAM curricula can be elaborated and promoted. All of them are equally valid if the goal roots in the personalization of the learning. It is important to consider the knowledge, skills, level, interest, attitudes, and the concept of culture that learners bring to the setting to maximize their individual progress, and devise the tasks that are appropriate.

Learning (information, subject matter) with understanding (why it is taught) should emphasize, at any level, the literacies (reading, writing, arithmetic, digital, and visual) behind thinking and problem-solving skills, harder to accomplish than simply memorizing. Students' skills to organize facts and information are actually enhanced when they are engaged to meaningful problemsolving activities, and someone else help to understand the how (action and expression), the why (engagement), the what (representation), the who (source), the where (space), and the when (time); as well as those facts and skills that are relevant (Zapata-Ros, 2013) for the activity.

For scholars, to be expert in something means that the goal should be purposeful, motivated, resourceful, knowledgeable, strategic, and goal directed. To promote expert leaners, the teaching strategies should take into account some basics such as giving access to previous knowledge, guiding the personal understanding to build new knowledge, and teaching to internalize the knowledge acquisition (CAST, 2018).

The access to previous knowledge should be promoted by optimizing individual options and autonomy (customizing information, different sources for perception (all the senses), different haptic devices), optimizing the relevance, the value, and the authenticity; and minimizing threats and distractions.

To build expert knowledge, the learner needs nurturers, guiders, and witnesses of his progress; effort and persistence, collaboration among peers, and relationships with other members of the Atrium. Also, people need tools like language, vocabulary, grammar, symbols, and aesthetic

\footnotetext{
44 Informal Education: "the truly lifelong process whereby every individual acquires attitudes, values, skills and knowledge from daily experience and the educative influences and resources in his or her environment - from family and neighbors, from work and play, from the market place, the library, and the mass media" (yeu-international.org, 2017).
} 
understanding to help to decode texts in any of its formats. Nowadays long-life learning benefits from multiple digital platforms for communication, blended spaces that bring experiences together, different levels for practice and performance; and meaningful feedback along the whole process, giving voice to learners of any age.

The learner needs opportunities for positive motivation, guided information and visualization, skills and strategies for planning and development, self-assessment and reflection, tools to monitor the progress, and chances to maximize the transfer and therefore, internalize the acquisition of knowledge.

There are many factors that affect a learner's developmental process during lifetime. Like the movable panes inside the Learning Atrium, those factors will help the iScholars to take control of their own learning, extend their skills and competencies beyond contexts, dive deeper among subject fields, construct conceptual understanding of abstract ideas, transfer the learning to new contexts, and develop a personal feeling for new creative solutions.

The haptic input, as the main driver of the haptic generation, has a profound impact in what iScholars will discover under the learning prism, and how they will organize, present, interpret, and curate the content under their own perspective, which will affect their abilities to solve problems, remember facts, reason conclusions, and instruct others. The foundations and the panes of the Atrium will guide experts to set innovative smart scenarios based on motivational factors for the denizens where boredom is hardly perceived.

The iScholars, right now playing with haptic devices due to their short age, can take advantage of the incredible opportunity for learning that, by serendipity, the combination of settings offers. Haptic devices can help children to reach their full learning potential and become experts by creating positive learning experiences in a rich and multimodal environment where every child has the opportunity to take decisions and model their interests.

\subsubsection{Fostering Reasoning}

Haptic feedback provokes that the previous experiences that denizens bring to the atrium are quite powerful. Haptic interaction facilitates quick access to relevant information related to the topic of interest. The amount of information students can acquire when using the devices increases exponentially compared to traditional means based on written information. Because of that, it is imperative that learners develop competence in the area of inquiry by having deep foundations on new literacies to understand the facts and develop their own ideas about themselves within a conceptual framework; by organizing their assumptions in ways that facilitate retrieval from memory and application on other concepts; and by being adept at thinking metacognitively (thinking about one's thinking) to transfer to new settings and events.

Conceptual understanding lets us dig inside the meaning of the information around us. The extracted information is not apparent and the process helps to select and remember relevant information that can be transfer to other contexts (National Research Council, 2000). For instance, Google Earth provides authentic, real, and accurate images for and with geographical information. Its street view feature allows the user to interact with the information provided what allows to 
understand information that is not explicit on the images, but implicit; among others the type of vegetation, well-being of the citizens, and welfare of the place, etc.

Inquiry implies to ask denizens to verbalize their thinking in a way that they can monitor their own understanding, making note of when additional information is required for understanding (Pedaste et al., 2015).

Metacognition, an internal conversation, or dialogue in the students' brains, can help them to discover how to control their learning process while predicting the good or bad outcomes. Using metacognition, the learner explains to himself what he is learning to improve understanding, note his own failures when comprehending, activate his knowledge about the subject matter, plan next steps, and distribute his time and the memory to be used. After students have an understanding of what to think about their own thinking means, and they realize that their brains are wired for growth, then they are ready to be open minded, objective and resilient. Because of that, it is important for educators to model what metacognition looks like through think-alouds (D. S. Wilson, 1988) and smart perception of the learning path.

To achieve the learning goals requires the coordination of several cognitive and neural processes (executive function). To do so, the learner needs to be aware and self-regulate his own learning (metacognition). The ability to do that can be improved with other cognitive interventions and life span. The executive function enables denizens to guide their behavior toward their goals incorporating feedback and adjusting actions to motivations in order to foster knowledge and reasoning. Self-regulation allows denizens to adjust the goals to obtain the results desired and control the strategies to follow aimed to build learning habits and skills (California Science Teachers Association, 2002).

Building knowledge requires three basic steps that occur through reflection: to accumulate information, tag this information as relevant or not, and integrate the information in different and separated episodes. Using haptic devices, learners of all ages acquire knowledge also by interaction, experience, and in many of the cases with non-explicit teaching. When observing the action (HG Case Study. Child I), the child is at her own pace building understanding of facts, accumulating them, and producing new understanding that enriches her knowledge by reasoning.

Denizens make logical correlations from different sources of information, according to their values, motivation, and interest. Once organized, they draw outcomes through inductive, abducting, and deductive reasoning (Seel, 2012). For example, to comprehend a digital image the viewer needs to read the information inferenced from the photo, track the meaning, evaluate, categorize, fill the gaps of information not given, and construct their meaning through effective problem solving, and critical thinking. Effective problem solving requires, at the same time, memory retrieval and other cognitive processes to adapt previous knowledge to new situations.

Memories enhance expertise because they can be applied, reshaped for the new scenario, and tailored for reasoning. Expertise as a goal to excel learning drills on flexible knowledge use, selfdirect learning, effective problem-solving skills, collaboration among learners, and stirs motivation, creativity, and interest through expert reasoning (National Research Council, 2000).

Reasoning abilities vary with age, with the use of some cognitive skills, and depend on intellectual development. Accumulated knowledge through life span facilitates expertise if the new learning 
is related to an existing domain. Adult denizens select settings for education, hobbies, and preferences as they age to improve their repertoire and become experts (Baltes \& Baltes, 1990). Haptic generation children have already got a variety of rich and interactive experiences, off or within standard education, that with appropriate fostering can enhance their knowledge retention.

\subsubsection{Enhancing Knowledge Retention}

The Science of Learning approach considers different learning perspectives to acknowledge how people learn. The National Research Council (US) has already evaluated the best environments to achieve the educational goals of any curricula: assessment-centered, community-centered, knowledge-centered, and student-centered, highlighting the importance of alignment and coordination among all of them during the learning process in all their phases (National Research Council, 2000).

According to Dr. Merrill, the phases of learning are: (a) to identify an interest in a topic or in developing a skill (identify), (b) to be familiar with the topic by building more knowledge around that (demonstration), (c) to practice what has been learnt (application), and (d) to apply that

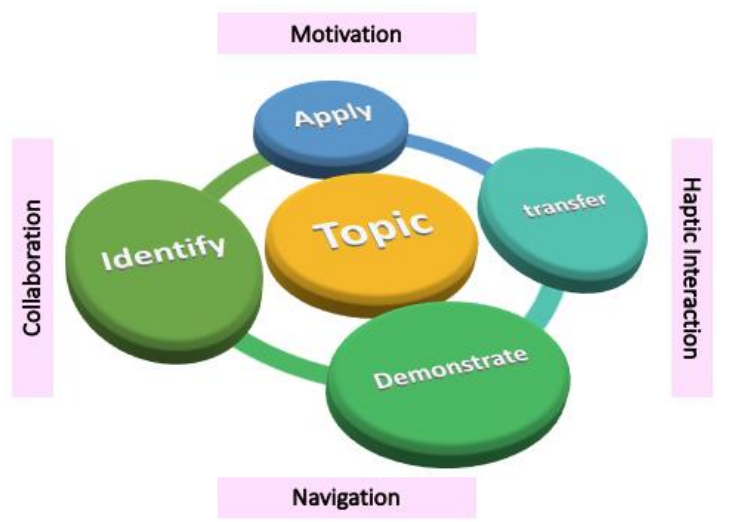

Fig. 31 Learning Phases and haptic interaction new problems. knowledge into real-world activities (transfer) (Merrill, 2002) (Fig. 31).

Researchers have identified some strategies that help learners to develop the mental models needed during the phases of learning for knowledge retention. Learners can use them to make inferences and solve

Among them, we select the following cognitive, understanding, and integrating strategies that are directly related with haptic interaction and the enhancement of knowledge retention.

\section{Cognitive Strategies}

Retrieval Practice is a strategy that focuses on getting information out of student's reasoning. Students retrieve key concepts from memory, examining what they really know and remember. Struggle for remembering improves memory, and increases understanding. The technique helps to identify gaps during the learning process (metacognition) (Agarwal, Roediger, McDaniel, \& McDermott, 2018). The strategy helps to recall of texts, and the act of failing when retrieving helps to encode the information.

Spaced practice as strategy distributes the learning on longer periods of time. Separating the different parts of a learning object by at least one day, maximizes the long-term retention of the material. Spacing show great effect for history facts, motor skills, grammatical rules, vocabulary 
learning, etc. (Carpenter \& Agarwal, 2019). The technique leads to greater recall than massed practice (all in one session) because the process or the concept is repeated after a period, so students use again the mental operations to recover what they just forgot (Perruchet, 1989). The optimal distribution depends on the material to retain, and how long is needed to acquire expert learning.

To Transfer the learning to another setting. Using transfer technique, the knowledge, and skills that the learner has acquired in one context enables him to apply it to different context, providing new solutions to new problems, transforming novice understanding into expertise. Transferring the learner's comprehension allows him to recognize what is relevant or not, and allows to apply it effectively outside of the box (Barnett \& Ceci, 2002). Extending what was learnt to other contexts allows to focus on core concepts, provide comparative scenarios, answer new questions, solve new problems, and facilitate new learning because the learner uses the information in a different way than before.

Interleaved and Variable practice: These strategies refer to how to present the information in different ways and by mixing different activities to students so they can improve the same skills from different points of view. the information is arranged in a way that cannot be solved by the same strategy (Academies of Science, Engineering, and Medicine, 2018).

\section{Understanding and Integrating Strategies}

Aesthetic development. This strategy enhances the student's experience and understanding when dealing information and texts in image or video format; integrating reading and writing skills. When observing a photo or a video, the information is gathered through observation, previous experience, content questions, etc. The viewers understand the information provided following stages to make sense of the image (Housen, 2002) and facilitate discussion to transform the learning input into personal learning output.

- Stage 1 -Accountive: Viewers use their senses, memories, and personal associations, when facing an image, to make concrete observations that are woven into a narrative. In this stage, judgments are based on what is known and what is liked.

- $\quad$ Stage 2 -Constructive: Viewers use the most logical and accessible tools to build the framework of comprehension: own perceptions, knowledge of the natural world, and the values of his social, moral, and conventional world. Their sense of what is realistic is the standard often applied to determine the value of the information.

- $\quad$ Stage 3-Classifying: Viewers use their intellect and memory to place the image within a place and time. They decode the work using their memorized data, to proper categorization, rationalization, and explanation of the message.

- $\quad$ Stage 4 - Interpretive: Viewers use their critical thinking skills, intuition, and feelings, to seek for rational understanding and application. Each image or video is a new opportunity for new knowledge, insight, and experiences.

- Stage 5-Re-Creative: The viewer creates the ecology of the image: timing, history, questions, etc. combining personal beliefs with universal understanding to provide new insights and to apply it to other scenarios, or problems. 
Summarizing and drawing. To portray important concepts and relationship we can summarize the information with verbal description or drawing to transform it into a different representation. Both ways imply to identify the theory behind, to curate the information, and to use prior reasoning before writing or drawing the synthesis of what has been understood (Fiorella \& Mayer, 2016). The quality of the summaries or draws relies on core literacy skills where, for haptic generation visual literacy starts to be as important as reading and writing, as well as on the nature of the learning materials. Note-taking by handwriting on a paper or on an interactive screen increase the conceptual understanding, and the ability to synthesize information. To do that, the student must listen/read/see in the digital format provided, digest the information, and condense it capturing the main ideas. Mueller and Oppenheimer (2014) when comparing note-taking by hand with typed concluded that "typing notes does not promote understanding or application of the information"; and that "notes in the students' own words and handwriting may serve as more effective memory prompts by recreating context (e.g., thought processes, conclusions) and content from the original lecture" (Mueller \& Oppenheimer, 2016).

Creative Explanations include several strategies that make that the student verbalizes what infers from the learning input. There are several techniques that include: elaborative interrogation where students are encouraged to ask themselves questions for deep reasoning having a positive effect in comprehension, memory retention, and understanding (Graesser \& Lehman, 2012); selfexplanation where the students provide explanations of the material they are trying to learn using their own thoughts while reading, answering questions, or solving problems. This technique allows further comprehension of concepts of the text (Wylie \& Chi, 2014); and the third technique: teaching others: force the student to construct explanations, express themselves in a relevant, immediate, and informative way that others can understand. Preparing oneself to teach something to others, requires active organization, integration, and building of knowledge. This helps to encourage learners to focus on concrete questions, and level their comprehension because somebody else must understand what the student has understood. Teaching has been proved as the most effective learning strategy (Biswas, Leelawong, Schwartz, Vye, \& The Teachable Agents Group at Vande, 2005)

Feedback as a strategy is the most powerful tool to enhance understanding and integration on knowledge retention (Hattie, 1999). The main objectives of feedback are to guide students on what steps to take to improve their own learning, and to develop their capability to monitor, evaluate and regulate their own learning (Nicol, 2010). To benefit the student learning process, the feedback must be constructive, timely, and meaningful. Feedback during the learning process is valuable only if when it is received, one understands it, and act on it.

\subsubsection{Blending the Inner space}

We live in a changing world where information and knowledge flow everywhere and change rapidly. Children and youngers are witnesses of how technological innovations and social challenges appear constantly and transform their surroundings.

From this perspective, it is necessary that the educational system and its educational institutions reflect on this new reality and organize themselves to equip our students with the competencies, skills and knowledge that will allow them to develop personally, socially, and professionally in a 
world that will be different if compared to older generations. In it, the ability "to learn to learn", the adaptation to change, the creativity, the resilience, and the adoption of networking will be essential to generate progress and create a better society.

This change in higher education institutions (HEls) must start from a deep understanding of who our students are, what they want to achieve, and how they prefer to perform, to implement realistic and ambitious innovation plans that cover all fields, different type of learners, and teaching methodologies of any educative curricula in constant evolution.

The haptic experience must be optimally challenging, engaging, meaningful, related with their lives, interactive, sometimes passive, and sometimes mediated by adult interaction to make it count as beneficial, positive, and worth it for learning purposes. The accessed contents are not only aimed to a separated discipline, e.g.: math, literature, art, etc., but they are displayed interconnected to enrich and improve learning, and understanding from several perspectives. For instance, to improve STEM ${ }^{45}$ literacy (foundation for Engineering students), what we need is an aesthetic approach to interpret and communicate the results in a way that not only scientists can understand, but other learners, and citizens. If the experience is in English, the learner needs basic understanding of the language used to orally communicate the results.

In brief, to obtain scholar results in STEM fields, students should master some other skills like digital competence, visual literacy, oral and written communication, humanistic and historical knowledge, linguistic understanding, reasoning, the ability to transfer knowledge from one setting to another setting, ethical decision making, and aesthetical understanding, among others. Skills that are hardly encouraged by technical university curricula aimed to Engineering Education but necessary to accomplish full knowledge and reasoning.

The acronym STEM relates the academic disciplines of Science: science, technology, engineering, and mathematics (Bybee, 2010). "STEM adheres to the development of scientific, technological and mathematical insights, concepts and practices and how to use and apply them in practice in order to solve complex questions or real-life challenges" (Goździk \& Korda, 2016) in line with one of the eight key competences defined by the "2018 Council Recommendation on Key Competences for Lifelong Learning": "Mathematical competence and competence in science, technology, and engineering" (Council of European Commision, 2018).

Different actions, policy, practices, programs, and initiatives based in STEM competencies are organized across Europe in line with European commission calls, policies, and Bologna Process implementation in Higher Education, to guide technological development and innovation, forecast and plan for future job prospects, cultural awareness, and well-informed citizens (Goździk \& Korda, 2016). Those practices to promote technology in educative programs aim to identify social and scientific challenges, and solve them in an inquiry-based way.

As it has been also pointed out throughout this dissertation, to solve complex problems and understand what are the motives, desires, and needs to propose those answers, denizens require a holistic education that encloses more than technical expertise, and solutions.

\footnotetext{
45 STEM stands for Science, Technology, Engineering and Mathematics disciplines.
} 
Haptic generation children, among them the iScholars, in a short time-frame, will be facing global challenges from different perspectives. They will have to build on smart specialization for mitigating risks, improving quality of life, and ensuring basic needs (Dron, 2018). They will use their skills, passions, and creativity as catalyst for building a better future, develop new products, and help society to grow. To do that, once they arrive to engineering universities, they will ask for a broad education that helps them to acquire STEM competencies, as well as the multilingual, digital, citizenship, cultural, literacy, personal, social, and entrepreneurship competences that normally are acquired from other subject areas: Arts and Humanities, Health \& Social Care, and Social Sciences.

Each HEl has set, under the umbrella of Bologna Process, its own programs and models as reference to common curricula design, focusing under the different subject areas: Arts and Humanities, Health \& Social Care, Social Sciences, and STEM.

But the new context where the students move around, indistinctly from formal, non-formal, and informal settings, and enhanced by haptic interaction (what implies the acquisition of new learning abilities and, let us remind that in it the iScholars are already nurturing their knowledge and competencies), demands a new scope that includes skills from other disciplines: The STEHEAM Scope.

\subsubsection{From STEM to STEHEAM}

Academic disciplines were thought to be the main source of expertise, creativity, and innovation for students. Therefore, they owned the education of highly skilled, and increasing specialized workforce. The irruption of haptic devices has broken the exclusivity of the teaching, and students switch among formal, informal, and non-formal education, subject areas and disciplines, modes of inquiry, and pedagogies, to create their own knowledge by making connections among all of them. Multimodal and digital formats draw upon interdisciplinary outputs that fulfill the standards of the scientific, medical, technological, artistic, and humanistic fields. It is the integration of all of them what will help to face the global and multidimensional challenges of the society.

The STEHEAM scope offers an integrative blending between Humanities, English, and Aesthetics, with Science, Technology, Engineering, and Mathematics. Each discipline offers new tools, media and ideas that complement the others, brings innovation, reflexivity, and a deeper understanding of the context explored by giving more insight in the subject of study. The benefits of the integration are intrinsic and instrumental (Academies of Science, Engineering, and Medicine, 2018b). STEM need the skills, methods, and insights of humanities, arts, and aesthetics to understand the implications of their work from a philosophical, historical, and ethical perspective; and HEA need the insights, skills, and methods of scientists to interpret and communicate the data, phenomena, and facts behind any creative act. By creating a digital story, the learners compile and interpret the findings (e.g. big data, internet sources), reflect on them, summarize, and communicate the results (curated content) with an artistic medium: i.e. the video accessible with a fingertip on an interactive screen. 
New curricula aimed to 2030 Engineering students should bridge in an interdisciplinary, transdisciplinary, and multidisciplinary way Science, Technology, Engineering, Humanities, English, Aesthetics, and Mathematics to break the boundaries of the disciplines in isolation.

Every field of study has its own epistemology. We describe and summarize in the following paragraphs the practices and teachings of the different disciplines to help to understand the relation among them and the implications of their integration:

Science (Academies of Science, Engineering, and Medicine, 2018b):

- Deals with matter and energy, and their interactions.

- Teaches "the use of evidence to construct testable explanations and predictions of natural phenomena, as well as the knowledge generated through this process."

- Science disciplines cover the physical and mathematical sciences (i.e., chemistry, physics, and mathematics), the life sciences (e.g., cell biology, ecology, and genetics), the geosciences, computer science, and the quantitative social sciences (e.g., anthropology and sociology).

- The scientific method includes objective observation, evidence, experimentation, induction, repetition, critical analysis, verification, and testing.

Technology (Studies Authority, 2008):

- Deals with the human ability to shape and change the physical world to meet needs, by manipulating materials and tools with techniques.

- Teaches about the development of artefacts (things that are made by people from materials or resources), processes (ways people manipulate, change or work with resources), systems (Ways of organizing people or components to make things work or happen), environments (Interior or exterior places that are designed by people), and the delivery of services (When people provide or make available artefacts, processes, systems or designed environments to meet a particular purpose or need) will impact on people and places in different ways.

- Engaging with technology means designing, creating, using, envisioning, responding to and reflecting on the designed world, and considering how it affects everyday life.

Engineering (Academies of Science, Engineering, and Medicine, 2018b):

- Deals with "the study and practice of designing artifacts and processes under the constraints of "the laws of nature or science", and also under the variables of time, money, available materials, ergonomics, environmental regulations, manufacturability, and reparability."

- Teaches how to "develop plans and directions for constructing artifacts and processes, such as computer chips, bridges, and drug manufacturing processes. Uses design as a problem-solving approach that can integrate various skills and types of thinkinganalytical and synthetic things; detailed understanding and holistic understanding; planning and building; and implicit, procedural knowledge and explicit, declarative knowledge." 
- Engineering disciplines "focus on specific aspects of technology or the natural world, such as electrical, mechanical, chemical, civil, environmental, computer, biomedical, aerospace, and systems engineering."

- The engineering design process "is generally iterative; thus, each new version of the design is tested and then modified based on what has been learned up to that point."

Mathematics (Alpers et al., 2013):

- Deals with evidence-based practices by knowing where and how to find the best possible sources of evidence, formulating clear questions, search for the relevant answers, and determine when and how to integrate findings into theory and practice, including deductive and inductive reasoning.

- Teaches the acquisition of the eight mathematical competencies: $M$-thinking, $M$ reasoning, M-problem solving, M-modelling, M-representing, symbols, and formalism, communicating, aids and tools; using algebra, analysis, calculus, discrete mathematics, geometry, trigonometry, statistics, and probability.

- Mathematics discipline includes knowledge, skills, and practices based on the theories, beliefs, and experiences to different cultures. Mathematical competence means "the ability to understand, judge, do, and use mathematics in a variety of intra-and extra mathematical contexts and situations in which mathematics plays or could play a role. Necessary, but certainly not sufficient, prerequisites for mathematical competence are lots of factual knowledge and technical skills" (Niss, 2003).

Humanities (Academies of Science, Engineering, and Medicine, 2018b):

- Deal with aspects of human society and culture, and themes and contents, stories, ideas, and words that help us understand our lives and our world.

- Teach "close reading practices as an essential tool, an appreciation for context across time and space, qualitative analysis of social structures and relationships, the importance of perspective, the capacity for empathic understanding, analysis of the structure of an argument (or of the analysis itself), and study of phenomenology in the human world."

- Humanity disciplines are "language, both modern and classical; linguistics; literature; history; jurisprudence; philosophy; archeology; comparative religion; ethics; the history, criticism, and theory of the arts; those aspects of the social science."

English Language (European Commission/EACEA/Eurydice, 2018):

- Deals with English language awareness. Integrating other languages makes possible to provide more authentic learning geared towards real-life situations. Awareness of the importance of language learning, and of the educational, cognitive, social, intercultural, professional, and economic benefits.

- Teaches English at Conversational language, also called "basic interpersonal communication skills," meaning the language necessary for everyday life, including conversation with friends or informal interactions; and at formal academic level, or 
"cognitive academic language proficiency," meaning the language necessary to understand and discuss content in the classroom, which is more cognitively challenging.

- English language disciplines are those in which language is central to our identity. By valuing all cultures and languages we aim to promote each learner's self-esteem and encourage international mindedness. Used as a language of instruction either with formal contents or passive media contents, it aims to achieve additive bilingualism, raise awareness of diversity, extensive reading in a variety of text types in other language, focus on different aspects of language use.

- Haptic devices and the affordance of quick access to any type of multimedia format in English can massively support broadening the language offer, provide opportunities for language exposure, and be very useful for supporting the language in a natural and native way which is not taught in public Spanish schools.

Aesthetic (Doane University, 2016):

- Deals with perception through senses, and the nature of art, beauty, and taste. Notions like beauty, ugliness, the sublime, the comic, are interpreted from a philosophical perspective that seeks for expertise, pleasure, style, self-expression, love, symmetry, and complexity, among others.

- Teaches "the process of learning something new, of being introduced to a medium never known before in a particular way. It is the incorporation of the arts across the curricula in a way that fosters a heightened awareness of and appreciation for all that touches a human's life. Students discover new ways of looking at, listening to, moving in, and speaking of their everyday experiences."

- Aesthetic $s$ a quality is concentrated in the arts, the study of music, dance, drama, and the visual arts, extremely needed to understand from the haptic feedback and interaction point of view.

- Builds on "empathy and create new meaning for individuals in fields not limited to those traditionally associated with the arts, such as the social sciences."

These definitions highlight the most defining aspects of each discipline and illustrate how the different disciplines consider and make use of different forms of evidence. Yet these definitions also demonstrate that the disciplines share the root purpose of creating knowledge.

The proposed Humanities, English, and Aesthetics skills (HEA) that can be integrated into STEM (Science, Technology, Engineering, and Math) disciplines for engineering students are:

- effective communication outside of the field;

- critical thinking, problem solving, leadership;

- creativity, innovation, curiosity;

- broad social and cultural impact understanding;

- reasoning;

- human history and culture for work context;

- self-expression, empathy, flexibility; and

- multilingual approach. 
Similarly, the Science, Technology, Engineering, and Math skills (STEM) to integrate into HEA (Humanities, English, and Aesthetics) disciplines are:

- $\quad$ scientific and technological literacy;

- grasp knowledge across multiple domains;

- insights into the human-designed, physical, and natural worlds;

- strength and deepen learning;

- scientific method and scientific thinking; and

- exposure to STEM ideas.

The STEHEAM scope bridges the enhanced success in STEM through engagement with ideas, methods, and contributions of HEA. 


\subsection{The Experts}

In Section 7.3 we have exposed how learners construct new knowledge and understanding based on what they already know and believe. To avoid false beliefs or incomplete understanding, other adult denizens of the Atrium (like parents or caregivers) must interact in their learning. As part of the expert body that include instructors, coaches, lecturers, teachers, and tutors, among others, they should also focus on novice concepts and basic understanding that hover within the Atrium with the aim to make learners achieve mature understanding, expertise, and scholar reasoning.

The Learning Atrium perspective welcomes learning diversity: cultural, developmental, contextual, social, generational, or historical; and aims to provide each learner with what he needs. However, this individualized attention becomes complex within a formal and closed educative system, with little tendency to mobility (Touron \& Martín, 2019).

We have analyzed how to foster knowledge and reasoning by conceptual understanding, the pursuit of inquiry competence, and a metacognitive conversation within the learner's brain. This core precepts have implications on how to guide their learning process. Teaching strategies, the environment, the family costumes, personality, feelings, and the adults that guide the learning process have a profound implication in students' motivation for learning, what affects directly their learning outputs to achieve when wandering in inner of the learning Atrium.

There is no unique learning as there is no standard learner. It is not possible to find a group of equal students who, therefore, achieve similar performances because every individual has a unique space and time position, different experiences of life, different adult interaction, beliefs, and personal needs. As we have already seen, each learner uses different cognitive resources to mold his intellectual needs that fit in his social, biological, familiar, and cultural contexts (California Science Teachers Association, 2002).

Experts then should be open to a new smart learning scenario that considers the innovative options that the digital paradigm offers, and will offer in the future, and adapt their expertise to motivate students towards excellence. Experts should pay attention to learners' knowledge and beliefs when performing, and be witnesses of students' brain changes towards expertise. Experts of the Atrium must use motivational drivers as starting points for new instruction, and monitor students' changing conceptions as instruction proceeds (National Research Council, 2000).

\subsubsection{Feeling the Digital Diversity}

Learning is keystone in any educative level, but it does not come naturally to learners, or at the same time, or form. During the last decade, a cultural shift toward digital activities, enhanced by haptic devices, has changed the preferences and priorities of the students outside, and inside classrooms. Nowadays, students of any age, even the youngest ones, turn to online content to learn formal subject matters, life skills, or curious facts. 
In Chapter 4 we provided data from online surveys and opinion writings in English language realized by university students during 2018/19 academic year (ZG Case Study). The students were enrolled in a grade B2-English subject at UPV, where I am part of the lecturing staff. The teaching groups were $95 \%$ Gen Z students, and $5 \%$ of other generational cohorts. $96 \%$ of the students were Spanish who shared their learning experiences with a $4 \%$ of Erasmus students from different European or Asian countries, and programs.

Analyzed data revealed that all the students:

- owned a smartphone;

- $\quad$ used several devices for learning purposes (tablet, laptop, smartphone);

- $\quad$ were completely immersed in digital practices despite the age and the proficiency level when using the devices;

- got bored at some point of their degrees because there is a gap between their everyday digital interaction, and the way classes are conducted and organized.

The $46 \%$ of UPV population is ZGen student. As we have analyzed in ZG Case Study, for them, technology is neither a barrier or an opportunity, but part their everyday experience. Going online, texting, chatting, consuming video streaming, gaming, shopping online, and browser searching are everyday gestures and activities, that conform their attitudes and behaviors. They use multiple devices, an online identity, and fast apps to multitask during their hyper-connected activities. Immediacy is their motto.

YouTube, Wikipedia, and google search are resources to explore, discover, and connect with the information that is not easily accessed; and teamwork activities are done online. Students do not meet but use google docs to accomplish team tasks. i.e. During a regular B2 session, the lecturer facilitated some curated links to follow the topic of the session. Only the $2 \%$ of the students used the links, the rest used YouTube and google search to find the main information about the topic.

The instant access to information provided by those tools can be very helpful in a learning scenario despite it has drawback like distracting (pop-up of publicity or notifications on the screens), poor reading (they do not read the whole content, but skim the information to find a quick solution to their need), access to untruthful sources of information (not curated), and boredom at course load (to study something takes time, and immediacy is the main trait of younger generations).

Spanish Bachelor degrees are composed by 240 ETCS credits of basic compulsory, compulsory specialized, related, and optional subjects, Internship, and final project dissertation. Assistance to lectures and practical sessions is compulsory in more than $80 \%$ of the subjects. One ECTS corresponds to 25 to 30 hours of student workload ${ }^{46}$ (European Commission/EACEA/Eurydice, 2012); an average of 50-60 hours per week that a full-time student has to dedicate in activities such as lectures, seminars, projects, practical work, work placements, and individual study.

\footnotetext{
${ }^{46}$ Student Workload: time the individual typically needs to complete all learning activities to achieve the defined learning outcomes in formal learning environments.
} 
(McGraw-Hill, 2017) study reports that only 9\% of university students spend more than 20 hours. per week in student workload. According to their data students spend $7 \mathrm{~h} /$ day checking social media, watching streaming services, or texting/messaging, and $6 \mathrm{~h} /$ day studying (at home, going to lectures, or at the library).

If we add to the online spending time data, personal factors like age (university average age ranges from 18 to 25), social interaction needs, poor reading, visual inputs to generate their reflections, and a mobile mindset, then boredom, drop rates, and disconnection of the formal learning system are served.

$89 \%$ of the university students surveyed (ZG Case Study) reported that having a university degree is valuable, but also that they get bored, the learning materials are complex, and lecturers are far away from their current needs and online uses (digital literacy). For the $65 \%$ of the students, the subjects are mainly in-person instruction inside a rigid, one-size-fits-all schedule, which do not fit their self-pace online attitudes. The tools and devices used in class are: for the $53 \%$ of the students, printed material; for the $55 \%$ smartphones; for $63 \%$ laptops; and for the $21 \%$ a tablet (McGraw-Hill, 2017) in 2018, and $100 \%$ of them use several tools indistinctively. Regarding the number of devices they use, the $100 \%$ of them own a smartphone, and either a laptop or a tablet; in some cases the three of them. Their study routines vary: the $95 \%$ use YouTube as a source of information that summarizes the contents and explains the specific topics, the $15 \%$ review handwriting notes in class, and only the $4 \%$ study daily, postponing the load of study to the day before exams.

Outside of the formal setting, the students have acquired new abilities and capabilities (soft and hard skills) with the use of haptic devices in a connected social environment. Their minds switch back and forth from one topic to another in a short span of time while running the computer or devices in multitasking mode ${ }^{47}$. Shorter attention span (Pearson, 2018) is largely due to the use of technological devices, personal digital assistants, email, and instant responses to their haptic interaction. Students are peer-oriented, search for support networks, and their social life is immediately broadcasted in social media: Instagram, Facebook, twitter, etc. They have access to infinite online information from their homes, and when learning, they ask for online collaboration from people they know, but also from people they do not know.

As data of ZG Case Study illustrate, from an educational point of view, students are changing the way of learning, their desires, and their needs; as well the age at which they have access to learning and knowledge contents. The experts that guide that learning, must meet their expectations, understand the reality they are immersed in, motivate them, and create new teaching strategies that map learners needs according to how they are learning since they are born. In other words, the expert denizens must ignite an open learner-centered approach that addresses how students are willing to learn.

\footnotetext{
${ }^{47}$ Multitasking for people means doing two things at the same time consciously, almost impossible. Computers can multitask, but no humans.
} 
Following (Selingo, 2018), the university students can be divided into five categories attending to their purpose for learning when learning in formal settings:

- The hobby learner (24\%): "self-directed learners with high academic abilities who appreciate a mix of learning styles, including digital, books, and in-person".

- $\quad$ The career learner (19\%): "Their passion is focused in obtaining a certificate of degree to pursuit a job or career. They are digitally savvy, far preferring to learn that way over any other method, including in person or through books".

- The traditional learner (25\%): "Passionate students for learning in a conventional environment. They favor in-person interactions with classmates and professors and prefers reading and listening to lectures over group study and watching videos".

- The skeptical learner (15\%): "They like the social aspects of education, such as seeing friends, but not the academic pursuit. They prefer digital online by far over in-person and books."

- The reluctant learner (17\%): "They are academically average students who have little passion for learning. They prefer education on their time and in their place, and favor face-to-face when possible. Mainly they show lack of interest toward education."

Considering the attitude toward learning, Selingo's mapping can also be rearranged into the following categories:

- Among the ones that have a positive attitude towards education, one can find the multimodal and self-motivated ones, that pursuit excellence or try to. They feel passion for learning, either by family tradition, or because they like the wander of the unknown.

- Among the ones that have a negative attitude, we find the ones that have a compulsory attitude and low motivation for learning within the institution. They must be there because the parents pay and they do not know where else to go or to do. They must spend their time somewhere, acting as a powerful distractor and lowering the level of the expertise of the group. They only want to pass the subject and be granted for little effort.

- And finally, the students with no attitude for learning, neither motivation to pursuit excellence or achieve academic goals. With no attitude for learning, they try in formal setting, but they exit because they do not like, do not see the importance of the learning outcomes, and become de-educated. Normally those learners end working in nonqualified positions, and do not see academic learning as something useful.

The attitude toward learning can change during lifetime either by a desire to improve their jobs, by personal life circumstances, or just because they find themselves in a moment for learning. Reaching adulthood and other family responsibilities, the preferences change and those learners that seemed reluctant or skeptical with no attitude or compulsory attitude toward learning, join the settings again and become multimodal and self-motivated. Those adult students that belong normally to a different generation have a completely different attitude in formal settings, they have personal motivations, and they approach learning from a different perspective than younger students. 
Considering the frequency in haptic interaction (HA_int) (described in Chapters 4 and $\underline{6}$ ), and the proficiency level in the use of haptic devices that the HapGens are already acquiring at early childhood, we propose to rearrange Selingo's mapping into other categories that envision the future students that university will be hosting in 2030.

- The iScholars (> 75\% of HA_int) pursuit expert knowledge, skills, and competences. They have a highly-specialized level of digital competence in the areas of information and data literacy, communication and collaboration, digital content creation, safety, and problem solving. They are able to solve complex problems with many interacting factors, propose new ideas and processes to the field, and pursuits content creation that serves their and somebody else purposes.

- The Hi-Techs (> 50\% of HA_int) show an advance digital competence level in the four areas. They are able to adapt to others in complex digital contexts, guide them in digital use, apply and evaluate digital contents.

- The Savvy-Techs (> 25\% of HA_int) have an intermediate level of digital competence. They are good in performing routine device tasks by themselves. They show an independent use according to their needs. They are able to understand digital contents.

- The Analogs (> 0\% of HA_int) with a basic level of digital competence that show little autonomy, need guideline, perform very simple tasks, and are able to remember digital content but prefer other means to obtain information. These users are competent in communicating with haptic devices and are media consumers, but do not have any interest in other areas.

The learning Atrium, as a future conceptual setting where formal, informal, and non-formal learning meet, should consider the purpose of the learning, the attitude towards learning, and the frequency of HA_int of each student that will share the same inner space. It should pay special attention to iScholars that score the highest HA_int frequency, are hobby and career learners, and have a positive attitude towards learning. The Learning Atrium welcomes and adapts itself to any student but specially to those who have a curiosity for learning since they were born. The seeds for learning are placed in haptic devices of the next generation university students. Haptic input, as it has been largely explained in Chapter 5 , is able to drive early childhood play into scholar understanding and reasoning with the appropriate support of the expert denizens that guide their learning.

These denizens include faculty and those who are approached at multimodal digital sites like YouTube videos, podcasts, video streaming, hyperlinks, etc.; from recognized institutions were recognized experts share their experience, expertise, and curated content through digital interaction. Some examples are: Khan Academy (www.khanacademy.org), TedTalks (www.ted.com), MIT University (ocw.mit.edu), Nobel Laureated Lectures (Yoshinori Ohsumi (2016), Elizabeth Blackburn (2009) Michael Young (2018)).

Online content is reachable from a simple gesture on an interactive screen at any age. Taking the gesture as the best opportunity for learning, not only the content but also in English language, haptic devices, used in an appropriate way, seem the best tools to enhance learning, activate young brains, and drive into motivation. 


\subsubsection{Innovating}

To incorporate haptic devices into the panes of the learning atrium means that experts should also consider technological and digital innovations that are just at an early stage, and are having an exponential impact on our daily lives. Big Data, Artificial Intelligence, Augmented Reality, Virtual Reality, the Internet of Things, Wearables, cloud computing, voice agents, drones ${ }^{48}$, and BOTs $^{49}$; are powerful tools that applied into the educative arena, can transform not only the learning experience, but also the already known settings towards non-physical spaces.

We are going to introduce a few concepts that have been ignited after the dissertation was in the process of writing and have been briefly analyzed under an educative point of view due to their promising usage with learning purposes. The technological concepts are still in their early stages and are subject to further future research.

\section{Wearables}

Among wearables, MUV's BIRD (MUV Interactive, 2015) (Fig. 32) integrates a full spectrum of interactivity (touch, mouse functionality, gesture control, hover, and voice command,) into a single wearable controller. The interface, worn on the index finger, combines three types of smart sensors that takes inputs from the physical environment. Optics sensing detects user's position in space; inertia sensing determines what the fingers are doing, and wearable sensing determines the proximity to the device. The smart sensors allow the user to interact with a full range of media, including video, projected images, and augmented scenarios, by transforming any surface into a multi-touch interface with 3D interactive capabilities.

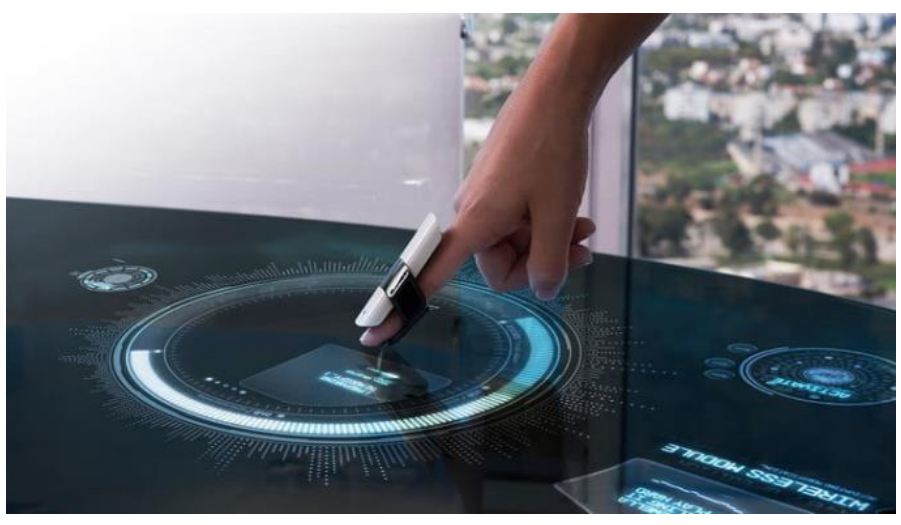

Fig. 32 Bird Interactive Device

The YouTube video "MUV wearable tech: Dream, Touch, Play!" shows how BIRD was been introduced to kids 7-15 and how quickly they got used to it by trying the amazing learning possibilities of having any type of surface to draw, game, or interact at their fingertips (MUV media lab, 2015). The possibilities of gadgets like MUV BIRD in Education are enormous because the user

\footnotetext{
${ }^{48}$ DRONE: in technological terms, is a flying robot with sensors and GPS that can be remotely controlled. Drones can arrive where human being cannot and deliver tools for learning in rural areas (Webopedia.com, 2011).

${ }^{49}$ BOT: in technological terms, is an internet robot: software application that runs automated tasks over internet. BOTs are used for language learning, with its users can chat with a robot in English and practice (Webopedia.com, 2011).
} 
can create an interactive screen in any wall or space, there so blended learning or lecturing can happen in any space where an interactive screen is projected on any surface and manipulated by Bird fingers like any other touchscreen.

\section{Other Realities (VR, AR, MR)}

Virtual reality (VR) enables users to physically walk around objects and touch those objects as they were real. Augmented Reality (AR) combines augmented objects or information placed in a real scenario. AR/VR/MR applications focus on professional usages (Fig. 33) that focus in the perception of an object, scenario, or task that can be visualized in a complex $3 \mathrm{D}$ environment without having it in real (Boyles, 2017). For example, the App AR Anatomy by Jump Simulation

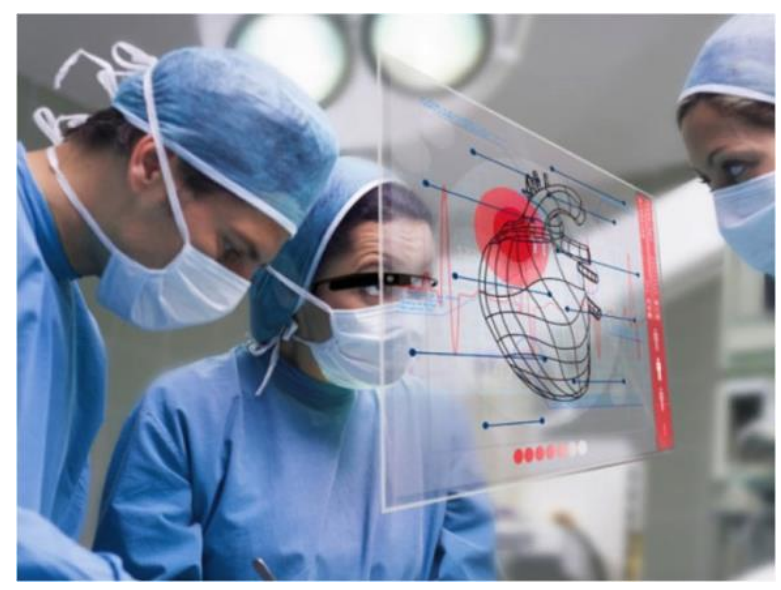

Fig. 33 VR in Medicine provides a 3D animated augmented reality look at anatomical systems with different pathological conditions that the user can use. Those apps use VR and AR mode to see the inner of the bones, contain audio commentaries, and descriptions in English language provided by experts, capture screenshot to share or to use in user's notes, and it is rated 4+. What it means that any aged learner can use it anytime, anywhere. AR/AV act as facilitators to deliver knowledge content while engage and empower students because they have control over the learning process.

Education can benefit from these tools in medical education, science, engineering, history and social sciences, foreign languages, distance learning, among many others. The students learn through experimentation at their pace. They can learn abstract concepts and test objects of different scales because they can visualize it (Boyles, 2017). Simulations can be used to mimic a scenario or activity in a repeatable and cost-effective manner. Depending on the task, practicing in real world situations can be expensive, dangerous, or prohibitive (Bacca, Baldiris, Fabregat, \& Graf, 2014). Techniques involving VR have been found to helpful in training children with Autism Spectrum Disorder because they can facilitate immersive training content (Maich et al., 2017).

\section{The Internet of Things (IOT)}

The Internet of Things (IOT), "a network of physical objects that contain embedded technology to communicate and interact with the external environment" (Garnet, 2017), allows that routines like turn on/off the lights, lock the house or the car from a distance, manage digital appliances (i.e. heat systems, voice agents, home robots, etc.) can be done from our smartphones with just a fingertip. With loT, users avoid switching devices and control their connected objects from any spot on the planet making them to work without waiting time. The only requirement is the internet connection (Wi-Fi, 3G, 4G, 5G). Education can benefit from this concept to increase the efficiency in day-to-day tuition routines, monitor students' performance, and security; as helping hand for the disabled (e.g. sensors get signals to provide feedback), among many others. 


\section{Big Data}

Big Data gathers customer's digital uses and interprets the information to customize the benefits. Education can use Big Data to collect, store and analyze big collections of information regarding students learning preferences and assessment, can capture intricated details of the learners, their learning process, preferences, as well as their learning inputs and results (Fig. 34). To have this information at hand will help Higher Education, researchers, and lecturers to customize curricula for improved learning outcomes, to improve students' performance, and enhance their university experience by connecting with their likes and dislikes (Sin \& Muthu, 2015).

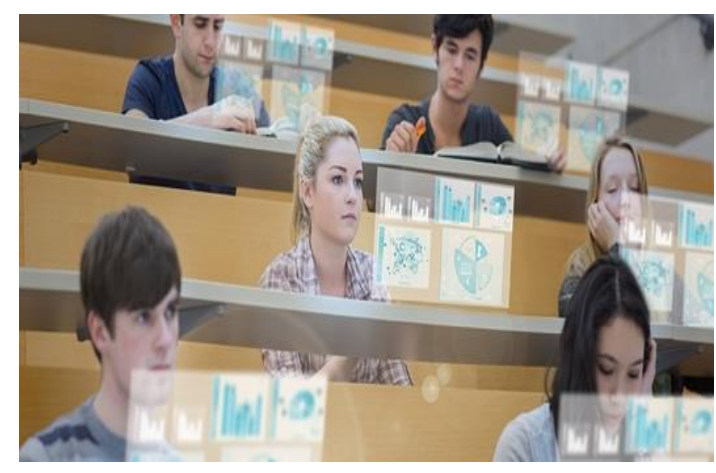

Fig. 34 Big Data in Education

All those concepts and devices are redefining digital interaction in education. The intuitiveness, immediate feedback on data, and real-world contextualization of concepts while using the technology free learning and age limitations. Interactive contents, 3D materials, 3D models, visuals, web-based applications, animations, infographics, etc. accessed anywhere anytime, engage denizens.

In this new ecology for learning, education requires reshaping in a broad sense. Connect face-toface, post questions, get answers to the questions, participate on surveys, create Apps, share knowledge, or create curate content are just a few examples of new powerful tools that can be used in the classroom and never existed before.

Haptic devices can provide multiple means to engage, represent, research, take action and express knowledge. Diversity, as we explained previously, is placed in the proficient usage of digital devices and media content (Digital diversity), and how this proficient usage makes that users approach to learning by using the different tools that they have at hand taking advantage of them in their conception of academic learning. To be aware of these possibilities is necessary in order not to fail the expectorations of the HapGens.

In the case of our haptic generation, they are not only students with interest, intuition, creativity, inborn abilities, and motivations for learning, they are also iScholars (hapter 6). Hence, they are students with an Active role and participants of their own learning who foster for Reasoning of the unknown since early childhood with an exceptional Open minded vision and growth mindset; and are driven by a proficient use of HAptic interactions as innate learning style to promote their expert and curated knowledge at the distance of a fingertip. 


\subsubsection{Driving Motivation}

Motivation is an important driver in the learning process because it activates and sustains the achievement of a goal (Academies of Science, Engineering, and Medicine, 2018a). When learners expect success, they are motivated to learn so they value learning, persist at difficult tasks, and perform better. Motivation increases or decreases over time, and it is subjective to change because of personal experiences. It is well known that motivated students are really engaged with the subject matter, persist longer when learning, play an active role, and obtain better results. If a person does not feel motivated when doing something, it is not able to leave the comfort zone when learning. Consequently, understanding and reasoning on the subject matter are not possible. It is very important to feel the usefulness of the learning and how this learning can impact others (ZG Case Study).

From the theoretical perspective, the main motivational reasons that help people to learn are their learning goals, the social and cultural surroundings, the intrinsic motivation (Academies of Science, Engineering, and Medicine, 2018a), and the personal mindset: "set of assumptions, values, and beliefs about oneself and the world that influence how one perceives, interprets, and acts upon one's environment" (Dweck, 1999). Learners develop mindsets over time, by fixing goals and taking choices to address attention and effort.

Among the learners' beliefs and values that affect motivation we can find: how the learners see themselves as learners (self-efficacy: capabilities to achieve a task), the values to achieve their goals, and the interest placed in the field domain. Interest affects also performance, positive attitude, and engagement.

Learners' behavior is influenced by intrinsic motivation (autonomy, competence, and the sudden urge to interact with). Learners should engage on an activity when the activity is seen as interesting, and enjoyable. Learners need to perceive the personal challenges that represent to deal with learning if the objective is to increase the motivation. Going out of the comfort zone has many benefits for scholar reasoning. This sort of challenge goes hand by hand with motivation, overcome fears, helps feel confidence, improve knowledge, and brings the need to achieve new goals.

There are strong social and cultural influences on motivation. The Mashup generation that is cohabitating in the present society, is facing unprecedented challenges driven by globalization, and faster rate of technological changes at any level; what provides new opportunities to grow, learn, and advance (OECD, 2018b). The intuitivism and interactivity of the haptic devices, as well as the way those devices have permeated so quickly into personal habits, have converted the devices into motivational tools to enhance learning at any age. Its extensive use by the society and its cultural connotations, highlights the importance of identifying the role of haptic devices in the learning process to generate engagement, greater interest, and success in academic pursuit.

The aim of the learning goal is also very important when talking about motivation. Learners have individual and multiple goals that can change in accordance with new events and experiences, community belongingness, personal autonomy, and subjective sense of competence. Academic goals are linked to motivation in career expectations (Academies of Science, Engineering, and 
Medicine, 2018a). If there is enough motivation the goals will persist despite the obstacles or problems that the learners face.

Foster motivation at any age is fundamental for a growth mindset (Fig. 35) (Blackwell, Trzesniewski, \& Dweck, 2007) and scholar development. By fostering motivation, lifelong learners can increase resilience, grit, imagination, curiosity, and self-regulation. Experts, instructors, coaches, lecturers, and teachers as the best adult interaction needed in any learning process, should help learners' motivation by focusing on their performance, degree of engagement, and persistence. Some examples are guiding the desired learning goals with appropriate challenges and scaffolded learning experiences, supporting their autonomy, monitoring the progress, and supporting their emotions and feelings (Academies of Science, Engineering, and Medicine, 2018a).

Motivation affects the amount of time that learners devote to learning, how the

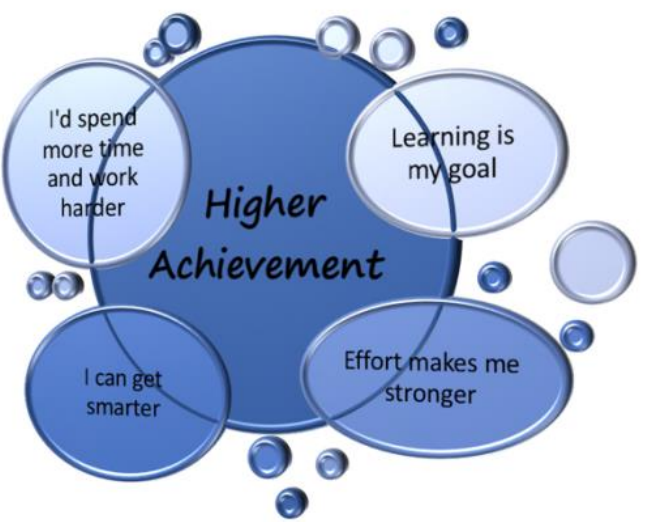

Fig. 35 The growth mindset learner faces the challenges, and the social opportunities the student can have. The age of the learner, his emotions, his physical conditions, the nutrition, the amount of sleep (Academies of Science, Engineering, and Medicine, 2018a) influence in the motivation of the learner. The technological savvy tools to use, the environment, the surroundings, the culture, and the most important, the online curated contents they have access to guided adult interaction, not only influence in the learner motivation, but also drive it toward success.

\subsubsection{Smart Learning Scenario}

There are many factors that affect motivation, and motivation affects other factors of learning. Nowadays, it is very difficult for faculty staff to motivate learners from in a formal scenario because the borders among formal, informal, and non-formal are disappearing. There are many ways to acquire expert knowledge and achieve reasonability.

The Atrium considers the disappearance of borders and insist on the opportunity that haptic interaction offers to young children, the iScholars students that Higher Education Institutions (HEls) will face in 2030 offering them an STEHEAM approach in their Curricula. It is imperative a long conversation among denizens (experts, and learners), stakeholders, and HEls in search of teaching strategies that convert novice's brains into expert ones taking advantage of digital and visual literacies, because what limits learning is what can happen inside the learner's brain, not the experience of the experts.

Promoting meaningful thought processes and guiding the social process of learning is a fundamental role of the adult denizens (lecturer, teacher, mentor, and parents). Their role in the learning process is to inspire, to challenge, to excite students to want to learn. They also explain, 
demonstrate, and show things, but the most important thing a denizen does is to make students to train their mind to think by themselves. Expert denizens are the modern influencers of learning.

The ideal learning scenario for ZGens, and future HapGen students, personal and full of choices should be accessible connecting formal, informal, and non-formal learning, to ensure that learners achieve the same learning goal from different perspectives and different tools (Sharples et al., 2015). In order to take into consideration, the three settings for learning, the educational contents can be linked to issues that matter to learners in their normal lives, so that the learning experience is enriched by experiences from everyday activities, and the informal learning can be deepened with curate contents, new questions, and scholar knowledge.

In our understanding they should develop scientific argumentation and aesthetic skills. This way, the learners can advance their understanding of science, relate with aesthetic concepts. Argumentation helps visual literacy to enrich the experience and contrast other information, helping to interchange ideas with peers, refute or set conclusions.

The scenario should take into account the unexpected learning that may occur when doing an activity that it is not aimed at that learning output (Sharples et al., 2015), like the use of the haptic devices that promote the learning of the purposed subject, the proficiency of digital skills, and the acquisition of the English language; when dealing with the different apps in English. Device use has modified daily routines, like the search for a location in a map, or send an email to peers, or modify a collaborative document hosted in the cloud, read cloud-stored content, and so on; and provides many opportunities to improve the use of the devices and apply it to other haptic devices. This type of learning is autonomous, unexpected, without certification, but can trigger self-reflection, expertise, and the application to other contexts.

The materials, equipment, and subject to learn should be authentic and context-based (Sharples et al., 2015). Context-based allows to learn from experience, interact with the surroundings, hold conversations, and modify beliefs by exposing the learners to real situations, even if they are performed in virtual or augmented environments (VR/AR). By being authentic the material is meant for purposes other than teaching what provides situational language, and exposition to real discourse, and communicative language.

If the learner is immersed in a smart learning scenario full of choices including the ubiquity of digitalization, where the unexpected learning is taken into account, and where he has the opportunity to face authentic and contextbased material, the innovative teaching strategy of "learning by doing" can be approached from many perspectives, could contribute to improve conceptual understanding, increase motivation and build soft skills on inquiry (finding answers to questions); design (crafting solutions to problems); debate (building a strong evidence-based case for a position on an issue); expression (creatively expressing personal voice and perspectives in

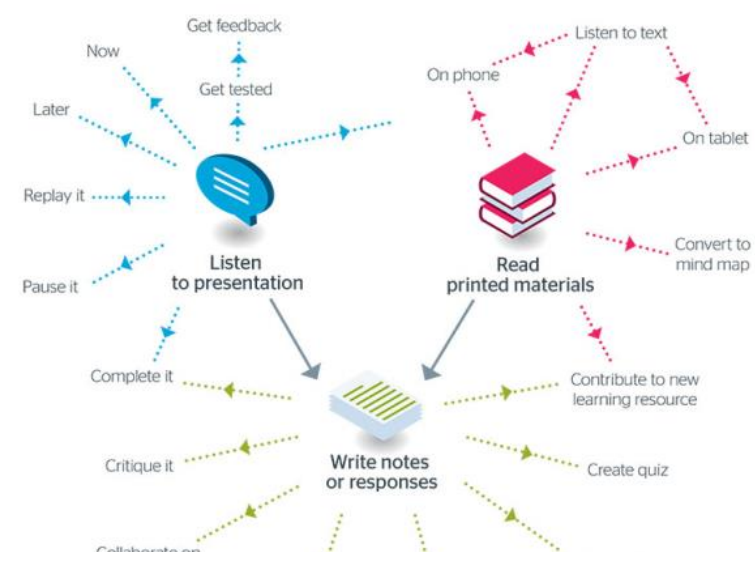

Fig. 36 Enhancing the digital student experience 
The Learning Atrium

different media); and self-development (setting and reaching personal goals) without fear of falling into boredom (National Center for Research in Advanced Information and Digital Technologies, 2018). A smart learning scenario is necessary to transform traditional teaching and learning, improve accessibility from digital diversity, engagement and ultimately achievement (Fig. 36). 


\section{5 ischolars Wandering Around}

The iScholars happen to be the main denizens of the learning Atrium that fill the classroom with skills, attitudes, knowledge, and preconceptions about how the world works. During their childhood they have been developing sophisticated understandings mainly from haptic interaction (visual, tactile, auditive) with digital devices around them, and as global citizens with the possibility to do it in English, because as it has been explained in Chapter 5, the informal use haptic devices in English has the potential to make kids learn the language as they were bilinguals, either simultaneous or sequential.

The adequate use of haptic devices during early childhood to boost creativity, literacy learning and English language (Chapter 5), promotes social, emotional, language, and cognitive development. A simple gesture has the power to excel children's interest and curiosity towards erudition and scholarship at early ages. Learner active role, guided by adult supervision, correct device use, as well as supervised screen time, all of that melted with pro-active attitudes can boost their creativity, their foundational literacy learning, and bilingualism in a natural way, as they were just playing.

Some factors influence the learning output: the context where the learning takes place, the relationships created around the goal, and the tools within the social context that support the core learning values.

The haptic interaction, socially contextualized for communication, leisure and entertainment, creation and productivity, and information and learning; has a powerful effect on the integration of new concepts that affect learning, industry, and research; and the type of information that the students manage to make sense of the learning and be able to apply it at professional levels. If the understanding is accurate, it provides a foundation for building up knowledge. Otherwise it provides misconceptions, stereotypes, and simplifications.

\subsubsection{Feeling the Rush}

The multidisciplinary perspective of the Science of Learning combines rigorous qualitative research to understand how children, embedded in a social context, make sense of the world by thinking and understanding. Cognitive Development studies differentiate aspects of a child brain development, like how information is processed, the conceptual resources and perceptual skill used, the language learning obtained, among other aspects of brain development and cognitive psychology compared to adults (Bjorklund \& Causey, 2018).

The social context of the haptic generation is an ecosystem produced by the imitative brain (Meltzoff, 2002) of an infant growing into an adult, specifically, when imitating other adults while using haptic devices, (e.g. apps, photos and video, browser searches, etc.) for different purposes like Communication, Leisure and Entertainment, Creation and Productivity, and Information and Learning. The ecosystem also includes natural curiosity, persistence, and adult-child relationships 
that facilitate learning by regulating tasks, scaffolding mature performances, framing language, and connecting new to familiar situations. For HapGens that evolve into a long-life learner developing sophisticated understanding mainly from haptic interaction, it is also important the early experience with or without the device, and the instruction in specific piece of information.

By combining cognitive development and imitation, children create the concept of culture that will start providing them enough knowledge to improve significantly their foundational abilities to become active learners who seek for understanding with the aim to transfer it to new problems and settings. One important ability that affects the creation of the concept is memory performance (remembering) that increases with age and by learning to use strategies like rehearsal (to improve rote recall); elaboration (to improve retention of more meaningful units like sentences); summarization (to increase retention and comprehension); and clustering to organize knowledge (to improve the performance). Depending on the concept created, different abilities and skills will emerge allowing the child to think and understand what is seen, felt, understood, and learnt.

Since the arrival of haptic devices, knowledge and understanding is gathered through text, hypertext, images, and sound; in the form of summary content (RSS), infographics, images, short text messages, enriched texts, and short videos; either by printed material or on interactive screens. Nowadays, people read more summarized than long texts on daily basis. If they are interested in the topic they can learn about through a whole and long text but always combined with images, hyperlinks to access to new content, and infographics. If the content is on an interactive screen, they skim text and do not complete paragraphs, they skip them with finger swaps (Yelland, 2018). As learners, in general, we have lost the habit of reading words in contextbased texts while we are exposed to images that summarize what learners must infer from texts, what eases the task and saves time. The loose of habits can lead to literacy problems, but technology and new ways to arrive to information do not create literacy problems. It is regression and inattention to that literacy what create the problems in acquiring knowledge and understanding (Martinussen, Grimbos, \& Ferrari, 2014).

Haptic generation is processing information, remembering, and solving problems mainly in the same way: through visual inputs like images, videos, and infographics. The first inputs that a baby receives and start the learning process is also via visual inputs. When they grow, they increase the number of images, words, and sounds as input and start inferring meaning when they develop reading skills. Pedagogical teaching styles in early childhood should be aimed to decipher those visual inputs (images, videos, infographics), that are different from words read in text. Also, they should foster the acquisitions of reading skills in the different stages of their learning process. Reading can be differentiate in five stages: Stage 0 (pre-reading), Stage 1 (initial reading, writing and decoding), stage 2 (confirmation and fluency), stage 3 (reading to learn the new), stage 4 (synthesizing information and applying multiple perspective), and stage 5 (critical literacy in work and society) (Brace, 2017).

Early childhood is immersed since 2010 in a new scenario where image visualization on an interactive screen is the foremost input for learning. For them it is compulsory to learn to read images in a way that they can interpret to infer as much meaning as other generation used to do with long written texts, and adding, at the same time, cognitive, psychological, language, and 
social values, of great importance in the different stages of their development and acquisition of literacy.

Literacy acquisition can be fostered in multiple contexts including people, purposes, places, cultures, tools, and sources through cognitive development, and instruction. It requires to establish solid practices to bring up literate identities, and to develop knowledge by the strength, in first place, of print concepts, phonological awareness, phonics and word recognition, vocabulary building, supported reading, fluency, and the development of oral skills to shape different discourses in different contexts (Brace, 2017). Actions like forming and informing teachers and parents, the production of quality and profitable materials and resources at hand, the knowledge of the possibilities of the digital tools that are nurturing the generation, among other actions, will help to grow curious brains, expert learners, and passionate denizens with active participation in their own learning.

Haptic interaction leads to repeating tasks that become automatic, but also naturally helps to develop fundamental basic skills that will improve knowledge and expertise. Acquiring expertise is fundamental to develop new ideas that connect disparate actions or facts from different moments of the learning process. By developing expertise, students increase the speed and accuracy to complete recurrent tasks; handle complex problems with less effort, and extract relevant information from the context that can be used by their innate capacity to deal with problems to discern and precise information to complete the tasks. Expertise also helps to use denizen's environment as a resource for cognitive knowledge. Using haptic devices as tools where the learner looks for further information, helps to develop proficient skills, to know which research tools are available at their disposal, and to find specialized networks where to dig deeper in their interests and curiosity. By gaining expertise, students find easier to apply new and related information to their acquired knowledge to start over again (Academies of Science, Engineering, and Medicine, 2018a).

For our haptic generation, it is extremely important to add to formal curricula at early stages, visual thinking and digital literacies that will increase the proficiency of the core literacies reading, writing, and arithmetic. Visual thinking strategies (Hattie \& Yates, 2013) will increase learning, understanding, and creativity mainly promoted by haptic inputs and foster learners' experiences across contexts, and flattening age variable when accessing authentic digital content.

\subsubsection{Pursuing Academic Learning}

Overviewed in Chapter 1, haptic devices offer multiple means to engage and enhance learning, but not all the users will be engaged in the same way. Factors like frequency (no, low, medium, high, sporadic) of haptic devices use as well as digital content preferences (passive consume, gaming, socializing, utility oriented, shopping, information exchange), purpose of the interaction (communication, leisure, entertainment, creation, productivity, information or learning), adult and school involvement (non, low, medium, high, sporadic), passive or active role (creator, collector, spectator) mastery when using the tools and apps (basic, advanced, independent, proficiency) (Brandtzæg, 2010), and personal motivation (communication, leisure or entertainment, creation and productivity, or information and learning) when using the device will influence in the way they hand haptic devices and use them with academic purposes. 
Students entering the different levels of our educative system have different ways to approach the learning outputs depending on their attitude and perception about learning. Likely, their attitudes and perceptions are influenced by their conception of how academic education should be. The concept that students have about learning is also biased by how academic learning is understood and promoted in their family environments, which in turn will affect the way students perceive higher education and its implication in the curricula of their preference. If haptic devices are added as drivers in the educational environment of the haptic generation, the digital literacy implications for Higher Education Institutions are enough to suggest a shift in the curricula model.

Formal education is shifting from structured classrooms to collaborative ones, from textbooks to portable texts, from over projected slides and PowerPoint presentations to infographics, short video presentation and talks. Words are progressively replaced by symbols or emojis and images that contains the full meaning. In brief, we have adapted written communication to modern technology (McCrindle \& Wolfinger, 2009).

Lecture rooms at university level in Spain are mainly still based on an industrial model. Attendance is compulsory and learning is optional. Some student-based learning factors that can affect university lectures and lessons are motivation (non, low, medium, high) expectation (work in something of their interest, just have a degree, work in something, do something, research), attitude (positive, negative), goals (purpose, motivation, resourceful, knowledgeable, strategies, goal-directed), and the active or passive role of the student.

Nowadays students are no longer waiting for instructions to learn, they access learning contents when and wherever they want through a wireless and mobile connection. They are multi-modal learners and demand different communication styles to engage their multiple learning channels, so their motivation, expectation, attitude, and goals are very influence by their command of digital devices and the expertise of the lecture staff that can follow their needs and can create a fluid dialog among their needs, the academic success, and job applications.

Considering as variables to perceive academics as an enhanced learning experience:

a) the learning attitudes and behaviors that a student can have;

b) the level of digital competence that haptic interaction provokes;

c) the multi-modal attitude of the student when dealing with contents; and

d) the advent of powerful tools at hand (i.e. real-time connections, the creation of useful and personalized apps, the analysis of "big data," cloud computing, the simulating scenarios, robot interaction, smart toys, etc.);

then, the future learners will be digitally competent diverse, and will influence not only the configuration of the policies of future formal educative settings, but also how education and learning is culturally understood in a way that the home environment can empower the learning process towards a national intellectual growth.

Measuring their digital diversity; their personal factors like interest, intuition, creativity; their already learned literacies and skills; and how they cope with motivation for a blended comprehension of the student desires when wandering around, will play a major role in the configuration of the learning Atrium, with the objective to adjust the panes based in its solid foundations to the future learning demands. 


\subsubsection{Expertise as Learning Output}

By learning, denizens accumulate information, experiences, and memories. They integrate the knowledge obtained over time, in different spaces, and under personal circumstances into the different formats (audio, video, text, etc.) that the digital landscape offers to obtain new and curated information that provokes linked memories, and more understanding. The process of integration leads to gain more understanding that comes from different episodes and moments during the life span, transforming novice knowledge into expert (Academies of Science, Engineering, and Medicine, 2018a) even when they do not receive explicit taught.

Achieving expertise (building knowledge) requires accumulation of information, classifying it as relevant or not, integrating it along different moments during the long life process, and to extend the knowledge by reasoning and imagining (Salthouse, 2010).

The benefits of expertise in academic learning are:

- an increment of speed and accuracy to complete recurrent tasks,

- to find new and better solutions for complex problems,

- the skill of extracting from the situation or text the relevant information (curated content),

- the ability to use the environment as a source of information (available tools, other experts in the field), and

- to gain more knowledge because it eases the learning of related and new information.

(Seel, 2012) states, in the Encyclopedia of the Sciences of Learning, that the learner needs inferential thinking to generalize, comprehend, and categorize. Inferential reasoning refers to "making logical connections between pieces of information in order to organize knowledge for understanding and to drawing conclusions through deductive reasoning, inductive reasoning, and abductive reasoning."

An example of inferential reasoning is how a child of Haptic Gen manipulates any haptic device to read, play, or search for information. The inferences that children obtain while interacting with the devices through one app, help them to track and integrate the intuitive actions or gestures into more complicated apps, recruiting extra information aimed to expertise and advanced use. The interaction generates a productive extension of prior learning actions to acquire new understanding.

To solve problems with efficiency and efficacy, learners need to retrieve previous knowledge and memories, adapt them, and transform them to fit new scenarios. The memories are formed in learners' brain, can be adapted to other scenarios, and re-used to infer reasoning. "The goal of problem-based learning is to instill in the learner, flexible knowledge use, effective problem-solving skills, self-directed learning, collaboration, and intrinsic motivation. These goals are in line with several of the goals identified in other contexts as important for success in life and work" (National Research Council, 2000).

Reasoning ability is determinant for academic learning, and allows people to achieve their academic and life interests. Trajectories for knowledge acquisition and reasoning differ across the life span of the individual (i.e. decline through adulthood but not the ability to take good decisions, 
skills, age), and among individuals (i.e. heath, social surroundings, life experiences, skills). Personal decision on hobbies, work, or education fit their selection and allow them different approaches to expertise (Seel, 2012). There so, for better retainment, learners need to train and improve their memory, make sense of the new information, and develop new knowledge, using strategies like the ones described in Subsection 7.3.3 like retrieved practice, spaced practice, interleaved an varied practice, summarizing and drawing; and explanations: elaborative interrogation, selfexplanation, and teaching; as they have (Academies of Science, Engineering, and Medicine, 2018a). 


\subsection{The STEHEAM Scope}

\subsubsection{Embracing the ISTE Standards}

The curricula to feed the iScholar needs should equip them with the tools, skills, and competencies to deal with the multidimensional challenges that nowadays innovation and technology are heading to, and that transgresses the boundaries of the disciplines. iScholars will need to take informed decisions, distinguish wrong from right, and falsehood from truth inside the massive digital information that they are going to find. To do that they need different methods from different disciplines and their implications: ethical, social, political, aesthetic, cultural, technological, etc. They will need to understand public policies, and the impact of their decision in multiple dimensions, adding the digital one, that was not at stage before.

The STEHEAM scope brings together diverse traditions, pedagogies, epistemologies, viewpoints, so that the students gain a broad perspective where to intersect their own ideas and creativity. It also identifies core areas of strength to guide ischolars to discover more about the world they live in; make them think how their work is relevant and relates to global issues, helping them to answer the critical questions society will face. The approach will produce discoveries, breakthrough, and innovation because of development guided by their own deep concern of building smart solutions.

This scope will support the iScholars in gaining momentum and presence on the international stage and will increasingly get them recognized for the quality of their work, assuring, in line with ISTE standards for Educators (Trust, 2018), that the iScholars will be:

- Empowered students with an active role in choosing, achieving, and demonstrating competency in their learning goals.

- Digital citizens that recognize the rights, responsibilities, and opportunities of living, learning, and working in an interconnected digital world, and they act and model in ways that are safe, legal, and ethical.

- Knowledge constructors that critically curate a variety of resources using digital tools to construct knowledge, produce creative artifacts and make meaningful learning experiences for themselves and others.

- Innovative Designers because they will use a variety of technologies within a design process to identify and solve problems by creating new, useful, or imaginative solutions.

- Computational Thinkers as they will develop and employ strategies for understanding and solving problems in ways that leverage the power of technological methods to develop and test solutions.

- Creative Communicators to communicate clearly and express themselves creatively for a variety of purposes using the platforms, tools, styles, formats, and digital media appropriate to their goals. 
- Global Collaborators by using digital tools to broaden their perspectives and enrich their learning by collaborating with others and working effectively in teams locally and globally.

Also, the approach will assure also the National Network's Common Employability Skills, developed by a consortium of industry employers to highlight "a core set of fundamental skills that potential employees need in the workplace." (Fidler, 2016): personal Skills, people skills, applied knowledge, and workplace skills.

Personal and People Skills include those abilities to act as a hard worker and witty player at the same time. Among other skills, iScholars will master:

- Resilience as "the ability to competently overcome setbacks, challenges, and other obstacles."

- Cross-cultural competency to "move effective and efficiently across a broad range of environments and to quickly switch between contexts," improved thanks to language skills acquired since very young ages, and respond to new contexts.

- Social intelligence to "develop and maintain face-to-face social skills during critical periods of social development when so many interactions are mediated through social platforms"

- Virtual collaboration. Nowadays work is "starting to be divided into micro-tasks that call for specialists who can be based anywhere, so workers should demonstrate a certain level of comfort with this arrangement in order to be successful."

Applied knowledge is defined as "the ability to logically analyze information." Among other skills, iScholars will master:

- Novel and adaptive thinking skills to be successful in an increasingly mechanized environment cultivated by insight, creativity, and adaptability skills. This facilitates quick responses to unexpected circumstances normally in a coordinated process where team interactions take place at the individual level.

- Cognitive load management skills to manage tremendous amount of data so that it creates assets, rather than obstacles. Workers are required to develop relevant digital practices to foresee how information is packaged and disseminated.

- Sense making as a higher-level cognitive skill which helps to create unique insights that offer different solutions to problems.

Workplace skills are defined as "the ability to solve problems and make decisions." Among other skills, iScholars will master:

- New media literacy including particular demands on digital identity. This will be imperative to communicate efficiently using a variety of media platforms.

- Effective content curation which involves seeking, sensing, and sharing information and reduces the cognitive load while it improves social intelligence through sharing and feedback. It helps to highlight valued information following the process of: validating, synthesizing, presenting, contextualizing, questioning, and comparing.

- Design mindset as an aptitude for creative problem solving. It reflects a combination of divergent and convergent thinking including creativity and innovative problem solving. 
- Transdisciplinarity which helps to generate, instead of interchange new types of knowledge. It integrates humanities, aesthetics, and English learning into the STEM paradigm to foster novel concepts and methods that go beyond the basic scaffolding of interdisciplinary work and includes a participatory element.

- Computational thinking that is "the ability for individuals to see and manipulate connections across digital systems." The value of this skill increases with the empowerment of the digital interaction.

\subsubsection{Spanish Universities Heading 2030}

Spanish education faces serious problems such as high drop-out and repetition rates, demotivation, and low level of competency among students, as shown in the 2015 PISA international report. The same report points out that Valencian students fail in understanding written texts, and, especially, in their production. Written expression is by far the greatest difficulty that students of all educational levels in Spain encounter. The analysis reports that these same students excel in oral comprehension and in some mathematical skills, but not in all of them. The causes of the low rates set down possible social reasons: in general, children read less, they like to use short and simple texts that succeed in digital media, they prefer video and photo inputs, and they avoid to devote attention for deep understanding. In addition, writing with correctness and following conventions is no longer a value, and learners are losing the ability to work on a text in depth, with time, unraveling what it says, what it means, and how it does; because they do not practice enough. Students lack basic knowledge on lexicon, spelling, grammar, and syntax, which hinders learning at all levels. PISA points out that these deficiencies are because students believe they do not need this training, and because of the influence of digital media where video and image are the main sources for information (Instituto Nacional Español de Estadística, 2016).

The PISA results in focus (OECD, 2016) analyses for the first-time student's well-being, their sense of belonging at school but also their relationships with peers and teachers, their home life, and how they spend their time outside of school. Indicators and data reported by PISA, and EU commission reports (Union, 2015) alert university policymakers, business and lecture staff the need to shift towards innovative, creative, personalized, active, and student centered pedagogies in order to successfully attract, recruit and retain students from all generations and levels since the arrival of screen interactivity in haptic devices.

Social well-being includes new elements like global connectivity, smart machines, haptic inputs, and new media literacies since 2010. Those new elements are reshaping how to acquire knowledge, how to work, and how to be productive. The new configuration has a profound impact in the educative landscape that is provoking a disruptive shift.

The main driver that is provoking the shift, as we have seen along the dissertation, is the irruption of Haptic Devices in users normal lives, and the influence of this irruption in some of the Haptic Generation children that are right now no older than 9 years old, who are filling our schools with more tools in their hands than formal schools offer, and will join university around 2030, the ischolars. 
iScholars are committed to excellence, passion, and impact. They are already avid researchers through haptic interaction since they were born, so they will excel in constant questioning, testing, and reasoning. The current university curricula system has lost value in the workplace, shifted toward innovation and automation in an emerging learning economy. Long-life learning through haptic devices is the new gold coin that will reorient education toward excellence based in intellectual effort.

The change of paradigm at university level linked to those drivers, brings the need of reshaping the STEM focus towards an STEHEAM scope to meet the inner configuration of the new and possible learning scenario: The Learning Atrium.

The Learning Atrium considers some variables which were not considered in the actual Spanish model and introduces haptic interaction as innate generational trait that directs the digital society where population is already immerse to formulate new scenarios. We must bear in mind that the actual Spanish model was created, developed, and updated in the pre-haptic era (last modification was in 2010 when meeting the expectation of the Bologna process for degree configuration). The new model should blend Humanities, English, and Aesthetics (HEA) with Science, Technology, Engineering, and Mathematics (STEM) skills into any university discipline configuring their subjects from a haptic interaction perspective to improve student's education and careers, and best prepare the ischolars for life, work, and digital citizenship.

Haptic Interaction at early childhood brings the perfect excuse to start designing an educative system where interaction, personalization, student perspectives, knowledge enhancement, motivations and haptic devices meet and bridge formal, non-formal, and informal settings. The aim of the new design should feed expert learning and include interactive and multi-modal contents, giving place to enjoyment and information at the same time, keeping their attention, and sparking curiosity for every single interaction with scholar content. 


\section{Conclusions}





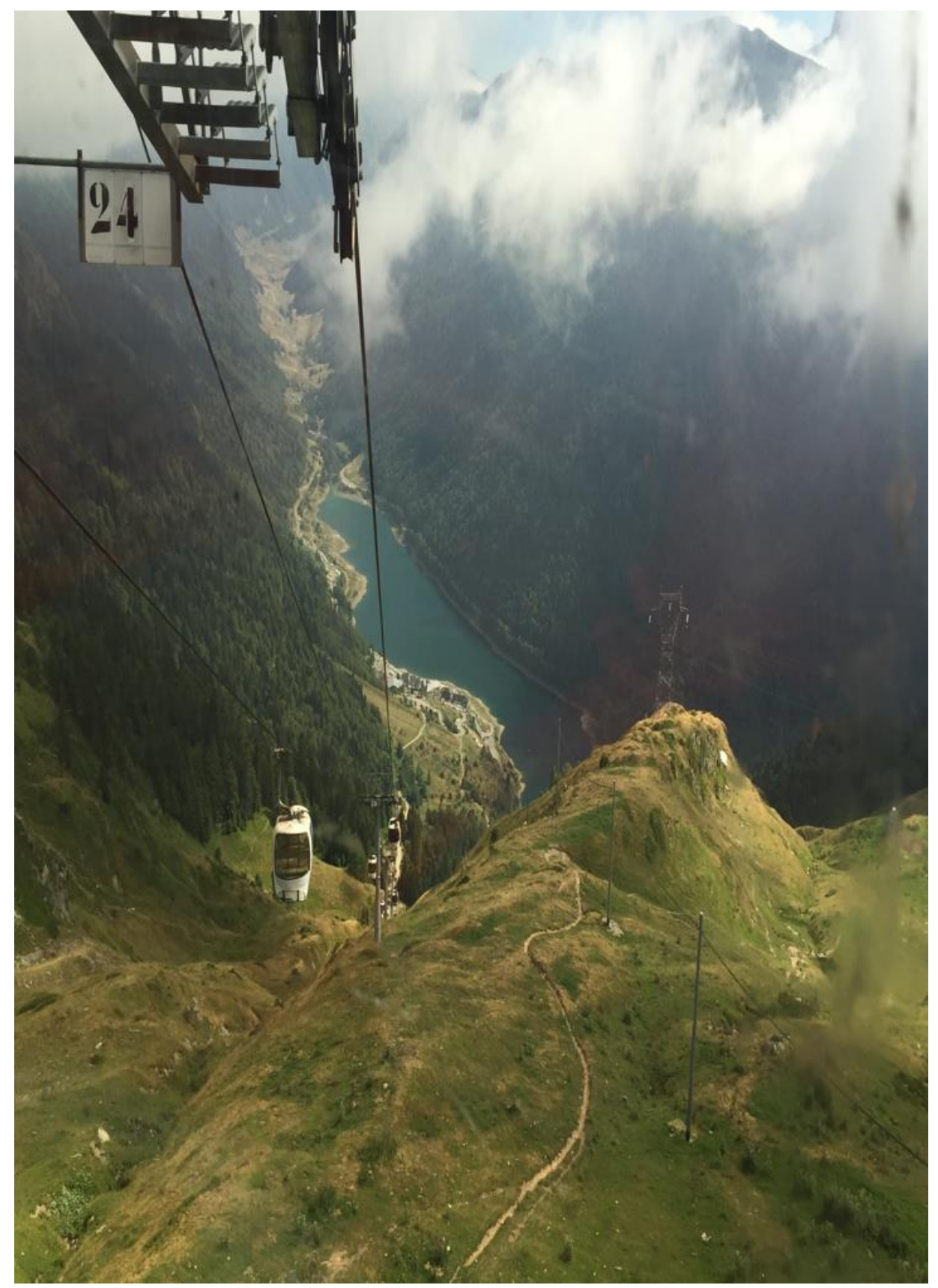

Conclusions 

"What's wrong with education cannot be fixed with technology."

Steve Jobs 



\section{Conclusions on the Findings}

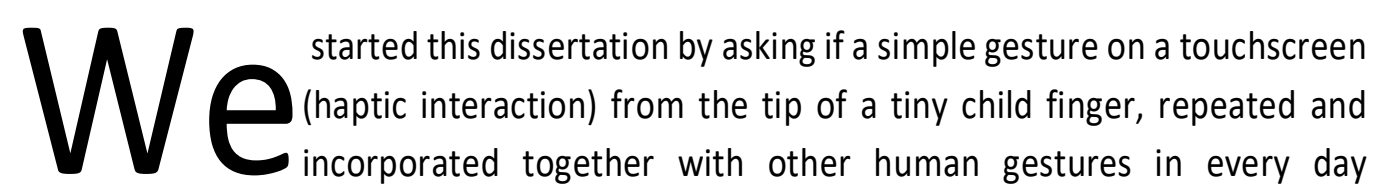
routines might provoke a new ecology for learning, weakening the configuration of formal education in such a way that it enforces a new design of education strategies.

The answers to the proposed research questions envisions that it is feasible, and indeed needed if as a society we want to succeed and give value to scholar effort.

In Chapter 5 we have analyzed the different variables and features that make possible for children to boost creativity, literacy learning, and English language learning when they are using haptic devices. When children get involved in the learning experience that the haptic device brings, they are active, engaged, interacting with their social context, and developing socio-emotional skills while they find meaningful learning in their scaffolded exploration (Hirsh-Pasek et al., 2015). Parents and school teachers are keystones for the boosting. From the research conducted in HG Case Study we can state that parents need more information about the possibilities for literacy learning and how to behave when children hold devices and what to allow them to do if they want to use, because there is a lot of misinformation not supported with scientific data. One remarkable detail purported by (Paciga \& Donohue, 2017) in their report is that the papers that conclude about the negative aspects of the usage of haptic devices in the hands of the children were in open sources, and the majority of the papers that concluded positively were in online repositories where it is needed to pay to access to the results, as a consequence, the negative opinion about using the devices is disseminated more easily in web searchers.

We find, extreme and urgently necessary to inform the society about the positive uses of the haptic devices that go further than communicating and entertaining.

In a few years, the community will be better informed about the positive effects of the haptic interaction (HA_Int) if used appropriately. Meanwhile, more children will be more proficient in 
digital competences, as well as other competencies, passing from being Analog with little HA_int, to Savvy-Tech, then Hi-Tech, or to iScholar ( $\underline{\text { Chapter } 7)}$, what means that more and more digital skilled children will fill the primary, secondary and high school classrooms.

As we have defined in Chapter 6 , iScholars are those children of the haptic generation (fully digital environment) (2010-...) that are nurturing their academic knowledge, skills, and competences through haptic inputs on interactive screens since early childhood (Llobregat-Gómez \& SánchezRuiz, 2015b). They are fully influenced by the digital landscape where they live immersed since they were born. Using tools like haptic devices since they are very young, the learners try new ideas and possibilities, through trial and error, and have no fear to risk. A simple fingertip sparks their curiosity to an active and open-minded reasoning in a single haptic interaction movement.

iScholars learn by being Active actors of their own learning process. For them, Reasoning and discovery come innate and instinctive with every finger touch on an interactive screen. They have an Open-minded attitude, and growth mindset to solve problems taking advantage of their creativity, curiosity, talent, and innovative skills. They perform Haptic Actions on tech-devices to excel their skills and power their knowledge through one simple gesture that brings three senses in one: touch, hearing, and sight.

Section 5.6 covers the instances of conducted research on haptic devices and early childhood with positive literacy skills achievement what gives an insight of what children are able to achieve having those devices in their hands.

Researcher Patricia Kuhl affirms that exposure to a foreign language ignites infants' learning (Kuhl, 2010). Onsite experiments (HG Case Study) also brings to the research arena the possibility of acquiring a second language while interacting with the device in another language (passive and active content). One of the children of the HG Case Study with Spanish mother tongue gave some outputs of advanced English skills while other kids of her age, less usage of the haptic device in English and the same school setting did not. The implications of those experiences point out beneficial results for knowledge acquisition and reasoning, and open a new door to research in a field still not explored because haptic devices are very recent and children very young.

Our first conclusion is that children can boost creativity, literacy and second language learning if they start using the device at early ages, perform with curiosity on haptic devices, use the device and content in the intended second language, make use of in-built device features, and serve from the devices to complement other learning processes. Some children are already nurturing their academic knowledge, skills, and competencies with innate AROHA Learning Style (Active, Reasoning, Open-minded, HAptic Devices) to promote expert understanding.

The next question addresses their future needs when they enter the university by 2030. The conclusions for ZG Case Study together with the analysis of the different variables that affect formal, non-formal, and informal settings, lead us to propose a new learning space that embraces and integrates digitalization in all its forms: The Learning Atrium.

The proposed Atrium is characterized by lifelong learning; shaped by the ubiquity of the information retrieved by haptic feedback that enhances learning; and guided learning from the community. Its role is to create dialogs, interaction, collaboration, and positive encounters among the learners, the movable elements that will guide their learning path, the experts, and the 
foundations that guide the process. Personalization, collaboration, and informalization (informal learning) are at the core of the denizens' learning paths, giving rise to new skills and literacies required for a new way of learning (Kampylis et al., 2015).

Major paradigms give understanding about how explicit and implicit learning happens (the foundations), that reasoning can be fostered from formal, informal, and non-formal settings to enhance knowledge retention if there is a blended inner space that covers a new scope further than STEM, the STEHEAM scope (the panes). Experts and faculty should accept and join the digital diversity and innovate in their way of teaching students with the aim to drive their motivation in a new learning scenario where the iScholars will be wandering around, feeling the rush to pursuit academic learning and expertise as their main objective.

\section{Dissertation New Concepts}

This dissertation proposes new concepts that did not exist in literature up till now. The definitions serve for the purpose of the comprehension of its contents but also for future references as they are fully explained and justified along the chapters.

\section{Haptic Device}

Haptic Device is defined in this dissertation as a mobile digital device with high-resolution Multi-Touch $^{\text {TM }}$ display and touchscreen interface that let users physically interact with applications and content using fingertips. The device should contain, at least, application programs, voice recognition software, integrated camera, internet connection and an operating system software to run the device (Chapter 1 ).

\section{Haptic Interaction}

Haptic Interaction (Llobregat-Gómez \& Sánchez-Ruiz, 2015b) (Patchan \& Puranik, 2016) provides a way to physically engage users with tactile feedback to get attention on the action performed, and reinforce new ones. Haptic interaction has helped to open new human neural possibilities through new habits that involve the tactile, the auditory, and the visual sense in just one fingertip. With the arrival of new habits, new ways of understanding are expected, expressing and approaching to knowledge (Llobregat-Gómez \& Sánchez-Ruiz, 2015b). The inclusion in our households of such devices has given birth to a new type of student, the iScholar, an already born member of the Haptic Generation (Chapter 1).

\section{Tech-User Digital Diversity}

Tech-User Digital Diversity is placed in the proficient use of digital devices and media content (Digital diversity) (Chapter 2 ) by the members of the different generational cohort. 


\section{Mashup Generation}

The Mashup Generation (Mashups) is the generational cohort formed by users of different ages that started using computer technology when it was available in the market and irrupted in the current society, and, consequently, in citizens' lives, changing customs, habits, and perceptions (Chapter 2).

\section{Haptic Generation}

Haptic Generation (HapGens) refers to the generational citizens born in 2010 or after. Children of this generational cohort are already exposed to diverse learning environments (Chapter 2).

\section{The ischolar}

iScholars are defined as those children of the Haptic Generation (fully digital environment) (2010...) that are nurturing their academic knowledge, skills, and competences through haptic inputs on interactive screens since early childhood (Llobregat-Gómez \& Sánchez-Ruiz, 2015b), (LlobregatGómez \& Sánchez-Ruiz, 2015c) and (Llobregat-Gómez \& Sánchez-Ruiz, 2015a). They are fully influenced by the digital landscape where they live immersed since they were born. Using tools like haptic devices since they are very young, the learners try new ideas and possibilities, through trial and error, and have no fear to risk. A simple fingertip sparks their curiosity to an active, resilient, open, and haptic action (Chapter 6).

\section{AROHA Learning Style}

Learning Style that promotes expert understanding with an Active role in their own learning, the pursuing of Reasoning with an exceptional Open-minded vision and growth mindset to solve problems taking advantage of their creativity, curiosity, talent, and innovative skills; and driven by HAptic interactions on tech-devices that excel their skills and power their knowledge through one simple gesture that brings three senses in one: touch, hearing, and sight (Chapter 6).

\section{The Learning Atrium}

Polyvalent space where our iScholars, children of the Haptic Generation, nurture their knowledge, skills, and competencies to become experts out of novices. Atrium is characterized by lifelong learning; shaped by the ubiquity of the information retrieved by haptic feedback that enhances learning; and guided learning from the community. Personalization, collaboration, and informalization are at the core of the denizens' learning paths, giving rise to new skills and literacies required for a new way of learning (Kampylis et al., 2015) (Chapter 7). 


\section{Implications}

Taking into account the figures and data of PISA report for Spain (Instituto Nacional Español de Estadística, 2016), the qualitative study about young children and digital technology (Chaudron et al., 2018) and the ethnographic research conducted that foresees the possibility to enhance knowledge acquisition and competencies achievement through Haptic Interaction, the Spanish educational system has a timely reason, challenge and obligation to promote a relevant change in how faculty comprehend the recent digital irruption that is shifting the students learning attitude, consequently facilitating to reduce drop rates, nurture academic learning, improve the assessment results, and increase higher education performance as other countries like Singapore, Canada or Finland.

Student retention rates can be improved in the Spanish educative system if we look closely to the possibilities that the haptic devices offer to education (Chapter 1), what it means for population (Chapter 2), how early childhood is using the haptic devices (Chapter 5), and the future implication of the digital tools in their lives (Chapter 6 ), giving them a new learning setting where all instances for learning are taken as positive inputs and encouraged (Chapter 7).

The STEM scope falls short, and technical university degrees should go towards an STEHEAM scope to offer an integrative blending between Humanities, English, and Aesthetics, with Science, Technology, Engineering, and Mathematics. STEM need skills, methods, and insights of humanities, arts, and aesthetics to understand the implications of their work from a philosophical, historical, and ethical perspective.

New university curricula aimed to 2030 Engineering students should bridge in an interdisciplinary, transdisciplinary, and multidisciplinary way Science, Technology, Engineering, Humanities, English, Aesthetics, and Mathematics to break the boundaries of the disciplines in isolation.

Science of Learning should inform the educational paradigms to fulfill the demands of the new students from a SMART approach (Specific, Measurable, imply different type of Answers, and deliver information that is Relevant and Targets the initial problem).

New basic literacies should be included in kindergarten learning curricula: digital literacy and visual literacy to learn to read images as a main form of textual input.

Web 4.0 trends move towards highly collaborative and social networks. Hence the importance of using all kinds of tools and resources to learn how to "curate" content in the classroom to get a critical future approach when contrasting information and be fully informed.

Educators, faculty, stakeholders, policymakers must focus on students future learning needs, the tools they are going to use, and their preferences to approach learning. In the same line, Higher Education strategies should analyze the new generational context where children are being educated and nurtured, their opinion when tackling learning goals, the new role of the lecturer in a conventional classroom, as well as children future demands when they become university students based on their culture, background, and motivation; as part of the 2030 challenges in the educational landscape (Sánchez-Ruiz \& Llobregat-Gómez, 2019). 


\section{Further Research}

This dissertation opens the door to future research on the advantages of Haptic Interaction for boosting learning, and specifically for the acquisition of second language learning and the formal formulation of what visual literacy learning could mean for students of technical universities not fully trained in aesthetic interpretation.

HEls should take into account and advantage of the innate Learning Style that the future students will bring to our campuses, as well as their voices as the soil to rethink on the curricula and build new strategies to offer formal educative solutions to the challenges of the London Agenda (SEFI, 2016). 


\section{Autobiographical Reflection}

\section{January 2015}

Esta es la historia de un iScholar, un bebé, entre muchos, de los nacidos desde 2010 en un lugar llamado España. Su infancia, como la de muchos otros niños de su edad, transcurrió entre juguetes y personas que velaban por su seguridad y su bienestar. Era feliz, le gustaba leer, aprender, soñar y decidió ir a la Universidad; tal y como habían hecho las generaciones precedentes.

$[\ldots]$

A Wink le gustaba tocar todo lo que llegaba a sus pequeñas manos. Le divertía imitar, le fascinaba experimentar, jugar a ser científica de líquidos y, sobre todo, le entusiasmaba descubrir cosas nuevas usando el tacto, la vista y el oído con un solo gesto (tap-tap).

Sus juegos de un solo gesto simulaban situaciones de su día a día, imitaba a quien le rodeaba y emulaba lenguaje y vivencias cotidianas. Desde muy pequeña dibujaba, pintaba, leía, escribía, contaba historias... Exactamente igual que otros niños de generaciones anteriores.

Pero Wink lo hacía de forma diferente, con un solo gesto.

Un día, cuando apenas tenía tres años garabateó, sobre un pañuelo de papel, un mapa para llegar a un lugar. Con su lengua de trapo decía como llegar al destino, qué dirección tomar: "qui, lli, no, vale, qui, qui". Las indicaciones simples, infantiles, cambiaban cada vez que presionaba el papel con aquel gesto: tap-tap. Ese discreto rozar el papel, le ampliaban el recorrido y hasta le hacía ver edificios en 3D en su imaginación.

$[\ldots]$

Fue entonces, cuando alguien se fijó en su acción; la congeló; hizo zoom con un toque en la pequeña pantalla y, como si de una foto ampliada se tratase, observó que para Wink el pañuelo de papel garabateado simulaba una pantalla táctil y los garabatos un mapa muy similar a los que mostraba la App de Google Earth. Sus toques (tap-tap) sobre el papel imitaban exactamente los mismos gestos que sus padres hacían al usar sus dispositivos móviles cuando querían llegar a un lugar.

El mapa, en principio como cualquier otro, mostraba unos detalles y unas dimensiones impensables antes del 2010. De líneas métricas cartográficas a imágenes reales y dimensionadas.

Lo que para Wink era un mapa normal, era extraordinario para los adultos de su alrededor, las generaciones precedentes. Se podía viajar sin salir de casa, recrear una historia del pasado, revivir un recuerdo y estar justo en el lugar preciso, en el recuerdo exacto de aquella emoción ya sentida.

$[\ldots]$

Con curiosidad, el investigador dio al play para ver cómo Wink interaccionaba con su pequeño mundo familiar; cómo jugaba, qué imitaba, cuáles eran sus escenarios más repetidos y mezclados. 


\section{Conclusions}

Fue entonces cuando se percató que cuando Wink nació, lo segundo que percibió fue el sonido de esos tap-tap sobre pequeñas pantallas interactivas, gestos que inmortalizaban la felicidad, cualquier avance en su crecimiento: su primera sonrisa, su primera palabra, hasta su primer movimiento háptico. A su alcance había Smartphones, Apps, internet, Siri, contenidos digitales, ... un sinfín de conceptos nuevos.

Entre sus juguetes, mezclado entre peluches a los que enseñar, probetas donde hacer experimentos, lápices para pintar, instrumentos de música, juegos, libretas... había un iPad donde, por instinto, Wink dejaba el rastro de lo que hacía; el rastro de una interacción acumulada, su huella digital.

$[\ldots]$

Aquel rastro, su huella digital, contaba una historia. Hablaba de una infancia que, aunque conservaba tintes tradicionales analógicos y tecnológicos, reflejaba unas aptitudes y unas habilidades desconocidas basadas en el sentido disruptivo del tacto que podía convertir su conocimiento en algo extraordinario o, por el contrario, en cuestión de segundos, podía sumirlo en una debilidad.

La serendipia de la interacción háptica (vista, oído y tacto en un solo gesto) traía, agazapado en su interface, la innovación, lo multidisciplinar y el poder de crear un impacto positivo en el mundo desde el conocimiento práctico.

En un parpadeo, en un wink, agazapado en sus componentes y formatos, aquello que había sido creado para entretener posibilitaba a los usuarios que abrieran desde o en cualquier lugar las puertas de la mente a lo bueno, lo malo y a lo desconocido.

$[\ldots]$

Pero ¿qué le hacía a Wink convertirse en un iScholar? ¿Qué le distinguía de otros niños de su edad?

Le distinguía su forma de aprender, su forma de descubrir el mundo usando su competencia digital; competencia que pasó de básica a avanzada la par que crecía y sin que nadie le explicara cómo hacerlo.

Le bastaba observar, imitar cómo los mayores lo hacían para descubrir lo que había detrás y así seguir investigando, abriendo puertas al conocimiento.

Desde su acceso a contenidos digitales supervisados aprendía de forma Activa, Razonada, con mente abierta, Objetiva usando interacciones HÁpticas. Un estilo de aprendizaje incipiente ante el que la sociedad, el sistema educativo y la universidad no debían permanecer impasibles.

Desde muy pequeña, Wink ya sabía, con un solo tap-tap, cómo ver y hablar con sus familiares que vivían lejos usando FaceTime, como localizar a su madre en caso de emergencia, sabía que detrás de aquellas pantallas había gente que velaba por ella.

Dibujaba, pintaba, escribía y leía no solo sobre el papel sino también en Apps instaladas en el iPad con las que interaccionaba con sus pequeños dedos y con su lápiz óptico. 
Hacía fotos que contaban historias, grababa videos donde expresaba y contaba todo aquello que aprendía o lo que le llamaba la atención... "Hola a todos, today I am..."; creaba música, buscaba sus canciones favoritas.

Sabía conjugar los diferentes gestos para crear cosas nuevas que ni siquiera sus padres sabían hacer.

$[\ldots]$

Instintivamente, con un solo dedo, como si fuera una varita mágica, podía llegar a cualquier lugar del mundo y ampliarlo. Escudriñar su interior, visualizar sus calles, su forma de vida y contrastarlas con su ciudad, su país, su historia, su familia.

Australia, de donde venía su nombre, era su "más favorita" ... su música, su idioma, su cultura aborigen, sus recuerdos inventados. Inconscientemente, sin saberlo, mientras jugaba a imaginar que vivía allí, descubría sus rasgos culturales y los hacía familiares, relacionaba conceptos difíciles de entender para su edad cronológica en un idioma que, por nacimiento, no era el suyo.

Y esto ocurría porque Wink tenía acceso a contenidos y ejemplos auténticos de la vida real. En ellos podía aprender cómo comía una planta carnívora, cómo funcionaba una máquina de escribir o el fax, cómo se producían los fenómenos meteorológicos, dónde estaban los 206 huesos del cuerpo humano y cómo eran por dentro...

Como si de un juego más se tratase, a más gestos en la pantalla interactiva, más necesidad de conocimiento profundo tenía. A medida que Wink crecía, crecía su curiosidad, su mente investigadora, su erudición.

$[\ldots]$

El investigador, rodeado de escenarios formales, no formales e informales, tenía mucho que analizar desde su mirada educativa. Pero aún le quedaba algo por descubrir.

Cuando pensaba que ya tenía todos los datos y que ya podía marcharse, amplió por última vez aquellas escenas cotidianas y se percató de algo apenas perceptible por su naturalidad.

Subió el volumen y comprobó que la interacción con el dispositivo era siempre en inglés, en la lengua original de los contenidos seleccionados, de aquello que le había llamado la atención y de lo que Wink aprendía.

Nuestro iScholar, con su corta edad, relacionaba, entendía y soñaba en dos idiomas diferentes, español e inglés, como si hubiese tenido al nacer dos lenguas maternas.

De forma pasiva, sin percatarse, había contribuido a la adquisición de una segunda lengua como, otra vez, si de un juego se tratase.

De nuevo, lo que para un iScholar podía ser normal, lo cotidiano; era sorprendente e increíble para las generaciones anteriores, incluso para otros niños de su misma edad. Sin darse cuenta su mente bilingüe, multiplicaba la estadística de su lenguaje.

$[\ldots]$ 


\section{Conclusions}

Pasó el tiempo y algunos de sus juegos pasaron a ser costumbres, modos de aprendizaje, de expresión y de vida. Su competencia digital y visual se hizo altamente especializada, experta.

Aprendió diferentes formas de relacionarse, de comunicarse, de vivir, de interactuar, de aprender globalmente sin barreras ni fronteras.

Soñaba con dar respuestas a problemas que aún no existían desde un ámbito amplio que abarcara todas las materias al mismo tiempo, que interaccionaran y confluyeran como si fuera una sola perspectiva y no varias, haciéndolas todas igual de relevantes para el propósito alcanzable.

Sin saberlo, mientras crecía, mientras jugaba, se convirtió en un iScholar que soñaba, como muchos otros, con ir a la universidad a partir del 2030 y resolver nuevas dudas, proponer nuevos planteamientos; exactamente igual que hicieron las generaciones anteriores.

Fue entonces cuando el investigador silencioso, con apenas dos toques de pantalla, alejó el zoom del iScholar, abrió una App de notas y amplió la imagen de la universidad pública española. Fue entonces cuando le surgieron muchas preguntas, dudas, inquietudes, preocupaciones, incluso miedos.

Respiró hondo, bajó la mirada, puso su iPad en la mochila y caminó en silencio en busca de respuestas.

November 2019 
Reference List 



\section{Reference List}

Abdullah, A., Adil, M., Rosenbaum, L., Shah, M., Abrahamson, D., \& Neff, M. (2017). Intelligent Virtual Agents, 10498, 1-14. https://doi.org/10.1007/978-3-319-67401-8

Academies of Science, Engineering, and Medicine, N. (2018a). How People Learn II: Learners, Contexts, and Cultures. Washington, DC: The National Academies Press. https://doi.org/10.17226/24783

Academies of Science, Engineering, and Medicine, N. (2018b). The Integration of the Humanities and Arts with Sciences, Engineering, and Medicine in Higher Education: Branches from the Same Tree. (D. Skorton \& A. Bear, Eds.). Washington, DC: The National Academies Press. https://doi.org/10.17226/24988

ACRL. (2008). Visual Literacy Competency Standards for Higher Education. Retrieved July 16, 2018, from http://www.ala.org/acrl/standards/visualliteracy

Adams Becker, S., Pasquini, L. A., \& Zentner, A. (2017). 2017 Digital Literacy Impact Study: an NMC Horizon Project strategic Brief. (Vol. 3.5). Austin, Texas:

Agarwal, P. K., Roediger, H. L., McDaniel, M. A., \& McDermott, K. B. (2018). How To Use Retrieval Practice To Improve Learning. St. Louis.

Ageing Well S.L. (2018). Joyners app. Retrieved September 17, 2018, from https://www.joyners.es/aplicacion-movil

Akbari, \& Razavi, A. (2016). Using authentic materials in the foreign language classrooms: Teachers' perspectives in EFL classes. International Journal of Research Studies in Education, 5(2), 105-116. https://doi.org/10.5861/ijrse.2015.1189

Akçayır, M., \& Akçayır, G. (2017). Advantages and challenges associated with augmented reality for education: A systematic review of the literature. Educational Research Review, 20, 1-11. https://doi.org/10.1016/j.edurev.2016.11.002

Aladé, F., Lauricella, A. R., Beaudoin-ryan, L., \& Wartella, E. (2016). Measuring with Murray: Touchscreen technology and preschoolers ' STEM learning. Computers in Human Behavior, 62, 433-441. https://doi.org/10.1016/j.chb.2016.03.080

Albiladi, W. S., Abdeen, F. H., \& Lincoln, F. (2018). Learning English through Movies: Adult English Language Learners' Perceptions. Theory and Practice in Language Studies, 8(12), 1567. https://doi.org/10.17507/tpls.0812.01

Allaboutstevejobs.com. (2010). iPad introduction (27/01/10) [video]. Retrieved April 20, 2018, from https://www.youtube.com/watch?v=jj6q_z2Ni9M

Allen, M. L., Hartley, C., \& Cain, K. (2015). Do iPads promote symbolic understanding and word learning in children with autism? Frontiers in Psychology, 6(FEB), 1-9. https://doi.org/10.3389/fpsyg.2015.00138

Alpers, B. A., Demlova, M., Fant, C. H., Gustafsson, T., Lawson, D., Mustoe, L., ... Velichova, D. (2013). A framework for mathematics curricula in engineering education: a Report of the Mathematics Working Group of the European Society for Engineering Education (SEFI). Brussels.

Álvarez_Monzonillo, J. M., \& De Haro, G. (2017). Millennials. La generación Emprendedora. (Editorial Ariel, Ed.), telefonicaeducaciondigital.com. Madrid.

Anderson, D. R., \& Pempek, T. A. (2005). Television and Very Young Children. American Behavioral Scientist, 48(5), 505-522. https://doi.org/10.1177/0002764204271506

Apple Developer. (2016). How iOS Security Really Works. Retrieved May 18, 2018, from https://developer.apple.com/videos/play/wwdc2016/705/

Apple Events. (1998). Apple Back On Track 1998 [video]. Retrieved April 20, 2018, from https://www.youtube.com/watch?v=Quy7Jnmb0LU

Apple Inc. (2006). 2006 Unaudited Summary Data. Retrieved April 20, 2018, from www.apple.com/newsroom/pdfs/q106data_sum.pdf

Apple Inc. (2007). Apple Reinvents the Phone with iPhone. Retrieved April 20, 2018, from 
https://www.apple.com/newsroom/2007/01/09Apple-Reinvents-the-Phone-with-iPhone/

Apple Inc. (2010). Apple Launches iPad. Retrieved April 20, 2018, from https://www.apple.com/newsroom/2010/01/27Apple-Launches-iPad/

Apple Inc. (2018a). Apple.com. Retrieved April 20, 2018, from https://www.apple.com/

Apple Inc. (2018b). iPad Pro. Retrieved June 22, 2018, from https://www.apple.com/lae/ipad-pro/

Apple Inc. (2018). Everyone Can Create. Retrieved June 22, 2018, from https://www.apple.com/education/everyonecan-create/

Archive.org. (2001). Internet Archive. Wayback Machine. Retrieved July 5, 2018, from https://web.archive.org/

Arnott, L., Grogan, D., \& Duncan, P. (2016). Lessons from using iPads to understand young children's creativity. Contemporary Issues in Early Childhood, 17(2), 157-173. https://doi.org/10.1177/1463949116633347

Atkinson, R. C., \& Shiffrin, R. M. (1971). The Control of Short-Term Memory. Scientific American. Scientific American, a division of Nature America, Inc. https://doi.org/10.2307/24922803

Bacca, J., Baldiris, S., Fabregat, R., \& Graf, S. (2014). Augmented Reality Trends in Education: A Systematic Review of Research and Applications. Educational Technology \& Society, 17(4), 133-149. https://doi.org/ISSN 14364522 (online)

Bacon, S. M., \& Finnemann, M. D. (1990). A Study of the Attitudes, Motives, and Strategies of University Foreign Language Students and Their Disposition to Authentic Oral and Written Input. The Modern Language Journal, 74(4), 459-473. https://doi.org/10.1111/j.1540-4781.1990.tb05338.x

Baddeley, A. D., \& Hitch, G. (1974). Working memory. The Psychology of Learning and Motivation, 47-89. https://doi.org/10.1016/s0079-7421(08)60452-1

Baltes, P. B., \& Baltes, M. M. (1990). Psychological perspectives on successful aging: The model of selective optimization with compensation. Successful Aging: Perspectives from the Behavioral Sciences, 1(1), 1-34.

Barlow, J. P. (1996). A Declaration of the Independence of Cyberspace. Retrieved May 5, 2017, from https://www.eff.org/cyberspace-independence

Barnett, S. M., \& Ceci, S. J. (2002). When and where do we apply what we learn?: A taxonomy for far transfer. Psychological Bulletin, 128(4), 612.

Barr, R., Shuck, L., Salerno, K., Atkinson, E., \& Linebarger, D. L. (2010). Music interferes with learning from television during infancy. Infant and Child Development, 19(3), n/a-n/a. https://doi.org/10.1002/icd.666

Barrows, H. S. (1986). A taxonomy of problem-based learning methods. Medical Education, 20(6), 481-486. https://doi.org/10.1111/j.1365-2923.1986.tb01386.x

Bates, A. T. (2018). Teaching in a Digital Age: Guidelines for designing teaching and learning. (C. C. 4.0, Ed.) (1st Editio). Vancouver BC: Tony Bates Associates LTD.

Baumrind, D. (1966). Effects of authoritative parental control on child behavior. Child Development, 887-907.

BBC News. (2007). How the Spectrum began a revolution. Retrieved October 31, 2018, from http://news.bbc.co.uk/2/hi/technology/6572711.stm

Bencsik, A., Juhász, T., \& Horváth-Csikós, G. (2016). Y and Z Generations at Workplaces. Journal of Competitiveness, 8(3), 90-106. https://doi.org/10.7441/joc.2016.03.06

Benedict, J., \& Benedict, I. (1989). Visual Literacy Collection. Retrieved May 10, 2018, from https://lib.asu.edu/archives/benedict

Benelux Bologna Secretariat. (2007). From London to Leuven/Louvain-la-Neuve Report on the Work Programme of the Bologna Follow-up Group. Retrieved March 18, 2018, from http://www.ehea.info/media.ehea.info/file/2009_Leuven_Louvain-laNeuve/92/1/Bologna_Work_Programme_2007_2009_Report_594921.pdf

Benelux Bologna Secretariat. (2009). Bologna beyond 2010. Report on the development of the European Higher Education Area. Bologna Process. Leuven. https://doi.org/D/2009/3241/142 
Benjamin, A. S., \& Tullis, J. (2010). What makes distributed practice effective? Cognitive Psychology, 61(3), 228-247. https://doi.org/10.1016/j.cogpsych.2010.05.004.

Berengueras Pont, M., \& Vera Mur, J. M. (2015). Las leyes de educación en España en los últimos doscientos años. Supervisión 21, 38, 1-23.

Berners-Lee, T. C., Cailliau, R., \& ECP. (1990). WorldWideWeb. Proposal for a HyperText Project. WorldWideWeb Proposal, 8.

Bird, J., \& Edwards, S. (2015). Children learning to use technologies through play: A Digital Play Framework. British Journal of Educational Technology, 46(6), 1149-1160. https://doi.org/10.1111/bjet.12191

Biswas, G., Leelawong, K., Schwartz, D., Vye, N., \& The Teachable Agents Group at Vande, T. T. A. G. at. (2005). Learning by teaching: a new agent paradigm for educational software. Applied Artificial Intelligence, 19(3-4), 363392. https://doi.org/10.1080/08839510590910200

Bjorklund, D. F., \& Causey, K. B. (2018). Children's Thinking: Cognitive Development and Individual Differences. (Thousand Oaks, Ed.) (6th ed.). Florida: SAGE Publications.

Blackmore, S. (2000). The meme machine (Vol. 25). Oxford Paperbacks.

Blackwell, L. S., Trzesniewski, K. H., \& Dweck, C. S. (2007). Implicit theories of intelligence predict achievement across an adolescent transition: A longitudinal study and an intervention. Child Development, 78(1), 246-263.

Boellstorff, T., Nardi, B., Pearce, C., \& Taylor, T. L. (2012). Ethnography and virtual worlds: A handbook of method. Princeton University Press.

Boyle, M. W. O., \& Gill, H. S. (1998). On the Relevance of Research Findings in Cognitive Neuroscience to Educational Practice. Educational Psychology Review, 10(4), 397-409. https://doi.org/Doi 10.1023/A:1022889317826

Boyles, B. (2017). Virtual Reality and Augmented Reality in Education. United States Military Academy.

Brace, E. (2017). Stages of Literacy Development. Retrieved March 8, 2018, from https://www.theliteracybug.com/stages/

Brandtzæg, P. B. (2010). Towards a unified Media-User Typology (MUT): A meta-analysis and review of the research literature on media-user typologies. Computers in Human Behavior, 26(5), 940-956. https://doi.org/10.1016/J.CHB.2010.02.008

Bransford, J. B., Brown, A. L., \& Cocking, R. R. (1999). How people learn : brain, mind, experience, and school. Harvard University press.

Breeze, R. (2013). Corporate discourse. (Bloomsbury Academic, Ed.). London/New York.

Britannica. (2018). Education. Retrieved March 12, 2018, from https://corporate.britannica.com/privacy.html

Brown, R. B. (2006). Doing your dissertation in business and management: the reality of researching and writing. Sage.

Bruner, J. S. (1961). The act of discovery. Harvard Educational Review, 31, 21-32.

Buchenscheit, A., Könings, B., Neubert, A., Schaub, F., Schneider, M., \& Kargl, F. (2014). Privacy implications of presence sharing in mobile messaging applications. In Proceedings of the 13th International Conference on Mobile and Ubiquitous Multimedia - MUM '14 (pp. 20-29). New York, New York, USA: ACM Press. https://doi.org/10.1145/2677972.2677980

Burnett, N., Guttman, C., Hinchliffe, K., Leclercq, F., Nsengimana, D., Nzomini, B., ... Kennedy, A. (2005a). Education for All. Literacy for life. Paris.

Burnett, N., Guttman, C., Hinchliffe, K., Leclercq, F., Nsengimana, D., Nzomini, B., .. Kennedy, A. (2005b). Understandings of literacy. Education for All Global Monitor Report.

Bus, A. G., Takacs, Z. K., \& Kegel, C. A. T. (2015). Affordances and limitations of electronic storybooks for young children's emergent literacy. Developmental Review, 35, 79-97. https://doi.org/10.1016/j.dr.2014.12.004

Bybee, R. W. (2010). Advancing STEM Education: a 2020 Vision. Technology and Engineering Teacher, 70(1), 30-35.

California Science Teachers Association. (2002). What we know about how people learn. California Journal of Science Education, 2(2), 75-99. 
Carpenter, S. K., \& Agarwal, P. K. (2019). How To Use Spaced Retrieval Practice Boost Learning. lowa.

Carretero, S., Vuorikari, R., \& Punie, Y. (2017). DigCom 2.1: The Digital Competence Framework for Citizens with eight proficiency levels and examples of use. https://doi.org/10.2760/38842

Cassavoy, L. (2007). In Pictures: A History of Cell Phones. Retrieved August 6, 2018, from https://www.pcworld.com/article/131450/in_pictures_a_history_of_cell_phones.html

CAST. (2018). Universal Design for Learning Guidelines. Retrieved November 26, 2018, from http://udlguidelines.cast.org/

Castells, M. (1996). The Rise of the Network Society, The Information Age: Economy, Society and Culture Vol. I. (Blackwell, Ed.) (2nd ed.). Cambridge, Massachusetts: Oxford, UK.

Castells, M. (2007). Communication, Power and Counter-power in the Network Society. International Journal of Communication, 1, 238-266.

Castells, M., Fernández-Ardèvol, M., Linchuan-Qiu, J., \& Sey, A. (2006). Mobile communication and society: a global perspective. MIT Press.

Caxton College. (2015). Reception and Primary education. Retrieved November 2, 2018, from https://caxtoncollege.com/en/admissions/primary-admissions/

Caxton College. (2016). ALUMNOS SIGLO XXI - Caxton College. Retrieved November 2, 2018, from https://caxtoncollege.com/en/21st-century-pupils/

Chall, J. S. (1996). American Reading Achievement: Should We Worry? Research in the Teaching of English. National Council of Teachers of English. https://doi.org/10.2307/40171366

ChanLin, L.-J. (2015). Tablet Reading Service for College Students. Procedia - Social and Behavioral Sciences, 197(February), 231-235. https://doi.org/10.1016/j.sbspro.2015.07.129

Chapelle, C. A., Schmidgall, J., Lopez, A., Blood, I., Wain, J., Cho, Y., ... Dursun, A. (2018). Designing a Prototype Tablet-Based Learning-Oriented Assessment for Middle School English Learners: An Evidence-Centered Design Approach. ETS Research Report Series, 2018(1). https://doi.org/10.1002/ets2.12232

Chaudron, S., Di Gioia, R., \& Gemo, M. (2018). Young Children (0-8) and Digital Technology - A qualitative study across Europe - European Commission. EUR 29070, 1-266. https://doi.org/10.2760/294383

Cheney, M. (2012). Do You Know What's In Your Digital Dossier? Retrieved October 15, 2018, from https://bigthink.com/humanizing-technology/do-you-know-whats-in-your-digital-dossier

Cheng, Y., Yen, K., Chen, Y., Chen, S., \& Hiniker, A. (2018). Why Doesn't It Work? Voice-Driven Interfaces and Young Children's Communication Repair Strategies. Idc 2018, 337-348. https://doi.org/10.1145/3202185.3202749

Chien, M. E., Jheng, C. M., Lin, N. M., Tang, H. H., Taele, P., Tseng, W. S., \& Chen, M. Y. (2015). iCAN: A tablet-based pedagogical system for improving communication skills of children with autism. International Journal of Human Computer Studies, 73, 79-90. https://doi.org/10.1016/j.ijhcs.2014.06.001

Childnet. (2018). 7 in 10 children are using voice assisted technology finds new research from UKSIC partner Childnet | Safer Internet Centre. Retrieved January 17, 2019, from https://www.saferinternet.org.uk

Chmiliar, L. (2017). Improving Learning Outcomes: The iPad and Preschool Children with Disabilities. Frontiers in Psychology, 8(660), 1-11. https://doi.org/10.3389/fpsyg.2017.00660

Chomsky, N. (2000). The Architecture of Language. Oxford University Press.

Church, K., \& de Oliveira, R. (2013). What's up with whatsapp?: comparing mobile instant messaging behaviour with traditional SMS. In Proceedings of the 15th international conference on Human-computer interaction with mobile devices and services - MobileHCl '13 (pp. 352-361). New York, New York, USA: ACM Press. https://doi.org/10.1145/2493190.2493225

Ciampa, K. (2014). Learning in a mobile age: an investigation of student motivation. Journal of Computer Assisted Learningurnal of Computer Assisted Learning, 30, 82-96. https://doi.org/10.1111/jcal.12036

Clark, C. M. (2007). Iron kingdom : the rise and downfall of Prussia, 1600-1947. Penguin. 
Clarke, L., \& Abbott, L. (2016). Young pupils', their teacher's and classroom assistants' experiences of iPads in a Northern Ireland school: "Four and five years old, who would have thought they could do that?" British Journal of Educational Technology, 47(6), 1051-1064. https://doi.org/10.1111/bjet.12266

ClassDojo, I. (2011). ClassDojo. Retrieved November 2, 2018, from https://www.class dojo.com/about/

Coffield, F. (2008). Just suppose teaching and learning became the first priority... London, UK: Learning and Skills Network London.

Cohen, J. N., \& Mihailidis, P. (2013). Exploring Curation as a core competency in digital and media literacy education. Faculty Works:Digital Humanities and New Media, 4.

COM. (2010). EUROPE 2020. A strategy for smart, sustainable and inclusive growth (No. 2020). Brussels: European Commission.

COM. (2018). Digital Education Action Plan (No. SWD (2018) 12). Brussels, Brussels: European Commission.

Commission/EACEA/Eurydice, E. (2018). The European Higher Education Area in 2018: Bologna Process Implementation Report. Office of the EC. Luxembourg. https://doi.org/10.2797/265898

Concejo, E. (2018). Descubre a qué generación perteneces según tu fecha de nacimiento. Retrieved September 21, 2018, from https://www.lavanguardia.com/vivo/20180408/442342457884/descubre-que-generacionperteneces.html

Coniam, D. (1999). Voice recognition software accuracy with second language speakers of English. System, 27, 49-64.

Cordero, K., Nussbaum, M., Ibaseta, V., Otaíza, M. J., \& Chiuminatto, P. (2018). Read, write, touch: Co-construction and multiliteracies in a third-grade digital writing exercise. Journal of Computer Assisted Learning, 34(2), 162173.

Corthals, P. (2011). Language and gender effects in the phonetics of Parentese. In American speech-language-hearning association: beacons of inspiration: innovation tot action. San Diego, CA, USA.

Council of European Commision. Council Recommendation of 22 May 2018 on key competences for lifelong learning, Pub. L. No. 2018/C 189/01, Official Journal of the European Union (2018).

Couse, L. J., \& Chen, D. W. (2010). A Tablet Computer for Young Children? Exploring its Viability for Early Childhood Education. Journal of Research on Technology in Education, 43(1), 75-96. https://doi.org/10.1080/15391523.2010.10782562

Crescenzi, L., Jewitt, C., \& Price, S. (2014). The role of touch in preschool children 's learning using iPad versus paper interaction. Australian JOurnal of Lnaguage and Literacy, 37(2), 86-96.

Danby, S. (2017). Technologies, Child-Centred Practice and Listening to Children. In L. Arnott (Ed.), Digital Technologoies and Learning in the Early Years (pp. 127-138). London, UK: SAGE Publications.

Danby, S., Evaldsson, A. C., Melander, H., \& Aarsand, P. (2018). Situated collaboration and problem solving in young children's digital gameplay. British Journal of Educational Technology, 49(5), 959-972. https://doi.org/10.1111/bjet.12636

Debes, J. L. (1969). The Loom of Visual Literacy--An Overview. Audiovisual Instruction, 14(8), 25-27.

Delors, J. (1996). Learning: The treasure Within. (United Nations Educational, Ed.). France.

Des Roches Rosa, S. (2010). The iPad: a Near-Miracle for My Son With Autism. SHEKNOWS.COM.

Development Data Group. (2018). Individuals using the Internet (\% of population). Retrieved November 6, 2018, from https://data.worldbank.org/indicator/IT.NET.USER.ZS

DITRENDIA. (2016). Informe Mobile en el España y en el Mundo 2016. Madrid.

DITRENDIA. (2018). Informe Mobile en España y en el Mundo 2018. Ditrendia. Madrid.

Doane University. (2016). Benefits of an Aesthetic Education | Doane University. Retrieved July 18, 2018, from https://www.doane.edu/facstaff/resources/cetl-home/arts-are-basic/32485

Dron, J. (2018). Smart learning environments, and not so smart learning environments: a systems view. Smart Learning Environments, 5(1), 25. https://doi.org/10.1186/s40561-018-0075-9 
Dropbox Inc. (2007). Dropbox.com. Retrieved March 6, 2016, from www.dropbox.com

Druga, S., Williams, R., Breazeal, C., \& Resnick, M. (2017). "Hey Google is it OK if I eat you?" Initial Explorations in Child-Agent Interaction. Proceedings of the 2017 Conference on Interaction Design and Children - IDC '17, 595600. https://doi.org/10.1145/3078072.3084330

Dunn, Jeff. (2011). The Evolution of Classroom Technology. Retrieved from http://www.edudemic.com/classroomtechnology/

Dunn, Jill, \& Sweeney, T. (2018). Writing and iPads in the early years: Perspectives from within the classroom. British Journal of Educational Technology, 49(5), 859-869. https://doi.org/10.1111/bjet.12621

Dunn, O. (2011). How young children learn English as another language. Retrieved July 25, 2018, from http://learnenglishkids.britishcouncil.org/en/helping-your-child/how-young-children-learn-english-anotherlanguage

Dweck, C. S. (1999). Self-theories: their role in motivation, personality, and development. Trad. it. Teorie Del Sé. Intelligenza, Motivazione, Personalità e Sviluppo, Ed A. Moè (Trento: Erickson), 29-38.

EFA_Global. (2005). Literacy for life. (UNESCO Publishing, Ed.). United Nations Educational.

Eisen, S., \& Lillard, A. S. (2016). Just google it: Young children's preferences for touchscreens versus books in hypothetical learning tasks. Frontiers in Psychology, 7(SEP), 1-8. https://doi.org/10.3389/fpsyg.2016.01431

EnlightED.education. (2019). EnlightED 2019. Retrieved November 11, 2019, from https://enlighted.education/en/home/\#intro

Epic! Creations, I. (2016). Epic! Retrieved October 10, 2018, from https://www.getepic.com/

Erickson, C. (2012). The Touching History of Touchscreen Tech. Retrieved July 20, 2018, from https://mashable.com/2012/11/09/touchscreen-history/?europe=true\#8L.HGaHklsqr

Erikson Institute. (2017). Media Literacy in Early Childhood. A critical conversation. Retrieved May 8, 2017, from teccenter.erikson.edu

EuropaPress. (2018, August 30). Telemedicina: la respuesta a la falta de médicos en zonas rurales despobladas. Infosalus.Com.

European Commission/EACEA/Eurydice. (2012). The European Higher Education Area in 2012: Bologna Process Implementation. Office of the European Union. Brussels. https://doi.org/10.2797/81203

European Commission/EACEA/Eurydice. (2015). The Changing Pedagogical Landscape: New ways of teaching and learning and their implications for higher education policy. https://doi.org/10.2766/72063

European Commission/EACEA/Eurydice. (2018). Council Recommendation on a Comprehensive approach to the teaching and learning of languages. Brussels.

European Students' Union-ESU. (2015). Bologna with Student Eyes 2015. Time to meet the expectations from 1999. Brussels.

Falloon, G. (2013a). Creating content: Building literacy skills in year 1 students using open format apps. Computers in New Zealand Schools: Learning, Teaching, Technology, 25(1-3), 77-95.

Falloon, G. (2013b). Young students using iPads: App design and content influences on their learning pathways. Computers and Education, 68, 505-521. https://doi.org/10.1016/j.compedu.2013.06.006

Falloon, G. (2014). What's going on behind the screens? Researching young students' learning pathways using iPads. Journal of Computer Assisted Learning, 30, 318-336. https://doi.org/10.1111/jcal.12044

Falloon, G. (2015). What's the difference? Learning collaboratively using iPads in conventional classrooms. Computers and Education, 84, 62-77. https://doi.org/10.1016/j.compedu.2015.01.010

Falloon, G., \& Khoo, E. (2014). Exploring young students' talk in iPad-supported collaborative learning environments. Computers and Education, 77, 13-28. https://doi.org/10.1016/j.compedu.2014.04.008

Felten, P. (2008). Visual Literacy. Change, 40(6), 60-63. 
Fernández Enguita, M., \& Vázquez Cupeiro, S. (2016). La larga y compleja marcha del CLIP al CLIC Escuela y profesorado ante el nuevo entorno digital.

Ferrer, I., \& Carrió, P. (2013). Abierto todo el día. Unit experimental. Valencia: La imprenta.

Fidler, D. (2016). Future 2020 Skills: Update and literature review. Institute for the Future.

Fiorella, L., \& Mayer, R. E. (2016). Eight Ways to Promote Generative Learning. Educational Psychology Review, 28, 717-741. https://doi.org/10.1007/s10648-015-9348-9

Fisch, S. M. (2004). Children's Learning From Educational Television: Sesame Street and Beyond (LEA's comm). Erlbaum: Lawrence Erlbaum Associates, Inc.

Fleer, M. (2013). Digital positioning for inclusive practice in early childhood: The cultural practices surrounding digital tablets in family homes. Computers in New Zealand Schools: Learning, Teaching, Technology, 25(1-3), 56-76.

Fleer, M. (2018). Digital animation: New conditions for children's development in play-based setting. British Journal of Educational Technology, 49(5), 943-958. https://doi.org/10.1111/bjet.12637

Flewitt, R., Messer, D., \& Kucirkova, N. (2015). New directions for early literacy in a digital age: The iPad. Journal of Early Childhood Literacy, 15(3), 289-310. https://doi.org/10.1177/1468798414533560

Fokides, E. (2017). Tablets, Very Young Primary School Students, and Basic Programming Concepts. Asian Journal of Education and E-Learning, 05(03), 86-94.

Fred Rogers Center. (2015). Fred Rogers Center for Early Learning and Children's Media. Retrieved May 15, 2018, from http://www.fredrogerscenter.org/

Fredricks, J. A., Blumenfeld, P. C., \& Paris, A. H. (2004). School Engagement: Potential of the Concept, State of the Evidence. Review of Educational Research, 74(1), 59-109. https://doi.org/10.3102/00346543074001059

Fridberg, M., Thulin, S., \& Redfors, A. (2018). Preschool children's Collaborative Science Learning Scaffolded by Tablets. Research in Science Education, 48(5), 1007-1026. https://doi.org/10.1007/s11165-016-9596-9

Fund. Telefónica. (2007). La Sociedad de la Información en España 2006. (Ed. Ariel, Ed.). Barcelona.

Fund. Telefónica. (2008). La Sociedad de la Información en España 2007. (Ariel, Ed.). Barcelona.

Fund. Telefónica. (2009). La Sociedad de la Información en España 2008. (Ariel, Ed.). Barcelona.

Fund. Telefónica. (2013). La Sociedad de la Información en España 2012. (Ariel, Ed.). Barcelona.

Fund. Telefónica. (2015). La Sociedad de la Información en España 2014. (Ariel, Ed.). Barcelona.

Fund. Telefónica. (2016). La Sociedad de la Información en España 2015. (Ariel, Ed.). Barcelona.

Fund. Telefónica. (2018a). La Sociedad Digital en España 2017. (Ariel, Ed.). Barcelona.

Fund. Telefónica. (2018b). Presentación Sociedad Digital en España 2017. Madrid: YouTube. Fundación Telefónica.

Fund. Telefónica. (2018c). Tech \& society. Un foro para pensar sobre el futuro de la sociedad tecnológica. (Ariel, Ed.). Madrid: Fundación Telefónica.

Fund. Telefónica. (2019). Sociedad Digital en España 2018. Madrid: Taurus y Fundación Telefónica.

Gachago, D., Strydom, S., Hanekom, P., Simons, S., \& Walters, S. (2015). Crossing boundaries : lectures' perspectives on the use of WhatsApp to support teaching and learning in higher education. Progressio, 37(1), 172-187.

Gallagher, S. A. (2017). Sket with Glass. Diller Scofidio + Renfo, 14-21.

Gallese, V., \& Lakoff, G. (2005). The Brain's concepts: the role of the Sensory-motor system in conceptual knowledge. Cognitive Neuropsychology, 22(3-4), 455-479. https://doi.org/10.1080/02643290442000310

Gallo, C. (2011). Steve Jobs: The World's Most Inspiring Communicator. Retrieved July 17, 2018, from https://www.forbes.com/sites/carminegallo/2011/08/26/steve-jobs-the-worlds-most-inspiringcommunicator/\#2280a7dc6132

Gallo, C. (2017). 5 Reasons Why Steve Jobs's iPhone Keynote Is Still the Best Presentation of All Time | Inc.com. 
Retrieved July 17, 2018, from https://www.inc.com/carmine-gallo/5-reasons-why-steve-jobs-iphone-keynote-isstill-the-best-presentation-of-all-ti.html

Ganea, P. A., Pickard, M. B., \& DeLoache, J. S. (2008). Transfer between Picture Books and the Real World by Very Young Children. Journal of Cognition and Development, 9(1), 46-66. https://doi.org/10.1080/15248370701836592

Garcia-Sierra, A., Rivera-Gaxiola, M., Percaccio, C. R., Conboy, B. T., Romo, H., Klarman, L., ... Kuhl, P. K. (2011). Bilingual language learning: An ERP study relating early brain responses to speech, language input, and later word production. Journal of Phonetics, 39, 546-557. https://doi.org/10.1016/j.wocn.2011.07.002

Gardner, H., \& Davis, K. (2013). The app generation: How today's youth navigate identity, intimacy, and imagination in a digital world. Yale University Press.

Gargallo-López, B. (2008). Estilos de docencia y evaluacion de los profesores universitarios y su influencia sobre los modos de aprender de sus estudiantes. Revista Espanola de Pedagogia, 66(241), 425-446.

Garnet. (2017). Internet of Things. Retrieved June 18, 2018, from https://www.gartner.com/it-glossary/internet-of-things/

Gesell, A., \& Frances, L. (1949). Child Development- An introduction to the Study of Human Growth. New York: Harper \& Row.

Gillen, J., \& Kucirkova, N. (2018). Percolating spaces: Creative ways of using digital technologies to connect young children's school and home lives. British Journal of Educational Technology, 49(5), 834-846. https://doi.org/10.1111/bjet.12666

Gobo, G. (2008). Doing ethnography. Sage.

Goldman, A. I. (2012). Theory of Mind. In E. Margolis, R. Samuels, \& S. P. Stich (Eds.), The Oxford Handbook of Philosophy of Cognitive Science (Vol. 1). Oxford University Press. https://doi.org/10.1093/oxfordhb/9780195309799.013.0017

Gómez-Domingo, M., \& Badia-Garganté, A. (2016). Exploring the use of educational technology in primary education: Teachers ' perception of mobile technology learning impacts and applications ' use in the classroom. Computers in Human Behavior, 56, 21-28. https://doi.org/10.1016/j.chb.2015.11.023

Google LLC. (2017). Google Earth. Retrieved May 24, 2018, from https://www.google.com/earth/

Google LLC. (2018). Street View. Retrieved January 19, 2019, from https://www.google.es/int//es/streetview/

Gopnik, A. (2009). The philosophical baby: What children's minds tell us about truth, love \& the meaning of life. (S. and G. Farrar, Ed.). New York: Farrar: Random House.

Gopnik, A., Meltzoff, A. N., \& Kuhl, P. K. (2001). The scientist in the crib: what early learning tells us about the mind. New York, NY, US: HarperPerennial.

Gopnik, A., \& Schulz, L. (2007). Causal learning: Psychology, philosophy, and computation. Oxford University Press.

Goździk, A., \& Korda, M. (2016). D3.1 Report on Education on STEM (No. EDU-ARCTIC N 710240).

Grabinger, R. S., \& Dunlap, J. C. (1995). Rich environments for active learning: a definition. ALT-J, 3(2), 5-34. https://doi.org/10.1080/0968776950030202

Graesser, A., \& Lehman, B. (2012). Questions drive comprehension of text and multimedia. Text Relevance and Learning from Text, 53-74.

Grenfell, M., Bloome, D., Hardy, C., Pahl, K., Rowsell, J., \& Street, B. V. (2013). Classroom Ethnography. In Language, Ethnography, and Education (pp. 13-32). Routledge.

Grunwald, M. (Ed.). (2008). Human Haptic Perception. Basics and Applications. Basel - Boston - Berlin.

Guo, A., Kamar, E., Vaughan, J. W., Wallach, H., \& Morris, M. R. (2019). Toward Fairness in Al for People with Disabilities: A Research Roadmap. ArXiv Preprint ArXiv:1907.02227.

Hadlington, L., White, H., \& Curtis, S. (2019). "I cannot live without my [ tablet ]" : Children's experiences of using table t technology within the home. Computers in Human Behavior, 94(January), 19-24. https://doi.org/10.1016/j.chb.2018.12.043 
HarperCollins Publishers Limited. (2018). Collins Dictionary.com. Retrieved January 9, 2019, from https://www.collinsdictionary.com

Harris, K. R. (1990). Developing Self-Regulated Learners: The Role of Private Speech and Self-Instructions. Educational Psychologist, 25(1), 35-49. https://doi.org/10.1207/s15326985ep2501_4

Hatherly, A., \& Chapman, B. (2013). Fostering motivation for literacy in early childhood education using iPads. Computers in New Zealand Schools: Learning, Teaching, Technology, 25(1-3), 138-151.

Hattie, J. (1999). Influences on student learning. Inaugural Lecture given on August, 2, 1999.

Hattie, J., \& Yates, G. C. R. (2013). Visible Learning and the Science of How We Learn. [electronic resource].

Hatzigianni, M., Gregoriadis, A., Karagiorgou, I., \& Chatzigeorgiadou, S. (2018). Using tablets in free play: The implementation of the digital play framework in Greece. British Journal of Educational Technology, 49(5), 928942. https://doi.org/10.1111/bjet.12620

Hayes, M., Van Stolk-Cooke, K., \& Muench, F. (2015). Understanding Facebook use and the psychological affects of use across generations. Computers in Human Behavior, 49, 507-511. https://doi.org/10.1016/j.chb.2015.03.040

Heitin, L. (2016). What is Digital Literacy? An Evolving Definition. Education Week, 36(12), 5-6.

Hemmi, A., Bayne, S., \& Land, R. (2009). The appropriation and repurposing of social technologies in higher education. Journal of Computer Assisted Learning, 25(1), 19-30. https://doi.org/10.1111/j.1365-2729.2008.00306.x

Herodotou, C. (2018). Young children and tablets: A systematic review of effects on learning and development. Journal of Computer Assisted Learning, 34(1), 1-9. https://doi.org/10.1111/jcal.12220

Heuer, H. (2016). Technologies shape sensorimotor skills and abilities. https://doi.org/10.1016/j.tine.2016.06.001

Hill, L. A., Brandeau, G., Truelove, E., \& Lineback, K. (2014). Collective genius: The art and practice of leading innovation. Harvard Business Review Press.

Hiniker, A., Sobel, K., Hong, S. R., Suh, H., Irish, I., Kim, D., \& Kientz, J. A. (2015). Touchscreen Prompts for Preschoolers: Designing Developmentally Appropriate Techniques for Teaching Young Children to Perform Gestures. In Proceedings of the 14th International Conference on Interaction Design and Children (pp. 109-118). Medford, MA, USA. https://doi.org/10.1145/2771839.2771851

Hinojosa, S. (2016). The History of Word Processors -. Retrieved October 15, 2018, from http://thetech.ninja/historyword-processors/

Hirsh-Pasek, K., Zosh, J. M., Golinkoff, R. M., Gray, J. H., Robb, M. B., \& Kaufman, J. (2015). Putting Education in "Educational" Apps: Lessons From the Science of Learning. Psychological Science in the Public Interest, 16(1), 3-34. https://doi.org/10.1177/1529100615569721

Hoffmann, M. H. W. (2011). Fairly certifying competences, objectively assessing creativity. 2011 IEEE Global Engineering Education Conference, EDUCON 2011, 270-277. https://doi.org/10.1109/EDUCON.2011.5773148

Hopkins, B. A. E. (2012). A Rhetorical Examination of the Product Keynotes of Steve Jobs. Inquiries Journal/Student Pulse, 4(2012), 1-67.

Horovitz, B. (2012). After Gen X, Millennials, what should the next generation be called? - USATODAY.com. Retrieved January 21, 2018, from http://usatoday30.usatoday.com/money/advertising/story/2012-05-03/naming-the-nextgeneration/54737518/1

Hourcade, J. P., Mascher, S. L., Wu, D., \& Pantoja, L. (2015). Look, My Baby Is Using an iPad! An Analysis of YouTube Videos of Infants and Toddlers Using Tablets. In Proceedings of the 33rd Annual ACM Conference on Human Factors in Computing Systems - CHI '15 (pp. 1915-1924). https://doi.org/10.1145/2702123.2702266

Housen, A. C. (2002). Aesthetic Thought, Critical Thinking and Transfer. Arts and Learning Research, 18(1), 99-132.

Hu, W. (2011). Math That Moves: Schools Embrace the iPad. Retrieved June 21, 2018, from https://www.nytimes.com/2011/01/05/education/05tablets.html

Huber, B., Highfield, K., \& Kaufman, J. (2018a). Detailing the digital experience: Parent reports of children's media use in the home learning environment. British Journal of Educational Technology, 49(5), 821-833. https://doi.org/10.1111/bjet.12667 
Huber, B., Highfield, K., \& Kaufman, J. (2018b). media use in the home learning environment. British Journal of Educational Technology, 49(5), 821-833. https://doi.org/10.1111/bjet.12667

Huber, B., Tarasuik, J., Antoniou, M. N., Garrett, C., Bowe, S. J., \& Kaufman, J. (2016). Young children's transfer of learning from a touchscreen device. Computers in Human Behavior, 56, 56-64. https://doi.org/10.1016/j.chb.2015.11.010

Huber, B., Yeates, M., Meyer, D., Fleckhammer, L., \& Kaufman, J. (2018). The effects of screen media content on young children's executive functioning. Journal of Experimental Child Psychology, 170, 72-85. https://doi.org/10.1016/j.jecp.2018.01.006

Hung, W. Y. (2003). Architectural Aspects of Atrium. International Journal on Engineering Performance-Based Fire Codes, 5(4), 131-137.

Hutchison, A., Beschorner, B., \& Schmidt-Crawford, D. (2012). Exploring the use of the iPAD for literacy learning. Reading Teacher, 66(1), 15-23. https://doi.org/10.1002/TRTR.01090

IDATE Digiworld. (2017). DigiWorld Yearbook 2017. Www.Idate.Org, 91, 0-194.

ILABS. (2014). Module 4: The Power of Learning through Imitation [online module]. Retrieved December 8, 2018, from http://modules.ilabs.uw.edu/module/The-power-of-learning/

ILABS. (2016). Module 2: Why the First 2000 days Matter: A look inside the Brain (online module). Retrieved February 6, 2019, from http://modules.ilabs.uw.edu/module/first-2000-days-matter/acknowledgments/

ILABS. (2017). Module 16: Foundations of Literacy [online module]. Retrieved December 10, 2018, from http://modules.ilabs.uw.edu/module/foundations-of-literacy/

Instituto Nacional Español de Estadística. (2016). PISA 2015. Programa para la Evaluación Internacional de los Alumnos. Informe Español. (MECyD, Ed.). Madrid.

Instituto Nacional Español de Estadística. (2018a). Principales series de población por edad, sexo y año. Retrieved September 15, 2018, from http://www.ine.es/jaxi/Datos.htm?path=/t20/e245/p08//0/\&file=02003.px

Instituto Nacional Español de Estadística. (2018b, July 18). Encuesta sobre Equipamiento y Uso de Tecnologías de Información y Comunicación en los Hogares 2018. Notas de Prensa, pp. 1-11.

IRChelp.org. (2013). Internet Rely Chat. Retrieved November 7, 2017, from http://www.irchelp.org

Isaacson, W. (2011). Steve Jobs (1st Ed.). New York: Simon \& Schuster.

Janssen, D. (2016). What is a Digital Footprint? -Techopedia. Retrieved October 15, 2018, from https://www.techopedia.com/definition/2396/digital-footprint

Javorsky, K. (2014). Digital Print Concepts: Conceptualizing a modern framework for measuring emerging knowledge. University of Nebraska-Lincoln. University of Nebraska-Lincoln.

Jig.space. (2018). JigSpace - We learn better in 3D. Retrieved June 4, 2018, from https://jig.space/

JISC. (2016). Digital capabilities: The six elements. Retrieved March 1, 2017, from https://www.jisc.ac.uk/rd/projects/building-digital-capability

Johnson, E. A. (1965). Touch display-a novel input/output device for computers. Electronics Letters, 1(8), 219. https://doi.org/10.1049/el:19650200

Johnston, K., Highfield, K., \& Hadley, F. (2018). Supporting young children as digital citizens: The importance of shared understandings of technology to support integration in play-based learning. British Journal of Educational Technology, 49(5), 896-910. https://doi.org/10.1111/bjet.12664

Jütte, R. (2008). Haptic perception: an historical approach. In M. (Ed. . Grunwald (Ed.), Human Haptic Perception: Basics and Applications (pp. 3-14). Birkhäuser.

Kabali, H. K., Irigoyen, M. M., Nunez-Davis, R., Budacki, J. G., Mohanty, S. H., Leister, K. P., \& Bonner, R. L. (2015). Exposure and Use of Mobile Media Devices by Young Children. Pediatrics, 136(6), 1044-1050. https://doi.org/10.1542/peds.2015-2151

Kampylis, P., Punie, Y., \& Devine, J. (2015). Promoting Effective Digital-Age Learning. https://doi.org/10.2791/54070 
Kanero, J., Geçkin, V., Oranç, C., Mamus, E., Küntay, A. C., \& Göksun, T. (2018). Social Robots for Early Language Learning: Current Evidence and Future Directions. Child Development Perspectives, 12(3), 146-151. https://doi.org/10.1111/cdep.12277

Kanga, M. (2018). Engineerinng Education Initiatives in Africa. In GLOBALENGINEER (Vol. 3, pp. 1-23).

Karavanidou, E. (2017). Is handwriting relevant in the digital era? Antistasis, 7(1), 153-167.

Kerslake, L., \& Wegerif, R. (2017). The Semiotics of Emoji: The Rise of Visual Language in the Age of the Internet. Media and Communication, 5(4), 75. https://doi.org/10.17645/mac.v5i4.1041

Khoo, E., Bennett, T., \& Macmillan, N. (2013). Early childhood education teachers' iPad-supported practices in young children's learning and exploration. Computer in New Zealand Schools: Learning, Teaching, Technology, 25(13), 3-20.

Khoo, E. G. L., Falloon, G., \& Nguyen, N. H. (2016). iPad-mediated talk in young children's learning and exploration of interests. In DEANZ2016 Biennal Conference (pp. 163-167). DEANZ.

Khoo, E., Khoo, E., Merry, R., \& Bennett, T. (2015). "I want to say ..." Privileging young children 's voices in iPadsupported assessment for learning. Early Childhood Folio, 19(September 2015). https://doi.org/10.18296/ecf.0002

Khoo, E., Merry, R., Nguyen, N. H., Bennett, T., \& Macmillan, N. (2015). iPads and opportunities for teaching and learning for young children ( iPads $n$ kids ). (Hamilton, Ed.). New Zealand: Wilf Malcom Institute of Educational Research.

Kirkorian, H. L. (2018). When and how do interactive digital media help children connect what they see on and off the screen? Child Development Perspectives, 12(3), 210-214.

Kirkorian, H. L., Choi, K., \& Pempek, T. A. (2016). Toddlers ' Word Learning From Contingent and Noncontingent Video on Touch Screens. Child Development, 87(2), 405-413. https://doi.org/10.1111/cdev.12508

Kirkorian, H. L., Etta, R., Yoo, S. H., Jin, M., \& Skora, E. (2016). Video deficit. Oxford Bibilographies, 1-20. https://doi.org/10.1093/OBO/9780199756841-0187

Kirova, A., \& Jamison, N. M. (2018). Peer scaffolding techniques and approaches in preschool children's multiliteracy practices with iPads. Journal of Early Childhood Research, 16(3), 245-257.

Kołata, L. J. (2009). A Sample Typology of Texts in Corporate Discourse, (1), 1-6.

Kory Westlund, J. M., Jeong, S., Park, H. W., Ronfard, S., Adhikari, A., Harris, P. L., ... Breazeal, C. L. (2017). Flat vs. Expressive Storytelling: Young Children's Learning and Retention of a Social Robot's Narrative. Frontiers in Human Neuroscience, 11(June), 1-20. https://doi.org/10.3389/fnhum.2017.00295

Krashen, S. D. (1989). Language acquisition and language education: Extensions and applications. Prentice Hall International New York.

Kuato Studios. (2018). Kuato Studios. Retrieved May 18, 2018, from http://kuatostudios.com/

Kucirkova, N. (2013). Children's interactions with iPad books: Research chapters still to be written. Frontiers in Psychology, 4(DEC), 2012-2014. https://doi.org/10.3389/fpsyg.2013.00995

Kucirkova, N., Messer, D., Critten, V., \& Harwood, J. (2014). Story-making on the iPad when children have complex needs: Two case studies. Communication Disorders Quarterly, 36(1), 44-54. https://doi.org/10.1177/1525740114525226

Kucirkova, N., Messer, D., Sheehy, K., \& Fernández, C. (2014). Children's engagement with educational iPad apps: Insights from a Spanish classroom. Computers \& Education, 71, 175-184. https://doi.org/10.1016/j.compedu.2013.10.003

Kucirkova, N., Messer, D., Sheehy, K., \& Flewitt, R. (2013). Sharing personalised stories on iPads : a close look at one parent-child interaction. Literacy, 47(3), 115-122.

Kucirkova, N., Sheehy, K., \& Messer, D. (2015). A Vygotskian perspective on parent-child talk during iPad story sharing. Journal of Research in Reading, 38(4), 428-441. https://doi.org/10.1111/1467-9817.12030

Kuhl, P. K. (2010). Review Brain Mechanisms in Early Language Acquisition. Neuron, 67, $713-727$. https://doi.org/10.1016/j.neuron.2010.08.038 
Kumar, S. (2017). Evolution of Internet of Things(loT). Retrieved November 10, 2018, from https://codeforbillion.blogspot.com/2017/10/evolution-of-internet-of-thingsiot.html

Kumpulainen, K., \& Gillen, J. (2017). Young Children's Digital Literacy Practices in the Home: A review of the Liter ature. COST ACTIONS ISI 1410 DigiLit EY, 1-34.

Kurkela, J. L. O., Hämäläinen, J. A., Leppänen, P. H. T., Shu, H., \& Astikainen, P. (2019). Passive exposure to speech sounds modifies change detection brain responses in adults. Neurolmage, 188, 208-216. https://doi.org/10.1016/J.NEUROIMAGE.2018.12.010

Kuther, T. L. (2019). Physical and Cognitive Development in Early Children. In Lifespan development - Lives in Context (pp. 4-50). SAGE Publications.

LeCompte, M. D., \& Schensul, J. J. (2010). Designing and conducting ethnographic research: An introduction (Vol. 1). Rowman Altamira.

Lerner, C., \& Barr, R. (2014). Screen Sense: Setting the Record Straight Research-Based Guidelines for Screen Use for Children Under 3 Years Old. Zero to Three, 1-10.

Leslie, J., \& Dora, W. (2010). A Tablet Computer for Young Children? Exploring Its Viability for Early Childhood Education. Journal of Research on Technology in Education, 43(1), 75.

LindenLab. (2003). Second Life - Virtual Worlds, Virtual Reality, VR, Avatars, Free 3D Chat. Retrieved January 18, 2018, from https://secondlife.com/

Lissitsa, S., \& Kol, O. (2016). Generation X vs. Generation Y - A decade of online shopping. Journal of Retailing and Consumer Services, 31, 304-312. https://doi.org/10.1016/j.jretconser.2016.04.015

Livingstone, S., \& Sefton-Green, J. (2016). The Class. Living and learning in the Digital Age. (New York University Press, Ed.). New York.

Llobregat-Gómez, N., \& Sánchez-Ruiz, L. M. (2015a). Capítulo 1 El Emergente Ciudadano Digital. In Manuel G. Gericota y Juan Manuel Santos Gago (Ed.), TICAI 2015: TICs para el Aprendizaje de la Ingeniería (pp. 9-14). IEEE, Sociedad de Educación: Capítulos Español y Portugues.

Llobregat-Gómez, N., \& Sánchez-Ruiz, L. M. (2015b). Defining the Engineering Student of 2030. In Proceedings of the 43rd SEFI Annual Conference 2015 - Diversity in Engineering Education: An Opportunity to Face the New Trends of Engineering, SEFI 2015.

Llobregat-Gómez, N., \& Sánchez-Ruiz, L. M. (2015c). Digital citizen in a Resilience Society. In 2015 International Conference on Interactive Collaborative Learning (ICL) (pp. 1026-1030). IEEE. https://doi.org/10.1109/ICL.2015.7318171

Lovato, S. B., \& Waxman, S. R. (2016). Young children learning from touch screens: Taking a wider view. Frontiers in Psychology, 7(JUL), 1-6. https://doi.org/10.3389/fpsyg.2016.01078

Maich, K., Sider, S., Hall, C., \& Henning, M. (2017). Making the iPad an accessible tool for students with exceptionalities: Assessing and teaching its essential prerequisite skills. DADD (Division of Autism and Developmental Disabilities) Online Journal, 4(1), 110-122.

Maiden, N., Turner, I., Zachos, K., D'Souza, S., Jones, S., Müller, L., ... Rose, M. (2013). Computing technologies for reflective, creative care of people with dementia. Communications of the ACM, 56(11), 60-67. https://doi.org/10.1145/2500495

Mangen, A., \& Balsvik, L. (2016). Pen or keyboard in beginning writing instruction? Some perspectives from embodied cognition. Trends in Neuroscience and Education, 5(3), 99-106.

Mangen, A., \& Velay, J.-L. (2010). Digitizing Literacy: Reflections on the Haptics of Writing. In Advances in Haptics. InTech. https://doi.org/10.5772/8710

Marin-García, J. A. (2003). Proyecto Docente. RIUNET depositorio. UPV.

Marina, J. A. (2012). Los trastornos del aprendizaje. Pediatría Integral, XVI(1), 84-87.

Marsh, J., Plowman, L., Yamada-Rice, D., Bishop, J., Lahmar, J., \& Scott, F. (2018). Play and creativity in young children's use of apps. British Journal of Educational Technology, 49(5), 870-882. https://doi.org/10.1111/bjet.12622 
Martin-Rhee, M., \& Bialystok, E. (2008). The development of two types of inhibitory control in monolingual and bilingual children. Bilingualism: Language and Cognition, 11(01), 81-93. https://doi.org/10.1017/S1366728907003227

Martinussen, R., Grimbos, T., \& Ferrari, J. L. S. (2014). Word-Level Reading Achievement and Behavioral Inattention: Exploring Their Overlap and Relations with Naming Speed and Phonemic Awareness in a Community Sample of Children. Archives of Clinical Neuropsychology, 29(7), 680-690. https://doi.org/10.1093/arclin/acu040

McCaffrey, T., \& Matthews, P. G. (2017). An Emoji Is Worth a Thousand Variables. The Mathematics Teacher, 111(2), 96. https://doi.org/10.5951/mathteacher.111.2.0096

McClanahan, B., Williams, K., Kennedy, E., \& Tate, S. (2012). A Breakthrough for Josh: How Use of an iPad Facilitated Reading Improvement. TechTrends. https://doi.org/10.1007/s11528-012-0572-6

McCrindle, M. (2011). Influences on 21st Century Language. Word Up, 22-52.

McCrindle, M., \& Wolfinger, E. (2009). The ABC of XYZ: understanding the global generations. UNSW Press.

McCrindle, M., \& Wolfinger, E. (2011). Word up: the lexicon and language guide to changing times and emerging generations. Halstead Press.

McDowell, J. (2013). iPad skills: A quick inventory of some beginning skills for a young student with low vision (Annual Conference).

McGraw-Hill, E. (2017). 2017 digital study trends survey. Retrieved February 10, 2018, from https://www.mheducation.com/highered/explore/studytrends.html

Mcquillan, J. (2006). iPod in Education: The Potential for Language Acquisition. Sponsored by Apple Computer, Inc.

Meisel, J. M., Clahsen, H., \& Pienemann, M. (1981). On Determining Developmental Stages in Natural Second Language Acquisition. Studies in Second Language Acquisiton, 3(2), 109-135. https://doi.org/10.1017/S0272263100004137

Melhuish, K., \& Falloon, G. (2010). Melhuish, K. \& Falloon, G. (2010). Looking to the future: M-learning with the iPad. Computer in New Zealand Schools: Learning, Teaching, Technology, 22(3), 1-16.

Meltzoff, A. N. (1988). Imitation of televised models by infants. Child Development, 59(5), 1221-1229.

Meltzoff, A. N. (1999). Born to learn: What infants learn from watching us. The Role of Early Experiences in Infant Development, 145-164.

Meltzoff, A. N. (2002). Elements of a developmental theory of imitation. In A. N. Meltzoff \& W. Prinz (Eds.), The Imitative Mind. Development, Evolution, and Brain Bases (pp. 19-41). Cambridge University Press: Cambridge University Press. https://doi.org/10.1017/CBO9780511489969

Meltzoff, A. N. (2007a). Infants' Causal Learning: Intervention, Observation, Imitation. Causal Learning: Psychology, Philosophy, and Computation, 37-47. https://doi.org/10.1093/acprof:oso/9780195176803.003.0003

Meltzoff, A. N. (2007b). 'Like me': a foundation for social cognition. Developmental Science, 10(1), $126-134$. https://doi.org/10.1111/j.1467-7687.2007.00574.x

Meltzoff, A. N., \& Kuhl, P. K. (2016). Exploring the Infant Social Brain: What's Going on in There? Zero to Three, 36(3), $2-9$.

Meltzoff, A. N., Kuhl, P. K., Movellan, J., \& Sejnowski, T. J. (2009). Foundations for a new science of learning. Science, 325(5938), 284-288. https://doi.org/10.1126/science.1175626

Meltzoff, A. N., \& Moore, M. K. (1977). Imitation of facial and manual gestures by human neonates. Science (New York, N.Y.), 198(4312), 75-78. https://doi.org/10.1126/science.198.4312.75

Merriam-Webster, I. (2015). Merriam-Webster Dictionary. Retrieved July 26, 2018, from https://www.merriamwebster.com/

Merrill, M. D. (2002). First Principles of Instruction. ETR\&D, 50(3), 43-59.

Metlife F. (2004). The power of Play. Retrieved May 19, 2017, from www.zerotothree.org

Miller, B. T., Krockover, G. H., \& Doughty, T. (2013). Using iPads to teach inquiry science to students with a moderate to severe intellectual disability: A pilot study. Journal of Research in Science Teaching. 
https://doi.org/10.1002/tea.21091

Miller, J. L., Paciga, K. A., Danby, S., Beaudoin-Ryan, L., \& Kaldor, T. (2017). Looking beyond swiping and tapping: Review of design and methodologies for researching young children's use of digital technologies. Cyberpsychology: Journal of Psychosocial Research on Cyberspace, 11(3/6). https://doi.org/10.5817/CP2017-36

Miller, N. E., \& Dollard, J. (1941). Social learning and imitation. Yale University Press. New Haven, CT, US: Yale University Press.

Milman, N. B., Carlson-Bancroft, A., \& Boogart, A. Vanden. (2014). Examining Differentiation and Utilization of iPads Across Content Areas in an Independent, PreK-4th Grade Elementary School. Computers in the Schools, 31(3), 119-133. https://doi.org/10.1080/07380569.2014.931776

Mitra, S. (2003). Minimally invasive education: a progress report on the \&quot;hole-in-the-wall\&quot; experiments. British Journal of Educational Technology, 34(3), 367-371. https://doi.org/10.1111/1467-8535.00333

Mitra, S., \& Quiroga, M. (2012). Children and the Internet-A Preliminary Study in Uruguay. International Journal of Humanities and Social Science, 2(15), 123-129.

Mobileworldcapital.com. (2013). Móvil y tercera edad: mHealth. Retrieved September 17, 2018, from https://mobileworldcapital.com/es/2013/09/05/154/

Morelli, L. (2017). From one generation to the next - the importance of keeping culture. Retrieved November 27, 2018, from https://www.sbs.com.au/nitv/family-rules/article/2017/01/13/one-generation-next-importance-keepingculture

Moser, A., Olsen, S., Rusnak, S. N., Barr, R., \& Gerhardstein, P. (2019). How self-generated labelling shapes transfer of learning during early childhood: The role of individual differences. British Journal of Developmental Psychology, 37(1), 68-83.

Mueller, P. A., \& Oppenheimer, D. M. (2014). The pen is mightier than the keyboard: Advantages of longhand over laptop note taking. Psychological Science, 25(6), 1159-1168. https://doi.org/10.1177/0956797614524581

Mueller, P. A., \& Oppenheimer, D. M. (2016). Technology and note-taking in the classroom, boardroom, hospital room, and courtroom. Trends in Neuroscience and Education, 5(3), 139-145. https://doi.org/10.1016/J.TINE.2016.06.002

MUV Interactive. (2015). BIRD. Retrieved January 18, 2019, from https://www.muvinteractive.com/about

MUV media lab. (2015). MUV wearable tech: Dream, Touch, Play! - YouTube [Video]. Retrieved June 18, 2019, from https://www.youtube.com/watch?time_continue $=123 \& \mathrm{v}=$ FIOsWPrd4U0

Myers, L. J., LeWitt, R. B., Gallo, R. E., \& Maselli, N. M. (2017). Baby FaceTime: can toddlers learn from online video chat? Developmental Science, 20(4), e12430. https://doi.org/10.1111/desc.12430

NAEYC. (1998). Learning to Read and Write: Developmentally Appropriate Practices for Young Children. In Young Children, 53(4), 30-46.

National Center for Research in Advanced Information and Digital Technologies. (2018). Digital Promise. Retrieved June 27, 2018, from https://digitalpromise.org

National Research Council. (2000). How People Learn: Brain, Mind, Experience, and School: Expanded Edition (Paperback). Washington, DC: The National Academies Press. https://doi.org/10.17226/9853

Neumann, M. M. (2014). An examination of touch screen tablets and emergent literacy in Australian pre-school children. Australian Journal of Education, 58(2), 109-122. https://doi.org/10.1177/0004944114523368

Neumann, M. M. (2016). Young children's use of touch screen tablets for writing and reading at home: Relationships with emergent literacy. Computers and Education, 97, 61-68. https://doi.org/10.1016/j.compedu.2016.02.013

Neumann, M. M. (2018). Using tablets and apps to enhance emergent literacy skills in young children. Early Childhood Research Quarterly, 42(October 2016), 239-246. https://doi.org/10.1016/j.ecresq.2017.10.006

Neumann, M. M., Finger, G., \& Neumann, D. L. (2017). A Conceptual Framework for Emergent Digital Literacy. Early Childhood Education Journal, (45), 471-479. https://doi.org/10.1007/s10643-016-0792-z 
Neumann, M. M., \& Neumann, D. L. (2014). Touch Screen Tablets and Emergent Literacy. Early Childhood Education Journal, 42(4), 231-239. https://doi.org/10.1007/s10643-013-0608-3

Nicol, D. (2010). From monologue to dialogue: improving written feedback processes in mass higher education. Assessment \& Evaluation in Higher Education, 35(5), 501-517. https://doi.org/10.1080/02602931003786559

Niss, M. (2003). Mathematical competencies and the learning of mathematics: The Danish KOM project. In 3rd Mediterranean conference on mathematical education (pp. 115-124).

NMC Horizon Report. (2016). Horizon Report - 2016 Higher Education Edition. NMC Horizon Report. https://doi.org/ISBN 978-0-9968527-5-3

Noorhidawati, A., Ghalebandi, S. G., \& Hajar, R. S. (2015). How Do Young Children Engage with Mobile Apps? Cognitive, Psychomotor, and Affective Perspective. Computers \& Education. https://doi.org/10.1016/j.compedu.2015.07.005

Novak_Djokovic, F. (2015). Steve Jobs Schools: Swapping Books for iPads. Retrieved July 11, 2015, from https://novakdjokovicfoundation.org/steve-jobs-schools-swapping-books-for-ipads/

O'Byrne, W. I., Stone, R., \& White, M. (2018). Digital storytelling in early childhood: Student illustrations shaping social interactions. Frontiers in Psychology, 9(OCT), 1-14. https://doi.org/10.3389/fpsyg.2018.01800

OECD. (2015). Students, Computers and Learning: Making the Connection. (O. Publishing, Ed.). Paris: PISA. https://doi.org/https://doi.org/10.1787/9789264239555-en.

OECD. (2016). PISA 2015 Results (Volume I) Excellence and Equity in Education. Paris: OECD Publishing. https://doi.org/http://dx.doi.org/10.1787/9789264266490-en

OECD. (2018a). Education at a Glance 2018 OECD INDICATORS. https://doi.org/10.1787/eag-2018-en

OECD. (2018b). The Future of Education and Skills: Education 2030. OECD. https://doi.org/10.1111/j.14401827.2012.02814.x

OECD. (2019). OECD Skills Outlook 2019:Thriving in a Digital World. (OECD Publishing, Ed.). Paris. https://doi.org/https:/doi.org/10.1787/df80bc12-en

Ofcom. (2017). Children and Parents : Media Use and Attitudes Report.

Ofcom. (2018). The Communications Market 2018: Narrative report.

Olsen, R. K., Pangelinan, M. M., Bogulski, C., Chakravarty, M. M., Luk, G., Grady, C., \& Bialystok, E. (2015). The effect of lifelong bilingualism on regional grey and white matter volume. Brain Research, 1612.

Oprah. (2010). Oprah's Ultimate Favorite Things. Retrieved June 18, 2018, from http://www.oprah.com/oprahshow/oprahs-ultimate-favorite-things-2010/2

Orozco, C., Esteban, P., \& Trefftz, H. (2006). Collaborative and distributed augmented reality in teaching multivariate calculus. In The Fifth IASTED International Conference on web-based education. Puerto Ballarta, México.

Österberg, M. (2016). Web Strategy for Everyone. (Creative Commons Atribution-ShareAlike 4.0, Ed.) (1st ed.). Intranätverk.

Paciga, K. A., \& Donohue, C. (2017). Technology and Interactive Media for Young Children: A whole Child Approach Connecting the Vision of Fred Rogers with Research and Practice. Latrobe, PA.

Pagán Velez, A. (2015). Avant-garde Literature, Definition. Retrieved May 20, 2018, from https://enciclopediapr.org/en/encyclopedia/avant-garde-literature/

Paris, S. G. (2005). Reinterpreting the development of reading skills. Reading Research Quarterly, 40(2), 184-202. https://doi.org/10.1598/RRQ.40.2.3

Patchan, M. M., \& Puranik, C. S. (2016). Using tablet computers to teach preschool children to write letters: Exploring the impact of extrinsic and intrinsic feedback. Computers \& Education, 102, 128-137. https://doi.org/10.1016/J.COMPEDU.2016.07.007

Pearson, E. (2018). Higher Education.

Pearson UK. (2016). Primary Home: Bug Club. Retrieved December 2, 2018, from 
https://www.pearsonschoolsandfecolleges.co.uk/Primary/Literacy/AllLiteracyresources/BugClub/bug -cluboverview.aspx

Pedaste, M., Mäeots, M., Siiman, L. A., de Jong, T., van Riesen, S. A. N., Kamp, E. T., ... Tsourlidaki, E. (2015). Phases of inquiry-based learning: Definitions and the inquiry cycle. Educational Research Review, 14, 47-61. https://doi.org/10.1016/J.EDUREV.2015.02.003

Peebles, A., Bonus, J. A., \& Mares, M.-L. (2018). Questions+ answers+ agency: Interactive touchscreens and Children's learning from a socio-emotional TV story. Computers in Human Behavior, 85, 339-348.

Pellerin, M. (2013). E-inclusion in early french immersion classrooms: Using digital technologies to support inclusive practices that meet the needs of all learners. Canadian Journal of Education, 36(1), 44-70.

Perruchet, P. (1989). The effect of spaced practice on explicit and implicit memory. British Journal of Psychology, 80(1), 113-130. https://doi.org/10.1111/j.2044-8295.1989.tb02306.x

Photopedagogy.com. (2018). Photo literacy. Retrieved December 16, 2018, from https://www.photopedagogy.com/photo-literacy.html

Piaget, J. (1976). Piaget's Theory. In Piaget and His School (pp. 11-23). Berlin, Heidelberg: Springer Berlin Heidelberg. https://doi.org/10.1007/978-3-642-46323-5_2

Pilcher, J. (1994). Mannheim's sociology of generations: an undervalued legacy. BJS, 45(3), 481-495.

Pixlee team. (2017). PIXLEE.COM. Retrieved September 13, 2018, from https://www.pixlee.com/definitions/definitionsocial-media-influencer

Plaza Escudero, L., Morales Gómez, A., Bermejo López, M. L., \& Martínez Murillo, J. M. (2014). Diccionario visual de términos arquitectónicos. Cátedra.

Plowman, L., Stevenson, O., Mcpake, J., Stephen, C., \& Adey, C. (2011). Parents, pre-schoolers and learning with technology at home: Some implications for policy. Journal of Computer Assisted Learning, 27(4), 361-371. https://doi.org/10.1111/j.1365-2729.2011.00432.x

Prensky, M. (2001). Digital Natives, Digital Immigrants Part 1. On the Horizon, 9(5), 1-6. https://doi.org/10.1108/10748120110424816

Prensky, M. (2004). The emerging online life of the digital native. Consultado Em, 1-14.

Prensky, M. (2010). Teaching digital natives : partnering for real learning. (S. C. Corwin, Ed.).

Price, S., Jewitt, C., \& Crescenzi, L. (2015). The role of iPads in pre-school children's mark making development. Computers and Education, 87, 131-141. https://doi.org/10.1016/j.compedu.2015.04.003

Proctor, T. (2005). Essentials of marketing research. Pearson Education.

Profuturo Educacion. (2017). La vocación de unir esfuerzos para comenzar en Lupane. Retrieved July 26, 2018, from https://profuturo.education/la-vocacion-de-unir-esfuerzos-para-comenzar-enlupane/?_ga=2.177522541.974378856.1532581536-32492910.1526961346

Quora. (2016). What five items do you never leave home without? Retrieved September 17, 2017, from https://www.quora.com/What-five-items-do-you-never-leave-home-without

Ramirez-Esparza, N., Garcia-Sierra, A., \& Kuhl, P. K. (2014). Look who's talking: Speech style and social context in language input to infants are linked to concurrent and future speech development. Developmental Science, 17(6), 880-891. https://doi.org/10.1111/desc. 12172

Ramirez-Esparza, N., Garcia-Sierra, A., \& Kuhl, P. K. (2017). Look Who's Talking NOW! Parentese Speech, Social Context, and Language Development Across Time. Frontiers in Psychology, 8(Article 1008). https://doi.org/10.3389/fpsyg.2017.01008

Ready, D. A., Conger, J. A., \& Hill, L. A. (2010). Are you a high potential? Harvard Business Review, 88(6), 78-84.

Reich, J. (2013). The iPad as a Tool for Creation to Strengthen Learning. Retrieved May 20, 2018, from https://www.kqed.org/mindshift/30073/potential-and-reality-the-ipad-as-a-tool-for-creation

Rice, N. (2016). Visual Thinking Strategies for Medical Students. University of Oregon. 
Rich, M. (2018). Literacy Debate: Online, R U Really Reading? Retrieved November 11, 2018, from https://www.nytimes.com/2008/07/27/books/27reading.html

Richard Paul, B., \& Elder, L. (2007). A Guide for Educators to The Foundation for Critical Thinking Critical Thinking Competency Standards Standards, Principles, Performance Indicators, and Outcomes With a Critical Thinking Master Rubric.

Ritchie, R. (2015). iPad and its impact: Five years later. Retrieved June 22, 2018, from https://www.imore.com/ipad-andits-impact-five-years-later

Rivera, C. J., Mason, L., Moser, J., \& Ahlgrim-Delzell, L. (2014). The Effects of an iPad® Multimedia Shared Story Intervention on Vocabulary Acquisition for an English Language Learner. Journal of Special Education Technology, 29(4), 31-48. https://doi.org/10.1177/016264341402900403

Rogers, C., \& Medley, F. W. (1988). Language With A Purpose: Using Authentic Materials in the Foreign Language Classroom. Foreign Language Annals, 21(5), 467-478. https://doi.org/10.1111/j.1944-9720.1988.tb01098.x

Rogers, F., \& Head, B. (1983). Mister Rogers talks with parents. (I. Family Communications, Ed.). Berkley Books.

Romero-Bruzon, E., Rioja-Del-Rio, C., \& Morgado-Estevez, A. (2015). Experience of the design of a MOOC in Engineering for the learning of microcontrollers. Proceedings of the 43rd SEFI Annual Conference 2015 Education Excellence for Sustainability, SEFI 2015.

Rosales, A., \& Fernández-Ardevol, M. (2016). Beyond WhatsApp: Older people and smartphones. Revista Română de Comunicare Şi Relaţii Publice, 18(1), 27-47.

Rosique, R. (2009). Un asomo a la Educación y Web 1.0, 2.0 y 3.0 - Educrea. Retrieved November 5, 2017, from https://educrea.cl/un-asomo-a-la-educacion-y-web-1-0-2-0-y-3-0/

Ross, N. (1989). Advent of the internet. Retrieved August 2, 2018, from http://www.abc.net.au/archives/80days/stories/2012/01/19/3411679.htm

Rossetto, A. D. F., \& Dutra, A. (2016). The analysis of the use of mobile technology in 6-8 years old children's literacy process. 2016 International Symposium on Computers in Education, SIIE 2016: Learning Analytics Technologies, 9-12. https://doi.org/10.1109/SIIE.2016.7751830

Russo-Johnson, C., Troseth, G., Duncan, C., \& Mesghina, A. (2017). All tapped out: Touchscreen interactivity and young children's word learning. Frontiers in Psychology, 8(APR), 1-15. https://doi.org/10.3389/fpsyg.2017.00578

Saby, J. N., Meltzoff, A. N., \& Marshall, P. J. (2013). Infants' Somatotopic Neural Responses to Seeing Human Actions: I've Got You under My Skin. PLoS ONE, 8(10), e77905. https://doi.org/10.1371/journal.pone.0077905

Salthouse, T. (2010). Major issues in cognitive aging (Vol. 49). Oxford University Press.

Samur, Y. (2019). Kes Sesi: A mobile game designed to improve kindergarteners' recognition of letter sounds. Journal of Computer Assisted Learning, 35(2), 294-304.

Sánchez-Ruiz, L. M., \& Llobregat-Gómez, N. (2019). Assessment of Zgen Students Competencies by Digital Inmigrants. 10th International Sumposium on Innovation and Technology (ISIT), 1, 41-44.

Sánchez-Ruiz, L. M., Llobregat-Gómez, N., Moll, S., Moraño, J. A., \& Roselló, M. D. (2016). Sophomore Students Perception in the Flipped Classroom Uptaking. In 44th Annual Conference of the European Society for Engineering Education - Engineering Education on Top of the World: Industry-University Cooperation, SEFI 2016.

Sandvik, M., Smørdal, O., \& Østerud, S. (2012). Exploring iPads in Practitioners' Repertoires for Language Learning and Literacy Practices in Kindergarten. NORDIC JOURNAL OF DIGITAL LITERACY (Vol. 7).

Sanmartin Ortí, A., Prat Pérez, C., Rodríguez Felipe, M. A., Rubio Castillo, A., \& Jover Olmeda, G. (2016). La Educación En España. El Horizonte 2020. (F. de ayuda C. la Drogadicción, Ed.).

Santiuste, C., Pernas-Sánchez, J., Artero-Guerrero, J. A., Varas, D., Ruiz-Navas, E., \& Segovia, D. (2017). Design of a learning method based on Flipped-Classroom methodologies using SPOCs in an engineering course. Proceedings of the 45th SEFI Annual Conference 2017 - Education Excellence for Sustainability, SEFI 2017, (2011), 407-413.

Schroeder, E. L., \& Kirkorian, H. L. (2016). When seeing is better than doing: Preschoolers' transfer of STEM skills using touchscreen games. Frontiers in Psychology, 7(SEP), 1-12. https://doi.org/10.3389/fpsyg.2016.01377 
Seel, N. M. (2012). Assimilation theory of learning. Encyclopedia of the Sciences of Learning, 324-326.

SEFI. (2016). The London Agenda. 8th European Convention of Engineering Deans. Brussels.

Selingo, J. J. (2018). The Future Learners An Innovative Approach to Understanding the Higher Education Market And Building A Student-Centered University.

Shanahan, T. (2005). The National Reading Panel Report: Practical Advice for Teachers.

Sharot, T. (2017). Why do babies love iPhones? Retrieved May 7, 2018, from https://ideas.ted.com/

Sharples, M., Adams, A., Alozie, N., Ferguson, R., FitzGerald, E., Gaved, M., ... Yarnall, L. (2015). Innovating Pedagogy 2015: Open University Innovation Report 4. MIlton Keynes: The Open University. United Kigdom.

Sheehan, K. J., \& Uttal, D. H. (2016). Children's Learning from Touch Screens: A Dual Representation Perspective. Frontiers in Psychology, 7(1220). https://doi.org/10.3389/fpsyg.2016.01220

Sherman, W. R., \& Craig, A. B. (2003). Understanding virtual reality: interface, application, and design. Morgan Kaufmann.

Siemens, G. (2005). Connectivism: a learning theory for the digital age. International Journal of Instructional Technology and Distance Learning, 2, 1-9. https://doi.org/10.1.1.87.3793

SIIU. (2019). Datos y cifras del Sistema Universitario Español. Curso 2017-2018. https://doi.org/e-NIPO: 692190159

Silksoundbooks, L. (2015). The History of the audiobooks. Retrieved April 20, 2018, from http://www.silksoundbooks.com/history-of-audiobooks.html

Simon, H. A. (1996). Models of my life. MIT press.

Simón Ruiz, A. (2008). Tuenti, la competencia de Facebook hecha en España. Retrieved October 16, 2018, from https://cincodias.elpais.com/cincodias/2008/04/11/empresas/1207921214 850215.html

Simpson, A., \& Walsh, M. (2017). Multimodal Layering: Students Learning with iPads in Primary School Classrooms. In The Case of the iPad (pp. 67-85). Singapore: Springer Singapore. https://doi.org/10.1007/978-981-10-4364-2_5

Sin, K., \& Muthu, L. (2015). Application of Big Data in Education. Data Mining and learning Analytics. A literature Review. ICTACT JOURNAL ON SOFT COMPUTING: SPECIAL ISSUE ON SOFT COMPUTING MODELS FOR BIG DATA, 4.

SIUVP. (2019). Sistema de Información Universitario Valenciano Público. Curso 2017-2018. Retrieved June 21, 2019, from http://www.siuvp.es/es/

Skinner, B. F. (1963). Operant behavior. American Psychologist, 18(8), 503-515. https://doi.org/10.1037/h0045185

Snell, S., \& Snell-Siddle, C. (2013). Mobile learning: The effects of gender and age on perceptions of the use of mobile tools. In The second international conference on informatics engineering \& information science (pp. 274-281).

Sorace, A., \& Serratrice, L. (2009). Internal and external interfaces in bilingual language development: Beyond structural overlap. International Journal of Bilingualism, 13(2), 195-210. https://doi.org/10.1177/1367006909339810

Spencer, K. M., Coutts, T., Fagan, T., \& King, A. (2013). Connections, diversity, coherence: Three vignettes exploring learning with iPads in primary schools. Computer in New Zealand Schools: Learning, Teaching, Technology, 25(1-3), 38-55.

Spradley, J. P. (1980). Participant observation. (Holt, Ed.). New York, NY, US: Rinehart and Winston.

Stacy, S. T., Cartwright, M., Arwood, Z., Canfield, J. P., \& Kloos, H. (2017). Addressing the math-practice gap in elementary school: Are tablets a feasible tool for informal math practice? Frontiers in Psychology, 8(FEB), 1-12. https://doi.org/10.3389/fpsyg.2017.00179

Stahl, K. A. D. (2011). Applying New Visions of Reading Development in Today's Classrooms. The Reading Teacher, 65(1), 52-56. https://doi.org/10.1598/RT.65.1.7

Stephenson, J., \& Limbrick, L. (2015). A Review of the Use of Touch-Screen Mobile Devices by People with Developmental Disabilities. Journal of Autism and Developmental Disorders, 45(12), 3777-3791. https://doi.org/10.1007/s10803-013-1878-8 
Sterbenz, C. (2015). What is Generation Alpha? Retrieved October 15, 2017, from https://www.businessinsider.com/generation-alpha-2014-7-2?IR=T

Stromquist, N. P. (2005). The Political benefits of adult literacy. https://doi.org/2006/ED/EFA/MRT/PI/93

Studies Authority, Q. (2008). Learning about technology. Queensland, AU.

Taillard, M. (2000). Persuasive communication : marketing * The case of. Bach, 12, 145-174.

Taipale, S. (2014). The affordances of reading/writing on paper and digitally in Finland. Telematics and Informatics, 31(4), 532-542. https://doi.org/10.1016/j.tele.2013.11.003

Tarasuik, J., Demaria, A., \& Kaufman, J. (2017). Transfer of Problem Solving Skills from Touchscreen to 3D Model by 3- to 6-Year-Olds. Frontiers in Psychology, 8(1586). https://doi.org/10.3389/fpsyg.2017.01586

Tee, K., Bernheim Brush, A. J., \& Inkpen, K. M. (2009). Exploring communication and sharing between extended families. International Journal of Human Computer Studies, 67(2), 128-138. https://doi.org/https://doi.org/10.1016/j.jijhcs.2008.09.007

Terras, M. M., \& Ramsay, J. (2016). Family Digital Literacy Practices and Children's Mobile Phone Use. Frontiers in Psychology, 7(1957). https://doi.org/10.3389/fpsyg.2016.01957

The Guardian. (2010). Barack Obama becomes first US president to autograph an iPad | Richard Adams | US news | The Guardian. Retrieved June 18, 2018, from https://www.theguardian.com/world/richard-adamsblog/2010/oct/22/barack-obama-ipad-signature

The World Bank. (2019). Individuals using the Internet (\% of population) - Spain. Retrieved from https://data.worldbank.org/indicator/IT.NET.USER.ZS?end=2018\&locations=ES\&start=1990\&view=chart

Think Big. (2012). La historia de Internet en España. Retrieved August 6, 2018, from https://blogthinkbig.com/historiade-internet-en-espana

Time Magazine, T. (2010). iPad - The Top 10 Everything of 2010 - TIME. Retrieved June 18, 2018, from http://content.time.com/time/specials/packages/article/0,28804,2035319_2033840_2033838,00.html

Toohey, K., Dagenais, D., Fodor, A., Hof, L., Nuñez, O., Singh, A., \& Schule, L. (2015). "That Sounds So Cooool": Entanglements of Children, Digital Tools, and Literacy Practices. TESOL Quarterly, 49(3), 461-485. https://doi.org/10.1002/tesq.236

Toor, S.-R., \& Ofori, G. (2008). Developing Construction Professionals of the 21st Century: Renewed Vision for Leadership. Journal of Professional Issues in Engineering Education and Practice, 134(3), 279-286. https://doi.org/10.1061/(ASCE)1052-3928(2008)134:3(279)

Touron, J., \& Martín, D. (2019). Aprender y enseñar en la Universidad hoy. (U. I. de la Rioja, Ed.) (Primera Ed). Logroño: UNIR.

Traxler, J. (2010). Students and mobile devices. ALT-J, 18(2), 149-160. https://doi.org/10.1080/09687769.2010.492847

Trifunović, A., Čičević, S., Lazarević, D., Mitrović, S., \& Dragović, M. (2018). Comparing tablets (touchscreen devices) and PCs in preschool children' education: Testing spatial relationship using geometric symbols on traffic signs. IETI Transactions on ERgonomics and Safety, 2(1), 35-41. https://doi.org/10.6722/TES.201808_2(1).0004

Trust, T. (2018). 2017 ISTE Standards for Educators: From Teaching With Technology to Using Technology to Empower Learners. Journal of Digital Learning in Teacher Education, 34(1), 1-3. https://doi.org/10.1080/21532974.2017.1398980

Turk, V. (2017). Understanding Generation Generation Alpha.

Twitter Inc. (2006). Twitter. Retrieved October 10, 2015, from www.twitter.com

Tyner, B. (2012). The literacy jigsaw puzzle: assembling the critical pieces of literacy instruction. Newwark, DE: International Reading Association.

UK Government. (2017). Development matters in the early years foundation stage (EYFS). London: Early Education. London, UK.

UNESCO. (2017a). Initiative for Literacy. Retrieved July 26, 2018, from www.projectliteracy.com 
UNESCO. (2017b). Literacy. Retrieved July 8, 2019, from https://en.unesco.org/themes/literacy

UNESCO. (2017c). Literacy Rates Continue to Rise from One Generation to the Next.

Union, E. (2015). The Changing Pedagogical Landscape. New ways of teaching and learning and their implications for Higher education policy. Luxembourg. https://doi.org/10.2766/57677

Universidad Senior. (2015). Universidad Senior: UPV. Retrieved September 17, 2017, from http://www.upv.es/entidades/AUS/indexc.html

Universidad Senior. (2019). Universidad Senior (UPV) curso 2017-2018. Retrieved June 10, 2018, from http://www.upv.es/entidades/AUS/indexc.html

UPV-VECA. (2019). Convocatoria Aprendizaje + Docencia 2020. Retrieved October 21, 2019, from http://www.upv.es/contenidos/ICEP/info/Convocatoria_2019_C.pdf

UPV. (2013). Oferta formativa y gestión de la de la Universidad Sénior 2012-13. PEGASUS, 4.

UPV. (2017). Memoria Curso academico 16-17 UPV. Valencia.

UPV. (2019). Memoria Curso Academico 17-18. Valencia.

Vachher, H. (2014). White Paper- Need for Gesture Recognition. HCL Technologies.

Vaikutytè-Paškauskè, J., Vaičiukynaitè, J., \& Pocius, D. (2018). Research for CULT Committee -Digital Skills in the 21st century (Policy Departmento for Structural and Cohesion Policies). Brussels.

Valdivieso Burón, J. A., Reoyo Serrano, N., Martín Antón, L. J., Carbonero Martín, M. Á., \& Freitas Resende, A. (2016). Estilos de Enseñanza y Autoeficacia Docente en Educación Primaria. International Journal of Developmental and Educational Psychology. Revista INFAD de Psicología., 387. https://doi.org/10.17060/ijodaep.2014.n1.v5.698

VanPatten, B., \& Benati, A. G. (2015). Key terms in second language acquisition. Bloomsbury Publishing.

Vargason, D. (2017). Meet Geneartion Alpha: 3 Things educators should know. Retrieved March 1, 2018, from https:/www.nwea.org/blog/2017/meet-generation-alpha-3-things-educators-know/

Vassilev, A. (2015). Establishment of Modern "Atrium" Buildings as a Model for Sustainable Energy Efficient Architecture, 2(3), 36-45. https://doi.org/10.14621/tna.20150404

Vatalaro, A., Culp, A. M. D., Hahs-Vaughn, D. L., \& Barnes, A. C. (2018). A Quasi-Experiment Examining Expressive and Receptive Vocabulary Knowledge of Preschool Head Start Children Using Mobile Media Apps. Early Childhood Education Journal, 46(4), 451-466. https://doi.org/10.1007/s10643-017-0877-3

Vatavu, R. D., Cramariuc, G., \& Schipor, D. M. (2015). Touch interaction for children aged 3 to 6 years: Experimental findings and relationship to motor skills. International Journal of Human Computer Studies, 74, 54-76. https://doi.org/10.1016/j.ijhcs.2014.10.007

Vermesan, O., \& Friess, P. (2015). Building the hyperconnected society: IoT research and innovation value chains, ecosystems and markets. (River Publishers, Ed.).

Villamor, C., Willi, D., \& Wroblewski, L. (2011). Touch Gesture Reference Guide. Retrieved from www.lukew.com/touch/

Virginia University. (2011). WIRELESS NETWORKING. Virginia.

Völkel, S., Wuttke, M., \& Ohler, P. (2017). Preschool Learning with a Fingertip. Springer International Pyblishing AG. LCT 2017, Part II, LNCS, 10296, 110-119. https://doi.org/10.1007/978-3-319-58515-4_9

Voxpro. (2015). Voxpro - Global Customer Experience Outsourcer. Retrieved October 1, 2017, from https://www.voxprogroup.com/approach/

VTECH. (2017). Kidizoom. Durabe, kid-friendly tech for kids. Retrieved November 13, 2018, from https://www.vtechkids.com/brands/brand_view/smartwatch

Vuorikari, R., Punie, Y., Carretero, S., \& Van Den Brande, L. (2016). DigComp 2.0: The Digital Competence Framework for Citizens. JRC Science for Policy Report. https://doi.org/10.2791/11517 
Vygotsky, L. (1978). Interaction between learning and development. Cambridge, MA: Harvard University Press.

Vygotsky, L. S. (1987). The collected works of LS Vygotsky: the fundamentals of defectology (Vol. 2). Springer Science \& Business Media.

Wallop, H. (2014). Gen Z, Gen Y, baby boomers - a guide to the generations - Telegraph. Retrieved January 21, 2018, from https://www.telegraph.co.uk/news/features/11002767/Gen-Z-Gen-Y-baby-boomers-a-guide-to-thegenerations.html

Walter-Laager, C., Brandenberg, K., Tinguely, L., Schwarz, J., Pfiffner, M. R., \& Moschner, B. (2017). Media-assisted language learning for young children: Effects of a word-learning app on the vocabulary acquisition of two-yearolds. British Journal of Educational Technology, 48(4), 1062-1072. https://doi.org/10.1111/bjet.12472

Wang, F., Xie, H., Wang, Y., Hao, Y., \& An, J. (2016). Using touchscreen tablets to help young children learn to tell time. Frontiers in Psychology, 7(NOV), 1-8. https://doi.org/10.3389/fpsyg.2016.01800

Webopedia.com. (2011). Definition. Retrieved July 20, 2018, from webopedia.com

Weissberg, R. P., Durlak, J. A., Domitrovich, C. E., \& Gullotta, T. P. (Eds.). (2015). Social and emotional learning: Past, present, and future. In Handbook of social and emotional learning: Research and practice. (pp. 3-19). New York, NY, US: Guilford Press.

Wertsch, J. V. (1991). Voices of the mind: Sociocultural approach to mediated action. Cambridge, MA: Harvard University Press.

Westlund, J. K., Dickens, L., Jeong, S., Harris, P., DeSteno, D., \& Breazeal, C. (2015). A comparison of children learning new words from robots, tablets, \& people. In Proceedings of the 1st international conference on social robots in therapy and education.

WeVideo, I. (2011). WeVideo: Free Video Editing App for Youtube and More. Retrieved July 8, 2019, from https://www.wevideo.com

Whatls.com. (2018). What is haptics? - Definition from Whatls.com. Retrieved January 9, 2019, from https://whatis.techtarget.com/definition/haptics

WhatsApp Inc. (2009). WhatsApp. Retrieved March 28, 2017, from https://www.whatsapp.com/

Whitehead, T. L. (2005). Basic classical ethnographic research methods. Cultural Ecology of Health and Change, 1, 129.

Williams, J., Figueroa, D. T., Golden, J., \& Crosby, S. (2018). Education Policy Outlook: SPAIN.

Willingham, D. B., Nissen, M. J., \& Bullemer, P. (1989). On the development of procedural knowledge. Journal of Experimental Psychology: Learning, Memory, and Cognition, 15(6), 1047.

Wilson, D., \& Conyers, M. (2016). Engaging Parental Support for Smarter Thinking. Retrieved December 9, 2017, from https://www.edutopia.org/blog/parental-support-for-smarter-thinking-donna-wilson-marcus-conyers

Wilson, D. S. (1988). Strategies of knowledge acquisition. Journal of Social and Biological Systems, 11(1), 161-163. https://doi.org/10.1016/0140-1750(88)90058-9

WIRED.com. (2012). Vint Cerf: We Knew What We Were Unleashing on the World. Retrieved October 24, 2018, from https://www.wired.com/2012/04/epicenter-isoc-famers-qa-cerf/

WIRED.com. (2017). 8 Kids Test Their Speech on Siri, Echo and Google Home [video]. Retrieved November 13, 2018, from https://www.youtube.com/watch?v=GZnUibN6m4A

Wohlwend, K. E. (2015). One Screen, Many Fingers: Young Children's Collaborative Literacy Play With Digital Puppetry Apps and Touchscreen Technologies. Theory into Practice, 54(2), 154-162. https://doi.org/10.1080/00405841.2015.1010837

Wolfe, A. (2018). Guess how often you use your phone every day. Retrieved January 9, 2019, from https://www.journalofaccountancy.com/newsletters/2018/apr/how-often-use-phone-every-day.html

Wong, L. (2012). A learner-centric view of mobile seamless learning. British Journal of Educational Technology, 43(1), E19-E23.

Wong, S. S.-H. (2015). Mobile Digital Devices and Preschoolers' Home Multiliteracy Practices. Language and Literacy, 
17(2), 75-90. https://doi.org/10.20360/G2CP49

Wood, D., Bruner, J. S., \& Ross, G. (1976). the Role of Tutoring in Problem Solving. Journal of Child Psychology and Psychiatry, 17(2), 89-100. https://doi.org/10.1111/j.1469-7610.1976.tb00381.x

Wylie, R., \& Chi, M. T. H. (2014). 17 The Self-Explanation Principle in Multimedia Learning. The Cambridge Handbook of Multimedia Learning, 413.

Xie, H., Peng, J., Qin, M., Huang, X., Tian, F., \& Zhou, Z. (2018). Can Touchscreen Devices be Used to Facilitate Young Children's Learning? A Meta-Analysis of Touchscreen Learning Effect. Frontiers in Psychology, 9(2580). https://doi.org/10.3389/fpsyg.2018.02580

Yang, D., Sidman, J., \& Bushnell, E. W. (2010). Beyond the information given: Infants' transfer of actions learned through imitation. Journal of Experimental Child Psychology, 106(1), 62-81. https://doi.org/10.1016/j.jecp.2009.12.005

Yau, J. M., Kim, S. S., Thakur, P. H., \& Bensmaia, S. J. (2016). Feeling form: the neural basis of haptic shape perception. Journal of Neurophysiology, 115(2), 631-642. https://doi.org/10.1152/jn.00598.2015

Yelland, N. J. (2018). A pedagogy of multiliteracies: Young children and multimodal learning with tablets. British Journal of Educational Technology, 49(5), 847-858. https://doi.org/10.1111/bjet.12635

Yenawine, P. (2013). Visual thinking strategies: using art to deepen learning across school disciplines. (Harvard Education Press, Ed.). Harvard Education Publishing Group.

yeu-international.org. (2017). YEU International. Retrieved April 23, 2018, from http://www.yeu-international.org/en/nonformal-education

Young, K. S. (1998). Internet Addiction: The Emergence of a New Clinical Disorder. CyberPsychology \& Behavior, 1(3), 237-244. https://doi.org/10.1089/cpb.1998.1.237

Yuill, N., \& Martin, A. F. (2018). Curling Up With a Good E-Book: Mother-Child Shared Story Reading on Screen or Paper Affects Embodied Interaction and Warmth. Frontiers in Psychology, 7(1951). https://doi.org/10.3389/fpsyg.2016.01951

Zack, E., Barr, R., Gerhardstein, P., Dickerson, K., \& Meltzoff, A. N. (2009). Infant imitation from television using novel touch screen technology. British Journal of Developmental Psychology, 27(1), 13-26. https://doi.org/10.1348/026151008X334700

Zack, E., Peter, G., Meltzoff, A. N., \& Barr, R. (2013). 15-Month-Olds' Transfer of Learning between Touch Screen and Real World Displays: Language Cues and Cognition. Scandinavian Journal of Psychology, 54(1), $20-25$. https://doi.org/10.1111/sjop.12001.15-Month-Olds

Zapata-Ros, M. (2013). Analítica de aprendizaje y personalización. Revista Científica de Tecnología Educativa, 2(2), $2255-1514$

Zhang, Y., Tardif, T., Shu, H., Li, H., Liu, H., McBride-Chang, C., ... Zhang, Z. (2013). Phonological skills and vocabulary knowledge mediate socioeconomic status effects in predicting reading outcomes for Chinese children. Developmental Psychology, 49(4), 665.

Zimmerman, F. J., Christakis, D. A., \& Meltzoff, A. N. (2007). Associations between media viewing and language development in children under age 2 years. The Journal of Pediatrics, 151(4), 364-368. https://doi.org/10.1016/j.jpeds.2007.04.071

Zimmermann, L., Moser, A., Lee, H., Gerhardstein, P., \& Barr, R. (2017). The Ghost in the Touchscreen : Social Scaffolds Promote Learning by Toddlers. Child Development, 88(6), 2013-2025. https://doi.org/10.1111/cdev.12683

Zmily, A., Mowafi, Y., \& Mashal, E. (2014). Study of the usability of spaced retrieval exercise using mobile devices for Alzheimer's disease rehabilitation. JMIR MHealth and UHealth, 2(3), e31. https://doi.org/10.2196/mhealth.3136 
Figure, Tables and Photo Captions 



\section{Figure List}

\begin{tabular}{|c|c|c|}
\hline Figures & Source & Page \\
\hline Fig. 1 Arthur C. Clarke Interview & https://www.youtube.com/watch?v=bXxyCyDEaEg & 25 \\
\hline Fig. 2 From Basic Mobile Phone to Interactive & (Fund. Telefónica, 2009) & 28 \\
\hline Fig. 3 First Experiments with Touchscreens & (Zack et al., 2009) & 37 \\
\hline Fig. 4 Handwriting in A Tablet Device. (Preschool) & ○ Nllobre (own source) & 49 \\
\hline $\begin{array}{l}\text { Fig. } 5 \text { Haptic Device Usage as Literacy Facilitator } \\
\text { (Kindergarten) }\end{array}$ & ๑ Nllobre (Own source) & 51 \\
\hline $\begin{array}{l}\text { Fig. } 6 \text { AR: 3D Object from Jigspace App in a real } \\
\text { home desk setting }\end{array}$ & ๑ Nllobre (Own source) & 52 \\
\hline $\begin{array}{l}\text { Fig. } 7 \text { 96-year-old woman coloring with a haptic } \\
\text { Device }\end{array}$ & $\begin{array}{c}\text { https://todosalta.com/contenido/9795/entregaran- } \\
\text { 1700-tablets-a-jubilados }\end{array}$ & 62 \\
\hline Fig. 8 ZGen Teenager Teaching Silents & https://www.europapress.es/epsocial// & 63 \\
\hline Fig. 9 Tech Gadgets in the seventies & $\begin{array}{l}\text { https://es.slideshare.net/rosalbaloaiza/la- } \\
\text { tecnologia-en-los-aos-70 }\end{array}$ & 64 \\
\hline Fig. 10 Tech Gadgets in the eighties & $\begin{array}{c}\text { http://images6.fanpop.com/image/photos/4270000 } \\
\text { o/Best-Of-80s-Technology-the-80s-42745099-236- } \\
\text { 292.jpg }\end{array}$ & 66 \\
\hline Fig. 11 YGens Meeting Friends & $\begin{array}{l}\text { https://www.elcomercio.es/sociedad/vida- } \\
\text { millennial-explicada-baby-boomer- } \\
\text { 20190620162936-nt.html }\end{array}$ & 68 \\
\hline Fig. 12 ZGens Meeting Friends: A Selfie & $\begin{array}{c}\text { https://www.forbes.com/sites/ashleystahl/2019/og/ } \\
\text { 10/how-generation-z-will-revolutionize-the- } \\
\text { workplace/\#450dda284f53 }\end{array}$ & 69 \\
\hline Fig. 13 UPV Population by Generational Cohorts & ( ) Nllobre (Own source) & 71 \\
\hline Fig. 14 Spanish Internet Users In 2018: 86\% & $\begin{array}{c}\text { https://data.worldbank.org/indicator/IT.NET.USER. } \\
\underline{\text { ZS?end=2017\&locations=ES\&start=1990\&view }=\text { char }} \\
\underline{\mathrm{t}}\end{array}$ & 72 \\
\hline $\begin{array}{l}\text { Fig. } 15 \text { Inserted Personal Gadgets in a Haptic } \\
\text { Device }\end{array}$ & ๑ Nllobre (Own source) & 73 \\
\hline Fig. 16 Devices in a 2018 Work Setting & $\begin{array}{c}\text { https://thenextweb.com/lifehacks/2014/11/21/produ } \\
\text { ctivity-advice-learned-people-smarter/ }\end{array}$ & 75 \\
\hline $\begin{array}{l}\text { Fig. } 17 \text { Most Frequent Spanish Formal Classroom } \\
\text { Setting }\end{array}$ & https://efs.efeservicios.com/ & 76 \\
\hline $\begin{array}{l}\text { Fig. } 18 \text { Caxton Reception Class Working with } \\
\text { Tablets }\end{array}$ & $\begin{array}{c}\text { https://caxtoncollegeschoolblog.caxtoncollege.co } \\
\text { m/page/16/ } \\
\text { https://www.elmundo.es/comunidad- } \\
\text { valenciana/2015/11/23/56520811ca47415f568b45bg.h } \\
\underline{\text { tml }}\end{array}$ & 80 \\
\hline $\begin{array}{l}\text { Fig. } 19 \text { Learning in a New Playmat (Swinburne } \\
\text { Babylab) }\end{array}$ & $\begin{array}{l}\text { (1) Brittany Huber. Swinburne Babylab. } \\
\text { https://www.swinburne.edu.au/research/mental- } \\
\text { health/facilities/babylab/team/ }\end{array}$ & 89 \\
\hline $\begin{array}{l}\text { Fig. } 20 \text { EYFS } 2017 \text { Framework adapted to haptic } \\
\text { devices }\end{array}$ & @ Nllobre (Own Source) & 184 \\
\hline Fig. 21 Infant Manipulating a Tablet & $\begin{array}{c}\text { https://www.telegraph.co.uk/news/2017/04/13/ipad } \\
\text { s-could-hinder-babies-sleep-brain-development- } \\
\text { study-suggests/ }\end{array}$ & 186 \\
\hline Fig. 22 Wevideo Screenshot & () Nllobre (Own source) & 203 \\
\hline
\end{tabular}




\begin{tabular}{|c|c|c|}
\hline Figures & Source & Page \\
\hline Fig. 23 Digital Pen Scribbling (Preschool) & (c) Nllobre (Own source) & 205 \\
\hline $\begin{array}{l}\text { Fig. } 24 \text { Using AR In Primary Teaching. Curiscope } \\
\text { App }\end{array}$ & https://www.curiscope.com/pages/education & 207 \\
\hline $\begin{array}{l}\text { Fig. } 25 \text { Activelearn Platform screenshot } \\
\text { (Preschool) }\end{array}$ & @ Nllobre (Own source) & 212 \\
\hline $\begin{array}{l}\text { Fig. } 26 \text { Sending an email without instructions } \\
\text { (Kindergarten) }\end{array}$ & ๑ Nllobre (Own source) & 214 \\
\hline $\begin{array}{l}\text { Fig. } 27 \text { Watching English Contents with The } \\
\text { Tablet While Playing Puzzles (Toddler) }\end{array}$ & @ Nllobre (Own source) & 229 \\
\hline Fig. 28 Child I English Writing (Preschool) & ( ) Nllobre (Own source) & 231 \\
\hline Fig. 29 Helix Hotel & $\begin{array}{l}\text { https://decoracion2.com/hotel-helix-un-paraiso- } \\
\text { ecologico-en-abu-dhabi/ }\end{array}$ & 263 \\
\hline Fig. 30 Atrium as example of flexible space & https://www.emergingedtech.com/ & 264 \\
\hline Fig. 31 Learning Phases and Haptic Interaction & ( ) Nllobre (Own source) & 274 \\
\hline Fig. 32 Bird Interactive Device & (MUV Interactive, 2015) & 288 \\
\hline Fig. 33 VR In Medicine & $\begin{array}{l}\text { https://www.medgadget.com/2018/og/augmented- } \\
\text { reality-in-healthcare-market-innovation-by-google- } \\
\text { llc-microsoft-corporation-augmedix-and-medical- } \\
\text { realities-till-2023-marketresearchfuture-com.html }\end{array}$ & 289 \\
\hline Fig. 34 Big Data in Education & $\begin{array}{l}\text { https://rd.acer.org/article/big-data-in-higher- } \\
\text { education }\end{array}$ & 290 \\
\hline Fig. 35 The Growth Mindset & (Blackwell et al., 2007) & 292 \\
\hline Fig. 36 Enhancing the Digital Student Experience & ๑ Jisc and Bonner McHardy CC BY-NC-ND & 293 \\
\hline
\end{tabular}


Figure, Table and Photo Lists

\section{Table List}

TABLE I UPV POPULATION. 20I7-I8 ACADEMIC YEAR (OWN SOURCE) 150

TABLE 2 NUMBER OF PAPERS REVIEWED that MET THE DIFFERENT VARIABLES SET (OWN SOURCE). 157

TABLE 3 CHART SHOWING THE INCREASE OF PAPERS CONDUCTING RESEARCH WITH HAPTIC DEVICES (OWN SOURCE).......157

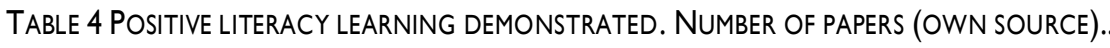
.158

TABLe 5 Positive literacy learning DeMONSTRATED. Chart (OWN SOURCE) .158

TABLE 6 CHILD I AT DIFFERENT STAGES MANIPULATING HER TABLET (OWN SOURCE)... .214

TABLE 7 HAPTIC USE AND INTERACTION DURING RESEARCH (OWN SOURCE).. .243

TABLE 8 Haptic INTERAction FreQuency. HG CASE Study (OWN SOURCE). .244 


\section{Photo Captions}

Introduction. Red Center Landscape, Australia. Onllobre 2009

Chapter 1. Food Art Painting. Onllobre 2017

Chapter 2. Two generations. Onllobre 2015

Chapter 3. Aboriginal Hand Painting, Australia. Onllobre 2009

Chapter 4. Giving driving Directions. Onllobre 2015

Chapter 5. Drawing with my Tablet. Onllobre 2017

Chapter 6. The ischolar. Cnllobre 2014

Chapter 7. Atrium and Space. OSergio Llobregat 2019

Conclusions. Valle d'Ossau, France. Onllobre 2016

Addenda. Learning about Human Body@ 4. Onllobre 2017 


\section{Abbreviations}





\section{Acronym}

CEO

EHEA

HapGen

HEA

HEI

ICT

IRC

PISA

STEHEAM

STEM

Summer Campus

The Boomers

The Grands

The Silents

UPV

XGen

YGen

ZGen

\section{Meaning}

Chief Executive Officer

European Higher Education Area

The Spanish Haptic Generation cohort

Humanities, English, and Aesthetics

Higher Education Institution

Information and Communication Technology

Internet Relay Chat

Programme for International Student Assessment

Science, Technology, Engineering, Humanities, English, Aesthetics, and Mathematics

Science, Technology, Engineering, and Mathematics

UPV Children Summer School Campus

The Spanish Boomer Generation cohort

The Spanish Greatest Generation cohort

The Spanish Silent Generation cohort

Universitat Politècnica de Valencia

The Spanish X Generation cohort

The Spanish Y Generation cohort

The Spanish Z Generation cohort 



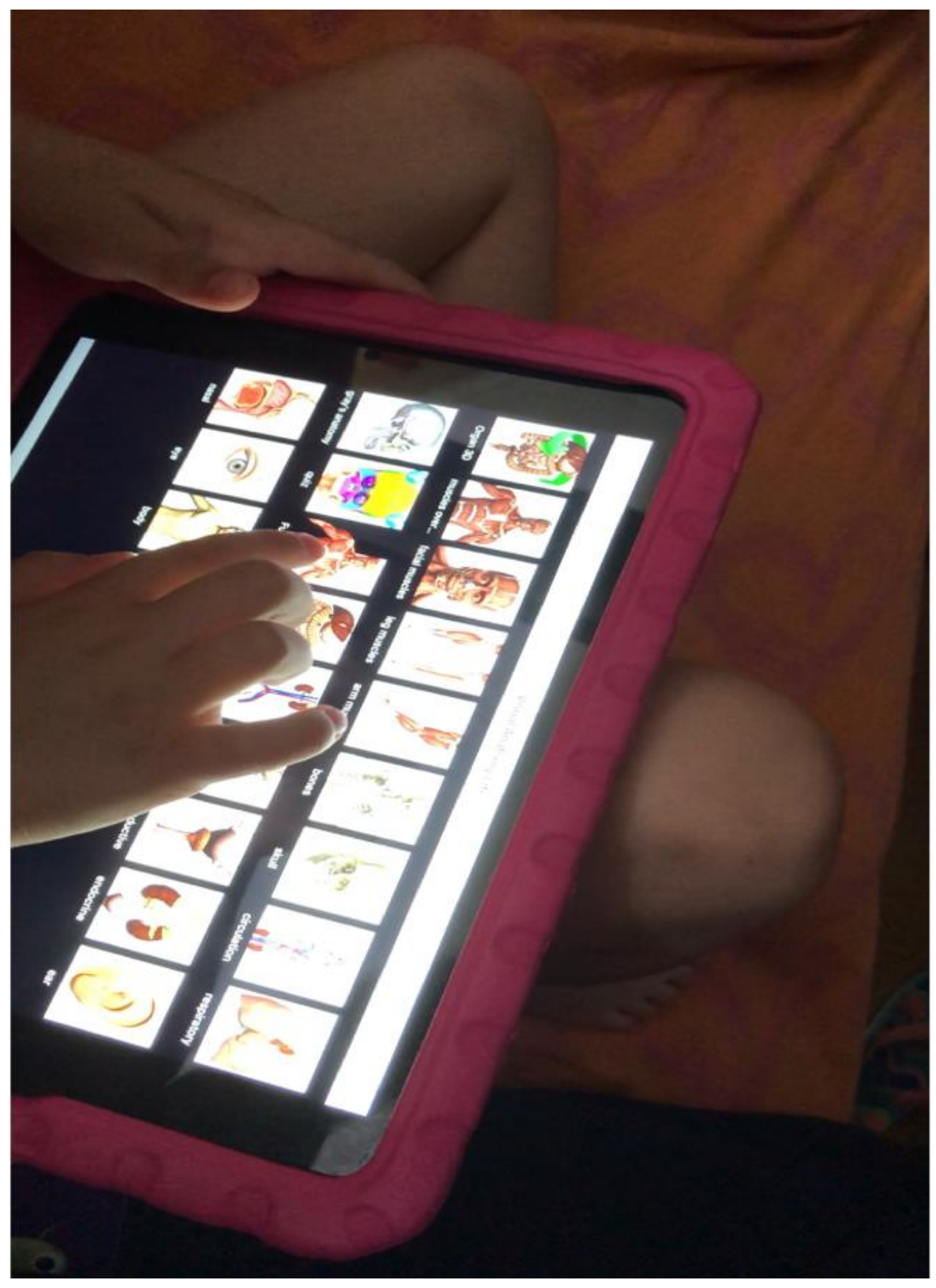

Addenda 

A HG_ Case Study

A1. Family Summary template

A2. Consentimiento Informado

A3. Young Children and Use of Table Survey.

Google Doc. Template

A4. Niños entre $0-8$ años y Tablets/móviles.

Google Doc. Template

B ZG_Case Study

B1 Alumnos y dispositivos móviles. Uso educativo.

Google Doc. Template

B2. Essays. Templates 



\section{Family X. Child X}

Interviews with parents on January 2015 for period 2013-14, January 2017 for period 15-16, and January 2019 for period $17-18$

Family variables

Family data:

- Family Members:

- education attainment:

- employment status:

- type of work:

- Living in:

Home environment: number of haptic devices:

- $2012 \rightarrow$

- $2015 \rightarrow$

- $2018 \rightarrow$

Adult device's interaction:

Physical space

Parenting style for haptic device use following (Baumrind, 1966):

Parents and child relationship when using the device:

Language for interaction with the Device:

Parents motivation .

Time allowed.

child

Born:

Child age at first interaction:

Child motivation to use the tablet:

Child involvement in the learning experience:

Device used:

Type of Apps used

- Developers' apps (the most used):

- Web search apps:

- In Built apps: 


\section{HG Case Study: Family X}

Device using conditions

- Who supports the interaction.

- Places allowed to use the devices:

- Who owns the device?

- Was it used as a babysitter?

- Were the children using other digital/technological/personal devices?

- Timing:

- Child general Interaction:

- Activity Code:

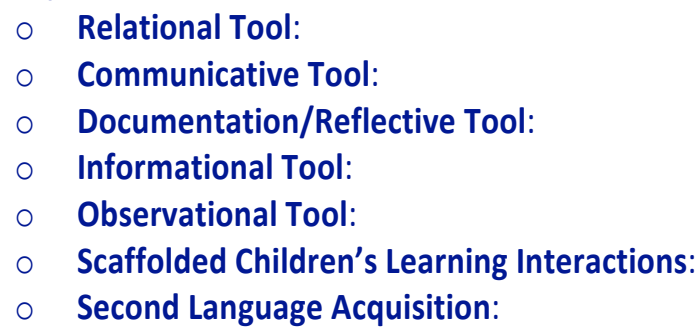

Emotional constructs when using the device

observations, and researcher's conclusions.

RESULT

\begin{tabular}{|c|c|c|c|c|}
\hline$\%$ haptic Use & 2013-14 & $15-16$ & $17-18$ & MEDIA \\
\hline Child Vb (2012) & & & & \\
\hline
\end{tabular}

- Child \% of HA_int. 


\section{CONSENTIMIENTO INFORMADO}

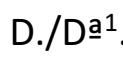

en calidad $\mathrm{de}^{2}$

He/hemos leído la hoja de información que se me/nos ha entregado, copia de la cual figura en el reverso de este documento, y la he/hemos comprendido en todos sus términos.

$\mathrm{He} /$ hemos sido suficientemente informado/s y he/hemos podido hacer preguntas sobre los objetivos y metodología aplicados en el proyecto de investigación de la tesis: STEM Subjects face the Haptic Generation: the iScholars

De la Universitat Politècnica de Valencia

y para el que se ha pedido la colaboración de mi/nuestro. (hijo, pupilo o representado $)^{3}$

Comprendo/comprendemos que la participación es voluntaria y que el menor en cuya representación actúo/actuamos puede retirarse del mismo

- cuando quiera;

- sin tener que dar explicaciones y exponer mis motivos; y

- sin ningún tipo de repercusión negativa.

Por todo lo cual, PRESTO/PRESTAMOS EL CONSENTIMIENTO para la participación en el proyecto de investigación al que este documento hace referencia y para que los datos de carácter personal del menor sean tratados, según la normativa vigente y la política de protección de datos de la UPV ${ }^{4}$, para el uso exclusivo en este proyecto 5 .

\footnotetext{
${ }^{1}$ Los padres, si ambos ejercen la patria potestad, deben firmar conjuntamente este consentimiento informado.

2 Padres, tutor o representante legal del menor.

3 Nombre completo del menor

${ }^{4}$ https:/www.upv.es

${ }^{5}$ De conformidad con lo dispuesto en la Ley Orgánica 3/2018 de 5 de diciembre de protección de datos personales y garantía de derechos digitales y en el Reglamento (UE) 2016/679 del Parlamento Europeo y del Consejo, de 27 de Abril de 2016, relativo a la protección de las personas físicas en lo que respecta al tratamiento de datos personales y a la libre circulación de estos datos, el/la IP del proyecto manifiesta que los datos personales incorporados en el presente formulario, los recabados en la relación del proyecto de investigación, así como aquellos otros conexos que pudieran ser obtenidos, se incorporarán y tratarán en un fichero automatizado de datos de carácter personal para su uso dentro del Proyecto, con la base legal del previo consentimiento expreso y para la finalidad investigadora del mismo.
} 
En . de de

Fdo.

Los datos tratados no serán cedidos salvo previa petición y en los casos previstos legalmente, y se conservarán durante el tiempo legalmente establecido y el necesario para cumplir con estos fines.

Las personas legitimadas para ello podrán ejercitar los derechos de acceso, rectificación, cancelación y oposición reconocidos en dicha normativa acreditando fehacientemente su identidad aportando copia de su Documento Nacional de Identidad o documento equivalente.

Contacto IP, responsable del proyecto: (poner aquí la dirección de correo electrónico o tlf) Más información sobre la Política de Protección de Datos de la UNED: https://www.uned.es/universidad/inicio/institucional/proteccion-datos.html 


\section{Young children and the use of Tablets (0-8)}

$\mathrm{Hi}$, I'm conducting a research on Children under 8 and their use of Tablets.

The results will be used ONLY for research purposes. No personal data is collected. No personal emails are asked or collected.

If you have a kid between 0 and 8 , your opinion is very important for us.

Please, answer the following questions, and fill as many questionaries as kids under 8.

You can find more information in http://bit.do/Nuria-Thesis.

Thanks for your cooperation. Nuria Llobregat

*Obligatorio

\section{Kid's age *}

Marca solo un óvalo.

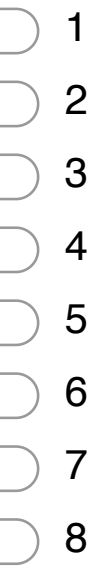

2. Think about the use you give normally to your tablet or smartphone. Selecciona todos los que correspondan.

Communication

Creation and Productivity

Leisure and Entertainment

Information and Learning

Otro: 
3. Which actions do you think that your kid is imitating from you when you interact with your device? Name a few. e.g.: camera use, taking notes, app use, pretend play, etc.

4. Do you think your kid has acquired new skills while using the tablet/smartphone? Name them. e.g.: information search, creativity, oral skills, linking ideas, etc.

5. Can you name any anecdote relating your kid and the use of the tablet/smartphone that kept your attention because it was unexpected? Retell please.

6. Do you think your kid is learning when using the tablet? Marca solo un óvalo.
Yes
No

$\bigcirc$ Otro: 
7. If Yes. What do you think the kid has learnt? e.g. reading, maths, English/Spanish Vocabulary, create videos or audios, etc.

8. Do you think tablet use will have an impact in your kid's learning style?

Marca solo un óvalo.

Yes

No

Maybe

9. Tell us why.

10. Does your kid use video chat to communicate with older members of the family? e.g. FaceTime, Skype, etc.

Selecciona todos los que correspondan.

Yes

No

Otro:

If you would like to tell us more about the topic or find out about our results send us an email to nllobre.upv@gmail.com 


\section{Niños entre 0-8 y tablets/móviles}

HOla,

Estoy realizando un estudio sobre niños y el uso que hacen de las tablets.

Las respuestas serán usadas única y exclusivamente para un trabajo de investigación. No se recogen datos personales ni direcciones de correo electrónico. Si tienes un/a hijo/a entre esas edades, tu opinión nos interesa mucho.

Por favor, contesta a las siguientes preguntas. Puedes encontrar más información en http://bit.do/Nuria-Thesis.

Muchas gracias por tu cooperación. Nuria Llobregat

\section{*Obligatorio}

\section{Edad de tu hijo/hija *}

Marca solo un óvalo.

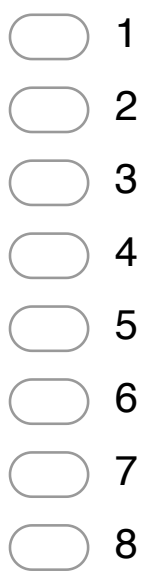

2. Dinos para qué usas normalmente el móvil o la tablet

Selecciona todos los que correspondan.

Dara Comunicarte

Para trabajar y crear contenidos

Dara entrenimiento

$\square$ Para aprender e informarme de temas que me interesan

Otro: 
3. Cuando usas el dispositivo ¿ en qué cosas crees que tu hijo/a puede imitarte? Nombra algunas. Ej. Usar la cámara, tomar notas, llamar a familiares y amigos...

4. ¿Crees que tu hijo/a ha adquirido nuevas habilidades mientras usaba la tablet o el móvil? Nombra algunas. Ej. Hacer videos, audios. Buscar información. Aprender palabras en otro idioma, etc.

5. ¿Puedes contarnos alguna anécdota que relacione a tu hijo/a con la tablet que te haya llamado la atención? ¿algo que no te esperabas? Cuéntanoslo por favor

6. ¿Crees que tu hijo/a está aprendiendo cuando usa la tablet? Marca solo un óvalo.

Si

No

quizás

Otro: 
7. Si tu respuesta es Si. ¿qué crees que está aprendiendo? e.j. a leer, a escribir, a contar cosas, algo de matemáticas...

8. ¿Crees que el uso que le da tu hijo/a a la tablet influirá en su modo de aprender en su etapa escolar?

Marca solo un óvalo.

Si

No

Quizás

9. Dinos por qué

10. ¿Usa el dispositivo para comunicarse con familiares usando la video Ilamada (FaceTime, Skype etc)?

Selecciona todos los que correspondan.

$\square$ Si

No

Otro:

Si te apetece compartir algún pensamiento/idea/preocupación o más información sobre este tema, o quieres saber los resultados del estudio cuando esté finalizado, por favor envía un email a: nllobre.upv@gmail.com 
Google Forms 


\section{Alumnos y Dispositivos Móviles. Uso Educativo}

HOla,

Estoy realizando un estudio sobre el uso de los dispositivos móviles en el contexto universitario. Las respuestas serán usadas única y exclusivamente para un trabajo de investigación. No se recogen datos personales ni direcciones de correo electrónico. Al ser estudiante de Grado/Master, creemos que tienes bastante que aportar y por ello pedimos tu colaboración. Puedes encontrar más información en http://bit.do/Nuria-Thesis.

Por favor, contesta a las siguientes preguntas. Las que tienen un círculo solo admiten una respuesta y las que tienen cuadrados admiten respuesta múltiple.

Muchas gracias. Nuria Llobregat

\section{${ }^{*}$ Obligatorio}

\section{Año de nacimiento *}

Marca solo un óvalo.
1946-1964 (BB)
1965-1979 (X)
1980-1994 (Y)
1995-2009 (Z)

\section{2. ¿Por qué estás estudiando una carrera?}

Selecciona todos los que correspondan.

Para tener un título universitario

$\square$ Para trabajar en lo que me gusta

$\square$ Para trabajar

$\square$ Por hacer algo

$\square$ Porque cuando acabe mis estudios quiero investigar

$\square$ Porque mis padres me lo han dicho 
3. Grado de motivación para seguir en la Universidad Marca solo un óvalo.

No tengo motivación. Estoy porque tengo que estar

$\bigcirc$ Algo

Poca

Bastante

$\longrightarrow$ Mucha

4. ¿Te gusta lo que estudias?

Marca solo un óvalo.

Nada

Apenas

Algo

Bastante

Mucho

5. Uso principal que le das a tu Smartphone:

Marca solo un óvalo.

Para comunicarme con familiares y amigos

Para crear contenidos digitales

Para entretenerme

$\bigcirc$ Para buscar información de los temas que me interesan

$\bigcirc$ Para estar conectado en mis redes sociales

$\longrightarrow$ Otro:

6. Uso principal que le das a tu Tablet:

Marca solo un óvalo.

Para comunicarme con familiares y amigos

para crear contenidos digitales

Para entretenerme

Para buscar información de los temas que me interesan

Para estar conectado en mis redes sociales

No tengo tablet

$\bigcirc$ Otro: 
7. Uso principal que le das a tu ordenador/laptop:

Marca solo un óvalo.

Para comunicarme con familiares y amigos

para crear contenidos digitales

Para entretenerme

Para buscar información de los temas que me interesan

Para estar conectado en mis redes sociales

No tengo ordenador/laptop

Otro:

8. Al navegar por contenidos web en inglés, ¿crees que tu nivel de inglés ha mejorado? *

Marca solo un óvalo.

si

No

No soy consciente de haber aprendido inglés aunque sí visito páginas en inglés

No visito páginas en inglés

9. Pensando en el uso que le das al dispositivo móvil para estudiar, dinos si realizas alguna/algunas de estas tareas

Selecciona todos los que correspondan.

- Trabajo colaborativo en la nube

Crear y producir videos (trabajos de clase)

$\square$ Crear infografías

Seguir cursos online a través de plataformas MOOC

Uso de redes sociales para seguir un tema concreto de interés para tus estudios (Twitter, Facebook, Instagram)

I leer solo RSS (resúmenes de noticias y contenidos)

$\square$ Leer textos completos de interés

$\square$ Busco información para complementar la materia seguida en clase

$\square$ Contacto por Email entre compañeros y profesores

Otro: 
10. Sobre las funciones creativas en los dispositivos móviles. Selecciona si estás de acuerdo

Selecciona todos los que correspondan.

Las apps que uso las puedo personalizar

Con el uso avanzado puedo crear contenidos y publicarlos

Con los dispositivos móviles ahorro tiempo para hacer mis tareas

Puedo conectarme desde cualquier sitio y eso me ahorra tiempo

Uso el modo multi-tarea

Uso FaceTime or Skype para trabajar en modo online con mis compañeros

Uso lápices digitales para tomar notas y escribir

11. ¿La manera en la que presentan los contenidos los profesores es adecuada a la materia que imparte?

Marca solo un óvalo.

$\bigcirc$ No

Algo

Bastante

Sí

12. ¿Qué tipo de contenido digital usas para estudiar?

Selecciona todos los que correspondan.

imágenes

videos

Infografías

Cursos Online en plataformas MOOC

- Referencias en Google Scholar

Referencias en buscadores tipo Google o DuckDuck Go

$\square$ Texto pdf

Solo el material que me sugieren en las guías docentes

Otro: 
13. Cual es tu método de estudio:

Selecciona todos los que correspondan.

Hago o creo contenidos Multimedia

Uso vídeos formativos/informativos

Busco información online para completar otros contenidos

Colaboro en equipo con compañeros

Me aprendo de memoria los contenidos

Reescribo lo que tengo que aprender

Aplico lo que aprendo a ejemplos de la vida real

Otro:

14. ¿Cómo aprendes mejor los contenidos de las asignaturas? Marca solo un óvalo.

Con prácticas (hands-on experience)

Resolviendo problemas reales (problem-based)

Memorizando datos (memorizing)

$\Longrightarrow$ Trabajando en Equipo (team-building skills)

$\bigcirc$ Con explicaciones del profesor (Face-to-Face)

$\bigcirc$ Otro:

15. Durante la carrera he aprendido sobre herramientas y habilidades digitales

Marca solo un óvalo.

Si y son necesarias

Si pero no son necesarias

No pero son necesarias

No y no lo veo necesario

16. Cuando acabes la universidad, ¿crees que estarás preparado para afrontar el mundo laboral?

Marca solo un óvalo.

No

Algo

Bastante

Si. 


\section{Selecciona una opción}

Marca solo un óvalo.

Lo que aprendo en las asignaturas es lo que más me ayudará cuando trabaje

Lo que aprendo por mi cuenta es lo que más me ayudará cuando trabaje

Las dos cosas son necesarias y complementarias

Otro:

18. Termina la frase: Mi motivación para estudiar aumentará cuando...

Con la tecnología de

Google Forms 


\section{EXTRA WRITING}

Please, print this page and handwrite your answer:

Surname, Name

As a member of the generation that you are ( $Z$ or $Y)$, tell me your learning preferences (write more than 100 words) 


\section{EXTRA WRITING}

Please, print this page and handwrite your answer:

Surname, Name

As university lecturers, we think that you get bored when learning at university.

Normally, this is because something: boring lessons, boring ways to teach, not feeling that you are learning, boring lectures, or whatever other personal reasons.

From your experience, write why you get bored at university classes, and what would you change to improve them and help to end with the boredom. 